\title{
Archeological Testing and Data Recovery at 41ZV202, Zavala County, Texas
}

\author{
Raymond P. Mauldin \\ Center for Archeological Research, University of Texas at San Antonio \\ Russell D. Greaves \\ Jennifer L. Thompson \\ Cynthia M. Munoz \\ Center for Archeological Research, University of Texas at San Antonio \\ Leonard Kemp \\ Center for Archeological Research, University of Texas at San Antonio
}

See next page for additional authors

Follow this and additional works at: https://scholarworks.sfasu.edu/ita

Part of the American Material Culture Commons, Archaeological Anthropology Commons, Environmental Studies Commons, Other American Studies Commons, Other Arts and Humanities Commons, Other History of Art, Architecture, and Archaeology Commons, and the United States History Commons

Tell us how this article helped you.

This Article is brought to you for free and open access by the Center for Regional Heritage Research at SFA ScholarWorks. It has been accepted for inclusion in Index of Texas Archaeology: Open Access Gray Literature from the Lone Star State by an authorized editor of SFA ScholarWorks. For more information, please contact cdsscholarworks@sfasu.edu. 


\section{Archeological Testing and Data Recovery at 41ZV202, Zavala County, Texas}

\section{Authors}

Raymond P. Mauldin, Russell D. Greaves, Jennifer L. Thompson, Cynthia M. Munoz, Leonard Kemp, Barbara A. Meissner, Bruce K. Moses, and Steve A. Tomka

\section{Licensing Statement}

This is a work produced for the Texas Department of Transportation (TxDOT) by the report producer. TxDOT and the report producer jointly own all rights, title, and interest in and to all intellectual property developed under TxDOT's contract with the report producer. The report may be cited and brief passages from this publication may be reproduced without permission provided that credit is given to both TxDOT and the report producer. Permission to reprint an entire chapter, section, figures or tables must be obtained in advance from either the Supervisor of the Archeological Studies Branch, Environmental Affairs Division, Texas Department of Transportation, 125 East 11th Street, Austin, Texas, 78701 or from the report producer. 


\section{Archeological Testing and Data Recovery at $41 \mathrm{ZV202}$, Zavala County, Texas}

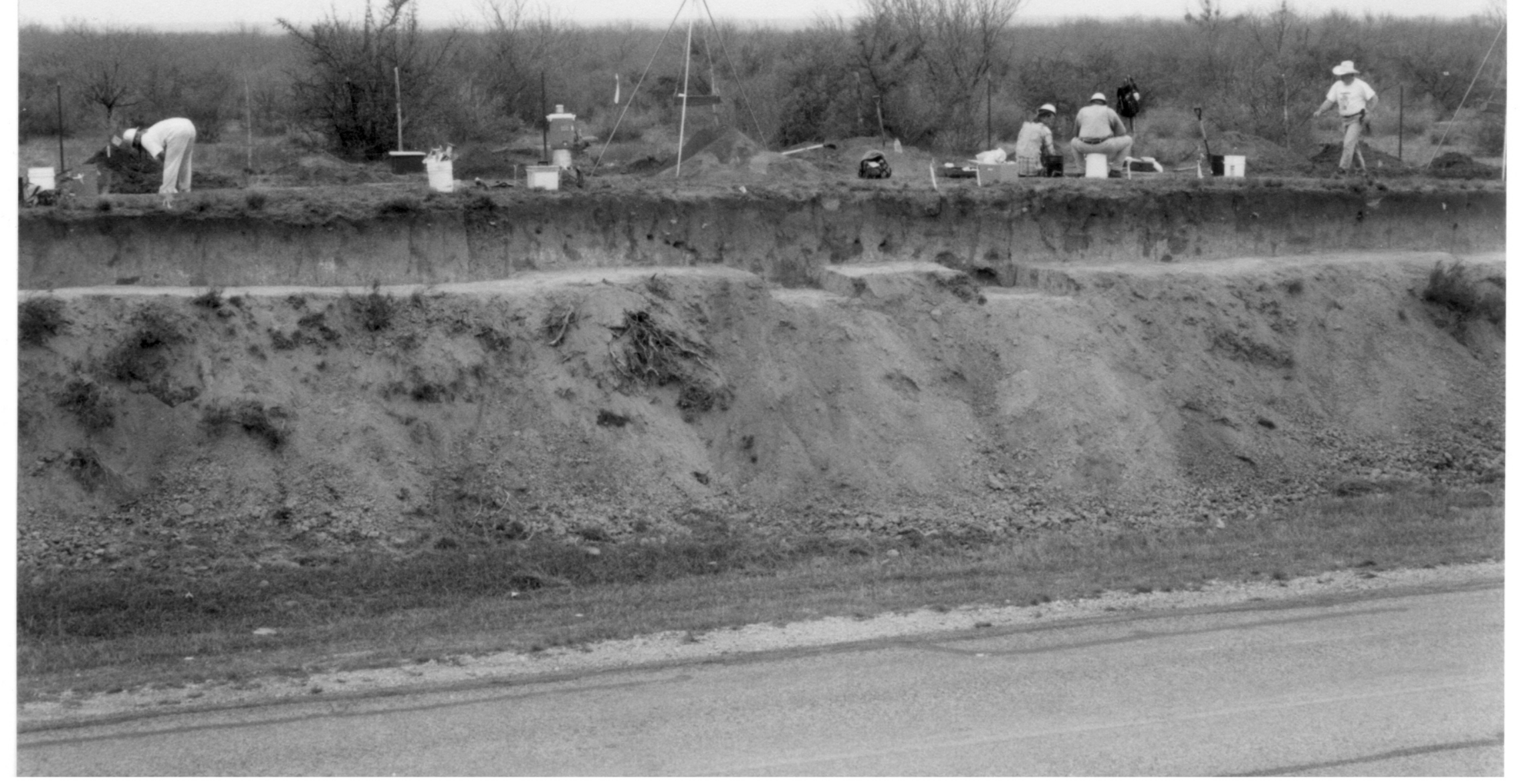

by

Raymond P. Mauldin, Russell D. Greaves, Jennifer L. Thompson, Cynthia M. Munoz,

Leonard Kemp, Barbara A. Meissner, Bruce K. Moses, and Steve A. Tomka

with contributions by

J. Philip Dering, M.E. Malainey, C. Britt Bousman, and Rupali Datta

Texas Antiquities Permit Number: 3071

Work Authorization: 57518 SA005

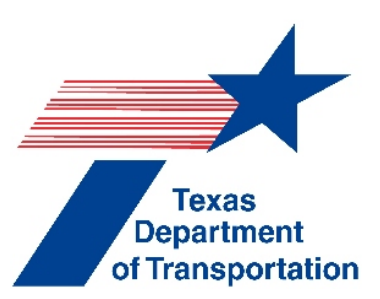

Environmental Affairs Division

Texas Department of Transportation Archeological Studies Program, Report No. 121

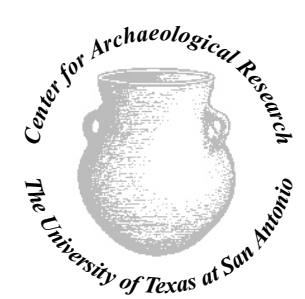

Center for Archaeological Research The University of Texas at San Antonio Archaeological Report, No. 409 


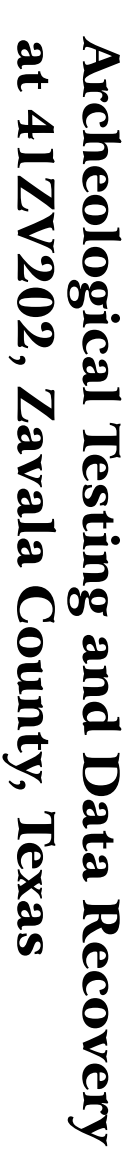

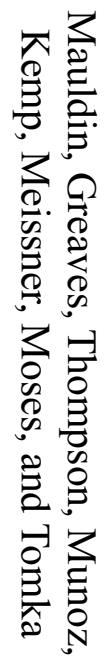

\begin{tabular}{l}
$\overrightarrow{0}$ \\
$\mathbb{0}$ \\
$:$ \\
\hline \\
0 \\
0 \\
0 \\
0 \\
0 \\
0 \\
0 \\
0 \\
0 \\
0
\end{tabular}

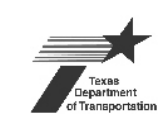

AR \#409

ASPR \#121 


\title{
Archeological Testing and Data Recovery at 41ZV202, Zavala County, Texas
}

\author{
by \\ Raymond P. Mauldin, Russell D. Greaves, Jennifer L. Thompson, Cynthia M. Munoz, \\ Leonard Kemp, Barbara A. Meissner, Bruce K. Moses, and Steve A. Tomka \\ with contributions by \\ J. Philip Dering, M.E. Malainey, C. Britt Bousman, and Rupali Datta
}

Texas Antiquities Committee Permit No. 3071

Principal Investigator

Steve A. Tomka

Work Authorization No. 575-18-SA005

CSJ No. 1590-02-006

Prepared for:

Environmental Affairs Division

Texas Department of Transportation Archeological Studies Program, Report No. 121

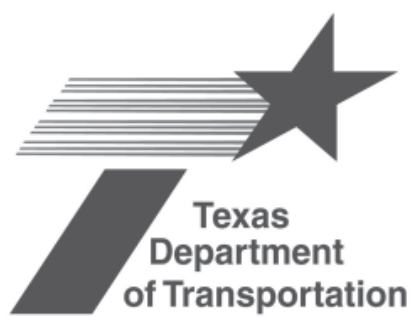

Prepared by:

Center for Archaeological Research The University of Texas at San Antonio Archaeological Report No. 409

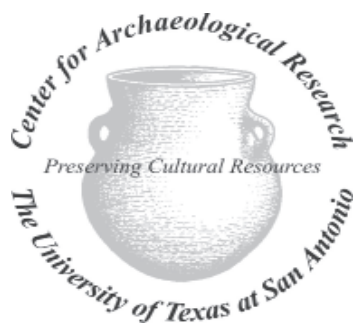




\title{
Archeological Testing and Data Recovery at 41ZV202, Zavala County, Texas
}

\author{
Copyright ${ }^{\circledR} 2010$ \\ Texas Department of Transportation (TxDOT) and Center for Archaeological Research, \\ The University of Texas at San Antonio (CAR-UTSA)
}

All rights reserved

TxDOT and CAR-UTSA jointly own all rights, title, and interest in and to all data and other information developed for this project under Contracts 57313SA002 and 57518SA005. Brief passages from this publication may be reproduced without permission provided that credit is given to TxDOT and CAR-UTSA. Permission to reprint an entire chapter, section, figures or tables must be obtained in advance from the Supervisor of the Archeological Studies Program, Environmental Affairs Division, Texas Department of Transportation, 125 East $11^{\text {th }}$ Street, Austin, 78701. Copies of this publication have been deposited with the Texas State Library in compliance with the State Depository requirements.

Printed by Blue Tape, San Antonio

2010

jointly published by

Texas Department of Transportation

Environmental Affairs Division

Archeological Studies Program

Scott Pletka, Ph.D., Supervisor

Archeological Studies Program, Report No. 121

A. McGraw, Series Editor

and

Center for Archaeological Research

The University of Texas at San Antonio

Archaeological Report, No. 409

ISBN: 1-930788-90-8 


\begin{abstract}
:
At the request of the Texas Department of Transportation, Environmental Affairs Division (TxDOT-ENV), the Center for Archaeological Research (CAR) of The University of Texas at San Antonio (UTSA) conducted archeological significance testing at 41ZV202, a prehistoric site located in northwestern Zavala County, in March of 2003. The work, conducted under Texas Antiquities Permit No. 3071 issued to Dr. Steven A. Tomka, was done in anticipation of the potential widening by TxDOT of FM 481. While materials dating to the Archaic were also present, the testing demonstrated the presence of significant Late Prehistoric (Austin Interval) deposits with good integrity within a portion of the TxDOT right-of-way (ROW). As TxDOT construction could not avoid these deposits, and as both the Texas Historical Commission (THC) and TxDOT concurred with CAR's recommendations that the deposits were eligible for listing on the National Register of Historic Places (NRHP) under criterion d of 36CFR 60.4, data recovery investigations were initiated. CAR began that work in July and August of 2003. The testing permit was amended to include the data recovery efforts. Dr. Russell Greaves served as project archeologist for both the testing and data recovery effort at 41ZV202.
\end{abstract}

The testing and data recovery work consisted of the excavation of a 53-m-long Gradall trench, exposing and profiling a 75-m-long road cut, and the hand excavation of $521 \times 1$ meter units that removed approximately $34.6 \mathrm{~m}^{3}$ of soil. Testing identified two large, dark stained areas designated Features 4 and 5, an associated hearth (Feature 7), and a small cluster of FCR (Feature 6). Just over 1,000 chipped stone items were recovered, including several Scallorn points, one reworked dart point, several bifaces, and two flake tools. Eleven AMS radiocarbon dates were submitted from deposits, with eight clustering around 1000 вр. Data recovery efforts defined FCR features 8 through 13. In addition, 24 arrow points, several dart points, a variety of unifacial and bifacial tools, a small number of cores, roughly 6,000 pieces of debitage, and a variety of burned sandstone, were recovered. We also collected small quantities of bone and mussel shell along with about 14,350 gastropod shells, and a variety of soil samples. Finally, all calcium carbonate nodules were retained from the screens.

Following the completion of data recovery efforts, the CAR was directed by TxDOT to develop a research design for the analysis of the material from 41ZV202. TxDOT and THC accepted that research design in November of 2004, at which time the CAR began analysis and report production. Unfortunately, by 2005 project archeologist Russell Greaves had left the CAR. At that point, CAR assistant director Dr. Raymond Mauldin took over the project. The analysis of the 41ZV202 Late Prehistoric data outlined in this report is conducted in the context of a large-scale, theoretically driven model of adaptation for hunters and gatherers loosely based on aspects of Optimal Foraging Theory. In addition to 41ZV202, the approach relies on comparative data sets from Late Archaic and other Late Prehistoric sites from South and South-Central Texas to investigate shifts in subsistence, technology, and mobility across this broad region.

At this time, discard decisions have not been made. However, all artifacts and associated samples collected and retained during this project, along with all project-associated documentation, are to be permanently curated at the CAR according to Texas Historical Commission guidelines. 


\section{Table of Contents:}

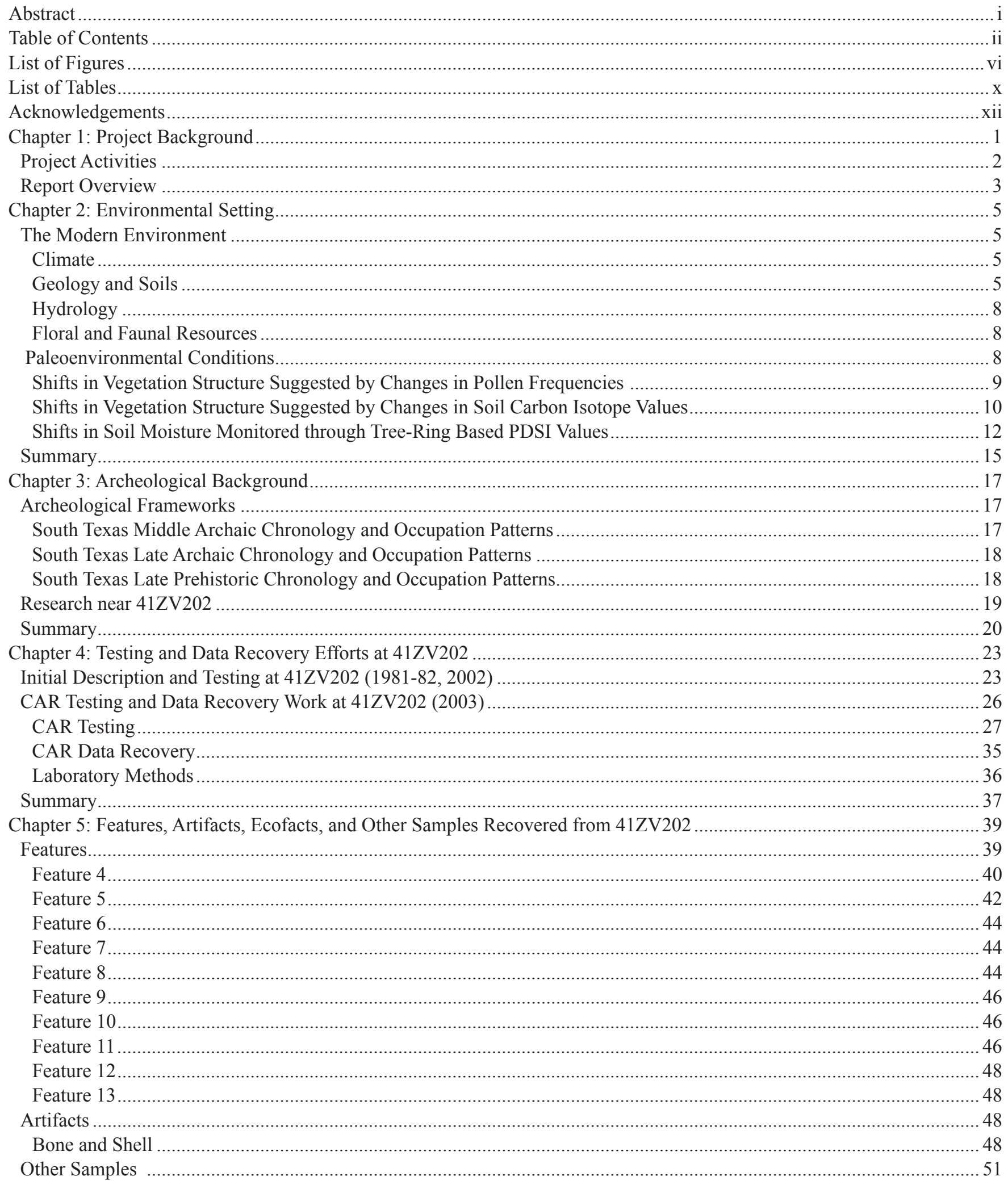




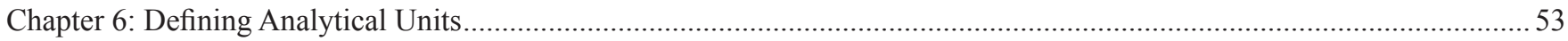

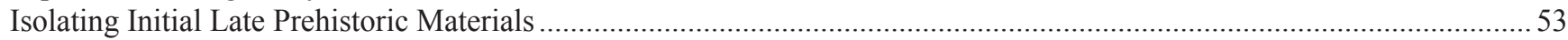

Assessing Integrity and Horizontal Distribution of the Late Prehistoric Materials .............................................................58

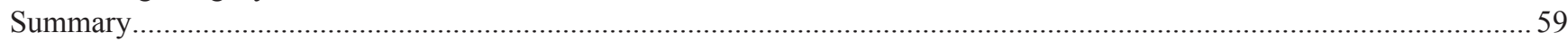

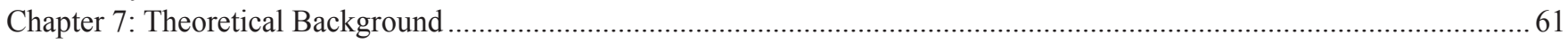

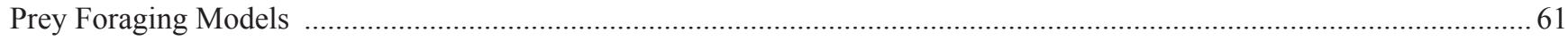

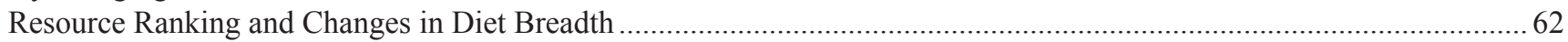

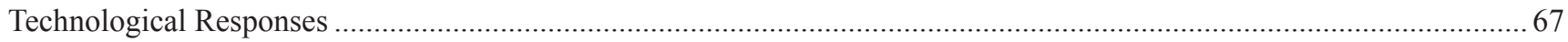

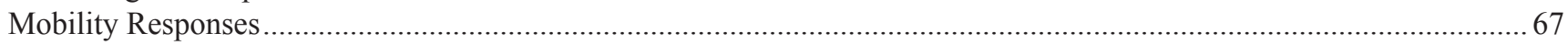

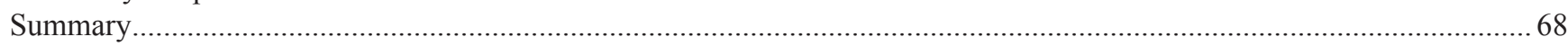

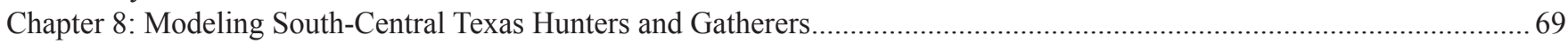

Patterns of Bison Presence/ Absence in Central and South Texas: Archeological Data ...................................................69

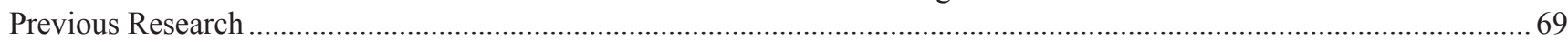

Reconsidering Late Holocene Bison Availability in Central and South Texas ................................................................. 70

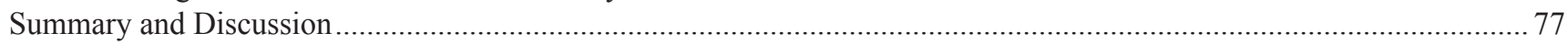

Patterns of Bison Abundance in Central and South Texas: Paleoclimate Data and Historic Accounts .......................78

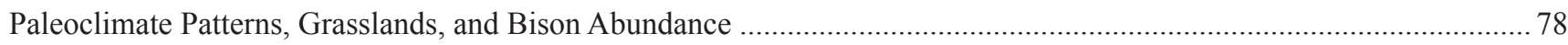

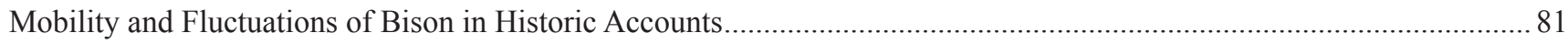

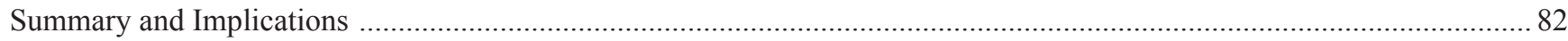

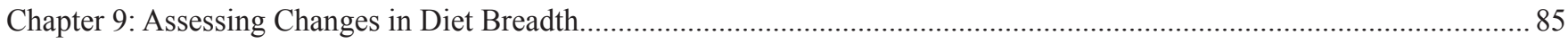

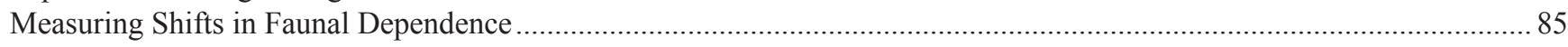

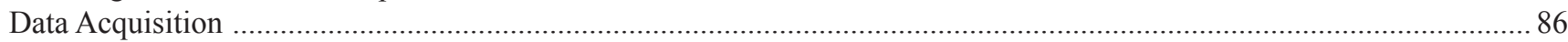

Faunal Results: Shifts through Time in the Number of Groups Represented ................................................................ 89

Faunal Results: Shifts in Mammal Fragmentation Data ............................................................................................... 91

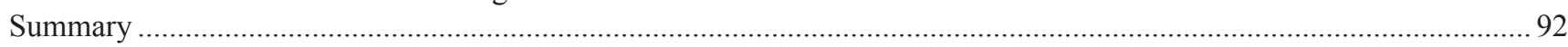

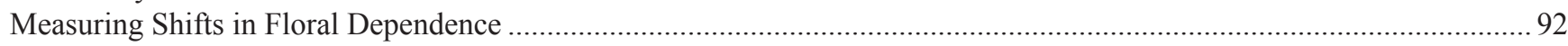

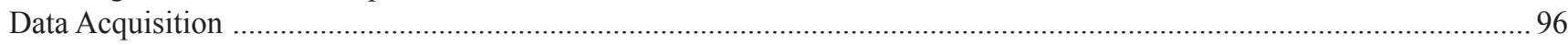

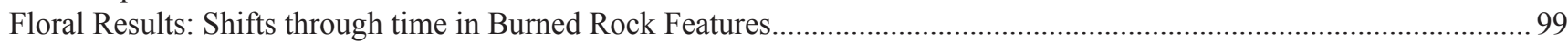

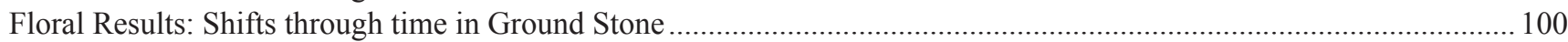

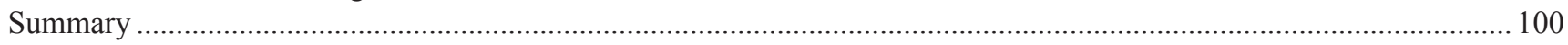

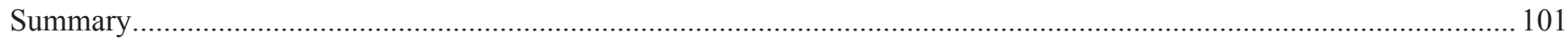

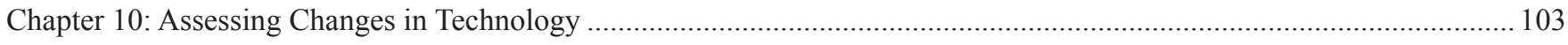

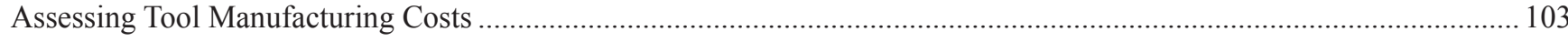

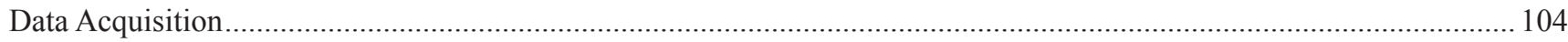

Shifts in Tool Manufacturing Costs ………………….......................................................................................... 106

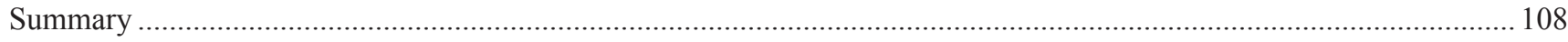

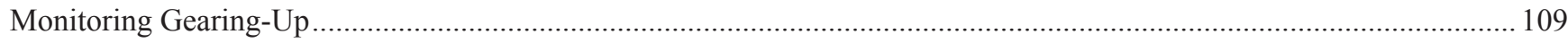

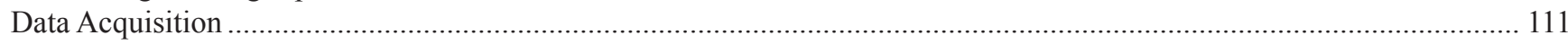

Shifts in Tool Replacement Strategies- Gearing-up and On-Demand Replacement ...................................................... 111

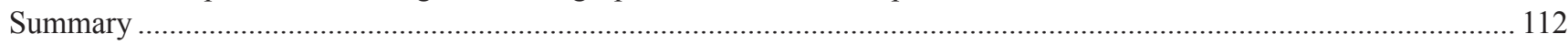

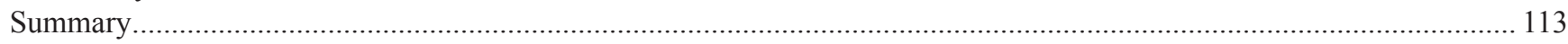

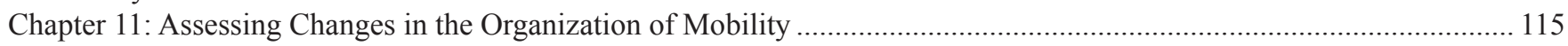

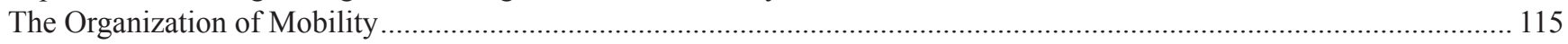

Distinguishing between Collecting and Foraging Locations through Artifact Variety .................................................... 115

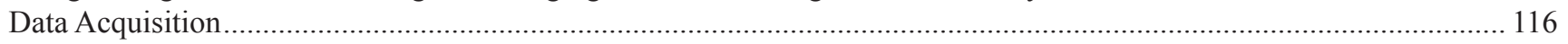

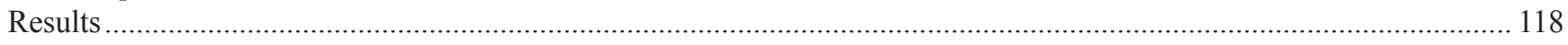

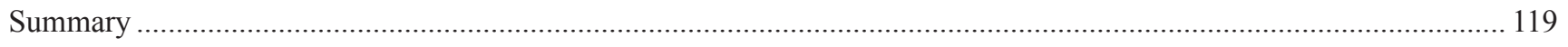

Distinguishing between Collecting and Foraging Locations through Site Maintenance .................................................. 119

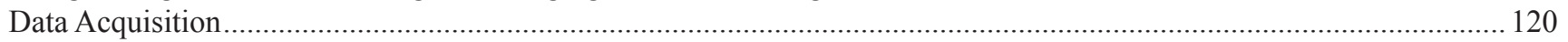

Results- Variability in Soil Chemistry and Magnetic Susceptibility Values ................................................................. 120

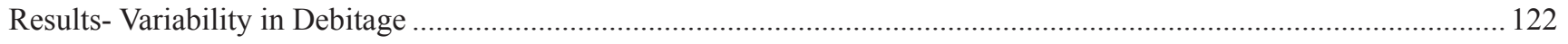

Results- Relationships and Spatial Patterning in Soil Chemistry and Debitage .............................................................. 124

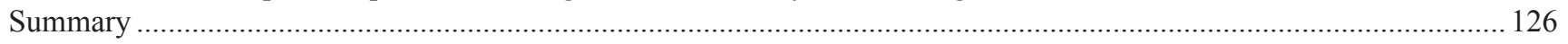

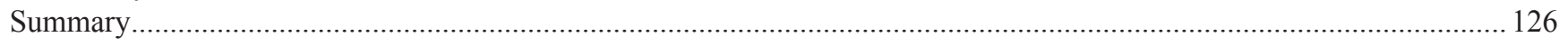




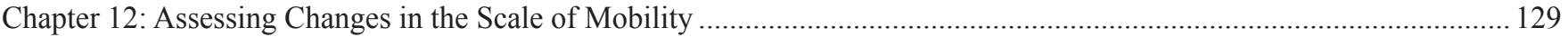

Investigating the Scale of Mobility- Chert Sources and Mobility Shifts ................................................................... 129

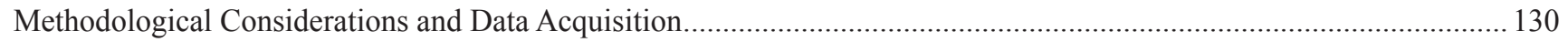

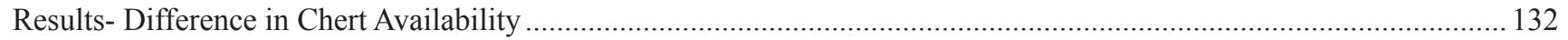

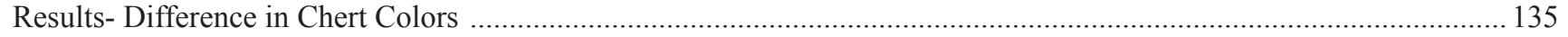

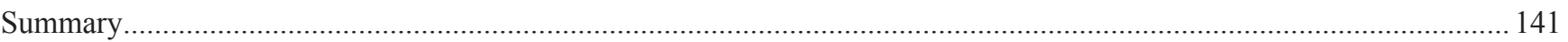

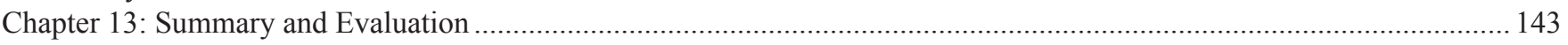

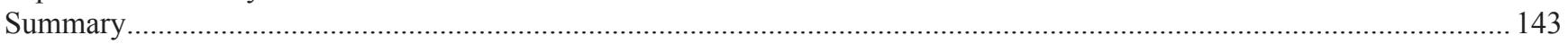

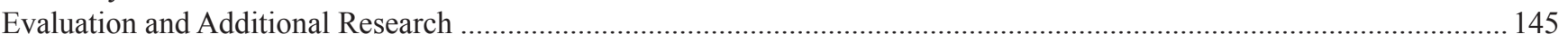

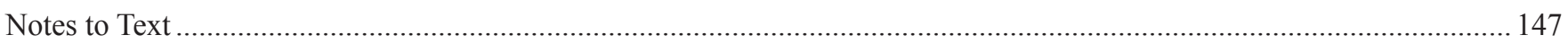

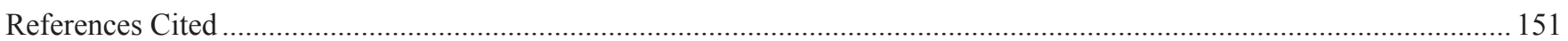

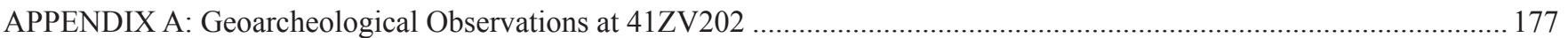

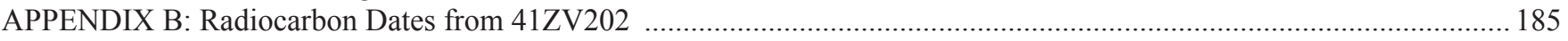

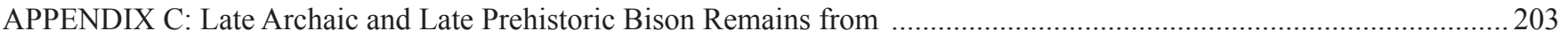

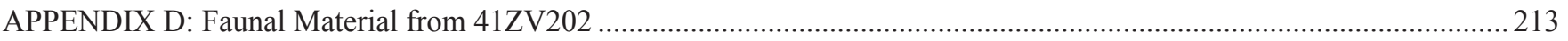

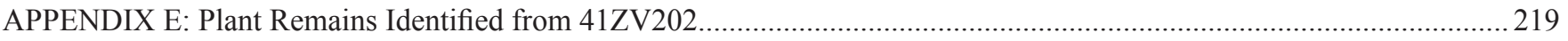

APPENDIX F: Analysis of the Fatty Acid Compositions of Archeological Rock Residues from 41ZV202 ........................ 223

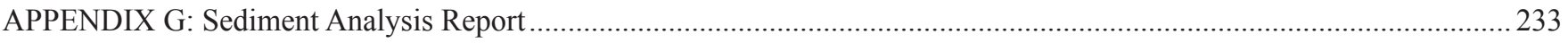

APPENDIX H: Magnetic Soil Susceptibility Results from Features 4 and 5 at 41ZV202 ……………............................241

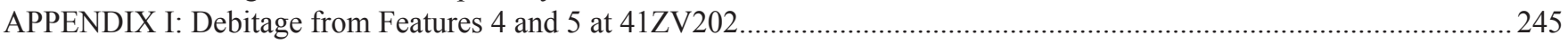




\section{List of Figures:}

Figure 1-1. Location and approximate boundary of 41ZV202 in northwest Zavala County............................................... 1

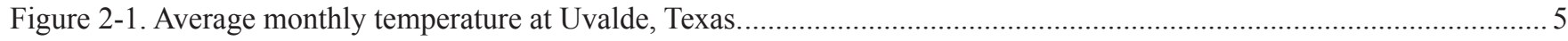

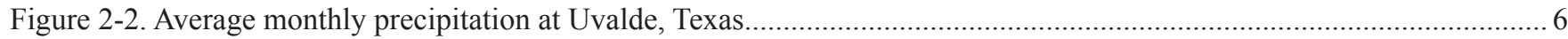

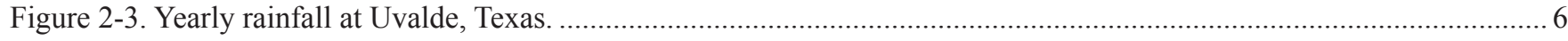

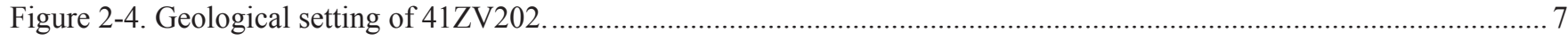

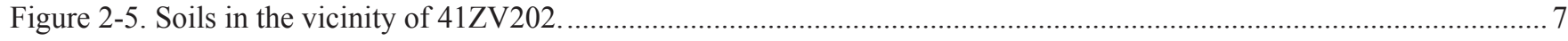

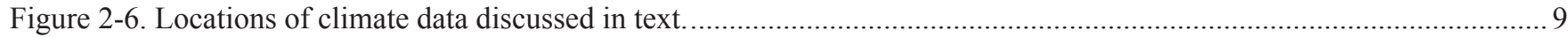

Figure 2-7. Boriack, Weakly, and Patschke bog pollen data....................................................................................... 10

Figure 2-8. Stable carbon isotope variation in soils from Median River (dashed line) and Hall's Cave

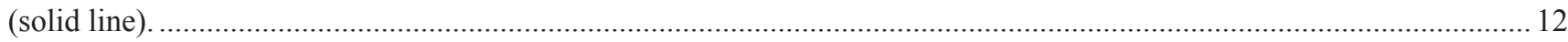

Figure 2-9. Actual and predicted Palmer Drought Severity Indices (PDSI) for grid point 166

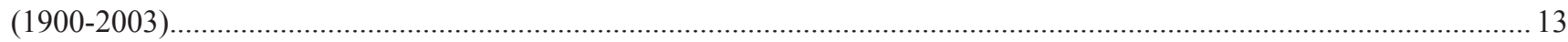

Figure 2-10. Mean and 95\% confidence intervals for PDSI values (top) and variability (bottom) at

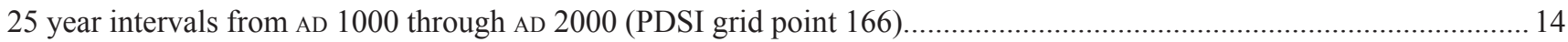

Figure 3-1. Location of selected archeological sites and projects discussed in the text......................................................2 20

Figure 4-1. Dart points recovered during TxDOT's 1981 testing at 41ZV202 include: a) Marcos;

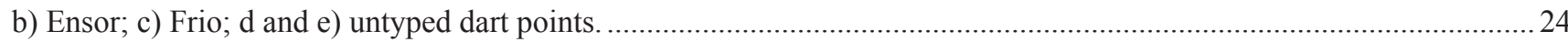

Figure 4-2. Selected ground stone and chipped stone tools recovered from 41ZV202 TxDOT's

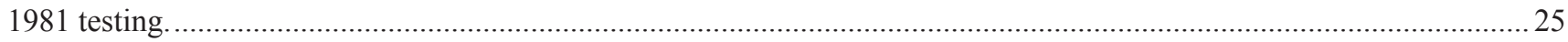

Figure 4-3. TxDOT and SWCA profiling and Gradall Trenching (2002) at 41ZV202. .................................................2 26

Figure 4-4. CAR Gradall Trenching (GT 3) and testing activities at 41ZV202 ...........................................................2

Figure 4-5. Cleaned 75 meter road cut profile. Note dark staining near top and areas of disturbance...................................22

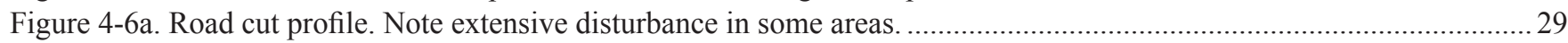

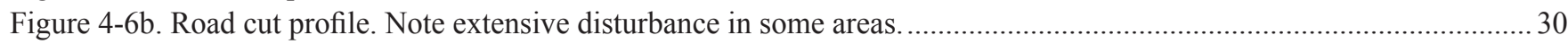

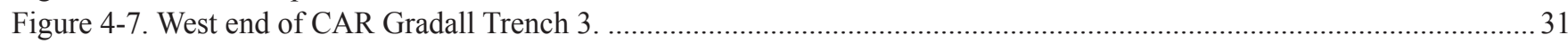

Figure 4-8. Surface of Feature 4 stain (top) and Feature 5 stain (bottom) as exposed in Gradall

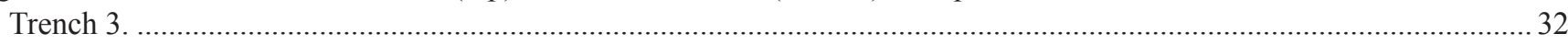

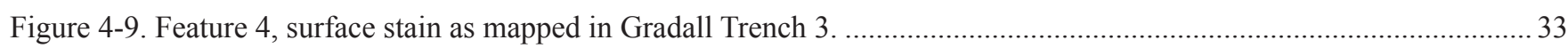

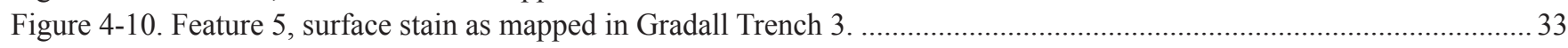

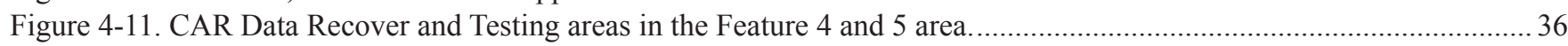

Figure 5-1. Location of features identified by CAR at 41ZV202. Note that Feature 6, defined at

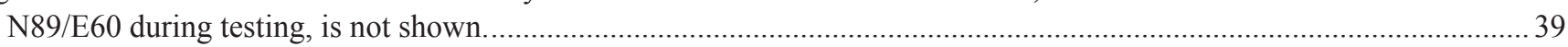

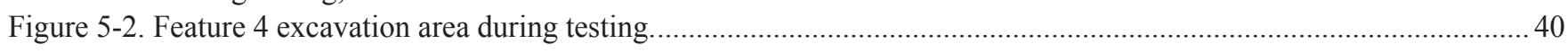

Figure 5-3. Feature 4, south wall profile and photos following testing. Note that the ${ }^{14} \mathrm{C}$ samples are

not from the profiled wall, but were piece-plotted on the floor of specific 1-x-1 meter units. ............................................ 41

Figure 5-4. Feature 5 excavation area during testing. Note stain/FCR concentration (Feature 7) centered at N94.5/E76.

Figure 5-5. Feature 5, south wall profile and photos (E81-E77 section) following testing. Note that the ${ }^{14} \mathrm{C}$ samples are not from the profiled wall, but were piece-plotted on the floor of specific

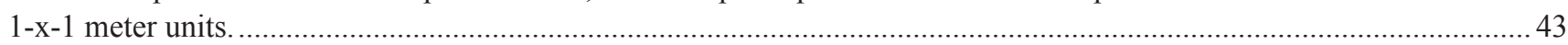

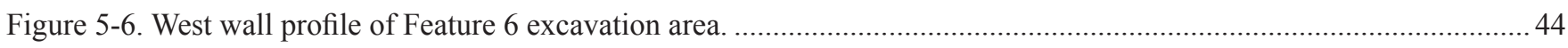

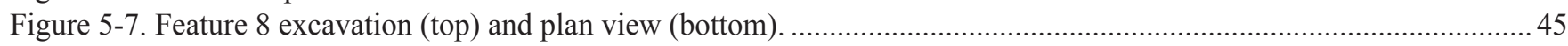

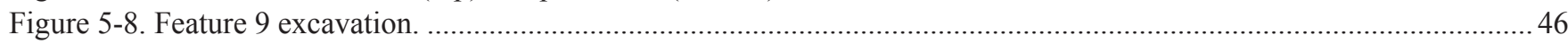

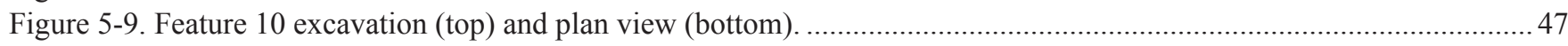

Figure 5-10. Feature 13 excavation (top) and plan view (bottom). …......................................................................... 49

Figure 5-11. Late prehistoric projectile points from 41ZV202. a-w) Scallorn; $x$ ) Caracara. ................................................ 50

Figure 5-12. Dart points recovered during data recovery excavations at 41ZV202. a-c) untyped dart points; d) Andice stem; e) Ensor point; f) untyped lanceolate dart point. 
Figure 5-13. Selected tools from data recovery excavations at 41ZV202. a) biface with graver;

b) uniface fragment; c-d) drills; e-j) miscellaneous bifaces........................................................................................5 52

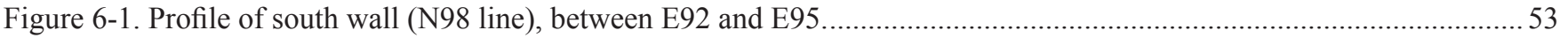

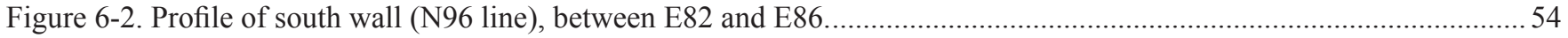

Figure 6-3. Profile of south wall (N93 line), between E77 and E80............................................................................. 54

Figure 6-4. Calibrated, corrected radiocarbon dates from 41ZV202. Plots are probability distributions.

Blue dates are from the $\mathrm{A} 2$ horizon, red dates are from the $\mathrm{Bw}$ horizon, and the purple date is from

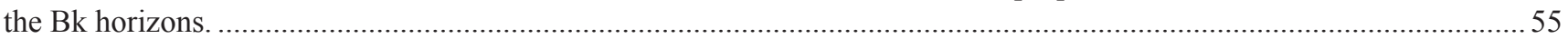

Figure 6-5. Debitage counts by level for data recovery excavation at 41ZV202 ….......................................................5 56

Figure 6-6. Burned rock weights by level for data recovery excavation at 41ZV202 _........................................................56

Figure 6-7. Plan and profile view of point-provenienced items recorded during data recovery in the

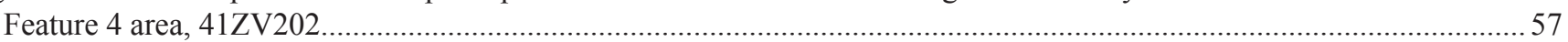

Figure 6-8. Carbonate nodule weights by level for data recovery excavations at 41ZV202 _.............................................5 58

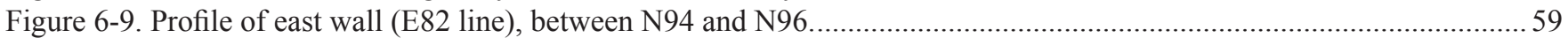

Figure 6-10. Distribution of Late Prehistoric arrow points and earlier dart points, Levels 2-5, at $41 \mathrm{ZV} 202$.

Figure 7-1. Post-encounter return rates (handling cost) by resource class (from Cane 1987;

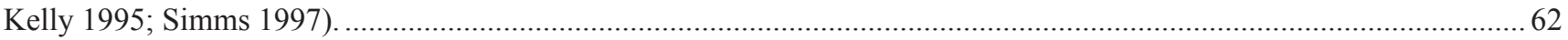

Figure 7-2. Optimal diet set as defined in prey models (after MacArthur and Pianka 1966)...............................................63

Figure 7-3. Seasonal changes in the nutritional quality of mule deer (from Anderson et al. 1972)......................................64 64

Figure 7-4. Yearly fluctuation in mesquite seeds and prickly pear fruit (from Windberg 1997)...........................................64

Figure 7-5. An example of diet expansion from 4 (A) to 5 (B) resources under conditions of closely ranked prey profitability and decreasing encounter rates.

Figure 7-6. An example of the potential impacts of radical differences in prey profitability

(resources 4 and 5). Under these conditions, diet expansion may not occur with decreasing

encounter rates (A to B).

Figure 8-1. Region and components investigated for bison presence/absence.................................................................... 71

Figure 8-2. Bison presence (yellow) and absence (red) on Initial Late Archaic components. ..............................................75

Figure 8-3. Bison presence (yellow) and absence (red) on Middle Late Archaic components. ............................................... 75

Figure 8-4. Bison presence (yellow) and absence (red) on Terminal Late Archaic components............................................. 76

Figure 8-5. Bison presence (yellow) and absence (red) on Initial Late Prehistoric components. ........................................... 76

Figure 8-6. Bison presence (yellow) and absence (red) on Terminal Late Prehistoric components....................................... 77

Figure 8-7. Comparison of graphs of bog pollen data and stable carbon isotope variation at selected

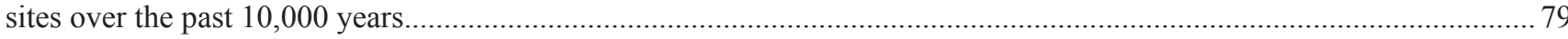

Figure 8-8. PDSI values (top) and variability (bottom) at 25 year intervals from AD 1000 through

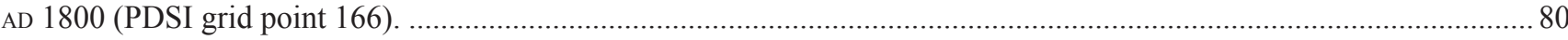

Figure 9-1. 41ZV202 and comparative sites used in fauna and floral investigations........................................................ 87

Figure 9-2. Number of faunal groups present through time (see Tables 9-1, 9-2) ............................................................. 89

Figure 9-3. Top: Number of faunal types by NISP. Bottom: Transformed number of types by NISP with 95\% confidence intervals (see Table 9-2).

Figure 9-4. Shifts in the average number of low return faunal groups (see Table 9-1) present through time. Sample size is the average NISP for low return groups by component................................................................. 91

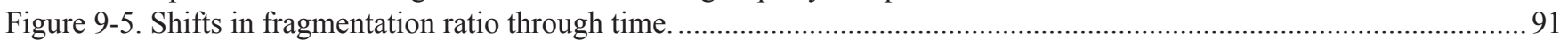

Figure 9-6. Percentage of fragmentation data composed of very large mammals by time period. ........................................92

Figure 9-7. Ethnographically reported cooking time for plants (top) and meat (bottom). Bars show the interquartile range (from Wandsnider 1997).

Figure 9-8. Changes in burned rock feature density through time (see Table 9-4). Sample size is the average number of rock features per component.

Figure 9-9. Changes in median area of features through time (see Table 9-6). Sample size is total rock features by time period.

Figure 9-10. Percent of components in our database that lack FCR feature by temporal period (see Table 9-4). Sample size is total number of components.

Figure 9-11. Shifts in ground stone density through time (see Table 9-4, 9-6). Sample size is the average number of ground stone per component used. 
Figure 10-1. Examples of tool cost categories from 41ZV202.

105

Figure 10-2. 41ZV202 and comparative sites used in technological investigations.......................................................... 106

Figure 10-3. Percentage of expensive tools through time (see Table 10-1) ........................................................................ 107

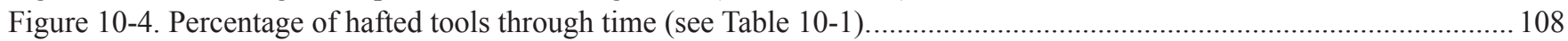

Figure 10-5. Percentage of inexpensive tools through time (see Table 10-1) ................................................................. 108

Figure 10-6. Proposed relationship between manufacture-failed and use-related items for locations

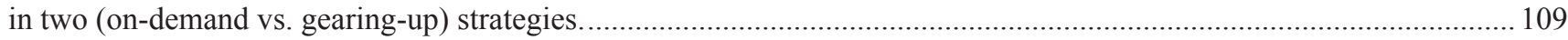

Figure 10-7. Examples of use-ware breakage and manufacture failure on artifacts from 41ZV202 .................................. 110

Figure 10-8. Breakage patterns for expensive tools on Late Archaic tools. .................................................................... 112

Figure 10-9. Breakage patterns for expensive tools on Initial Late Prehistoric tools......................................................... 112

Figure 10-10. Breakage patterns for expensive tools on Terminal Late Prehistoric tools.................................................. 113

Figure 11-1.Expected relationship between the number of artifact types and sample size for

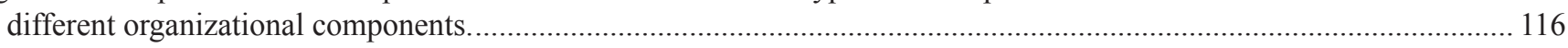

Figure 11-2. Number of artifacts plotted against the square of the number of artifact types. ............................................ 118

Figure 11-3. Units and levels in Features 4 and 5 selected for detailed comparison......................................................... 121

Figure 11-4. Adjusted residuals from cortex groups $(0 \%, 1-10 \%,+10 \%)$ by sample unit

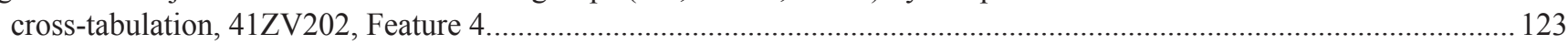

Figure 11-5. Adjusted residuals from cortex groups $(0 \%, 1-10 \%,+10 \%)$ by sample unit cross-tabulation, 41ZV202, Feature 5.

Figure 11-6. Bivariate plot of debitage counts and soil susceptibility values for 40 proveniences in Features 4 and 5.

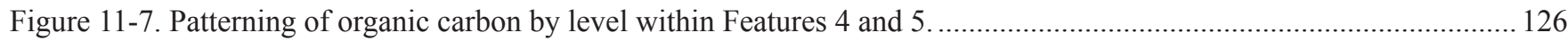

Figure 11-8. Patterning of debitage counts by level within Features 4 and 5............................................................... 126

Figure 11-9. Patterning of mass specific soil susceptibility values by level within Features 4 and 5............................... 127

Figure 12-1. Anticipated relationship between scale and the number of raw material types. ............................................ 129

Figure 12-2. An example of the impact of a Gaussian Blur highlighted within the black circle........................................ 130

Figure 12-3. Plot of red and green values for debitage, bifacial tools, and hafted items from 41ZV202. ........................... 131

Figure 12-4. Plot of red and blue values for debitage, bifacial tools, and hafted items from 41ZV202 ............................. 131

Figure 12-5. Plot of green and blue values for debitage, bifacial tools, and hafted items from 41ZV202.......................... 132

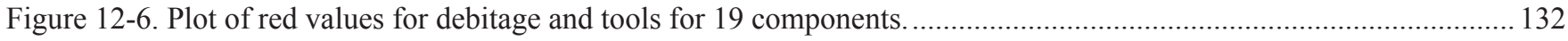

Figure 12-7. Geological units with chert (dark brown) present within $30 \mathrm{~km}$ of sites.................................................. 134

Figure 12-8. Confidence intervals (95\%) for blue mean values at 41ZV202 by artifact types. ..................................... 135

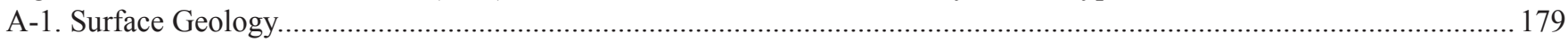

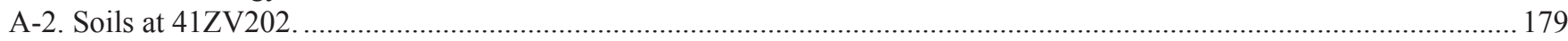

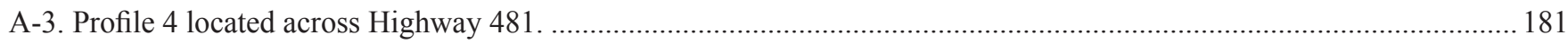

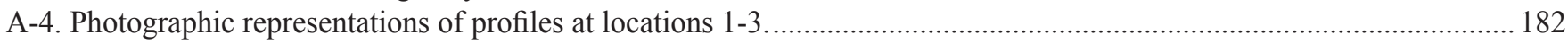

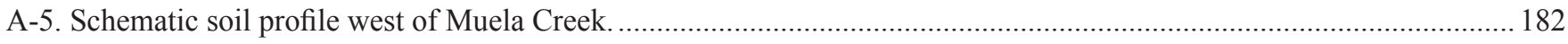

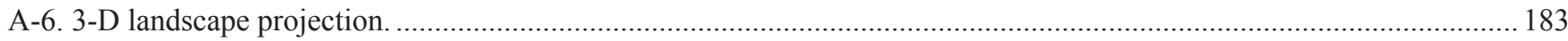




\section{List of Tables:}

Table 6-1. Distribution of Temporally Diagnostic Artifacts by Level Below Surface for Data

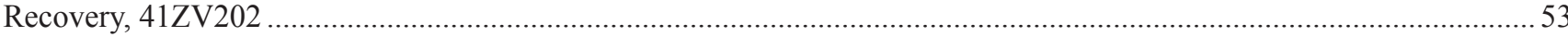

Table 8-1. Temporal Periods and Associated Diagnostic Artifacts for Central and South Texas................................. 71

Table 8-2. Component Level Bison Presence Data (NISP) for Sites Identified in Figure 8-1.............................................72

Table 8-3. Component Summary Statistics for Bison Presence Data in Table 8-2 ........................................................... 74

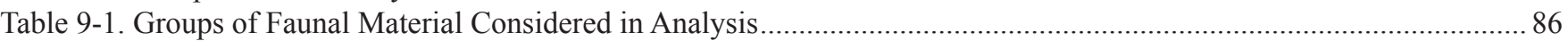

Table 9-2. Faunal Data Used to Assess Suggested Changes in Diet Breadth ..................................................................87

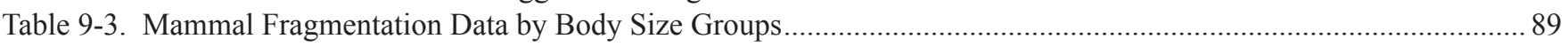

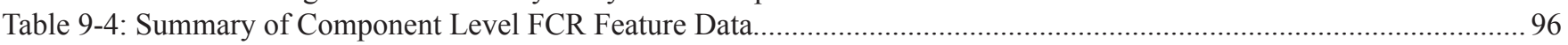

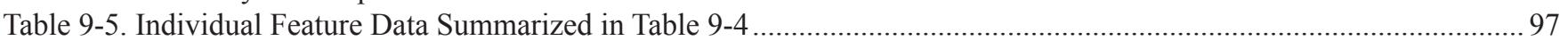

Table 9-6. Ground Stone Data at the Component Level ............................................................................................. 98

Table 10-1. Samples of Tools from 41ZV202 and Comparative Components Partitioned by Expense................................ 107

Table 10-2. Breakage Patterns on Formal Tools* ................................................................................................... 111

Table 11-1. Artifact Types Proposed for Use in Sample Size and Type Comparisons ...................................................... 117

Table 11-2. Artifact Variety and Sample Sizes for 41ZV202 and Comparative Components ............................................ 117

Table 11-3. Summary Statistics for Multiple Elements and Magnetic Soil Susceptibility Values,

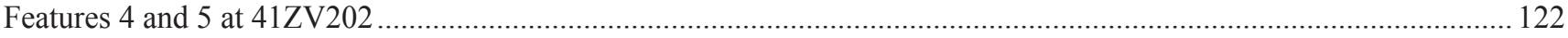

Table 11-4. Debitage Counts and Maximum Size for Selected Proveniences in Features 4 and 5,

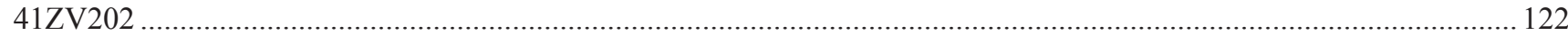

Table 11-5. Pearson's Correlation Coeffients on Selected Elements in Features 4 and 5................................................ 124

Table 11-6. Mass Specific Soil Susceptibility Values for Selected Locations and Temperature

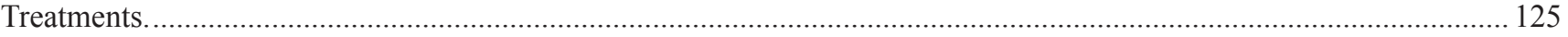

Table 12-1. RGB Statistics for Debitage from 41ZV202 and Comparative Components ................................................ 133

Table 12-2. RGB Statistics for Expensive Tools from 41ZV202 and Comparative Components ....................................... 133

Table 12-3. Chert Availability within a $30 \mathrm{Km}$ Radius of a Site ...................................................................................... 135

Table 12-4. Averages and Standard Deviations on RGB for Late Archaic Assemblages ................................................ 136

Table 12-5. Averages and Standard Deviations on RGB for Late Prehistoric Assemblages .............................................. 137

Table 12-6. T-Test Results for RGB Comparisons - Late Archaic Chipped Stone Samples................................................. 138

Table 12-7. T-Test Results for RGB Comparisons - Initial Late Prehistoric Chipped Stone Samples ................................. 139

Table 12-8. T-Test Results for RGB Comparisons - Terminal Late Prehistoric Chipped Stone Samples ............................. 139

Table 12-9. All Significant Mann-Whitney Test Results for RGB Comparisons on Debitage and

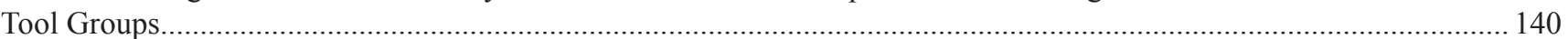

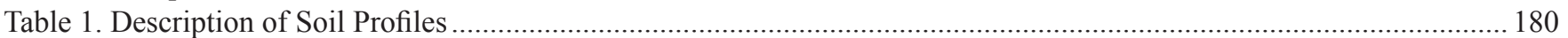

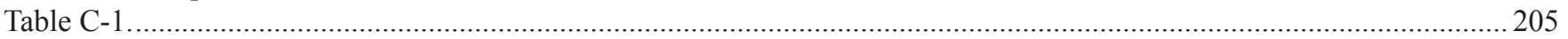

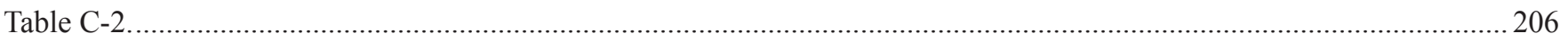

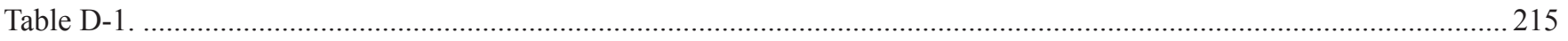

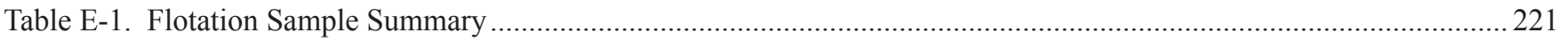

Table E-2. Contents of the Flotation and Macrobotanical Samples.........................................................................221

Table F-1. Summary of Average Fatty Acid Compositions of Modern Food Groups Generated

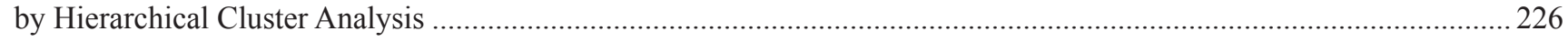

Table F-2. Criteria for the Identification of Archaeological Residues Based on the Decomposition

Patterns of Experimental Cooking Residues Prepared in Pottery Vessels ..............................................................227

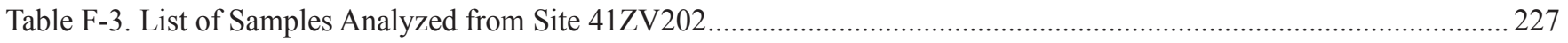

Table F-4. Fatty Acid Composition and Identification of Residues from Site 41ZV202 ................................................228

Table G-1 Results: Inorganic, Organic, and Total Carbon (Mean Values \pm SD) ..........................................................235

Table G-2. Inorganic Carbon Reproducibility-(Replicate Check) ...............................................................................235

Table G-3. Organic Carbon Reproducibility-(Replicate Check) ................................................................................236

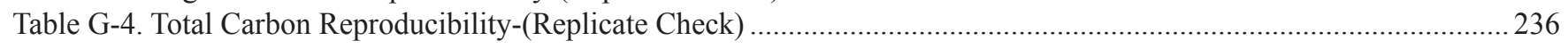

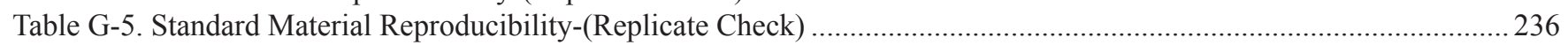




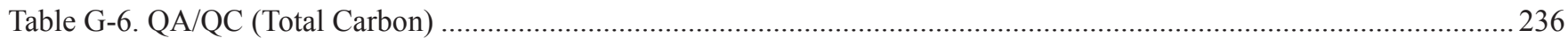

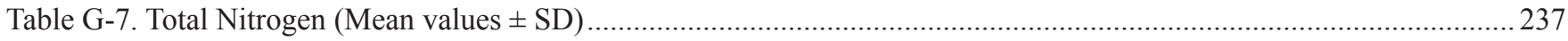

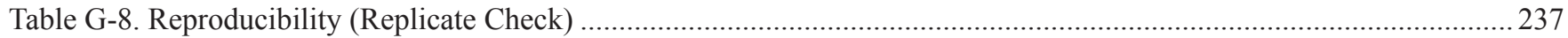

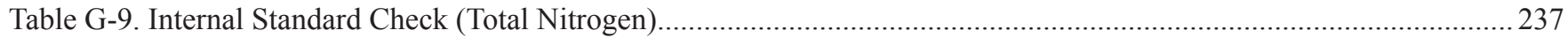

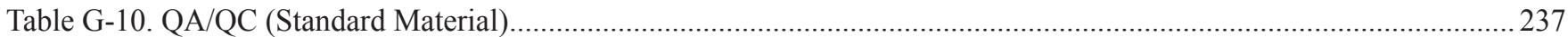

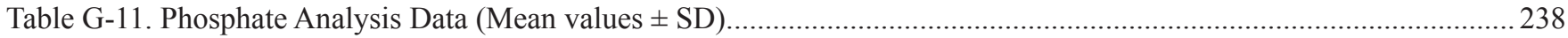

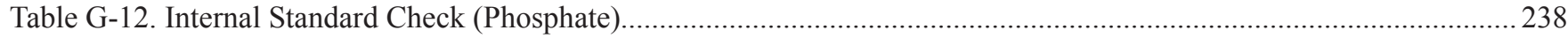

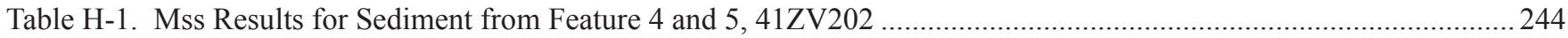

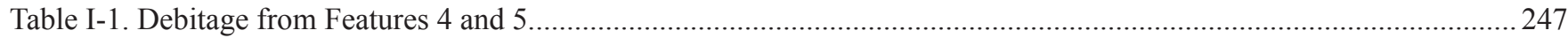




\section{Acknowledgements:}

In 2003, several individuals conducted the field work described in this report. Unfortunately, as the senior author of this report (Mauldin), I was not really one of them. I do have a vague memory of helping with Feature 6 for a day in the spring of 2003, but the image is fleeting. Consequently, in constructing these acknowledgements, I am certain to overlook a number of critical people. Sorry about that, but these acknowledgements are primarily being constructed from contract documents, field notes, and my increasingly faulty memory of who worked on a project almost seven years ago.

First off, Russell Greaves oversaw all CAR fieldwork at 41ZV202, along with the initial data cleanup. Rusty wrote a series of post-field and interim reports, along with an early version of a research design, which described the work at 41ZV202. These documents were extremely helpful and I have, wherever possible, incorporated his text in this document. The testing and data recovery field crews consisted of Jason Weston, Leonard Kemp, Bryant Saner, David Hafernik, Stacy Waggner, M. Parks, R. Davies, Mathew Senn, and Waldo Troell. Marybeth Tomka and Cynthia Munoz oversaw lab work on the project at CAR. Thanks specifically to Cathy Stacy for her help in tracking down various problems that seemed to spring up from time to time.

I originally developed the research design that guided this analysis over a week of intensive conversations with CAR director Steven Tomka sometime in 2004. Subsequent discussions and conversations with Jennifer Thompson (CAR), Cynthia Munoz (CAR), Robert Hard (UTSA), James Abbott (TxDOT), John Arrn (TxDOT), and Leonard Kemp (Geo-Marine) have helped shape these ideas. Before leaving CAR for greener pastures, Leonard also conducted much of the photography for the RGB color analysis of lithic tools and debitage from 41ZV202 and comparative collections, with help from Bruce Moses. Leonard also was instrumental in tracking down and compiling much of the bison information presented in Appendix C. Joey Thompson and Jason Perez both helped with debitage analysis and Steven Tomka helped with aspects of the tool analysis. Barbara Meissner played a critical role, spending a lot of time at the Texas Archeological Research Laboratory in Austin, as well as at the CAR lab, looking over faunal collections. Thanks Barbara. Bruce Moses, with the help of Rick Young, served as the site surveyor. Dr. Phil Dering (Shumla Archaeobotanical), Dr. Mary E. Malainey, and Dr. Ruapli Datta (UTSA- Environmental Sciences) conducted the specialized analyses of the 41ZV202 material. Dr. Britt Bousman of the Center for Archaeological Studies at Texas State conducted geoarcheological work during testing. Bruce Moses, Rick Young, and Leonard Kemp created the figures in this report. Jennifer Thompson and Bruce Moses edited the text. Steven Tomka also served as Principal Investigator. Thank you all for your tremendous help.

Marybeth Tomka of CAR helped with access to HIT collections and records located at the Center. Laura H. Nightengale and Carolyn Spock of the Texas Archeological Research Laboratory facilitated access to collections and records at that institution. Thanks to Robert Blasing of the US Bureau of Reclamation for allowing access to Choke Canyon collections and records, and to Patty Patterson of the US Army Corps of Engineers, Fort Worth District, for granting access to the collections from 41WM267. I appreciate their willingness to facilitate research.

Finally, there are a bunch of people from THC and TxDOT to thank. Some of them still work at these institutions, while others have moved on to other places. Specifically, I need to thank James Bruseth, Mark Denton, Owen Lindauer, G. Lain Ellis, James Abbott, Scott Pletka, Al McGraw, Christopher Ringstaff, Nancy Kenmotsu, Timothy Meade, and Sergio Iruegas. They helped in conducting and completing the field work, facilitated the analysis, and provided valuable feedback along the way. Christopher Ringstaff, James Abbott, and Jason Barrett provided helpful comments on the draft report.

Raymond Mauldin 


\section{Chapter 1: Project Background}

\author{
Raymond Mauldin
}

Site 41ZV202 is a multi-component site in northwestern Zavala County, Texas, along a segment of FM 481 (Figure 1-1). The site is on the west bank of Muela Creek, on a slightly elevated Pleistocene alluvial fan at roughly 775 ft (235M) AMSL (Abbott 2002). The highway bisects the site. The site boundaries shown in Figure 1-1 are estimates. The site is roughly $120 \mathrm{~m}$ east-west and extends an unknown distance north south. The current roadway cuts approximately $10-15 \mathrm{ft}$ below grade, essentially cutting through the terrace and destroying much of the archeological deposits within the TxDOT right-of-way (ROW). However, two roughly 8 to $10 \mathrm{ft}$ wide swaths located to the north and south of the east-west running roadway remain (see Figure 1-1). These remnants contain Late Archaic and Late Prehistoric materials and would be impacted by roadway expansion.

Originally identified and recorded by TxDOT in 1981 (see Crawford 1981; Mauldin et al. 2004), 41ZV202 was subsequently tested in 1981 by Jerry Henderson, TxDOT archeologist, and was also examined by SWCA in May and June of 2002 (O'Farrell and Miller 2002). In November of 2002, TxDOT further investigated the deposits using two Gradall trenches (Abbott 2002). Based on these preliminary investigations, TxDOT issued Work Authorization No. 573-02SA002 to the Center for Archaeological Research (CAR) to conduct testing at 41ZV202. The testing was designed to determine if the site was eligible for listing on the National Register of Historic Places (NRHP) and to determine if 41ZV202 warranted designation as a State Archeological Landmark (SAL). That testing, conducted in March of 2003, was undertaken in the context of anticipated road improvements to FM 481 including the potential widening of the roadway along the section containing 41ZV202. Dr. Russell Greaves served as project archeologist.

The testing undertaken by CAR demonstrated the presence of significant Late Prehistoric (Austin Interval) deposits in the ROW. The deposits had good integrity. Included in the deposits were features with ethnobotanical remains, small amounts of faunal material, and a variety of chipped stone tool forms (Greaves 2002). Based on these results, CAR recommended that the site was eligible for inclusion to the NRHP under criterion $\mathrm{d}$ of $36 \mathrm{CFR} 60.4$, in that it was likely to yield information important in prehistory. In addition, we suggested that the site warranted designation as a SAL under criteria 1 and 3 of the Texas Antiquities Code. The site had the potential to contribute to a better understanding of the prehistory of Texas by the addition of new and important information (criterion 1), and the site possesses unique or rare attributes concerning Texas prehistory (criterion 3). Given these recommendations and the scale of the impacts associated with the anticipated work within the ROW, we further recommended that if construction impacts to the site could not be avoided, data recovery efforts directed at recovering the significant data associated with the Late Prehistoric period be initiated at 41ZV202.

The Texas Historical Commission (THC) and TxDOT concurred with those recommendations. As construction impacts to the site associated with the anticipated work along FM 481 could not be avoided, data recovery investigations were initiated by CAR in the summer of 2003 under TxDOT Work Authorization No. 573-06-SA002. The work was conducted between July 9 and August 1, 2003, under Texas

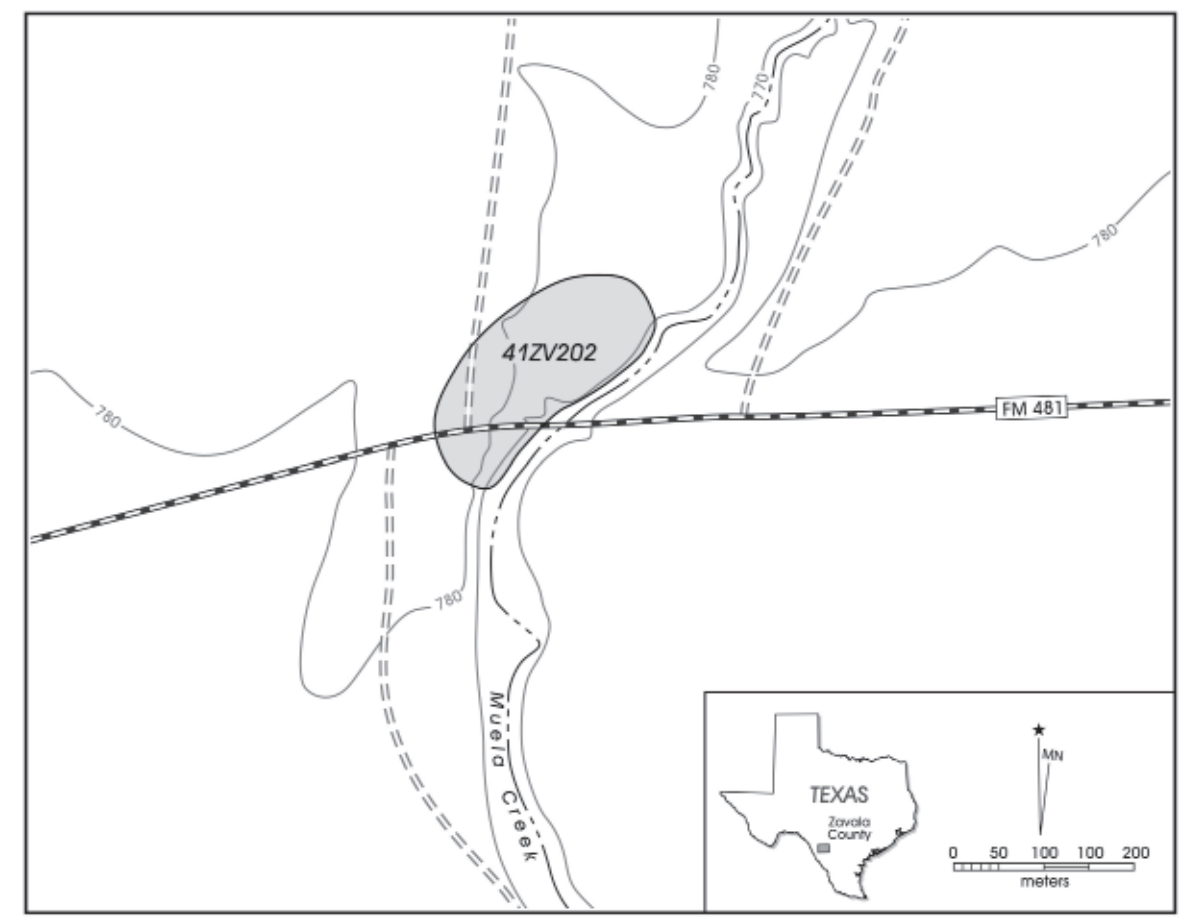

Figure 1-1. Location and approximate boundary of 41ZV202 in northwest Zavala County. 
Antiquities Committee (TAC) permit no. 3071 issued to Dr. Steve A. Tomka. Dr. Russell Greaves again served as project archeologist.

Following the completion of data recovery efforts, CAR was directed to develop a research design linking the data recovered from 41ZV202 with research goals. That research design (Tomka et al. 2004a) was developed under Work Authorization No. 573-13-SA002. Following TxDOT and THC acceptance of the research design in November of 2004, CAR began analysis and report production under Work Authorization No. 575-18-SA005. Unfortunately, following the completion of the field work, but subsequent to the production of the research design, project archeologist Dr. Russell Greaves left CAR. Dr. Raymond Mauldin subsequently took over the project.

\section{Project Activities}

CAR conducted NRHP eligibility testing at 41ZV202 during March 2003. Based on previous work at the site, CAR focused testing, as well as subsequent data recovery efforts, in the southern area of the ROW, an area estimated to be roughly $490 \mathrm{~m}^{2}$. The northern portion of the ROW, covering an area of roughly $400 \mathrm{~m}^{2}$, had been subject to significant impacts from road improvement and underground utility installation. No surface material and only very thin remnant $\mathrm{A}$ and $\mathrm{B}$ horizons were present on the northern side of FM 481. CAR undertook three principal tasks during the March 2003 testing of 41ZV202. First among these was a geomorphic re-examination of the site through profiling a 75-m-long segment of the southern road cut exposure of FM 481. Secondly, we conducted Gradall trenching to expose potential buried features along a 53-m-long corridor placed on what was judged, based on previous work, to be the most intact portion of the site. Finally, we manually excavated selected features exposed by the Gradall trenching.

CAR personnel excavated 12 1-x-1-m test units to depths of $70-100 \mathrm{~cm}$ below datum (bd; slightly more than $9 \mathrm{~m}^{3}$ ). This testing identified two large, dark stained areas designated Features 4 and 5, an associated hearth (Feature 7), and a small cluster of FCR. The small FCR accumulation, designated Feature 6 , was at the western end of the 75 -m-long road cut profile. The 10 excavation units in the Feature 4 and 5 area produced just over 1,000 lithics that included three Scallorn points, one reworked dart point, several bifaces, and two flake tools. Twenty-nine charcoal samples were collected from the Feature 4, 5, and 7 areas, and 11 were submitted for AMS dating. Eight of those samples produced dates of approximately 1000 BP. Dating indicated a high probability that Features 4, 5, and 7 represented closely spaced occupational events. Based on these testing results, CAR suggested that site 41ZV202 had good integrity and contained Late Prehistoric (Austin Interval) data that were likely to yield important information on a variety of research topics, including subsistence, technological organization, site structure, and mobility.

With the concurrence of TxDOT and THC, CAR initiated data recovery efforts at the site. These efforts included the hand-excavation of 40 contiguous $1-x-1-m$ units. These units encircled the 10 previously excavated units, producing 50 contiguous $1-\mathrm{x}-1-\mathrm{m}$ units (see Figure 1-2). Two-hundred forty-six levels were excavated and screened during the data recovery efforts, while 81 levels were excavated in this same area during testing. These data recovery efforts defined FCR features 8 through 13 . Features 8, 10, and 13 were associated with the A horizon deposits that appear heavily organically enriched and were identified as Feature 4 during the March 2003 testing while Features 9, 11, and 12 were all situated in the western portion of the site in the area designated as Feature 5 during the March 2003 testing.

Data recovery produced 30 projectile points, including 24 arrow points and six dart points. The vast majority of the arrow points are consistent with the type descriptions for Late Prehistoric Scallorn forms (Turner and Hester 1999:230). Earlier point types include what is probably an Early Archaic Andice stem fragment (Turner and Hester 1999:71-72), a Late Archaic Ensor form (Turner and Hester 1999:114), and the base of a small, untyped lanceolate point. In addition, a variety of unifacial and bifacial tools were recovered, along with a small number of cores and just over 6,000 pieces of debitage. Burned rocks were recorded during both phases of CAR's work at 41ZV202. Small quantities of modern items were collected during the data recovery work. A small quantity of bone, all of which is highly fragmentary, and a few pieces of mussel shell, were collected. In addition, roughly 14,350 complete and fragmentary gastropod shells were recovered from screening during data recovery. Ninetyseven piece-plotted charcoal samples were collected during testing and data recovery excavations. One hundred sixtytwo soil samples, each consisting of roughly 0.5 liters of soil, were collected from the 40 block excavation units dug during data recovery. Finally, all calcium carbonate nodules were retained from the screens for quantification.

The research design, developed in the fall of 2004, is an explicit, theoretically based approach to the analysis of the Initial Late Prehistoric, or Austin Phase, material collected by CAR during testing and data recovery efforts at 41ZV202. The approach is grounded in the principals of Optimal Foraging Theory developed primarily in biology (Stephens and Krebs 
1986; see also Bird and O'Connell 2006; Winterhalder 1981). The approach uses a cost/benefit framework to model aspects of prehistoric hunter-gatherer behavior (e.g., Kelly 1995; Simms 1987) in South-Central Texas. While human huntergatherers violate many of the assumptions of classic foraging models, and while parameters specified for analysis (e.g., return rates, search costs) are often difficult to estimate in archeological situations, we find the models appealing as they provide an explicit analytical framework.

The analysis phase of the project, governed primarily by the research design, began in the spring of 2005. Rather than focusing extensively on the Initial Late Prehistoric (Austin) data identified at 41ZV202, much of the analysis was focused on identifying and acquiring comparative data on subsistence, technological, and mobility related topics from Late Archaic, Initial Late Prehistoric, and Toyah Interval (Terminal Late Prehistoric) components represented on multiple sites from across South-Central Texas. The comparative data types were identified in the context of a large-scale, theoretically driven model of adaptation for hunters and gatherers. The data derived from the Austin component at 41ZV202, in conjunction with other Late Prehistoric and Late Archaic components from across the region, are used to evaluate the utility of the model. In turn, the model provides a context for interpreting the 41ZV202 material. This type of approach, with a heavy reliance on comparative material, is not common in cultural resource management investigations. Following the completion of the analysis phase of the project, Dr. Raymond Mauldin of CAR began the writing of this draft report in the fall of 2008. The draft report was completed in the summer of 2009, and this final report was completed in the winter of that year.

\section{Report Overview}

This final report on testing and data recovery at 41ZV202 consists of 13 chapters and nine appendices. This initial chapter introduces the project. Chapter 2 summarizes aspects of the modern project area environment. A review of what we think we know regarding prehistoric climate regimes in the region is also provided in that chapter. The third chapter provides a review of the culture history for the region, along with a summary of previous archeological research in the region. Included in that chapter is information on previous research at 41ZV202. Chapter 4 summarizes the testing and data recovery efforts undertaken by CAR at the site, while Chapter 5 provides a discussion of the materials recovered from 41ZV202. The sixth chapter uses the data in Chapter 5 and geomorphic data developed during testing to assess the overall integrity of deposits. We isolate a single analytical unit, dating to the Initial Late Prehistoric period, for subsequent analysis. Chapter 7 provides an overview of the theoretical position that governed the analysis. As mentioned previously, cost/benefit analysis developed in evolutionary ecology heavily influences the approach. Based on Chapter 7, the eighth chapter develops a general model of hunter-gatherer adaptations for South-Central Texas. A critical component of that model involves a re-assessment of presence/ absence data on bison within Central and South Texas during the Late Archaic and Late Prehistoric periods. We suggest that contrary to earlier reviews (see Dillehay 1974; Huebner 1991), bison are not absent from this portion of the state during the Initial Late Prehistoric period (Austin Interval). The continued availability of this high return resource leads to a series of expectations regarding the organization of subsistence, technology, and mobility for the Late Archaic and Late Prehistoric periods. Chapter 9 is the first of several chapters that use data from 41ZV202, in association with data from other components, to assess these expectations derived from the general hunter-gatherer model. Chapter 9 deals specifically with assessing changes in diet breadth, with Chapter 10 looking at changes in technological organization. The eleventh and twelfth chapters investigate changes in mobility through time. Chapter 13 provides a general summary, and considers the utility of the overall approach. Finally, a short "notes to text" section follows the $13^{\text {th }}$ Chapter. This section provided clarification on objections raised by TxDOT reviewers to both the overall approach as well as to several specific points.

Nine appendices support the 13 chapters. These include a geoarcheological summary (Appendix A) prepared by Dr. C. Britt Bousman of Texas State University following the testing phase of the work at 41ZV202. Appendix B provides a summary of radiocarbon results supplied by Beta Analytic. Appendix C, complied by Raymond Mauldin and Leonard Kemp, present data on bison availability for a series of site and components from Central and South Texas. Appendix $\mathrm{D}$, by Barbara Meissner of CAR, presents the analytical results for faunal material from 41ZV202. Appendix E, by Dr. Phil Dering of Shumla Archaeobotanical Services presents the 41ZV202 ethnobotanical results. Appendix F, by Dr. M. Malainey presents the analysis of fatty acids from selected 41ZV202 feature rock. Appendix G, prepared by Dr. Rupali Datta of the Environmental Geochemistry Laboratory at UTSA, presents an analysis of sediment from 41ZV202. Finally, Appendix H presents data on magnetic soils susceptibility for 41ZV202, while Appendix I presents data on the chipped stone recovered from the site. 



\section{Chapter 2: Environmental Setting}

\section{Raymond Mauldin}

This chapter provides an overview of the environment of the general project area. Included are short discussions of the physiographic setting, climate, geology, soils, vegetation, and faunal resources. In the second section of the chapter, paleoenvironmental conditions during the Late Holocene, the temporal period reflected in the archeological material at 41ZV202, are considered.

\section{The Modern Environment}

The project area is in northwest Zavala County, roughly $30 \mathrm{~km}$ to the southwest of the town of Uvalde, and $50 \mathrm{~km}$ to the northeast of the town of Eagle Pass. The area is on the northern edge of the Tamaulipan biotic province (Blair 1950). In this portion of the province, the region is a sparsely vegetated plain characterized by a semi-arid climatic regime. Often referred to as the Coastal Plain, Rio Grande Plain, or South Texas Plain, the region has low topographic relief and intermittent drainages, although several larger rivers, including the Nueces, Frio, and Rio Grande cut through the general area. About $50 \mathrm{~km}$ to the north of the project area is the Edwards Plateau, an uplifted, limestone-dominated region characterized by relatively denser vegetation. Here, oak and juniper, often underlain by a variety of grasses, are common, and the setting is dramatically different from that of the mesquite-acacia brushy flats of the project area.
The data in Figure 2-2 show that the rainfall tends to be bimodal, with peaks in the early summer months of May and June, and a smaller peak in late summer (August). The late winter to early spring months are the driest, with January, February, and March all having rainfall of around one inch (SRCC 2003c). Year-to-year variability in rainfall is shown in Figure 2-3 with data from 1913 through 1982 (National Climate Data Center [NCDC] 2004). The wettest year during this period was 1976 with over 45 inches of precipitation, while the driest year was 1956, with less than 10 inches of rainfall recorded.

\section{Geology and Soils}

As Figure 2-4, adapted from the Del Rio (Barnes 1977) and San Antonio (Barnes 1983) sheets of the Geological Atlas of Texas shows, cherts are not common near 41ZV202. However, a variety of materials well suited for hearth stones (sandstone and limestone) are available. At a regional level, Cretaceous age limestone and marl deposits (Kac) dominate the northern area (Figure 2-4). This formation lacks chert. The Anacacho Limestone (Kac) does contain isolated deposits of igneous rock (Ki), including basalt. Much of the region is mapped as Pleistocene fluviatile terrace deposits (Qt) that are associated with the Edwards Plateau. These deposits often contain chert gravels. Holocene age alluvium (Qal) floodplain deposits are associated with many of the

\section{Climate}

Presently, the climate of the study area is sub-tropical, with hot, humid summers and mild, dry winters (Stevens and Richmond 1976:98). Figure 2-1 presents the average minimum and maximum monthly temperatures at Uvalde, Texas between 1971 and 2000 (Southern Regional Climate Center [SRCC] 2003a, 2003b). During this period, July and August were the warmest months, with December and January being the coolest. The growing season in Uvalde County averages about 256 days per year. On average, 26 days a year are at or below freezing. The maximum temperature exceeds $99^{\circ} \mathrm{F} 41$ times a year (Stevens and Richmond 1976:98-99).

The average annual precipitation between 1971 and 2000 at Uvalde was 23.43 inches.

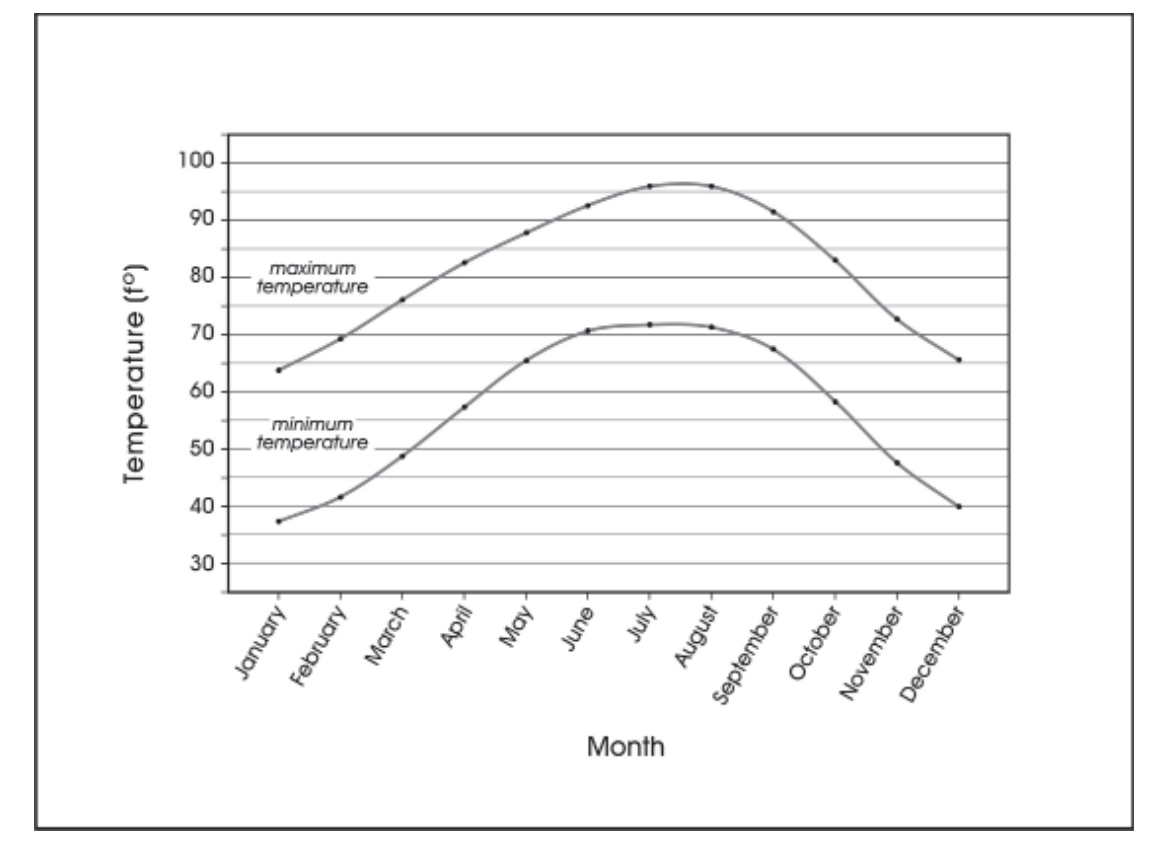

Figure 2-1. Average monthly temperature at Uvalde, Texas. 


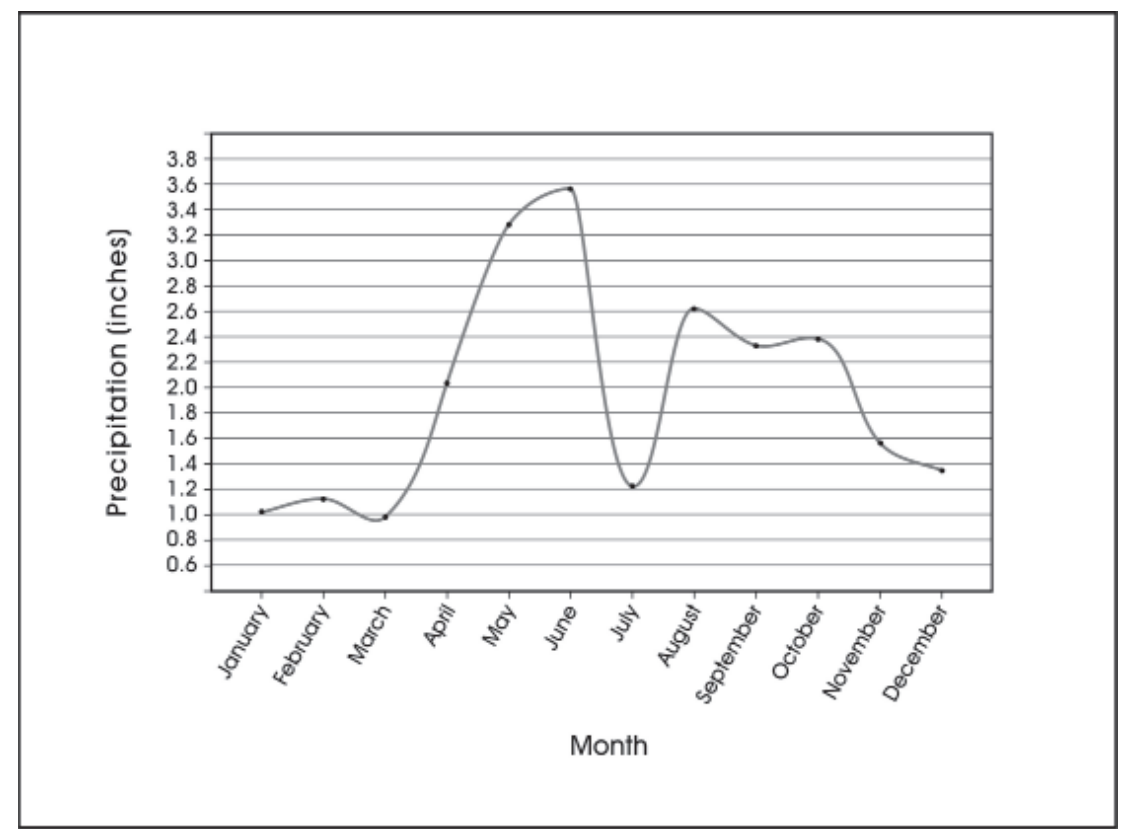

Figure 2-2. Average monthly precipitation at Uvalde, Texas.

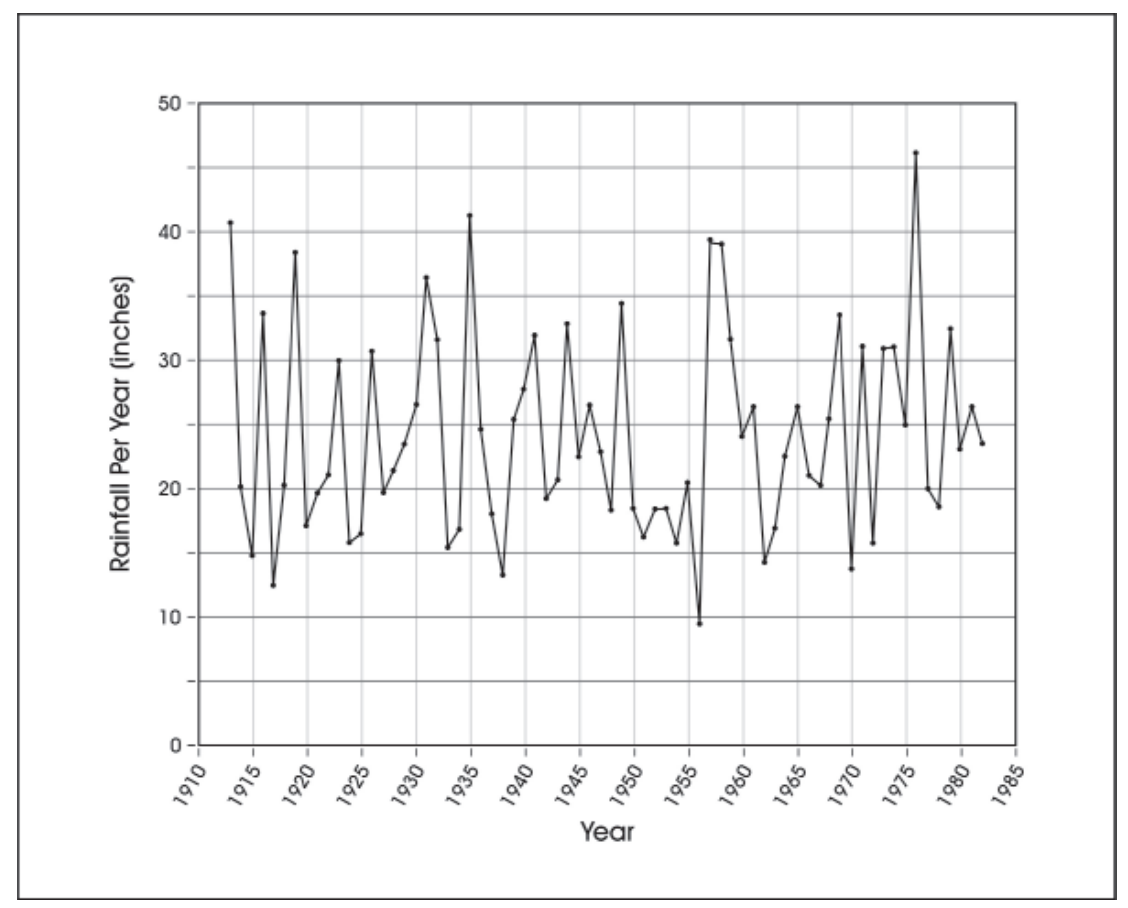

Figure 2-3. Yearly rainfall at Uvalde, Texas.

drainages. The Escondido Formation (Kes), also present in the current project area, contains shale, siltstone, and sandstone. The Eocene age Indio Formation (Ei) also contains sandstone, shale, and siltstone.

There is some disagreement regarding the geological age and origin of the site specific deposits. The site sediments are mapped as Quaternary alluvial terrace (Qt), but across Muela Creek deposits are identified as a Quaternary age alluvial fan (Qf). In his original characterization of the site setting for SWCA, Kuehn (2002) suggested that the site specific deposits represented middle to late Holocene age formation produced by multiple episodes of overbank flooding, presumably from Muela Creek. The site geology was reexamined by Abbott (2002). He argued that the deposit was probably Pleistocene, rather than Holocene in age. He also suggested that the deposits were unlikely to be associated with overbank flooding associated with Muela Creek. He based that suggestion on the height of the ridge deposit above Muela Creek, the elevation above the larger Chaparrosa valley to the west, and the relatively small size of Muela Creek. Rather than representing stream alluvium, Abbott suggested that the underlying landform was Pleistocene in age. He further suggested that the cultural material was contained in an eolian veneer. During CAR's testing of 41ZV202, Bousman (Appendix A) described a series of profiles on site. He concluded that the ridge feature containing 41ZV202 is probably part of the alluvial fan complex that is mapped on the east side of Muela Creek (Qf) and not an alluvial terrace. He identified two sedimentary units within the deposit, and while the age of the lower sedimentary unit could not be determined, Bousman concluded that the upper unit probably dates to the Late Holocene (see Appendix A).

Figure 2-5 presents the soils surrounding 41ZV202 (Stevens and Arriaga 1985). Much of the surrounding area is dominated by Uvalde silty clay loam (UVB), with Pryor sandy clay loam (PYB), Chacon clay loam (CKB), and Caid sandy clay loam (CDB) common. All of these soils are deep and well drained, with the Chacon, Uvalde, and Caid series being frequently associated with drainages. Tonio fine sandy loam (TOB), Zavco sandy clay loam (ZVB), and Montell Clay (MOA) are also mapped within the immediate area. 41ZV202 sits on Uvalde silty clay loam (see Appendix A). 


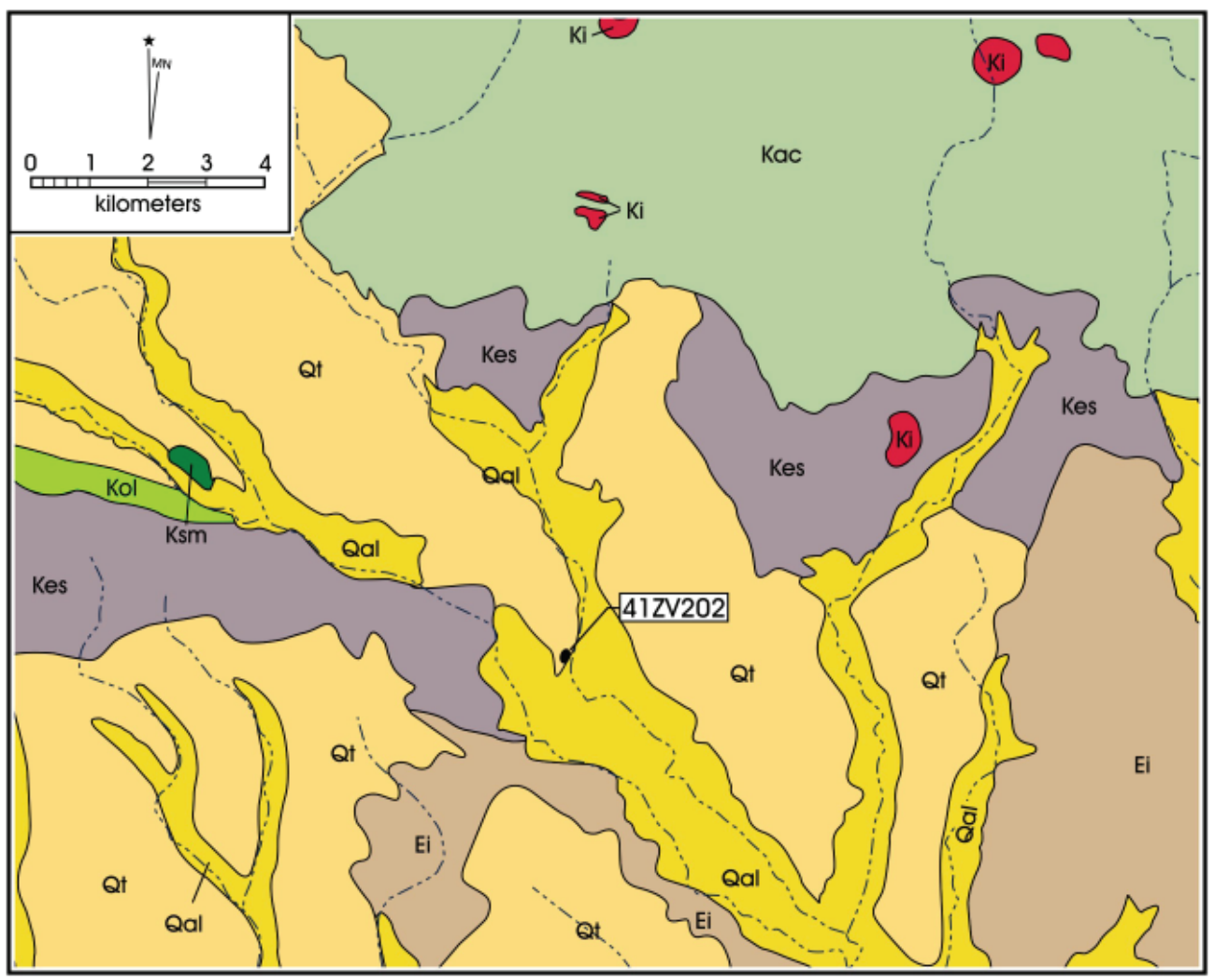

Figure 2-4. Geological setting of 41ZV202.

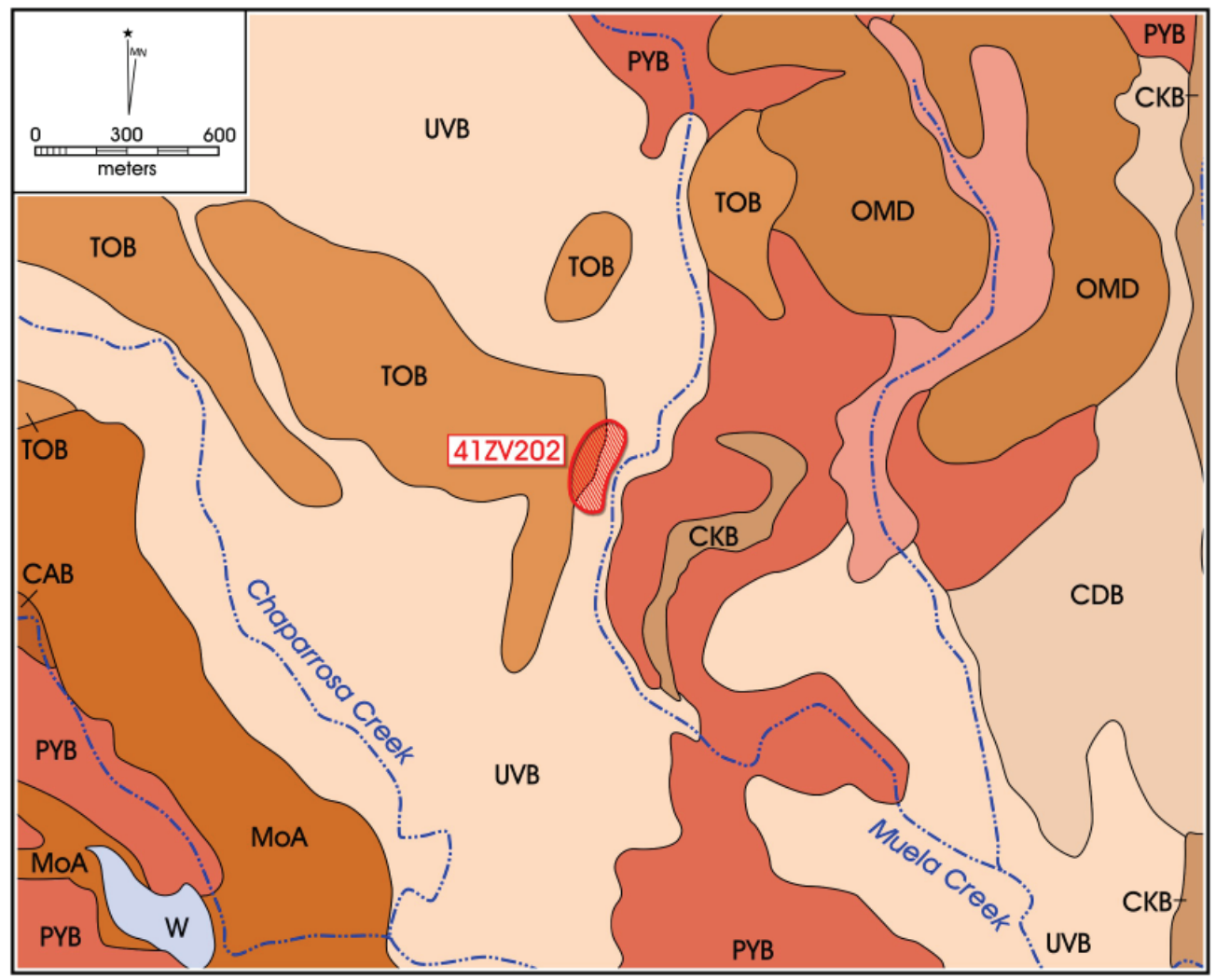

Figure 2-5. Soils in the vicinity of $41 Z$ V202. 


\section{Hydrology}

As noted previously, several large, permanently flowing rivers cut through the South Texas region, and a variety of smaller creeks and drainages are clearly present. Within the region, major rivers include the Rio Grande, Nueces, Frio, and Sabinal. Many of these drain out of the Balcones Escarpment, and several are principally spring fed. The Nueces River lies about $22.5 \mathrm{~km}$ to the west of 41ZV202. Within the immediate area, Turkey Creek, a semi-permanent drainage, is roughly $10.5 \mathrm{~km}$ to the east of $41 \mathrm{ZV} 202$, and is currently the primary source of surface water in the immediate area. Chaparrosa Creek is located about $1.0 \mathrm{~km}$ to the west. The relatively small drainage of Muela Creek is located immediately east of 41ZV202. The creek was dry throughout our visits to the site, and flows are probably present only under conditions of heavy localized rainfall. This current picture of water availability, however, is probably not reflective of past conditions. Twentieth-century deep water wells in the region appear to have dramatically lowered the water table, probably resulting in less surface flow (see Hester 1980).

\section{Floral and Faunal Resources}

Currently, mesquite (Prosopis glandulosa) and blackbrush (Acacia rigidula) dominate much of the surrounding region, with small pockets of native and introduced grasses present (Texas Parks and Wildlife Department [TPWD] 1999). Riparian zones are dominated by sycamore (Platanus occidentalis), black willow (Salix nigra), and button brush (Cephalantus occidentalis), along with catclaw (Acacia sp.), whitebrush (Aloysis gratissima), and mesquite. At the time of CAR's work, vegetation at 41ZV202 was dominated by grass and low forbs, with small amounts of mesquite also present.

Like the hydrology of the area, the vegetation structure has clearly been impacted by European settlement and land-use practices. The introduction of domestic livestock, fencing, and fire suppression, combined with overgrazing and deep well irrigation, seems to have contributed both to a lowering of the water table and the spread of brushy vegetation, especially mesquite (see Hall 1985; Hester 1995). Early Spanish accounts of the Zavala County area suggest that much of the land was a prairie, with dense forests in the riparian areas, with infrequent thickets of mesquite (Robbins 1998). It appears, then, that the brush and shrubs that dominate the region today had a more restricted distribution in the past.

Blair (1950) lists over 60 mammalian species for the Tamaulipan biotic province. These include white-tailed deer (Odocoileus virginianus), the major native herbivore in the region today, and a variety of smaller mammals, including cottontail rabbit (Sylvilagus sp.), jackrabbit (Lepus californicus), coyote (Canis latrans), and small rodents. Blair (1950) also lists 36 species of snakes and 19 species of lizards for this province. Historically and prehistorically, a variety of additional species, including several economically important animals such as bison and antelope, were also present (see Davis and Schmidly 1997; Montgomery 1978).

\section{Paleoenvironmental Conditions}

The prehistoric occupation of 41ZV202 seems to have primarily occurred during the Late Archaic and Late Prehistoric periods. This time frame, roughly corresponding to the last 4,000 years, is the focus of this section. While some research has certainly been undertaken in South Texas (e.g., Dering 2002, 2004; Robinson 1979, 1982), much of what we think we know about South Texas comes from Central Texas. This is due both to poor preservation conditions and to a lack of environmental features (e.g., peat bogs, dry cave deposits) that are conducive to preserving paleoenvironmental data. The Central Texas climate reconstructions rely on a variety of different data sets. These data sets include shifts in pollen (see Bousman 1998; Bryant and Holloway 1985; Nickels and Mauldin 2001), changes in stream flow geomorphology (Nordt 1992), variation in small vertebrate fauna (see Toomey 1993), and shifts in carbon isotopic signatures in sediments (e.g., Cooke 2005; Nordt et al. 1994; Nordt et al. 2002).

Shifts in these various data sets support a variety of climate change scenarios. Unfortunately, the application of these scenarios to our particular South Texas study area is unclear. In part, this ambiguity is related to the distance between 41ZV202 and many of the previously mentioned studies. However, it is also the case that there is little consensus between several of the scenarios for the Late Holocene. This is not surprising given the diverse data sets that are certainly responding to different temporal and spatial scales (see Ellis et al. 1995). That is, the temperature and rainfall patterns that influence shifts in the relative dominance of least and desert shrews (see Toomey 1993: 190-203) are likely operating at different spatial and temporal scales than those that produce shifts in the relative abundance of arboreal and grass pollen (see Bousman 1998) or shifts in phytoliths (Robinson 1979, 1982).

This problem of scale is exacerbated by temporal uncertainty on any given data point (e.g., +/- 200 years) and, in many cases, a small number of data points in portions of several long-term sequences. The resulting picture is one where several different scenarios of climate change are supported for roughly the same area (e.g., Johnson and Goode 1994; 
Nordt et al. 1994; Toomey et al. 1993). It is unclear if these are recording the same climate sequence, but monitoring that sequence at different temporal and spatial scales, or if one or several of these sequences are simply wrong (see Ellis et al. 1995: 411-414).

Subsequently, we focus our paleoclimate review on three different data types, and pay particular attention to questions of scale. Figure 2-6 provides locations for these data sets relative to 41ZV202. The first uses shifts in pollen from three bog sites in east-central Texas (Figure 2-6). These shifts probably reflect long temporal periods, perhaps several hundred years, and regional spatial scales. The second type monitors stable carbon isotopes in sediments. We focus on shifts in isotopic values as a way to monitor the relative contribution of plants that use $\mathrm{a}_{3}$ or $\mathrm{C}_{4}$ photosynthetic pathway. These shifts generally reflect long-term temporal scales, but small spatial scales. That is, these data sets are probably generated over several hundred years but essentially reflect local conditions. We consider three different carbon isotope data sets that are located to the northeast, east, and southwest of 41ZV202 (Figure 2-6, Hall's Cave,

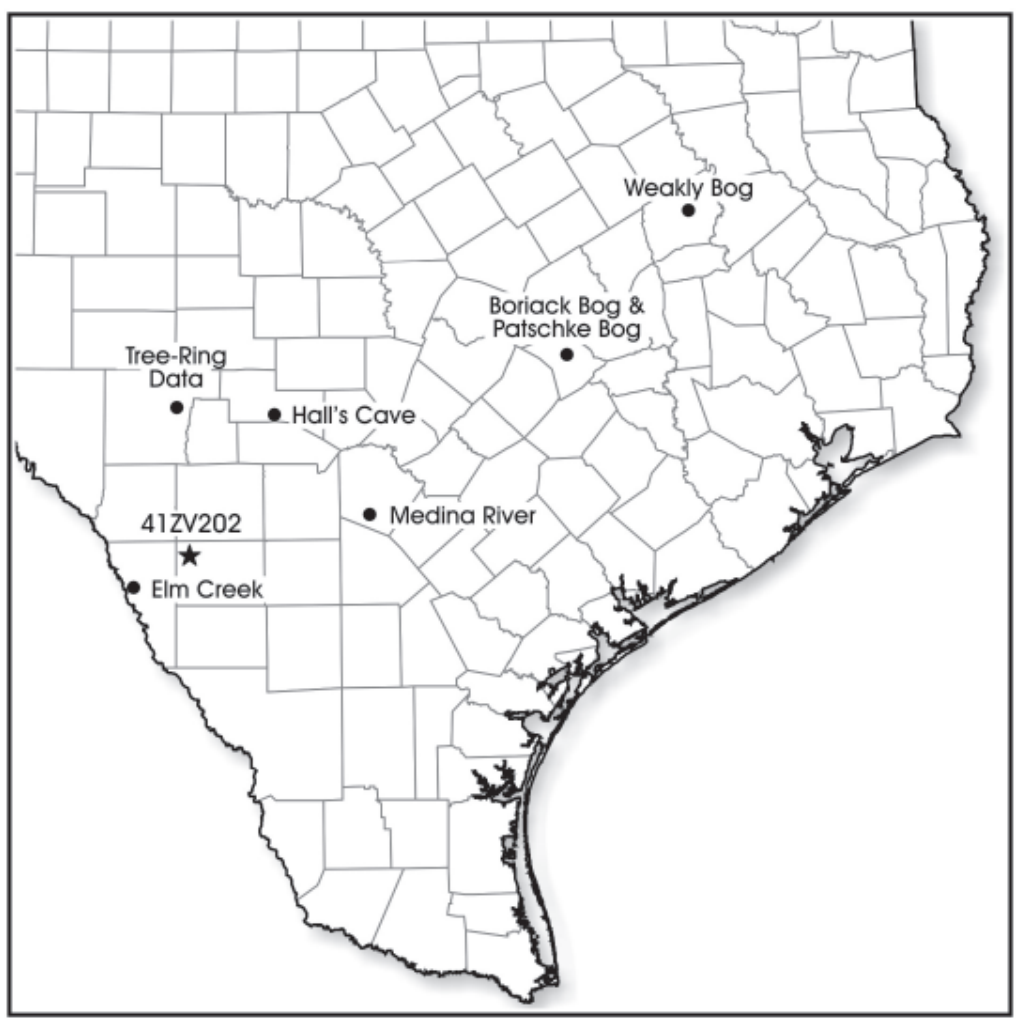

Figure 2-6. Locations of climate data discussed in text.
Medina River, Elm Creek). The final data type monitors shifts in soil moisture through shifts in drought indices derived from variation in tree-rings. These data, which are only available back to about AD 1000 for the region, provide extremely short temporal resolution, but large scale spatial resolution (see Figure 2-6). We discuss each of these various data sets and the suggested vegetation and climate patterns below.

\section{Shifts in Vegetation Structure Suggested by Changes in Pollen Frequencies}

Figure 2-7 presents two versions of changes in paleovegetation based on bog pollen sequences derived from three different bogs. These are located about $350 \mathrm{~km}$ to the northeast of the current study area (see Figure 2-6). The Boriack/Weakly bog series is derived from Bousman (1998) while the Patschke series is taken form Nickels and Mauldin (2001; see also Camper 1991). Both sequences are poorly dated, with the Boriack core relying on four radiocarbon dates from a nearby core, and Patschke having only 4 radiocarbon dates to anchor the 18,000 year sequence. Patschke is represented by roughly 52 data points, an average of roughly 350 years between points, while the Weakly sequence (0-3000 BP) averages 167 years and the Boriack sequence (3000-16500 вр) averages 250 years between data points. In both sequences, the analysis eliminated local marsh pollen from consideration, producing a record that relied primarily on shifts in regional pollen data. Bousman (1998) estimated large-scale shifts in canopy cover between grasslands and woodlands, while Nickels and Mauldin (2001) focus on relative changes in grassland pollen frequencies, without linking them directly to shifts in cover. The resulting pattern, then, is one that has large scale temporal resolution and operates at a regional spatial scale.

Figure 2-7 shows estimated shifts in woodlands and grasslands for Boriak/Weakly and shifts in grass pollen for Patschke over the last 10,000 years, though our primary concern here is with the last 4,000 years. Comparisons of the two trend lines in Figure 2-7 suggest a similar overall pattern, though the timing of individual increases or decreases are out of sequence. Given the temporal issues noted previously, this lack of specific agreement is not surprising. The Boriak/ Weakly trend shows a decline in grassland after a peak at about $5000 \mathrm{BP}$, with that decline accelerating after about 1200 BP. The Patschke pollen data suggest an increase in grass pollen, and by extension grasslands, that peak at around 3,400 years ago. Grass pollen percentages then begin a slow, though variable decline. That decline accelerates after about 800 BP. Given the location of these sequences in the oak woodlands and blackland prairie area, it is probable that decreasing grasslands are consistent with generally wetter and/or cooler conditions in this section of Texas. 


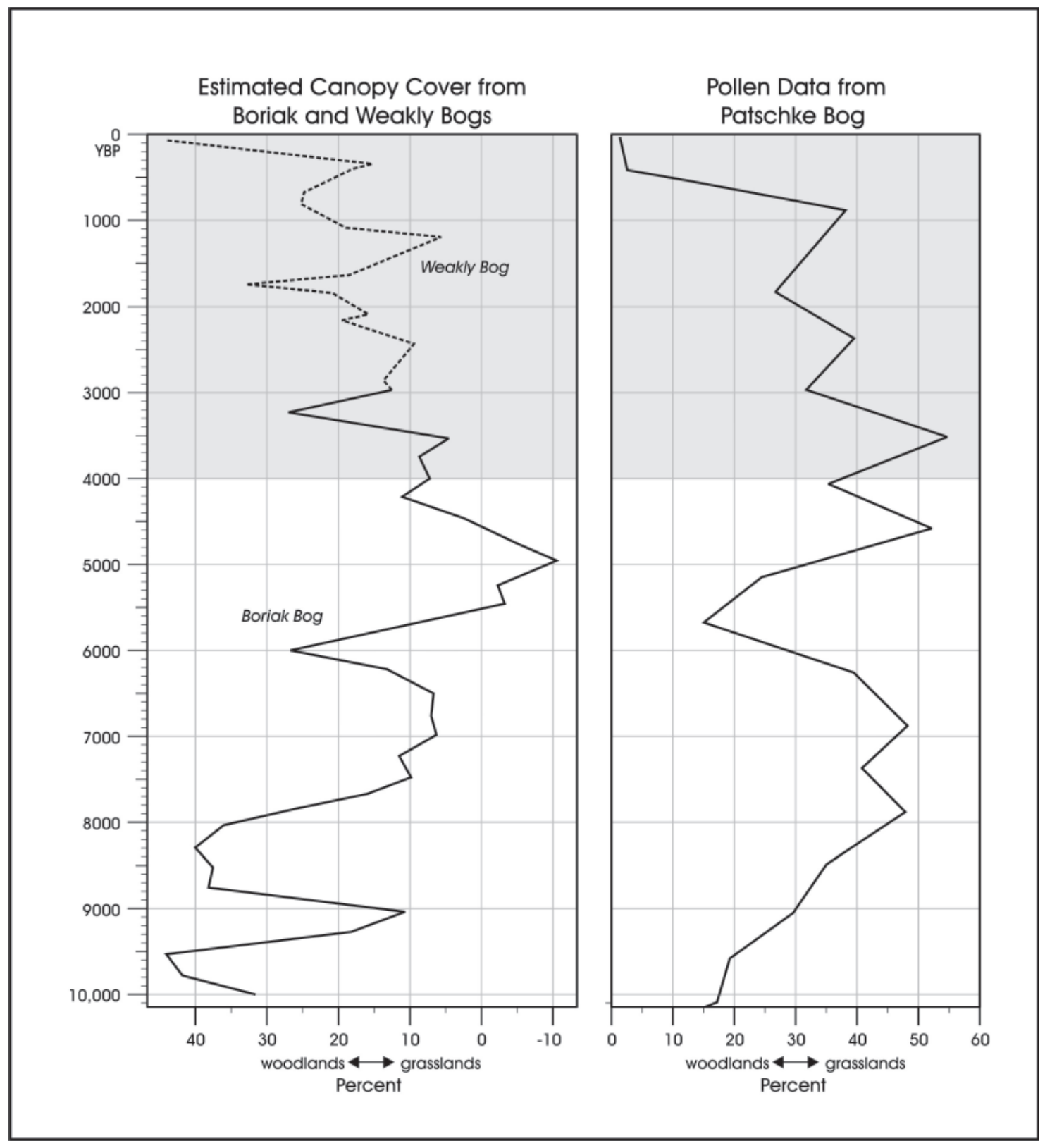

Figure 2-7. Boriack, Weakly, and Patschke bog pollen data.

\section{Shifts in Vegetation Structure Suggested by Changes in Soil Carbon Isotope Values}

Terrestrial plants use one of three different photosynthetic pathways, termed $\mathrm{C}_{3}, \mathrm{C}_{4}$, and $\mathrm{CAM}$, to fix carbon from atmospheric $\mathrm{CO}_{2}$. These different pathways, which produce distinct stable carbon isotopic signatures, represent a response, in part, to different environmental conditions. The $\mathrm{C}_{3}$ pathway is the most common. Plants that thrive in cool, moist settings use this pathway. All trees, most shrubs, and all cool season grasses use the $\mathrm{C}_{3}$ pathway (O'Leary 1988; Sharp 2007). The stable carbon isotope signatures of $C_{3}$ plants range from around -32 mill to -22 mill, with an average of around -27 mill (Deines 1980; O’Leary 1988). In contrast, warm season grasses, as well as a few dicotyledonous taxa (e.g., Amaranthus, Euporbia, Portulaca), use the $\mathrm{C}_{4}$ pathway (Ehleringer et al. 1997). The stable carbon isotopic values of $C_{4}$ plants do not overlap with the $\mathrm{C}_{3}$ values. $\mathrm{C}_{4}$ plants have stable carbon isotopic signatures that range from -17 to -9 mill, with an average of around -13 mill (Deines 1980; O'Leary 1988). The $\mathrm{C}_{4}$ pathway in grasses is favored by warmer temperatures (Ehleringer et al. 1997; Long 1999; Teeri and Stowe 1976), while $\mathrm{C}_{4}$ dicotyledonous taxa are associated with increased aridity (Ehleringer et al. 1997; Long 1999; Stowe and Teeri 1978). The final pathway, termed CAM (crassulacean acid metabolism), is used by most succulents (Bender et al. 1973; 
Ranson and Thomas 1960). CAM plants can mimic either $\mathrm{C}_{3}$ or $\mathrm{C}_{4}$ stable carbon isotopic signatures and have ranges from around -33 to -14 mill (Bender et al. 1973; Griffiths 1992). However, in Central and South Texas, CAM plants seem to produce isotopic signatures that are comparable to the lower range of $\mathrm{C}_{4}$ plants (see Boutton et al. 1998: 18; Quigg 2000). The isotopic values produced by these three different vegetation pathways are not significantly altered by decomposition, though ${ }^{13} \mathrm{C}$ values appear to be 1 to 3 mill greater at depths below surface in many cases (see Boutton et al. 1998.). Consequently, measurements of stable carbon isotope ratios in organic mater in soil from Central and South Texas can provide an estimate of the relative contribution of $\mathrm{C}_{4} / \mathrm{CAM}$ and $\mathrm{C}_{3}$ plants at a location. By measuring the stable carbon isotopic signatures from several dated, buried soils within a profile, or from multiple dated locations from the same general area, researchers can monitor shifts in vegetation and, by extension, shifts in temperature and moisture.

Soils are commonly dated by radiocarbon dates, with an associated error range, as well as stratigraphic position within a profile or stream setting. In addition, note that the stable carbon isotopic value for a given data point represents a pooled value of vegetation that existed on that surface. The value is a function of the turnover rate in soil organic mater and soil formation (Boutton et al. 1998). Given these consideration, any shifts in carbon isotopic values observed will probably reflect long temporal periods, approximating several centuries under most depositional conditions. Spatial scales appear to be local though erosion and redeposition of deposits can, especially in stream settings, complicate interpretations of the spatial as well as the temporal scale.

Reference to Figure 2-6 identifies three Central and South Texas locations (Hall's cave, Medina River, Rio Grande/ Elm's Creek,) that contain relatively long sequences of stable isotope values derived from carbon in soil. Figure 2-8 compares two of these sequences, Hall's Cave, located about $140 \mathrm{~km}$ to the northeast of 41ZV202 and the Medina River sequence, located about $150 \mathrm{~km}$ east of the site. The Hall's Cave carbon isotope data, shown as a solid line in the figure, are derived from buried sediments from an extremely well-dated sinkhole deposit in Kerr County (see Cooke 2005; Toomey 1993). Unfortunately, there are only 16 sample points over the 10,000 year sequence shown in Figure 2-8, or one data point for every 625 calendar years. For the last 4,000 , only five data points are present. Examination of the Figure 2-8 Hall's Cave sequence shows a gradual, though variable increase in $\mathrm{C}_{4}$ vegetation from just before 7000 вр to around $1800 \mathrm{BP}$. This suggests warming temperatures over this period. A rapid decline is then initiated, suggesting a return to cooler temperatures over the last 1,800 years. The Medina River sequence (see Figure 2-6) is shown as a dashed line in Figure 2-8 (see Nordt et al. 2002). These stable carbon isotope data come from a series of stream terrace deposits. For the 10,000 years shown in the figure, seven radiocarbon dates are present, and there are 32 data points, but only eight data points in the last 4,000 years. Examination of the Medina sequence suggests a gradual, though variable increase in $\mathrm{C}_{4}$ plants, and by extension an increase in temperatures, from the beginning of the sequence until just before $3000 \mathrm{BP}$. The contribution of $\mathrm{C}_{4}$ plants appears to remain constant for the next 1,700 years, though this period lacks data points. Over the last 1,400 years, decreased $\mathrm{C}_{4}$ production occurs with a sharp decline occurring late in the sequence suggesting a return to cooler temperatures.

The final sequence considered is from Maverick County, roughly $60 \mathrm{~km}$ to the southwest of the current study area (Figure 2-6, Elm Creek), and is from alluvial deposits associated with both Elm Creek and the Rio Grande (Nordt 1998). Focusing on the end of his poorly dated sequence, the stable carbon isotope data seem to suggest that $\mathrm{C}_{4}$ plants increased to around $4000 \mathrm{BP}$, and generally decreased after that date suggesting cooler temperatures. There are two possible exceptions to this cooling trend. In the Rio Grand sequence, Nordt (1998: 73) suggests slightly higher $\mathrm{C}_{4}$, and by extension slightly warmer temperatures, occurred between $2200 \mathrm{BP}$ and $1200 \mathrm{BP}$, with a second increase sometime after 1000 вр (Nordt 1998:73-75). Nordt (1998:73) also suggests that the late shifts in $\mathrm{C}_{4}$ abundance in the Rio Grand sequence may also reflect "differences in depositional facies and water table levels." In the poorly dated Elm Creek sequence, Nordt's data (1998:74) fail to show either of these warmer intervals late in time. The Elm Creek data do, however, show steady increases in $\mathrm{C}_{4}$ abundance from around $7500 \mathrm{BP}$ through sometime approaching $4000 \mathrm{BP}$. The post $4000 \mathrm{BP}$ record at Elm Creek is compressed, but there is a dramatic decrease in $\mathrm{C}_{4}$ production at the end of the sequence (Nordt 1998: 73-75).

The stable carbon isotope sequences discussed in this section vary in specifics. For example, the overall position of the Hall's Cave stable carbon isotope sequence in Figure 2-8 is consistently more negative, suggesting a more $\mathrm{C}_{3}$ dominated setting, than the Medina River sequence. Medina River reflects more $\mathrm{C}_{4}$ production during all periods shown. This is not surprising given that the sequences reflect local conditions. The sequences do, however, seem to reflect roughly similar overall temporal trends. Most sequences show a variable but consistent increase in $\mathrm{C}_{4}$ production probably reflecting an increase in temperature and/or aridity from early in time through around 2000 to 3000 BP. Stable or declining $\mathrm{C}_{4}$ contributions are present for the remainder of the sequences. This decline appears to be rapid, at least in the case of Hall's Cave. This post 3000 BP pattern is consistent with decreasing temperatures, especially near the end of the sequences. 


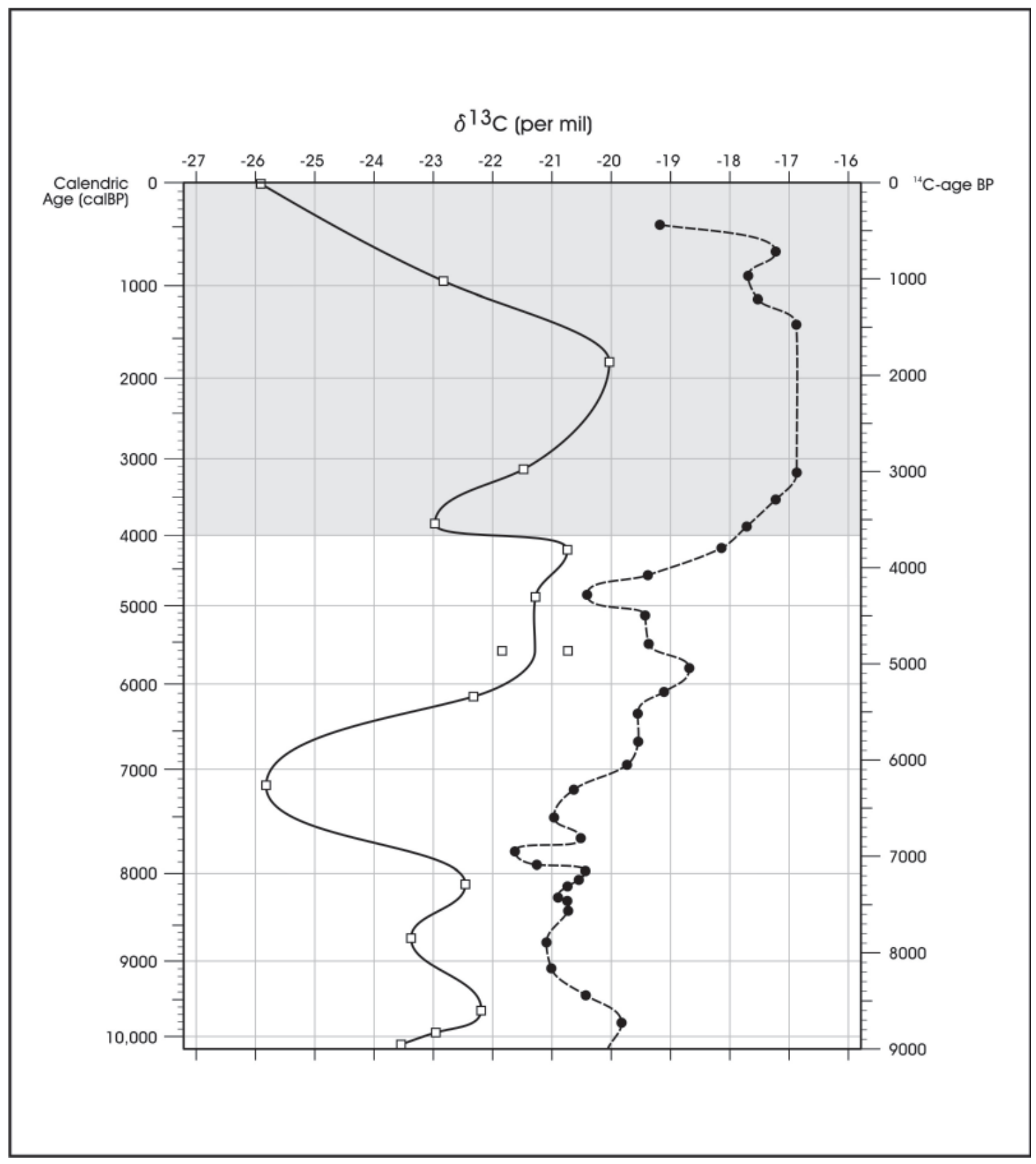

Figure 2-8. Stable carbon isotope variation in soils from Median River (dashed line) and Hall's Cave (solid line).

\section{Shifts in Soil Moisture Monitored through Tree-Ring Based PDSI Values}

The final data type considered relies on tree-ring based measures of drought that have recently become available for the region (Cook and Krusic 2004). The data provide extremely high temporal resolution. However, the spatial scale is somewhat ambiguous, and the temporal range is limited, extending back only to AD 1000. The data set consists of tree-ring based estimates of summer values for the Palmer Drought Severity Index (PDSI), a commonly used measure of drought. Here we use these data in two different ways.
Grouping the data at 25 year intervals, we first consider shifts through time in the PDSI value from AD 1000 through 2000. We also use these data to focus on year to year variability.

The Palmer Index, developed in the early 1960s as a way to quantify drought (Palmer 1965), is a relative measure of soil moisture. Several factors, including temperature, rainfall, potential evaporation, transpiration, soil type, and runoff are used in calculating the index (see Alley 1984; Karl 1986). While higher and lower values are possible, the index generally ranges from a value of four (extreme wet spell) to a negative four (extreme drought), with a normal 
period designated as zero. Cook and Krusic (2004; see also Cook et al. 1999) developed the reconstructed summer PDSI database used here from tree-rings using a point-by-point regression method and 835 tree-ring chronologies from across North America. They established a 2.5 degree latitude by 2.5 degree longitude grid, consisting of 286 locations, that provides yearly drought data for the United States, Canada, and Mexico (Cook and Krusic 2004). For all 286 grid points, Cook and Krusic (2004) calibrate and verify their tree-ring-based reconstructed summer PDSI values against actual summer PDSI values derived from modern weather stations. Here, we focus our investigation of PDSI values on one of these 286 grid points, designated as point 166 . The point is located $70 \mathrm{~km}$ due north of 41ZV202. The grid point provides yearly PDSI values for the region that stretch from the modern period to AD 1000 .

Figure 2-9 provides an example of the relationship between reconstructed PDSI values (Y axis) and actual PDSI values (X axis) between 1900 and 2003 for grid point 166. Pearson's Correlation Coefficient (R) for these 103 points is $.834\left(\mathrm{R}^{2}=.695\right)$ and there are no significant outliers. The figure demonstrates that the PDSI reconstruction is a strong reflection of the actual PDSI values. That is, it is clear that the reconstructed values are a good relative measure of soil moisture at an extremely fine grained temporal scale. The appropriate spatial scale is more difficult to ascertain, though it is likely to minimally consist of the 2.5 degree latitude by 2.5 degree longitude grid size, a scale of several hundred kilometers within the study area.

What is also not clear is the specific interpretation of the reconstructed PDSI values. At least for the last century and with data sets near San Antonio, we have shown that there is a significant, positive relationship between precipitation and PDSI values (Mauldin 2003). However, other shifts, such as changes in temperature, could be operating at the relatively long time scales considered here. PDSI is a composite of several climate (e.g., precipitation, temperature) and abiotic (e.g., soil type) variables interacting in complex ways. This complexity renders any one to one correlation between changes in values and changes in specific climate parameters problematic.

Nevertheless, Figure 2-10 (top) presents the mean PDSI values and associated 95\% confidence intervals on those means for grid point 166 from $\mathrm{AD} 1000$ to 2000 . We have grouped the data at 25 year intervals with plotting points at the center of those intervals. The resulting pattern suggests that from 1000 through about $\mathrm{AD} 1250$, the region is characterized by low PDSI values, with several periods that appear to represent sustained drought (e.g., AD 1200-1250). From AD 1250 to around 1475, PDSI values were closer to average conditions. From AD 1475 through 1675, PDSI values are higher than average. It appears that conditions over the last 325 years are close to the long term average.

The bottom graph in Figure 2-10 provides a measure of year to year variability in PDSI. The Y-axis value represents the mean absolute difference between PDSI scores for consecutive years grouped at 25. For example, in $\mathrm{AD} 1000$, a reconstructed PDSI of -1.98 was present at grid point 166 . The following year, the PDSI value was 1.857 , producing an absolute difference of 3.827 between these two years. We performed similar calculations for all years for the sequence and summarized mean absolute differences at 25-year intervals. Higher or lower mean values are associated with periods of high or low variability in PDSI values, and by extension, high or low variability in soil moisture. During the latter portion of the Initial Late Prehistoric (AD 1000-1250), variability in PDSI is low, averaging 1.54. This is below the overall average of 2.09 for the 1000 years shown in the figure.
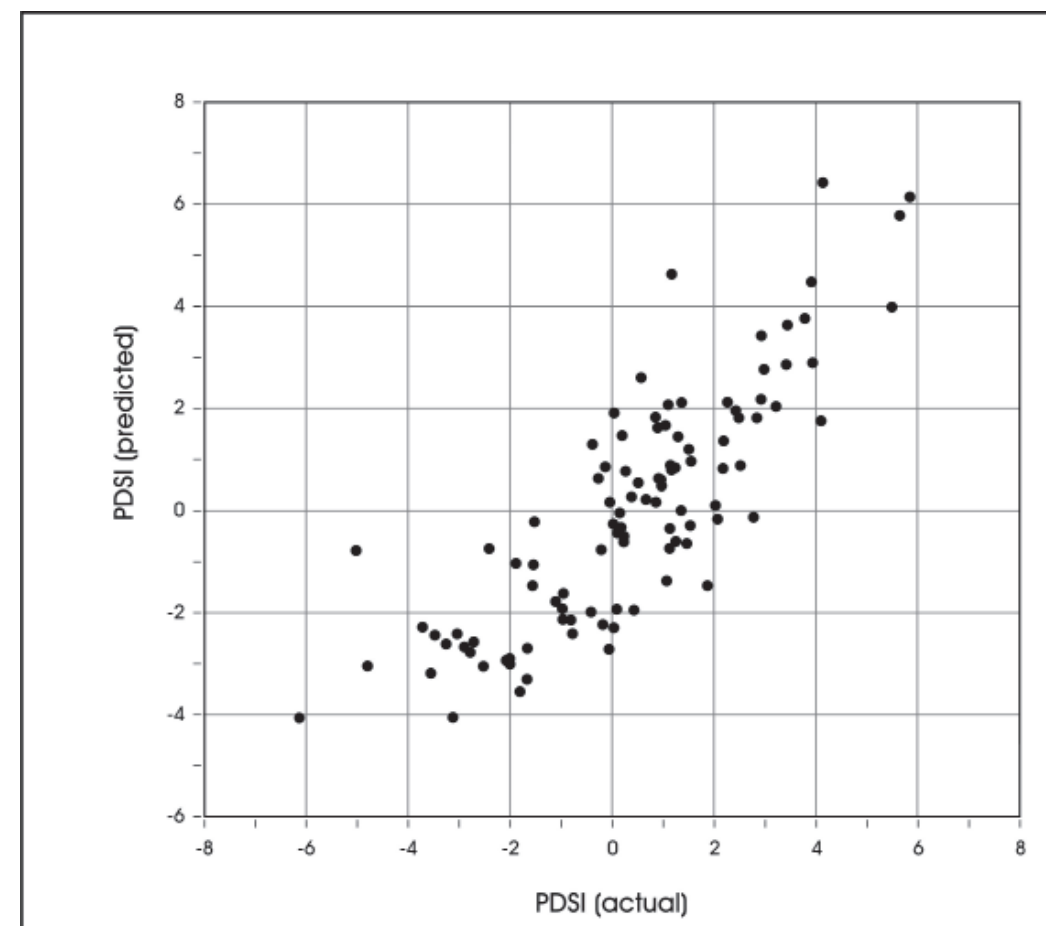

Figure 2-9. Actual and predicted Palmer Drought Severity Indices (PDSI) for grid point 166 (1900-2003). 

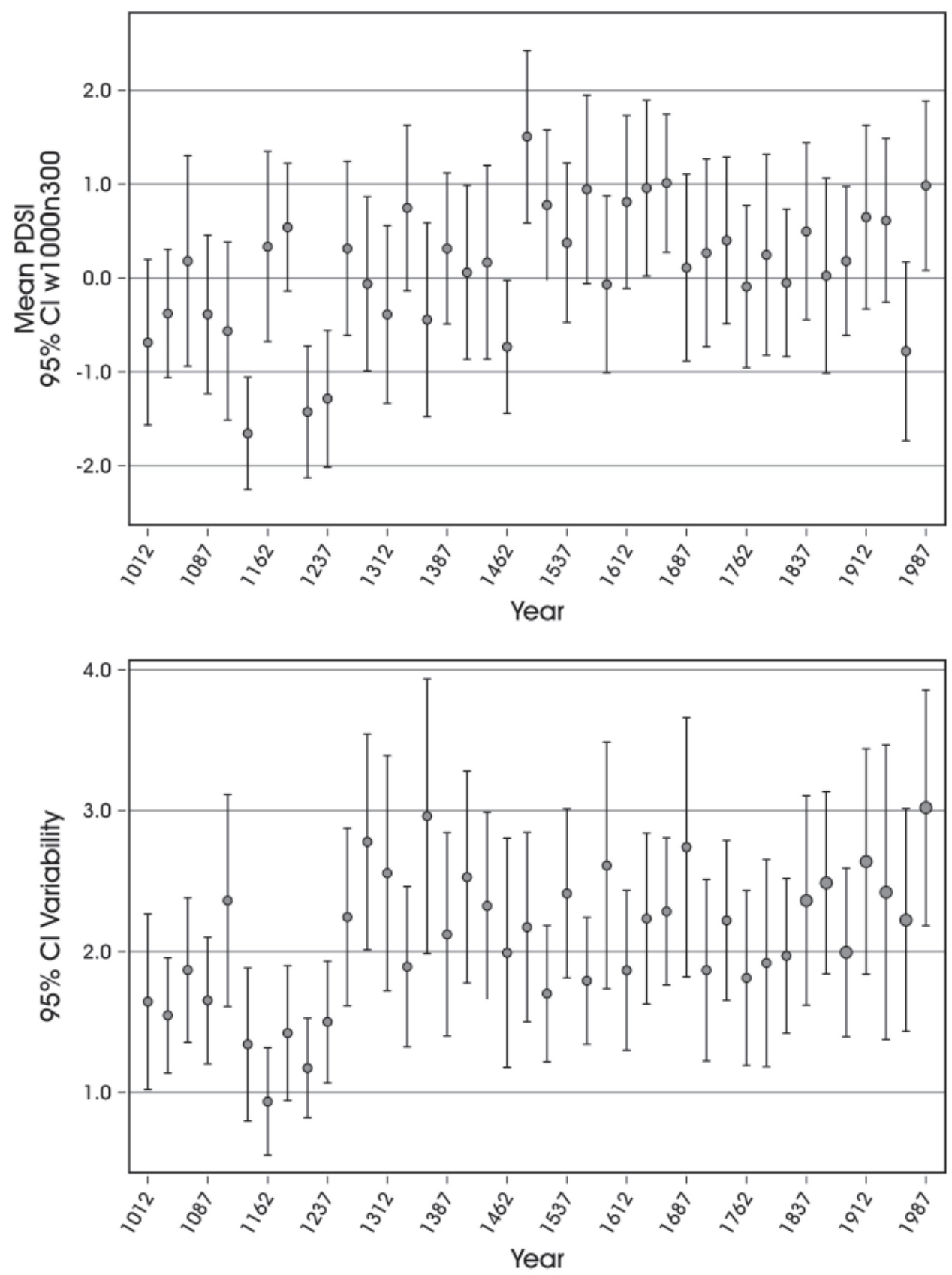

Figure 2-10. Mean and 95\% confidence intervals for PDSI values (top) and variability (bottom) at 25 year intervals from $A D 1000$ through $A D 2000$ (PDSI grid point 166).

Reference to the top potion of Figure 2-10 will show that this period was also below average in soil moisture. After $\mathrm{AD} 1250$, however, a different pattern is present. Between AD 1250 and 1550, year to year variability in PDSI values increase substantially, averaging 2.31 for a given 25 -year segment over this 300 year period. That high variability in soil moisture, combined with overall improving conditions in moisture amounts relative to the initial 250 years of the sequence, would produce high year-to-year fluctuations in resources within Central and South Texas. 


\section{Summary}

The pollen data, along with the stable carbon isotope information from soils, are operating at similar temporal scales, with the pollen information reflecting a regional spatial scale, and the stable carbon isotope data reflecting local scales. Over the last 4,000 years these data suggest that initially, warmer, and possibly drier conditions were present through sometime around 3000 BP. Cooler and possibly wetter conditions were then present, with this cooling trend becoming more pronounced over the last 1,000 years. The picture suggested by the fine-grained PDSI data conflicts, at least in the initial portion of the PDSI sequence, with the picture suggested by the pollen and stable carbon isotope data. Between AD 1000 and 1250, the PDSI data suggest dry conditions, with low variability. We have characterized this period as increasingly cooler and possibly wetter when considering the pollen and isotope data. This conflict may reflect weaknesses in one of these data sets. Recall, however, that the temporal scales are dramatically different. There are 10 equally spaced data points summarizing 250 individual years of data, in the Figure 2-10 plot from AD 1000 to 1250 . Reference to Figures 2-8, for example, shows that in both the Hall's Cave and Medina River sequences, this 250 year period contains a single data point. Note also that in the Medina River data, the shift between AD 1000 and about 1300 is consistent with the PDSI curve. After about AD 1250, all data sets, including the PDSI data, are consistent with cooler and possibly wetter conditions. In addition, the PDSI data set suggests that the $\mathrm{AD} 1250-1550$ period is highly variable from year to year. 



\section{Chapter 3: Archeological Background}

\author{
Raymond Mauldin and Bruce Moses
}

This chapter provides background material on the archeological record of the general study area. Included is a short review of the history of research in the region surrounding 41ZV202 and a brief summary of the cultural history focused primarily on South Texas. As with the paleoenvironmental discussion in the previous chapter, much of this review focuses on the last 4,000 years, the known timeframe of the archeological material reflected on the project, and relies, to a substantial degree, on data sets from better studied Central Texas. For our purposes, some reliance on Central Texas chronologies is appropriate as much of the comparative material used in subsequent chapters is located in Central Texas. Nevertheless, the current chapter focuses on South Texas where 41ZV202 is located.

\section{Archeological Frameworks}

The Rio Grand River on the east and south, the Guadalupe River and costal plain on the west, and the Edwards Plateau on the north geographically define the South Texas archeological record that forms much of this discussion. For much of the South Texas region, little archeological work was done before the late 1960s and early 1970s. The Hartle and Stephenson (1951) report on work performed at Falcon Reservoir probably represents one of the earliest professional publications in the area. Several major survey and testing projects have been undertaken in the region since the late 1960s. These include the Choke Canyon Project in Live Oak and McMullen counties (see Brown et al. 1982; Hall et al. 1982), the East Chacon project (McGraw and Knepper 1983) in Zavala and Uvalde counties, the Chaparrosa Ranch project in Zavala County (Hester 1978; Montgomery 1978), and the Applewhite project in southern Bexar County (McGraw and Hindes 1987). In addition, several testing and data recovery projects have been completed in South Texas (e.g., Black 1986; Goode 2002; Inman et al. 1998; Mauldin et al. 2004; Miller et al. 2000; Quigg et al. 2002; Quigg and Cordova 2000; Taylor and Highley 1995; Vierra 1998).

Surface sites in the region are frequently eroded, and while deeply stratified rock shelter deposits have been excavated in the Lower Pecos (see Turpin 2004), comparable South Texas sites have not been reported. As a result, the chronology of the region is under developed. Much of what seems to be known about the chronological sequence is from surface distributions of artifacts. Black (1989) and Hester (1995; Hester et al. 1989) have both reviewed the regional chronology, and reference to these documents will provide an overview of what is known concerning Paleoindian and Early Archaic occupation. We will not summarize these earlier temporal periods, as the components discussed in this document, including those at 41ZV202, date exclusively to the last 4000 years. In South Texas, this time frame includes material that has been grouped as reflecting the Middle and Late Archaic, as well as the Late Prehistoric (see Hall et al. 1986; Hester 1995). In Central Texas, the last 4000 years includes the Late Archaic and Late Prehistoric periods (Collins 2004; See also Johnson and Goode 1994).

\section{South Texas Middle Archaic Chronology and Occupation Patterns}

Hester (2004: 138-140), following primarily Hall et al. (1982, 1986), suggests that the Middle Archaic in South Texas is characterized by the regional appearance of triangular shaped dart points, such as Tortugas and Abasolo forms (see Turner and Hester 1999: 68, 188), along with Central Texas and Trans Pecos forms such as Pedernales and Langtry. Distally beveled, primarily unifacial tools that were probably used in wood working (Hester et al. 1973) seem to be common on Middle Archaic components in the region. Burned rock features are also widely documented at Middle Archaic components.

Hall et al. (1986:398) suggest a beginning date of $2500 \mathrm{BC}$ (ca. $4450 \mathrm{BP}$ ) with a terminal date of $400 \mathrm{BC}$. (ca. $2350 \mathrm{BP}$ ) for the South Texas Middle Archaic. The 2500 BC date for the initiation of this period is based on a single radiocarbon date from Feature 6 at 41LK31/32 at Choke Canyon (see Scott and Fox 1982). However, several later dates from other sites with Middle Archaic material support the broad temporal assignments as well as the terminal date of $400 \mathrm{BC}$ (see Brown et al. 1982; Hall et al. 1986). Note that much of this temporal range (2500-400 BC) for the South Texas Middle Archaic corresponds to the initial portion of the Late Archaic in Central Texas (see Collins 2004).

Settlement patterns for the Middle Archaic occupations in South Texas are primarily based on survey projects conducted at Choke Canyon (see Brown et al. 1982; Hall et al. 1982, 1986) and the East Chacon Project (McGraw and Knepper 1983). Components are primarily clustered along stream channels, especially early in the sequence. Hester (2004:139) suggests that later in the Middle Archaic, components are also present in a variety of floodplain settings, as well as along low terraces. 
Surprisingly little direct data on subsistence exists for the Middle Archaic in South Texas. In part, this lack of data is a result of poor vertebrate faunal preservation. Excavations at Choke Canyon produced quantities of mussel shell, as well as snail (Rabdotus), some of which appear to be associated with Middle Archaic materials. The remains of turtles, cottontail rabbit, and other small game are also present during this period, though in small numbers (e.g., Scott and Fox 1982). Hester (2004:139) reports that mesquite, acacia, oak, and hackberry seeds were used for food at Choke Canyon sites. He echoes the suggestions by Hall et al. (1986) that plant resources were heavily used during this time as evidenced by a preponderance of burned rock features. More recently, researchers in far south Texas (e.g., Quigg et al. 2002) have used lipid residue and isotopic analysis of burned rock from features in an attempt to flesh out subsistence. On Middle Archaic features from 41WB557 in Webb County, residue and lipid residues suggest that large (deer/antelope) and very large (i.e., bison) herbivores, as well as a variety of plants (e.g., legumes, nuts) were processed (Quigg et al. 2002: 365-371)

\section{South Texas Late Archaic Chronology and Occupation Patterns}

The Late Archaic in South Texas is slightly better known than the preceding Middle Archaic. Projectile point types found at components dating to the Late Archaic include South Texas forms such as Shumla, Catan, Zavala, and Matamoros points, along with a wide variety of Central Texas types such as Ensor, Ellis, Frio, Fairland, Montell, and Marcos (see Brown et al. 1982; Goode 2002; Hester 1978; Quigg et al. 2000). Late Archaic assemblages from some areas of South Texas frequently have "Olmos tools", small triangular bifaces possibly used as gouges (Shafer and Hester 1971). Manos and metates are also frequently found at sites from this time period, and many locations seem to have fire-cracked rock hearths in abundance (e.g., Goode 2002; Mauldin et al. 2004).

Hester (2004:140) suggests that the South Texas Late Archaic is relatively short, spanning only about 1,100 years from roughly $400 \mathrm{BC}$ to about 600 or AD 700. Hall et al. (1986:400401) suggest a termination date for the Late Archaic at Choke Canyon of AD 900, though this is not clearly supported by radiocarbon dates. A variety of radiocarbon dates are present from Late Archaic age deposits at Choke Canyon, including dates from 41LK67 (Brown et al. 1982), 41LK201 (Highley 1986), and 41MC296 (Hall et al. 1986). These dates demonstrate Late Archaic materials are present at least to about AD 600. In Central Texas, the $400 \mathrm{BC}$ to $\mathrm{AD} 700$ time frame falls at the end of the Late Archaic, defined by Collins (2004:113) as running from about $2050 \mathrm{BC}$ to $\mathrm{AD} 700$.
Late Archaic settlement patterns appear to be roughly similar to those seen previously for the Middle Archaic. Occupations are concentrated along streams and drainages, with high terraces and ridges providing sources for tool stone (e.g., Highley 1986; McGraw and Knepper 1983).

Like the preceding Middle Archaic, our knowledge of subsistence during the Late Archaic in South Texas is minimal, in part as a function of the eroded nature and poor preservation of sites throughout this region. However, excavations at Choke Canyon did recover fauna from a variety of small animals including large numbers of rabbits, along with rodents, and the remains of mussels, fish and turtles. Deer were also recovered (Brown et al. 1982; Hall et al. 1986). Hester (2004) suggests that the high frequency of snails in many Late Archaic sites in the Choke Canyon area reflects their use as food. Some dependence on plant remains is also suggested by the continued use of fire-cracked rock features, and by what appears to be an increase in manos and metates (see Hester 2004: 140-143).

\section{South Texas Late Prehistoric Chronology and Occupation Patterns}

The chronological patterns of the Late Prehistoric period in South Texas are somewhat better known than the Late Archaic, though gaps are still present, especially in the early part of the period where few components have been excavated. Summaries of this period for South Texas are provided by Black (1986, 1989), Highley (1986), and Hester (2004). The period is characterized by the introduction of the bow and arrow as well as ceramics. Point types include Scallorn, Edwards, Sabinal and Perdiz forms (Black 1986; Goode 2002), with Caracara, Star, Zavala, and a variety of other types also present (Turner and Hester 1999). In several contexts, small, Late Archaic forms such as Ensor, Catan, and Matamoros points, occur in Late Prehistoric assemblages (see Hester 2004:143; Turner and Hester 1999). It is unclear, though, if these associations are in good context. Bone-tempered pottery is also present during this period, along with end scrapers, beveled knives, perforators, and ground stone.

The Late Prehistoric dates from roughly AD 700 to AD 1550 or 1600. While Hester (2004:143-146) argues that the situation is ambiguous, especially in the early portions of the Late Prehistoric, most researchers divide the period into two intervals analogous to those defined in Central Texas (e.g., Black 1986). The early portion of the period, analogous to the Austin Interval, is characterized by side-notched and corner-notched arrow points (e.g., Scallorn, Edwards, possibly Caracara), as well as a lack or ceramics. Commonly 
suggested dates for this period in South Texas are from $\mathrm{AD}$ 700 to about AD 1250.

The period from AD 1250 to possibly as late as $\mathrm{AD} 1600$ can be characterized as the Toyah Interval (see Black 1986). Toyah assemblages are characterized by triangular shaped, contracting stem Perdiz points. End scrapers, beveled knives, perforators, and bone-tempered pottery are also frequently present. A variety of sites dating to this time period have been excavated in South Texas including 41JW8 (Black 1986), 41LK201 (Highley 1986), and 41WN88 (Nickels 2000).

Faunal materials from South Texas Late Prehistoric sites identified as Toyah Interval include a variety of taxa (e.g., Black 1986). While the assemblage and faunal material are often thought to reflect an adaptation focused on the exploitation of bison, Hester (1995; see also Black 1986; Hall et al., 1986) notes that 45 different taxa, including bison, deer, antelope, and a variety of smaller animals, including mussels and snails, have been recorded for Toyah sites in the region.

Settlement patterns for both the early, as well as Toyah Interval Late Prehistoric sites, appear to be similar, with components clustered along streams and drainages (e.g., Hall et al. 1986; McGraw and Knepper 1983). This distribution is similar, in general, to the preceding Late Archaic period.

\section{Research near 41ZV202}

Site 41ZV202 is located in far northwestern Zavala County. While close to Maverick, Uvalde, and Kimble counties, the topography and hydrology of site 41ZV202 is best reflected in Zavala County. Mauldin et al. (2004) conducted a review of the Texas Archeological Sites Atlas database in early 2004 that focused on Zavala County. Their review found 407 archeological sites listed in 2004. Of these, 221 lacked information on temporal placement. Of the remaining 186 sites, seven are recorded as Paleoindian, 90 are recorded as Archaic (with no information on subdivisions), and 24 were recorded as Late Prehistoric. The remaining 65 have material that appears to date to more than one broad temporal period. There are eight sites with Paleoindian, Archaic, and Late Prehistoric materials, eight sites with Paleoindian and Archaic remains, and 49 sites with Archaic and Late Prehistoric remains. Over $54 \%$ of the 407 sites lack any temporal information, and of those sites with temporally diagnostic artifacts $(\mathrm{n}=186), 35 \%(\mathrm{n}=65)$ are clearly multi-component, and the majority of the 90 "Archaic" sites probably contain point types that cross-cut large periods of time. This high frequency of multi-component sites probably is a result both of the erosion of deposits characteristic of the region noted earlier, as well as the probability that occupation was centered along the geographically limited riparian settings.

Extreme southern Texas has seen a variety of recent excavation projects (e.g., Mahoney et al. 2002; Quigg 2000; Quigg et al. 2002). However, surprisingly little excavation has been conducted in southern Uvalde or Zavala counties since several projects were undertaken in the 1970s and early 1980s. These early excavations include TxDOT's work at the Anton Site, 41UV60, located about $20 \mathrm{~km}$ to the northeast of $41 \mathrm{ZV} 202$ (Figure 3-1). The site, recently reported on by Goode (2002), was excavated in the mid 1970s. Though Goode reports primarily on the well defined Late Archaic "Round Rock" phase, a variety of time periods are represented at this site, with projectile points reflecting Paleoindian, Archaic, and Late Prehistoric use and radiocarbon dates reflecting occupation over the last 4,000 years (Goode 2002:214, 197). The site is primarily composed of a series of burned rock features and charcoal stains reflecting hearths and associated debitage and tools.

Hester and Hill (1972) provide details on testing at the Holdsworth Site (41ZV14), a multi-component Archaic and Late Prehistoric site located to the southeast of 41ZV202, and the Steward Site (41ZV121), an Archaic occupation (see Figure 3-1). Of specific interest was the recovery of faunal material from the Late Prehistoric occupation at 41ZV14. A summary by Gilbow (1972:73-75) suggests a wide variety of vertebrate fauna were potentially used by the Late Prehistoric occupants at 41ZV14. Tortoise, cottontail rabbit, cotton rat, and pack rat dominated the faunal remains, with whitetail deer and jack rabbit present in low numbers. Both land snails and mussel shell were also recovered at 41ZV14.

The East Chacon project, located to the east of 41ZV202, was primarily a survey project conducted in the early 1980s along the Nueces River in Uvalde and Zavala counties (Figure 3-1). Though under-reported, McGraw and Knepper (1983) do provide descriptive data on 66 surveyed sites, along with some testing information on one site. The utility of these site descriptions is limited by a lack of site temporal placement, although the project does provide data on site location that is consistent with the expectation that most recorded sites are along drainages.

The Chaparrosa Ranch project, located to the south of 41ZV202 (Figure 3-1), was a long-term investigation involving survey, testing, and large scale excavations (see Hester 1978). Several sites, including testing of the Late Prehistoric site 41ZV83 (Montgomery 1978) and site 41ZV10 (Hester 1978), were investigated in association with the Chaparrosa Ranch work. Unfortunately, much of this material remains unpublished or under-published. 


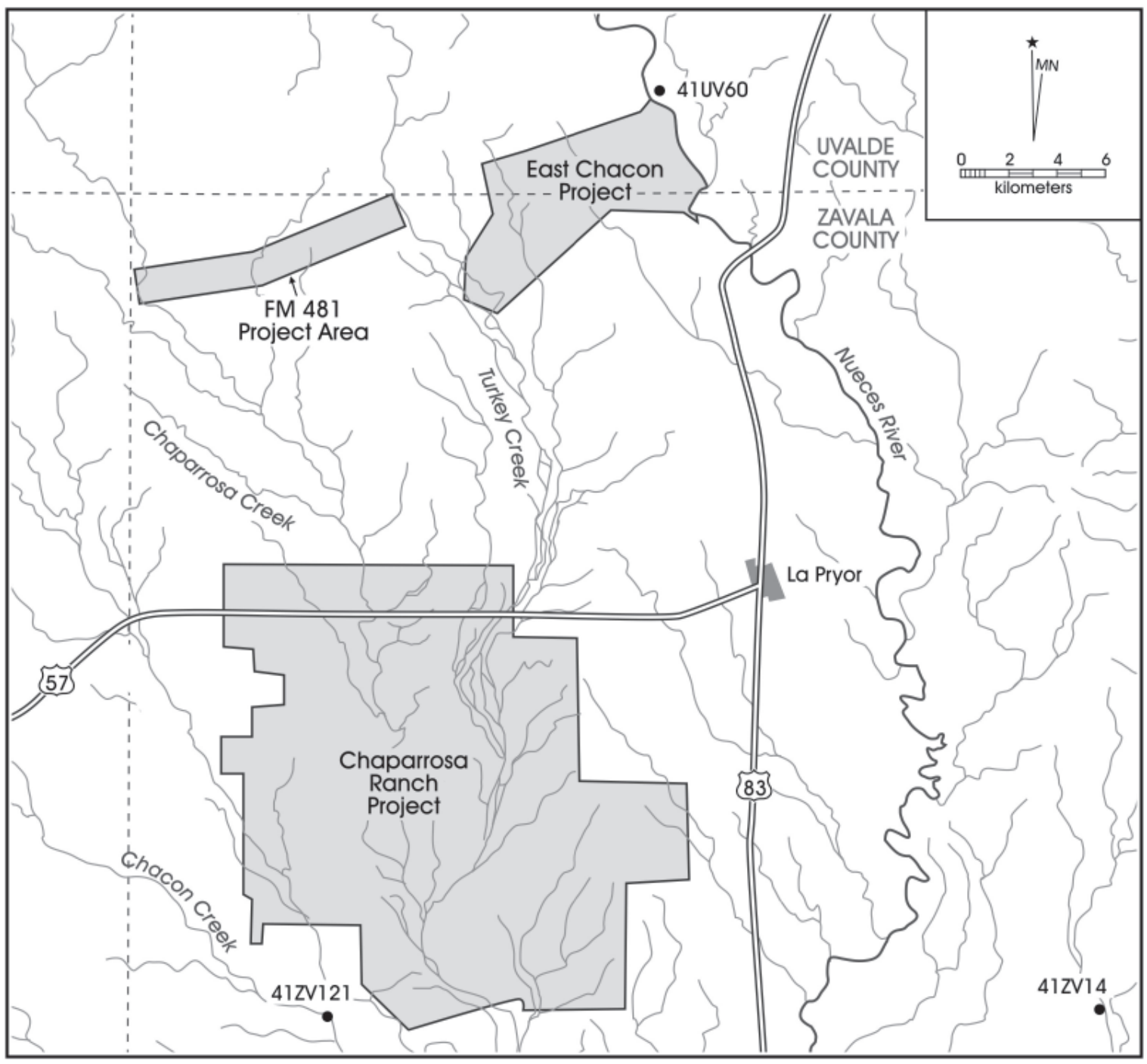

Figure 3-1. Location of selected archeological sites and projects discussed in the text.

Figure 3-1 also shows the location of a project designated FM481 in northwestern Zavala County. Daymond Crawford and Jerry Henderson oversaw this TxDOT project, conducted in 1981 and 1982. That work was associated with road improvements along FM481. No report was produced on the project until 2004 when, at the direction of TxDOT, CAR synthesized extant field notes, maps, and photos into a summary of the 1981 and 1982 work (Mauldin et al. 2004). In all, TxDOT conducted work on nine archeological sites along the FM481 right of way. That work included the identification and initial testing of site 41ZV202 which we will discuss in the following chapter. Other sites defined or investigated by TxDOT in the FM481 project area shown in Figure 3-1 include 41ZV197, 41ZV198, 41ZV201 41ZV226, 41ZV450, 41ZV451, 41ZV452, and 41ZV453 (see Mauldin et al. 2004: 23-64; Additional information is available in Houk et al. 2003 and O'Farrell and Miller 2002). In general, these sites consist of a moderate density of burned rock hearth features and low densities of chipped stone debitage, bifaces, unifaces, and projectile points. Where diagnostic points or radiocarbon dates are available, these sites date to the Late Archaic and Late Prehistoric periods. A small amount of faunal material, representing whitetail deer and what is probably bison, was recovered from 41ZV198. In addition, mussel shell and snail shell was present at most sites (see Mauldin et al. 2004:26-64).

\section{Summary}

As this brief review suggests, we have a limited understanding of many aspects of the archeological record of South Texas in general and the immediate area surrounding 41ZV202 in particular, for the last 4,000 years. In part, this is related to a lack of recent work, at least in Zavala and southern Uvalde counties, and the eroded and potentially multi-component 
nature of many of the sites that have been investigated. We currently have a limited understanding of chronological patterns in diagnostic point types, with what are presumed to be Late Archaic and Late Prehistoric types occasionally appearing in the same context. While it is likely that many of these situations simply represent cases with limited integrity, the resulting chronological confusion further limits our understanding of both subsistence and settlement patterns. Recovery of faunal material from many of the sites that have been excavated is minimal, and flotation results, at least from the portion of South Texas that immediately surrounds 41ZV202, is all but non-existent. As with the paleoenvironmental discussion in the previous chapter, much of what we think we know about the region relies on data sets from better studied Central Texas. Work at 41ZV202, then, provides an opportunity to potentially make significant contributions to our understanding of adaptations in this portion of South Texas. 



\title{
Chapter 4: Testing and Data Recovery Efforts at 41ZV202
}

\author{
Russell Greaves and Raymond Mauldin
}

Work at 41ZV202 spans over 25 years and involves several different organizations. As noted in the previous chapter, the initial recoding of site 41ZV202 was done by Daymond Crawford of TxDOT in 1981 in association with road work along FM481. TxDOT subsequently tested the site in October and November of that year. Archeologists from SWCA visited the site in April and June of 2002 at the request of TxDOT and in association with planned enhancements to FM481. Following examination of two cut bank profiles, limited shovel testing, and a geoarcheological assessment, SWCA recommended testing to assess the SAL/NRHP eligibility based on the potential of the location to provide new or important information concerning prehistory (Kuehn 2002; O'Farrell and Miller 2002). In November of 2002, archeologists James Abbott and Tim Mead (TxDOT ENV) inspected the site and excavated two Gradall trenches that exposed three small burned rock features and a small quantity of artifacts. They concurred with SWCA's recommendation for testing. At the request of TxDOT, CAR archeologists conducted eligibility testing at the site in the spring of 2003 . Data recovery excavations followed that effort in July and August of that same year (Greaves 2003). This chapter summarizes these various activities, with particular emphasis on the CAR testing, data recovery, and laboratory efforts.

\section{Initial Description and Testing at $41 \mathrm{ZV} 202$ (1981-82, 2002)}

D. Crawford of TxDOT recorded the site in 1981 during a survey project that was conducted in advance of the initial paving of FM481 (see Moses et al. 2004:58-64). The site form and associated notes for this site, reviewed by CAR in conjunction with the production of a report on the early 1980s work (see Mauldin et al. 2004) suggest that abundant surface artifacts and an unspecified number of hearth features were present on what is now the northern side of FM 481. Jerry Henderson of TxDOT directed the initial efforts at 41ZV202 in October of 1981. Archeologists were prematurely pulled off the testing in November of 1981. Testing on the project resumed in July and terminated in September of 1982. Note that during the July through September period, 41ZV202, along with at least five other sites, had some level of testing (see Mauldin et al. 2004:2-6; Moses et al. 2004:58-64).

At 41ZV202, a component of the initial testing efforts included an unsystematic surface collection. Following the surface collection, TxDOT excavated at least seven test units. Unfortunately, TxDOT did not use a grid system and the locations of the test pits within the site are not clear. The dimensions of TP2 and TP7 were not recorded, and we lack drawings or photographs for these two units. Most of the other test pits (TP3, 4, 5, and 6,) were associated with the excavation of coyote remains, which were ultimately determined to be modern (Moses et al. 2004:58-64). Other than the pits associated with the remains of at least five modern coyotes, no features were recorded during this initial TxDOT work, although reference to surface burned rock features are mentioned in the site notes (Moses et al. 2004:58$61)$. One thousand, five hundred and sixty-seven pieces of bone (814.96 gm) were recovered from excavations. Most were from TP3, TP4, TP5, and TP6 and were modern coyote $(\mathrm{n}=404)$. One rabbit (Sylvilagus sp.) bone, one rodent bone, and six bird bones also were identified. Three bones are from a large mammal (deer size). Unidentified mammal remains account for 952 elements and 154 other identified bones are canid-sized. Excavators also recovered snail and mussel shell (Moses et al. 2004:58-61).

These early test excavations and surface collections at 41ZV202 also produced a moderate quantity of chipped stone debitage and lithic tools, most of which were recovered from the upper levels of the excavations. Recovered projectile points, all of which appear to be Late Archaic in age, are shown in Figure 4-1. Figure 4-2 presents examples of other bifaces, unifaces, and ground stone collected off the site in the early 1980s (Moses et al. 2004:58-64).

A report was not prepared following the termination of the 1981-82 testing efforts at 41ZV202 (but see Mauldin et al. 2004). No additional work occurred at the site until April of 2002 at which time archeologists from SWCA conducted an impact evaluation of the location. By then, FM 481 had been constructed cutting through and destroying the central portion of the site. The SWCA evaluation was in conjunction with a proposed rehabilitation and widening of FM481 by TxDOT. SWCA archeologists noted artifacts on the surface on both the north and south remnant terraces. They also observed artifacts, including burned rock, eroding out of the cut banks. They concluded that 41ZV202 had good potential for buried features and intact cultural deposits within the TxDOT ROW (O’Farrell and Miller 2002).

In June 2002, SWCA archeologists conducted an archeological survey, including shovel testing, mechanical excavation, and a geomorphic assessment of the FM481 project area (Miller et al. 2002). As part of that assessment, two cut bank profiles, 


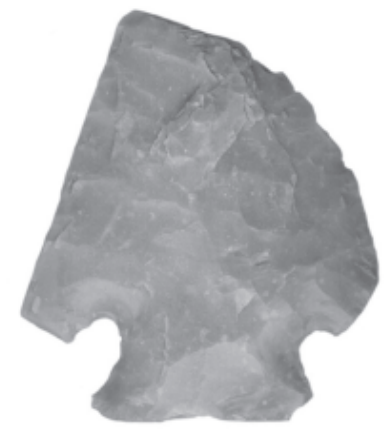

a

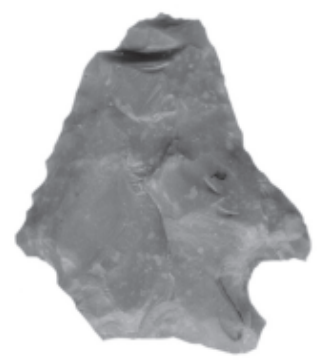

d

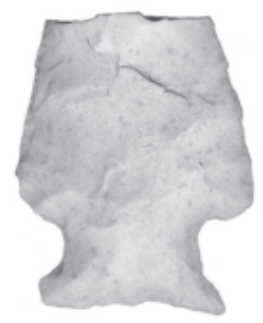

b

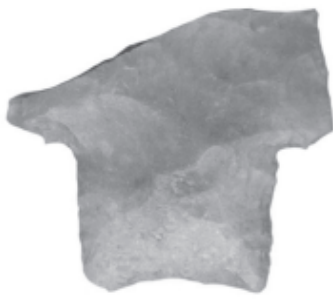

e

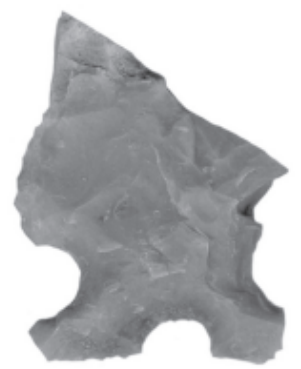

C

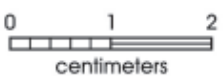

Figure 4-1. Dart points recovered during TxDOT's 1981 testing at 41ZV202 include: a) Marcos; b) Ensor; c) Frio; $d$ and e) untyped dart points.

one against the south remnant and one against the north, within 41ZV202, were cleaned with a backhoe. Dr. David Kuehn, SWCA geoarcheologist, examined both profiles. In addition, SWCA excavated five shovel tests within the ROW of the site. SWCA described one burned rock feature and noted an unspecified number of other features in the road cuts on the southern face. Artifacts were found to a depth of 50 cmbs on the southern remnant. No artifacts were recovered in the two shovel tests excavated on the northern remnant. SWCA recommended that $41 \mathrm{ZV} 202$ be tested to determine the potential eligibility of the site for NRHP nomination (Miller et al. 2002).

In November of 2002, following SWCA's work, TxDOT archeologists investigated the deposits at 41ZV202. They reexamined the SWCA profiles and excavated two short Gradall trenches on the southern terrace remnant (Abbott 2002). TxDOT excavated Gradall Trench 1 (GT1) on the eastern edge of the site, while Gradall Trench 2 (GT2) was excavated roughly $16 \mathrm{~m}$ west of GT1 near the apex of the southern ridge. Figure 4-3 provides an overall map of 41ZV202 that shows the approximate location of GT1, GT2, and the profiles described by SWCA and subsequently examined by TxDOT.

The excavation of GT1 exposed a small cluster of burned sandstone and an associated gray stain, subsequently designated as Feature 1, immediately below the surface (see Figure 4-3). GT1 was terminated at a depth of roughly $75 \mathrm{~cm}$ below surface. GT2 exposed two features. The first, designated Feature 2, was encountered $5 \mathrm{~cm}$ below the surface. The feature consisted of eight burned sandstone rocks in a "very dark grayish brown A horizon" (Abbott 2002:4). A tertiary flake was observed near Feature 2. In order to avoid further damage to Feature 2, TxDOT extended GT2 about 1.5 $\mathrm{m}$ to the west and continued the excavation. Feature 3 , a small 


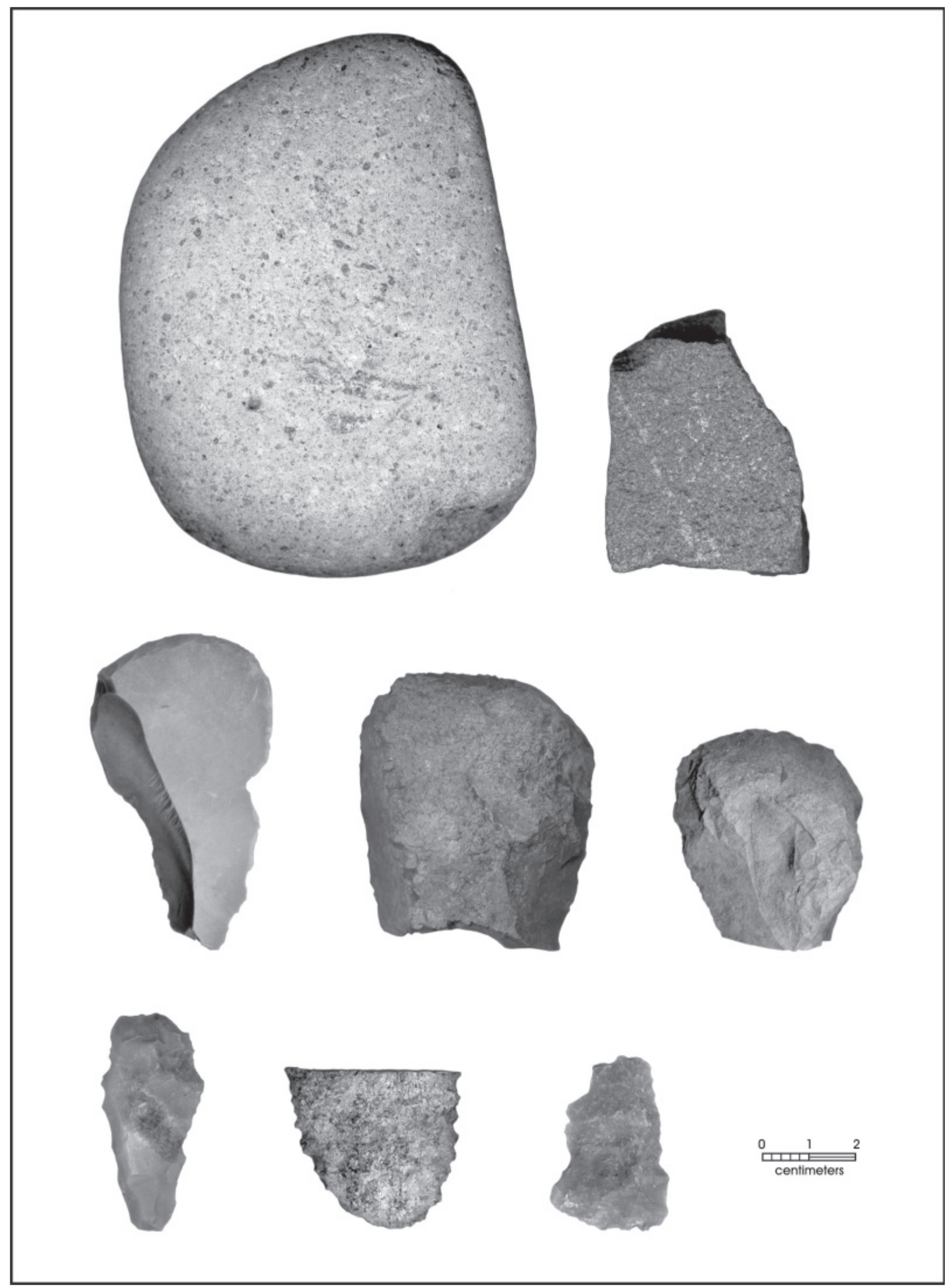

Figure 4-2. Selected ground stone and chipped stone tools recovered from 41ZV202 TxDOT's 1981 testing. 


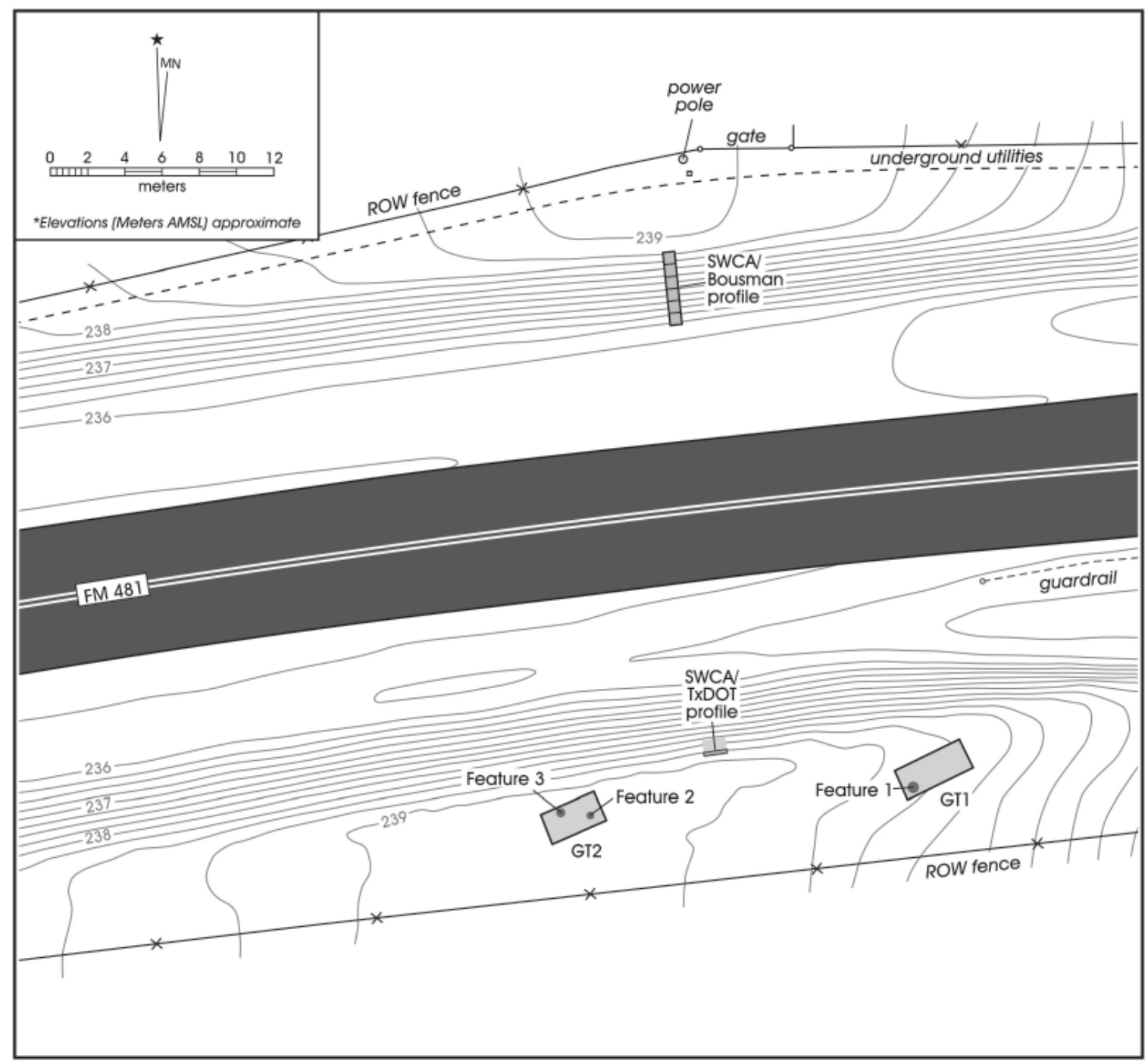

Figure 4-3. TxDOT and SWCA profiling and Gradall Trenching (2002) at 41ZV202.

cluster of three burned sandstone rocks, was encountered at $24 \mathrm{~cm}$ below surface in the western portion of the trench (Figure 4-3). TxDOT archeologists noted snail and mussel shell, as well as a single tertiary flake, in the immediate vicinity of Feature 3. TxDOT terminated GT2 at that point (Abbott 2002). As noted in Chapter 2, the Gradall trenching and the re-evaluation of the SWCA profiles by TxDOT lead them to disagree with the geological assessment made by SWCA geoarcheologist Kuehn. However, TxDOT did concur with SWCA's recommendations regarding the need for NRHP eligibility testing at 41ZV202 (Abbott 2002:6).

\section{CAR Testing and Data Recovery Work at 41ZV202 (2003)}

At the request of TxDOT, CAR undertook SAL and NRHP eligibility testing of 41ZV202 in March 2003. CAR conducted the work under Work Authorization No. 573-02SA002. Russell D. Greaves served as project archeologist and oversaw the testing efforts. C. Brit Bousman served as project geomorphologist. Steven A. Tomka served as principal investigator and the work was conducted under permit \#3701 issued by the Texas Historical Commission to Dr. Tomka. Following testing, and in consultation with both TxDOT and THC, CAR suggested that a portion of the site within the southern bank of the ROW for FM 481 contained a single component, Late Prehistoric occupation with high integrity. This portion of 41ZV202 contained a variety of data sets that could yield information important to prehistory. CAR recommended that $41 \mathrm{ZV} 202$ was eligible as a SAL and for nomination to the NRHP. The THC and TxDOT concurred with those recommendations. As construction impacts associated with work on FM481 could not be avoided, data recovery investigations were initiated by CAR in the summer of 2003. The work was conducted between July 9 and August 
1, 2003, under TxDOT Work Authorization No. 573-06SA002. Texas Antiquities permit no. 3071 was amended to include the data recovery work. Steven A. Tomka continued to serve as principal investigator and Russell Greaves again served as project archeologist for the data recovery effort. The following sections summarize the testing and data recovery efforts undertaken by CAR on 41ZV202.

\section{CAR Testing}

The purpose of the CAR testing was to conduct investigations necessary to determine site eligibility as an SAL and for listing on the NRHP. If the site was determined to be eligible, and data recovery was necessary prior to roadway construction, CAR was tasked with developing a research design and work plan for those data recovery efforts. Based on previous work at the site, CAR focused testing in the southern area of the ROW that covers an estimated $490 \mathrm{~m}^{2}$. The northern portion of the ROW, covering an area of roughly $400 \mathrm{~m}^{2}$, had been subject to significant impacts from road improvement and underground utility installation. No surface material and only very thin remnant $\mathrm{A}$ and $\mathrm{B}$ horizons were present on the northern side of FM 481 within the site.

Testing involved three specific efforts all designed to identify and document archeological deposits at 41ZV202. First, CAR cleaned and examined the cut bank on the southern ROW of FM 481. This provided a long profile of the site deposits. Secondly, we excavated a single Gradall trench (GT3) to expose possible features on the southern remnant. Based on these results, we then excavated a series of 1-x-1-m units placed to provide contiguous samples of deposits associated with features identified on the site surface and within GT3. Figure 4-4 provides a reference map for these various activities.

\section{Profiling}

Seventy-five meters of the existing southern cut bank of FM 481 was hand trimmed and profiled to identify the sediments, soils, and cultural deposits visible at 41ZV202 (Figure 4-4; Figure 4-5). Most of the cut bank profile was exposed only to the depth necessary to document the upper boundary of

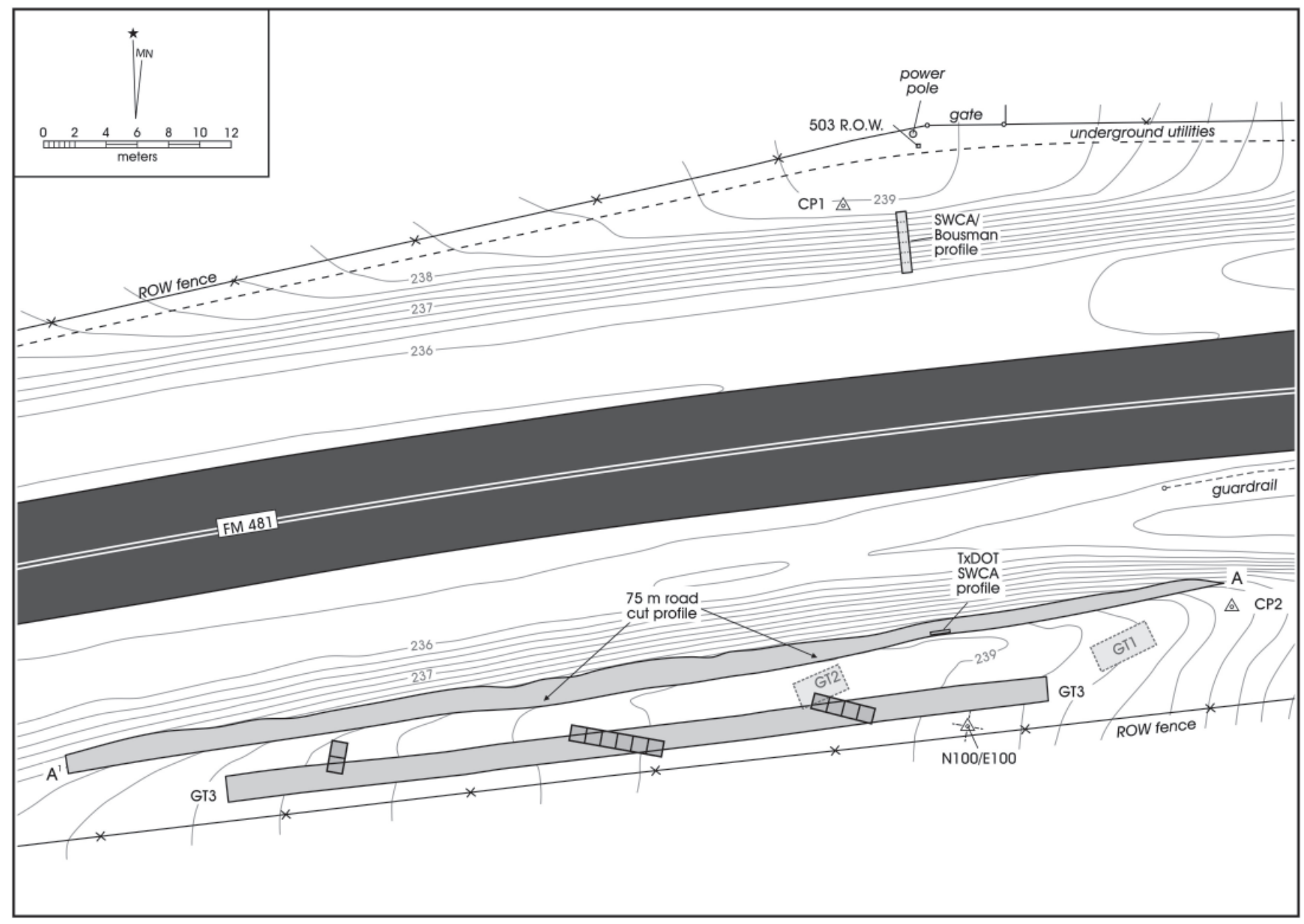

Figure 4-4. CAR Gradall Trenching (GT 3) and testing activities at 41ZV202. 


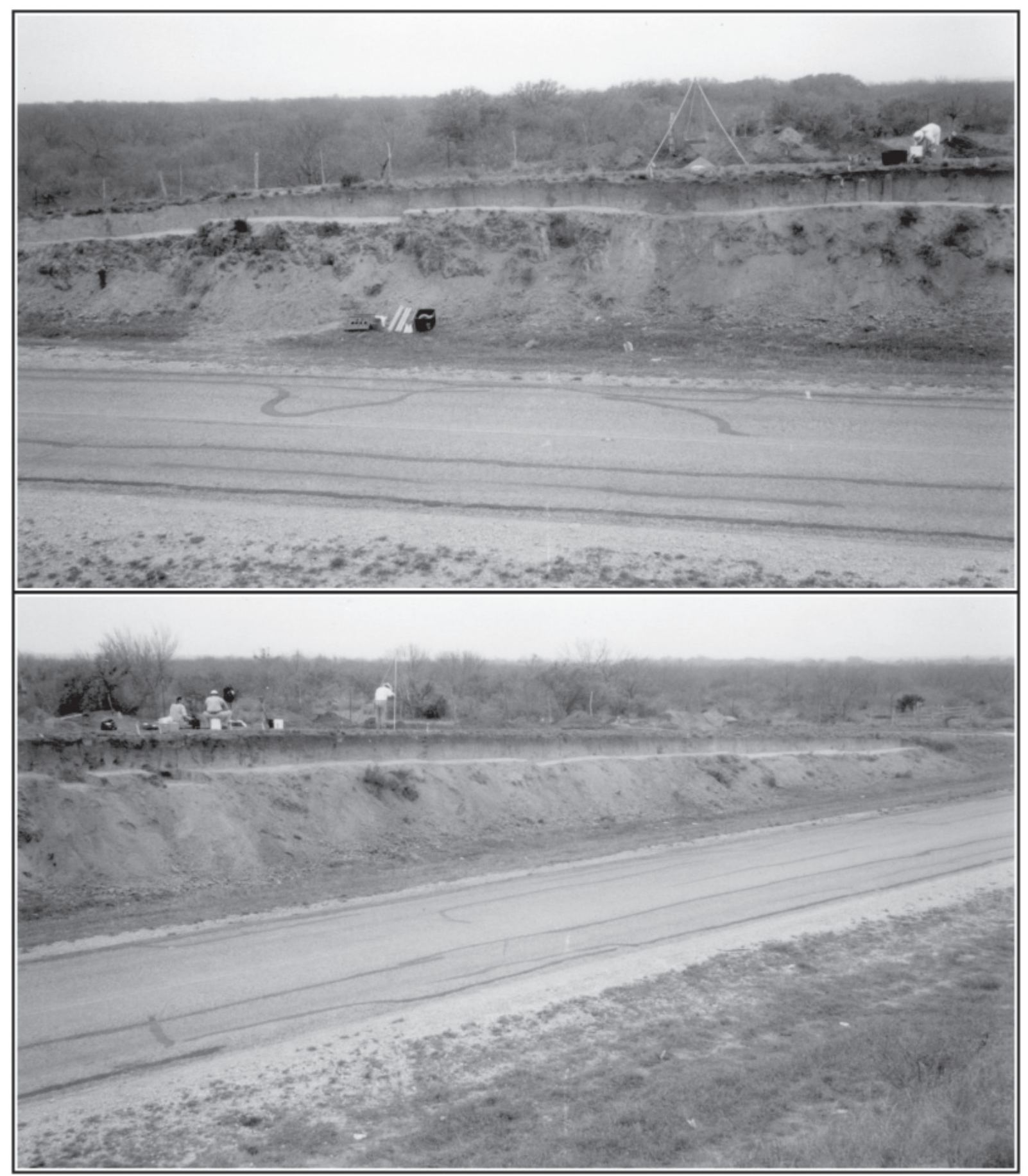

Figure 4-5. Cleaned 75 meter road cut profile. Note dark staining near top and areas of disturbance. Color images of selected sections are available in Appendix A.

the Bk3 horizon that Abbott (2002) identified as possibly Pleistocene in age. However, two areas were excavated to depths of 110-125 $\mathrm{cm}$ to expose disturbances that cut into the Bk soils. These areas have abundant evidence of recent bioturbation, and both appear to be associated with the internment of modern coyote carcasses discussed previously and encountered in the 1981 TxDOT work.
The project geoarcheologist, Dr. C. Britt Bousman, recorded detailed soil descriptions at three sections of the road cut profile (Appendix A). Figures 4-6a and 4-6b show the profile that was drawn subsequent to Bousman's examination. Sediments in this portion of the site are primarily sandy loam, with varying amounts of silt and sand. The Figure 4-6 profile, as well as photographs (see Figure 4-5), clearly document 


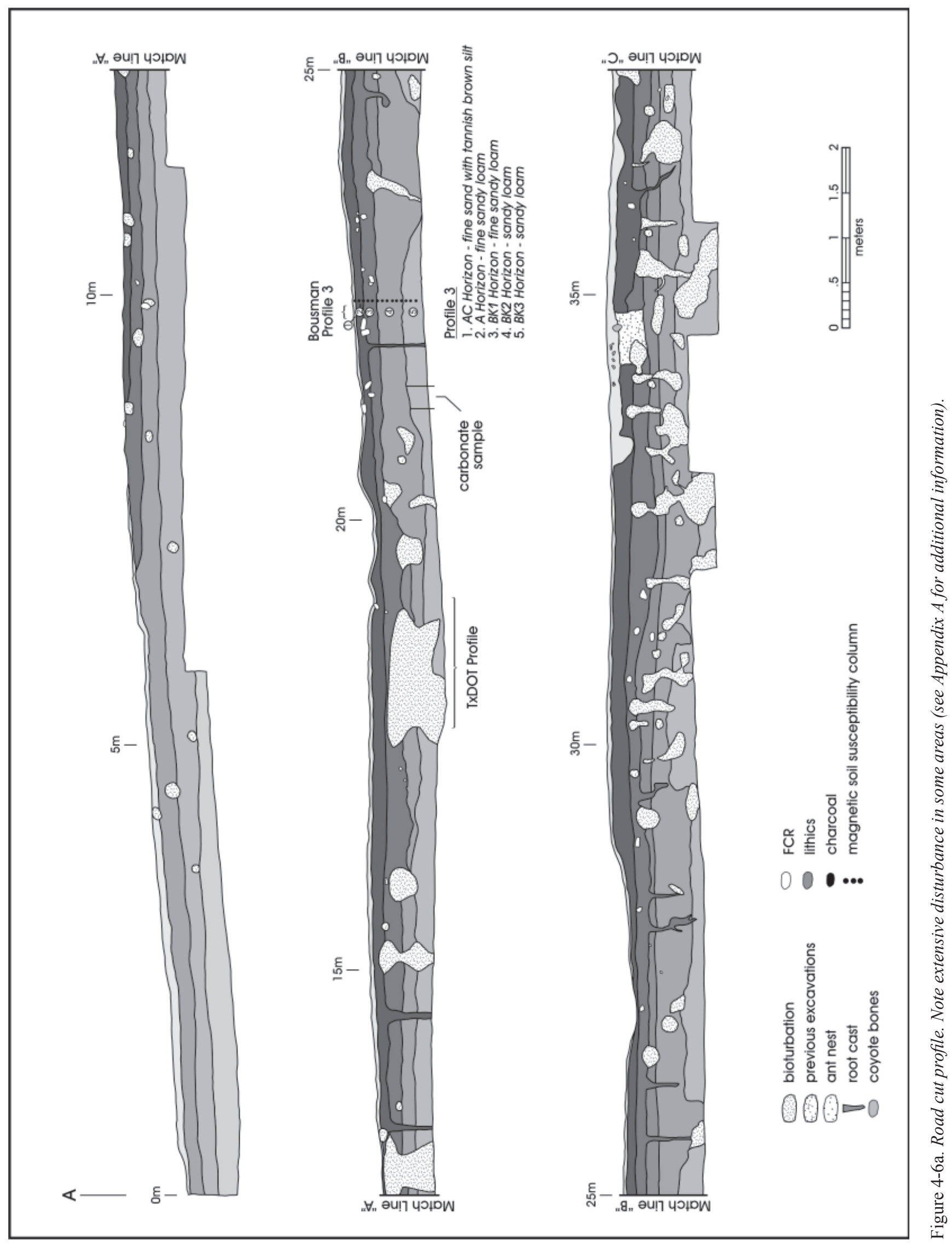




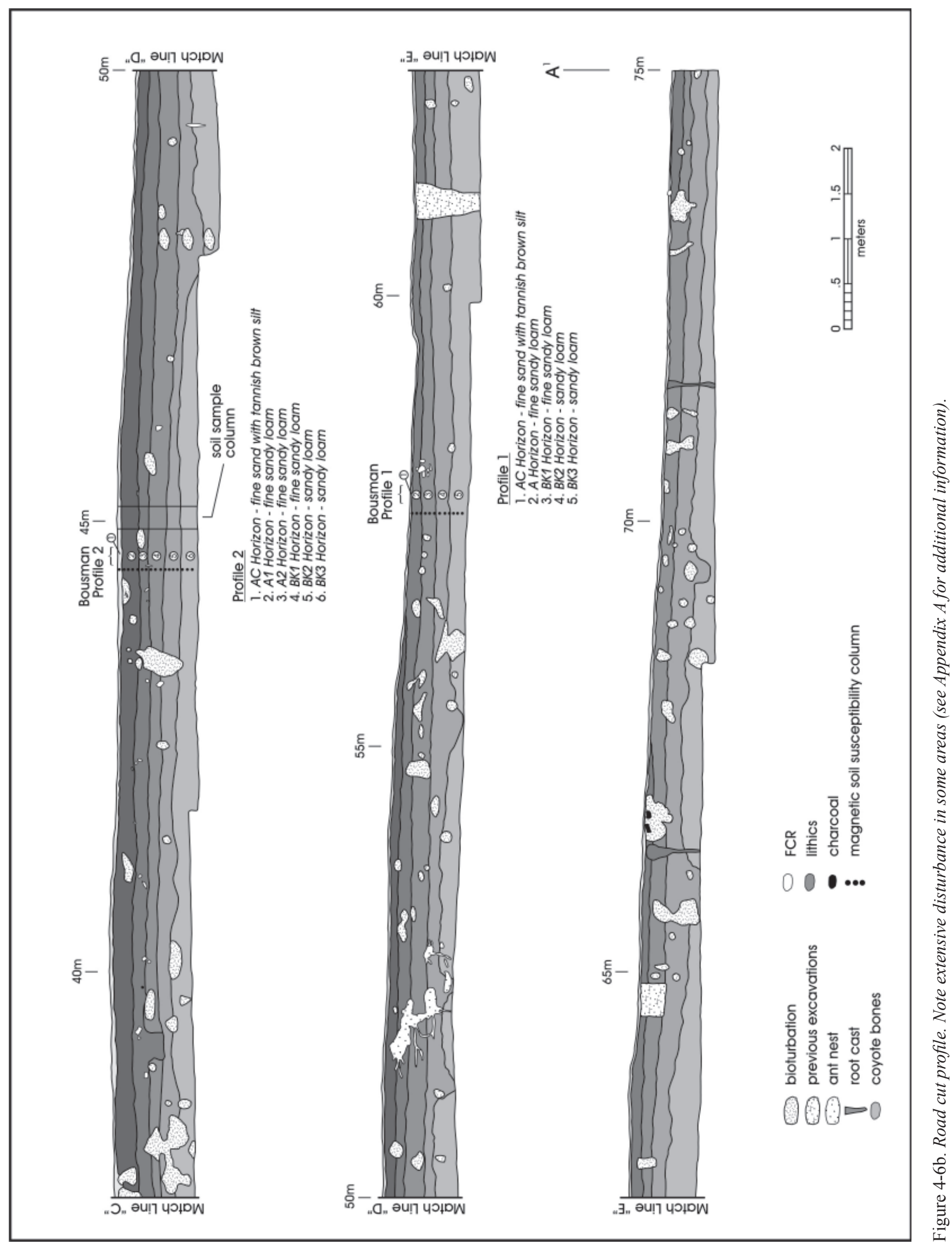


disturbances related to roots, insects, rodents, and previous excavations. As he discusses in Appendix A, Bousman identified two depositional Units at the site. Figure 4-6 shows only the upper Unit (Unit 1). Where not impacted by erosion, Unit 1 appears to be roughly $125 \mathrm{~cm}$ thick. When complete, the Unit consists of upper A horizons and three related $\mathrm{Bk}$ horizons. The lower Bk3 varies in depth (Figure 4-6). Units 2, consisting of Zones 6, 7, and 8, was exposed only on the north side on FM481 in Bousman's Profile 4 (Figure 4-4; Appendix A).

Magnetic soil susceptibility samples were collected adjacent to each of these described sections and soil samples were collected from each horizon adjacent to the geoarcheology Profile 2 location. Only the soil susceptibility samples associated with Bousman's Profile 2 location were analyzed (see Table 11-6). An additional sample of the carbonate rich Bk3 horizon was collected 21.25$21.5 \mathrm{~m}$ west of the eastern end of this profile (see Figure 4-6).

\section{Gradall Trench 3}

A single Gradall trench was excavated $53 \mathrm{~m}$ long on the ROW remnant between the road cut and existing fence line that marks private property (see Figure 4-4). This trench is identified as Gradall Trench 3 (GT 3), following the number of two previous trenches excavated by TxDOT. Excavation involved scraping of roughly 5 to 8 $\mathrm{cm}$ increments to look for evidence of features or significant archeological deposits. The width of GT 3 was about $160 \mathrm{~cm}$. The Gradall scraping was stopped in any location where more than one rock was exposed, dark stains were encountered, or significant amounts of dispersed charcoal were present. Two areas of the GT 3 were more deeply scraped to determine if deeply buried archeological remains were present. An area roughly $1.5 \mathrm{~m}$ just east of the site datum was excavated to about 70 $\mathrm{cm}$ below ground surface. The westernmost $3 \mathrm{~m}$ of GT 3 was excavated to roughly $1.5 \mathrm{~m}$ below ground surface (Figure 4-7). No evidence of cultural materials was encountered during scraping or inspection of the excavation sidewalls of these two deep areas.

The Gradall excavation did expose two areas of dark staining (Figure 4-8). The easternmost area, designated Feature 4, was roughly 3.6-4 m in maximum dimension when freshly exposed. The westernmost stain, Feature 5, was maximally $5.6 \mathrm{~m}$ in extent when uncovered in GT 3. There appeared to be a separation between the two areas of organic enrichment. The immediate area near what was subsequently designated as Feature 6 (see Figure 4-4) was not scraped with the Gradall. In this portion of the site a cluster of rocks was visible at the modern ground surface and a dense cluster had been exposed in the road cut profile.

\section{Test Excavations}

Following the Gradall trenching, areas were selected for test excavations based on the exposure of potential features. The two large, dark-stained areas (Features 4 and 5) represented the most robust opportunities for examination of cultural features in this portion of the site. Additional testing was performed in the vicinity of the

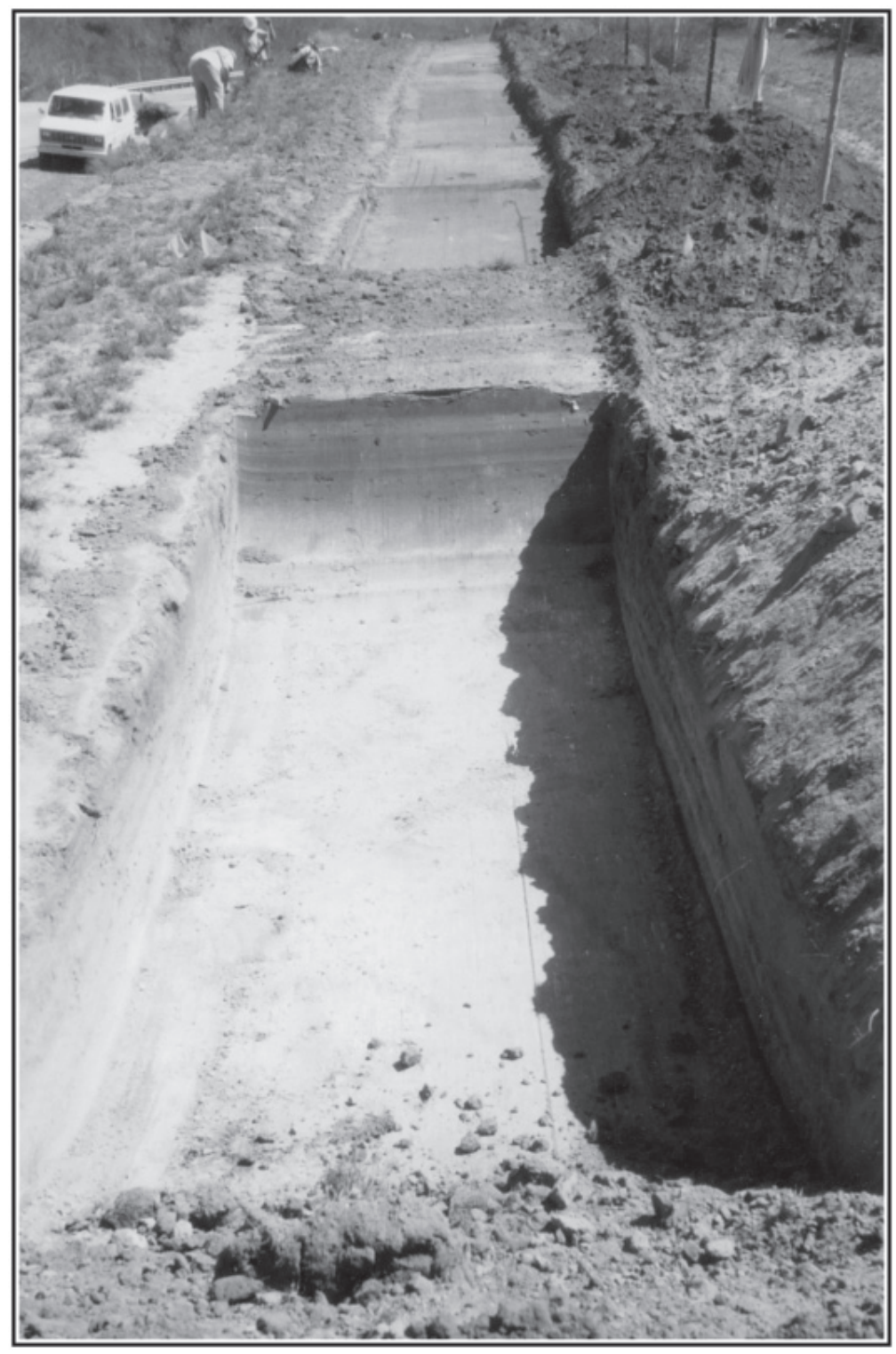

Figure 4-7. West end of CAR Gradall Trench 3. 


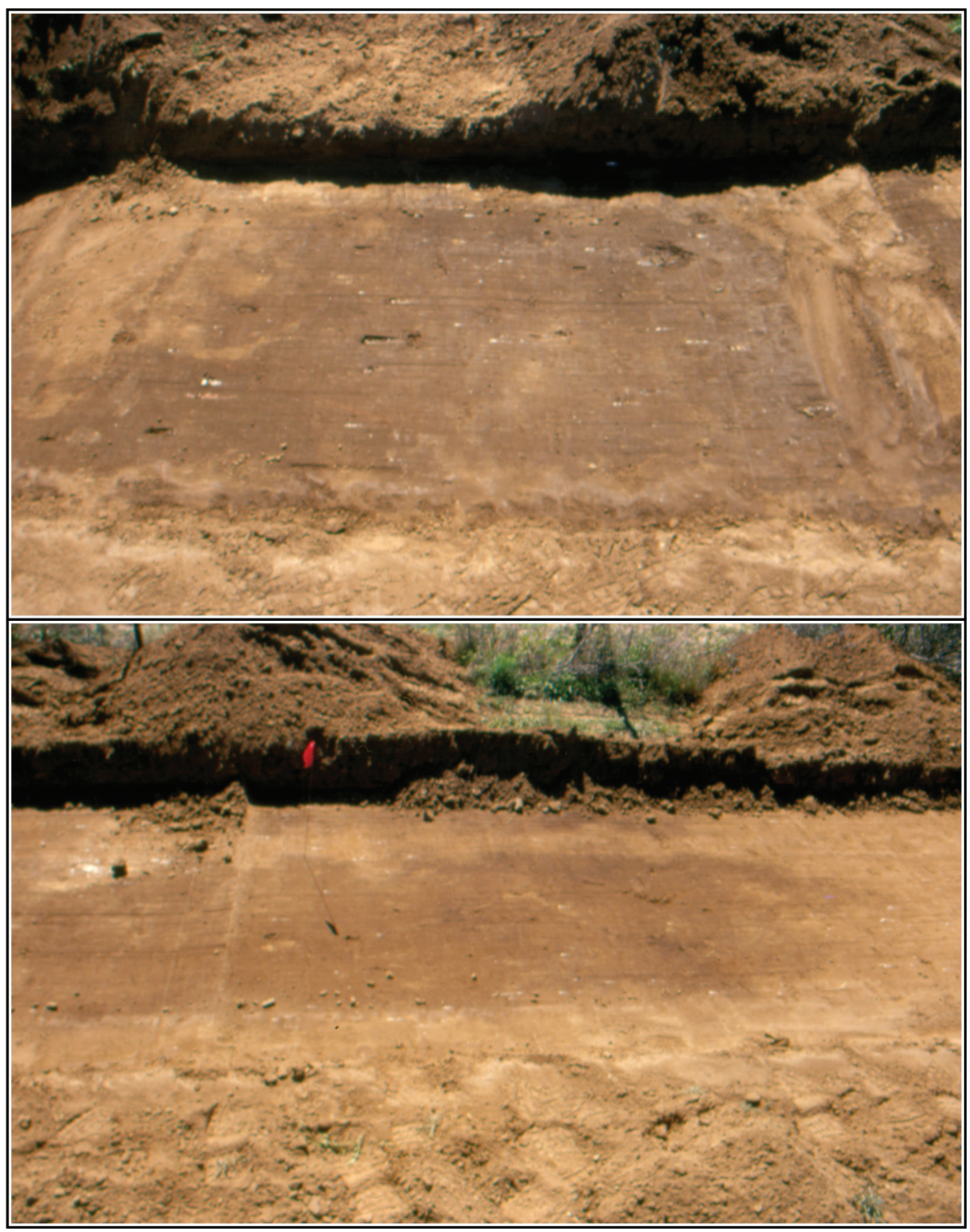

Figure 4-8. Surface of Feature 4 stain (top) and Feature 5 stain (bottom) as exposed in Gradall Trench 3. 
cluster of fire-cracked rock at the western end of the ROW identified as Feature 6 (see Figure 4-4).

A site grid was established using the approximate location of TxDOT's datum from their November investigation. This was a particular post on the existing fence line. A point was placed about $50 \mathrm{~cm}$ in from the fencepost to permit establishment of the Sokkia Total Station over that point during mapping of the site and excavation areas.

This point was designated as N100-E100. Grid points were established along the ROW area using a tape and Brunton pocket transit. The grid was oriented to magnetic north. All excavation units were referred to by the grid coordinate of their southwestern corner. Twelve $1-\mathrm{x}-1-\mathrm{m}$ test units were hand excavated at the site (see Figure 4-4). Four test units were excavated in Feature 4 (Figure 4-4, 4-9) and six were dug in association with Feature 5 (Figure 4-4, 4-10). Two test units were excavated in Feature 6 (N89-E50 and N90-E60; Figure 4-4). A single reference subdatum was established in each of the three excavation areas for the measurement of elevations. All subdatums were established at the same elevation.

Prior to excavations, surface elevations were obtained for each of the four corners and center of each 1-x-1-m unit. All excavations were performed in arbitrary $10 \mathrm{~cm}$ levels referenced to the subdatum not to ground surface elevations. Initial excavation was to the nearest even $10 \mathrm{~cm}$ increment. This resulted in the first excavation level usually being removed as a partial level so that excavation could proceed to even $10 \mathrm{~cm}$ increments for each level. The basal elevations of each excavation level also were checked in each corner and the center. Actual elevations were recorded, not simply the target

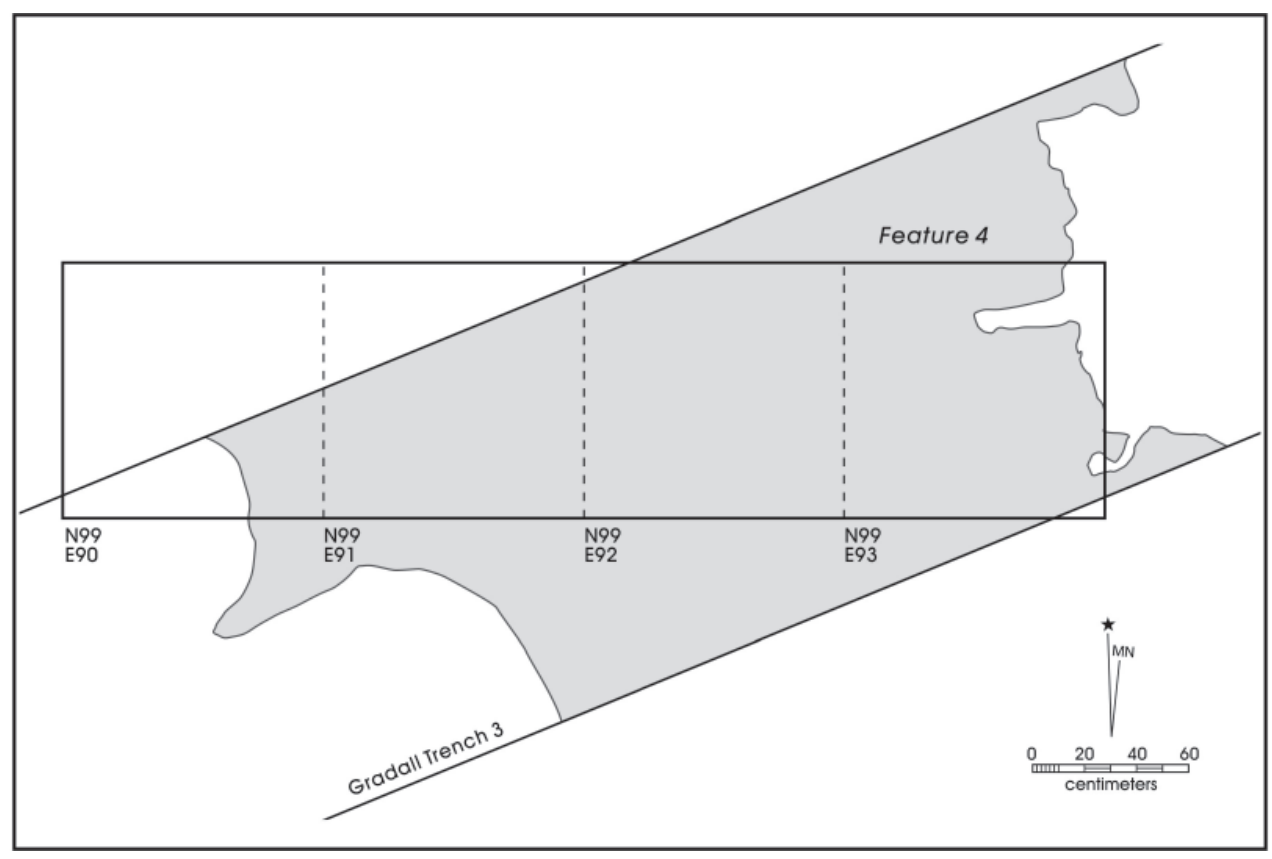

Figure 4-9. Feature 4, surface stain as mapped in Gradall Trench 3.

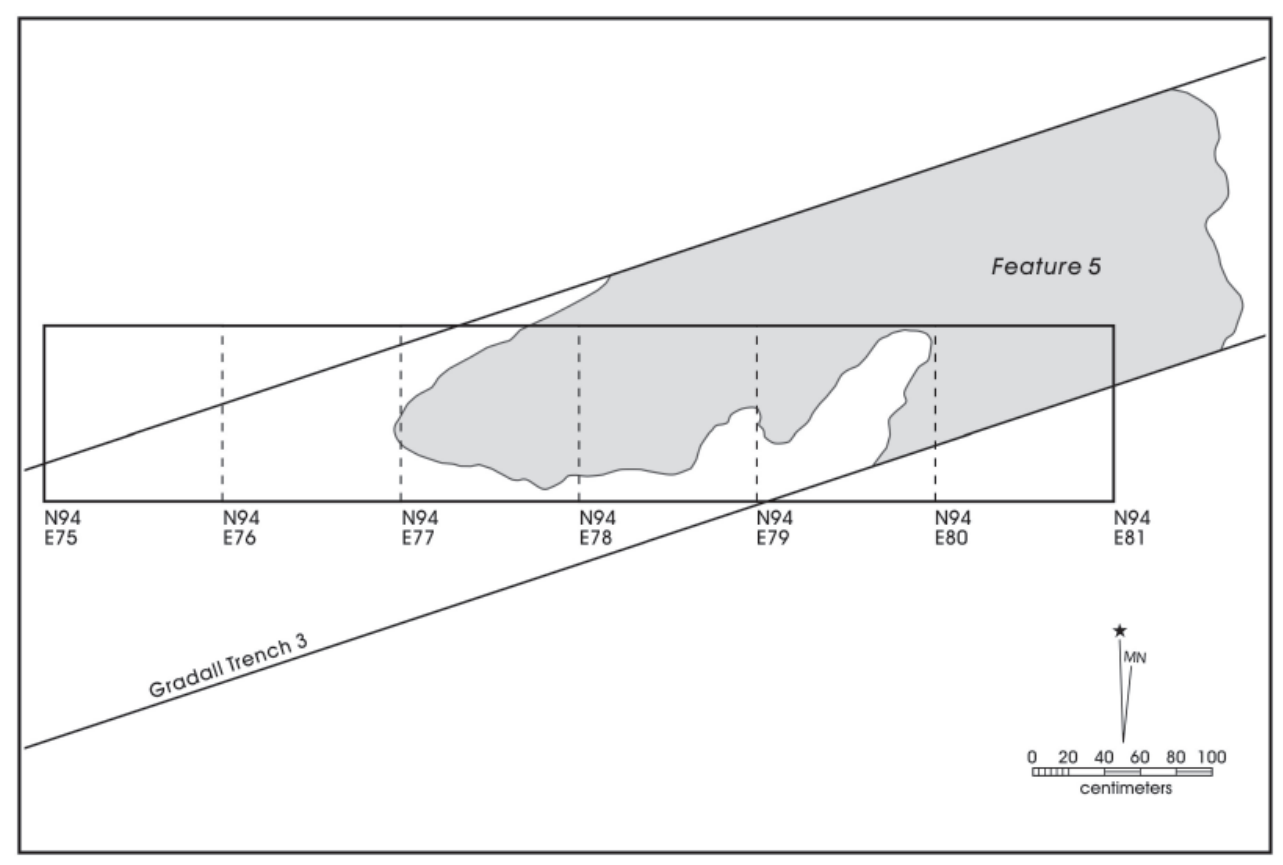

Figure 4-10. Feature 5, surface stain as mapped in Gradall Trench 3. elevations for each excavation level. Most excavation was performed using shovel skimming and all removed sediments were placed into a bucket and screened through $1 / 4$ inch hardware cloth.

Within the Feature 4 area, 32 levels were excavated with all units initiated at between 5 and about $22 \mathrm{cmbd}$, and all terminated at $90 \mathrm{cmbd}$. Three cubic meters were removed 
and screened from this area. The six units excavated in the Feature 5 area initiated at between 17 and $30 \mathrm{cmbd}$, with five of the six terminated at $100 \mathrm{cmbd}$, and the sixth terminated at $110 \mathrm{~cm}$. The 51 levels excavated removed roughly 4.52 $\mathrm{m}^{3}$. Finally, the two units excavated in Feature 6 removed $1.58 \mathrm{~m}^{3}$ of sediment in 15 levels. Both units were initiated at the surface, with one unit terminating at $78 \mathrm{~cm}$ and the second terminated at $80 \mathrm{~cm}$. In all, approximately 9.1 cubic meters of sediment were removed and screened during this testing effort.

All chipped stone, bone, gastropod, and bivalve remains were reserved from the screened matrix. Fire cracked rock or gravel clasts were quantified in the field and then discarded. These clasts were counted and the number of rocks of different sizes was recorded, along with their total weight by size class. Clasts were size-sorted by passing them through a template that separated rocks by $<1$ in, $1-2$ in, $2-3$ in, and $>3$ in. Weights were collected using a hanging spring scale with a precision of $8 \mathrm{oz}(\sim 230 \mathrm{gm})$. Several of the excavation levels produced clast weights of less than the minimal unit of precision $(<8 \mathrm{oz})$. Fire-cracked rock associated with Feature 7 was collected.

Shovel skimming was combined with troweling to assist collection of more detailed provenience data on larger artifacts. When we encountered clasts of approximately $3 \mathrm{~cm}$ or larger, attempts were made to record their in situ positions. Some artifacts slightly disturbed by shovel skimming also could be mapped if the impression of their original location could be identified. This combined method does not permit accurate identification of all clasts above the target size. The thinness of lithics makes this method less successful for recovering larger flakes or tools than troweling without shovel skimming. Plotting of the locations of larger lithics, fire cracked rock, and gravels was considered useful to determining the potential integrity of the archeological remains and the vertical distribution of artifacts in these deposits. One of the initial expectations was that there might be evidence of multiple occupational events represented at this site. Rather than rely on qualitative impressions of the vertical frequencies, separation of remains, or the aggregate count of clasts, measurement of the elevation or artifacts and fire-cracked rock were used to identify potential evidence of multiple occupational history. The convention used to obtain an elevation was to measure the depth below each subdatum of the highest surface on which any artifact was resting. Selection of the highest point recognizes that artifacts may be trampled or displaced deeper into soil cracks or bioturbation, but the highest surface on which it is resting is most likely to represent the least disturbed elevation of its deposit. This does not imply an expectation that artifacts have not been subject to a range of taphonomic events. It is merely a convention for measuring the potential effects of initial and post-depositional artifact movement and spatial association. Shovel skimming and troweling results in an unsystematic recovery of spatial provenience biased against smaller and thinner remains. However, it does provide some additional fine-scaled data on vertical distribution that was thought to be a useful procedure to identify and potentially separate palimpsest deposits as have commonly been encountered in sites along FM 481 (see Mauldin et al. 2004).

In addition to the recovery of artifacts from the $1 / 4$ inch screens and from piece plotting, adjunct samples were collected. Following excavation of the first complete 1-x-1-m unit in each of Features 4 and 5, 1 liter soil samples from either one or two levels in the dark feature fill (depending on the identified depth within each unit) were collected from every unit. These samples were not collected from the first excavation units in each feature (N99-E93 in Feature 4 and N94-E80 in Feature 5) because these were used to identify the stratigraphy so that sampling could more effectively target the feature deposits. Three soil samples were recovered from feature fill in N99-90, N99-E91, and N99-E92. Two additional samples were collected from underneath a large rock in Level 4 of N99-E90 and N99-E91. The position of this large manuport in Feature 4 is likely to identify a prehistoric surface during at least some of the occupation of 41ZV202 responsible for formation of Features 4 and 5. A set of soil samples $(n=7)$ was collected from all excavation levels in N94-E78 below the shallow surface materials of Level 1. An additional eleven samples of the fill in Feature 5 were collected form N94-E75 (2 samples), N94-E76 (3 sample), N94-E77 (3 samples), and from N94-E79 (3 samples). Flotation samples of the majority of the charcoal stained sediment ( $\sim 50.5$ liters) associated with Feature 7 also were collected.

Charcoal samples were collected when encountered in situ from contexts indicating that no obvious bioturbation or other disturbances were present. We collected 29 samples from the controlled excavation of $1-x-1-m$ units. Twelve samples were collected from Feature 4, eleven from Feature 5 , and four from Feature 7. Two samples that were collected from slightly above the Feature 7 and represent either charcoal associated with Feature 7 or materials associated with the majority of Feature 5 fill deposition. One additional charcoal sample was collected from the road cut profile wall. This charcoal was from an area of the profile in the vicinity of Feature 5 and is likely to represent deposits associated with that feature. CAR submitted eleven charcoal samples from Features 4, 5, and 7 for AMS dating. The results of AMS analyses of the charcoal samples are discussed in Chapters 5 and 6. Additional information is presented in Appendix B. 
Following excavations through Features 4, 5, and 6, one exposed wall of the excavation trench was profiled and a column of magnetic susceptibility samples (MS) was collected. The location of each MS sample was indicated on the profile. These samples were not analyzed. No descriptions of the soils were made, although the identified units are congruent with those identified by Bousman in the road bank profile (see Appendix A; Figure 4-6).

One carbonate sample from the road cut profile (Profile \# 4) and a series of samples from the northern side were collected for possible carbonate dating. MS soil samples were collected as a sample column from three profiles recorded by Bousman along the long road bank profile (Figure 4-6) and from one area within each excavations of Features 4, 5, and 6 (Figure 4-4). Sampling involved the use of standard template placed against the profile wall with holes drilled at $5 \mathrm{~cm}$ increments. Vials inserted into the holes effectively trapped sediments with almost no contamination from upper and lower contexts. Vials were labeled on their caps and placed within a single zip-lock bag for each sample column. The location of samples from each profile was drawn on those recorded profiles. An additional group of MS samples were collected as part of bulk soil from the profile on the northern road bank where approximately 265 $\mathrm{cm}$ of deposits were exposed.

\section{Summary}

Testing of 41ZV202 in March 2003 established the presence of two large stained areas identified as Features 4 and 5 on the southern ROW of FM 481. The soils and artifacts distributed within these areas of organic enrichment features represent a restricted temporal occupation of this site dating from approximately 1000 Bр (See Appendix B; Chapter 5). Testing indicated that the cultural deposits composing these features have a high degree of integrity and qualify as a significant resource. CAR recommended that 41ZV202 was eligible for listing on the NRHP under Criterion D (36 CFR $§ 60.4$ ). These cultural resources would have been adversely affected by the proposed roadway improvements. Both TxDOT and the THC agreed that the remainder of $41 Z \mathrm{~V} 202$ within the southern ROW of FM 481 was NRHP eligible (Meade 2002). They also concurred with the recommendation for data recovery of this portion of the site.

\section{CAR Data Recovery}

With the concurrence of TxDOT and THC, CAR initiated data recovery efforts at 41ZV202. The work was conducted between July 9 and August 1, 2003, under TxDOT Work Authorization No. 573-06-SA002. Texas Antiquities permit no. 3071 was amended to include the data recovery work. As with the testing, Russell Greaves directed the field work and Steve Tomka served as principal investigator.

Data recovery efforts focused on the area surrounding Features 4 and 5 defined during testing. CAR excavated 40 1-X-1-m units during the data recovery fieldwork at 41ZV202. These units were adjacent to $101-\mathrm{x}-1-\mathrm{m}$ units excavated during testing in this area. This produced a block excavation of 50 units (Figure 4-11).

Data recovery excavation procedures were similar to those described previously for the testing phase. All excavation involved shovel skimming and hand troweling. Except for the first excavation level in each unit, all levels were 10 $\mathrm{cm}$ thick. The first excavation levels of some units were slightly more or less than $10 \mathrm{~cm}$ because of the undulations in the modern ground surface. All excavation levels were taken to standard, arbitrary elevations referenced to a single elevation across the entire site. CAR excavated 246 levels during the data recovery efforts. Eighty-one levels were excavated in this same area during testing. During data recovery, CAR excavated six levels in most units, though in some we removed only 5 levels. Some areas of the site contained significant amounts of recently disturbed sediments and material from the backfilling performed after the March 2003 testing. Units with only five completed excavation levels are those that had significant overburden that we removed prior to starting work. All units terminated at $60 \mathrm{~cm}$ below ground surface. The $60 \mathrm{~cm}$ termination depth represented a modification to the data recovery scope of work that projected a terminal depth of $70 \mathrm{~cm}$. The 70 $\mathrm{cm}$ depth was to ensure that data recovery went below the $\mathrm{Bw}$ horizon that appears to be the base of the Late Prehistoric occupation. Testing demonstrated that there was a significant decrease in lithics and fire-cracked rock below the Bw horizon and bioturbation also increased. During data recovery, CAR determined that excavation to $60 \mathrm{~cm}$ depth adequately sampled the Bk horizon to a depth of $15-30 \mathrm{~cm}$. TxDOT staff approved this change.

With the exception of gastropods, we mapped all items $3 \mathrm{~cm}$ or larger that were encountered in situ. Charcoal was mapped and collected in sizes smaller than $3 \mathrm{~cm}$ (most samples are between $5 \mathrm{~mm}$ and $12 \mathrm{~mm}$ ). Seventy-eight piece-plotted charcoal samples were collected during data recovery excavations. Mapping involved recording a single point for each piece-plotted item that represents the three-dimensional provenience coordinate. Additionally, each artifact was drawn on a series of separate maps to be transferred to an overall excavation distribution map. In all, 1,615 artifacts were piece-plotted. 


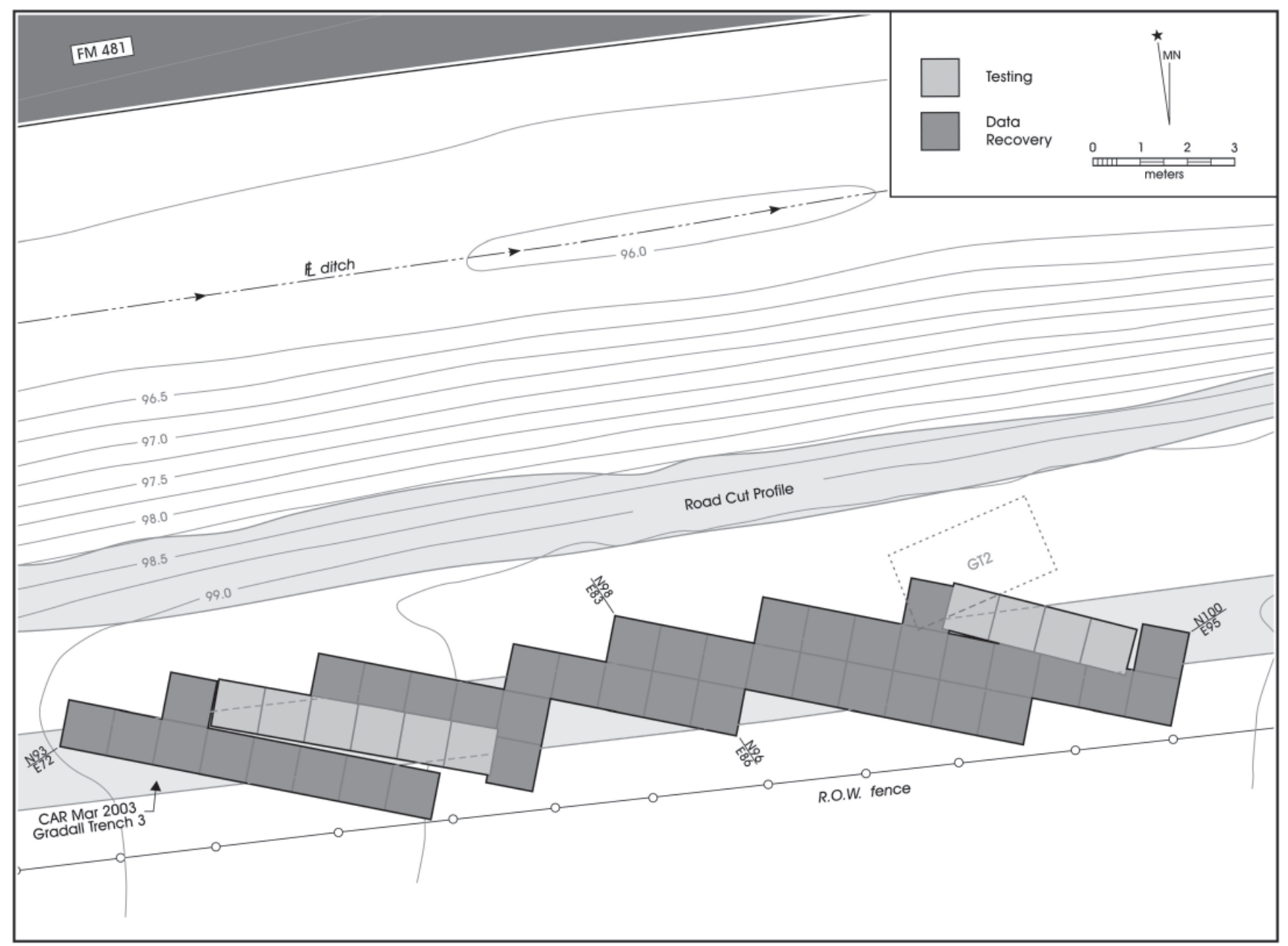

Figure 4-11. CAR Data Recover and Testing areas in the Feature 4 and 5 area.

We collected 162 soil samples, each approximately 0.5 liters in size, from the 40 data recovery units. This included samples from each of the six features identified during data recovery and samples collected from the A and Bw horizons across the area. In addition, 60 magnetic susceptibility samples were collected from an east-west transect of 20 units (N94-E81; N95-E77-81; N96-E81-85; N97-E83-91). All other soil was passed through $1 / 4$-inch mesh hardware cloth. Other than roots, all items that remained in the screens were collected for laboratory quantification. Screen residues collected included not only artifacts, but also all natural clasts (i.e., gravels, calcium carbonate nodules, gastropods, etc.).

\section{Profiling}

CAR staff drew $28 \mathrm{~m}$ of exposed profiles at the conclusion of the block excavation. A continuous profile was drawn of $20 \mathrm{~m}$ from the eastern wall of N99-E94 to N94-E81. Another $8 \mathrm{~m}$ exposure was drawn of the south wall of the contiguous exposure of N93-E72 to N93-E79 (see Figure
4-11). This presents a complete east-west section through the block excavations. Profiling involved identification of the boundaries between the uppermost disturbed sediments and soil divisions between the $\mathrm{A}, \mathrm{Bw}, \mathrm{Bk} 1$, and $\mathrm{Bk} 2$ horizons (note 1). Locations of clasts were mapped as well as areas of bioturbation. Soil descriptions were not performed during the data recovery work as those have previously been recorded for several locations at 41ZV202 (Abbott 2002; Kuehn 2002; Appendix A).

\section{Laboratory Methods}

A wide variety of materials and associated records were collected in connection with CAR's testing and data recovery work at 41ZV202. All cultural materials and records obtained and generated during the project were prepared in accordance with federal regulation $36 \mathrm{CFR}$ part 79 , and THC requirements for State Held-in-Trust collections. Additionally, the materials and records were curated at the Center for Archaeological Research in accordance with current Center guidelines. 
Artifacts processed in the CAR laboratory were washed, air-dried, and stored in 4 mil zip locking archival-quality bags. Organic materials and materials needing extra support were double-bagged. CAR staff placed acid-free labels in all artifact bags. Each laser printer generated label contained provenience information and a corresponding lot number. Staff labeled tools with permanent ink over a clear coat of acrylic and covered by another acrylic coat. In addition, CAR staff labeled a small sample of unmodified debitage from each lot with provenience data. The staff also separated artifacts by class and stored them in acid-free boxes identified with standard tags.

Staff placed all field notes, forms, photographs, and drawings in labeled archival folders. Photographs, slides, and negatives were labeled and placed in archival-quality sleeves. We used pencil on all field forms. Any soiled forms were placed in archival-quality page protectors. Text, data, and image electronic files, including PDF (portable document format) scans of all records, are stored on CDs or on DVDs and placed in a fire-proof cabinet in the Center's facility.

\section{Additional Considerations}

In consultation with the TxDOT and the THC, subsequent to proper analyses and quantification, artifacts and other materials collected on this project, but possessing little remaining scientific value, will be discarded pursuant to Chapter $26.27(\mathrm{~g})(2)$ of the Antiquities Code of Texas.
Material classes proposed for discard specific to this project included all unprocessed soil samples and soil susceptibility samples not directly associated with burned rock features, all debitage not associated with the Late Prehistoric period, all non-feature burned rock, all other rocks, all calcium carbonate nodules, all snails from non-feature contexts, and all modern materials (e.g., metal, plastic).

\section{Summary}

The 2003 CAR testing efforts at 41ZV202 determined that significant archeological deposits with good integrity were present within a portion of the southern ROW of FM481. As discussed subsequently, these deposits dated to around 1000 $\mathrm{BP}$ and contained a variety of data types that could yield information important to prehistory. CAR recommended that 41ZV202 was eligible as a SAL and for listing on the NRHP. The THC and TxDOT concurred with those recommendations. Construction impacts associated with the expansion of FM481 would damage these significant deposits. CAR, at the request of TxDOT, initiated efforts in July of 2003 to recover these significant data. Those efforts focused on Features 4 and 5, two organically enriched deposits. Within these two larger features, testing demonstrated that smaller fire-cracked rock features, associated chipped stone tools, debitage, and charcoal, were present. These features have a high degree of integrity and good data quality. Data recovery efforts terminated in August of 2003. 



\title{
Chapter 5: Features, Artifacts, Ecofacts, and Other Samples Recovered from 41ZV202
}

\author{
Raymond Mauldin and Russell Greaves
}

During the CAR testing and data recovery work at 41ZV202, a wide variety of data types were recovered. This included data on several features, burned rock, chipped stone debitage, a variety of tools, small amounts of vertebrate fauna, snails and mussel shell, charcoal samples, and soil samples. This chapter provides a short summary of these materials. Many of these data sets are used in Chapter 6 to isolate the Late Prehistoric analytical unit.

\section{Features}

In all, CAR defined ten features during work at 41ZV202. As noted in Chapter 4, CAR identified four anomalies as Features 4, 5, 6, and 7 during testing (Greaves 2003). Features 4 and 5 were areas of darker organic staining that were distinct from other areas of A horizon deposits at the site. Feature 6 was a small accumulation of rocks seen at the western end of the 75-m-long road cut profile. Feature 7 was an area of rock concentration associated with a dense charcoal accumulation. Features 8 through 13 were identified during data recovery. Features 8, 10, and 13 were associated with the A horizon deposits that appear heavily organically enriched and that were identified as Feature 4 during testing. Clusters of FCR mixed with lithic debris and charcoal defined all three features. Feature 9, 11, and 12 were all smaller clusters of FCR located to the west of Feature 4. All three were located below the organically enriched area identified as Feature 5. Features 1, 2, and 3, identified by TxDOT as small clusters of burned sandstone in gradall trenches 1 and 2 (see Chapter 4) were not excavated.

Figure 5-1 shows the location of nine of the 10 CAR features. Note that Feature 6, defined following Gradall trenching, was located at N89/E60, to the west of the nine features shown

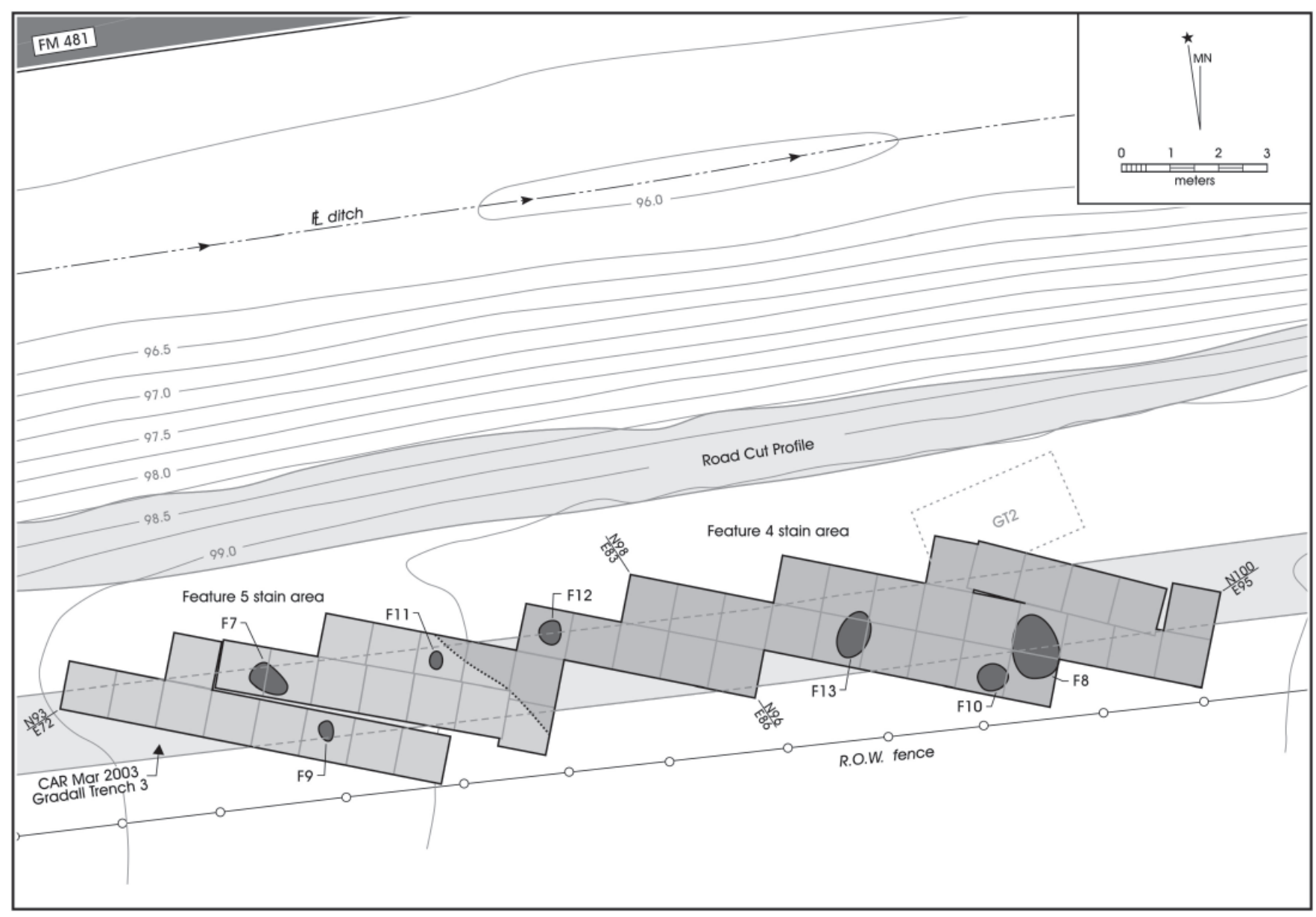

Figure 5-1. Location of features identified by CAR at 41ZV202. Note that Feature 6, defined at N89/E60 during testing, is not shown. 
in Figure 5-1. While all 10 features are discussed below, note that during testing CAR determined that there is little evidence that Feature 6 represents a discrete, thermal feature of archeological interest.

\section{Feature 4}

Feature 4, originally identified in GT3, contained very dark (10YR2/1) soil with a high density of artifacts. While testing notes suggest that the color of the Feature 4 soil was darker than the A horizon, it appears that subsequent investigations during data recovery considered Feature 4 and the A horizon to be identical. In any event, no spatial boundaries for this feature were defined during CAR's excavation. Figure 5-2 (see also 5-1) shows the Feature 4 area as it was defined during testing. While charcoal is present along with a low density of FCR, there is no evidence of thermal rubification and few of the artifacts present exhibit thermal fracturing. The lack of evidence of burning suggests that the color difference distinguishing Feature 4 is likely related to organic enrichment of these sediments. However, note that the dark color of the feature fill made any distinctions within the feature difficult. Scattered chipped stone debitage and several lithic tools, including a Late Prehistoric Scallorn point (see Turner and Hester 1999: 230), were associated with the Feature 4 fill.
Figure 5-3 presents a profile of the southern wall of the Feature 4 excavations prepared following testing. The top of the stain was encountered about 15 to $20 \mathrm{~cm}$ below the modern ground surface, and the feature appears to be roughly 12 to $20 \mathrm{~cm}$ thick. In Figure 5-3, the feature is shown as clearly distinct from the overlying A horizon, and resting on a $\mathrm{Bw}$ horizon that is consistently expressed across the majority of the landform. Also shown in the profile are the approximate vertical position and the corrected, calibrated radiocarbon age range, for five charcoal samples submitted to Beta Analytic following testing (see Appendix B; See also Chapter 6). Three of the five dates show a close temporal clustering (Beta Samples 177698, 177699, and 177701) between cal вP 950-720. Two of the samples produced significantly older dates (Beta Samples 177697 and 177700) from cal BP 1890-1290. The two older dates shown in the profile are at lower elevations near the base of the Bw horizon. However, it is uncertain whether elevation differences are stratigraphically significant. Given the close temporal clustering of most dates, the two outlying dates may represent older charcoal incorporated into younger sediments through insect or gastropod transport. Evidence of small insect burrows was common in these soils. Overall, the results appear to indicate a restricted time range, sometime around A.D. 1100, when Feature 4 formed.

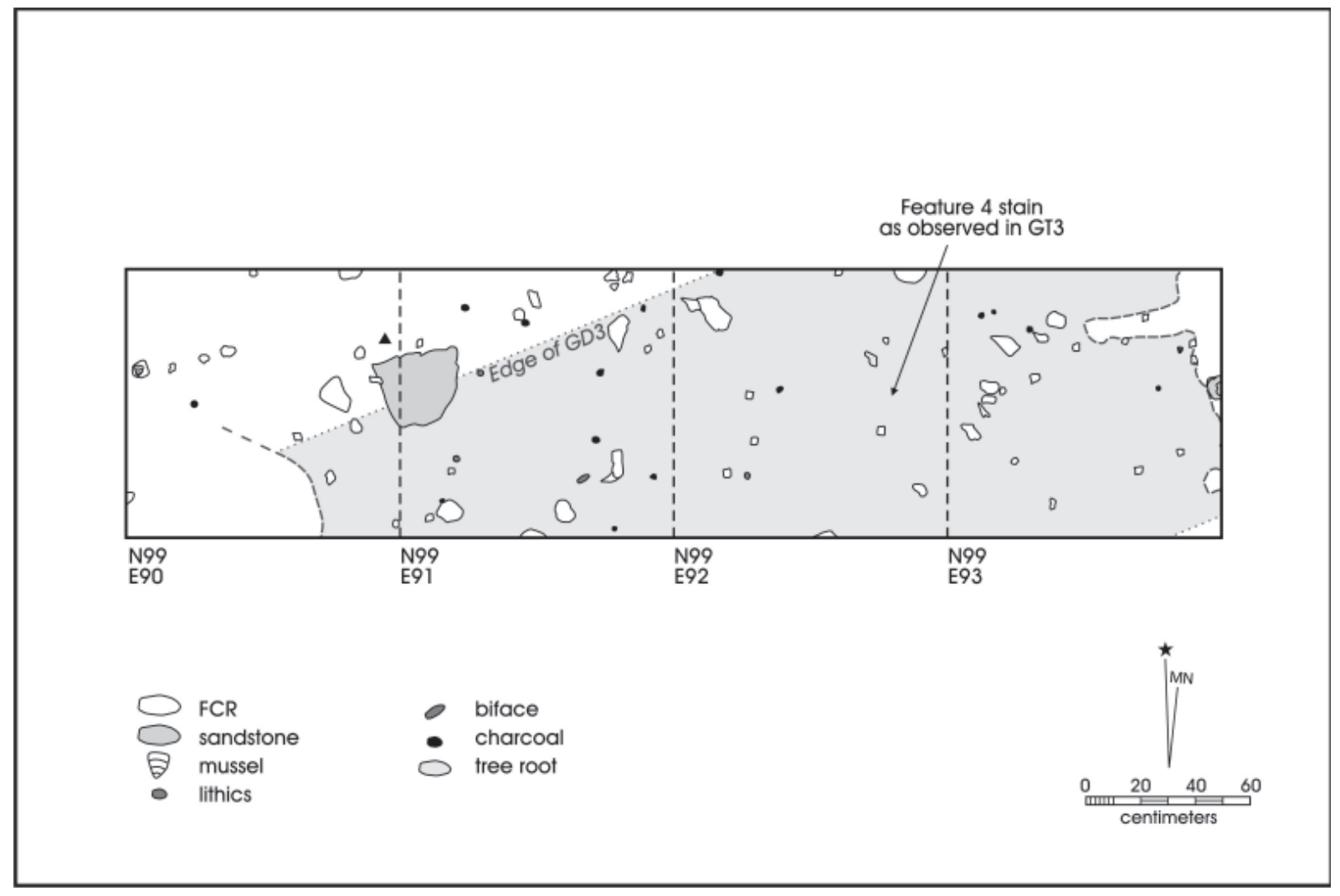

Figure 5-2. Feature 4 excavation area during testing. 


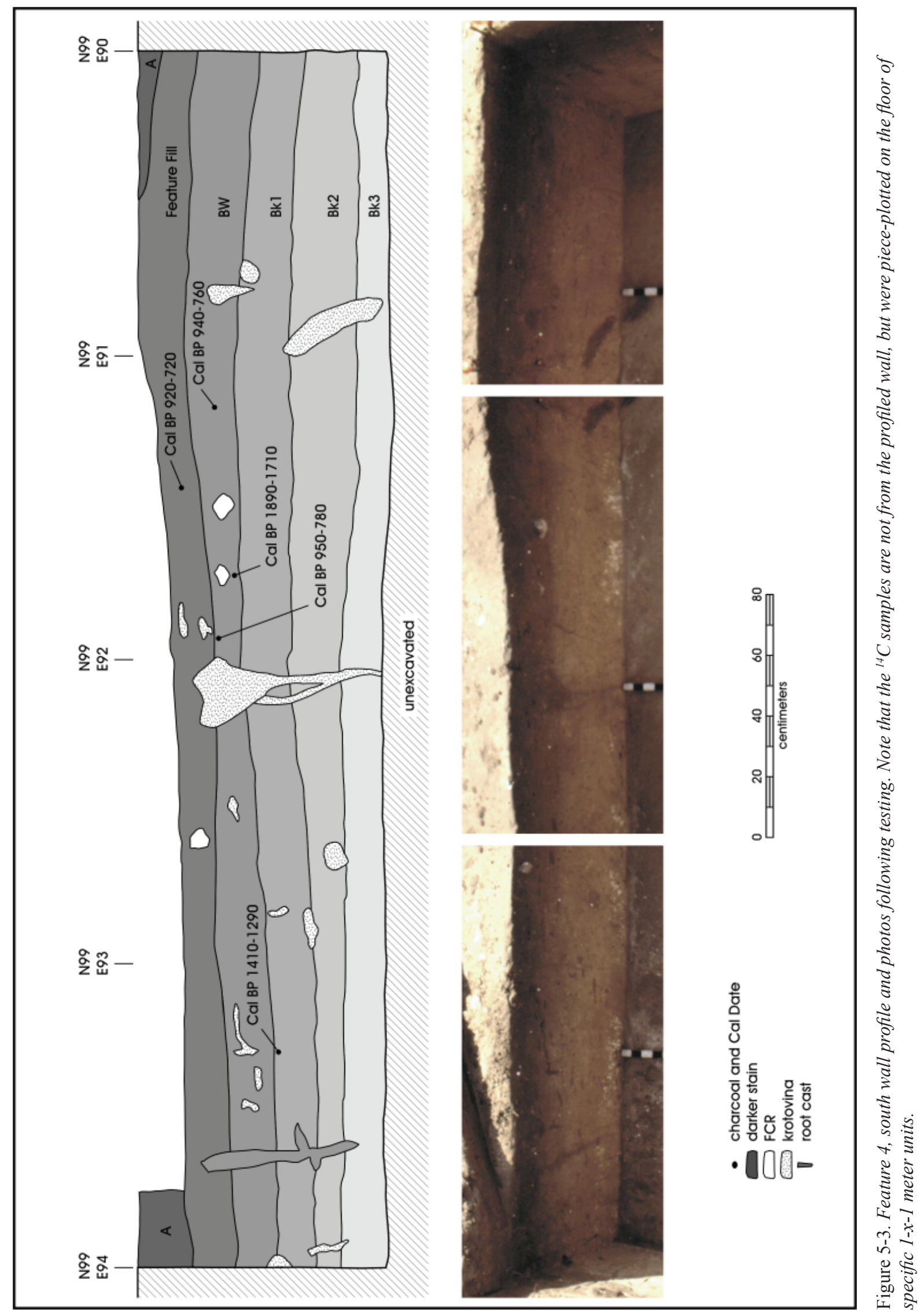


Data recovery work in the area served to more clearly define the western edge of Feature 4, though the overall size of the feature exceeded the excavated area (see Figure 5-1). Data recovery work defined several smaller FCR concentrations with charcoal and staining that clearly represent thermal features (e.g., Features 8, 10, 13) within the Feature 4 deposits. However, the additional excavations did not provide any additional evidence that Feature 4 itself was related to burning. The function of the feature remains unclear. Minimally, Feature 4 may be a midden deposit with significantly higher concentrations of artifact and organic debris than other portions of the site.

\section{Feature 5}

During testing, Feature 5 was identified as a dark stain in GT3. The feature was just to the west of Feature 4. When first defined in the trench, the stain was approximately $5 \mathrm{~m}$ in extent and appeared to have a well-defined margin at both the eastern and western ends, though these boundaries became increasingly obscure with subsequent work (see Figure 5-1). Figure 5-4 shows the Feature 5 plan view as defined during testing. Note that like Feature 4, Feature 5 consisted of area of dark (10YR4/3), organically enriched soil. While FCR was present at a low density, CAR could not identify any areas of charcoal concentration or evidence of thermal rubification.
As with Feature 4, this localized concentration of darker sediment appears to have formed through organic enrichment rather than burning. In addition to FCR, the feature contained chipped stone debitage and tools, including a blade fragment from what appears to be a Late Prehistoric point, possibly a Scallorn type, directly associated with the dark feature fill. Like Feature 4, Feature 5 contained at least one smaller burned rock and charcoal cluster, Feature 7 shown in Figure $5-4$, which clearly is related to burning.

The stratigraphy of Feature 5 as defined following testing is shown in Figure 5-5. In many respects, it is similar to that seen in the profile of Feature 4 (Figure 5-3). The thickness of the dark, organic rich soil is greater in Feature 5 because the Gradall did not excavate this feature as deeply as Feature 4. The A horizon identified in the Feature 4 profile is not shown in Feature 5, though, like Feature 4, the Feature 5 deposit rests on the Bw horizon. It may be the case that Feature 5 is, in fact, an A horizon identical to that shown in Feature 4. The approximate vertical position and the corrected, calibrated radiocarbon age range for six charcoal samples submitted to Beta Analytic following testing (see Appendix B; see also Chapter 6) is also shown in Figure 5-5. Two of these samples come from within Feature 5. Two other samples are from just above Feature 7, also within Feature 5. One sample comes from the top of the underlying $\mathrm{Bw}$ horizon, and the

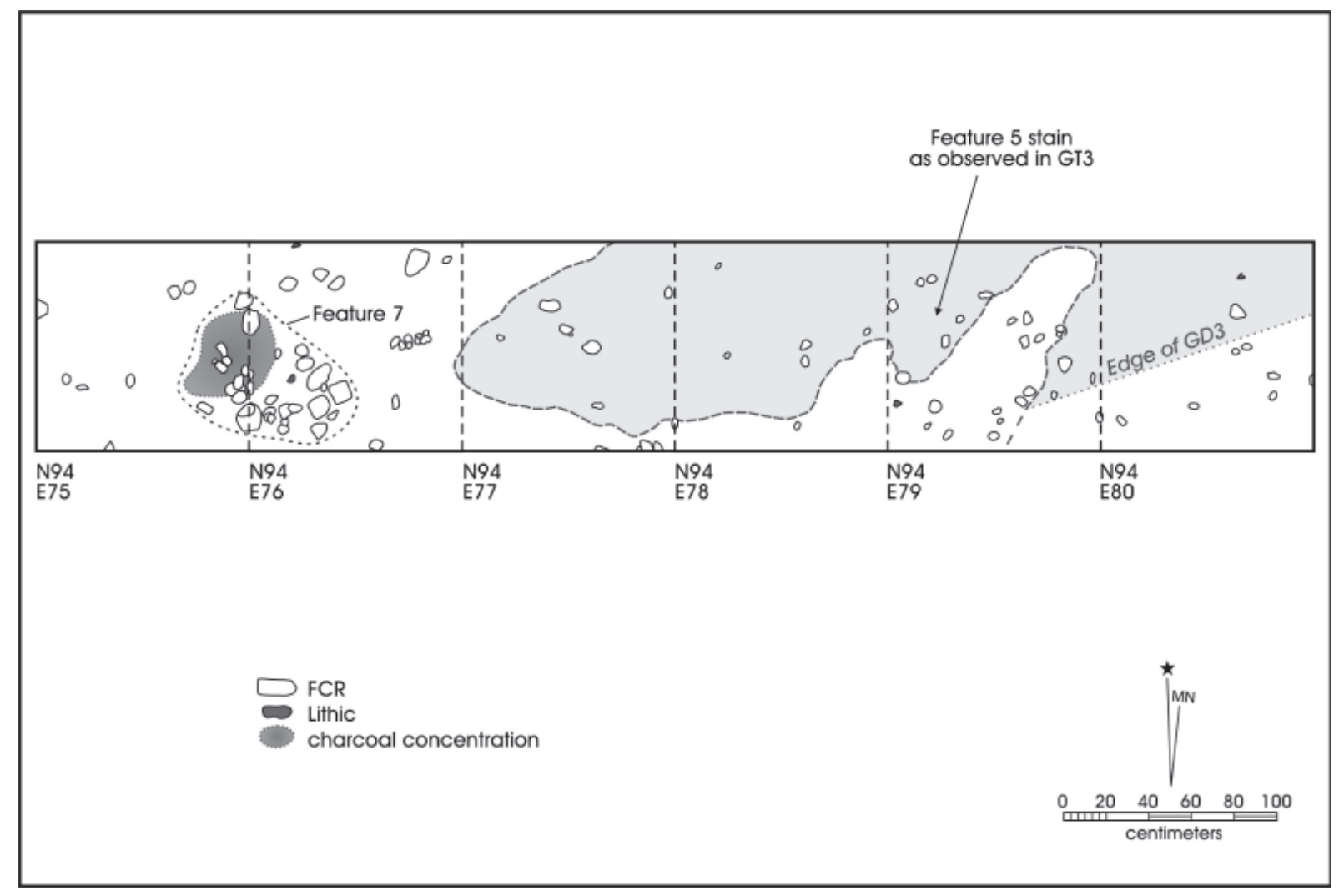

Figure 5-4. Feature 5 excavation area during testing. Note stain/FCR concentration (Feature 7) centered at N94.5/E76. 


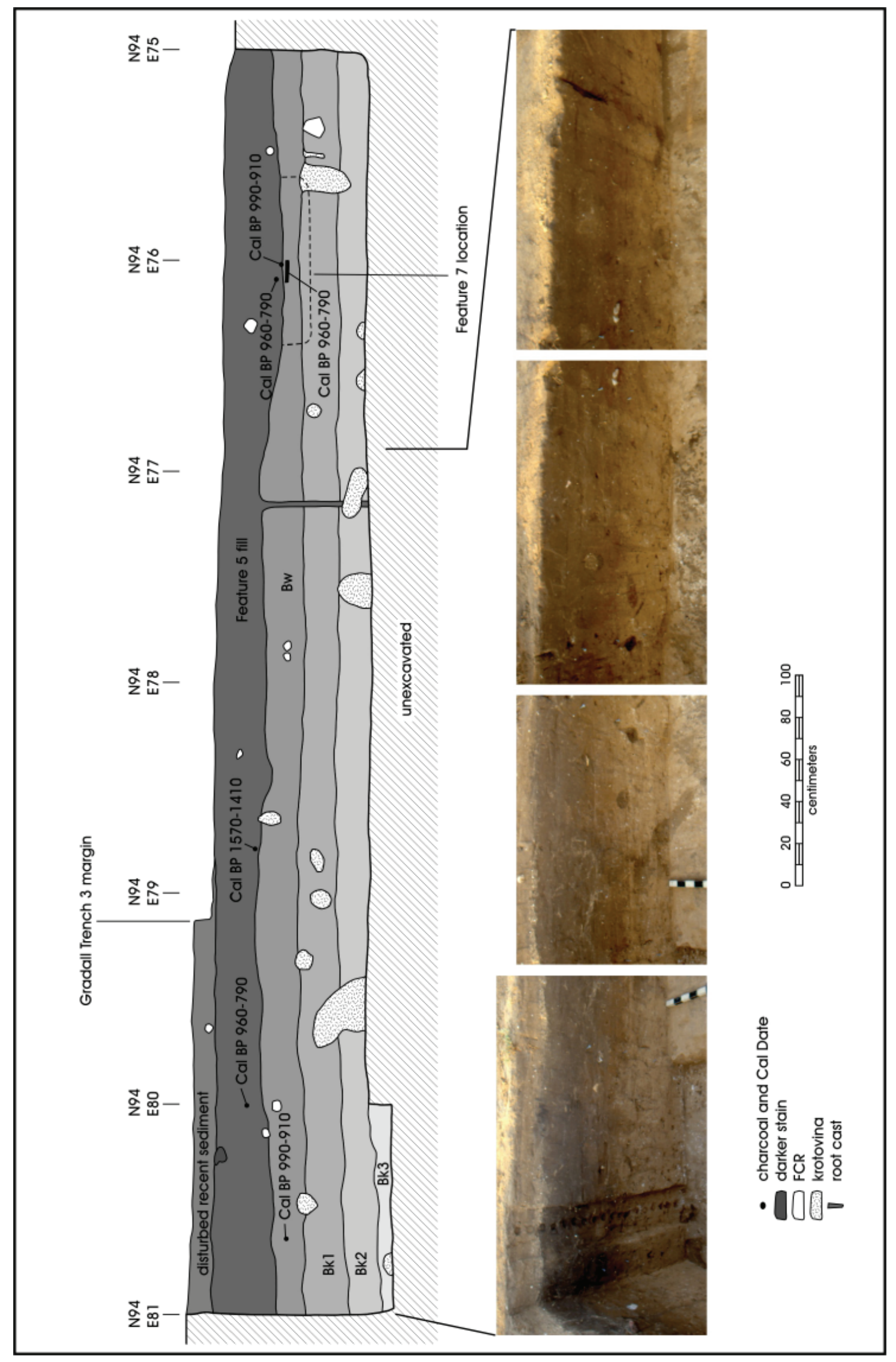

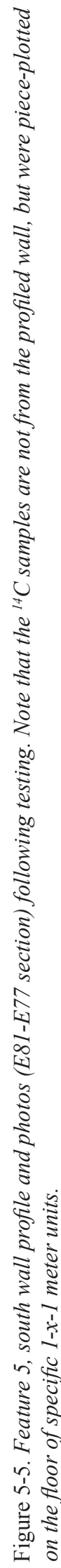


sixth sample is from within Feature 7. Five of the six samples date from between 990 and $790 \mathrm{BP}$, essentially identical with several of the Feature 4 dates. A sixth sample, collected from the base of Feature 5, returned an older date of 1570-1410 BP. As with the two earlier dates from Feature 4, this date probably represents older charcoal, perhaps related to the underlying $\mathrm{Bw} / \mathrm{Bk}$ horizons, which has been incorporated into the younger Feature 5 sediment.

As with Feature 4, data recovery work on Feature 5 served to more clearly define the eastern edge of the feature, but the overall size of the feature exceeded the excavated area (see Figure 5-1). Data recovery work defined Features 9 and 11, though as noted below both of these smaller FCR clusters were below the organically enriched level of Feature 5. The additional excavations did not provide any additional evidence that Feature 5 was formed by burning. Like Feature 4, Feature 5 may represent a Late Prehistoric midden deposit. In fact, given the similarity in dates, content, and stratigraphy, and the lack of clear separation between Features 4 and 5 following data recovery work (Figure 5-1), it is possible that the two features represent a single entity rather than two distinct deposits. It is also possible that both of the features are, in fact, an A horizon.

\section{Feature 6}

Feature 6 was defined during testing as a small, low density cluster of FCR on the surface at the far western edge of the site near the end of GT3 (see Figure 5-1). No Gradall scraping was performed at this location so that excavation could provide controlled recovery of all material associated with this feature. Four rocks were visible on the ground surface. The feature was excavated using two 1-x-1-m units (N89-E60 and N90-E60). FCR was encountered in low density to approximately $40 \mathrm{~cm}$ below the current ground surface. Rock was more common in the northernmost of two excavation units placed over the surface rock distribution. There was no apparent staining associated with these rocks, no patterning within the rock distribution, and artifacts were much less common than in other areas of the site. The western wall of the excavation was profiled (Figure 5-6). Note that the stratigraphy of this area was essentially identical to that seen in the road cut profile and in the Feature 4 and 5 areas. There is no evidence that would indicate the presence of a thermal feature at this location.

\section{Feature 7}

Feature 7 was a hearth within the Feature 5 stained area (Figure 5-1; 5-4). The feature was encountered during testing. It consisted of 39 pieces of burned sandstone, associated staining, and an accumulation of several large (5 to $7 \mathrm{~cm}$ ) pieces of charcoal. Consistent with the testing methodology, none of the rock was collected with the exception of samples for lipid residue analysis. The cluster of rock was approximately $65 \mathrm{~cm}$ east-west by $80 \mathrm{~cm}$ northsouth (see Figure 5-4). The feature was roughly 16 to $18 \mathrm{~cm}$ thick. The dark, Feature 5 fill is thicker at this location and shows a noticeably deeper extension into the Bw horizon. As noted in the Feature 4 discussion, three radiocarbon dates on charcoal place the feature at around AD 1100, a date essentially contemporaneous with Features 4 and 5. The charcoal enriched Feature 7 fill is resting directly on the Bk1 horizon.

\section{Feature 8}

Feature 8 was a large (ca. $130 \times 80 \mathrm{~cm}$ ) cluster of firecracked rock uncovered in N97/E91 and N98/ E91 during data recovery. The feature consisted of 582 pieces of burned sandstone with a total weight of $39 \mathrm{~kg}$. Also assigned to the feature are roughly 230 pieces of debitage and several lithic tools. The top portion of Figure 5-7 shows the main cluster of Feature 8 during excavation. The bottom portion of the figure highlights the distribution of the feature rock within the Feature 4 excavation. This feature was located within the dark, organically enriched Feature 4 (A horizon) area and on the upper portion of the $\mathrm{Bw}$ soil. Feature 8 was about 8 to 10

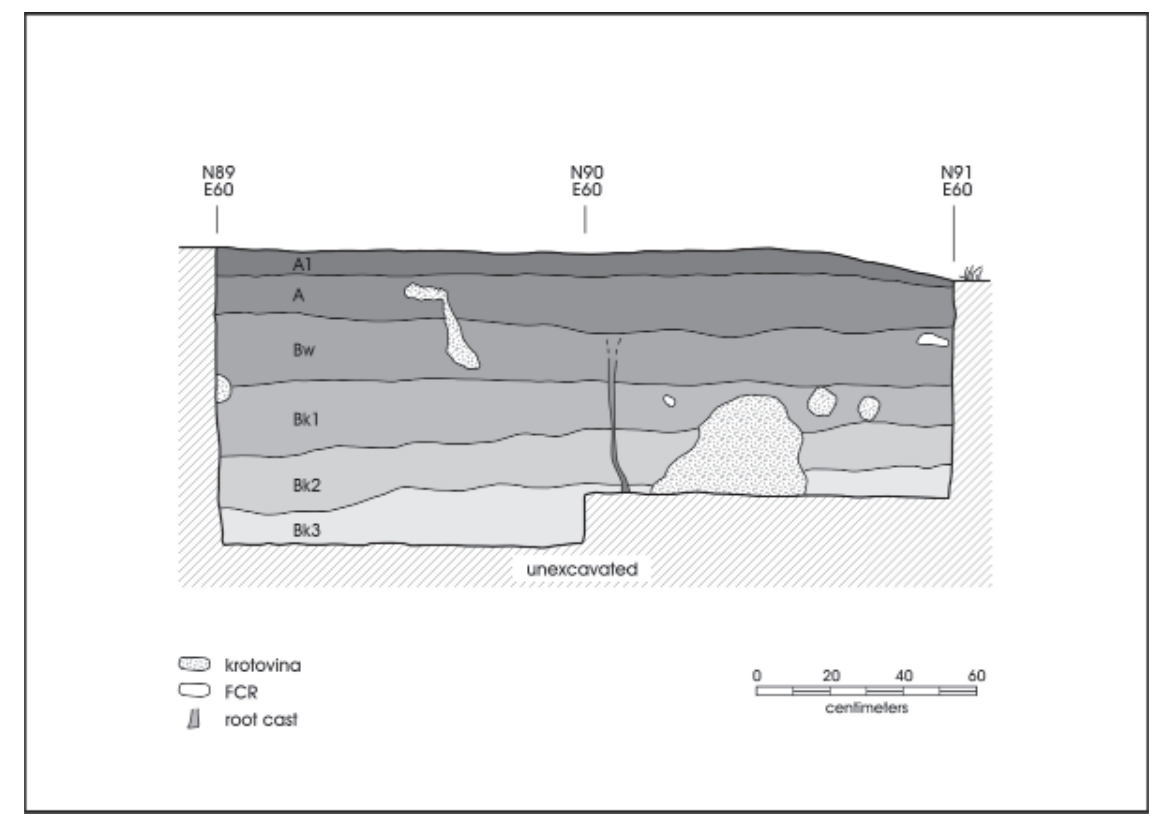

Figure 5-6. West wall profile of Feature 6 excavation area. 


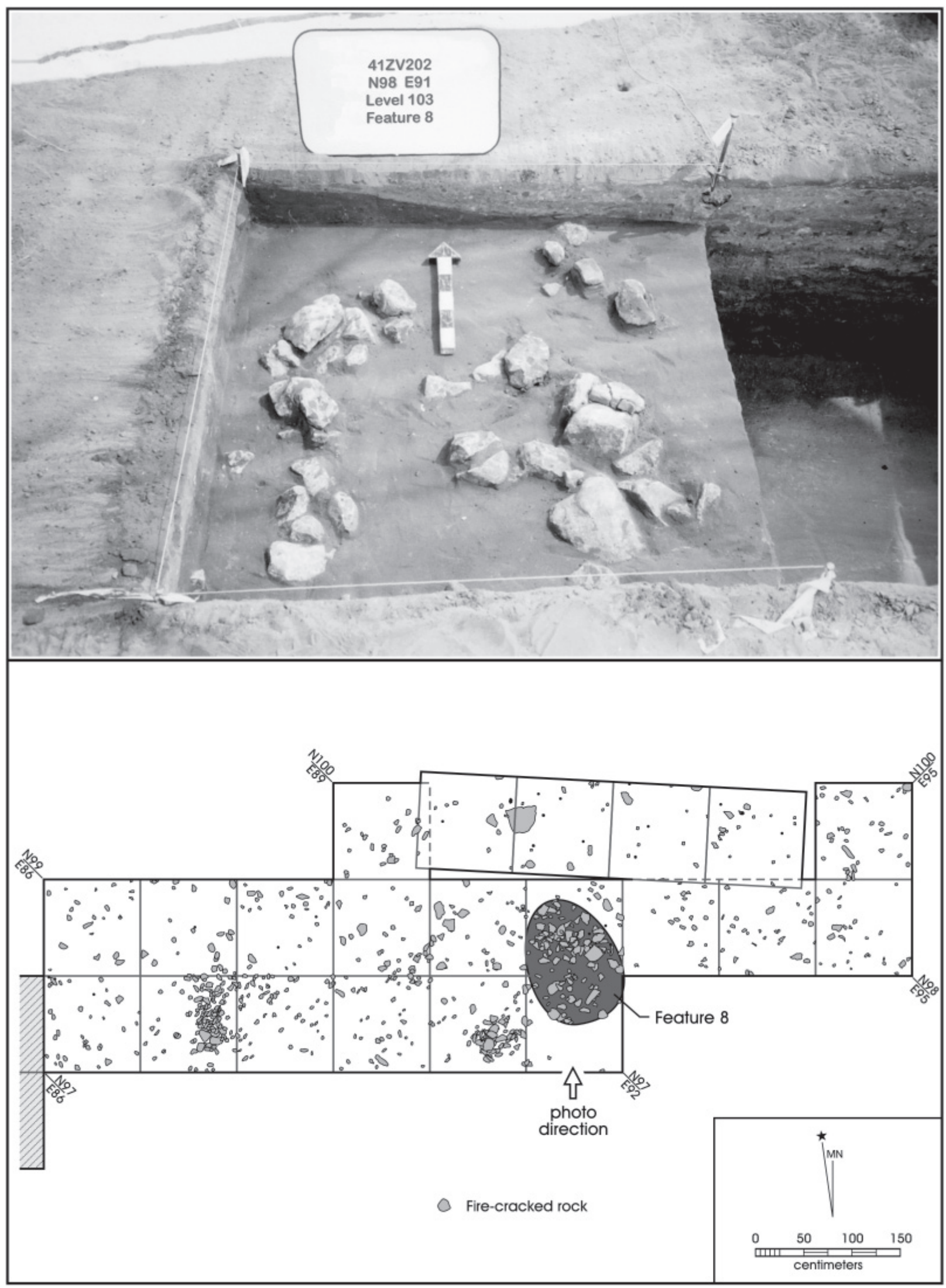

Figure 5-7. Feature 8 excavation (top) and plan view (bottom). 
$\mathrm{cm}$ thick and extended to about $30 \mathrm{~cm}$ below the surface. The feature was not associated with any clear pit. The southern portion of Feature 8 in N97/E91 has been slightly disturbed. Feature 10 is located $30 \mathrm{~cm}$ southwest of the margin of the scattered Feature 8 materials and might account for some of this disturbance. Given the stratigraphic location, this feature dates to the Late Prehistoric.

\section{Feature 9}

Feature 9, discovered during data recovery, was a small cluster of five sandstone FCRs in N93/E77. The feature was roughly $30 \mathrm{~cm}$ in diameter (Figure 5-8). These rocks were in the Bw soil and the upper portion of the Bk1 horizon. They represent a single layer with no more than a $2 \mathrm{~cm}$ variation in the surfaces where the rocks were resting. No pit was associated with the rocks. No charcoal or artifacts were assigned to this feature. The rocks weighed $4.2 \mathrm{~kg}$. Given the stratigraphic location, the feature probably predates the Late Prehistoric.

\section{Feature 10}

Feature 10 was a 40 x $30 \mathrm{~cm}$ cluster of sandstone FCR in the southeastern quadrant of N97/E90 (Figure 5-9). This feature was entirely within the dark, organically enriched A horizon (Feature 4) and was 10 to $13 \mathrm{~cm}$ thick. Bioturbation around the rocks of this feature may have obscured potential association with the uppermost portion of the Bw horizon. We recovered $271 \mathrm{FCR}$, weighing $15.3 \mathrm{~kg}$, from this feature. No associated pit was seen. Sixty-one chipped stone debitage and a single tool were associated with Feature 10. Given the stratigraphic position of Feature 10, it dates to the Late Prehistoric.

\section{Feature 11}

Feature 11 was a 20 x $30 \mathrm{~cm}$ cluster of small FCR in the center of N95/E79 at the contact between the lower $\mathrm{Bw}$ and upper Bk1 horizons. All rocks in Feature 11 were on a surface with only $3 \mathrm{~cm}$ of vertical variation. Excavation notes suggest that nine rocks, most probably sandstone, were associated with this feature. However, no Feature 11 burned rocks were present in the database. Excavators noted a significant amount of bioturbation. No pit was associated with the small cluster, and no artifacts were directly associated with the feature. Given the soil associations, the feature clearly predates the Late Prehistoric period.

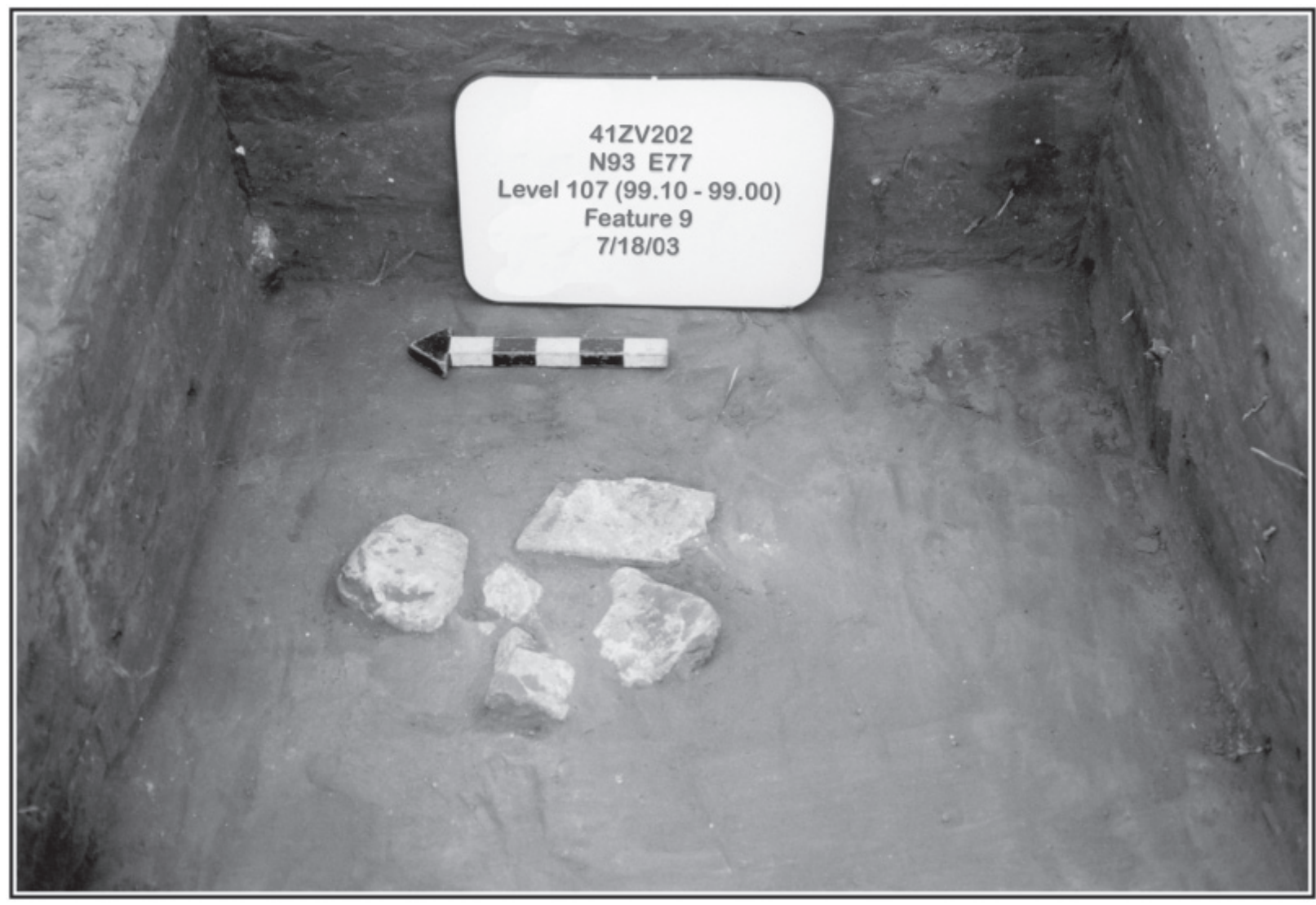

Figure 5-8. Feature 9 excavation. 


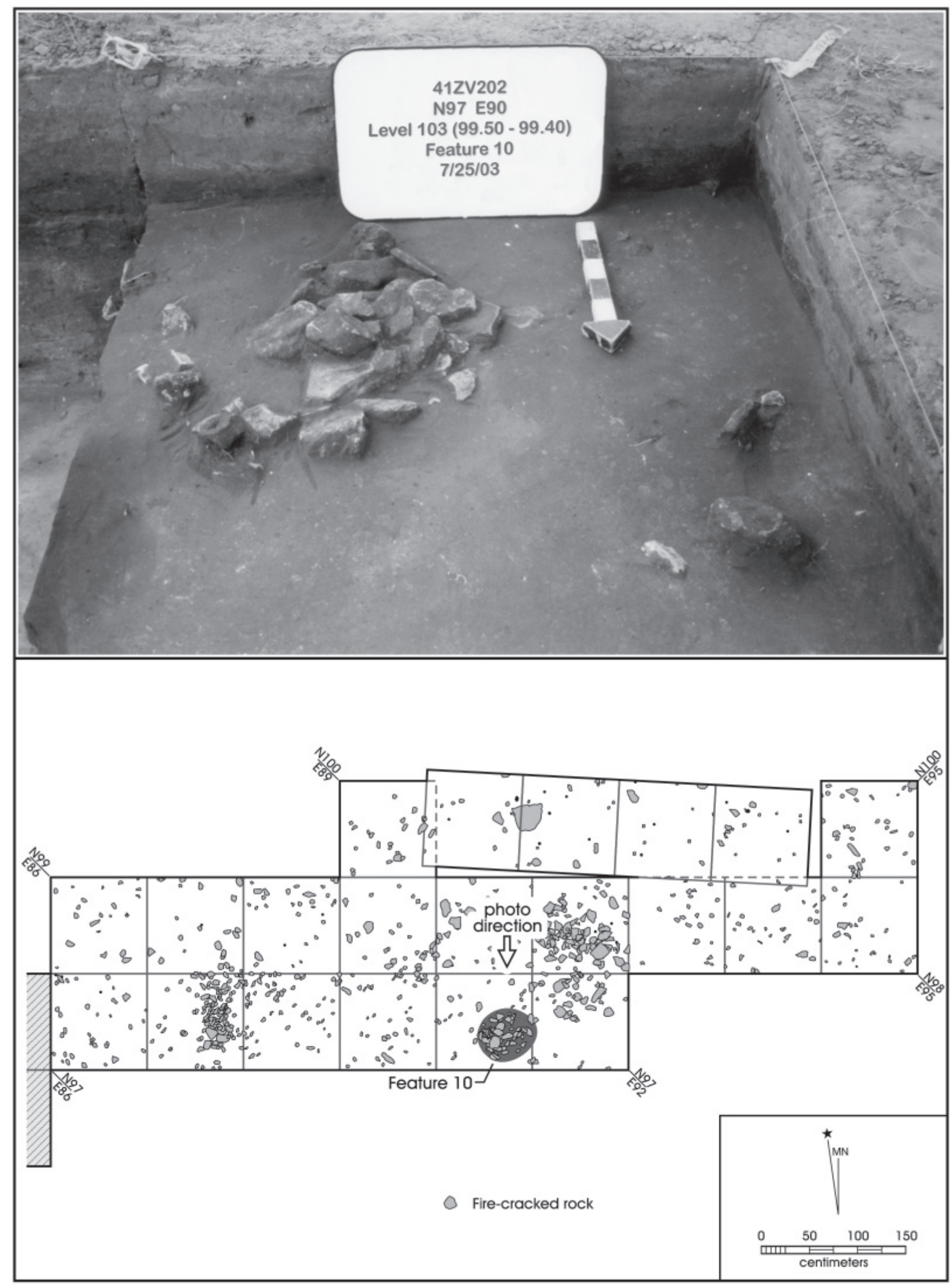

Figure 5-9. Feature 10 excavation (top) and plan view (bottom). 


\section{Feature 12}

Feature 12 was a $20 \times 30 \mathrm{~cm}$ area in the lower portion of the Bw horizon in N96/E81. Consisting of 10 sandstone rocks, the cluster was roughly $5 \mathrm{~cm}$ thick. There was significant krotovina and modern rodent disturbance associated with this unit and especially at the elevations where this feature was found. Feature 12 may not be cultural, and the rocks have been subjected to postdepositional movement. No charcoal or artifacts were associated directly with this feature.

\section{Feature 13}

Feature 13 was a 110 x $90 \mathrm{~cm}$ dense accumulation of FCR in the eastern half of N97/E87 (Figure 5-10). Four hundred and seventy-nine sandstone FCR, weighing 21.6 $\mathrm{kg}$, were associated with Feature 13. The rocks within Feature 13 were resting on surfaces that varied $29 \mathrm{~cm}$ vertically, and this was the thickest feature encountered in the CAR excavations. This feature extended throughout the A horizon and into the uppermost portion of the $\mathrm{Bw}$ horizon. No pit was seen in the field. Associated with this feature were 157 pieces of chipped stone and several lithic tools.

\section{Artifacts}

Artifacts recovered from testing included over 1,000 pieces of debitage and 17 tools. The tools included several bifaces and flaked tools, as well as two Scallorn points. Data recovery produced 30 projectile points, including 24 arrow points and six dart points. Figure 5-11 shows the 24 arrow points recovered from data recovery. All points have been typed by Dr. Steve Tomka of CAR. Twenty-three of the points are consistent with the type descriptions for Scallorn projectile points (Turner and Hester 1999:230). A single point (Figure 5-11x), though broken, fits the type description of a side-notched Caracara point (Turner and Hester 1999:205). Figure 5-12 presents six earlier, fragmentary dart points obtained during data recovery. Points a, b, and c are untyped, but may reflect Late Archaic Pedernales points (Turner and Hester 1999:171172). Point d in Figure 5-12 is probably an Early Archaic Andice stem fragment (Turner and Hester 1999:71-72), while e is a Late Archaic Ensor form (Turner and Hester 1999:114). Finally, a base of a small, untyped lanceolate point (Figure 5-12f) was recovered. The base of this point is ground.

Figure 5-13 presents a sample of the 41 unifacial and bifacial tools collected during data recovery. Included are a well-shaped biface (Figure 5-13a) with a concave notch and a graver. Several characteristics suggest that this is not a reworked point. There is a lack of basal thinning, no grinding at the base, and step fractures are present in the deepest portion of the notch. The specimen shown in Figure $5-13 \mathrm{~b}$ is a fragment of a uniface, while items c and $d$ are probably drills. Finally, items e through $\mathrm{j}$ are examples of other bifacial tools collected during data recovery efforts.

In addition to the tools and points, nine cores were recovered during data recovery, along with just over 6,000 pieces of debitage. Most of the debitage is small and lacks cortex. The tools, cores, and debitage also seem to reflect a wide range of chert colors. Burned rock was recovered during both phases of CAR's work at 41ZV202. During testing, burned rock was not collected, with the exception of some rock associated with Feature 7. During data recovery, 249.4 kilograms of burned rock $(n=15,357)$ were collected and returned to the CAR laboratory. The vast majority of this rock is sandstone. Finally, 54 modern items were collected during the data recovery work. These included glass fragments, pieces of metal, and pieces of plastic.

\section{Bone and Shell}

Few faunal remains were encountered during testing and data recovery excavations at 41ZV202. Sixteen bones were recovered during testing in March 2003. All of these came from a section of the long road profile and most represent intrusive recent coyote remains from a local eradication program noted during the initial testing in 1981 (see Chapter 3). During data recovery, 80 pieces of bone were collected. All of this bone is highly fragmented. Most represent recent rodent bones or small pieces that require laboratory analyses to establish the potential identification of elements and whether species or body size can be determined.

A small amount of mussel shell was recovered during testing (19 specimens) and about 315 pieces were recovered during data recovery. Some shell was damaged from shovel skimming and fragmentation has likely undercounted the presence of mussel shell. Although there is an unknown skew in the recovery of bivalve remains, their relative rarity suggests their inclusion in these deposits may be natural or the result of minimal cultural input.

Gastropods were also collected. Eighty specimens came from testing and roughly 14,350 complete and fragmentary 


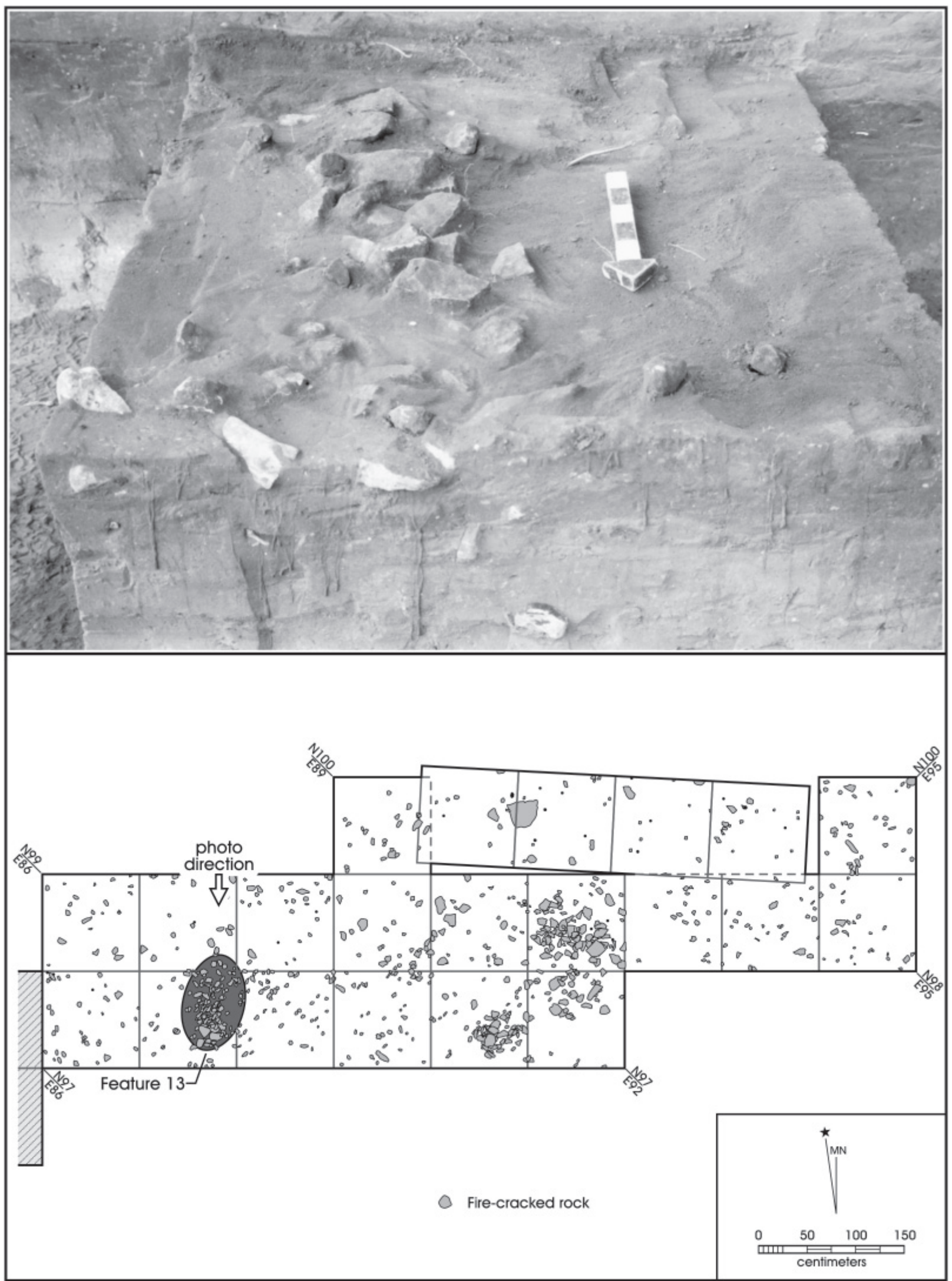

Figure 5-10. Feature 13 excavation (top) and plan view (bottom). 


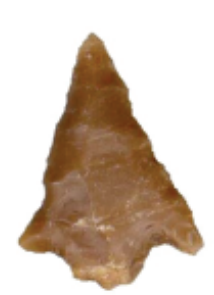

a

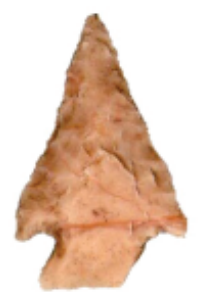

b

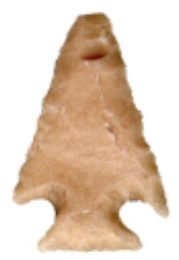

c

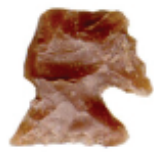

d

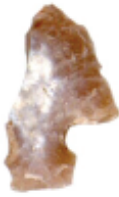

e

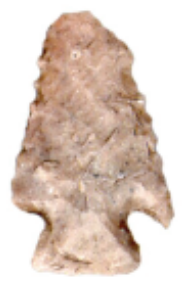

f

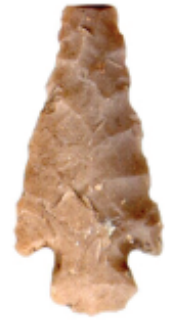

g

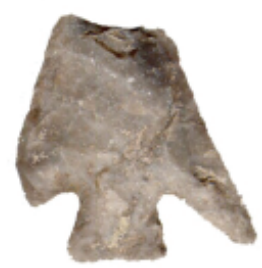

m

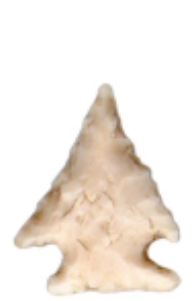

S

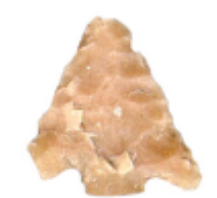

$\mathrm{h}$

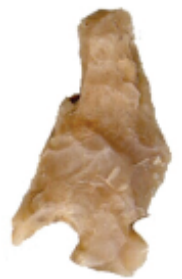

n

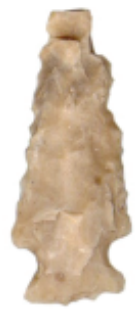

$\dagger$

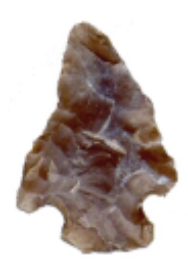

o

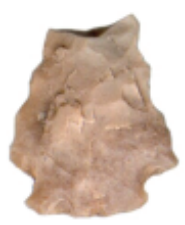

u
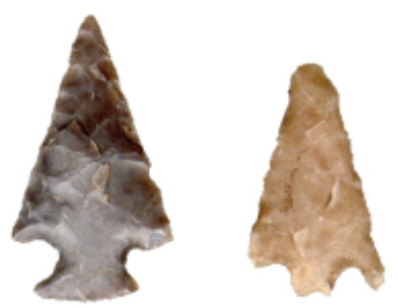

k

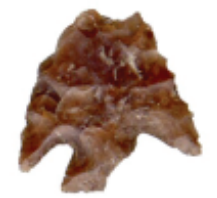

$p$

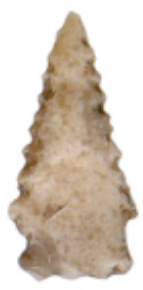

V

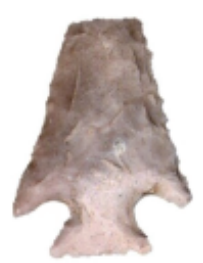

9

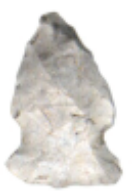

W

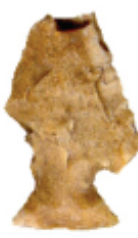

I

$$
\underset{\substack{0 \\ \text { centimeters }}}{2}
$$

Figure 5-11. Late prehistoric projectile points from 41ZV202. a-w) Scallorn; x) Caracara. 


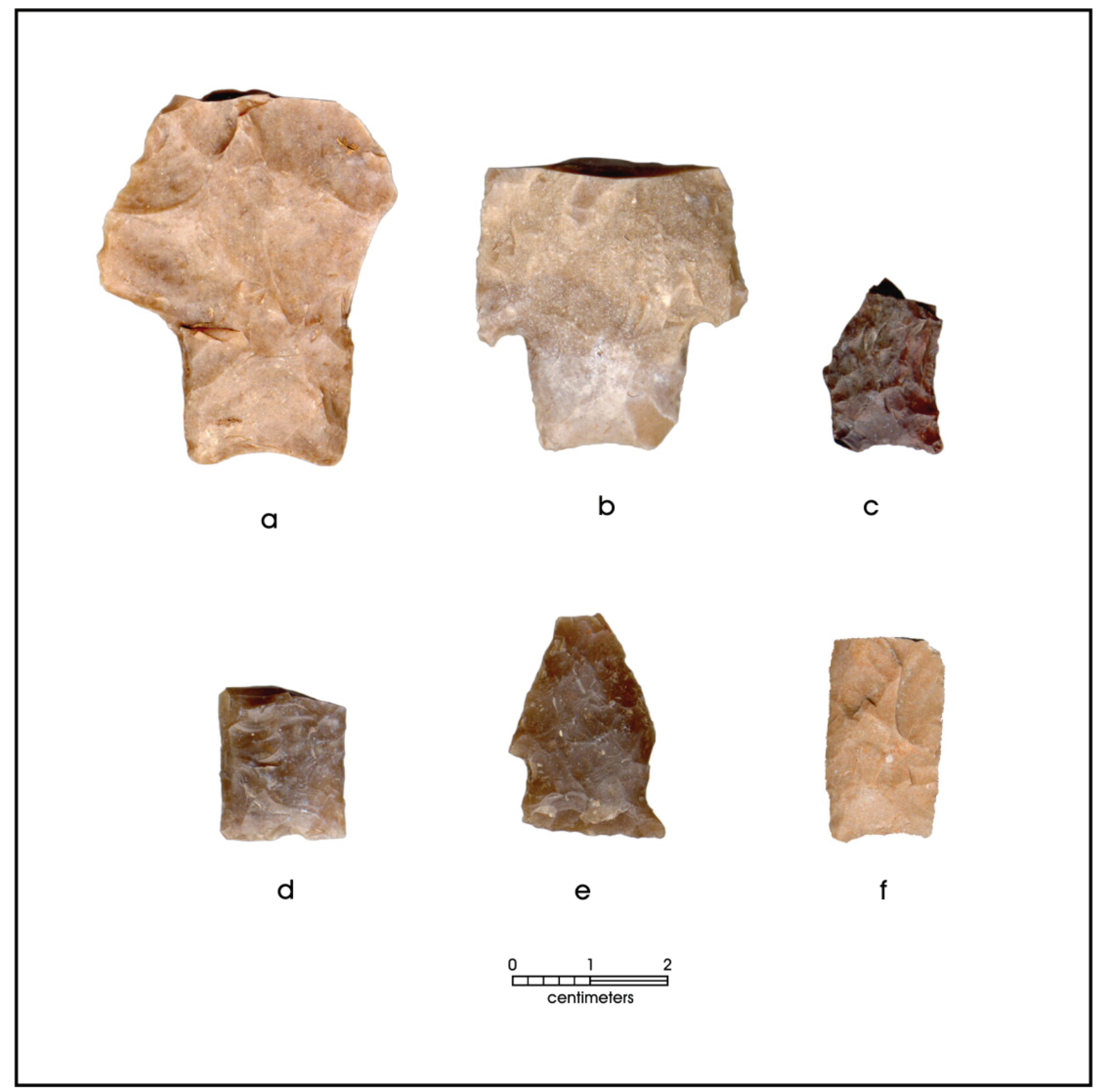

Figure 5-12. Dart points recovered during data recovery excavations at 41ZV202. a-c) untyped dart points; d) Andice stem; e) Ensor point; f) untyped lanceolate dart point.

shells were recovered from screening during data recovery. Gastropods were collected but not piece plotted during the data recovery. The remaining relative quantities of gastropods (almost exclusively Rabdotus) are likely valuable indicators of stable surfaces.

\section{Other Samples}

One hundred sixty-two soil samples were collected from the 40 block excavation units dug during data recovery. These samples were collected as combined pollen/ phytolith samples from the anthropically enriched A horizons and $\mathrm{Bw}$ units in all excavation units. They each consist of approximately 0.5 liters of soil. The majority of these samples are derived from general excavation levels, although a large number are also feature associated. An additional 57 soil samples were obtained during site testing. In total, 219 soil samples have been collected from the site. One hundred seventy MS samples were collected from the site. Sixty of these were obtained during data recovery, the remainder came from testing. Ninety-seven piece-plotted charcoal samples were collected during testing and data recovery excavations. Finally, all 20,249 calcium carbonate nodules were retained from the screens. 


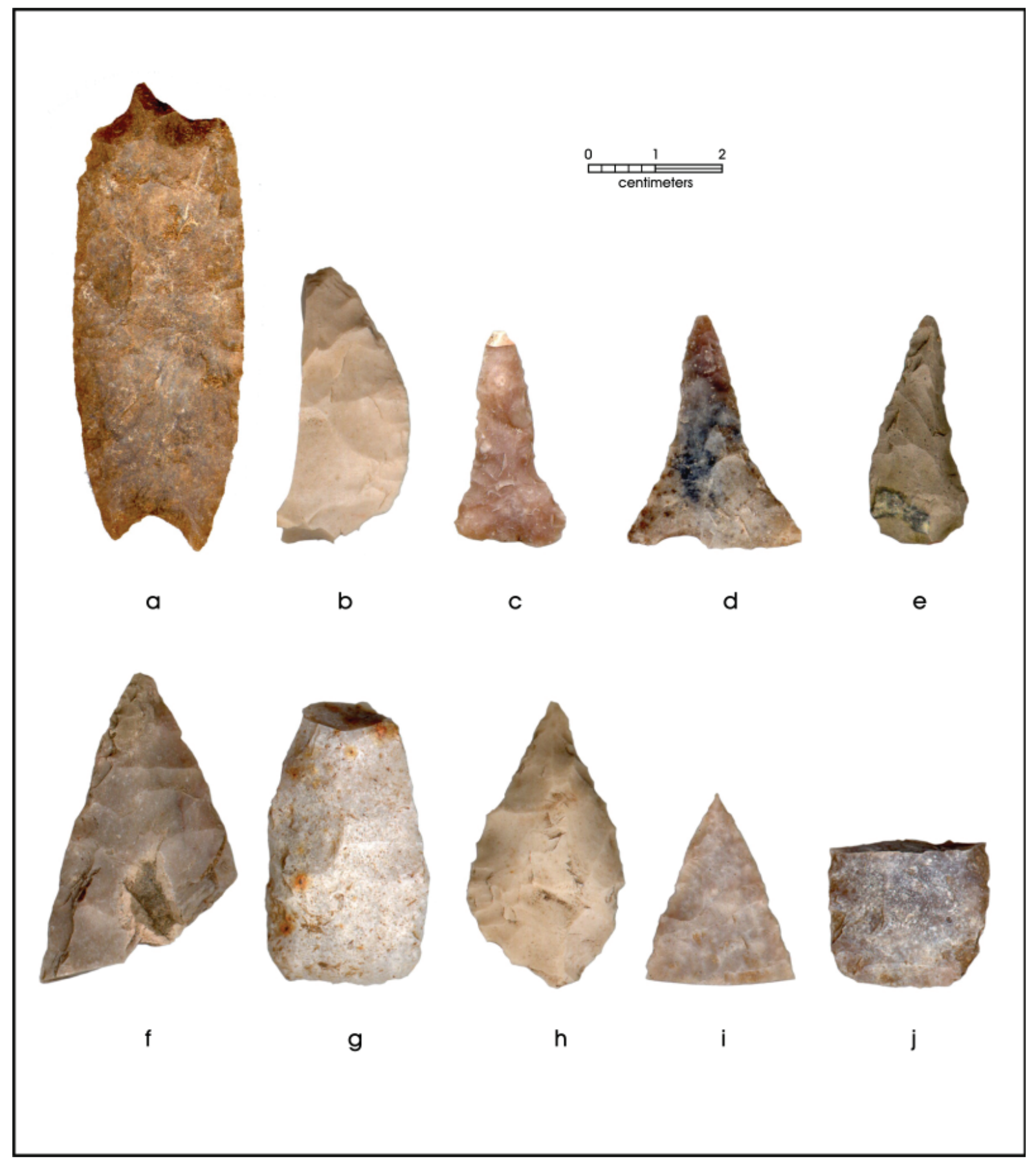

Figure 5-13. Selected tools from data recovery excavations at 41ZV202. a) biface with graver; b) uniface fragment; c-d) drills; e-j) miscellaneous bifaces. 


\section{Chapter 6: Defining Analytical Units}

\author{
Raymond Mauldin
}

The artifacts, features, and other samples summarized in the previous chapter reflect the data sets available for consideration. In this chapter, we define the analytical units that will be used to structure the analysis. While the vast majority of diagnostic points recovered from testing and data recovery fall into the Initial Late Prehistoric (Austin) time period, a small number of earlier point types are present both from CAR's work, as well as earlier investigations (see Chapter 3). In addition, the date ranges of three of the 11 radiocarbon samples predate the beginning of the Late Prehistoric temporal period. Some of the deposits, then, reflect earlier use. In addition, 54 items that are historic or modern in age were recovered during our work. Our goal in this chapter is to isolate deposits that date to the Initial Late Prehistoric Austin Interval from these earlier and later materials. It is data associated with this time period that provided the context for data recovery efforts at 41ZV202.

\section{Isolating Initial Late Prehistoric Materials}

Much of the work that CAR conducted at 41ZV202 was focused on the $50-\mathrm{m}^{2}$ portion of the site shown previously in Figure 4-11. This was the area where both Feature 4 and 5 were originally identified, and the area where all data recovery work was conducted. The only controlled excavation not conducted within this $50-\mathrm{m}^{2}$ area consisted of two 1-x-1-m units located near the end of Gradall Trench 3 and associated with what was thought to be a small burned rock feature (Feature 6). No dates are available for the excavations conducted around Feature 6. No diagnostics were associated with Feature 6. As we have no temporal information on this area of the site, the Feature 6 excavation area will be eliminated from any subsequent analysis.

Table 6-1 provides summary information on the depth below surface of the prehistoric, temporally diagnostic artifacts collected during data recovery, as well as the distribution of the small quantity of modern materials recovered. The modern materials are primarily present in Level 1
Table 6-1. Distribution of Temporally Diagnostic Artifacts by Level Below Surface for Data Recovery, 41ZV202

\begin{tabular}{|l|c|c|c|c|c|c|c|}
\hline & $\begin{array}{c}\text { Level } \\
\mathbf{1}\end{array}$ & $\begin{array}{c}\text { Level } \\
\mathbf{2}\end{array}$ & $\begin{array}{c}\text { Level } \\
\mathbf{3}\end{array}$ & $\begin{array}{c}\text { Level } \\
\mathbf{4}\end{array}$ & $\begin{array}{c}\text { Level } \\
\mathbf{5}\end{array}$ & $\begin{array}{c}\text { Level } \\
\mathbf{6 +}\end{array}$ & Totals \\
\hline $\begin{array}{l}\text { Modern/ Historic } \\
\text { Artifacts }\end{array}$ & 49 & 5 & 0 & 0 & 0 & 0 & 54 \\
\hline $\begin{array}{l}\text { Late Prehistoric } \\
\text { Projectile Points }\end{array}$ & 2 & 8 & 10 & 2 & 0 & 2 & 24 \\
\hline $\begin{array}{l}\text { Archaic } \\
\text { Projectile Points }\end{array}$ & 1 & 0 & 3 & 1 & 1 & 0 & 6 \\
\hline
\end{tabular}

(0-10 cmbs), with roughly $91 \%$ occurring in that level. No modern artifacts were present below Level 2 (10-20 cmbs). This material was consistently associated with deposits identified in the field as disturbed. These disturbed deposits represent deposition associated with backfilling of the Gradall trench excavated during testing, as well as recent deposits at the site. While Late Prehistoric points were present in both the upper level as well as in deposits below Level 3 (20-30 $\mathrm{cmbs}$ ), these points were concentrated in Levels 2 and 3, with $75 \%$ of the 24 items recovered during data recovery present in this $20-\mathrm{cm}$ range. Finally, the small number of Archaic points were concentrated in Level $3(20-30 \mathrm{cmbs})$, with $50 \%$ of the six items occurring at this depth.

Figures 6-1, 6-2, and 6-3 present a series of east-west running profiles of different sections of the site that clearly show that the upper portions of the deposits, designated "recent sediments,"

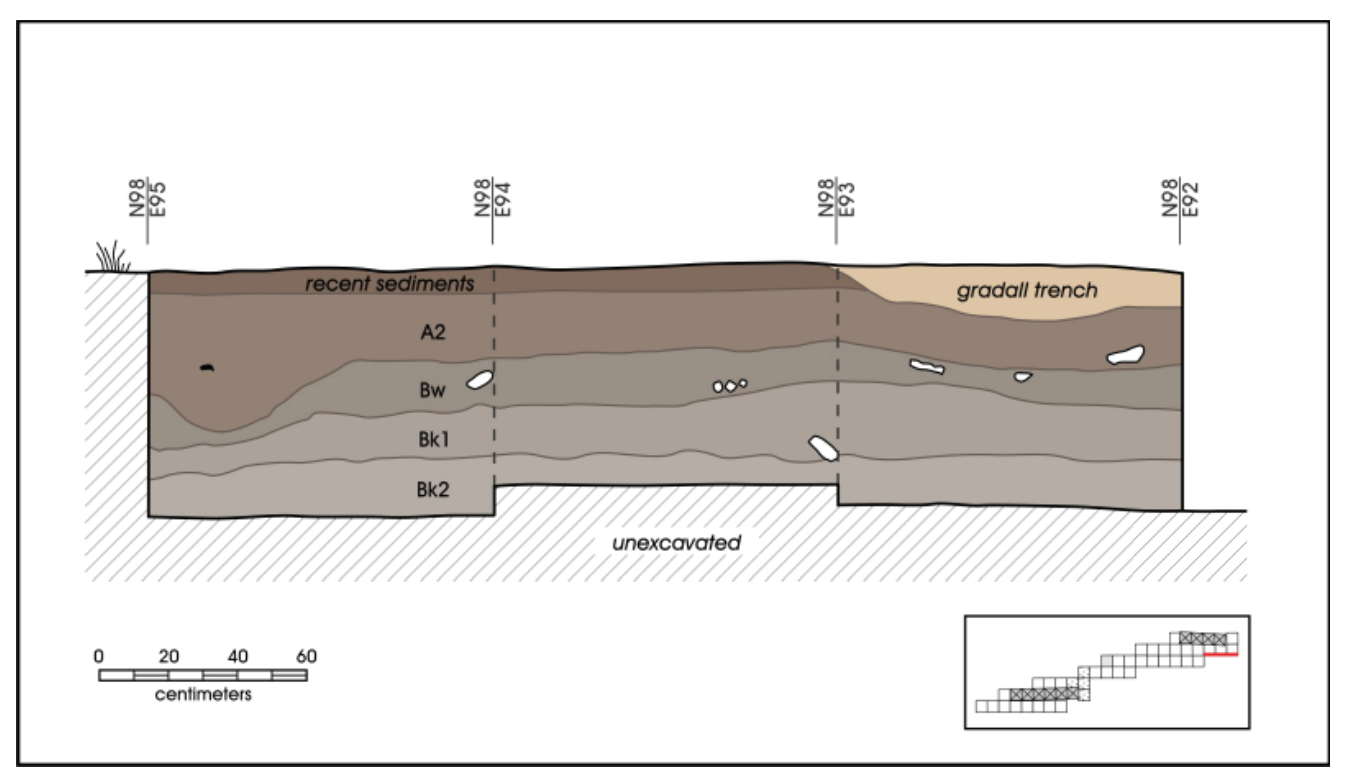

Figure 6-1. Profile of south wall (N98 line), between E92 and E95. 


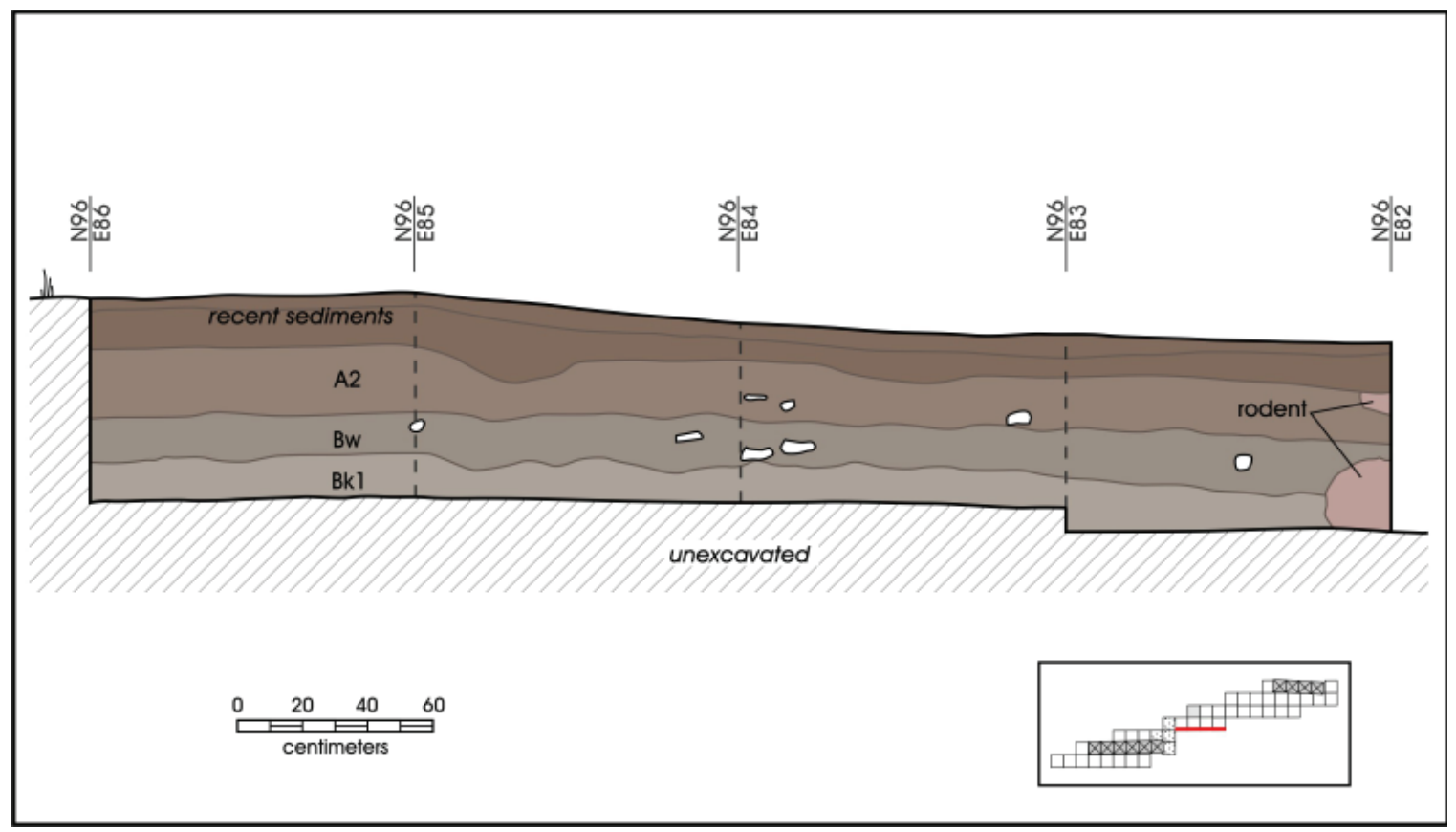

Figure 6-2. Profile of south wall (N96 line), between E82 and E86.

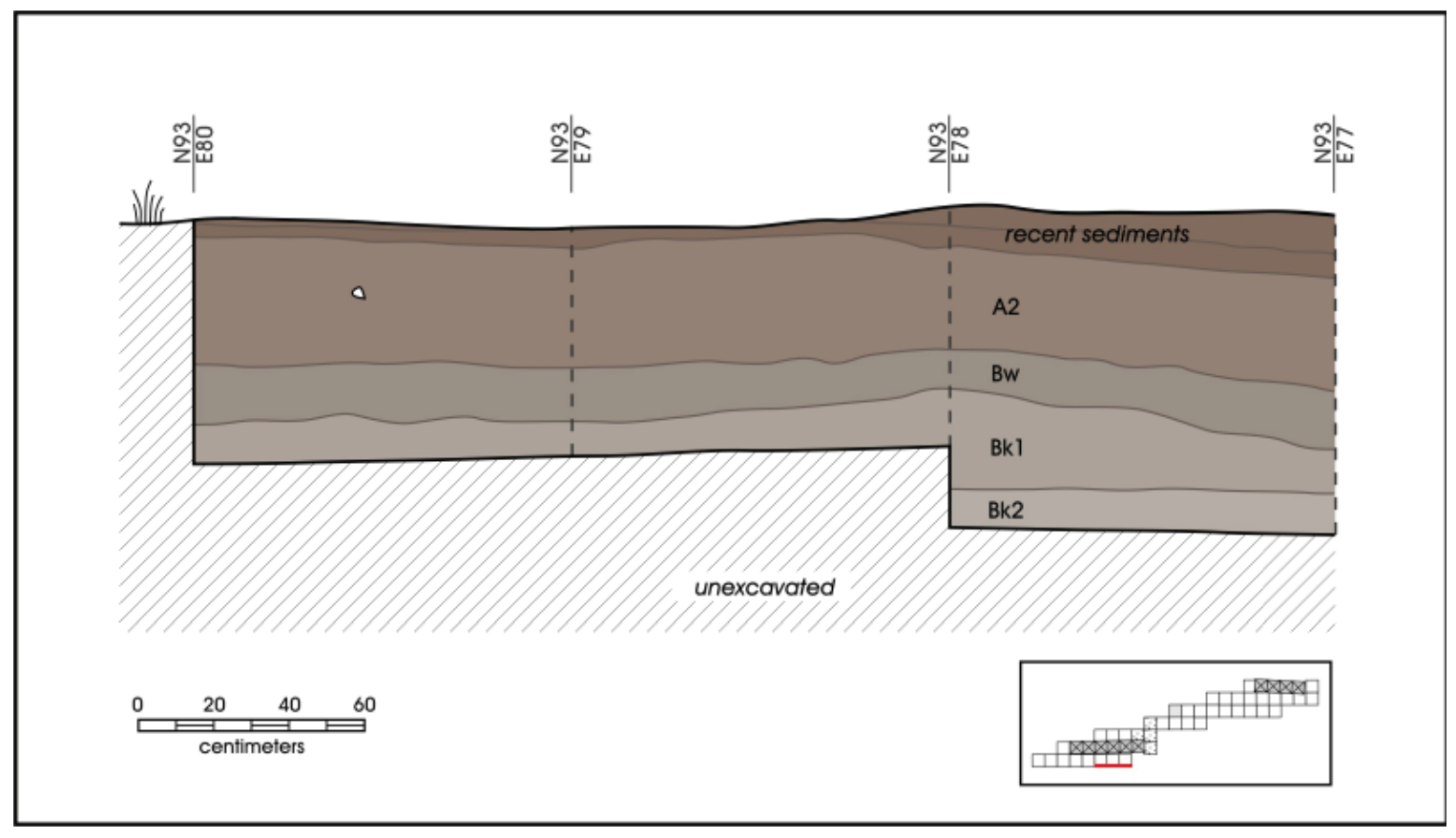

Figure 6-3. Profile of south wall (N93 line), between E77 and E80.

are consistently present across the area. A consideration of the profiles in the context of the distributions shown in Table 6-1 further suggests that Level 1 deposits, a level that contained $91 \%$ of the modern items, consistently are within the recent sediment zone. While the depth below surface for the identified deposits varies, the $\mathrm{A} 2$ and $\mathrm{Bw}$ deposits are generally associated with Levels 2 through 4 . Level 5 is sometimes associated with the lower portion of the $\mathrm{Bw}$, and sometimes associated with the upper portion of the underlying Bk soils. Depths below $50 \mathrm{~cm}$ appear to be consistently in the Bk deposits. Most of the prehistoric points, then, appear to be in deposits identified as A2 and Bw, with a few diagnostics present in the underlying Bk soils.

Figure 6-4 presents the corrected, calibrated AMS radiocarbon dates obtained by CAR on charcoal collected from 41ZV202 


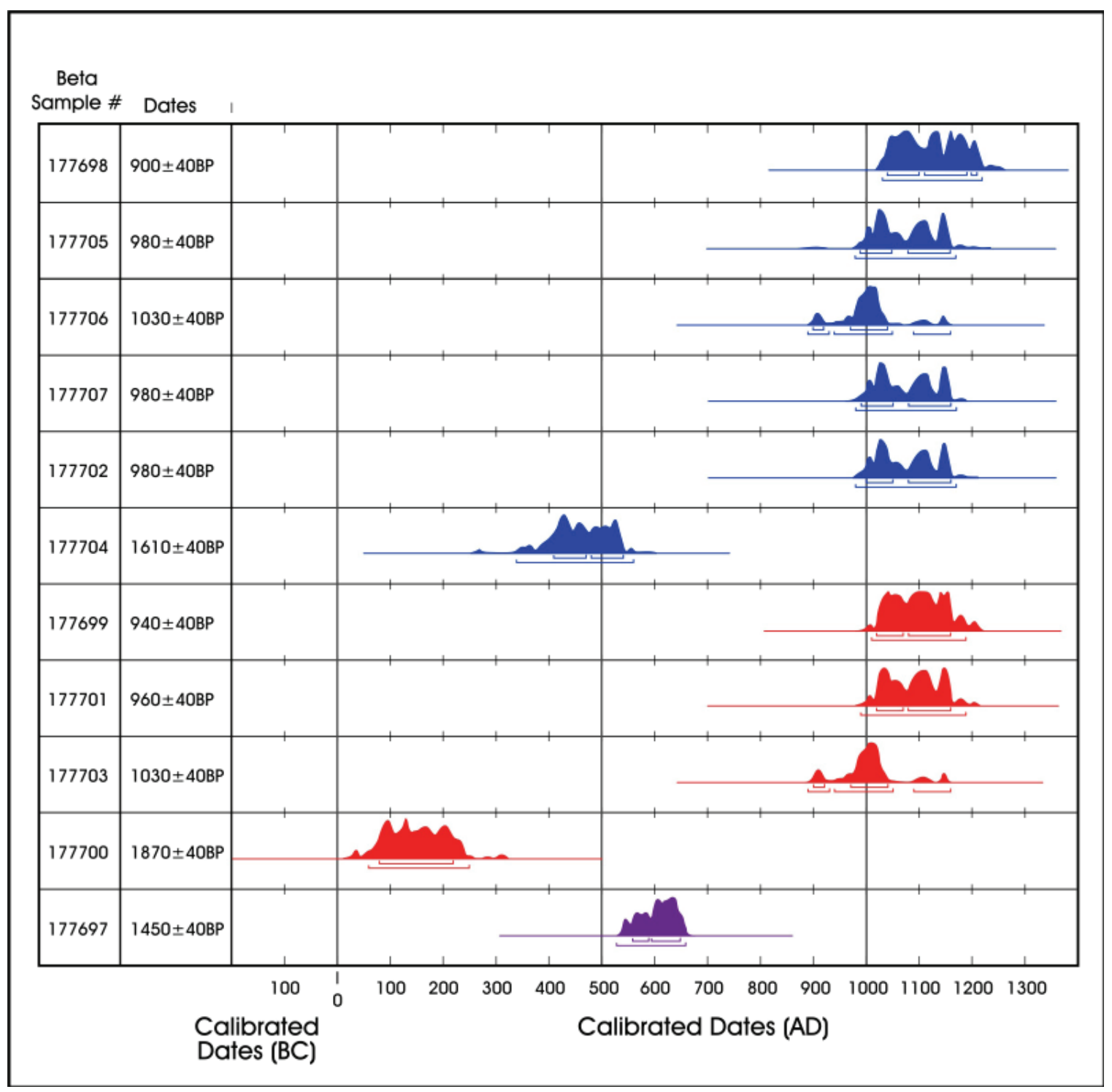

Figure 6-4. Calibrated, corrected radiocarbon dates from 41ZV202. Plots are probability distributions. Blue dates are from the $A 2$ horizon, red dates are from the Bw horizon, and the purple date is from the Bk horizons.

during testing. The dates have been calibrated and corrected using OxCAL version 3.9 (Ramsey 2003). Additional information on the context of these samples was presented in the previous chapter, and Appendix B provides additional details. Five of the six charcoal samples collected from the A2 soil (blue in Figure 6-4), and three of the four samples collected from the Bw horizon (red), have a high probability of dating after AD 900 and before AD 1200. The single date associated with the underlying Bk deposits falls in the Late Archaic.

Figures 6-5 and 6-6 consider the distribution of cultural material within the data recovery excavation area. Figure 6-5 presents the vertical distribution of debitage. Note that in this, as well as subsequent figures that use this same format, counts or weights have been corrected for the number of excavated levels. The 6-5 graph clearly shows a single peak, with most of the material concentrated in Levels 2, 3, and 4 that reflect the $\mathrm{A}$ and $\mathrm{Bw}$ horizons. There is a gradual fall-off below Level 3. Figure 6-6 presents a similar graph for burned rock weight. Here, a strong peak is present in Level 2 (A2 horizon), with a significant weight of burned rock also present in Levels 3, 4, and 5. The patterns in Figures 6-5 and 6-6 demonstrate that cultural material is highest overall in Levels 2, 3, and 4. These levels also contain the organically enriched zones designated Features 4 and 5 and thermal Features 7, 8, 10, and 13. The vertical distribution of larger artifacts is clearly visible in the profile view in Figure 6-7, which shows point-provenienced items in the Feature 4 area. 


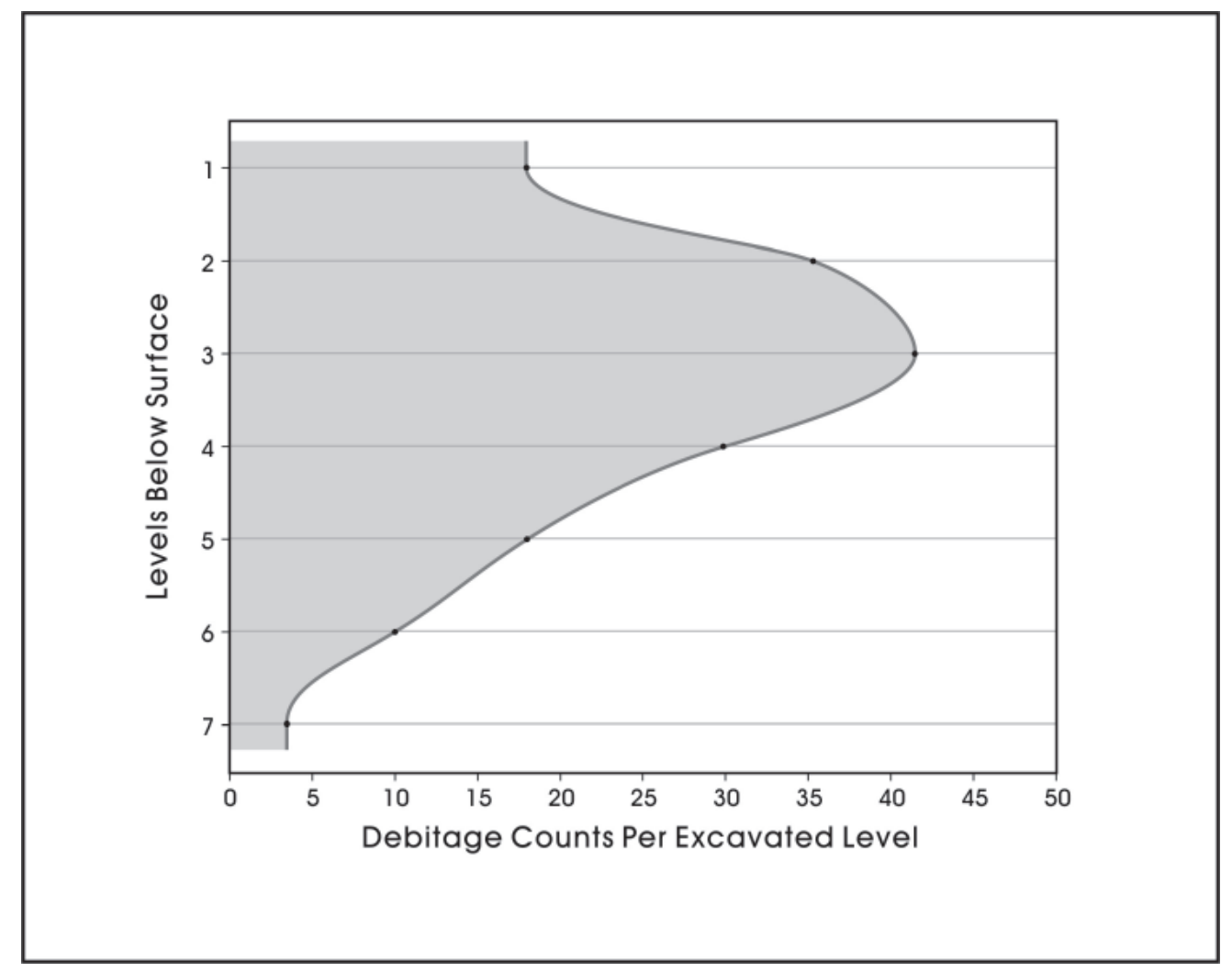

Figure 6-5. Debitage counts by level for data recovery excavation at 41ZV202.

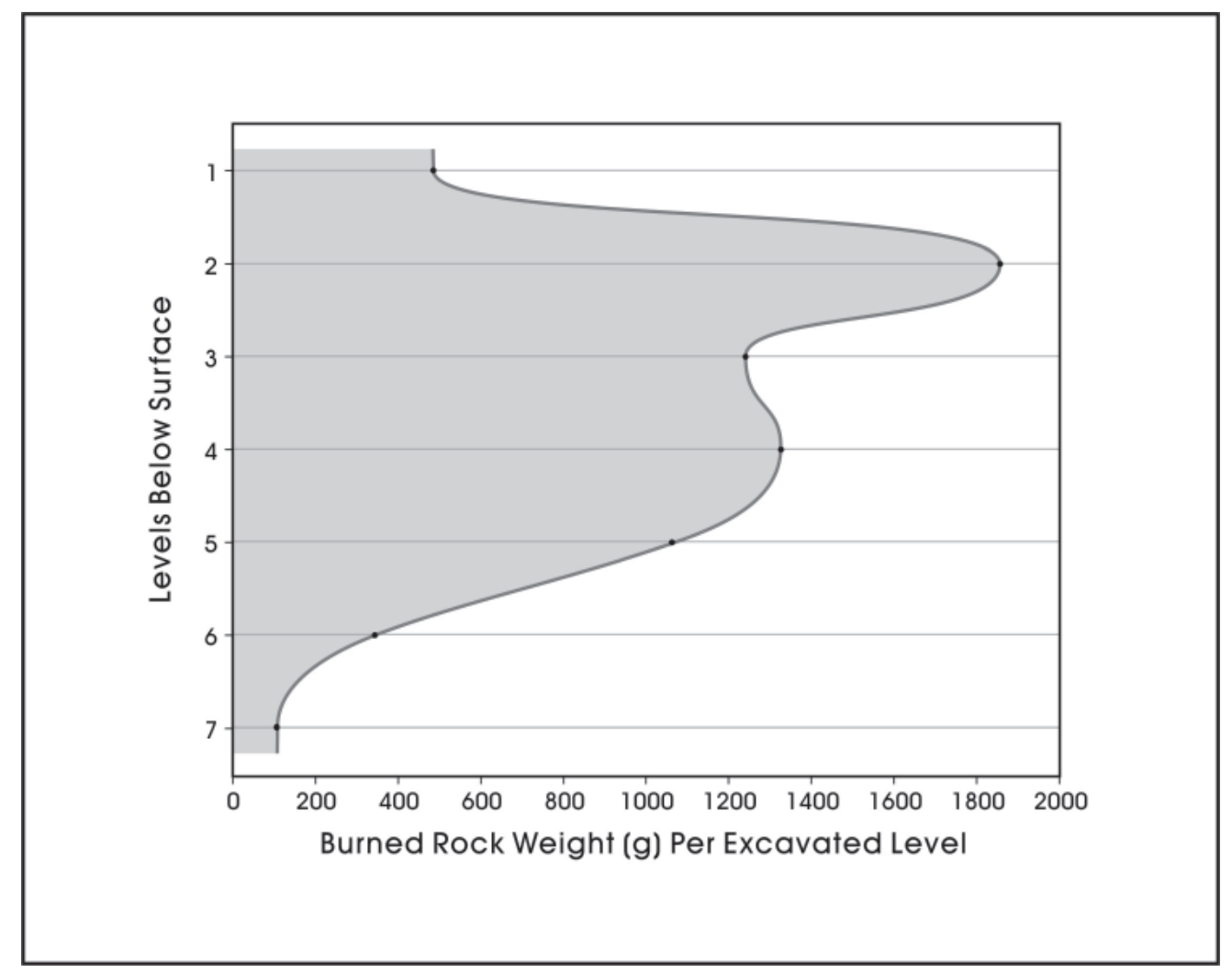

Figure 6-6. Burned rock weights by level for data recovery excavation at 41ZV202. 


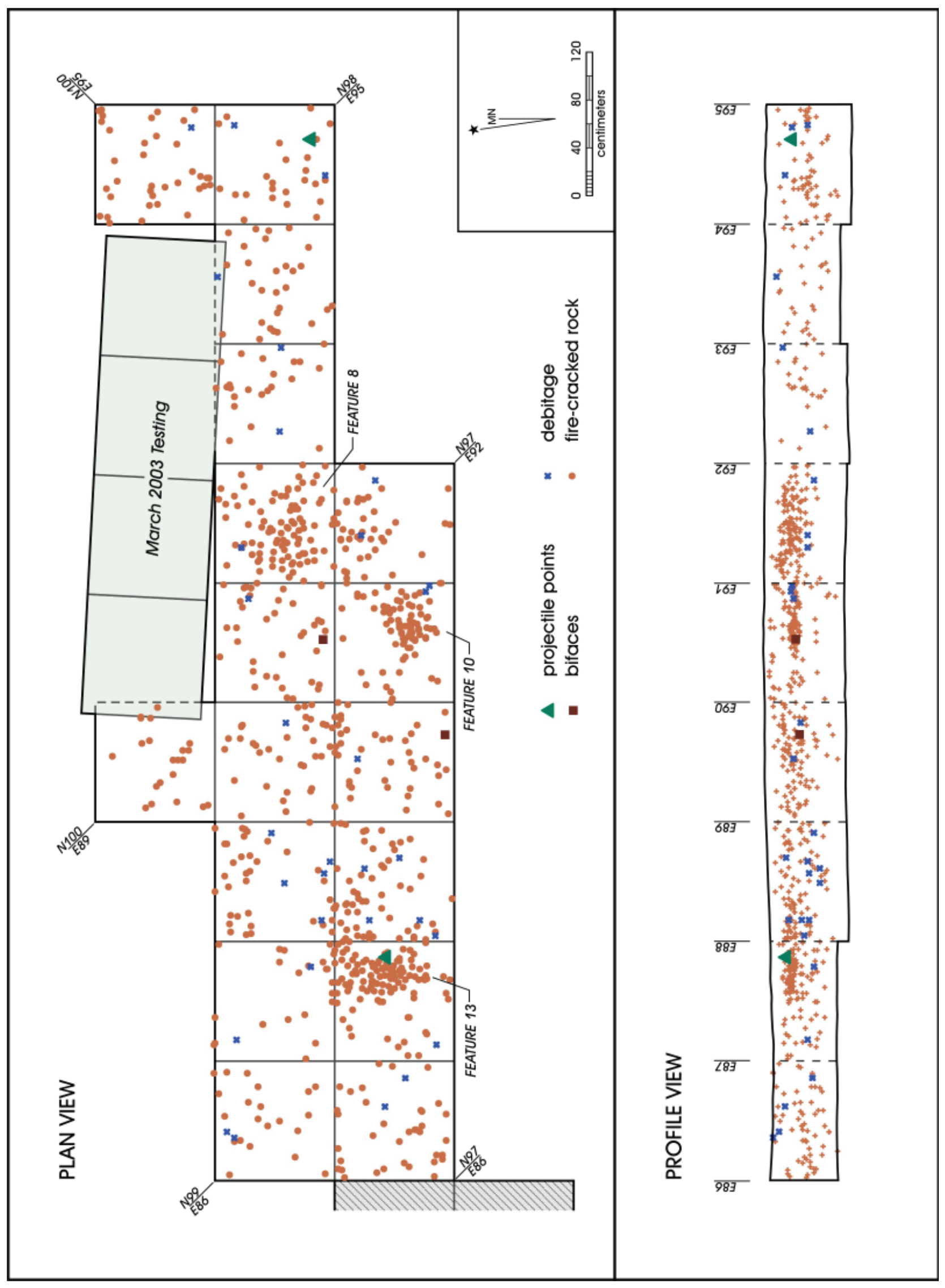

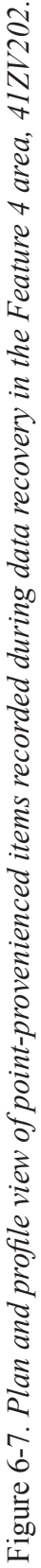


Finally, Figure 6-8 presents the weight of calcium carbonate nodules per excavation level. Carbonate nodules should form in the Bk deposits (see Appendix A), a depth that roughly corresponds to $50 \mathrm{~cm}$ below surface in this area. Their presence at higher levels clearly suggests that the nodules are out of place. The patterning in the figure suggests that Level 1 deposits are not in primary context as the highest calcium carbonate weights are associated with this initial excavation level. Nodule weights in Levels 2 through 4 are much lower. Weight increases in Levels 5 through 7 are consistent with the suggestion that the Bk deposits, and carbonate nodules, should be increasingly common below $50 \mathrm{~cm}$ because of pedogenic processes (see Gile et al. 1981).

Based on the distributions of diagnostic artifacts, modern materials, the density distributions of debitage and burned rock, soil profiles, patterns in carbonate nodule weights, and the distribution of the radiocarbon ages, it appears that the Late Prehistoric material is primarily found in Levels 2 through 5. Level 1 across the excavation appears to contain materials of questionable context. Deposits below Level 5 have an increasing likelihood of dating prior to the Initial
Late Prehistoric. Levels 2 through 5 also encompass Features $4,5,7,8,9,10,11,12$ and 13 .

\section{Assessing Integrity and Horizontal Distribution of the Late Prehistoric Materials}

The previous section has argued that a $40-\mathrm{cm}$ band (Levels 2 thorough 5) contains Late Prehistoric material at 41ZV202. A detailed review of all excavation forms suggests that within this band, the integrity of additional levels may be compromised. For example, Figure 6-9 presents a section of profile that clearly shows extensive bioturbation associated with squares N94/E81 and N95/E81. A review of these two units, as well as those in the immediate area, suggests that these two squares, along with adjacent units N96/E81 and N95/E80, have extensive rodent disturbance. While sections of these squares were identified in the notes as containing intact deposits, artifacts associated with these four squares are eliminated from consideration given the potential problems with their integrity. In addition, Levels 4 and 5 in N95/E79 and Levels 5 in N95/E78 also have extensive

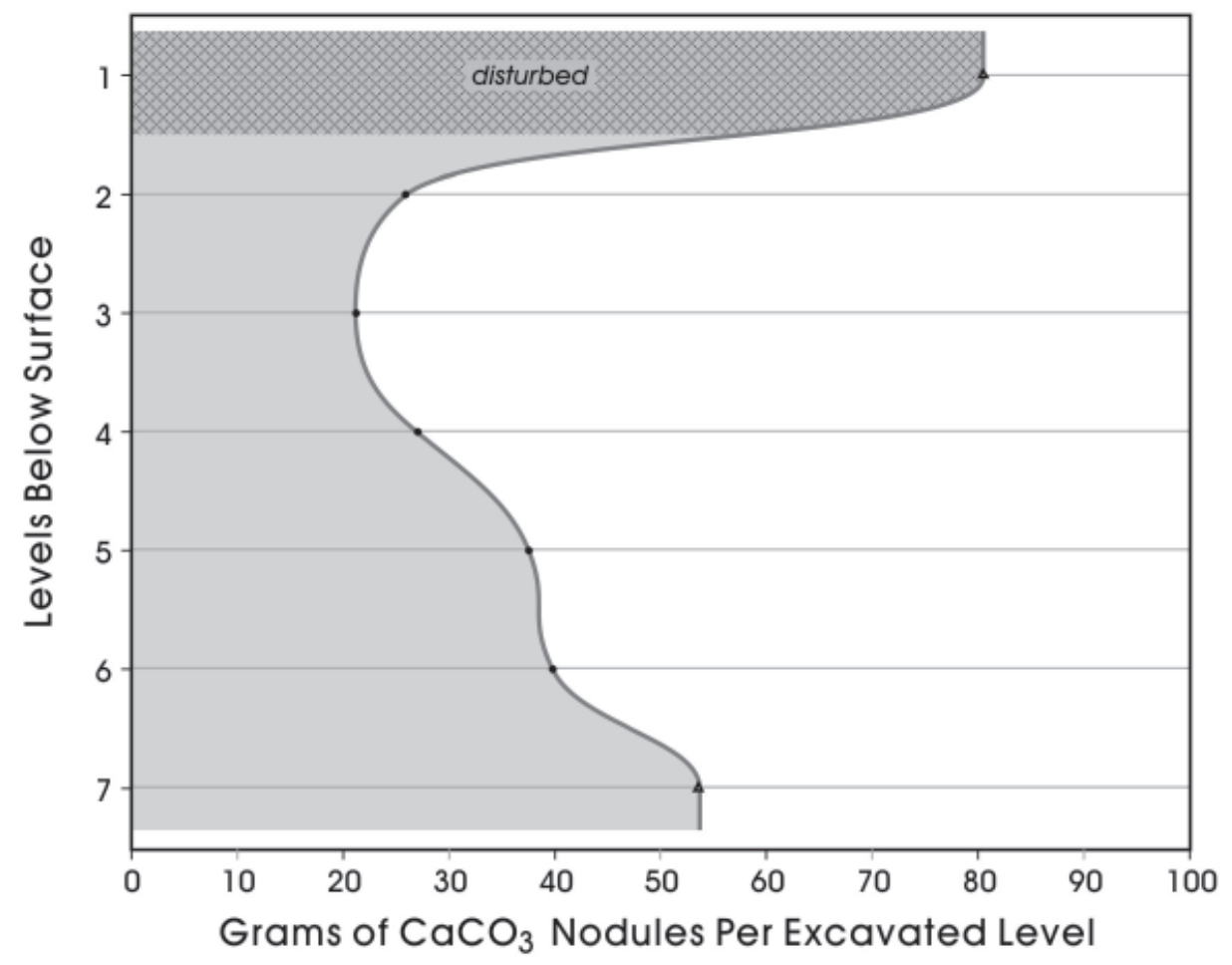

Figure 6-8. Carbonate nodule weights by level for data recovery excavations at 41ZV202. 


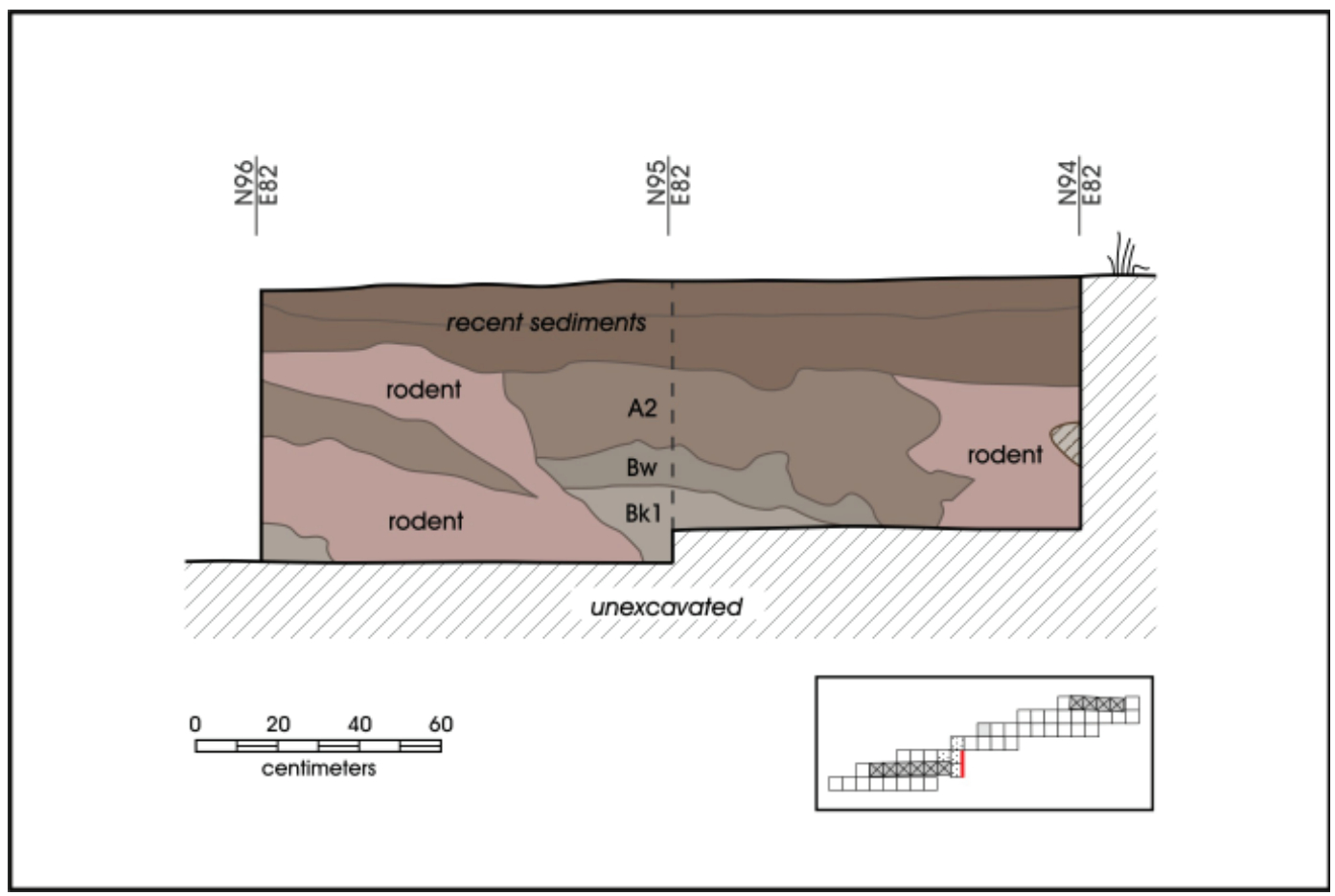

Figure 6-9. Profile of east wall (E82 line), between N94 and N96.

rodent disturbance recorded. Artifacts associated with these levels will not be included in the analysis. Note that Feature 11 is located in N95/E78 in Level 5, and Feature 12 is located in N96/E81. As with the artifacts, we will eliminate these two features from our analysis.

Note that Feature 9 is associated with the $\mathrm{Bw}$ and $\mathrm{Bk}$ deposits. It is unlikely that this feature dates to the Late Prehistoric period. However, the area around this feature is not bioturbated, and the feature occurs in Level 5, at the bottom of the deposits that we have assigned to the Late Prehistoric. While we include the feature in our analysis, it may date earlier than the Late Prehistoric.

Having eliminated those squares with extensive bioturbation from the sample, we now turn to a consideration of spatial patterning of material to further define the distribution of Late Prehistoric materials. Figure 6-10 presents the horizontal distribution of projectile points in Levels 2 through 5. Clearly, a cluster of Late Prehistoric points exists in the northeastern section of the site, the area designated as Feature 4. While the Feature 5 area only has a single Late Prehistoric point, recall that five of the six radiocarbon dates from this area fall within the Late Prehistoric. Having eliminated lower levels, only four dart points are now present in the analytical data set, with two of these, an Ensor and an Andice point, located in a single unit (N97/E83E). Given this distribution, the fact that no Late Prehistoric points are present in this location, and the fact that this unit is far from the testing areas that have radiocarbon dates, we have eliminated this square from the sample.

\section{Summary}

The remaining 132 levels excavated during data recovery contain a variety of data, including 48 chipped stone tools, just over 4,380 pieces of debitage, five cores, over 10,000 pieces of burned rock, 61.2 grams of mussel shell, 30 pieces of bone, 98 charcoal samples, 3497.5 grams of snail shell, and 124 soil samples. Three features identified during data recovery (Features 8, 10, and 13) are within the larger Feature 4 area. The Feature 4 area, located to the east of the bioturbated units (Figure 6-10), contains both higher densities of burned rock and debitage relative to the Feature 5 area, located to the west of the turbated units. Feature 9 is located in this Feature 5 area.

While of a slightly different quality, using the parameters developed from the data recovery to reassess the testing data we have an additional 900 pieces of chipped stone, 12 lithic tools, 19.7 grams of mussel shell, 508.5 grams of snail shell, and additional soil and charcoal samples. In addition, Feature 7, located in squares N94/E75 and N94/E76 and securely dated to the Late Prehistoric period, is also included in the analytical data set. 


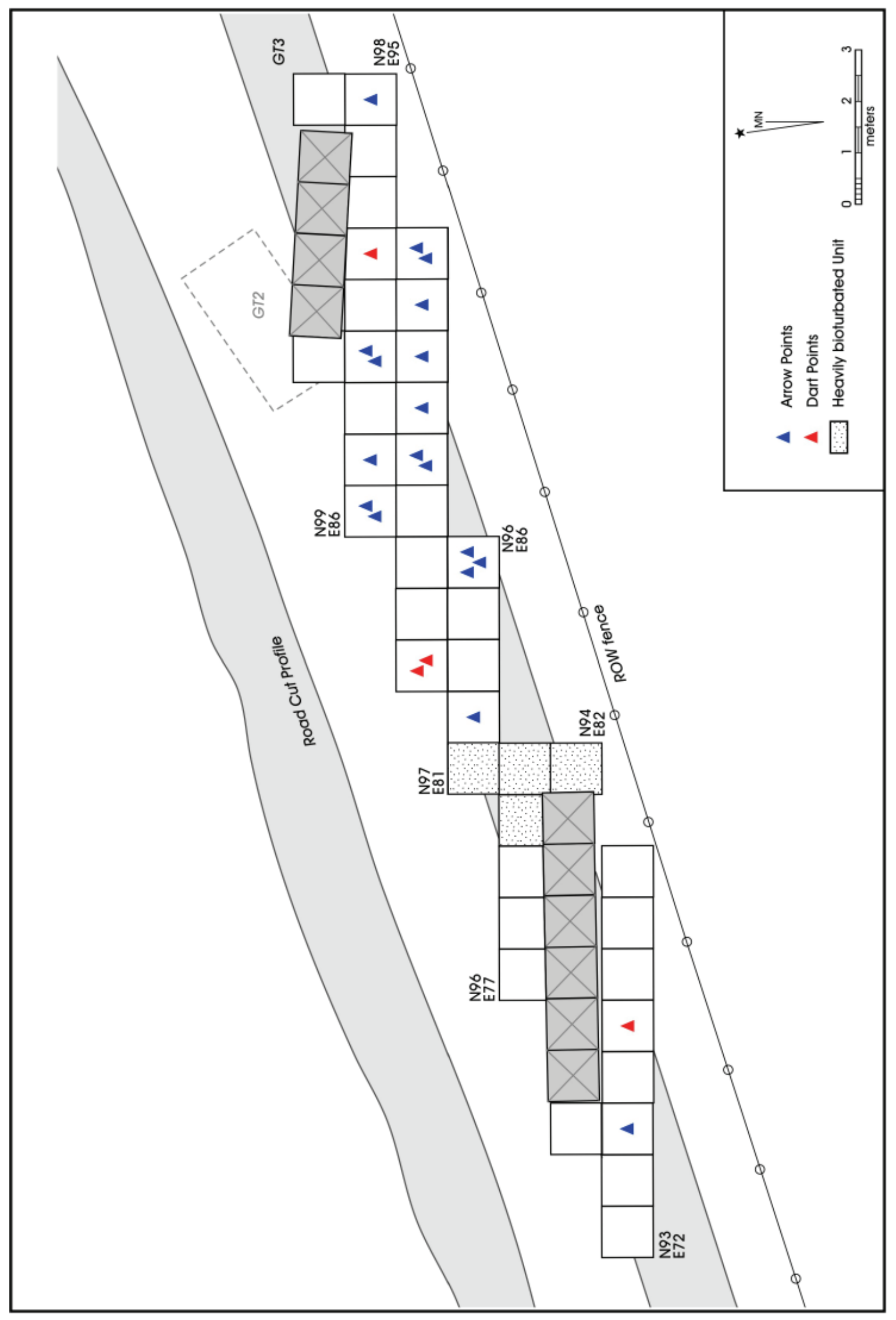

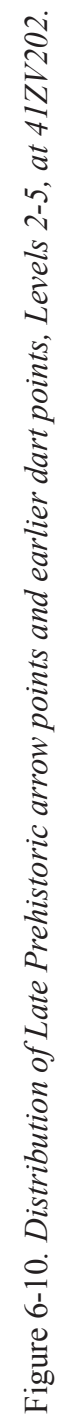




\section{Chapter 7: Theoretical Background}

\section{Raymond Mauldin, Jennifer Thompson, and Steve Tomka}

As demonstrated in the previous chapter, the testing and data recovery work conducted by CAR at $41 \mathrm{ZV} 202$ produced a variety of data sets that can be assigned to the Initial Late Prehistoric period. Here, we outline aspects of the theoretical scheme that will structure the analysis of that data. At a general level, that interpretive scheme comes from cultural ecology (see Kirch 1982; Netting 1986; Sutton and Anderson 2004). We view cultural systems as both adaptive and differentiated. By adaptive, we mean that cultural systems are continually responding to changes in their physical and social environment (see Bettinger 1982). Of particular concern for us are the responses, including technology, that are involved with procurement and processing of food, fuel, and raw materials from their environment. By differentiated, we mean that people conducted different activities at different times and locations depending on specific circumstances. As activities conducted by a group vary in space and through time, the material remains generated by conducting those activities will also vary. Consequently, individuals and groups operating within a cultural system potentially will generate radically different sets of material at various points on the landscape. Variations in material culture, both at the level of individual artifact forms (e.g., projectile points) and at an assemblage level, primarily reflect adaptive responses (see Binford 1978, 1983; Gamble 1986).

In our perspective, changes in cultural systems, including changes in material culture, are principally the result of changing parameters in the physical and social environment in which systems operate and to which they must adapt, rather than reflecting movement of groups with a shared culture or influences diffused from other groups. This is not to suggest that diffusion or migration does not occur. However, we are interested in why groups adopted traits or changed territories rather than tracing their historical connections through similarities in artifact form. We suggest that our understanding of the mechanisms of change, as well as our methodology for monitoring those mechanisms in the social realm, is not well developed at the current time. Clearly, social factors, such as territorial disputes and shifting alliances, can alter adaptive strategies, especially through altering access to resource areas. However, in our view, archeology currently lacks effective methods to monitor these social factors. In addition, even the best archeological data probably has a temporal resolution of decades, while most social alliances, especially in hunters and gatherers, commonly operated on a much shorter temporal scale and are, for all practical purposes, archeologically invisible ${ }^{\text {(note } 2)}$.
We focus here, then, on interactions between aspects of cultural adaptation and the ecological realm. At this level, we have better developed methods, though they are certainly not without problems. Especially critical in that interaction are strategies and tactics, including the organization of technology and mobility, which groups used to acquire resources. It is in this realm, where cultural systems interact with the natural environment, that humans modify extant adaptive strategies. In addition, at least some of these interactions operate at long temporal scales that have the potential to manifest themselves in the archeological record.

\section{Prey Foraging Models}

We can investigate the responses initiated by hunters and gatherers to various scales of spatial and temporal fluctuations or change in resources using a cost/benefit framework developed in evolutionary ecology. Here, we focus on "prey models" which were developed for a single predator, sequentially encountering potential prey in a homogenous environment (Charnov et al. 1976; Emlen 1966; MacArthur and Pianka 1966; Winterhalder 1981). Prey models (see Stephens and Krebs 1986) frequently quantify returns (benefits) as energy (kilocalories [Kcal]) obtained from food (but see Jochim 1975; Sih and Milton 1985; Speth and Spielmann 1983), and quantify costs as time expended on searching for, pursuing, capturing, and processing that food. They assume that foragers will attempt to maximize average return rates in the context of different cost/benefit ratios for different prey. Costs are usually broadly framed as search costs, the amount of time spent looking for resources, and handling costs, the amount of time required to pursue, capture, and process foods. Models assume that searching and handling are mutually exclusive, and that foragers have perfect knowledge of costs and benefits of all resources under consideration. The models focus on the question "should I pursue that resource, or should I continue to forage?"

Prey models are the simplest foraging models. Several other models are available, including patch choice models (Charnov 1976), central-place foraging models (Jones and Madsen 1989), models that focus on risk (see Stephens and Krebs 1986), that use other currency for costs and benefits (see Hill 1988; O'Connell and Hawkes 1981), and models that focus on mating and reproductive success (Hill and Hawkes 1983). While these alternatives are often more realistic in their assumptions regarding human foragers, they are significantly more complicated. The simplicity of prey models require 
fewer assumptions to be made regarding the nature of the archeological record, but the resulting explanations are not as comprehensive. Note, however, that human foragers violate, to some degree, even the simplistic assumptions of prey models. They often hunt in groups, focus on a specific prey identified prior to initiating a search, are assisted by technology, and frequently "maximize" non-energy related elements. Furthermore, significant methodological problems plague archeological applications of such models. Nevertheless, we find the explicit cost/benefit framework appealing. We use these cost/benefit models to frame possible explanations for complex human behavior. Models are, by design, simplifications of a complex reality that allow researchers to isolate a small number of variables that may prove critical and develop expectations as to how those variables should behave under different conditions. Any results that do not fit those expectations, and we anticipate that most will not, serve to inform the development of new research endeavors.

\section{Resource Ranking and Changes in Diet Breadth}

A critical element in prey models involves ranking of prey alternatives in terms of handling costs and benefits. For human foragers, this ranking often reflects body size with larger-bodied animals (e.g., mammoths, bison) being more profitable (higher returns relative to handling costs) than smaller-sized animals (e.g., rabbit, deer) and plants. Figure 7-1 presents box plots for a series of return rates gathered from experimental and ethnographic sources in the Great Basin of North America and in Australia (see Cane 1987; Kelly 1995; Simms 1987). In the figure, we have grouped animals by overall body size and plants by approximate seed size. The large animal class is composed of mule deer, mountain sheep, and antelope, while the small and medium size class is composed of jackrabbit, cottontail, squirrel, and gopher. Clearly, the return rates on large mammals in this example are extremely high, while those on collecting and processing

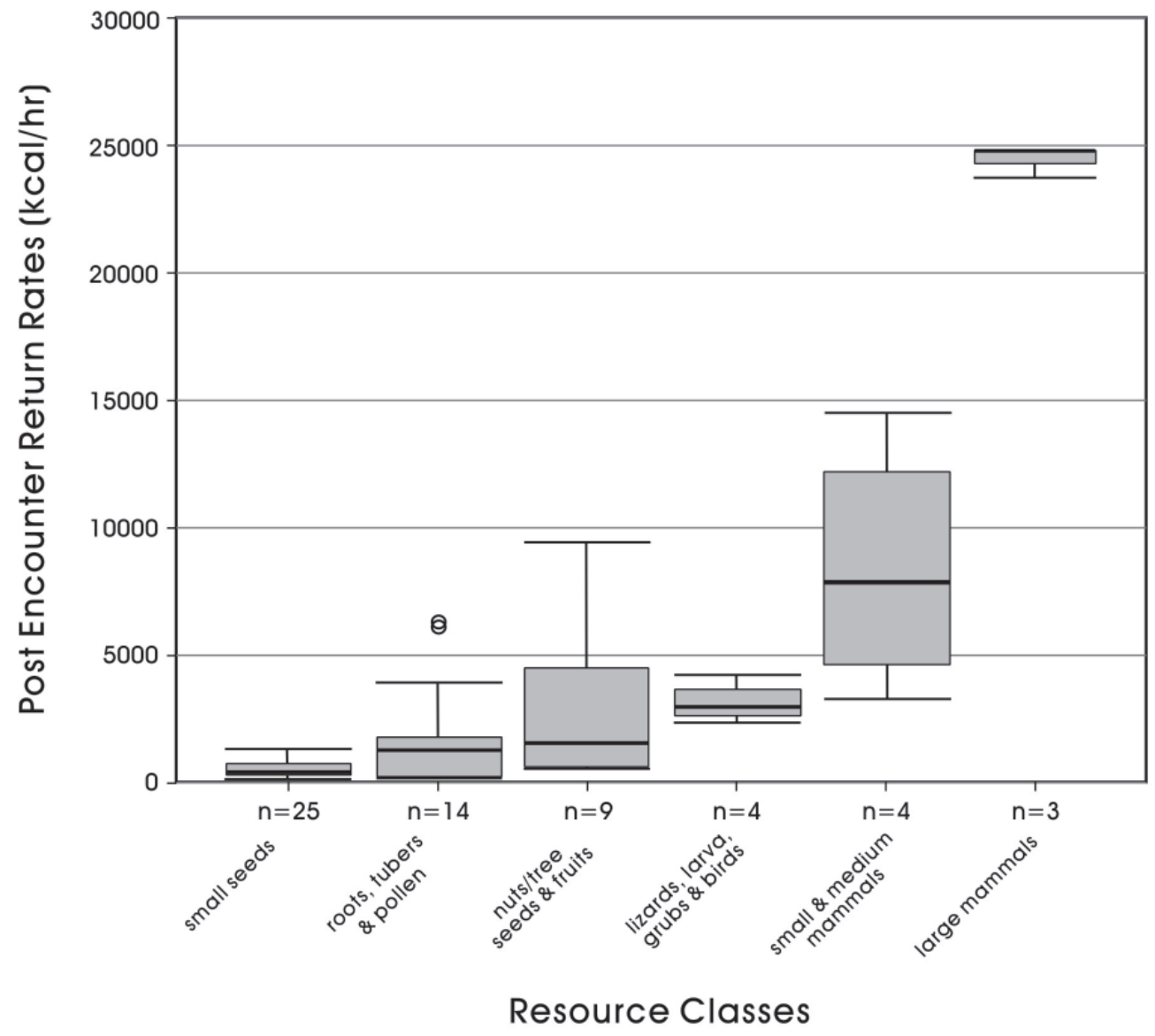

Figure 7-1. Post-encounter return rates (handling cost) by resource class (from Cane 1987; Kelly 1995; Simms 1997). 
small seeds are extremely low. While plants generally rank below animals, once hunters and gatherers encounter and decide to "pursue" plants they probably have a high success rate. Not all pursuits of animals result in a positive outcome for the pursuer. In fact, ethnographic accounts of hunting suggest that many pursuits of animals do not result in a successful kill. For example, Marks (1976:205-209) reports the number of kills per stalking event for various types of large mammals by Valley Bisa hunters in Zambia. Using muskets, Bisa hunter kill rates per stalking event vary from a low of $2.9 \%$ for impala to a high of $26 \%$ for buffalo. Success rates using more traditional technologies, such as bow and arrow, are probably lower (see Hill and Hawkes 1983:164), though we lack precise figures. Consequently, Figure 7-1 probably overestimated the return rates on animals because unsuccessful stalking events would result in no return. A more realistic ranking strategy would involve the ratio of energy captured per attack to the handling time per attack. This "prey profitability" ranking of plants and animals (Stephens and Krebs 1986:17-23) would result in a reduction of rankings of animals. Nevertheless, given the return rate disparity shown in Figure 7-1 it is likely that net energy return (profitability) of large-body sized animals would exceed returns on smaller animals and plants.

Search costs, though not taken into account in potential prey profitability rankings, play a critical role in determining the actual diet. In a classic prey foraging model, as foragers add more resource types to their diet, search costs decline because foragers encounter dietary items more frequently. There is a cost to incorporating less profitable resources into a diet. Time saved in search is offset by the higher handling cost and/or lower caloric benefits of lower ranking resources. The inclusion of a resource must serve the overall profitability of the diet and will not be included until the value of higher ranked resources drops below a certain threshold. Therefore, the inclusion of a low ranked resource is dependent on its profitability relative to that of higher ranked, more profitable resources ${ }^{\text {(note } 3)}$.

Foraging models predict a tradeoff, then, between handling cost, benefits (energy return), and search costs that will maximize the average return and produce an optimal diet. These models predict that foragers will continue to add lower-ranked resources to the diet, increasing the diet breadth, so long as the overall profitability of the diet, seen in terms of total costs to benefits, is increased. Furthermore, foragers should drop resources from the diet, reducing their diet breadth, when doing so would increase overall profitability (Figure 7-2). Many factors, however, influence the profitability of a food item including, but not limited to, relative scarcity, climate, rainfall, and food procurement and processing technologies.

Changes in types, quality, and abundance of resources result from variations in climate, combined with differences in elevation, soils, geology, and natural history. Such environmental factors can produce dramatic differences in profitability of resources at various temporal scales and shift which animals and plants are included in the diet (see Winterhalder 1981). For example, animals in the size range of mule deer should be highly ranked, and therefore included in the optimal diet set, in most settings given their overall body weight. However, as suggested in Figure 7-3, that ranking may shift seasonally because of shifts in deer nutritional quality. The post-encounter return rates on deer in the Figure 7-3 case differ by season, with higher returns during the fall and summer months, and lower returns during winter and spring. Therefore, the optimal diet shifts seasonally in this example as it would for other plants and mammals (see Speth 1983: 120-131) in other seasonal environments like Central and South Texas.

The scarcity and value of the highest ranked resource also effects the inclusion of all other diet options for a forager.

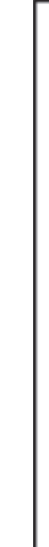

(1)
}

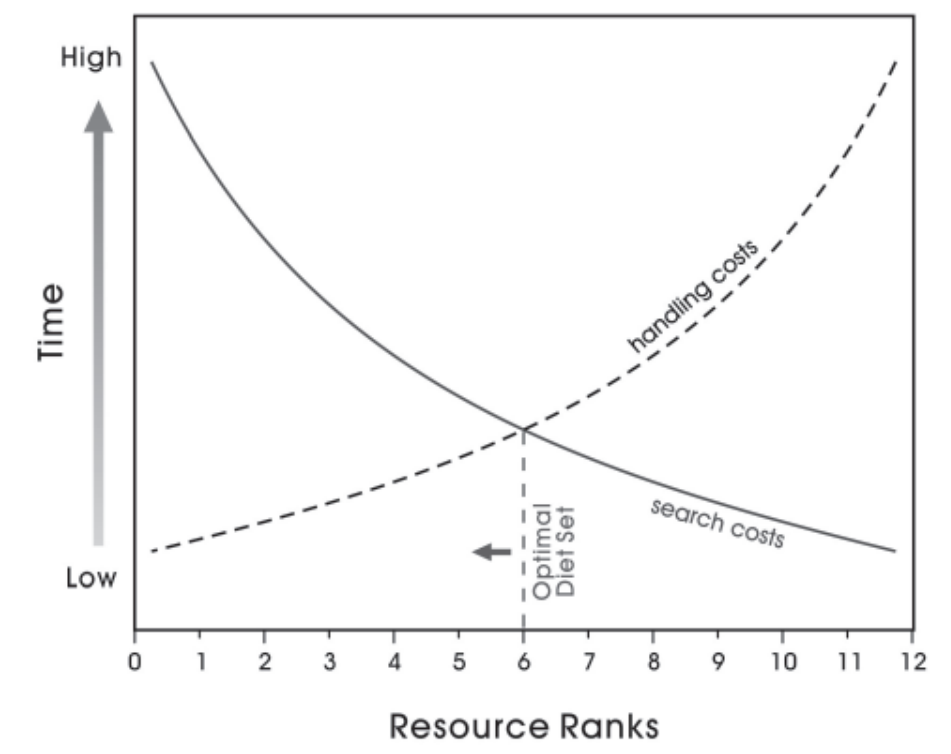

Figure 7-2. Optimal diet set as defined in prey models (after MacArthur and Pianka 1966). 


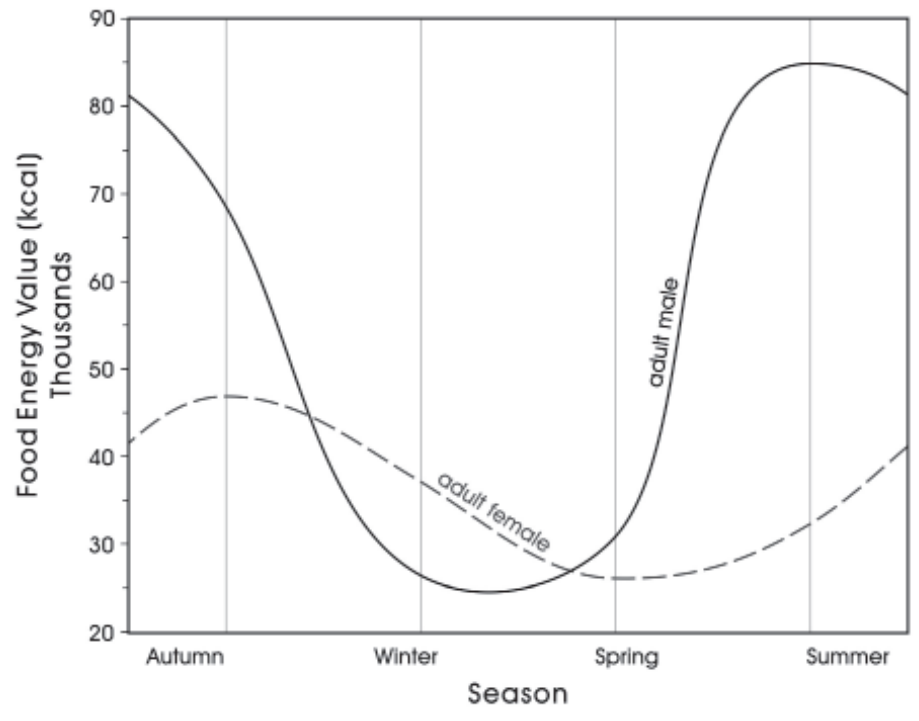

Figure 7-3. Seasonal changes in the nutritional quality of mule deer (from Anderson et al. 1972).

Though the value and abundance of lower ranked food items may fluctuate, their incorporation into a diet will only occur if the profitability of the highest-level food item drops significantly. Figure 7-4 shows two examples of yearly changes in productivity of the plants in South Texas (Windberg 1997). These data demonstrate fluctuations not in the nutritional quality of the plants, but in their yearly productivity by considering the percentage of prickly pear and mesquite that produce fruits or seeds over a 10 -year period. These changes in density, which are probably responding to variability in climate, will translate into different search costs. For example, costs associated with finding mesquite in 1979, 1980, and 1981 when productivity was low would be considerably greater than the 1982 through 1984 years, when productivity was high. However, the decision to include or exclude mesquite is not related to shifts in density of mesquite as such, but rather to shifts in the density of higher ranked prey items. In prey models, shifts in the density of a resource (e.g., mesquite) will have no impact on the use of that resource unless the resource is the highest ranked. This is because the focus is on the post-encounter decisions. In the case of encountering mesquite, for example, the question centers on whether foragers should quit searching and collect/process mesquite, or continue searching for a higher ranked resource. The density of the higher ranked resource is the determining element. In this example, the exploitation of mesquite is affected not by the availability of mesquite, but by the availability of higher ranked resources (e.g., deer).

In situations where the frequency of higher ranked items increase, foragers should drop lower ranked resources from the diet, thus increasing their average return (see Kaplan and Hill 1992: 168172; Stephens and Krebs 1986:13-37). However, especially in the case of human foragers, other responses may also occur that could result in maximizing the average return rate (see Hames 1992: 218-220). For example, technological changes, such as the abandonment of complex, expensive technologies in favor of those that are simpler and less costly to produce and maintain (Torrence 1989:5759), or abandonment of specialized search methods, may be a viable option under some conditions of increasing frequency of higher ranked resources. Conversely, when higher ranked items become increasingly less common, human foragers

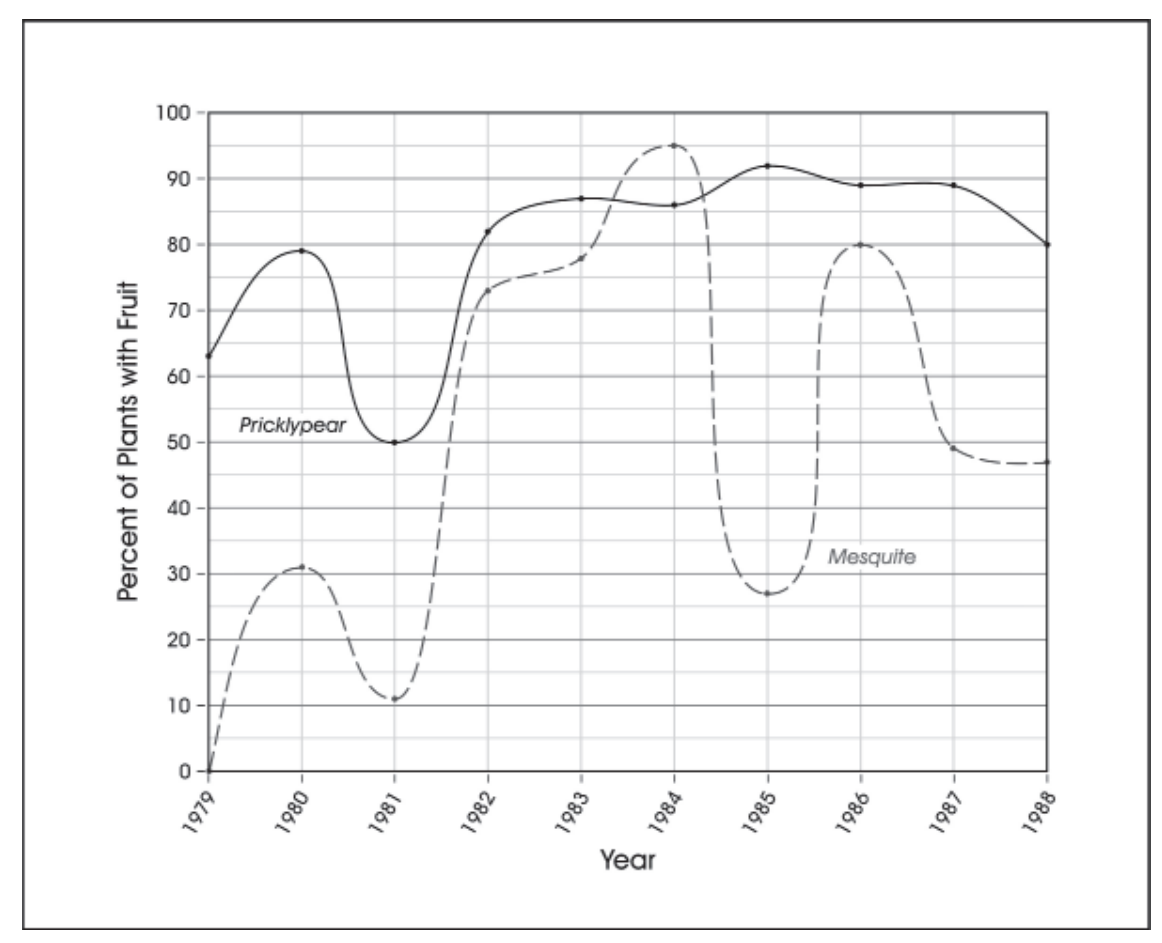

Figure 7-4. Yearly fluctuation in mesquite seeds and prickly pear fruit (from Windberg 1997). 
could switch to technologies that, although more expensive to produce and maintain, might increase the kill ratio, and thereby the profitability, of the less frequently encountered high ranked prey (see Smith 1991: 124-130; Yost and Kelley 1983). Foragers could also shift to search strategies that increase encounter rates for the high ranked prey.

The mix of possible responses used, beyond simply increasing or decreasing diet breadth, probably depends on a variety of elements, including the relative profitability of alternative resources, as well as the costs and benefits associated with extant and alternative technologies and search strategies. For example, Figure 7-5 depicts a simple expansion of the diet under falling encounter rates for a high return resource. The top portion of the Figure (A) shows encounter rates (search costs on $\mathrm{Y}$ axis), prey profitability (energy return per attack/ handling costs per attack- $\mathrm{X}$ axis), and an optimal diet in a hypothetical environment. The difference between the profitability of Resource 4, which is included in the diet, and Resource 5, which is excluded, is minimal. If a decline in the encounter rates for the highest ranked resource (Resource 1) occurs in this setting, it is likely that diet expansion will occur. Such an expansion is shown in Figure 7-5B (bottom)
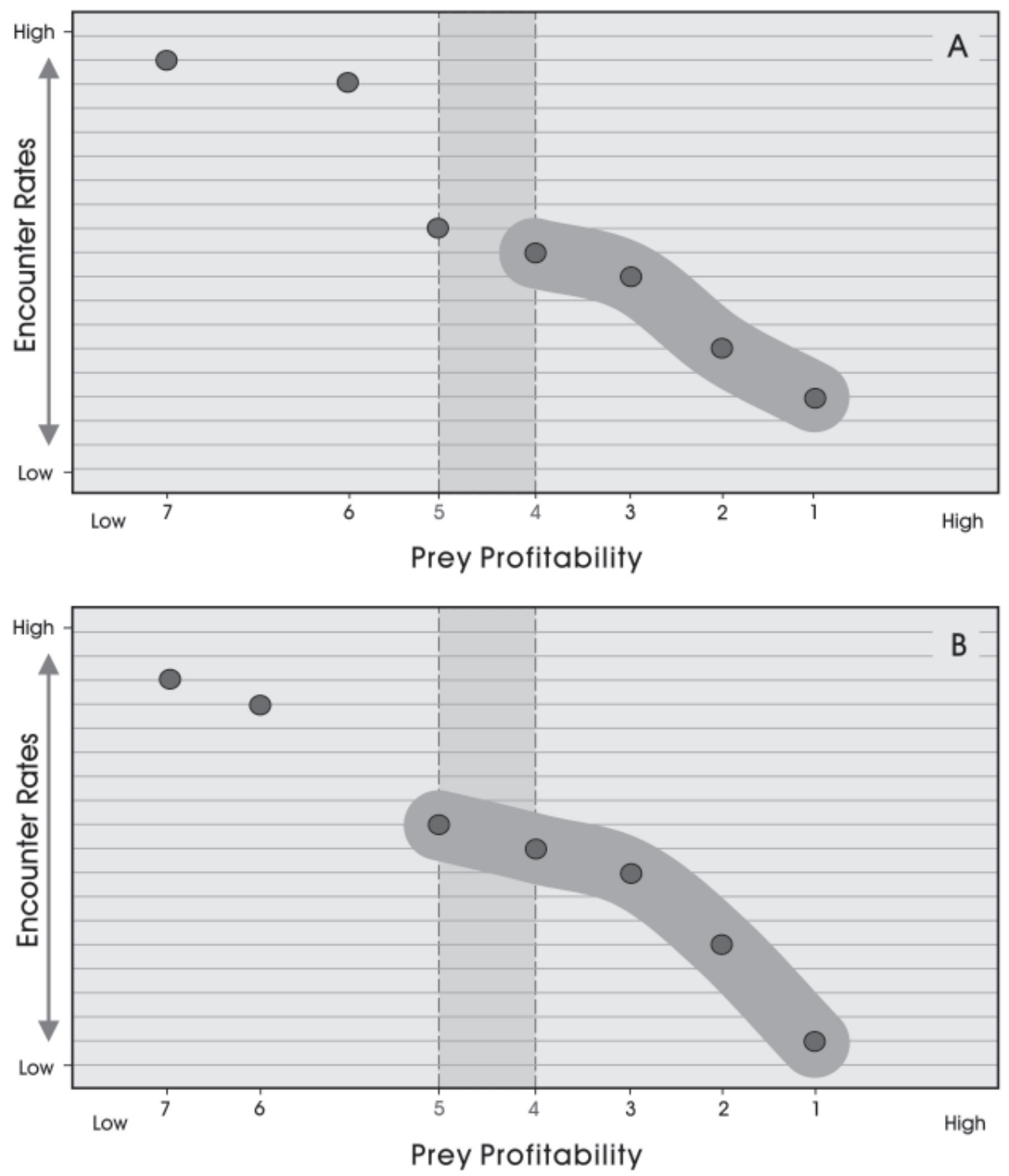

Figure 7-5. An example of diet expansion from $4(A)$ to 5 (B) resources under conditions of closely ranked prey profitability and decreasing encounter rates. 
with the inclusion of Resource 5 into the diet. Under these conditions, we would expect foragers to broaden their diet to include Resource 5 because its value is not much lower than Resource 4 and doing so would maximize the average return rates.

Figure 7-6A (Top) presents roughly the same initial conditions as in 7-5, but in this scenario, the profitability of Resource 5 is much lower than Resource 4. So low, in fact that if it were included it would not maximize overall return rates of foraging efforts. Therefore, the same drop in Resource 1 shown in Figure 7-5B would not necessarily produce the same outcome (see Figure 7-6B). Under the Figure 7-6B scenario, the overall return rate of the diet might well be maximized by shifts to more costly processing methods, changes in killing technologies, or search strategies that would increase the caloric returns, increase the success rate of kills, or increase the encounter rates with Resource 1.

Clearly, diet expansion or contraction is a complex issue. Expansion or contraction of what resources are in the diet may
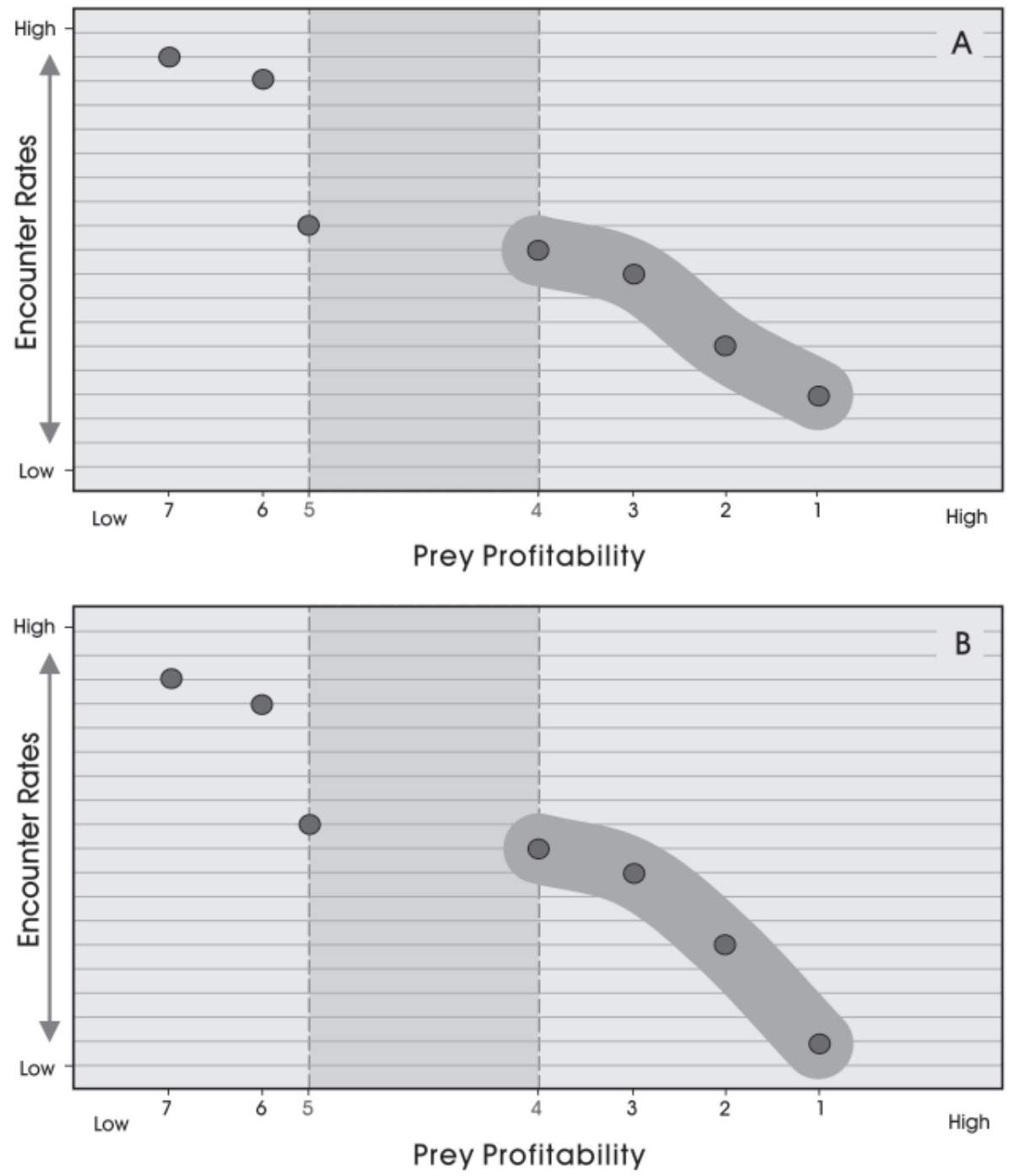

Figure 7-6. An example of the potential impacts of radical differences in prey profitability (resources 4 and 5). Under these conditions, diet expansion may not occur with decreasing encounter rates (A to B). 
be only one of several alternatives open to human foragers. In a given situation, other issues may prove to be critical. For example, the acquisition of several bison, especially by small groups, would require a series of decisions regarding both transport issues and processing/storage decisions that might significantly increase handling costs. These decisions may, depending on specific circumstances, result in the abandonment of usable product, and thus a lowering of caloric benefits if we measure those benefits only by body size. Other considerations, such as risk of injury or death, will also play into decisions.

\section{Technological Responses}

Shifts in the types of tools (e.g., use of ceramics) or processing facilities (e.g., features) will primarily influence handling costs associated with the acquisition of a given resource, although in some cases they may also influence kill or capture rates and nutritional returns. We envision facilities and tools as ranging from generalized to specialized in form. Specialized tools (e.g., ceramics, hafted lithic tools, bows and arrows) and features (e.g., burned rock middens) tend to be more expensive to produce. Formal tools require more time, are usually more complex, and in some cases may require specific raw materials that have limited distributions. As a group, hunters and gatherers frequently maintain specialized tools and facilities, also increasing their overall costs (see Binford 1977, 1979). However, because of their specialized nature, these tools and facilities tend to be more efficient at accomplishing their designed task. Generalized tools or facilities, conversely, are less expensive to produce. They are often expediently made (e.g., utilized flakes), they tend to have few components, and they may have more flexible raw material requirements. In addition, they often have short use-lives and minimum associated maintenance costs. While less costly and potentially useful in the performance of a variety of tasks, generalized tools and facilities will be less efficient at any given task ${ }^{\text {(note } 4)}$.

When seen from this perspective, the decision to employ a more specialized or a more generalized technological solution can be considered in the context of the overall costs associated with tool/feature production and maintenance relative to the benefits derived from that tool or features. The adoption of more specialized processing and killing methods clearly involves increased costs in terms of time and energy. For our Figure 7-6 Scenario B example, the increased investment in technology may be offset by the increased profitability of the overall diet relative to the profitability of the diet that would be present if, because of declines in Resource 1, Resource 5 was included without any other changes.

\section{Mobility Responses}

Another set of responses concerns shifts in mobility. Resources, including food, water, and raw material, are not uniformly distributed in space, nor are they of uniform quality or density through time. Hunter-gatherers commonly solve problems created by spatial variation in resources by mobility strategies that involve positioning and changes in the composition of the group. Mobility strategies have several components that can vary, including the frequency of moves, the distance moved, and the degree to which different types of organization (e.g., logistically organized task groups, higher residential mobility) are used. Hunters and gatherers solve temporal fluctuations in resources, including daily, seasonal, and year-to-year changes in resource availability and quality, as well as longer-term changes in resource structure, by shifts in mobility strategies, technological alterations, shifts in group size or composition, and through storage strategies (see Kelly 1995).

As noted above, mobility, in terms of search costs (travel time), plays a critical role in modeling diet breadth in prey models. Researchers increasingly discuss hunter-gatherer mobility systems in terms of "forager" and "collector" strategies (Binford 1980). Collector strategies have low residential mobility, relying extensively on task-specific groups to acquire resources and move those resources back to residential locations. Binford's foragers, in contrast, make frequent, shorter moves of residential camps and acquire food on a daily basis. Binford (1980; see also Kelly 1995) broadly framed these two strategies as responses to different environmental conditions, with foragers present in environments characterized by ubiquitous, low-density resources, and collectors present in settings with high temporal and/or spatial disparity in resources. In practice, these two strategies are frequently present within the same cultural system, with seasonal or resource-specific shifts in search strategies possible.

Logistical systems of resource procurement are a more specialized strategy relative to foraging-based systems. They are more costly in terms of distances covered, as well as requiring more planning, preparation, and coordination. Task groups of hunters and gatherers use logistical strategies to gather resources in excess of immediate needs, with that excess returned to residential locations. It is likely, then, that when logistical strategies are used, their target will tend to be higher-ranked resources. Low-return resources should not be exploited at great distances, as the longer travel time effectively negates any benefits. This is because the distance at which hunters and gatherers can effectively acquire resources in bulk is tied to the resources overall return rates (net calories gained), load-bearing abilities of the participants, 
and distance (e.g., Jones and Madsen 1989; Metcalfe and Barlow 1992). It is likely that the use of a logistical strategy would increase encounter rates for the targeted resource. In the Figure 7-6B scenario, if hunters and gatherers used a more costly logistical strategy but targeted Resource 1, the increased encounter rates for Resource 1 might offset that increased cost. Hunters and gatherers should use this strategy if doing so would increase the overall profitability of the diet relative to the profitability of the diet that would be present if they continued to pursue Resource 1 on an encounter basis, and they included Resource 5 without any other changes.

\section{Summary}

Using the cost/benefit framework provided by foraging theory, we have presented a number of general relationships that should be applicable to investigating aspects of subsistence, technology, and mobility in hunters and gatherers. Human foragers respond to short and long-term shifts in resource availability in complex ways. Those responses may involve various mixes or shifts in what resources are included and excluded from the diet, technological changes that alter handling costs and capture rates of dietary items, and shifts in mobility strategies that alter encounter rates. What specific response hunters and gatherers initiate will depend on extant adaptations, available alternatives, and the structure of resources. Changes in the quality and quantity of resources, such as those noted above (see Figures 7-3, 7-4), further complicate the development of any detailed response model. The fluctuations mean that prey profitability and encounter rates are probably constantly changing. We suggest that a hierarchy of responses may occur, with foragers potentially ignoring short-term fluctuations, or making minor alterations in diets such as the incorporation of alternative resources that have roughly similar ranks. Seasonal fluctuations in profitability, like those shown for deer, are likely to result in seasonal changes in what resources are included in the diet, along with short-term shifts in technology and mobility strategies to exploit these different sets of resources (see Winterhalder 1981). Multiyear, directional changes in climate (e.g., overall increase in moisture, decrease in temperatures over several decades, increased rainfall) that may result in shifts in resource quality, type, and density, are increasingly likely to result in significant shifts in what resources are included in the diet, as well as in the technology and mobility strategies used to acquire those resources.

In an archeological setting, we are unlikely to be able to monitor short term, or even yearly shifts in resources, tactics, or strategies. Even under exceptional conditions, the temporal scale at which we can define associated activities in archeological assemblages is on the order of several decades, and frequently centuries. Events that happen on a daily, seasonal, or yearly scale are invisible in most archeological contexts. In an archeological context, these short-term responses will simply add to the variability seen in adaptive responses at a location. In addition, note that the archeological record is not generated at a temporal scale that is analogous to the ethnographic time-frame where most human foraging cost/benefit models have been developed or explored (see Binford 1992; Dunnell 1992; Ebert 1992). An archeological site is, in most cases, likely the result of a variety of different activities conducted over different seasons, different years, and perhaps for radically different purposes. The artifacts and features at a location have, in addition, been impacted by a variety of post-depositional processes (e.g., Schiffer 1987). These factors, combined with different recording methods, including different site definitional criteria, all but assures that the archeological "site" is not analogous to ethnographic or historic descriptions of sites.

However, we argue that the long temporal framework provided by archeological research does provide a context for investigating broad-scale changes in a number of different areas. Multiyear directional changes in resource structure, such as those that result from climate shifts, shifts in population density, or shifts in resource structure, operate at a temporal scale that is well suited for archeological investigations. Documenting and exploring these multi-year, directional changes, and human responses to those changes at a variety of spatial scales, is the overall focus of our research. We begin to develop this perspective in the subsequent chapter. Specifically, we suggest that the fluctuations in bison availability within Texas (see Collins 1995; Dillehay 1974) provides a context for developing a general model that has implications for shifts in diet, technology, and mobility. 


\title{
Chapter 8: Modeling South-Central Texas Hunters and Gatherers
}

\author{
Raymond Mauldin, Jennifer Thompson, Cynthia Munoz, and Leonard Kemp
}

Using the cost/benefit framework provided by foraging theory, we have suggested a number of general relationships that should be applicable to investigating aspects of subsistence, technology, and mobility in hunters and gatherers. While Texas archeologists do not commonly conceptualize subsistence, technology, and mobility systems in cost/benefit terms, and while our ability to monitor aspects of these models in an archeological case are limited, components of foraging theory provide a coherent set of principals and an explicit analytical framework for investigating aspects of Texas archeology. In this chapter, we develop a framework for investigating South-Central Texas hunter-gather adaptations, and shifts in those adaptations, into which we can place the Initial Late Prehistoric material recovered from 41ZV202.

As noted in the previous chapter, the long temporal framework provided by archeological research provides a context for investigating human responses to directional changes in resource structure. We also suggested that in foraging theory, alterations in the availability of high-ranked resources should have a significant impact on diet breadth. All else being equal, low-ranked resources should be added to the diet when high-ranked resources are unavailable because their addition would increase the overall return rate. Conversely, some lower ranked resource should be eliminated from the diet when high-ranked resources become available as their elimination would increase the overall return rate ${ }^{\text {(note 5). }}$

In Texas, bison would clearly have been a high-ranked resource. With an overall average weight of about $600 \mathrm{~kg}$ [males range average ca. $850 \mathrm{~kg}$, females average ca. 350 $\mathrm{kg}$ (Davis and Schmidly 1997)] bison are by far the largest animals available in Texas, exceeding the weight of white tail deer by a factor of 12 . As we have suggested that animals generally rank higher than plant resources, and that return rates in animals are related to weight, bison should be the highest ranked resources. As such, fluctuations in that resource, like the periodic absences suggested by Dillehay (1974: see also Collins 2004; Huebner 1991), should have important ramifications for diet breadth, as well as for the technology and mobility systems of hunters and gatherers in the state. Here, we review bison presence/absence data for Initial Late Prehistoric (Austin), as well as the preceding Late Archaic, and subsequent Terminal Late Prehistoric (Toyah) periods. We recognize that an expansion or contraction of diet is a complex issue, and that shifts in diet may be only one of several alternatives open to human foragers. In a given situation, issues other than costs and benefits as we have defined them, such as risk of injury or death, may prove critical. Nevertheless, we can suggest that when bison are increasingly absent, an increasingly wide diet-breadth, with more dependence on lower-ranked resources such as smaller animals and plants, will occur. Conversely, when bison return to the region, we anticipate a dramatic narrowing of the diet, with a decreased use of lower-ranked plants and small animals. Given our discussion in the previous chapter, we also expect that these broad changes in diet breadth should have impacts on tool assemblages, as well as the scale and the organization of mobility.

\section{Patterns of Bison Presence/ Absence in Central and South Texas: Archeological Data}

While Dillehay (1974) has assessed bison presence/absence trends, his seminal work is now over 30 years old and was, even in 1974, intended as an initial, preliminary study. Over the past 30 years, many new sites have been excavated providing new data regarding bison presence/absence trends. It is, in part, as a response to this new information that Collins (1995) has revised the diachronic trends in bison presence/ absence in his recent review of Central Texas archeology. The model proposed by Collins differs from that presented by Dillehay, who suggests that bison presence ends at roughly AD 500, with bison returning at roughly AD 1250. Collins (1995) places the decline at roughly $\mathrm{AD} 650$, and sees the return of bison at about AD 1300. However, Collins presents no supporting data for his revisions, so currently it is unclear exactly what the pattern of bison presence/absence is within the state during this 1400-year period. Given the importance of clearly establishing the pattern of bison availability in our general model, we reviewed the post-1974 archeological literature within the research area for bison availability. The objectives of the review were twofold: (1) refine the temporal trends in bison population densities; and (2) define regional variability in bison availability. However, before proceeding, we provide a short review of earlier investigations of bison in Texas.

\section{Previous Research}

While earlier observations exist (e.g., Baerreis and Bryson 1965; Collins 1968; Dibble 1968), Dillehay's (1974) study represents the first significant attempt to model shifts in bison on the Southern Plains. Using published and unpublished data from about 150 archeological and paleontological sites from throughout the Southern Plains, he mapped bison presence/ absence over nearly 12,000 years. Time periods were 
assigned by reference to either associated radiocarbon dates, or, more commonly, through association with artifacts argued to be temporally diagnostic. Dillehay (1974) proposed a series of intervals for which he argued that bison were either present or absent across much of the region (Dillehay 1974:181). Of specific concern to the current study are patterns of bison absence in Texas suggested for the Initial (Austin) Late Prehistoric. Dillehay (1974:184-185) argued that following a roughly 3000year presence (Presence Period II; $2500 \mathrm{BC}$ to AD 500), bison were "absent" from Texas from AD 500 to 12001300 (Absence Period II; roughly equivalent to the Austin Phase). Bison returned at around AD 1200-1300 (Presence Period III), a time coeval with the development of Toyah material. Dillehay (1974:185-187) suggested that both the 700 -year absence of bison, as well as their return in the later half of the Late Prehistoric Period, were related to unspecified climate changes.

Following the publication of Dillehay's model, several researchers evaluated the suggested patterns of bison availability in the Late Prehistoric in detail. Results were mixed. Focusing on North Central Texas, Lynott (1979:98) found evidence of bison in the Initial Late Prehistoric, Dillehay's Absence Period II. Lynott (1979) also argued that while bison were clearly present in the Toyah Interval, they probably were never present in large numbers in this section of Texas. Working in Central and Western Oklahoma, Baugh (1986) demonstrated that bison were common throughout the Late Prehistoric. She found that bison were present on 11 of 14 sites (78\%) that were dated to between AD 300 and 1100 (Baugh 1986:84-91), a time that encompassed much of the “Absence Period II" (Dillehay 1974).

More directly relevant to our current investigations, Huebner (1991) undertook an extensive study of Dillehay's model focusing on Central and South Texas, as well as along the South Texas Coastal Plain, and on the Late Prehistoric Period (AD 700 to 1550). Huebner (1991:346-351) reviewed the presence/absence of bison, as well as the temporal placement of faunal remains, using data from 77 sites. Consistent with Dillehay's results, Huebner (1991) found that bison were common on Late Prehistoric sites dating after AD 1250 and he found no "definitive" evidence of bison on sites dating between AD 700 and 1250 (Huebner 1991:347).

\section{Reconsidering Late Holocene Bison Availability in Central and South Texas}

Huebner's 1991 study supports Dillehay's (1974) earlier observation that bison were present in sites throughout the region after AD 1300 and others (e.g., Creel 1990) clearly document their presence prior to AD 700. However, support for the suggested absence of bison in the Initial Late Prehistoric is variable. Huebner's (1991) work supports an absence period. Yet, both Lynott's (1979) and Baugh's studies (1986; see also Greer 1976) demonstrate that bison were present during this time in North Central Texas and Oklahoma. To clarify the pattern of bison presence in the Initial Late Prehistoric, as well as to refine the spatial distribution of this high-return resource, we focused on a roughly $150,000-\mathrm{km}^{2}$ area shown in Figure $8-1$. The area overlaps significantly with the earlier study by Huebner (1991). Those sites listed in Huebner (1991), as well as those listed by Dillehay (1974) that were within the Figure 8-1 boundary, formed our initial data set of 86 sites. An additional 28 sites within the region, most of which have been excavated within the last 15 years, were also reviewed. In all, we reviewed publications from 114 sites reflecting 181 Late Archaic and Late Prehistoric components. While we provide a short summary of the selection process here, Appendix $\mathrm{C}$ lists all sites used, provides data on bison presence or absence, identifies the temporal placement, assesses the strength of association between bison and the assigned temporal component, and provides a variety of additional information.

While we looked for components with radiocarbon dates as the primary temporal indicator, most assignments were based on the presence of temporally diagnostic artifacts such as point styles and ceramics. We arbitrarily split the relatively long Late Archaic into three blocks (Initial, Middle, Terminal), hoping to clarify temporal trends, while the Late Prehistoric was divided along traditional lines, with our Initial Late Prehistoric equivalent to the Austin Interval, and the Terminal Late Prehistoric equivalent to the Toyah Interval (see Appendix C). Table 8-1 presents the temporal ranges of the five components, along with the diagnostic artifacts used to assign material to one of these components.

It appears that Dillehay's original 1974 work used data from published and unpublished sources. These sources likely included communications with individual excavators and reviews of faunal assemblages in collections. When we reviewed the publications cited as sources for bison presence/ absence in Dillehay (1974), in several cases the cited work did not contain any discussion of faunal remains. In others, the publications failed to mention bison as present even though they were counted as present in the 1974 article. We encountered similar problems with components present in Huebner (1991). While bison may well have been present in such situations, we could not confirm that presence based on the source cited. For the Appendix $\mathrm{C}$ data, we relied only on faunal data published in primary sources to consider bison presence or absence. 


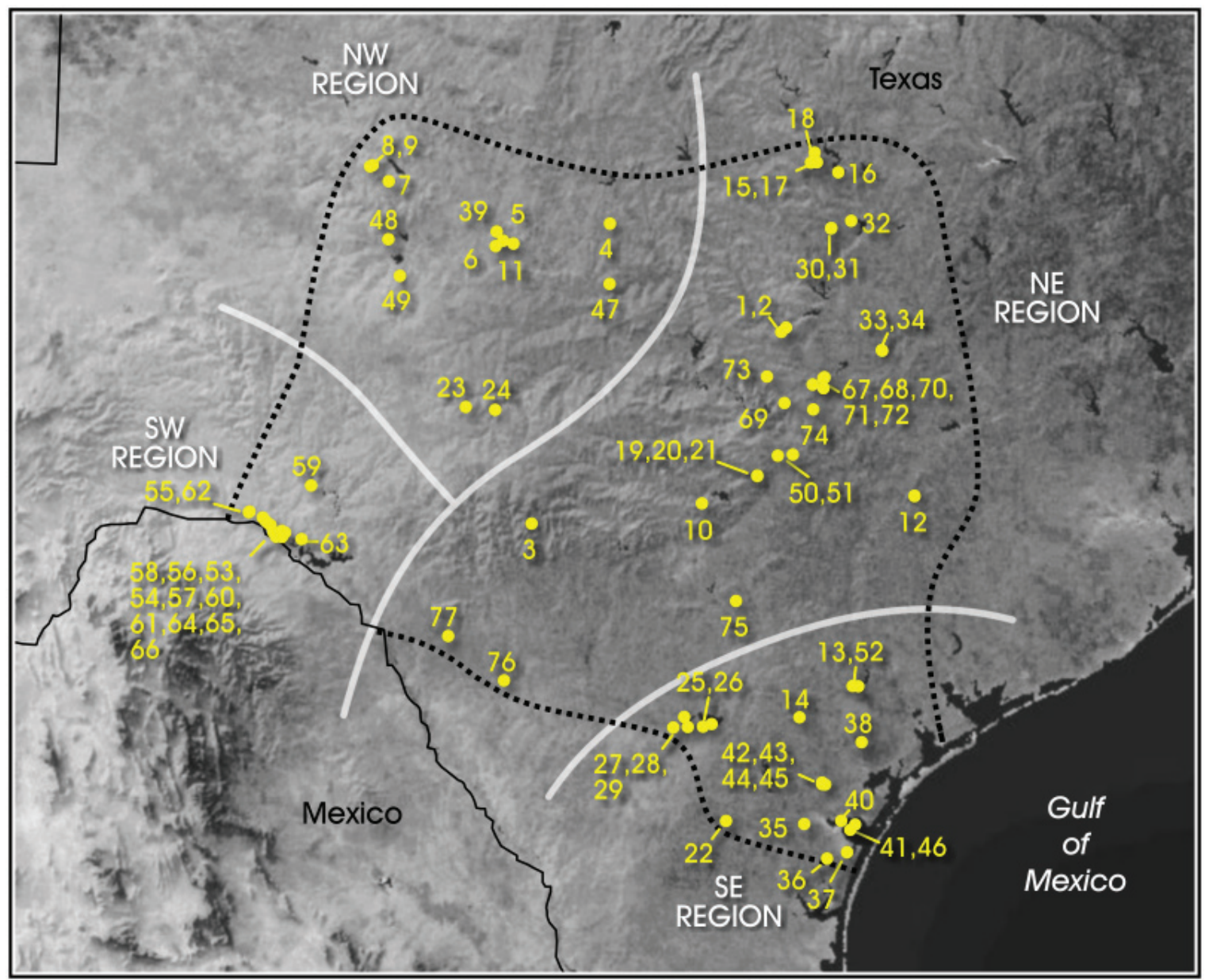

Figure 8-1. Region and components investigated for bison presencelabsence (see Table 8-2).

In addition, only components in which a researcher had clearly identified bison were considered as having bison "present." Specimens identified as "bison size," "bovid" or "very large mammal" were not counted as having bison. The context of the majority of "bovid," "bison size," and "very large mammal" recoveries, and the lack of alternative mammals in this size range in the region at this time, suggests that these remains probably represent bison that simply lacked diagnostic elements. We chose, however, to select parameters in which we had strong confidence. The inclusion of these excluded elements would probably change the details of the patterns presented here by increasing both the numbers of components with bison and the NISP counts on those components. We will demonstrate below that bison are present on between 20 and $39 \%$ of Late Archaic components, and that contrary to earlier summaries, bison are present on a moderate number (ca. 40\%) of our Initial Late Prehistoric components. Finally, bison are present on almost all of our Terminal Late Prehistoric components. The inclusion of "bovid" and "bison size"
Table 8-1. Temporal Periods and Associated Diagnostic Artifacts for Central and South Texas

\begin{tabular}{|c|c|c|c|c|c|}
\hline Time Period & Start (bp) & End (bp) & $\begin{array}{l}\text { Start (AD/ } \\
B C)\end{array}$ & $\begin{array}{l}\text { End (AD/ } \\
\text { BC) }\end{array}$ & $\begin{array}{c}\text { Diagnostic Projectile Point Types } \\
\text { and Other Artifacts }\end{array}$ \\
\hline $\begin{array}{l}\text { Initial Late } \\
\text { Archaic }\end{array}$ & 4450 & 2500 & $2500 \mathrm{BC}$ & $550 \mathrm{BC}$ & $\begin{array}{l}\text { Pedernales, Bulverde, Kinney, } \\
\text { Langtry, Val Verde }\end{array}$ \\
\hline $\begin{array}{l}\text { Middle Late } \\
\text { Archaic }\end{array}$ & 2500 & 1600 & $550 \mathrm{BC}$ & AD 350 & $\begin{array}{c}\text { Marcos, Montell, Castroville, } \\
\text { Lange, Marshall, Williams, Shumla }\end{array}$ \\
\hline $\begin{array}{l}\text { Terminal Late } \\
\text { Archaic }\end{array}$ & 1600 & 1250 & AD 350 & AD 700 & $\begin{array}{c}\text { Darl, Ensor, Frio, Fairland, Godley, } \\
\text { Figueroa, Ellis, Edgewood }\end{array}$ \\
\hline $\begin{array}{l}\text { Initial Late } \\
\text { Prehistoric }\end{array}$ & 1250 & 700 & AD 700 & AD 1250 & Scallorn, Edwards, Alba \\
\hline $\begin{array}{c}\text { Terminal Late } \\
\text { Prehistoric }\end{array}$ & 700 & 400 & AD 1250 & AD 1550 & $\begin{array}{l}\text { Perdiz, Clifton, Livermore. } \\
\text { Ceramics (including Rockport) }\end{array}$ \\
\hline
\end{tabular}


dates or temporally diagnostic artifacts (see Appendix C). When bison were present, we eliminated cases if we thought, based on the published stratigraphic descriptions and associations of temporally diagnostic artifacts, that the deposits were mixed. In cases where bison were absent from a component, we were primarily concerned with identifying what temporal periods were represented. Mixing of deposits was not an issue in these "bison absent" cases.

Following our review and the elimination of problematic components, we had 141 components from 77 archeological sites. Site locations are shown in Figure 8-1 with the assigned numbers in the Figure linked to Table 8-2. That table provides data for each component by site. Additional details are provided in Appendix C. When a component is absent from a site, the cell in Table 8-2 is blank. When a component is present, but bison are absent, a "0" appears. When bison are present, but the number of specimens identified as bison (NISP) are not known, an " $\mathrm{X}$ " appears in the cell. Finally, when we could ascertain NISP for bison from a component, we list that number in the cell. Overall, there are 18 Initial Late Archaic components, 20 Middle Late Archaic, and
30 Terminal Late Archaic components listed. For the Late Prehistoric, 73 components are listed, with 53 of these assigned to the Terminal Late Prehistoric and 20 dating to the Initial Late Prehistoric (see also Appendix C).

Table 8-3 provides summaries of the Table 8-2 data. Included in Table 8-3 is the relative frequency of components with bison present for each of the five intervals. In the Initial Late Archaic, about $39 \%$ of the components have bison present. The relative frequency of bison present declines throughout the Archaic, with about $35 \%$ of the Middle Late Archaic components having bison, and bison being present on about $20 \%$ of the Terminal Late Archaic components. Perhaps the most interesting aspect of the Table 8-3 summary is that our review does not support the Initial Late Prehistoric (Austin Phase) absence period proposed by Dillehay (1974) and supported by Huebner's (1991) work. Bison are not only present during this period, but occur with a frequency (40\%) that exceeds all earlier Late Archaic time periods. Finally, note that there is a significant jump in the Terminal Late Prehistoric, with bison present on $83 \%$ of the 53 components considered.

Table 8-2. Component Level Bison Presence Data (NISP) for Sites Identified in Figure 8-1

\begin{tabular}{|c|c|c|c|c|c|c|c|}
\hline $\begin{array}{c}\text { Figure } \\
8-1 \\
\text { Reference }\end{array}$ & $\begin{array}{c}\text { Site } \\
\text { Trinomial }\end{array}$ & $\begin{array}{c}\text { Initial Late } \\
\text { Archaic }\end{array}$ & $\begin{array}{l}\text { Middle Late } \\
\text { Archaic }\end{array}$ & $\begin{array}{c}\text { Terminal Late } \\
\text { Archaic }\end{array}$ & $\begin{array}{l}\text { Initial Late } \\
\text { Prehistoric }\end{array}$ & \begin{tabular}{|c|} 
Terminal Late \\
Prehistoric
\end{tabular} & Primary Reference \\
\hline 1 & 41BL104 & 21 & 15 & 17 & & 1 & Sorrow et al. 1967 \\
\hline 2 & 41BL85 & $x$ & & & & & Sorrow et al. 1967 \\
\hline 3 & 41BN33 & & & & 9 & 23 & Henderson 2001 \\
\hline 4 & 41BR420 & & & 0 & 3 & & Mauldin et al. 2003 \\
\hline 5 & $41 \mathrm{CC} 131$ & & & & & 3421 & Treece et al. 1993 \\
\hline 6 & $41 \mathrm{CC} 222$ & $x$ & & & & $x$ & Lintz et al. 1993 \\
\hline 7 & $41 \mathrm{CK} 30$ & & & & & $x$ & Shafer 1969 \\
\hline 8 & 41CK76 & & & & & 4 & Shafer 1971 \\
\hline 9 & $41 C K 79$ & & & & & 1 & Shafer 1971 \\
\hline 10 & $41 \mathrm{CM} 1$ & & 2 & $x$ & 0 & & Johnson et al. 1962 \\
\hline 11 & $41 \mathrm{CN} 95$ & & & 0 & & 938 & Treece et al. 1993 \\
\hline 12 & $41 \mathrm{FY} 74$ & & & & & 28 & Lord 1977 \\
\hline 13 & $41 \mathrm{GD} 21$ & 1 & & & & 3 & Fox 1979 \\
\hline 14 & 41GD4 & & & & & $x$ & Hester and Parker 1970 \\
\hline 15 & 41HI1 & & & & 0 & 4 & Jelks 1962 \\
\hline 16 & $41 \mathrm{HI} 117$ & 1 & 1 & & & 3 & Lynott 1978 \\
\hline 17 & $41 \mathrm{HI} 54$ & & & & 0 & 0 & Stephenson 1970 \\
\hline 18 & $41 \mathrm{HI} 55$ & & 0 & 0 & 0 & 0 & Stephenson 1970 \\
\hline 19 & $41 \mathrm{HY} 202 \mathrm{~A}$ & & & & & 32 & Ricklis and Collins 1994 \\
\hline 20 & $41 \mathrm{HY} 202 \mathrm{~B}$ & & 46 & & & & Ricklis and Collins 1994 \\
\hline 21 & 41HY209T & & & 0 & 1 & 121 & Ricklis and Collins 1994 \\
\hline 22 & 41JW8 & & & & & 45 & Black 1986 \\
\hline 23 & $41 \mathrm{KM} 16$ & & & & & 5 & Johnson 1994 \\
\hline 24 & $41 \mathrm{KM} 69$ & & & 0 & 0 & 1 & Thompson et al. 2007 \\
\hline 25 & 41LK201 & 1 & & & & 15 & Highley 1986 \\
\hline 26 & 41LK67 & 0 & & 0 & & 0 & Brown et al. 1982 \\
\hline 27 & $41 \mathrm{MC} 222$ & & & & & 33 & Hall et al. 1986 \\
\hline
\end{tabular}


Table 8-2. Continued...

\begin{tabular}{|c|c|c|c|c|c|c|c|}
\hline $\begin{array}{c}\text { Figure } \\
8-1 \\
\text { Reference }\end{array}$ & $\begin{array}{c}\text { Site } \\
\text { Trinomial }\end{array}$ & $\begin{array}{l}\text { Initial Late } \\
\text { Archaic }\end{array}$ & $\begin{array}{l}\text { Middle Late } \\
\text { Archaic }\end{array}$ & $\begin{array}{c}\text { Terminal Late } \\
\text { Archaic }\end{array}$ & $\begin{array}{l}\text { Initial Late } \\
\text { Prehistoric }\end{array}$ & \begin{tabular}{|c|} 
Terminal Late \\
Prehistoric
\end{tabular} & Primary Reference \\
\hline 28 & 41MC296 & & 1 & & 5 & 4 & Hall et al. 1986 \\
\hline 29 & 41MC55 & & & & & $x$ & Hall et al. 1986 \\
\hline 30 & 41ML35 & & & 0 & 0 & 0 & Story and Shafer 1965 \\
\hline 31 & 41ML37 & & & 0 & & & Story and Shafer 1965 \\
\hline 32 & 41ML39 & & & & & 0 & Watt 1965 \\
\hline 33 & $41 \mathrm{MM} 340$ & 0 & 1 & 0 & & & Mahoney et al. 2003 \\
\hline 34 & $41 \mathrm{MM} 341$ & & & & $0 / 0^{*}$ & & Gadus et al. 2006 \\
\hline 35 & 41NU221 & & & & & 19 & Ricklis 1987 \\
\hline 36 & 41NU37 & & & & & 6 & Patterson and Ford 1974 \\
\hline 37 & $41 \mathrm{NU} 4$ & & & & & 0 & Campbell 1956 \\
\hline 38 & 41RF21 & & & & & 289 & Ricklis 1990 \\
\hline 39 & 41RN169 & & & & & 10666 & Treece et al. 1993 \\
\hline 40 & 41SP103 & & & & & 3 & Ricklis 1987 \\
\hline 41 & 41SP120 & & & & 2 & 8 & Ricklis 1990 \\
\hline 42 & 41SP160 & & & & & 2 & Ricklis 1990 \\
\hline 43 & 41SP167 & & & & & 23 & Ricklis 1990 \\
\hline 44 & 41SP168 & & & & & 6 & Ricklis 1990 \\
\hline 45 & 41SP170 & & & & & 31 & Ricklis 1990 \\
\hline 46 & $41 \mathrm{SP} 43$ & & & & 0 & 0 & Ricklis 1990 \\
\hline 47 & $41 S S 20$ & & & & & $x$ & Greer and Hester 1973 \\
\hline 48 & $41 \mathrm{TG} 346^{* *}$ & & & & & 1111 & Quigg and Peck 1995 \\
\hline 49 & 41TG91 & & 0 & & & 143 & Creel 1990 \\
\hline 50 & 41TV42 & & & $x$ & 0 & $x$ & Suhm 1957 \\
\hline 51 & 41TV441 & & & & & 3 & Karbula et al. 2001 \\
\hline 52 & 41VT66 & & & & & 60 & Huebner 1987 \\
\hline 53 & 41VV161 & & 0 & 0 & & & Collins 1969 \\
\hline 54 & 41VV162 & 0 & 0 & 0 & & & Alexander 1974 \\
\hline 55 & 41VV167 & 0 & & 0 & & & Ross 1965 \\
\hline 56 & 41VV186 & 0 & & & & & Collins 1969 \\
\hline 57 & 41VV187 & 0 & & 0 & & & Alexander 1970 \\
\hline 58 & 41VV189 & 0 & & 0 & & & Epstein 1963 \\
\hline 59 & 41VV213 & 0 & 0 & 0 & & & Word and Douglas 1970 \\
\hline 60 & 41VV215 & 0 & 0 & 0 & & & Nunley et al. 1965 \\
\hline 61 & $41 \mathrm{VV} 216$ & & 0 & 0 & & & Nunley et al. 1965 \\
\hline 62 & 41VV218 & & 2152 & & & & Dibble 1968 \\
\hline 63 & $41 \mathrm{VV} 260$ & & 0 & 0 & & 0 & Greer 1968 \\
\hline 64 & $41 \mathrm{VV74}$ & 0 & & 0 & & & Parsons 1965 \\
\hline 65 & 41VV82 & 0 & 0 & 0 & & & Nunley et al. 1965 \\
\hline 66 & 41VV87 & & & 0 & & $x$ & Collins 1969 \\
\hline 67 & 41WM118 & & & 1 & & 1 & Eddy 1973 \\
\hline 68 & 41WM130 & & & 4 & 1 & 1 & Bond 1978 \\
\hline 69 & 41WM2 & $x$ & & $x$ & & & Campbell 1947 \\
\hline 70 & 41WM230 & & 0 & 0 & 1 & 0 & Prewitt 1974 \\
\hline 71 & 41WM267 & & 0 & 0 & & & Peter et al. 1982 \\
\hline 72 & 41WM437 & & & & & $x$ & Prewitt 1982 \\
\hline 73 & 41WM56 & & 0 & 0 & 0 & & Peter et al. 1982 \\
\hline 74 & 41WM815 & & 0 & & & & Brownlow 2003 \\
\hline 75 & 41WN88 & & & & & 1 & Nickels 2000 \\
\hline 76 & 41ZV155 & & & & 1 & 2 & Inman et al. 1998 \\
\hline 77 & 41ZV202 & & & & 0 & & This Report \\
\hline
\end{tabular}


Table 8-3. Component Summary Statistics for Bison Presence Data in Table 8-2

\begin{tabular}{|l|c|c|c|c|c|c|}
\hline Time Period & Components & $\begin{array}{c}\text { Bison } \\
\text { Present }\end{array}$ & $\begin{array}{c}\text { Percentage } \\
\text { with Bison }\end{array}$ & $\begin{array}{c}\text { NISP Data } \\
\text { Present }\end{array}$ & $\begin{array}{c}\text { Total Bison } \\
\text { NISP }\end{array}$ & $\begin{array}{c}\text { Average } \\
\text { Component NISP }\end{array}$ \\
\hline $\begin{array}{l}\text { Initial Late } \\
\text { Archaic }\end{array}$ & 18 & 7 & 38.9 & 4 & 24 & 6 \\
\hline $\begin{array}{l}\text { Middle Late } \\
\text { Archaic }\end{array}$ & 20 & 7 & 35 & 7 & 2218 & 316.9 \\
\hline $\begin{array}{l}\text { Terminal Late } \\
\text { Archaic }\end{array}$ & 30 & 6 & 20 & 3 & 22 & 7.3 \\
\hline $\begin{array}{l}\text { Initial Late } \\
\text { Prehistoric }\end{array}$ & 20 & 8 & 40 & 8 & 23 & 2.9 \\
\hline $\begin{array}{l}\text { Terminal Late } \\
\text { Prehistoric }\end{array}$ & 53 & 44 & 83 & 36 & 17057 & 473.8 \\
\hline
\end{tabular}

Figure 8-2 through 8-6 show bison distributional data for each of the five periods within the study area. For discussion purposes, we have divided the study area into four regions. In the subsequent discussion, we will refer to these areas as the northwest, southwest, northeast, and southeast regions (see Figures 8-2 through 8-6). The northwest cluster encompasses some of the Edwards Plateau and the southern Rolling Plains. The southwest cluster is limited primarily to sites within Val Verde County, many

Differences in the number of bison present on sites through time are also clearly visible in the bison NISP statistics in Table 8-3. The average bison NISP for the Initial Late Archaic components is six. This increases to about 317 for the Middle Late Archaic and then declines to around seven and three items for the Terminal Late Archaic and the Initial Late Prehistoric, respectively. For the 36 Terminal Late Prehistoric components with NISP values, just over 17,000 bison specimens were recorded, producing an average of about 475 items per component. This is a dramatic jump, especially over the average of about three bison specimens per Initial Late Prehistoric period. The high Terminal Late Prehistoric average, however, is somewhat misleading. Seven of the 36 Terminal Late Prehistoric components with NISP data account for $98 \%$ of the 17,057 pieces of bison (Table 8-2). In addition, note that $50 \%$ of the 36 cases have a bison NISP of less than 10. As a group, Terminal Late Prehistoric components differ from earlier periods primarily in that there are a handful of cases with extremely high bison NISP counts. However, the most frequently occurring value during all periods, including for the Terminal Late Prehistoric, is a bison NISP value of 1 (Table 8-2).

Clearly, additional component data will change the relative frequency patterns shown above. The 181 components initially investigated within Central and South Texas represented an extensive, though not exhaustive, search of data recovery and testing excavations. Patterns for periods with small sample sizes, such as the Initial Late Archaic, could be significantly altered by additional components. As we will show below, it is also the case that not all periods are well represented spatially across the study area. However, additions to the component data will not affect the core observation that given the temporal resolution of the archeological data sets, bison appear to be consistently present within the study area over the last 4,000 years. In addition, to the degree that relative frequency of bison present on archeological sites is an indicator of availability in the natural environment, bison are declining throughout the Late Archaic and increasing throughout the Late Prehistoric. of which are along the Rio Grand. The southeastern cluster consists of sites along the Texas Coast, as well as those in the Gulf Prairies and Marshes and the eastern portion of the South Texas Plains. Finally, the northwest cluster includes sites associated with the Edwards Plateau escarpment, as well as the Blackland Prairie, Post-Oak Savannah, and portions of the South Texas Plains. This "northeast" cluster includes sites located outside of the geographical northeast, including 41ZV202. However, our concern is less with the geographic accuracy of the characterization, and more with isolating roughly similar elevation and vegetation regimes.

For the Initial Late Archaic (see Figure 8-2), bison are noticeably absent (shown in red) from nine sites in the southwestern section (Val Verde County, see Appendix C) and are present (shown in yellow) in the northeast and southeast sections of the study area. The data set contains only a single Initial Late Archaic site in the northwest section during this time period, and that site contains bison. Bison are present in three of the four areas $(75 \%)$ with Initial Late Archaic sites. The Middle Late Archaic distribution (Figure 8-3) is similar, with bison present on only one of seven sites in the southwest (14\%). A single site, this time lacking bison, is present in the northwest. Bison are well represented $(54.5 \%)$ on the 11 Middle Late Archaic sites in the eastern portion of the study area. As with the preceding period, three of the four areas $(75 \%)$ that have Middle Late Archaic sites have bison present. In the following Terminal Late Archaic (Figure $8-4$ ), bison are noticeably more restricted, being present in only one of the four areas (25\%) with Terminal Late Archaic sites. A single Terminal Late Archaic site, lacking bison, is present in the southwest coastal area. Bison are only present in the northeast at a rate of $43 \%$ (6 of 14 sites). They are noticeably absent from the southwest, which has 12 sites with Terminal Late Archaic material, and in the northwest, where three sites, all of which lack bison during this period, are present. Figure 8-5 shows the Initial Late Prehistoric distribution. While there are no Initial Late Prehistoric sites in the southwestern region, bison are present in all other areas. In the northwest, bison are present on one of the two Initial Late Prehistoric sites. In the southeast, they are present 


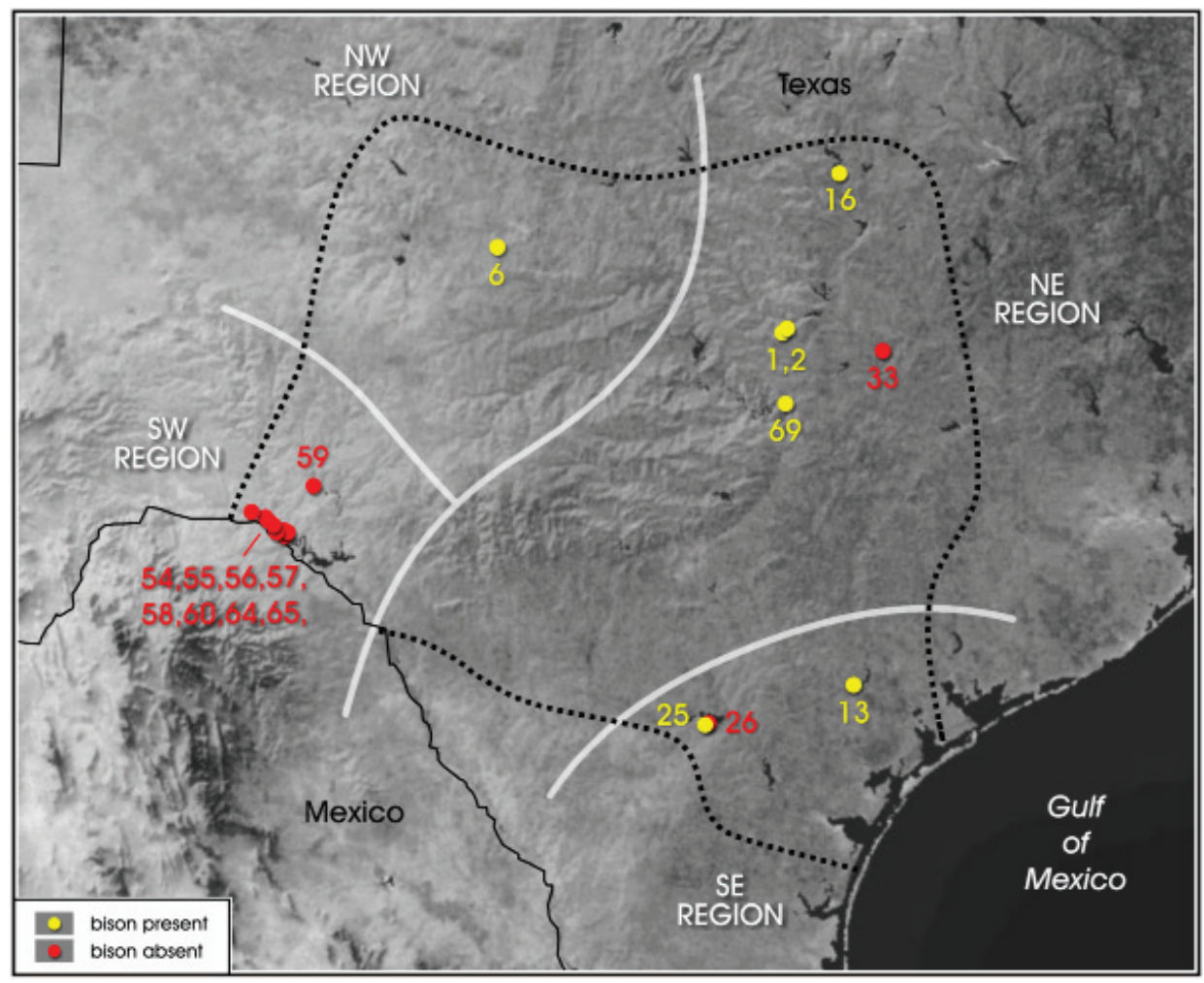

Figure 8-2. Bison presence (yellow) and absence (red) on Initial Late Archaic components (see Table 8-2).

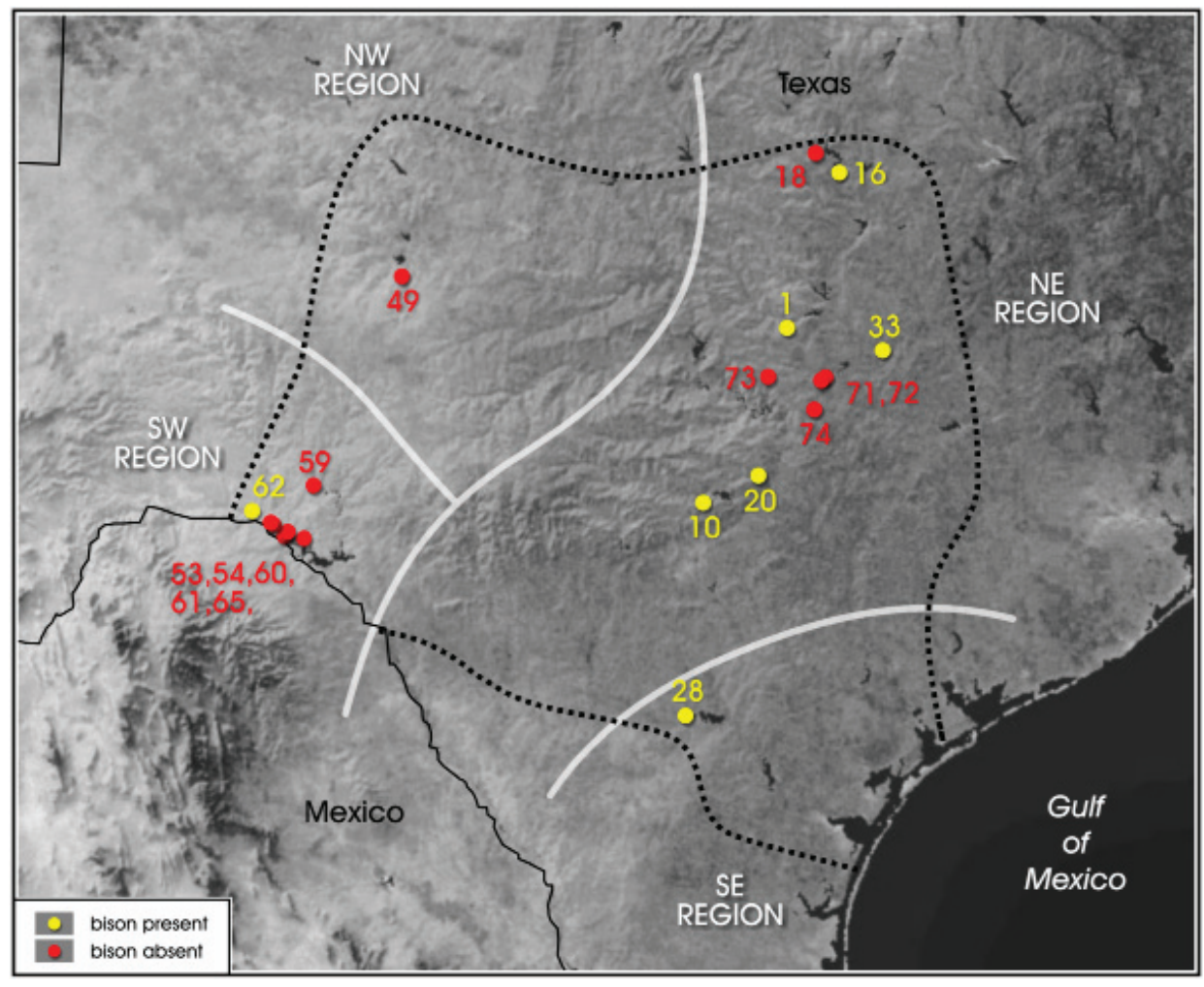

Figure 8-3. Bison presence (yellow) and absence (red) on Middle Late Archaic components (see Table 8-2). 


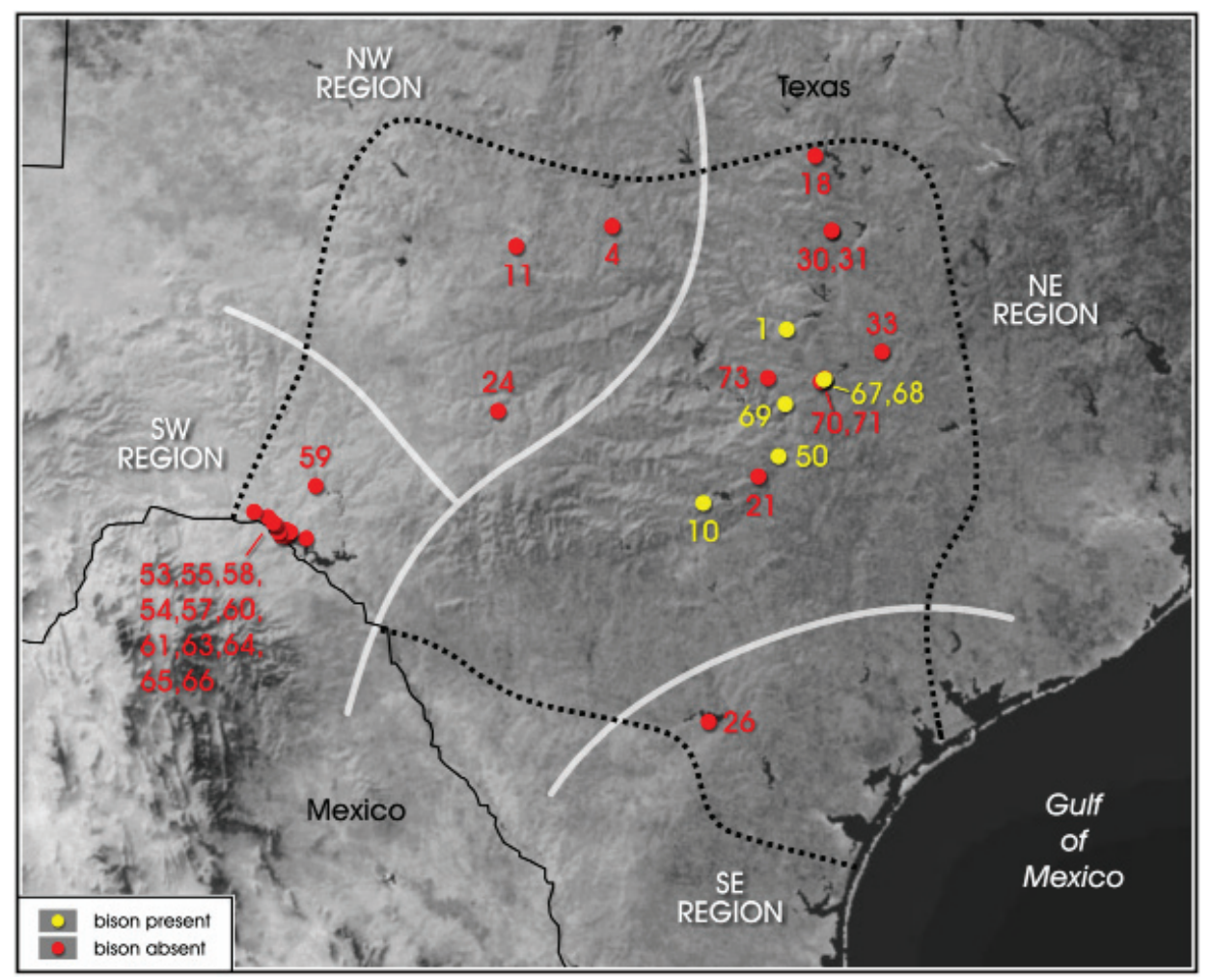

Figure 8-4. Bison presence (yellow) and absence (red) on Terminal Late Archaic components (see Table 8-2).

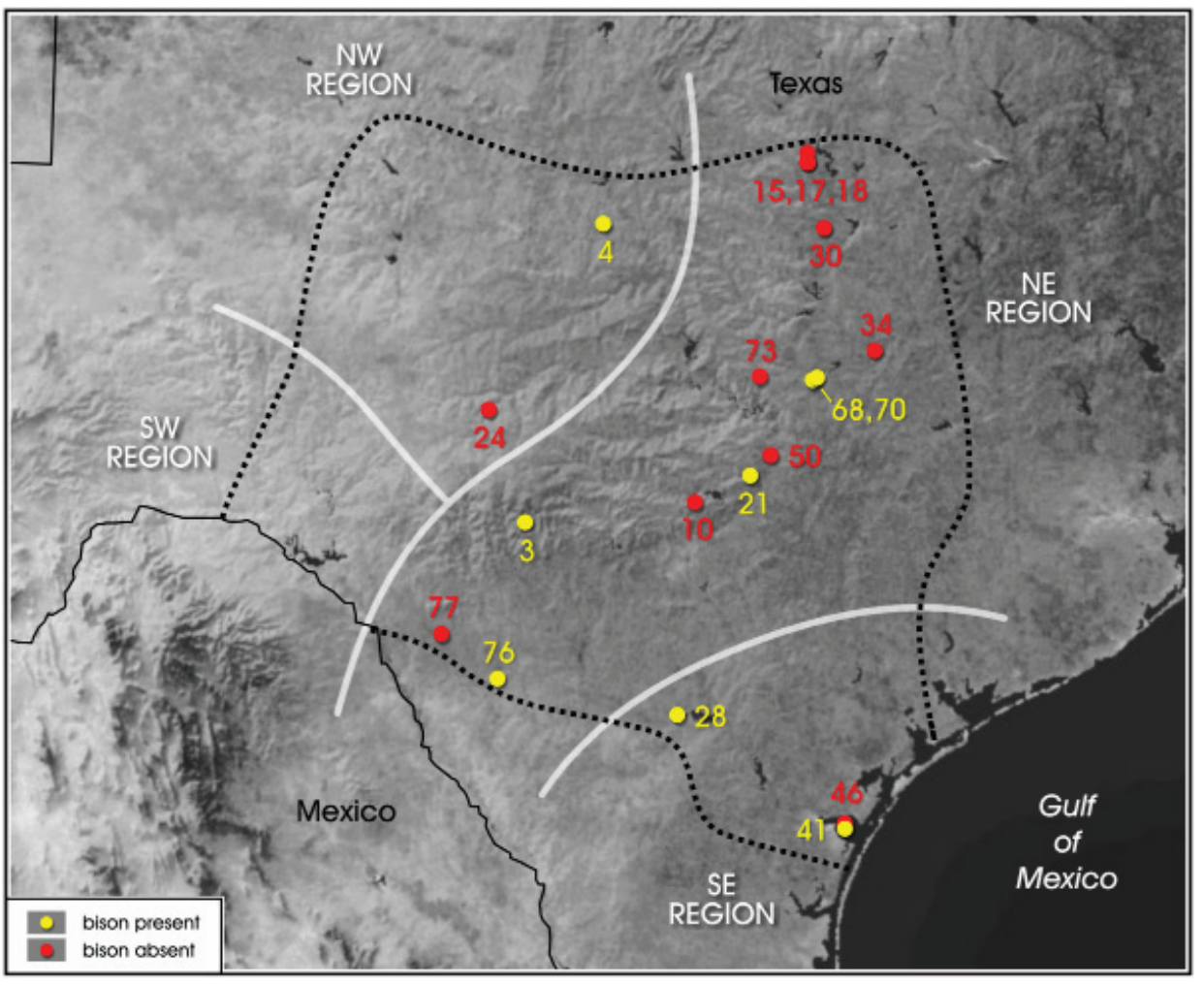

Figure 8-5. Bison presence (yellow) and absence (red) on Initial Late Prehistoric components (see Table 8-2). 
on two of three sites, and in the northeast, they are present on five of 15 sites. Finally, Figure 8-6 shows the near ubiquity of bison on Terminal Late Prehistoric sites. Like the earlier Initial Late Prehistoric period, all regions with sites present have bison present.

\section{Summary and Discussion}

As noted previously, to develop expectations for shifts in subsistence, mobility, and technology, we need to be able to assess patterns of availability in bison, a high ranked resource. We had anticipated, based on previous research, that bison would be absent during the Initial Late Prehistoric, providing a distinct contrast to earlier and later periods. However, the data presented above suggest that bison were always available in much of Central and South Texas from the Initial Late Archaic through the Terminal Late Prehistoric. Because bison were always present, it is necessary to develop measures of changing availability of this resource through time. That is, expectations for subsistence shifts, changes in mobility, and shifts in technology are dramatically different under scenarios where bison are increasing in frequency rather than decreasing in frequency.

Unfortunately, the relative frequency of sites with bison present during a given time period, distributional data on bison, and
NISP values presented above are not directly informing us about bison availability in the environment. Disregarding issues of sampling, analytical consistency, and preservation, for the patterns discussed above to directly reflect bison availability in the natural environment, several parameters need to remain constant. First, hunters and gatherers must encounter bison at a rate consistent with their true environmental density. They must pursue bison whenever they are encountered and they must have a consistent success rate in their pursuit of these animals. Once they acquire bison, they must use roughly similar butchering, transport, processing, and discard tactics (see Dickens and Wiederhold 2003), and occupation lengths for components must be roughly equivalent between periods. Any change in any of these parameters will affect the relationship between bison availability in the natural environment and the relative frequency of bison on sites, NISP values, and distributional data.

As several of these elements did not remain constant over the 3,500 years represented by the Late Archaic and Late Prehistoric, the patterns documented above are not an adequate measure of bison abundance. There are, for example, dramatic shifts in hunting weapons and processing technology (see Brown et al. 1982: 59-63; Collins 2004; Dering 2008), and probably in associated hunting tactics. Population levels certainly shifted over this time, influencing

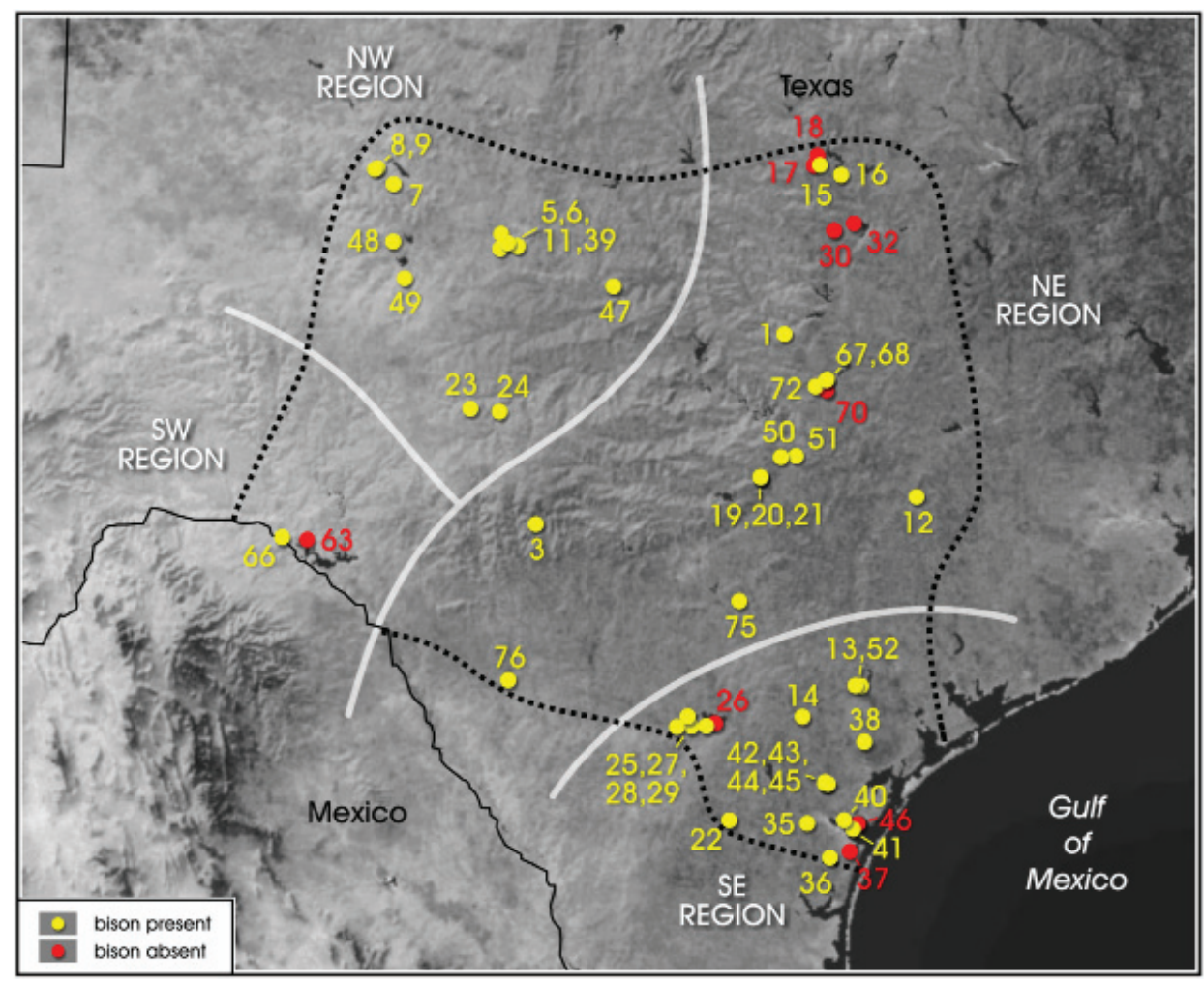

Figure 8-6. Bison presence (yellow) and absence (red) on Terminal Late Prehistoric components (see Table 8-2). 
mobility levels (see Johnson and Hard 2008) and levels of reoccupation. It is likely, in fact, that the magnitude of the bison NISP shifts between the Initial and Terminal Late Prehistoric shown above (Table 8-3), and the appearance of a small number of components with extremely high NISP bison counts in the Terminal Late Prehistoric (Table 8-2), signals a change in hunting organization, processing, and transport strategies (see Quigg 1997). Unfortunately, because faunal assemblages during some periods in Texas are extensively fragmented, perhaps in association with grease and marrow extraction, detailed skeletal element frequencies that might provide clues to organizational or transport strategies (see e.g., Emerson 1990, 1993; Speth and Rautman 2003) are seldom available. While we certainly do not dismiss the patterns shown above, they cannot be used to directly monitor changes in the availability of bison in the natural environment. They do not provide a measure that is independent of the archeological record. Below, we consider additional data sets, including paleoclimate data summarized in Chapter 2 and historic accounts of bison within the state, in order to develop a more independent, though admittedly indirect, measure of bison availability.

\section{Patterns of Bison Abundance in Central and South Texas: Paleoclimate Data and Historic Accounts}

In this section, we initially review a variety of paleoenvironmental data discussed in Chapter 2. Our focus is on changes in grasslands during the Late Archaic and Late Prehistoric periods. While the archeological data summarized above demonstrated that bison were present throughout the period of interest, our goal in this section is to gather information on bison abundance and understand factors that may have influenced shifts in that density in Texas. We conclude that although bison were present throughout much of Central and South Texas for all periods of concern here, there does appear to be fluctuations in their densities, at least as can be inferred from historic accounts and indirectly through fluctuations in grasslands ${ }^{(\text {note } 6)}$.

\section{Paleoclimate Patterns, Grasslands, and Bison Abundance}

Though certainly present in woodland settings, historically the core range of bison (Bison bison) extended from Alberta, Canada in the north down to north-central Texas in the south, a range consistent with the approximate limits of the Great Plains grassland (McDonald 1981:104). Not surprising given that distribution, bison are primarily grazers with grasses, and to a lesser degree sedges, comprising over $90 \%$ of their diet (Coppedge et al. 1998; Peden 1976; Peden et al.
1974). While other factors (e.g., water availability, levels of predation, snow depth, extreme heat, etc.) will influence bison abundance and mobility, there should be a strong relationship between the quantity and quality of grass and bison abundance (see Emerson 1990). On the Great Plains, several factors interact to produce grass of varying density and quality for bison consumption, including soil types (e.g., Epstein et al. 1997), fire frequency, and levels of grazing pressure (see Knapp et al. 1999). However, different mixes of temperature and rainfall are the primary determinate of cool season $\left(\mathrm{C}_{3}\right)$ and warm season $\left(\mathrm{C}_{4}\right)$ grass productivity (see Bamforth 1988; Brown 1993; Epstein et al. 1997; Paruelo and Lauenroth 1996; Teeri and Stowe 1976). Shifts in forage availability should be tied to shifts in bison abundance mediated primarily through shifts in mobility. Other things being equal, when forage availability or quality decline, we expect that the scale of bison mobility will increase and herd size will decrease. When forage availability and quality increase, bison mobility should be lower and larger group sizes are probable (see Bailey et al. 1996; Bamforth 1988: 44-52; Coppock et al. 1983; Hanley 1982).

Figure 8-7 contrasts grass pollen percentages and stable carbon isotope values from sediment over the last 10,000 years. We presented and discussed details of these long-term paleoenvironmental data sets in Chapter 2 (see Figures 2-6, $2-7$, and 2-8). The two stable carbon isotope data sets come from the Medina River in southern Bexar County and Hall's cave in Kerr County. The bog pollen data come from Boriak, Weakly, and Patschke bogs, located in Lee and Leon counties (see Chapter 2; Figure 2-6). The fluctuations in grass pollen percentage are, in effect, tracking fluctuations in $\mathrm{C}_{4}$ warm season grasses as $\mathrm{C}_{3}$ grasses within Texas are minimal (see Epstein et al. 1997; Sims et al 1978; Teeri and Stowe 1976). The primary contributor to fluctuations in $\mathrm{C}_{4}$ isotopic values in the soils data are also $\mathrm{C}_{4}$ grasses.

We are primarily concerned with the shape of the overall curves in Figure 8-7 rather than the absolute values of the stable carbon isotopes or the grass pollen percentages. The absolute values, especially in the case of the stable carbon isotope data sets, are certainly reflecting local conditions. However, the general shapes of all four curves are potentially responding to regional changes in climate. While differing in detail and having extensive variation, both of the pollen curves show a general decline in grasslands throughout the Late Archaic. That decline accelerates in the Late Prehistoric (Figure 8-7). The two carbon isotope curves are also variable. However, they both seem to show an increase in grass in the initial portion of the Late Archaic, with a decline in grass in the Terminal Late Archaic. That decline accelerates in the Late Prehistoric, at least in the Medina River sequence (Figure 8-7). While we need both more detailed and better 


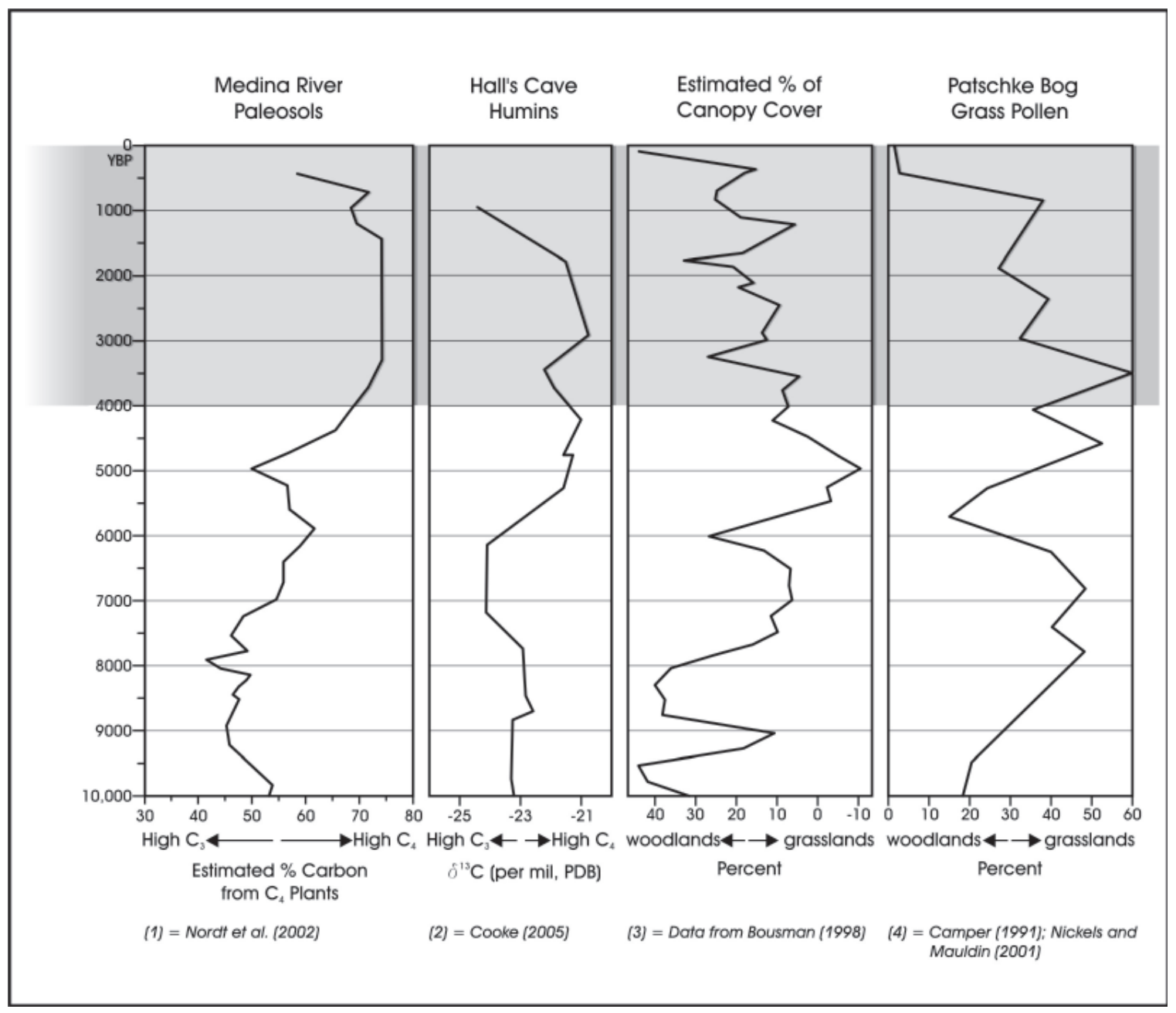

Figure 8-7. Comparison of graphs of bog pollen data and stable carbon isotope variation at selected sites over the past 10,000 years.

dated paleoclimate data to fully document these patterns, if these curves are responding to large scale climate trends, then following the Initial Late Archaic, grasslands, and by extension bison, seem to have declined through the Terminal Late Archaic. The decreased frequency of bison suggested here is consistent with the declining frequency of bison on archeological sites from these periods (see Table 8-3). During the Late Prehistoric, the decline in bison densities suggested by the Figure 8-7 data increases and continues throughout the historic period. This pattern is not consistent with the archeological data, which show an increased frequency of bison presence on components that date to the Initial Late Prehistoric and a dramatic jump in bison presence on components dating to the Terminal Late Prehistoric (see Table 8-3).

Figure 8-8 uses the PDSI tree-ring data discussed in Chapter 2 to further explore the implications of changing climate patterns in the Late Prehistoric period on bison abundance.
The drought data stretch back to $\mathrm{AD} 1000$ and the figure plots values from AD 1000 through 1800 with data grouped at 25 years and the mean value used as the plotting point (see Figure 2-10). The top line graph presents the PDSI values. A 25 year block dominated by normal moisture patterns would have values between 0.5 and -0.5 . PDSI values that exceed 0.5 indicate periods of increased moisture, while values below -0.5 indicate periods of increased drought. The bottom line graph measures year to year variability (see Chapter 2, Figure 2-10, bottom). Higher values are measuring greater year to year variability in PDSI during a 25 year segment.

While the short-term nature and high temporal precision of the Figure 8-8 data are far superior to the data sets used in Figure 8-7, there are a number of complications in using this drought data in this context. As noted in Chapter 2, the spatial scale of these data is not well defined. In addition, unlike the pollen or stable carbon isotope data sets, the interpretation of shifts in the PDSI values (Figure 8-8, top) in terms of shifts in 


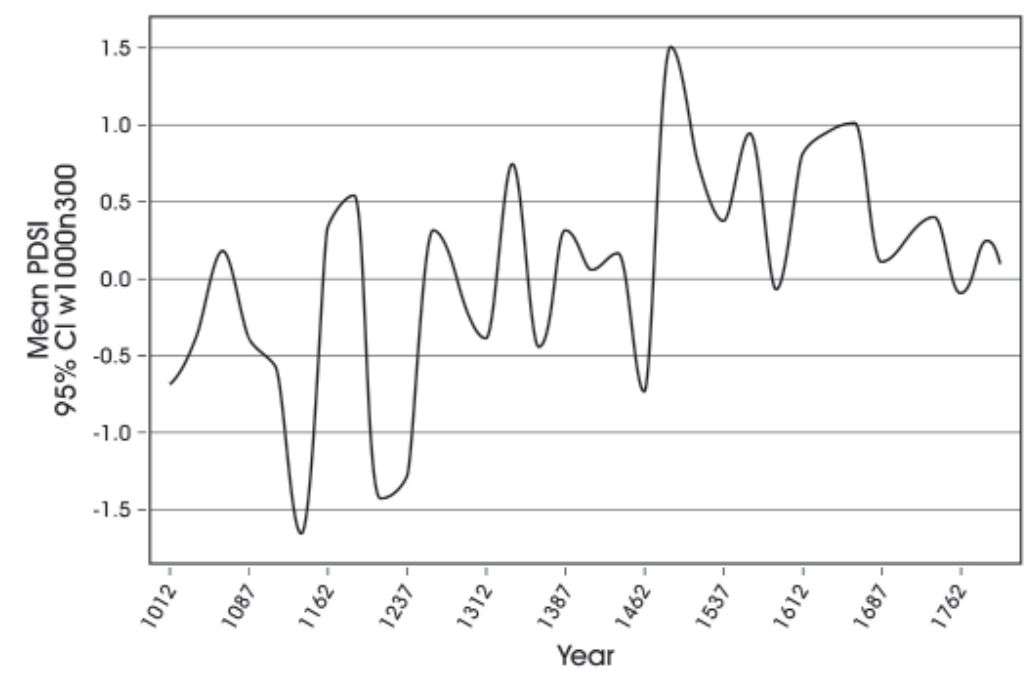

as a semi-arid landscape, drought would reduce grasslands. The same level of drought at the same location could, in fact, increase grasslands under one set of prior conditions and decrease grasslands under another set of conditions.

The top line graph in Figure 8-8 shows that while there is substantial variation in PDSI values between 25 year periods, the beginning of the sequence (ca. AD 1000-1250) is generally dry, with three 25 year sequences (AD 1126-1150; 12011225 ; 1226-1250) being extremely dry. Moisture levels increased after AD 1250, culminating in an extremely moist period from AD 1476-1500. Moisture levels remained close to, or slightly above normal into the 1800 s. Interpretations associated with these trends in terms of bison availability are ambiguous. However, if increased moisture is associated with increased forage, then throughout the portion of the Late Prehistoric for which we have data, (AD 1000-1550) grasslands may be improving, suggesting an expansion of bison ranges. This pattern is consistent with the archeological data for the Late Prehistoric, but is at odds with the long term climate data (Figure 8-7).

Figure 8-8. PDSI values (top) and variability (bottom) at 25 year intervals from $A D 1000$ through $A D 1800$ (PDSI grid point 166).

Finally, reference to Figure 8-8 (bottom) shows two distinct patterns of variability. Between AD 1000 and 1250, year to year shifts in PDSI

grasslands, and by extension changes in bison availability, are not clear. Increased PDSI values will produce an increase in grasslands, and by extension bison, under some conditions. Researchers working in a number of grassland settings have shown that late spring and summer precipitation events produce pulses of warm season grass that increase both the nutritional value of forage and the digestibility of grass for herbivores (see Hart et al. 1983; Razui and Dobrenz 1970; Sala and Lauenroth 1982). In some cases, then, higher PDSI values should produce increased forage. However, this is not always going to be the case. For example, a moderate increase in drought in some vegetation settings, such as woodlands, may increase grasslands, while in other settings, such values for a given 25 year period averages 1.55 . That is, at 25 year increments, the summed absolute difference in PDSI values between one year and the next over the 250 years (AD 1000-1250) averages 1.55. From 1251 through the remainder of the Late Prehistoric, there is a substantial increase in variability. During the Terminal Late Prehistoric, the absolute difference jumps to 2.3. Critically, the high year-to-year variation should have resulted in dramatic fluctuations in forage production, possibly producing higher levels of bison mobility and variable herd sizes during some years and clusters of bison with reduced mobility during others. While historic records are spotty, that high variability is reflected in those records. 


\section{Mobility and Fluctuations of Bison in Historic Accounts}

There are data from historic accounts that suggest that bison populations fluctuated in Texas along the lines suggested in Figure $8-8$ (bottom), at least during the $16^{\text {th }}, 17^{\text {th, }}$ and $18^{\text {th }}$ centuries. Bison sightings during these centuries are highly variable across the state, as well as through time.

Cabeza de Vaca provides the earliest historic account of bison in Texas. De Vaca and several comrades spent late 1528 until sometime in 1535 with indigenous groups located in coastal and southern Texas (Cabeza de Vaca 1555). Surprisingly De Vaca (1555) notes only "three or four" sightings of bison. If accurate, this account suggests that bison were not frequent during this seven-year period in the southern portion of the state. Shortly after this account, Spanish forces associated with De Soto's expedition entered Texas, probably late in 1541, after wandering through much of the Southeast (see Duncan 1997; Young and Hoffman 1999). While the length of time spent within Texas is probably minimal, there is no mention of bison in the De Soto chronicles. In that same year (1541), Spanish forces associated with Franciso Vasquez de Coronado noted bison after several days travel to the east and north of the Pecos River, in what is probably the panhandle region of Texas. Numbers of animals noted seem to increase the longer the journey continued, with high densities of bison noted to the north of the state (Hammond and Rey 1940; Winship 1904).

Detailed accounts of bison availability in Texas during the late 1600s come from recent summaries of Spanish expeditions onto the Edward's Plateau (see Wade 1998; 2003). One of the data sets compiled by Wade (1998: Appendix E; Wade 2003:152-157) includes both probable camp locations and observations on fauna, including bison, made by the Spanish. The appendix provides detailed route and camp information on ten expeditions to the Plateau conducted between 1675 and 1767, and information on 246 camps used by these expeditions (Wade 1998: Appendix E). Overall, these early expeditions noted bison on only 39 of the 246 camps (ca. $15 \%$ ). There is also extreme year-to-year variability in bison observations. In both 1683 and 1691, the Spanish noted bison on roughly $40 \%$ of their camps. Four of the remaining eight years also note bison as present, though the frequency is about $10 \%$ in one year, and below $5 \%$ in the three other years. Finally, in four of the 10 years, members of these expeditions did not mention bison.

At roughly the same time frame as some of these Spanish observations (1685-1687), French forces at Fort Saint Louis near the Texas coast frequently mention bison, including herds that numbered in the thousands (see Parkman 1883: 216-233; Wade 2003:156). In addition, in 1691 "great numbers" of bison were reported for Bexar, Medina, Wilson, Guadalupe, and Gonzales counties in southern Texas (see Weniger 1984:178). In the 1700s and into the early 1800 s, a number of accounts of bison in Texas are available that suggest the animals were common, especially in the westcentral portion of the state (see Doughty 1983; Folmer 1940; Newcomb 1961: 85-99, 112-117).

These historic accounts suggest that bison availability within the state was highly variable through time and across space. It is probable that at least during some short periods, bison were completely absent from much of Central and South Texas, and Wade's Spanish camp summary data (1998: Appendix E) suggest significant seasonal shifts in availability when they were present. Of 36 camp locations occupied during the winter months of December and January, the Spanish observed bison at only three locations $(8.3 \%)$. For the months of February, March, and April, there are 87 observations, 10 of which note bison (11.5\%). There are 105 observations during the months of May and June, with bison noted in 26 instances (24.8\%). Interestingly, while the number of observations are small $(n=28)$, the late summer months of July and August do not have recordings of bison. We have no fall observations. Bison populations, at least in this portion of South and Central Texas in the late 1600s and into the 1700s, probably declined in the late summer, with a gradual increase in numbers throughout the spring. Peak populations were present in the early summer months.

A variety of factors could account for these apparent fluctuations in bison sightings in the historic literature. Yet, the seasonal and yearly patterns of bison availability discussed above are consistent both with seasonal patterns in $\mathrm{C}_{4}$ grassland production in Texas as well as the post $\mathrm{AD}$ 1250 PDSI variability patterns shown in Figure 8-8 (bottom). These mobility based fluctuations in bison numbers are also consistent with variable forage production, with higher production occurring in the summer months. These fluctuations, in turn, should have resulted in varying periods of availability of bison in time and across space. During years of low production, or in regions of low production, it is probable that bison consumed increased quantities of low-quality forage, increased their overall mobility, and were positioned on the landscape in smaller sized herds. Conversely, during years of high production, or in areas of high production, it is likely that herd size increased, bison diet focused on higher quality forage, and mobility was reduced (see Bailey et al. 1996; Bamforth 1988: 44-52; Coppock et al. 1983; Senft et al. 1987). Finally, note that these anticipated responses are likely to be exacerbated when bison populations are at or near carrying capacity, a condition that may have been common 
given that Central and South Texas was, in effect, the southern range of bison distributions (see McDonald 1981:104).

\section{Summary and Implications}

With average weights of close to $600 \mathrm{~kg}$, bison would have been a high-ranked resource in Texas. As such, fluctuations in the availability of that resource, including periods of absence from the state (see Dillehay 1974; Huebner 1991), should have implications for shifts in diet breadth, as well as for changes in technology and mobility. Our review of bison presence/ absence on Late Archaic and Late Prehistoric archeological sites from a large area of Central and South Texas showed that, at least at the temporal scale considered, bison were never absent during any period. The data showed that bison were less common on archeological sties through the Late Archaic and were increasingly present on sites dating to the Late Prehistoric. However, in order to assume that there is a consistent relationship between the presence or absence of bison on an archeological site, and shifts in the availability of these high return animals in the natural environment, we must assume that the cultural systems have not changed significantly through time. At a minimum, hunting technology and organization, success rates, butchering and processing methods, discard tactics, and occupation length must remain roughly equivalent though time. While useful for establishing the presence of bison at various points in time, we cannot use these archeological patterns to directly monitor changes in the availability of bison in the natural environment. That is, they do not provide a measure that is independent of the archeological record.

In an effort to develop that independent measure of bison availability in the natural environment, we used several different data sets. Our review of several long-term data sets from different regions of Central and South Texas suggested that grasslands were probably gradually declining from the Initial Late Archaic through the Terminal Late Archaic. That decline seems to have accelerated in the Late Prehistoric and into the Historic Period. Tree-ring based PDSI values provide a short-term perspective on both forage production and variability in that production, at least for the close of the Initial Late Prehistoric and through the Terminal Late Prehistoric and Historic periods. While difficult to unambiguously interpret in terms of grass production, the PDSI values from just to the north of 41ZV202 do suggest a dry period at the end of the Initial Late Prehistoric (ca. AD 1000-1250). A period of increased moisture in the Terminal Late Prehistoric (AD 1250-1550) follows the dry period, with conditions remaining roughly the same throughout the following Historic period. Information on variability in PDSI values suggests that year to year fluctuations in moisture were minimal during the Initial Late Prehistoric.
These fluctuations, however, dramatically increased after $\mathrm{AD}$ 1250. This dramatically higher moisture variability would have produced significant differences in forage quantity and quality from year to year over a given 25-year period.

If the climate and vegetation reconstruction summarized here are close to accurate, grasslands are, in general, shrinking in size during much of the Late Archaic and through the Late Prehistoric period. One outcome of the shrinking grasslands would have been an increasingly more patchy spatial distribution of forage across the landscape and reduced overall forage. While reduced forage over the long term would reduce the number of bison, this smaller number of animals would be concentrated in fewer and fewer patches on the landscape. Late in the sequence, the PDSI data suggest increased temporal fluctuations (Figure 8-8, Bottom). These fluctuations should have affected short-term grass production and, by extension, bison distribution on the landscape. During some years, some locations would have received high rainfall throughout the year producing consistent forage. During other years, rainfall would have been spotty at these locations, and forage would have been quickly exhausted. As such, the presence of bison in any one area was increasingly unpredictable in time. Overall, as grasslands shrunk, the distribution of bison would have become more predictable in space, but less predictable in time (see also Kemp 2008). A short review of historic observations by Spanish and French explorers suggested that after AD 1550, bison populations seem to have varied seasonally and yearly. Examples of significant yearly differences in bison, as well as dramatic spatial differences in numbers of animals observed within the same year, are consistent with the high levels of year to year moisture suggested by the PDSI tree-ring variability late in the sequence.

The climate data suggest, then, that bison are probably declining in numbers in the natural environment following the Initial Late Archaic. That decline accelerated in the Initial Late Prehistoric and through the Terminal Late Prehistoric. In the previous chapter, we used aspects of prey models to suggest that when hunters and gatherers face declines in high ranked resources, such as bison, they have a number of possible responses. What response they initiate should depend, in part, on the extant resource structure in the environment, as well as their existing subsistence, mobility, and technology mix. At present, we do not have sufficient data on past plant and animal densities, paleoenvironmental conditions, return rates and changes in those rates given various processing technologies, and technological costs to allow for specific, detailed modeling of responses in this case. However, we can make some general statements regarding responses that hunters and gatherers might initiate as grasslands declined and became patchier through time, and as bison populations 
probably followed suit. First, under conditions of declining high ranked resources, hunters and gatherers should broaden their diet to include lower-ranked resources with lower search costs but higher processing costs (e.g., mussels, nuts, small seeds). They may also develop or implement new technologies that are more expensive to produce and maintain (e.g., ceramics rather than baskets) in an attempt to reduce the processing (handling) time or improve the nutritional quality of lower-ranked resources in the diet. They may shift or reorganize their mobility or search strategies, with specialized task groups targeting shrinking grasslands in an attempt to increase encounter rates with bison. They may shift to technologies that are more expensive to produce and maintain (e.g., bow and arrow), but which may increase the kill rates of more profitable animals given shifts in animal density or prey type. They may initiate all of these changes, as well as several others, in the context of maximizing the average return rate of their overall diet. We cannot predict, at present, what mix of responses would occur in a given situation. However, note that all of these suggested responses have a common element. They all involve increased costs. It is in the context of reduced access to high-ranked resources that increasing investment in these areas makes sense.

For example, Binford $(1977,1978,1979)$ reports that among the Nunamiut, over $70 \%$ of the yearly supply of meat is gathered during two brief periods that correspond to the spring and fall migrations of highly ranked caribou through mountain passes. In preparation for those migrations, hunters invest significant time and effort in acquiring materials, repairing, stocking and caching gear, and in producing highly reliable tools that have a low potential for failure during the hunt. Upfront preparation, positioning of backup gear, and the over designing of tools are all costly practices, but practices that make sense in terms of the risk of food loss if, for example, a tool failed at a critical point (see discussions in Bleed 1986; Torrence 1983, 1989). Suppose, however, that caribou were suddenly available for six months of the year, rather than two brief periods, or that they were suddenly available year round. What impacts would that have on this costly strategy? Would Nunamiut hunters continue to make a significant investment in over designing tools if caribou were ubiquitous? Increasing investment under these conditions seems unlikely. However, if caribou were suddenly available only once a year during their spring migration, or the number of animals was significantly reduced, then even greater investment in costly hunting strategies and tactics may be expected, along with other higher cost changes. Hunter gatherers should invest in more costly strategies under conditions of declining high return resources, as these resources are encountered less often.

If bison, a high return resource, are declining in density in Central and South Texas over the time frame considered here, we expect Texas hunters and gatherers to increasingly invest in more costly strategies. Those strategies may include a widening of the diet breadth through the addition of smaller animals and especially plants through time. They may include technological changes, with more investment in specialized tools to increase processing efficiency. They may include shifts in the way that they organize mobility in order to increase encounter rates with bison. We will use the foraging theory cost-benefit framework and the assumption that bison are declining throughout the Late Archaic and Late Prehistoric to consider changes in diet breadth, technology, and mobility in subsequent chapters. 



\title{
Chapter 9: Assessing Changes in Diet Breadth
}

\author{
Raymond Mauldin, Jennifer Thompson, and Barbara Meissner
}

In the previous two chapters, we argued that one set of responses to changes in the availability of higher ranked resources could involve changes in what resources are included in the diet. If bison densities gradually declined from the Initial Late Archaic through the Terminal Late Archaic, we would expect both a gradual expansion of the diet, with hunters and gatherers adding lower ranked plants and animals, and intensification on existing dietary items. That dietary expansion and intensification should accelerate in the Late Prehistoric period, especially in the Terminal Late Prehistoric. In this chapter, we assess the utility of this perspective, at least in terms of diet. We develop ways to measure changes in the use of plants and animals and assess temporal patterns for a variety of Late Archaic and Late Prehistoric components. For faunal remains, we suggest that two measures, changes in the number of taxa present in an assemblage and changes in bone fragment weights placed in size classes, can provide gross measures of faunal expansion or contraction. Measuring changes in plant use is more difficult, especially given problems with differential preservation and sampling. While we cannot measure shifts in plant taxa directly, we argue that the overall dependence on plant resources can be estimated by focusing on changes in the frequency of burned rock features and ground stone artifacts. We use data from 41ZV202 to assess some of the underlying assumptions regarding the use of the feature data as a proxy for plants.

The simplest measure of diet breadth in both floral and faunal resources is taxa richness. An increase in the number of species represented signals an increase in diet breadth while a decrease in number of species present signals a narrowing of the diet breadth. Unfortunately, such a measure is likely to be unworkable when we are dealing with archeological plant resources and may be limited when considering faunal remains. Preservation conditions will significantly impact the number of taxa represented in both floral and faunal resources. This is especially the case with floral resources, where recovery from open sites is likely to be limited to plant remains that happen to be burned, as well as hard shell nut resources (e.g., Dering 2003). The relationship between the number of plant taxa serendipitously preserved and recovered from a component and the variety of plant resources used by hunters and gatherers is unclear. The relationship between fluctuations in the range of faunal resources used and their representative preservation and recovery from an archeological component is also impacted by taphonomic processes (see Lyman 1984, 1994), and processing and transport decisions made by prehistoric hunters and gatherers.

\section{Measuring Shifts in Faunal Dependence}

Tomka et al. (2004b) recently used faunal taxa richness to identify some intriguing trends through time in a number of selected Central Texas assemblages dating from the Late Archaic through the Toyah Interval. The results are encouraging. They suggest that broad shifts in huntergatherer subsistence may be tracked through this simple measure. Based on our previous discussions, we expect that during the Initial Late Prehistoric, when bison are probably at their highest density, diets will be relatively narrow. They should increase throughout the Middle and Terminal Archaic and into the Initial Late Prehistoric. During the Terminal Late Prehistoric, we expect bison to undergo a significant decline in numbers and, at the same time, experience increased year to year fluctuations. Diets should expand significantly at that point. Partly in response to the available data and analysis constraints, we propose to use two measures to track changes in diet breadth in faunal material. These are 1) changes in species or taxa richness and 2) changes in the percentages of very large, large, medium/small, and very small body sized prey in bone fragments within assemblages.

To supplement the faunal analysis of the Initial Late Prehistoric material at 41ZV202, we reviewed a large number of archeological reports from the South-Central and Central Texas regions. Our initial selection criteria focused on finding sites that appeared to have an isolated Late Archaic and/or Late Prehistoric component with good integrity. In addition, sites had to have consistent recovery and screening methods and had to have collections and records available for study if needed. In addition, our initial reviews strongly suggested that different faunal analysts had different classification schemes, with some analysts willing to make finer-scale distinctions (e.g., species level) that others were unwilling or unable to make. As our primary goal was to assess what animals were present and what changes occurred across multiple time periods, a consistent classification approach for comparison was required. Consequently, we grouped individual species into 25 different classes that are generally tracking body size. Table 9-1 lists these classes. Ultimately, we relied on a literature review and selected reanalysis of 22 components on 12 archeological sites. These data were supplemented by a review of fauna from two Late Archaic and two Late Prehistoric components at 41KM69. Figure 9-1 presents the location of all sites reviewed for the faunal portion of this analysis. Barbara Meissner of CAR conducted all literature reviews and reanalysis. All data are on file 
Table 9-1. Groups of Faunal Material Considered in Analysis

\begin{tabular}{|c|c|l|}
\hline Group & $\begin{array}{c}\text { Class or } \\
\text { Order }\end{array}$ & \multicolumn{1}{|c|}{ Members/Analytical Groups Selected } \\
\hline 1 & Artiodactyla & Bison, Bovidae, Bison-Sized, Very Large Mammal \\
\hline 2 & Artiodactyla & Deer, Antelope, Sheep/Goat, Deer-Sized \\
\hline 3 & Artiodactyla & Peccary \\
\hline 4 & Carnivora & Canis, Dog-sized \\
\hline 5 & Carnivora & Felidae \\
\hline 6 & Carnivora & $\begin{array}{l}\text { Mustelidae (Skunks, Badgers) and Procyonidae } \\
\text { (Raccoon) }\end{array}$ \\
\hline 7 & Insectivora & Shrews \\
\hline 8 & Lagomorphia & Jackrabbit, Rabbit-Sized \\
\hline 9 & Lagomorphia & Cottontail \\
\hline 10 & Marsupialia & Opossum \\
\hline 11 & Rodentia & Beavers \\
\hline 12 & Rodentia & Gophers, Medium-sized Rodents \\
\hline 13 & Rodentia & Mice, Rats, Voles, Small Rodents \\
\hline 14 & Rodentia & Squirrel \\
\hline 15 & Aves & Turkey, Hawks, Eagles, Large birds \\
\hline 16 & Aves & Other Birds (Ducks, Quail, Medium and Small Birds) \\
\hline 17 & Reptilia & Snakes, Lizards \\
\hline 18 & Testudines & Turtles, Sliders, Tortoise \\
\hline 19 & Anura & Frogs, Toads \\
\hline 20 & Osteichtyes & Fish \\
\hline 21 & Various & Mussels, Oysters \\
\hline 22 & Various & Snails \\
\hline 23 & Various & Other \\
\hline 24 & Artiodactyla & Other, Unclassified \\
\hline 25 & Carnivora & Other, Unclassified \\
\hline
\end{tabular}

at CAR. The analysis of the Late Prehistoric fauna from 41ZV202 is presented in Appendix D.

Assessing increases or decreases in taxa present using the Table 9-1 body size groups is a relatively straightforward process. We expect that during periods of bison scarcity or decline, hunter-gatherer diets will contain a relatively wide range of fauna, with the addition of small-bodied animals that have low search time, high handling costs, and lower overall return rates. When bison are increasing in the region, we expect that hunter-gatherer diets will be narrow, with smaller animals being increasingly excluded from the diet.

Unfortunately, because of the intensive processing of skeletal remains for bone grease or marrow extraction, faunal remains from many archeological sites in Texas are often dominated by unidentified fragments. While this class of remains is frequently thought to have little analytical potential, the majority of the fragments can be classified into broad bodysize categories such as very large (i.e., bison), large (e.g., deer, antelope), medium/small (e.g., coyote, jackrabbit), and very small (e.g., rat, mouse). To the degree that these fragments reflect increased processing of skeletal elements, either for marrow or bone grease, we expect that the fragmentation should be common during periods of dietary stress, as hunters should increasingly use marginal elements of animals when high return resources are not common (see Burger et al. 2005; Cannon 2003; Outram 2001). We propose to use two measures to consider this proposition. The first is the ratio of very large fragment weights, which probably reflect bison, to the number of identified specimens within an assemblage. High ratios suggest that a significant proportion of faunal remains are being broken relative to those that can be identified. A second measure is the relative amount of the fragmented fauna that fall within the very large category. While very large (i.e., bison) and large (e.g., deer) herbivores should be the target of marrow and grease extraction during all periods, this should especially be the case during periods of stress (Burger et al. 2005; Cannon 2003). During periods of bison abundance, such as in the Initial Late Prehistoric, fragmentation because of intentional bone breakage for marrow extraction and/or grease processing should be less common. Fragmentation should increase, with a higher percentage of fragments associated with very large mammals (i.e., bison) throughout the Late Archaic and into the Initial Late Prehistoric. The Terminal Late Prehistoric components should have the highest ratios of fragmentation and the highest percentage of fragments classified as reflecting bison.

\section{Data Acquisition}

Data were gathered through a combination of literature reviews and re-analysis. Table 9-2 lists all sites and components reviewed (see Figure 9-1). Also listed in the table is the overall sample size present for that component, the number and type of faunal groups represented (see Table 9-1), the location of the collections and site records, and references for the site or component. We reviewed excavation notes for each site and assigned components based on radiocarbon dates and temporally diagnostic artifacts using the criteria developed previously (see Table 8-1). Meissner then reviewed each original excavation report and extracted as much data as possible for the component of interest. In the vast majority of cases, additional information was gathered through a review of site records and collections at TARL and CAR. This was especially the case with older excavations. Specific problems encountered included the fact that for some Choke Canyon sites (41LK201 and 41MC296) earlier researchers had removed bison from the collections. In these cases, we noted bison as present with a sample size of one, though in fact several pieces may have been removed. For 


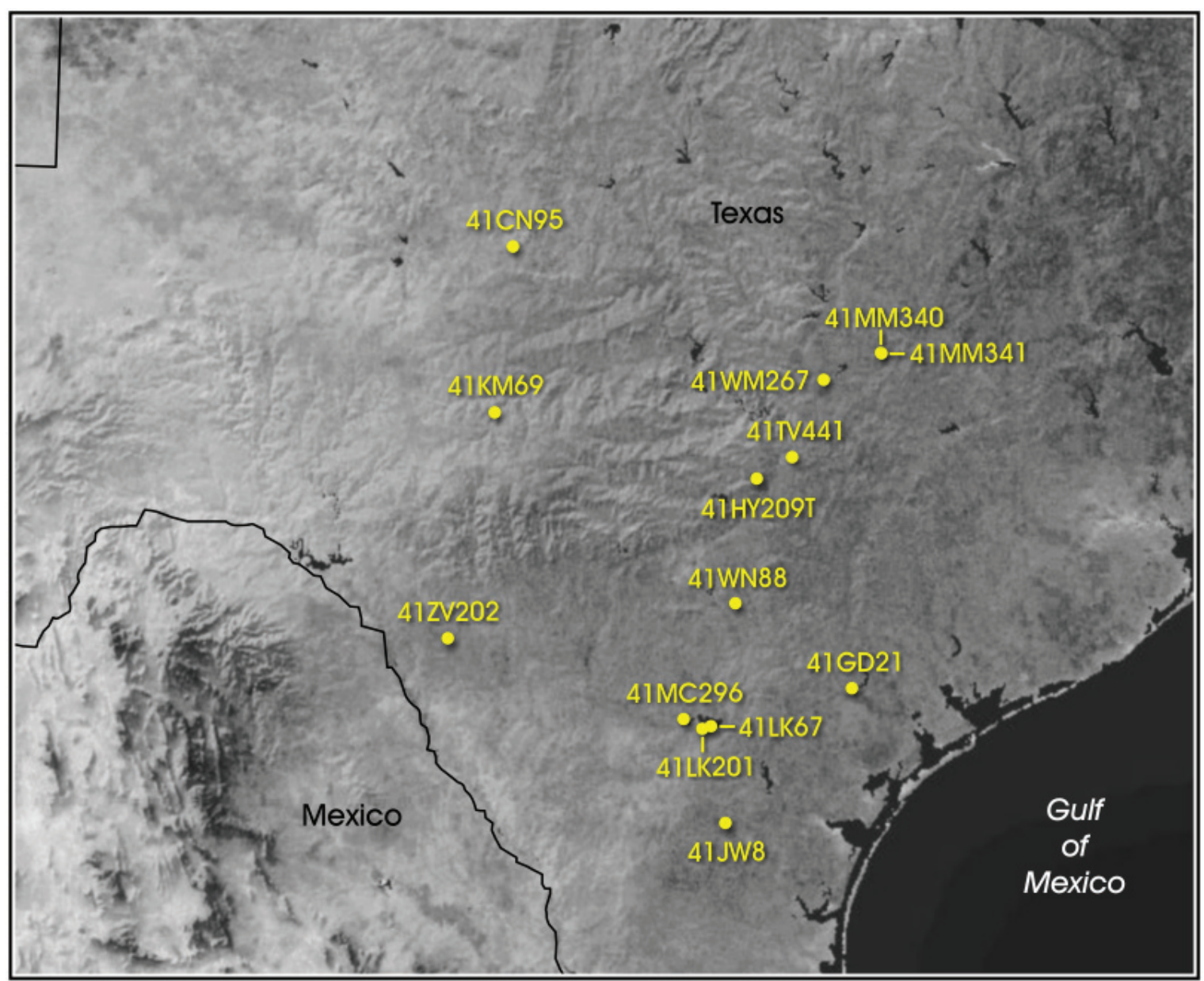

Figure 9-1. 41ZV202 and comparative sites used in fauna and floral investigations.

Table 9-2. Faunal Data Used to Assess Suggested Changes in Diet Breadth

\begin{tabular}{|c|c|c|c|c|c|l|}
\hline Site & Component & $\begin{array}{c}\text { Records/Collection } \\
\text { Location }\end{array}$ & $\begin{array}{c}\text { \# of } \\
\text { Groups }\end{array}$ & $\begin{array}{c}\text { Groups Present } \\
\text { (see Table 9-1) }\end{array}$ & $\begin{array}{c}\text { Sample } \\
\text { Size }\end{array}$ & \multicolumn{1}{|c|}{ Reference/ Reanalysis } \\
\hline 41CN95 & TLA & TARL & 5 & $1,9,13,15,21$ & 124 & Lintz et al. 1993 Treece et al. 1993 \\
\hline 41GD21 & ILA & CAR & 9 & $1,2,9,10,13,15,18,20,24$ & 91 & Meissner 2008 \\
\hline 41HY209T & ILP & TARL & 16 & $\begin{array}{c}1,2,4,8,9,12,13,14,15,16, \\
17,18,20,21,22,24\end{array}$ & 1294 & Ricklis and Collins 1994 \\
\hline 41HY209T & TLA & TARL & 14 & $\begin{array}{r}1,2,4,9,13,14,15,16,17,18, \\
20,21,22,24\end{array}$ & 503 & Ricklis and Collins 1994 \\
\hline 41JW8 & TLP & CAR & 23 & $\begin{array}{c}1,2,3,4,5,6,7,8,9,10,12,13,14, \\
15,16,17,18,19,20,22,23,24,25\end{array}$ & 3027 & Steele 1986; Meissner 2008 \\
\hline 41KM69 & ILP & CAR & 13 & $1,2,6,9,10,13,15,16,17,18,20,23,24$ & 70 & Meissner 2008 \\
\hline 41KM69 & MLA & CAR & $\mathbf{3}$ & $\mathbf{1 , 2 , 2 4}$ & $\mathbf{3}$ & Meissner 2008 \\
\hline 41KM69 & TLA & CAR & $\mathbf{1}$ & $\mathbf{1 5}$ & n/a & Meissner 2008 \\
\hline 41KM69 & TLP & CAR & 9 & $1,2,9,13,15,16,18,20,24$ & 30 & Meissner 2008 \\
\hline 41LK201 & ILA & CAR & 12 & $1,2,4,6,8,9,13,15,16,18,20,24$ & 63 & Meissner 2008 \\
\hline 41LK201 & TLP & CAR & 20 & $\begin{array}{c}1,2,3,4,6,8,9,10,12,13,15, \\
16,17,18,19,2021,23,24,25\end{array}$ & 2532 & Meissner 2008 \\
\hline 41LK67 & ILA & CAR & $\mathbf{2}$ & $\mathbf{2 1 , 2 2}$ & $\mathbf{5 4 9 2}$ & Meissner 2008 \\
\hline
\end{tabular}


Table 9-2. Continued...

\begin{tabular}{|c|c|c|c|c|c|c|}
\hline Site & Component & $\begin{array}{c}\text { Records/Collection } \\
\text { Location }\end{array}$ & $\begin{array}{c}\text { \# of } \\
\text { Groups }\end{array}$ & $\begin{array}{l}\text { Groups Present } \\
\text { (see Table 9-1) }\end{array}$ & \begin{tabular}{|c|} 
Sample \\
Size
\end{tabular} & Reference/ Reanalysis \\
\hline 41LK67 & TLA & CAR & 2 & 21,22 & 2479 & Meissner 2008 \\
\hline 41LK67 & TLP & CAR & 2 & 21,22 & 4594 & Meissner 2008 \\
\hline $41 \mathrm{MC} 296$ & ILP & CAR & 16 & $\begin{array}{c}1,2,3,4,6,8,9,13,15,16,17,18,19 \\
20,24,25\end{array}$ & 266 & Meissner 2008 \\
\hline $41 \mathrm{MC} 296$ & MLA & CAR & 17 & $\begin{array}{c}1,2,3,8,9,10,13,14,15,16,17,18 \\
19,20,23,24,25 \\
\end{array}$ & 1485 & Meissner 2008 \\
\hline $41 \mathrm{MC} 296$ & TLP & CAR & 14 & $1,2,4,8,9,13,14,15,16,17,18,19,20,24$ & 1244 & Meissner 2008 \\
\hline $41 \mathrm{MM} 340$ & ILA & CAR & 11 & $1,2,4,6,8,9,13,18,21,24,25$ & 1299 & $\begin{array}{l}\text { Howells et al. 2003; Meissner and } \\
\text { Mahoney } 2003\end{array}$ \\
\hline $41 \mathrm{MM} 340$ & MLA & CAR & 16 & $\begin{array}{c}1,2,4,6,8,9,10,11,13,15,16,17 \\
18,20,21,24\end{array}$ & 1387 & $\begin{array}{l}\text { Howells et al. 2003; Meissner and } \\
\text { Mahoney } 2003\end{array}$ \\
\hline $41 \mathrm{MM} 340$ & TLA & CAR & 14 & $1,2,4,6,8,9,11,13,15,16,18,21,24,25$ & 1002 & $\begin{array}{l}\text { Howells et al. 2003; Meissner and } \\
\text { Mahoney } 2003\end{array}$ \\
\hline $41 \mathrm{MM} 341$ & ILP-AU2 & CAR & 18 & $\begin{array}{c}1,2,4,6,8,9,11,12,13,14,15,17 \\
18,20,21,22,24,25 \\
\end{array}$ & 4994 & Gardner 2006a and 2006b; Shaffer 2006 \\
\hline $41 \mathrm{MM} 341$ & ILP-AU1 & CAR & 18 & $\begin{array}{c}1,2,4,6,8,9,10,11,12,13,14,15 \\
17,18,20,21,22,24 \\
\end{array}$ & 3351 & Gardner 2006a and 2006b; Shaffer 2006 \\
\hline 41TV441 & TLP & TARL & 7 & $1,2,4,15,18,22,24$ & 37 & Karbula et al. 2001 \\
\hline 41WM267 & MLA & TARL & 16 & $\begin{array}{c}1,2,4,6,8,9,12,13,14,15,16,17 \\
18,20,21,24\end{array}$ & 1214 & Peters et al. 1982 \\
\hline 41WM267 & TLA & TARL & 16 & $\begin{array}{c}1,2,4,9,10,12,13,15,16,17,18 \\
19,20,21,24,25 \\
\end{array}$ & 249 & Peters et al. 1982 \\
\hline $41 \mathrm{WN} 88$ & TLP & CAR & 20 & $\begin{array}{c}1,2,3,4,6,8,9,10,13,15,16,17 \\
18,19,20,21,22,23,24,25 \\
\end{array}$ & 5959 & Nickels 2000 \\
\hline 41ZV202 & ILP & CAR & 10 & $1,4,6,8,9,13,18,21,22,24$ & 635 & Appendix D \\
\hline
\end{tabular}

sites 41HY209T and 41WM267, the original excavation reports noted that mussel shell was present, though we could not locate the shell in collections. In these cases, we counted mussels as present, though they did not figure in the overall sample size counts for these components. In addition, several cases had bird fragments that could only be characterized as large/very large or small/medium size. In those instances, we counted birds as present in the appropriate cell (see Table 9-1, Groups 15, 16), but the sample sizes did not count in the component totals. A similar strategy was used for the "Very Large Mammals" group. If this group, which has a high probability of reflecting bison, was present in a component, bison was counted as present (Table 9-1; Group 1), but sample size was not affected. Finally, in two cases (41JW8; 41WN88) snails are known to be present, but could not be located in the collections. Like the mussel data for 41HY209T and 41WM267, snails are recorded as present for these two sites, but we lack counts so that they do not contribute to the overall sample size.

Areview of Table 9-2 shows that the three components, all from site 41LK67, are represented only by snail and mussel shell. This has a high probability of reflecting a preservation bias, and we have eliminated this site from further consideration. In addition, the Middle Late Archaic component at 41KM69 is only represented by three identifiable bones and the Terminal Late Archaic components at this site only has "large bird" fragments present. We also eliminated both of these components from further consideration. The eliminated components are highlighted in bold on Table 9-2.

The remaining 22 components are from 13 sites (see Table 9-2; Figure 9-1). There are three Initial Late Archaic components, three Middle Late Archaic components, four Terminal Late Archaic components, six Initial Late Prehistoric components, and six Terminal Late Prehistoric components. The size of the faunal sample identified for a component ranges from a low of 30 items to a high of 5,959 items, and the number of groups present (see Table 9-1) ranges from 2 to 23.

Table 9-3 presents mammal fragmentation data by size class for the 22 components. The table presents the weight, in grams, of the unidentified mammal fragments classified into four size groups, as well the total weight of classifiable mammalian fragments. Note that we also list the non-shell sample size for fauna. We eliminated mussel and snail shell counts from the NISP totals as we are primarily interested in comparing bone fragmentation against bone identifications. In so doing, we were forced to eliminate the Initial Late Archaic component at 41GD21 as it had a non-shell NISP count of zero. 
Table 9-3. Mammal Fragmentation Data by Body Size Groups

\begin{tabular}{|c|c|c|c|c|c|c|c|}
\hline Site & Component & $\begin{array}{l}\text { Non-shell Sample Size } \\
\text { (NISP) for Component }\end{array}$ & $\begin{array}{c}\text { Very Large } \\
\text { Fragment Weight* }\end{array}$ & $\begin{array}{c}\text { Large Fragment } \\
\text { Weight }^{*}\end{array}$ & $\begin{array}{c}\text { Medium/Small } \\
\text { Fragment Weight }^{*}\end{array}$ & $\begin{array}{c}\text { Very Small } \\
\text { Fragment Weight }\end{array}$ & $\begin{array}{c}\text { Total Fragment } \\
\text { Weight }^{*}\end{array}$ \\
\hline 41CN95 & TLA & 3 & 88.2 & 0.64 & 0 & 0.05 & 88.89 \\
\hline 41HY209T & ILP & 167 & 56.07 & 124.82 & 2.39 & 0.07 & 183.35 \\
\hline 41HY209T & TLA & 186 & 30.91 & 85.76 & 2.55 & 0 & 119.22 \\
\hline 41JW8 & TLP & 3027 & 2959.75 & 1787.07 & 36.27 & 0 & 4783.09 \\
\hline $41 \mathrm{KM} 69$ & ILP & 70 & 33.3 & 73.82 & 3.24 & 0.12 & 110.18 \\
\hline 41KM69 & TLP & 30 & 1603.55 & 158.89 & 0.51 & 0 & 1792.95 \\
\hline 41LK201 & ILA & 63 & 45.16 & 51.38 & 2.08 & 0.82 & 99.44 \\
\hline 41LK201 & TLP & 2530 & 1517.77 & 1309.7 & 40.29 & 1.76 & 2869.52 \\
\hline 41MC296 & ILP & 266 & 736.08 & 289.02 & 51.65 & 2.62 & 1079.37 \\
\hline 41MC296 & MLA & 1485 & 269.73 & 296.71 & 44.47 & 0 & 610.91 \\
\hline 41MC296 & TLP & 1244 & 1150.79 & 435.59 & 24.38 & 0.99 & 1611.75 \\
\hline $41 \mathrm{MM} 340$ & ILA & 258 & 174.93 & 664.18 & 9.32 & 0.01 & 848.44 \\
\hline 41MM340 & MLA & 240 & 324.32 & 752.86 & 13.28 & 0 & 1090.46 \\
\hline 41MM340 & TLA & 255 & 132.35 & 648.71 & 4.37 & 0 & 785.43 \\
\hline $41 \mathrm{MM} 341$ & ILP-AU2 & 807 & 2.67 & 86.85 & 7.62 & 0.29 & 97.43 \\
\hline 41MM341 & ILP-AU1 & 809 & 9.34 & 175.19 & 11.58 & 0.14 & 196.25 \\
\hline 41TV441 & TLP & 33 & 84.9 & 20.99 & 0.68 & 0 & 106.57 \\
\hline 41WM267 & MLA & 1214 & 129.72 & 176.2 & 6.91 & 9.21 & 322.04 \\
\hline 41WM267 & TLA & 249 & 30.36 & 79.93 & 4.52 & 3.66 & 118.47 \\
\hline 41WN88 & TLP & 453 & 1024.41 & 546.2 & 10.01 & 0.23 & 1580.85 \\
\hline 41ZV202 & ILP & 178 & 14.29 & 5.58 & 22.3 & 0.05 & 42.22 \\
\hline
\end{tabular}

${ }^{*}$ All weights in grams.

\section{Faunal Results: Shifts through Time in the Number of Groups Represented}

Figure 9-2 presents box plots (note 7) of the number of taxonomic groups (see Table 9-1) from the Initial Late Archaic through the Terminal Late Prehistoric using the data in Table 9-2. We suggested that as bison are declining throughout this period, there should be an increase in diet breadth. In the faunal data, this increase would show up both as an increase in the number of taxa present and an increase in the number of low ranked taxa. This would especially be the case late in the sequence. This is because grassland data suggest that in the Terminal Late Prehistoric, bison are declining in number and experiencing significant year to year fluctuations. This high level of fluctuation should show up as increased variation in the number of taxa during the Terminal Late Prehistoric. Focusing first on the shifts in the median values, Figure 9-2 shows that there is an overall increase in the number of types through time. Only the three components associated with the Middle Late Archaic do not follow the overall trend. In addition, the figure also shows that the maximum number of types present on any given component also increases through

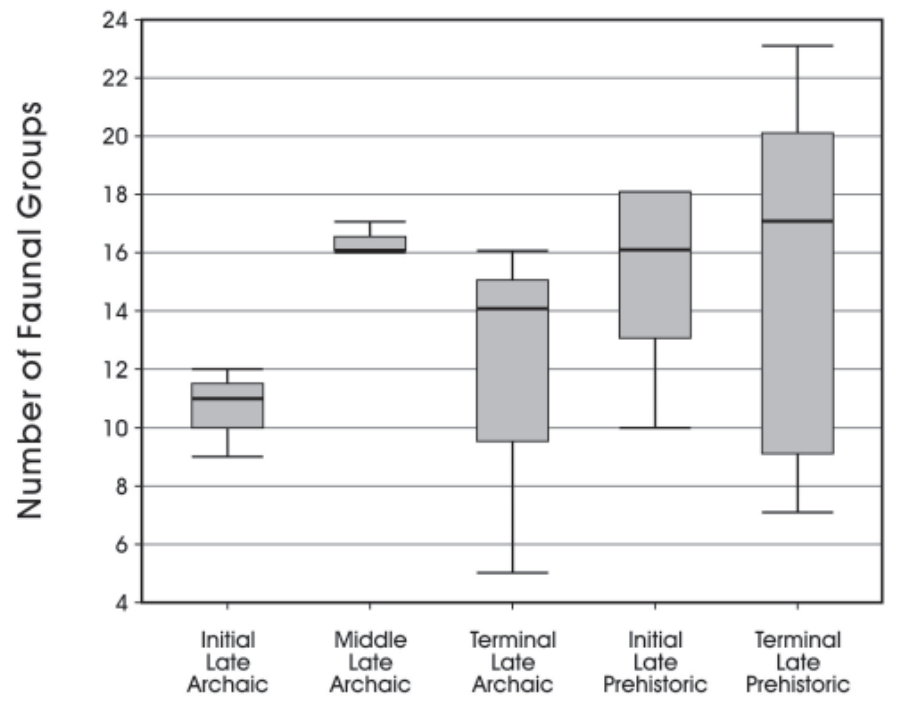

Time Period

Figure 9-2. Number of faunal groups present through time (see Tables 9-1, 9-2).

time, again with the exception of the Middle Late Archaic. Finally, the greater overall range of faunal groups in the Terminal Late Prehistoric supports the suggestion that higher variability between components should be present late in the sequence. 
The changes shown in Figure 9-2 are generally consistent with our expectations in that the number of faunal groups increases through time and is highest in the Terminal Late Prehistoric. However, while there is a significant increase in the maximum number of groups on a component in the Terminal Late Prehistoric, the increase in median values from the Initial Late Prehistoric to the Terminal Late Prehistoric is minimal. We had expected this increase to be substantial. In addition, note that the overall pattern of declining identifiable groups through time shown in Figure 9-2 is also consistent with deteriorating preservation of faunal remains. Older collections should have greater degrees of deterioration, both reducing the ease with which a type can be identified and reducing the overall sample size. Reference to Table 9-2 also suggests a possible relationship between the number of groups present and the overall sample size.

In order to consider the possible impacts of sample size on the number of types, we constructed Figure 9-3, which plots the number of faunal groups (y-axis) against the number of identifiable specimens (x-axis) on a component. The top figure clearly shows a strong (Pearson's R= 0.699), though slightly non-linear, relationship. As the sample size increases, the number of identifiable specimens also increases. The bottom portion of Figure 9-3 plots the square of the number of faunal types present by the number of identified specimens. We did this to lessen the impact of the nonlinearity. The transformation increases the Pearson's correlation coefficient to 0.733. Also shown in the bottom plot is the $95 \%$ confidence interval for the least-squares estimate. The majority of cases fall within, or very close to, that interval, suggesting that the number of types is not significantly different from what would be expected for that sample size. However, several cases are noticeably above or below the confidence interval. Having fewer types than expected for their samples size is the Initial Late Archaic component at 41MM340, the Terminal Late Archaic component at 41CN95, 41ZV202 (Initial Late Prehistoric), and the Terminal Late Prehistoric component at 41TV441 (Figure 9-3 Bottom). Three components, consisting of both the Middle Late Archaic and Initial Late Prehistoric components at 41MC296, and the Terminal Late Archaic occupation at 41WM67, have slightly higher counts than expected given their sample size. Two additional components, the Terminal Late Prehistoric occupation at 41LK201 and especially the Terminal Late Prehistoric occupation at 41JW8, both have significantly more types than expected even when controlling for impacts of varying sample size. While samples sizes do impact the
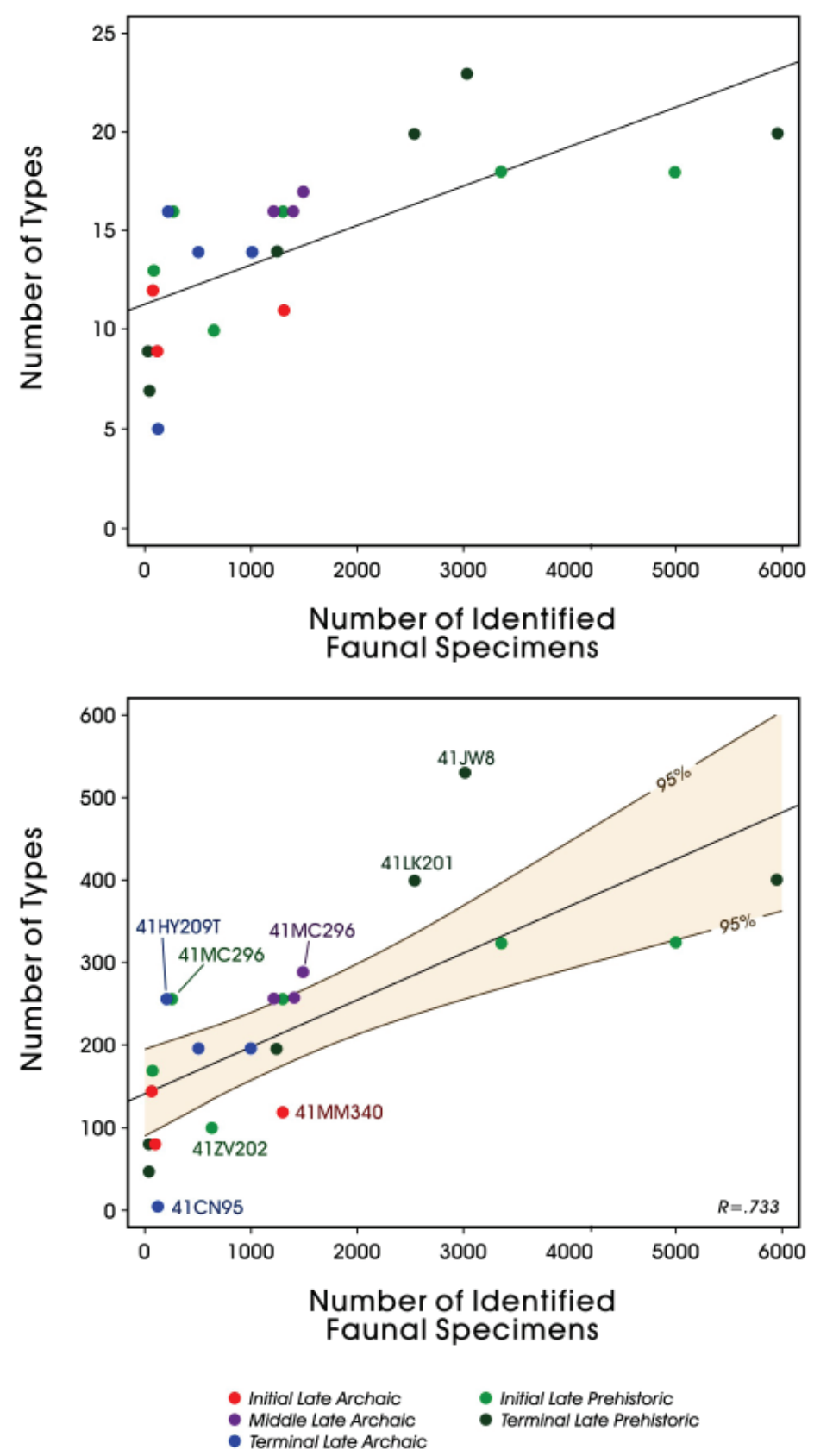

Figure 9-3. Top: Number of faunal types by NISP. Bottom: Transformed number of types by NISP with 95\% confidence intervals (see Table 9-2). 
overall patterns, the greater than expected number of types in these two Terminal Late Prehistoric components is consistent with a wider diet breadth late in time. Of course, this pattern would also be expected based only on preservation concerns. That is, we would expect more types to be recognized at younger sites.

Finally, we consider the possible addition of low ranked taxa through time. We have argued that as diet breadth expanded in response to declining bison availability, hunters and gatherers would differentially add lower ranked resources to their diet. Reviewing the faunal group size data in Table 9-1, we identified six classes of resources that, based primarily on body size, should have low caloric returns. These are groups 7, 13, 17, 19, 20, and 21 . They primarily reflect reptiles, amphibians, shrews, mice, rats, voles, snails, and fish. While the inclusion of fish may seem inappropriate, note that none of the sites considered here are locate near coastal settings where large bodied fish (e.g., black drum, redfish) are present. Fish are certainly available in rivers within the state, but they tend to be smaller in size relative to those available in costal settings (see Ricklis 1996: 1419; TPWD 2009). As shown in Figure 9-4, the average number of low return groups per component increases from a low of 1.7 in the Initial Late Archaic, to a high of 3.7 per component in the Terminal Late Prehistoric. This is generally consistent with our expectations, and the overall pattern is similar to that shown for all fauna groups in Figure 9-2. There is an unexpectedly high value in the Middle Late Archaic and only a minor increase between the Initial Late Prehistoric and the Terminal Late Prehistoric.

\section{Faunal Results: Shifts in Mammal Fragmentation Data}

One of the principal interpretive problems in comparing our expectations for shifts in the number of taxa with the archeological data is that the anticipated pattern is one of declining numbers of taxa with increased time depth. As noted previously, the pattern of decreasing taxa with increasing time depth may simply reflect preservation issues rather than any actual change in the number of different types of animals included in the diet. One of the advantages in considering changes in fragmentation rates is that the expectations of the model do not pattern with time. If bone fragmentation is responding to stress such that when dietary stress increases fragmentation rates should increase, then rates should be lowest in the Initial Late Archaic, the earliest time period considered here, and highest in the Terminal Late Prehistoric, the latest time period investigated. This expected pattern is the inverse of the pattern that should be produced by taphonomic processes.

Using the fragmentation data presented previously in Table 9-3, Figure 9-5 plots changes in ratio of fragment weight relative to non-shell NISP counts. We use the median values as plotting points because of the small number of components in the Initial Late Archaic $(n=2)$ and high

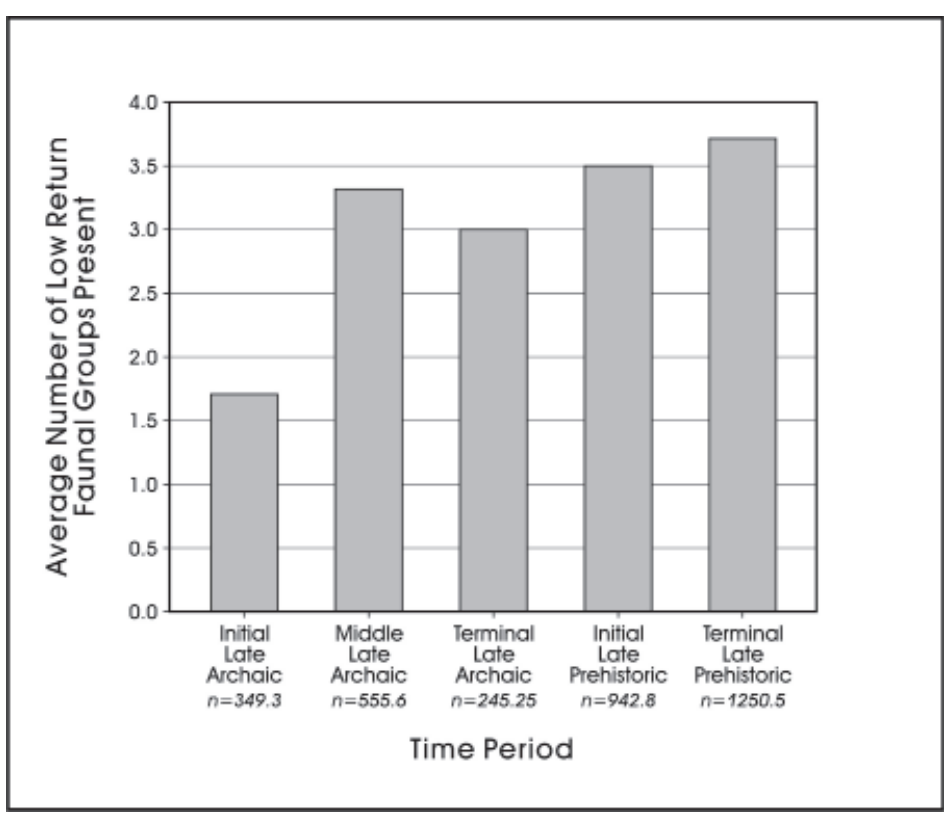

Figure 9-4. Shifts in the average number of low return faunal groups (see Table 9-1) present through time. Sample size is the average NISP for low return groups by component.

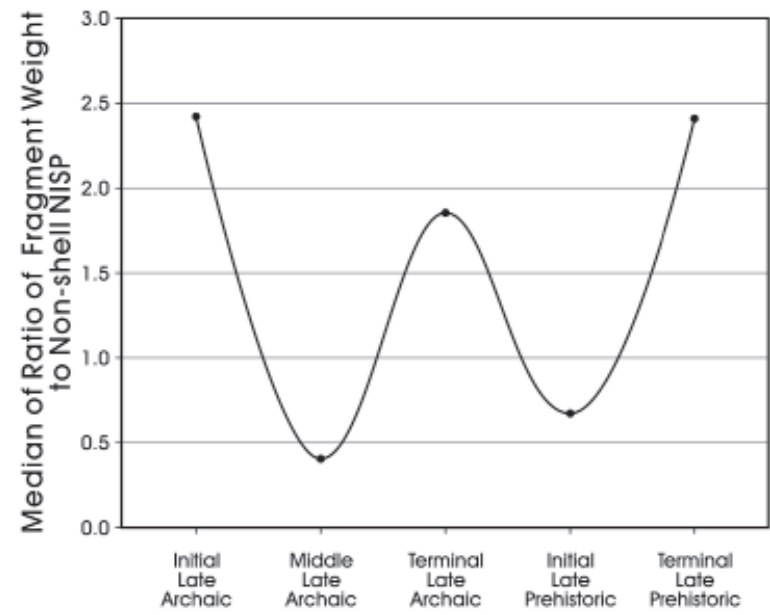

Time Period

Figure 9-5. Shifts in fragmentation ratio through time. 
variability in the values, especially in the Terminal Late Archaic $(\min =1.13, \max =59.8)$. Examination of Figure 9-5 suggests that the expectations of the model are not supported. While both the high values in the Terminal Late Prehistoric and the significant increase between the Initial and Terminal Late Prehistoric are consistent with expectations, the Archaic period does not pattern as expected. If this variable is monitoring levels of stress, we would expect the lowest ratios to be present in the Initial Late Prehistoric, and those ratios should increase through time.

Figure 9-6 considers the second expectation associated with the Table 9-3 fragmentation data, that higher percentage of fragments should be associated with very large mammals (i.e., bison) throughout the Late Archaic and into the Initial Late Prehistoric. The Terminal Late Prehistoric components should have the highest percentage of fragments classified as reflecting bison. The Figure 9-6 pattern is only partially consistent with these expectations. As expected, there is a significant increase associated with the Terminal Late Prehistoric relative to all earlier periods, and relative to the Initial Late Prehistoric. However, the anticipated pattern for the Archaic of a slow increase from low percentages of very large mammals in the Initial Late Archaic through higher values in the Middle and Terminal Archaic are not supported.

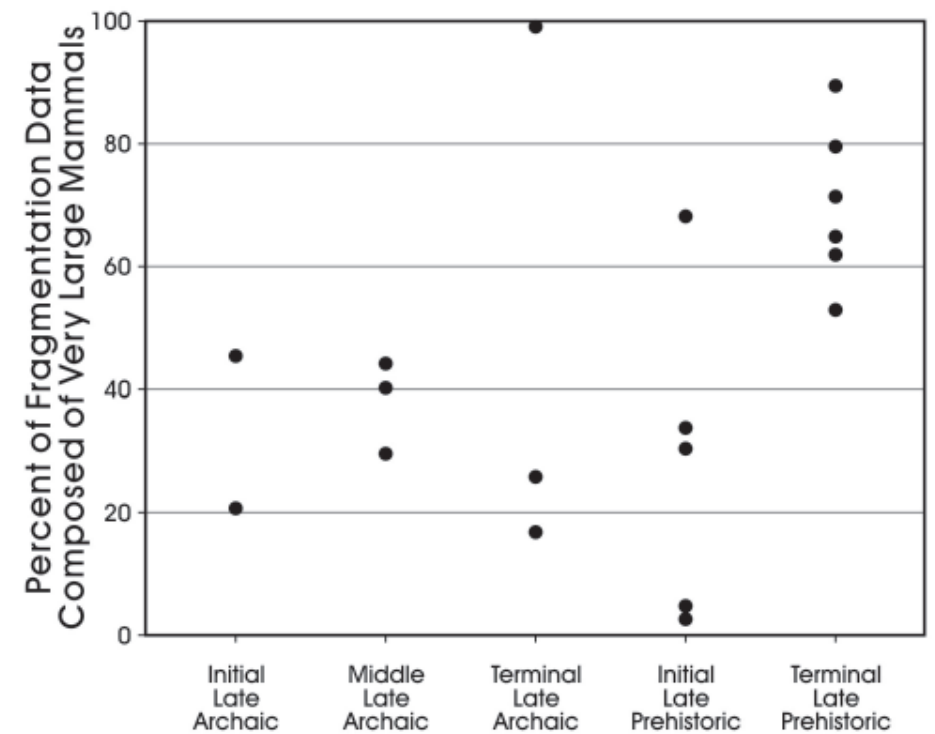

Time Period

Figure 9-6. Percentage of fragmentation data composed of very large mammals by time period.

\section{Summary}

The faunal data only partially supports our expectations of widening diet breadth though the Archaic, with dramatic increases between the Initial and Terminal Late Prehistoric periods in response to declining bison availability. There is an overall increase in the number of faunal groups represented through time, and the increase appears to be associated with the addition of lower ranked resources. Correcting for sample size differences, the patterns are still present. However, we cannot eliminate the possibility that taphonomic processes account for the shifts through time. Changes in the fragmentation data do not clarify the issues. Again, they are only partially consistent with the overall expectations.

\section{Measuring Shifts in Floral Dependence}

While the faunal measures considered above appear to be adequate for tracking changes in the number of animal resources collected through time, as well as for assessing the relative contribution of different body-size classes to diets, gauging the contribution of plant resources is much more complicated. In part, this is because of poor plant preservation from open-air sites. In addition, some of the sites used in our review were excavated before flotation analysis of feature fill became common practice. Consequently, we cannot rely on direct measures such as the number of different plant species present in a site to track temporal trends. Here, we use the frequency of two classes or archeological remains, rocklined hearths and ground stone artifacts, as gross proxy indicators of the intensity of plant processing and indirectly shifts in the role of plant resources in the diets of Texas hunter-gatherers. As with the faunal data discussed above, our focus will be on monitoring changes through time at a variety of Late Archaic and Late Prehistoric components.

Many plant resources such as bulbs, roots, and nuts often contain compounds that are not easily digestible by humans (see Thoms 1989, 2008, 2009). As a result, these classes of plants require extended cooking times to convert the indigestible compounds to digestible resources. Figure 9-7 (top) shows ethnographically reported minimum cooking times for a variety of plant tissues (Wandsnider 1997). Roots in general are reported to require between 15 and 20 hours of cooking, and cooking times for sotol, agave, yucca and camas 


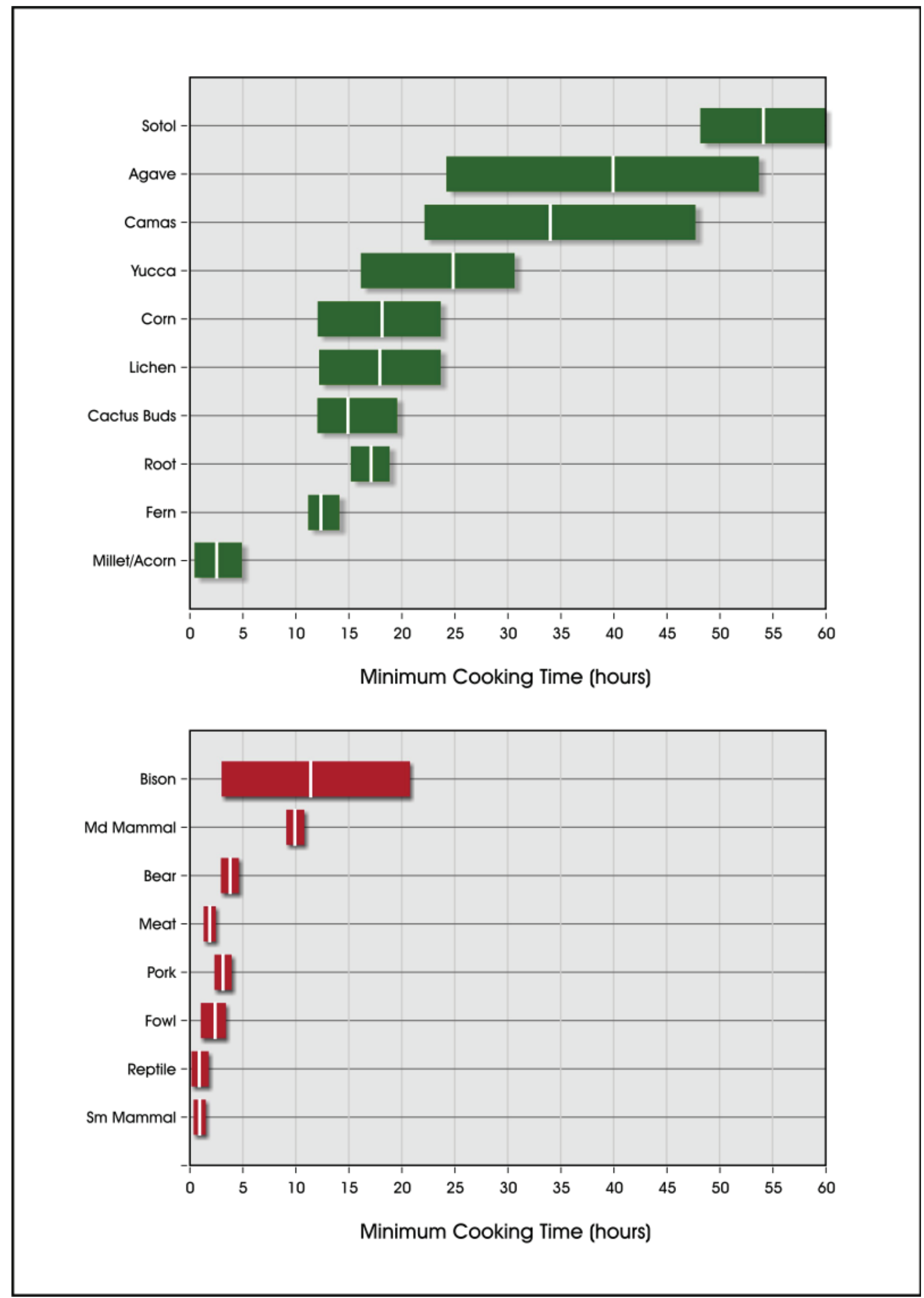

Figure 9-7. Ethnographically reported cooking time for plants (top) and meat (bottom). Bars show the interquartile range (from Wandsnider 1997). 
bulbs range from a minimum of 17 hours to nearly 60 hours. In contrast, cooking times for meats derived from a majority of species require a maximum of five hours or less (Figure 9-7, bottom). Only medium body size mammals, such as deer and antelope, may require 7-10 hours of preparation and only the preparation of bison may take as much as 20 hours depending on the size of the package cooked. In general, small meat packages such as a rack of ribs, meat fillets, and intestine can be prepared in 1-2 hours.

Cooking facilities such as hearths without rock are adequate in preparing foods that require short cooking times or are cooked in containers. However, when lengthier cooking times are needed, hunters and gatherers often use rock to increase heat storage and lengthen heat dissipation (see Thoms 2009). If Wandsnider's (1997) ethnographic patterns reflect a general relationship between plant and meat tissue cooking requirements, we would expect that many plants would be cooked in rock facilities, especially in the absence of ceramics. Wandsnider's (1997) search of the ethnographic literature revealed a series of case studies that seem to support aspects of this relationship. Seventy-six percent (55 of 72) of the features used to cook plants contain heated rocks, while in the majority of cases (75\%), features used to prepare animal tissue do not contain rocks. Given the ethnographic support for the relationship between cooking facilities and the cooking of plant or animal tissue, we propose to use the number of hearths with rock in a component as a proxy indicator of the relative importance of plant resources in prehistoric huntergatherer diets.

The feature data from 41ZV202 provides an opportunity to begin to assess the utility of our suggested association of burned rock features with plant processing. While only five intact features are associated with the Initial Late Prehistoric, we use three different data sets in this assessment. First, we submitted flotation samples from each of the discrete thermal features (\# 7, 8, 9, 10 and 13) in order to recover carbonized seeds or other plant parts that could reflect what items were cooked in the features. Second, we submitted three rocks from each of these five features for lipid residue analysis. The analysis of lipids from archeological specimens, first used by Condamin et al. (1976), has recently been expanded through the work of Marchbanks (1989), Skibo (1992), Loy (1994), and Malainey (2000). Lipids are abundant in plants and animals, and different groups of plants and animals have fatty acids with different molecular structure. These varying molecular signatures of fatty acids can be identified in archeological situations (see also Quigg et al. 2002). Several broad groups of plant and animal signatures have been developed based on fatty acid composition, and while some overlaps exist, lipid analysis can provide an additional clue to determining if plants or animals were processed in rock features at the site. Finally, we consider the total rock weights present in each of the five features in an effort to gauge their heating potential (see Black 2003). As we noted above, the ethnographic patterns suggest that features with large quantities of rock were used in plant processing.

Dr. Phil Dering of Shumla Archeobotanical Services conducted the flotation analysis. Appendix E presents the results from the five features that probably date to the Initial Late Prehistoric at 41ZV202. Flotation analysis produced no carbonized seeds or edible plant parts. Dering notes that low quantities of small pieces of wood charcoal were present. When samples were large enough for identification, mesquite was the only wood noted. In addition, indicators of disturbance, such as roots, fresh seeds, and insect parts, were common in many of the samples (Appendix E). Unfortunately, the flotation results produced no information on what types of resources were processed in these rock features.

Dr. M. Malainey conducted lipid analysis on 15 rocks from the Initial Late Prehistoric features at 41ZV202. Her results are presented in Appendix F. Here, we are primarily concerned with identifying whether or not a given rock was most likely used to process plants or animals, rather that identifying what specific animals or plants are represented. Two of the 15 rocks (sample \# 6, Feature 8 and \# 8, Feature 9) contained insufficient lipids for analysis, and a third (sample \# 5, Feature 8) produced ambiguous signatures. Of the remaining 12 specimens, nine (75\%) had fatty acid compositions strongly consistent with plants. These include all three samples from Feature 7, the single remaining sample from Feature 8, all three samples from Feature 10, and two of the three samples from Feature 13. The two samples from Feature 9 ( $\# 7$ and \#9) and the remaining sample from Feature 13 (\#14) have signatures that are present in some freshwater fish and snails, but they also have "long chain fatty acids" indicative of plants (Appendix F). The results suggest that Features 7, 8, 10 , and probably 13 are all involved with plant processing while Feature 9 may have been associated primarily with animal processing, though the data are suggestive of some plant residues as well.

Finally, we turn to a consideration of difference in rock weight within features. Black (2003) has suggested that the total weight of rock is a measure of the heating potential of the feature. While complicated by patterns of reuse and feature maintenance, the suggestion is that this variable should pattern with cooking requirements of different classes of foods (see Black 2003; Ellis 1997). Features used to process plants should have rock present, and those plants requiring long term heating should be processed in features with large quantities of rock. While, as summarized in Chapter 5, we have no reliable weight data for Feature 7, defined during 
testing, rock weights are available for the remaining four FCR features. Features 8, 10, and 13, all of which the lipid data suggest were involved primarily with plant processing, have an average FCR weight of just over $25 \mathrm{~kg}$ of rock, with a low of $15.3 \mathrm{~kg}$ (Feature 10) and a high of $39 \mathrm{~kg}$ (Feature 8). In contrast, the FCR weight for Feature 9, with residues primarily suggestive of animal processing, totals only $4.2 \mathrm{~kg}$.

While the results of the flotation analysis at 41ZV202 are disappointing, the lipid residue information and pattern in the overall weight of rock in FCR features at 41ZV202 are consistent with the ethnographic review that suggests burned rock features, especially those with larger quantities of rock, are likely to be used for plant processing. Using the 41ZV202 feature data, in combination with feature data from other components, we suggest that shifts in feature density are a useful proxy for shifts in the importance of plant resources in the diet of Late Archaic and Late Prehistoric populations.

The number of thermal features within a given component may be responding to a variety of other factors beyond increases or decreases in the importance of plants. These should include 1) the size of the excavated area, 2) the level of reuse, 3) the length of site occupation, 4) the number of people in the group, and 5) the way that cooking activities are organized (e.g., communal cooking versus individual household). We can lessen the impact of some of these on the proposed proxy. For example, we monitor the size of the area excavated on a given component and consider the number of features relative to the area sampled. We also monitor the size of features (length $\mathrm{x}$ width) and look for any shifts that might signal differences in the way that cooking activities are organized. From these data, we can produce a measure of the number of rock features per square meter of excavated space, as well as a measure of the relative amount of that space devoted to burned rock features, which will serve to lessen the impacts of some of these complicating factors.

Our primary interest is in monitoring shifts in the density of burned rock features through time as a measure of shifts in plant dependence. However, the number of features can remain constant, but the intensity with which features are used could increase. We need to be concerned, then, with changes in patterns of feature reuse. Rock size data, which would allow an independent assessment of feature reuse (see Mauldin et al. 1998), are not reported for most of the components considered here. We therefore will assume there are no directional changes in the level of reuse, or the intensity with which a given feature is used, that would account for any changes in feature density. This is probably incorrect. Focusing on rock size and feature density, we have shown that, at least in some areas of Central Texas, both the number of features and the intensity with which they are used increased through time, especially in the Terminal Late Prehistoric (see Mauldin et al. 2008; 2009). However, as we expect bison are declining during the Terminal Late Prehistoric, use should be more intensive late in time. Any shifts in feature density observed, then, would be in addition to the increase in intensity.

The major problem with the approach, however, centers on correcting for the length of time that features were used. Ideally, we need to be able to standardize the length of time that a given feature was used in our comparisons. That is, if new features are generated at new locations every season during one phase, and generated at new locations every five years during a second phase, strict density comparisons will be difficult to interpret in terms of shifting plant dependence. Shifts at this scale will, essentially, be invisible at an archeological time scale. Changes in feature use could be monitored to some degree, if we had multiple radiocarbon dates available for a given feature. That would at least provide a maximum time scale of use, though it likely would encompass several hundred years. However, the vast majority of features lack any radiocarbon dates that might help narrow the use span. Temporal assignment for features is primarily through diagnostic artifacts and is at the component level. All else being equal, if a given component lasts twice as long as another component, we would expect twice as many features to be produced. Consequently, we will standardize comparisons of features at the component level by considering the number of features per 100 years. This, in effect, assumes that all other elements that would impact the number of features (e.g., occupation duration, levels of mobility), are constant. We ultimately use data from 163 features from 29 components, including the five features on the Initial Late Prehistoric occupation at 41ZV202.

As a second measure of plant dependence, we will monitor the frequency of ground stone. Because many plant remains are ground before consumption, the presence of food processing ground stone tools (e.g., manos, metates, pestles) within an assemblage may provide an additional measure of the importance of plant remains. The use of the number of ground stone tools as a proxy for plant dependence is complicated by many of the same factors that we have discussed for FCR features. Foremost among these are 1) the size of the excavation, 2) the length of a phase and 3) patterns of breakage. We can essentially use the same measurements as we used previously for features to correct for excavation area and temporal placement. This will produce a measure of the number of ground stone items per 100 square meters of excavated space per 100 years of time for a component. In our review of published data, we attempted to monitor fragmentation data, but found that most of the time, this information is not provided in reports. Consequently, we will assume that breakage is constant through time. Ultimately, we use 172 ground stone items from 28 components to 
investigate changes in plant dependence through the Late Archaic and into the Late Prehistoric.

We realize that the association of shifts in the density of ground stone and in the density of burned rock features with plant processing is tenuous. Unfortunately, they are the best measures that we currently have available. Using these admittedly gross measures of plant dependence, we expect that if bison population densities decreased in the study area throughout the Late Archaic and into the Initial Late Prehistoric, the density and/or area devoted to rock hearths, as well as the density of ground stone tools, should increase as a reflection of the inclusion of lower-ranked plant resources. This should especially be apparent in the Terminal Late Prehistoric, where grassland data suggest that declines in bison were accelerating.

\section{Data Acquisition}

The same components and sites used previously in considering faunal changes (see Figure 9-1) form the basis of both the feature and ground stone data used here to investigate changes in plant use. Data were gathered primarily from the literature or from excavation notes on file at CAR. For the feature data, two additional sites, a Middle Late Archaic component from 41TG91 (Creel 1990) and a Terminal Late Archaic and an Initial Late Prehistoric component from 41ME35 (Story and Shafer 1965) are available. These had been part of the original faunal data sets, but we eliminated them from consideration given potential problems with data collection procedures and reporting. Both sites provide adequate information for the investigation of shifts in feature density, though we did drop 41TG91 from the ground stone data base given problems with collection procedures (see Creel 1990).

We encountered no significant methodological problems with the acquisition of the feature data. Table 9-4 presents these data summarized at the component level. For the 29 components reviewed, we list the site number, the component temporal designation, the number of rock features for that component, the number of rock features from which we obtained size measurements, the total area of the measured rock features in square meters, the excavated area that was sampled, and the

Table 9-4: Summary of Component Level FCR Feature Data

\begin{tabular}{|c|c|c|c|c|c|c|}
\hline Site & Component & $\begin{array}{c}\text { \# Rock } \\
\text { Features }\end{array}$ & $\begin{array}{c}\text { \# Rock Features } \\
\text { Meas. }\end{array}$ & $\begin{array}{c}\text { Area of Rock Thermal } \\
\text { Features }\left(\mathrm{m}^{2}\right)\end{array}$ & $\begin{array}{c}\text { Area Excavated } \\
\left(\mathrm{m}^{2}\right)\end{array}$ & References \\
\hline 41GD21 & ILA & 1 & 1 & 0.256 & 6 & Fox 1979 \\
\hline 41LK201 & ILA & 6 & 5 & 2.444 & 13 & Highley 1986 \\
\hline 41LK67 & ILA & 6 & 6 & 3.741 & 68 & Brown et al. 1982 \\
\hline $41 \mathrm{MM} 340$ & ILA & 7 & 4 & 3.241 & 56 & Mahoney et al. 2003 \\
\hline $41 \mathrm{KM} 69$ & MLA & 13 & 12 & 2.24 & 745 & Thompson et al. 2007 \\
\hline $41 \mathrm{MC} 296$ & MLA & 3 & 2 & 2.704 & 23 & Hall et al. 1986 \\
\hline $41 \mathrm{MM} 340$ & MLA & 7 & 5 & 2.511 & 56 & Mahoney et al. 2003 \\
\hline 41TG91 & MLA & 2 & 2 & 0.4713 & 36 & Creel 1990 \\
\hline 41WM267 & MLA & 3 & 2 & 2.623 & 25 & Peters et al. 1982 \\
\hline $41 \mathrm{CN} 95$ & TLA & 3 & 1 & 0.132 & 39 & Lintz et al. 1993; Treece et al. 1993 \\
\hline 41HY209T & TLA & 0 & 0 & 0 & 19 & Ricklis and Collins 1994 \\
\hline $41 \mathrm{KM} 69$ & TLA & 7 & 7 & 1.78 & 661 & Thompson et al. 2007 \\
\hline 41LK67 & TLA & 11 & 10 & 5.632 & 121 & Brown et al. 1982 \\
\hline 41ML35 & TLA & 2 & 0 & nd & 30.2 & Story and Shaffer 1965 \\
\hline $41 \mathrm{MM} 340$ & TLA & 12 & 9 & 6.276 & 56 & Mahoney et al. 2003 \\
\hline 41WM267 & TLA & 2 & 0 & nd & 21 & Peters et al. 1982 \\
\hline 41HY209T & ILP & 2 & 2 & 0.3696 & 25 & Ricklis and Collins 1994 \\
\hline $41 \mathrm{KM} 69$ & ILP & 17 & 17 & 104.72 & 738 & Thompson et al. 2007 \\
\hline $41 \mathrm{MC} 296$ & ILP & 0 & 0 & 0 & 30 & Brown et al. 1982 \\
\hline 41ML35 & ILP & 3 & 2 & 0.3797 & 34.85 & Story and Shaffer 1965 \\
\hline 41ZV202 & ILP & 5 & 5 & 2.8041 & 50 & This Report \\
\hline $41 \mathrm{MM} 341$ & ILP (AU 1+2) & 19 & 14 & 8.129 & 210 & Gadus et al. 2006 \\
\hline 41JW8 & TLP & 3 & 3 & 3 & 86 & Black 1986 \\
\hline 41KM69 & TLP & 10 & 9 & 6.095 & 714 & Thompson et al. 2007 \\
\hline 41LK201 & TLP & 0 & 0 & 0 & 61 & Highley 1986 \\
\hline 41LK67 & TLP & 0 & 0 & 0 & 68 & Brown et al. 1982 \\
\hline $41 \mathrm{MC} 296$ & TLP & 0 & 0 & 0 & 31 & Hall et al. 1986 \\
\hline 41TV441 & TLP & 16 & 12 & 6.995 & 42 & Karbula et al. 2001 \\
\hline 41WN88 & TLP & 2 & 2 & 0.462 & 15.5 & Nickels 2002 \\
\hline
\end{tabular}


source of the information for the site. In several cases, reports failed to present length and width data or plan views for all features. We were often able to estimate this data from report plan views or notes, if the notes or drawings were stored at CAR. In addition, it is often the case, especially with larger features, that only a portion of the feature was excavated. If it appeared that over $1 / 2$ of the feature was excavated, then we estimated the completed feature size and included it in our data set. If the feature size could not be estimated, but it was clearly an FCR feature, or if less than $1 / 2$ of the feature was

Table 9-5. Individual Feature Data Summarized in Table 9-4

\begin{tabular}{|c|c|c|c|c|c|c|}
\hline Site & Component & Feature \# & Shape & Length & Width & Area \\
\hline 41GD21 & ILA & 1 & circular & 0.6 & 0.55 & 0.26 \\
\hline 41LK201 & ILA & 4 & irregular & 0.6 & 0.3 & 0.16 \\
\hline 41LK201 & ILA & 5 & oval & 0.85 & 0.8 & 0.54 \\
\hline 41LK201 & ILA & 7 & irregular & 1.2 & 0.35 & 0.47 \\
\hline 41LK201 & ILA & 8 & irregular & 1.3 & 0.8 & 0.87 \\
\hline 41LK201 & ILA & 9 & oval & 0.8 & 0.65 & 0.42 \\
\hline 41LK67 & ILA & 8 & circular & 1.4 & 1.3 & 1.43 \\
\hline 41LK67 & ILA & 24 & irregular & 1.04 & 0.47 & 0.45 \\
\hline 41LK67 & ILA & 25 & irregular & 1.35 & 0.7 & 0.83 \\
\hline 41LK67 & ILA & 26 & \begin{tabular}{|l} 
irregular \\
\end{tabular} & 1.07 & 0.7 & 0.62 \\
\hline 41LK67 & ILA & 27 & irregular & 0.82 & 0.55 & 0.37 \\
\hline 41LK67 & ILA & 28 & & 0.3 & 0.22 & 0.05 \\
\hline $41 \mathrm{MM} 340$ & ILA & 36 & irregular & 1.9 & 0.9 & 1.54 \\
\hline $41 \mathrm{MM} 340$ & ILA & 44 & circular & 0.41 & 0.4 & 0.13 \\
\hline $41 \mathrm{MM} 340$ & ILA & 47 & oval & 1.3 & 1 & 1.04 \\
\hline $41 \mathrm{MM} 340$ & ILA & 49 & irregular & 1.25 & 0.4 & 0.54 \\
\hline $41 \mathrm{KM} 69$ & MLA & 35 & circular & 0.55 & 0.5 & 0.22 \\
\hline 41KM69 & MLA & 36 & irregular & 0.4 & 0.6 & 0.2 \\
\hline $41 \mathrm{KM} 69$ & MLA & 42 & & 0.75 & 0.5 & 0.31 \\
\hline $41 \mathrm{KM} 69$ & MLA & 43 & & 0.49 & 0.35 & 0.14 \\
\hline 41KM69 & MLA & 50 & oval & 0.6 & 0.42 & 0.2 \\
\hline 41KM69 & MLA & 55 & & 0.53 & 0.24 & 0.12 \\
\hline 41KM69 & MLA & 80 & oval & 0.54 & 0.32 & 0.15 \\
\hline 41KM69 & MLA & 88 & oval & 0.6 & 0.35 & 0.18 \\
\hline 41KM69 & MLA & 89 & oval & 0.4 & 0.5 & 0.16 \\
\hline 41KM69 & MLA & 97 & oval & 0.75 & 0.5 & 0.31 \\
\hline 41KM69 & MLA & 98 & circular & 0.6 & 0.6 & 0.28 \\
\hline 41KM69 & MLA & 99 & circular & 0.3 & 0.3 & 0.07 \\
\hline 41MC296 & MLA & 1 & oval & 2.2 & 1.4 & 2.54 \\
\hline $41 \mathrm{MC} 296$ & MLA & 3 & oval & 0.5 & 0.4 & 0.16 \\
\hline $41 \mathrm{MM} 340$ & MLA & 5 & circular & 0.6 & 0.52 & 0.25 \\
\hline $41 \mathrm{MM} 340$ & MLA & 16 & \begin{tabular}{|l} 
irregular \\
\end{tabular} & 0.89 & 0.49 & 0.37 \\
\hline $41 \mathrm{MM} 340$ & MLA & 23 & irregular & 1.55 & 0.9 & 1.18 \\
\hline $41 \mathrm{MM} 340$ & MLA & 27 & circular & 0.5 & 0.45 & 0.18 \\
\hline $41 \mathrm{MM} 340$ & MLA & 41 & circular & 0.85 & 0.8 & 0.54 \\
\hline 41TG91 & MLA & 16 & circular & 0.6 & 0.6 & 0.28 \\
\hline 41TG91 & MLA & 18 & circular & 0.53 & 0.45 & 0.19 \\
\hline 41WM267 & MLA & 4 & irregular & 1.4 & 0.95 & 1.08 \\
\hline 41WM267 & MLA & 11 & irregular & 1.75 & 1.05 & 1.54 \\
\hline 41CN95 & TLA & 5 & irregular & 0.53 & 0.29 & 0.13 \\
\hline 41KM69 & TLA & 40 & circular & 0.44 & 0.5 & 0.17 \\
\hline 41KM69 & TLA & 48 & oval & 1.25 & 0.93 & 0.93 \\
\hline 41KM69 & TLA & 49 & circular & 0.42 & 0.41 & 0.14 \\
\hline 41KM69 & TLA & 87 & irregular & 0.36 & 0.34 & 0.1 \\
\hline 41KM69 & TLA & 94 & oval & 0.45 & 0.35 & 0.13 \\
\hline 41KM69 & TLA & 95 & circular & 0.5 & 0.55 & 0.22 \\
\hline 41KM69 & TLA & 96 & circular & 0.4 & 0.4 & 0.13 \\
\hline 41LK67 & TLA & 2 & oval & 0.9 & 0.75 & 0.53 \\
\hline 41LK67 & TLA & 3 & oval & 0.7 & 0.58 & 0.32 \\
\hline
\end{tabular}

excavated, then we included the feature in the count of FCR features for that component but did not record it elsewhere or as a measured featured. These factors account for the differences in Table 9-4 between the number of rock features and the number of rock features with size measurements.

Table 9-5 lists the individual FCR features summarized in Table 9-4. In all, measurement data on 129 FCR features are presented. The table lists the site number, component

Table 9-5. Continued...

\begin{tabular}{|c|c|c|c|c|c|c|}
\hline Site & Component & Feature \# & Shape & Length & Width & Area \\
\hline 41LK67 & TLA & 4 & irregular & 1.2 & 0.4 & 0.5 \\
\hline 41LK67 & TLA & 6 & circular & 1.75 & 1.65 & 2.27 \\
\hline 41LK67 & TLA & 7 & oval & 1.2 & 0.65 & 0.67 \\
\hline 41LK67 & TLA & 19 & \begin{tabular}{|l} 
irregular \\
\end{tabular} & 0.37 & 0.28 & 0.08 \\
\hline 41LK67 & TLA & 20 & & 0.55 & 0.35 & 0.16 \\
\hline 41LK67 & TLA & 22 & & 0.7 & 0.3 & 0.2 \\
\hline 41LK67 & TLA & $1 \mathrm{~A}$ & \begin{tabular}{|l|} 
irregular \\
\end{tabular} & 0.95 & 0.7 & 0.53 \\
\hline 41LK67 & TLA & 1B & irregular & 0.75 & 0.6 & 0.36 \\
\hline $41 \mathrm{MM} 340$ & TLA & 11 & oval & 1.41 & 1.1 & 1.24 \\
\hline $41 \mathrm{MM} 340$ & TLA & 12 & \begin{tabular}{|l} 
irregular \\
\end{tabular} & 1.55 & 1.25 & 1.54 \\
\hline $41 \mathrm{MM} 340$ & TLA & 13 & oval & 0.92 & 0.69 & 0.51 \\
\hline $41 \mathrm{MM} 340$ & TLA & 14 & circular & 0.4 & 0.45 & 0.14 \\
\hline $41 \mathrm{MM} 340$ & TLA & 15 & \begin{tabular}{|l|} 
irregular \\
\end{tabular} & 0.65 & 0.3 & 0.18 \\
\hline $41 \mathrm{MM} 340$ & TLA & 26 & irregular & 0.81 & 0.65 & 0.42 \\
\hline $41 \mathrm{MM} 340$ & TLA & 31 & irregular & 1.1 & 0.7 & 0.64 \\
\hline $41 \mathrm{MM} 340$ & TLA & 37 & oval & 0.65 & 0.45 & 0.24 \\
\hline $41 \mathrm{MM} 340$ & TLA & 48 & oval & 1.45 & 1.2 & 1.38 \\
\hline 41HY209-T & ILP & 11 & oval & 0.5 & 0.32 & 0.13 \\
\hline 41HY209-T & ILP & 12 & irregular & 0.6 & 0.5 & 0.24 \\
\hline 41KM69 & ILP & 1 & circular & 11 & 10.7 & 92.46 \\
\hline 41KM69 & ILP & 5 & circular & 0.6 & 0.6 & 0.28 \\
\hline 41KM69 & ILP & 39 & circular & 0.41 & 0.37 & 0.12 \\
\hline 41KM69 & ILP & 45 & oval & 0.58 & 0.72 & 0.33 \\
\hline 41KM69 & ILP & 46 & irregular & 0.95 & 0.55 & 0.44 \\
\hline 41KM69 & ILP & 47 & circular & 0.55 & 0.6 & 0.26 \\
\hline 41KM69 & ILP & 53 & oval & 0.97 & 0.4 & 0.37 \\
\hline 41KM69 & ILP & 54 & & 0.14 & 0.23 & 0.03 \\
\hline $41 \mathrm{KM} 69$ & ILP & 81 & & 3 & 4 & 9.62 \\
\hline 41KM69 & ILP & 83 & oval & 0.4 & 0.3 & 0.1 \\
\hline 41KM69 & ILP & 84 & irregular & 0.36 & 0.32 & 0.09 \\
\hline 41KM69 & ILP & 85 & circular & 0.25 & 0.3 & 0.06 \\
\hline 41KM69 & ILP & 86 & circular & 0.5 & 0.45 & 0.18 \\
\hline 41KM69 & ILP & 93 & circular & 0.7 & 0.7 & 0.38 \\
\hline 41ML35 & ILP & 1 & & 0.533 & 0.427 & 0.18 \\
\hline 41ML35 & ILP & 2 & & 0.579 & 0.427 & 0.2 \\
\hline 41MM341 & ILP & 13 & irregular & 0.8 & 0.6 & 0.38 \\
\hline $41 \mathrm{MM} 341$ & ILP & 14 & \begin{tabular}{|l} 
irregular \\
\end{tabular} & 1.02 & 0.7 & 0.58 \\
\hline 41MM341 & ILP & 15 & circular & 0.4 & 0.42 & 0.13 \\
\hline $41 \mathrm{MM} 341$ & ILP & 18 & \begin{tabular}{|l} 
irregular \\
\end{tabular} & 1.3 & 0.8 & 0.87 \\
\hline $41 \mathrm{MM} 341$ & ILP & 28 & \begin{tabular}{|l} 
irregular \\
\end{tabular} & 0.44 & 0.3 & 0.11 \\
\hline 41MM341 & ILP & 36 & circular & 0.5 & 0.55 & 0.22 \\
\hline $41 \mathrm{MM} 341$ & ILP & 39 & oval & 0.86 & 0.62 & 0.43 \\
\hline $41 \mathrm{MM} 341$ & ILP & 45 & \begin{tabular}{|l} 
irregular \\
\end{tabular} & 0.62 & 0.48 & 0.24 \\
\hline 41MM341 & ILP & 48 & circular & 0.61 & 0.58 & 0.28 \\
\hline 41MM341 & ILP & $49 b$ & oval & 1.65 & 0.65 & 1.04 \\
\hline $41 \mathrm{MM} 341$ & ILP & $50-1$ & oval & 1.35 & 0.95 & 1.04 \\
\hline $41 \mathrm{MM} 341$ & ILP & $50-2$ & circular & 1.2 & 1.2 & 1.13 \\
\hline $41 \mathrm{MM} 341$ & ILP & $50-3$ & oval & 1.15 & 0.95 & 0.87 \\
\hline $41 \mathrm{MM} 341$ & ILP & $50-5$ & circular & 1.5 & 1.5 & 1.77 \\
\hline
\end{tabular}


Table 9-5. Continued...

\begin{tabular}{|c|c|c|c|c|c|c|}
\hline Site & Component & Feature \# & Shape & Length & Width & Area \\
\hline 41ZV202 & ILP & 7 & oval & 0.85 & 0.45 & 0.33 \\
\hline 41ZV202 & ILP & 8 & oval & 1.45 & 1.05 & 1.23 \\
\hline 41ZV202 & ILP & 9 & oval & 0.38 & 0.32 & 0.1 \\
\hline 41ZV202 & ILP & 10 & oval & 0.75 & 0.55 & 0.33 \\
\hline 41ZV202 & ILP & 13 & oval & 1.2 & 0.84 & 0.82 \\
\hline 41JW8 & TLP & 4 & oval & 0.46 & 0.5 & 0.18 \\
\hline 41JW8 & TLP & 6 & oval & 0.8 & 1.3 & 0.87 \\
\hline 41JW8 & TLP & 8 & irregular & 1.45 & 1.2 & 1.38 \\
\hline 41KM69 & TLP & 3 & oval & 0.67 & 0.57 & 0.3 \\
\hline 41KM69 & TLP & 10 & irregular & 0.87 & 0.69 & 0.48 \\
\hline 41KM69 & TLP & 57 & & 0.5 & 0.3 & 0.13 \\
\hline 41KM69 & TLP & 58 & circular & 0.5 & 0.45 & 0.18 \\
\hline 41KM69 & TLP & 59 & & 2.5 & 2 & 3.98 \\
\hline 41KM69 & TLP & 79 & circular & 0.75 & 0.8 & 0.47 \\
\hline 41KM69 & TLP & 82 & circular & 0.18 & 0.18 & 0.03 \\
\hline 41KM69 & TLP & 91 & irregular & 0.88 & 0.8 & 0.55 \\
\hline 41KM69 & TLP & 92 & oval & 0.2 & 0.3 & 0.05 \\
\hline 41TV441 & TLP & 1 & circular & 0.6 & 0.5 & 0.24 \\
\hline 41TV441 & TLP & 2 & oval & 2.1 & 1.3 & 2.27 \\
\hline 41TV441 & TLP & 3 & irregular & 1 & 0.6 & 0.5 \\
\hline 41TV441 & TLP & 4 & irregular & 0.8 & 0.5 & 0.33 \\
\hline 41TV441 & TLP & 11 & circular & 1 & 0.9 & 0.71 \\
\hline 41TV441 & TLP & 12 & oval & 0.85 & 0.5 & 0.36 \\
\hline 41TV441 & TLP & 13 & circular & 0.5 & 0.5 & 0.2 \\
\hline 41TV441 & TLP & 14 & circular & 0.85 & 0.8 & 0.53 \\
\hline 41TV441 & TLP & 15 & circular & 0.75 & 0.75 & 0.44 \\
\hline 41TV441 & TLP & 16 & circular & 1 & 1 & 0.79 \\
\hline 41TV441 & TLP & 18 & irregular & 0.87 & 0.5 & 0.37 \\
\hline 41TV441 & TLP & 24 & circular & 0.6 & 0.55 & 0.26 \\
\hline 41WN88 & TLP & 2 & circular & 0.48 & 0.45 & 0.17 \\
\hline 41WN88 & TLP & 4 & oval & 0.78 & 0.44 & 0.29 \\
\hline
\end{tabular}

designation, feature number as designated in the original report, feature shape, length and width in meters, and area in square meters. In several cases, only the feature length and width measurements were given and no plan drawing could be located. In these cases shape data are missing. Plan view shapes were partitioned into three major forms. Circular features had roughly similar length and width measurements, and consistent shapes. The designation of an oval shape was given to features described in reports as oval, ovoid, or roughly circular. Irregular features were amorphous in form. We had originally attempted to record profile information, but it was often the case that no staining was associated with the features, so no profile shape could be determined. We therefore dropped profile shape. References for the original reports are in Table 9-4.

Note that most of the features listed in the Table 9-5 are relatively small hearths. We classified only a single feature, Feature 1 at $41 \mathrm{KM} 69$, as a burned rock midden. Burned rock middens were present on some of the other sites reviewed, and they were counted as a burned rock feature in Table 9-4. However, it is seldom the case that an entire midden is excavated. Thompson et al. (2007) accomplished this task at 41KM69 with the help of a Gradall. In most cases, however, middens were only tested, and we were not certain of their size. These features were not included in Table 9-5. Of course, the presence of only a single feature during the Initial Late Prehistoric with an area of over $92 \mathrm{~m}^{2}$ is also problematic and will skew the mean during this period. We therefore will eliminate this feature, at least when we consider changes through time in feature size.

Table 9-6 provides summary data, at the component level, for ground stone. The Table lists the site number, component designation, the location of the collections (CAR/TARL), the number of ground stone items associated with the component, and the number of complete and fragmentary ground stone items. We had no significant problems acquiring the number of ground stone items, either through the report or through an examination of the notes and/or artifacts stored at CAR. While we did not check the TARL collections, there were, in several cases, discrepancies between the number of ground stone listed in the report and what was curated at CAR. This may be a function of re-assessment of the artifact status, differential assignment of items (e.g., different functional classifications) by the curatorial staff, or discard. Regardless of why the discrepancies exist, in those cases where there were differences we used the description of the number of ground stone items provided in the original report. We had attempted to assess whether a given item was complete of

Table 9-6. Ground Stone Data at the Component Level

\begin{tabular}{|c|c|c|c|c|}
\hline Site \# & Component & $\begin{array}{l}\text { Location of } \\
\text { Collection }\end{array}$ & $\begin{array}{l}\text { \# of Ground } \\
\text { Stone Items }\end{array}$ & $\begin{array}{l}\text { Complete/ } \\
\text { Fragment }\end{array}$ \\
\hline 41GD21 & ILA & CAR & 2 & * \\
\hline 41LK201 & ILA & CAR & 11 & * \\
\hline 41LK67 & ILA & CAR & 3 & 0 to 3 \\
\hline $41 \mathrm{MM} 340$ & ILA & CAR & 0 & 0 \\
\hline 41HY209T & ILP & TARL & 0 & 0 \\
\hline $41 \mathrm{KM} 69$ & ILP & CAR & 0 & 0 \\
\hline $41 \mathrm{MC} 296$ & ILP & CAR & 27 & * \\
\hline 41ML35 & ILP & TARL & 0 & 0 \\
\hline $41 \mathrm{MM} 341$ & ILP $(A \cup 1+2)$ & CAR & 7 & 0 of 7 \\
\hline 41ZV202 & ILP & CAR & 0 & 0 \\
\hline $41 \mathrm{KM} 69$ & MLA & CAR & 0 & 0 \\
\hline $41 \mathrm{MC} 296$ & MLA & CAR & 27 & * \\
\hline $41 \mathrm{MM} 340$ & MLA & CAR & 2 & 1 to 1 \\
\hline 41WM267 & MLA & TARL & 4 & * \\
\hline $41 \mathrm{CN} 95$ & TLA & TARL & 0 & 0 \\
\hline 41HY209T & TLA & TARL & 0 & 0 \\
\hline $41 \mathrm{KM} 69$ & TLA & CAR & 0 & 0 \\
\hline 41LK67 & TLA & CAR & 2 & 0 to 2 \\
\hline $41 \mathrm{ML} 35$ & TLA & TARL & 1 & 0 to 1 \\
\hline $41 \mathrm{MM} 340$ & TLA & CAR & 2 & 1 to 1 \\
\hline 41WM267 & TLA & TARL & 0 & 0 \\
\hline 41JW8 & TLP & CAR & 17 & 0 to 17 \\
\hline 41KM69 & TLP & CAR & 0 & 0 \\
\hline 41LK201 & TLP & CAR & 14 & * \\
\hline 41LK67 & TLP & CAR & 0 & 0 \\
\hline 41MC296 & TLP & CAR & 25 & * \\
\hline 41TV441 & TLP & TARL & 20 & 1 to 19 \\
\hline 41WN88 & TLP & CAR & 7 & 0 to 7 \\
\hline
\end{tabular}


fragmentary, but while most reports provided summary information at the site level for breakage patterns in ground stone, in most cases this information was not available at the component level. In cases where the material was stored at CAR, we reviewed the collections. However, as noted above, there were often discrepancies between the reports and the curational inventory. When the complete/fragment data are problematic, this is indicated by an asterisk in Table 9-6. We can say that only three of the 61 items that we could get fragmentation information on were complete. Given this low number, there is simply not sufficient data to allow a review of any temporal trends in breakage patterns. Finally, note that ground stone is not common. Twelve of the 28 components lacked ground stone.

\section{Floral Results: Shifts through time in Burned Rock Features}

The primary variable of interest is the density of burned rock features through time. If, as we have argued, bison abundance falls throughout the Late Archaic and into the Initial Late Prehistoric, with a significant decline in the Terminal Late Prehistoric, then we would expect that hunters and gatherers would increasingly incorporated lower ranked plant resources into their diet. We cannot measure shifts in the number of plant types directly because of problems with preservation and sampling. However, we can monitor shifts in the number of burned rock features. Because burned rock features are disproportionately associated with plant processing, the density of burned rock features should track the importance of plant resources in the diet, through not necessarily the number of different types of plant resources.

Figure 9-8 uses data presented in Table 9-4 to consider changes in burned rock features at the component level. For a given period, we created the values in the figure by first summing the number of features on components. The number of features was then divided by the total square meters excavated, and the result multiplied by 100 to avoid dealing with low numbers. This number was then adjusted for differences in phase lengths. The value was divided by the length of the phase, and again multiplied by 100. The bar heights in Figure 9-8 then are the numbers of FCR features per 100 square meters per 100 years. Figure 9-8 shows that our expectations are only partially supported by this data set. While there is a general increase through time, the lowest feature density is in the Middle Late Archaic, not in the Initial Late Archaic as we had expected. In addition, while there is a jump between the Initial Late Prehistoric and the Terminal Late Prehistoric, it is the Terminal Late Archaic, not the Terminal Late Prehistoric, that has the highest FCR density.
A consideration of shifts in feature size (see Table 9-6) hints at possible differences in area through time. Area was calculated as:

$$
\text { Area }=(3.1416) *[(\text { length }+ \text { width }) / 4]^{2}
$$

The area data sets are not normally distributed, with all sets skewed to the right. Mean values, then, are not appropriate for summarizing central tendencies. Figure 9-9 uses the median values for each phase. These clearly show that the largest features tend to be in the Initial Late Archaic, with a substantial drop in the Middle Late Archaic and a gradual rise throughout the remainder of the sequence. We would expect there to be an inverse relationship between FCR feature area and the number of features. All else being equal, if communal cooking activities are occurring more frequently, the density of features should be lower, and features should be larger, relative to situations that rely on more household level processing. The patterns in Figure 9-9 suggests that in terms of plant dependence, the high feature density values in the Initial Late Archaic (see Figure 9-8) may, in fact, be even higher than indicated by the 0.717 value.

The Figure 9-9 data do, however, underestimate feature size late in the sequence. This is especially the case in the Initial Late Prehistoric and the Terminal Late Prehistoric. Recall that burned rock middens are underrepresented in the Table 9-6 measurements. It is seldom the case that more than $50 \%$ of these features are excavated. As such, with the

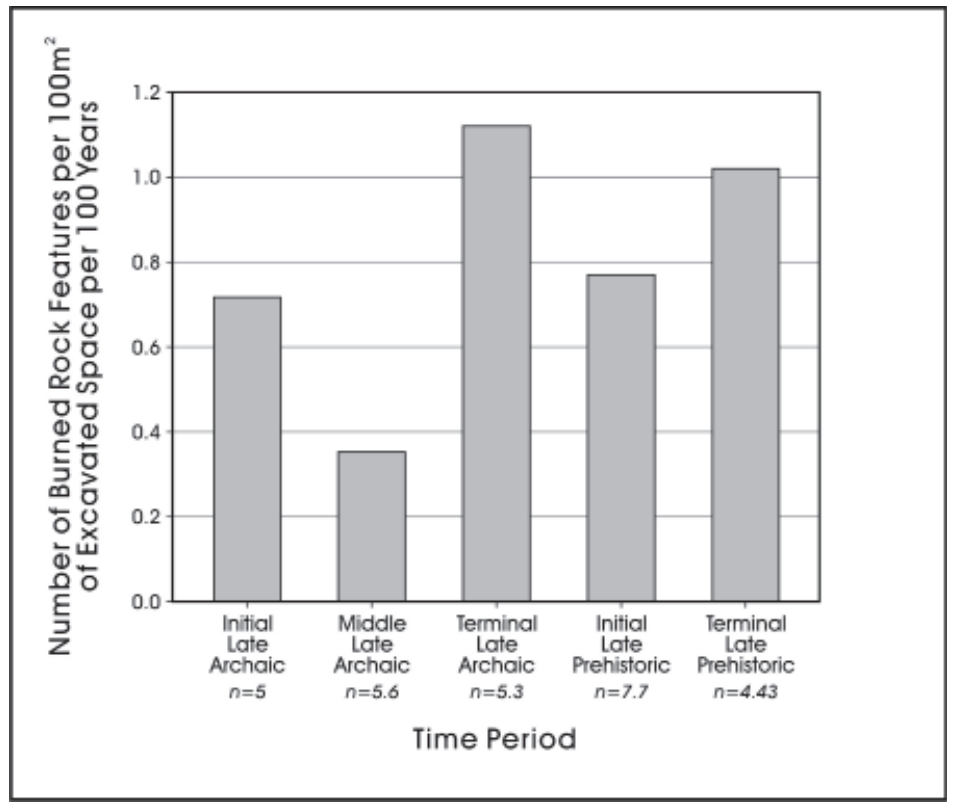

Figure 9-8. Changes in burned rock feature density through time (see Table 9-4). Sample size is the average number of rock features per component. 


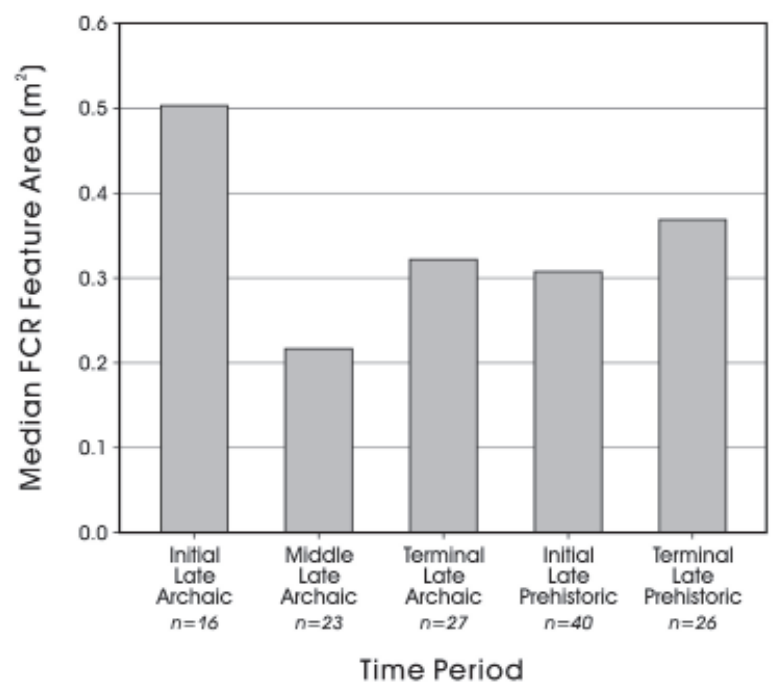

Figure 9-9. Changes in median area of features through time (see Table 9-6). Sample size is total rock features by time period.

single exception of Feature 1 at 41KM69, these features are not included in the size estimates. However, these extremely large features are clearly involved with plant processing (Black and Creel 1997; Mauldin et al. 2003). In addition, they tend to differentially date to the Late Prehistoric, probably peaking in the Initial Late Prehistoric (Black and Creel 1997; Mauldin et al. 2003). The size data in Figure 9-9, then, clearly underestimates FCR feature size, especially in the Initial Late Prehistoric.

Several additional elements in the Terminal Late Prehistoric may be related to an underestimate of plant dependence through FCR feature density. As we noted above, rock size data from 41KM69 (see Mauldin et al. 2008) clearly indicates a significant increase in the intensity of feature use during the Terminal Late Prehistoric period. That is, features appear to be reused more often during this period. Feature density would underestimate the importance of plant processing in this case. In addition, the Terminal Late Prehistoric period sees the introduction of ceramic technology that would allow direct fire cooking of plants. This would not necessarily require fire cracked rock. The importance of plants late in the sequence, then, may be underestimated by FCR feature density.

Finally, reference to Table 9-4 will show that $17 \%$ of the 29 components do not have any FCR features recorded. Figure 9-10 shows that the components that lack features increase through time. During the Terminal Late Prehistoric, roughly $43 \%$ or the seven components do not contain burned rock features. The lack of features on components clearly reduces the density values in Figure 9-8, especially during the Terminal Late Prehistoric. While the trend shown in Figure 9-10 may be related to differential preservation, if these components without burned rock features are eliminated from consideration, then the Terminal Late Prehistoric would have the highest feature density of any period, with 1.21 features per 100 square meters per 100 years. The increased frequency of components without features also hints at increasing component specialization late in the prehistoric sequence (see Dearing 2008).

\section{Floral Results: Shifts through time in Ground Stone}

As an additional measure of plant dependence, we focus on changes in the density of ground stone. We have argued that if bison population densities decreased in the study area throughout the Late Archaic and into the Initial Late Prehistoric, the density of ground stone tools should increase as a reflection of the inclusion of lowerranked plant resources, many of which require grinding before they are consumed. This increase should especially be apparent in the Terminal Late Prehistoric, where grassland data suggest accelerated bison declines, and we anticipated a greater variety of plant resources will be incorporated into the diet. Unfortunately, many of the same factors that we have discussed in the use of FCR features as a proxy for plant dependence complicate the use of density shifts in ground stone tools. We will create similar density per unit time measurements for ground stone as we used for FCR features.

Figure 9-11 uses ground stone counts presented in Table 9-6, the excavation areas per components listed in Table 9-4, and the phase length estimates to create a measure of ground stone density at the phase level. As with previous measures, the pattern of change in ground stone density is only partially consistent with expectations. Ground stone density declines slightly throughout the Late Archaic. We expected that there should be a slight increase over this time frame. However, ground stone density does increase from the Terminal Late Archaic into the Initial Late Prehistoric, and ground stone shows a dramatic increase during the Terminal Late prehistoric. These patterns are consistent with increased importance of plant resources during the Initial and especially during the Terminal Late Prehistoric as bison densities decline late in time.

\section{Summary}

We have used two classes of archeological data, changes in the density of FCR features and changes in the density of 


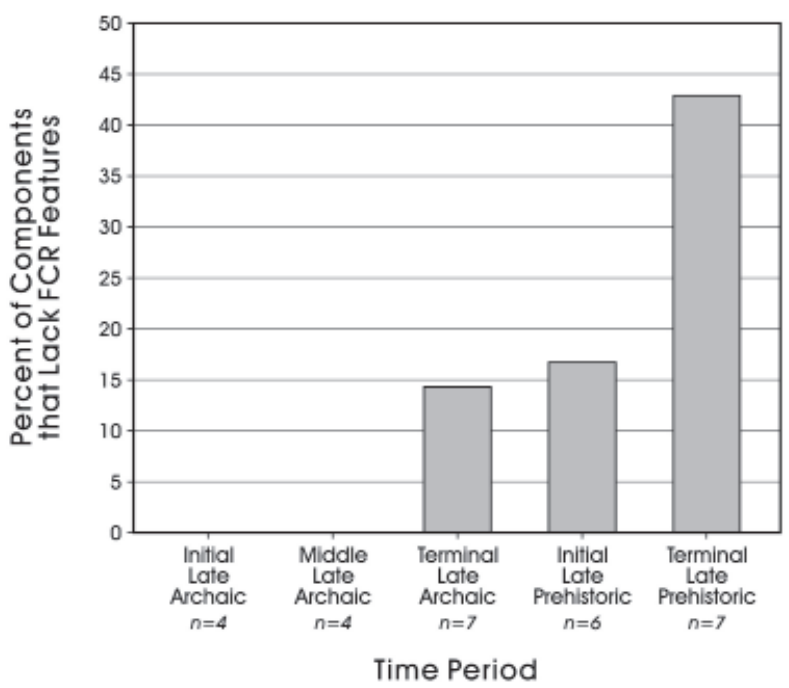

Figure 9-10. Percent of components in our database that lack FCR feature by temporal period (see Table 9-4). Sample size is total number of components.

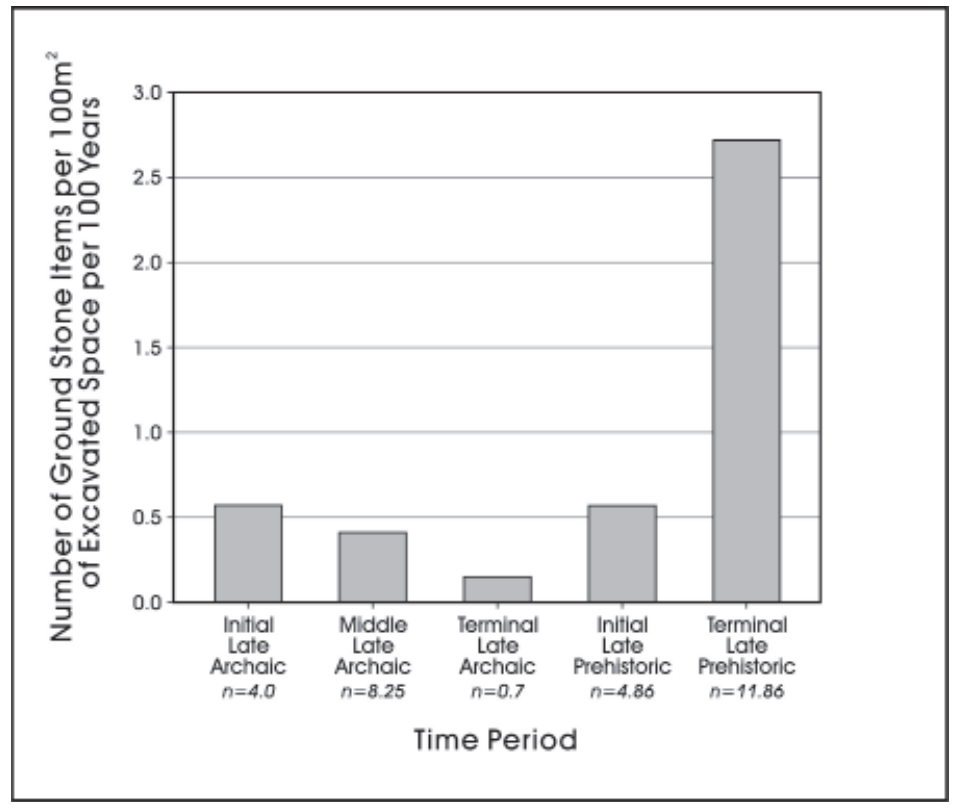

Figure 9-11. Shifts in ground stone density through time (see Table 9-4, 9-6). Sample size is the average number of ground stone per component used.

ground stone artifacts, as proxy measures for shifts in the intensity of plant processing and indirectly shifts in the role of plant resources in the diets of Texas hunter-gatherers. We suggested that as bison densities gradually declined from a high sometime in the Initial Late Archaic, that hunters and gatherers would add new, lower ranked plant resources to their diets and expand the use of plant resources already being used. We expected that this increased use of plants would be reflected in increases in the number of FCR features and ground stone artifacts. We expected this diet expansion to accelerate in the Late Prehistoric, with major differences clearly evident in FCR features and ground stone in the Terminal Late Prehistoric.

To consider the anticipated shifts in the FCR feature densities we used records from 162 FCR features on 28 different components that span roughly 4,000 years of Central and South-Central Texas prehistory. Our overall expectations, of increasing feature density through the Late Archaic and especially the Terminal Late Prehistoric, are only partially supported by these data. Note, however, that Mauldin et al. (2009), using a larger data set of 291 burned rock features from 60 Central and South Texas components, and focusing on the Middle and Terminal Archaic and the Initial and Terminal Late Prehistoric, have shown that the anticipated pattern of increased feature use late in time is strongly supported. They demonstrate a gradual change from a low of 0.28 FCR features per 100 square meters per 100 years in the Middle Late Archaic, to an overall high of 1.3 features in the Terminal Late Prehistoric. That larger data set includes many of the sites used here. The lack of strong patterning in the current data set may, then, simply be the result of a low sample size. In addition, a number of complications are evident, including possible shifts in intensity of feature use late in the sequence (see Mauldin et al. 2008), changes in the size of features (see Figure 9-9), under recording of burned rock midden features, and the introduction of ceramics late in the sequence that would allow for direct fire-cooking.

Patterns in ground stone density, derived from 171 items on 28 components, are also ambiguous with regard to the expectations of increasing plant dependence through time. Contrary to expectations, ground stone density declines slightly from the Initial Late Archaic through the Terminal Late Archaic. However, during the Initial Late Prehistoric, and especially the Terminal Late Prehistoric, the density of ground stone artifacts increases. These are consistent with expectations that plant resources should be increasingly used during these later periods.

\section{Summary}

Arguing from a general model of hunter-gatherer adaptation based on aspects of optimal foraging theory, we suggested in Chapters 7 and 8 that changes in the availability of higher ranked resources should result in expansion or contraction of the overall diet. If bison densities gradually declined from 
the Initial Late Archaic through the Terminal Late Archaic, as suggested by the grassland data, we expected hunters and gatherers to add lower ranked plants and animals to their diet, as well as intensify on those plants and animals already forming part of their diet. We expected that the dietary expansion and intensification, seen throughout the Late Archaic, should accelerate in the Late Prehistoric period, especially in the Terminal Late Prehistoric.

We first considered shifts in faunal resources. We suggested that two measures, changes in the number of taxa present in an assemblage and changes in bone fragment weights placed in size classes, should provide gross measures of faunal expansion or contraction. Using data from a variety of different components, the taxa expectations were generally supported. There is an overall increase in the number of faunal groups represented through time, and the increase appears to be associated with the addition of lower ranked resources. However, we cannot eliminate the possibility that taphonomic processes account for these shifts through time. Older assemblages should have a lower diversity of faunal types represented simply as a function of deterioration over time. Changes in the fragmentation data do not clarify the issues. They are only partially consistent with our overall expectations.
Estimating changes in the number of plant resources, as well as in the intensity of their use, proved problematic as no established methodology exists. We used changes in the density of FCR features and changes in the density of ground stone artifacts to estimate shifts in the intensity of plant processing and indirectly shifts in the role of plant resources in the diets. Only partial support for our expectation regarding FCR features was present in the data set. The ground stone data did demonstrate a significant increase associated with the Terminal Late Prehistoric, but patterns in the Late Archaic showed a gradual decrease in ground stone density rather than a gradual increase.

Overall, patterns in the Late Archaic tend to be opposite of what we predicted. Diet indicators suggest a contraction through time, rather than an expansion. However, the general patterns are not strong during this period. Review of the grassland data suggests that the shifts in grassland, and by extension bison, are gradual during the Late Archaic. They are not the dramatic declines that we see later in time. The pattern of diet expansion with falling bison densities is more clearly seen in the Terminal Late Prehistoric. The patterns here are stronger, consistent with expectations, and distinct from the Initial Late Prehistoric. 


\title{
Chapter 10: Assessing Changes in Technology
}

\author{
Raymond Mauldin, Steven Tomka, and Cynthia Munoz
}

In this chapter, we investigate changes in selected aspects of technological organization. Technological organization concerns how people structured activities associated with the manufacture, repair, use, and replacement of tools. Here, we focus on two aspects of technology. The first concerns the development and assessment of manufacturing costs. In our general hunter-gatherer model presented in Chapters 7 and 8 , we argued that changes in the presence/absence of large body-sized prey should have significant impact on tool design as well as in strategies of tool manufacture, use, and repair. Using shifts in grasslands as a base, we suggested that as bison are less common throughout the Late Archaic and into the Initial Late Prehistoric, the use of a tool kit that was more specialized, and consequently more expensive to both produce and maintain, should increase. This would especially be the case in the Terminal Late Prehistoric, when grassland data suggest bison are temporally and spatially restricted. The second aspect of technology investigated in this chapter involves assessing the frequency of what has been termed "gearing up" strategies. Specifically, gearing up involves the manufacture, at one location, of large numbers of tools in anticipation of future needs and failure rates, rather than replacing tools as they break. Hunters and gatherers are likely to use gearing up strategies under conditions where high return resources, such as bison, are increasingly restricted in time and space. These are precisely the conditions that we suggest followed the Initial Late Prehistoric.

\section{Assessing Tool Manufacturing Costs}

We envision tools as ranging from generalized to specialized in form. Specialized, formal tools (e.g., ceramics; hafted lithic tools, bows and arrows) tend to require more time to manufacture, are usually more complex, and in some cases may require specific raw materials that have limited distributions. As a group, hunters and gatherers frequently maintain specialized tools, also increasing their overall costs (see Binford 1977, 1979). However, because of their specialized nature, these tools are often more efficient at accomplishing a specific task. Generalized or expedient tools, conversely, are less expensive to produce, have fewer components, and often have short use-lives with minimum associated maintenance costs. While less costly and potentially useful in the performance of a variety of tasks, generalized tools are often less efficient at any given task. Working from our theoretical position, we assume that hunters and gatherers should invest time and effort on the production of specialized tools under conditions of declining encounters with high ranked resources.
However, there will be some functionally specific forms (e.g., projectile points, unifacially retouched hide scrapers) that may not fit these general expectations since manufacture costs tend to be conditioned by the degree of dependence of the tool user upon the specific tool (Tomka 2001). That is, some tools will be designed to carry out a specific task, and the frequency of that task may dictate the frequency of the tool. Bison procurement may be one such task where some specific tools are required regardless of increases or decreases in abundance of the animal. If that is the case, then the patterns of specialized tool abundance, at least in some functional sets, will pattern exactly opposite of what we have suggested. Under this alternative scenario, increasing bison will require the use of more specialized tools within an assemblage, while decreasing bison will require relatively fewer specialized tools since they will be used less often. While acknowledging this possibility for specific tool forms, we still anticipate that the frequency of specialized tools will increase with decreasing bison numbers. However, this statement is not meant to imply that all specialized tools are directly related in a functional sense to bison procurement.

To investigate this suggested relationship between energy expended in the manufacture of tools and bison availability, we need to categorize each tool according to the level of energy that was expended for its manufacture. To do this, we focus on the area covered by retouch (i.e., flake removals) on a tool as a proxy for the level of effort expended in its manufacture. Although the stone portion of a lithic tool often represents only one element of a compound tool, we assume that there is a correlation between the level of effort expended in overall tool manufacture and the level of effort invested in the manufacture of the stone portion of that tool. We categorized stone tools into one of five categories, with our focus on manufacturing costs. From the least energy expensive to the most expensive these categories are: (1) utilized flakes; (2) marginally retouched items; (3) unifacially retouched specimens; (4) bifacially retouched forms; and (5) retouched items with haft elements. This classification scheme assumes that as the amount of retouch increases, the time required in the manufacture of the tool also increases. It also assumes that the construction of haft elements will increase the manufacture costs of hafted tools, both in terms of the specific requirements of the haft production, and in the production of the other elements of the tool. For example, we would argue that a "crude" uniface is less expensive, in terms of time to produce, than a formal uniface with a hafting element (e.g., "Clear Fork" uniface). Not only do the latter probably require more time to produce, but also the presence 
of the hafting element implies that the uniface, as such, is only one element of a more complex tool ${ }^{\text {(note } 8)}$.

We define utilized flakes as any flake containing consistent damage evidenced by small (ca. $+/-1 \mathrm{~mm}$ ) flake scars along one or more edges. Retouched items are defined as having retouch on one or more faces that does not cover more than $1 / 3$ of the face. Unifaces are defined as having retouch on one face that covers more than $1 / 3$ of the face. Biface tools have retouch covering more than $1 / 3$ or both faces. The final category, identified as retouched items with hafting, includes tools commonly classified as projectile points, formal knives, formal scrapers, and other items that appear to have hafting elements. In addition, specialized bifaces tools, such as drills, are included in this category. Note that the five categories are mutually exclusive as we always classify a given item into the most expensive group possible. That is, we would classify a biface that also has evidence of use along one or more edges as a biface, not as a utilized flake. Figure 10-1 presents examples from 41ZV202 of these various groupings. While complicated by the possibility that some tools may be reworked from older tools, and while some groups (e.g., bifacially retouched forms) may have a large number of items that are not finished and reflect production steps and not necessarily finished products, the scheme generally reflects the manufacturing costs in most cases.

\section{Data Acquisition}

Using this scheme, we can quantify manufacture costs at a component level by comparing the relative proportions of tools found within each of our five categories. For example, the combined data recovery and testing Initial Late Prehistoric material from 41ZV202 contains 78 tools. Our review of these data placed 38 tools in the bifacially retouched group $(48.7 \%)$ and 24 in the retouched with hafting element group (30.8\%). Overall, these two expensive groups account for just over $79 \%$ of the $41 \mathrm{ZV} 202$ tools. At the other end of the spectrum, there are three (3.8\%) utilized flakes and 11 (14\%) marginally retouched items. Unifaces account for the remaining two tools. For comparative material, we reviewed lithic tools from a series of Late Archaic and Late Prehistoric components in Central and South-Central Texas. We focused on the components identified previously in Table 9-6 that have assemblages housed at CAR. Treating the two Initial Late Prehistoric components at 41MM341 (see Gadus et al. 2006) as separate analytical units, this resulted in our review of 21 components on 10 different sites (Figure 10-2).

One of the initial complications in developing the proportional comparison data sets is developing comparable measures across components. While the lead author of this chapter reviewed and classified all reported tools, we felt that utilized flakes were most likely to be under-recorded in reports. In order to correct for this under representation, we selected a random sample of about 500 flakes for review. These were scanned for macroscopic evidence of use wear. Our goal was to quantify the number of utilized flakes. As such, we treated each flake with use wear present as a single tool, rather than treating each edge of a flake as a potential tool. In a small number of cases, macroscopic analysis regarding use was ambiguous. We subjected these to low-power micro-wear analysis at 50-80-times magnification to discern the utilized edge. We used the percentage of single-use and multiple-use flakes in the sample to estimate the total number of single and multiple tools in the overall assemblage.

We encountered problems with two of the 21 components reviewed. The first of these was the Initial Late Archaic component on 41GD21. During an initial search of CAR curatorial records associated with the faunal review presented in the previous chapter, both debitage and tools were listed as present in this collection. However, our search for debitage and tools from specific proveniences associated with the Initial Late Archaic occupation at this site failed to recover any tools. The tools shown in our initial review were only derived from shovel testing. A detailed review of all original records associated with the site suggests that all tools recovered from excavation contexts may have been "loaned" to the land owner shortly after the site report was published in 1979. The tools are not currently available. Without the tools for comparison, the review of a sample of debitage for utilized flakes becomes meaningless.

The second component to present problems was the Terminal Late Prehistoric component on site 41WN88. Portions of the tools, consisting of all projectile points, some of the unifaces, and the utilized flakes, were not found in the collections at CAR. A number of bifaces, as well as several unifaces are present in the collections, and there are black and white photographs of all projectile points. The lack of many of the more expensive, hafted tools limits the analysis. Consequently, we eliminated any debitage analysis from this component, and we were unable to review many of the tools. Nevertheless, using a combination of photographs, previous analysis conducted by David Nickels (2000), and a review of the tools present in the CAR collection, we can provide an estimate of tool costs for this component. Note, however, that no debitage analysis was conducted. The number of utilized flakes at 41WN88 may, therefore, be slightly low relative to the true number.

With the elimination of 41GD21, 20 components remain. Table 10-1 presents the information collected on these components. Included in the table are the site, component designation 


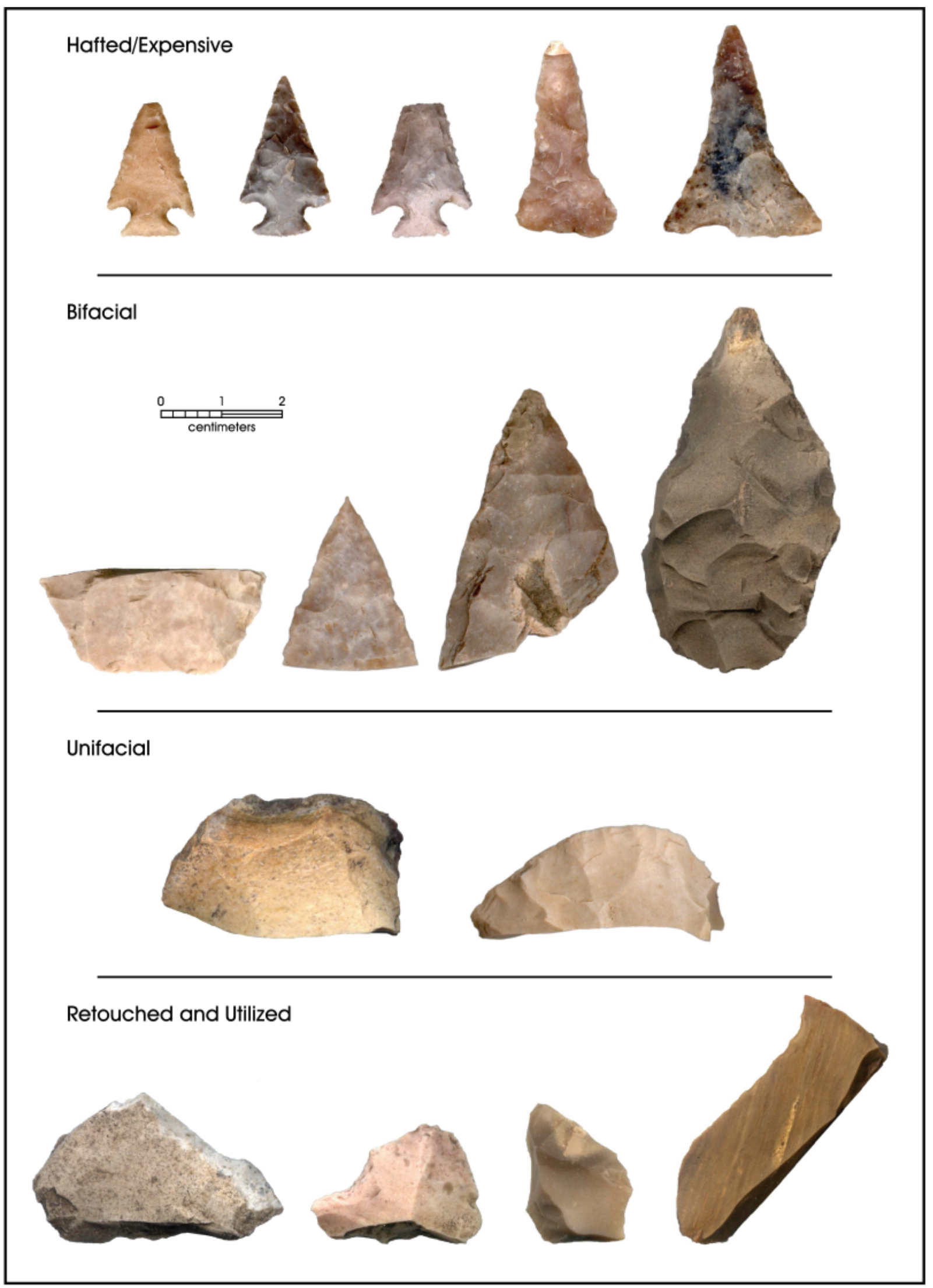

Figure 10-1. Examples of tool cost categories from 41ZV202. 


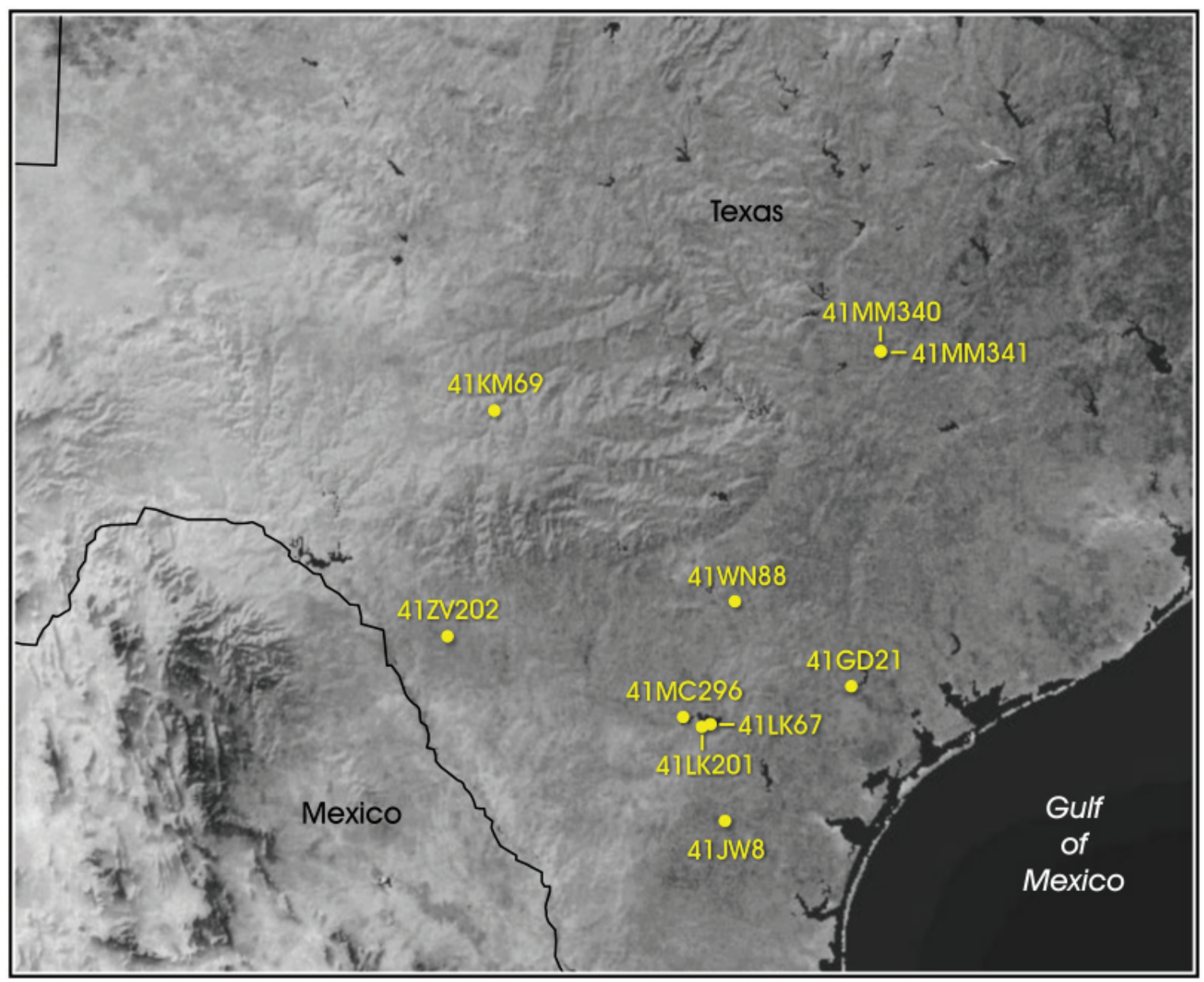

Figure 10-2. 41ZV202 and comparative sites used in technological investigations.

(e.g., ILA- Initial Late Archaic, MLA- Middle Late Archaic), information on the debitage reviewed and information on tool costs. The debitage data includes overall counts by component, the number of flakes reviewed, the percent of the total, the number of utilized flakes seen, the estimated number of new utilized flakes present in the assemblage (based on the $\%$ sampled, the number of new utilized flakes, and the total debitage counts), and the number of utilized flakes observed in the tools. The cost data is shaded. For each component, we present the number of utilized flakes (estimated new utilized flakes plus the original utilized flakes), and the numbers of marginally retouched flakes, unifaces, bifaces, expensive and hafted items, and the total number of tools present.

Table 10-1 shows that on 19 components a sample of debitage ranging between 433 and 530 items was scanned for the presence of utilized flakes. The average sample size reviewed $(n=489)$ is just under the target sample of 500 items per component. The debitage sample reviewed represents a random sample of between 39.6 and 2.4\% that was drawn using functions in Excel. The sample operated at the bag level rather than the level of the individual artifact. Consequently, depending on the number of items in a given bag and on which bag was randomly selected, some variability in numbers were produced. In addition, note that in a small number of cases, items assigned as debitage were, in fact, burned rock or other items. While this was not frequent, most components had at least a few items that were not debitage. We eliminated these, further reducing the targeted 500 items per sample. Surprisingly, our review shows that researchers do not commonly overlook utilized flakes in most assemblages. None of the assemblages we reviewed had more than a single utilized item discovered. However, given the small percentages of debitage reviewed in most cases, the discovery of a single flake resulted in an estimated increase of between 3 and 35 utilized flakes at an assemblage level.

\section{Shifts in Tool Manufacturing Costs}

Does the use of a more expensive tool kit increase through time as bison availability declines, as we have suggested? Is this increase especially apparent in the Terminal Late Prehistoric, when grassland data suggest bison are temporally and spatially restricted? 
Table 10-1. Samples of Tools from 41ZV202 and Comparative Components Partitioned by Expense

\begin{tabular}{|c|c|c|c|c|c|c|c|c|c|c|c|c|c|}
\hline 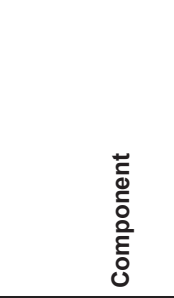 & 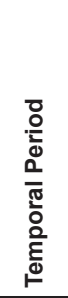 & 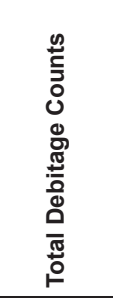 & 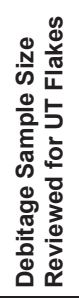 & 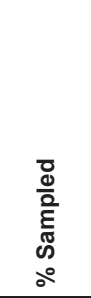 & 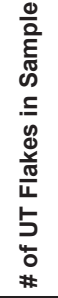 & 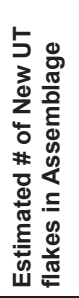 & 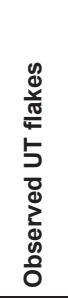 & 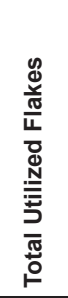 & 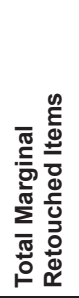 & 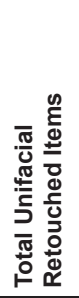 & 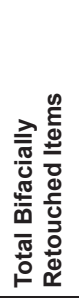 & 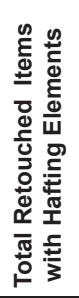 & 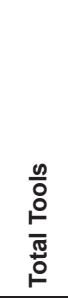 \\
\hline $41 \mathrm{MM} 340$ & ILA & 9,636 & 469 & 4.87 & 0 & 0 & 16 & 16 & 23 & 1 & 26 & 23 & 89 \\
\hline 41LK67 & ILA & 1,296 & 492 & 37.96 & 0 & 0 & 10 & 10 & 6 & 1 & 5 & 1 & 23 \\
\hline 41LK201 & ILA & 1,736 & 474 & 27.3 & 1 & 4 & 1 & 5 & 4 & 2 & 6 & 3 & 20 \\
\hline 41MM340 & MLA & 20,282 & 506 & 2.49 & 0 & 0 & 94 & 94 & 29 & 8 & 52 & 34 & 217 \\
\hline $41 \mathrm{MC} 296$ & MLA & 1,454 & 506 & 34.8 & 1 & 3 & 5 & 8 & 5 & 1 & 6 & 1 & 21 \\
\hline 41KM69 & MLA & 5,511 & 502 & 9.11 & 1 & 11 & 1 & 12 & 7 & 0 & 24 & 11 & 54 \\
\hline 41MM340 & TLA & 18,010 & 522 & 2.9 & 1 & 35 & 30 & 65 & 24 & 1 & 35 & 29 & 154 \\
\hline 41LK67 & TLA & 4,598 & 473 & 10.29 & 0 & 0 & 23 & 23 & 33 & 7 & 18 & 3 & 84 \\
\hline 41KM69 & TLA & 9,981 & 433 & 4.34 & 1 & 23 & 1 & 23 & 5 & 11 & 36 & 26 & 102 \\
\hline 41ZV202 & ILP & 5,251 & 476 & 9.06 & 0 & 0 & 3 & 3 & 11 & 2 & 38 & 24 & 78 \\
\hline 41MM341-Au2 & ILP & 13,712 & 520 & 3.79 & 1 & 26 & 81 & 107 & 43 & 4 & 64 & 24 & 242 \\
\hline 41MM341-Au1 & ILP & 21,769 & 531 & 2.44 & 0 & 0 & 148 & 148 & 73 & 16 & 98 & 44 & 379 \\
\hline $41 \mathrm{MC} 296$ & ILP & 1,103 & 437 & 39.62 & 0 & 0 & 7 & 7 & 3 & 0 & 13 & 1 & 24 \\
\hline 41KM69 & ILP & 17,684 & 509 & 2.88 & 0 & 0 & 1 & 1 & 11 & 10 & 72 & 18 & 112 \\
\hline $41 \mathrm{MC} 296$ & TLP & 3,142 & 489 & 15.56 & 0 & 0 & 4 & 4 & 19 & 11 & 27 & 36 & 97 \\
\hline 41LK67 & TLP & 1,907 & 463 & 24.28 & 0 & 0 & 11 & 11 & 9 & 3 & 7 & 5 & 35 \\
\hline 41LK201 & TLP & 15,972 & 530 & 3.32 & 0 & 0 & 9 & 9 & 33 & 11 & 85 & 72 & 210 \\
\hline 41KM69 & TLP & 3,298 & 465 & 14.1 & 0 & 0 & 1 & 1 & 5 & 10 & 8 & 21 & 45 \\
\hline 41JW8 & TLP & 12,665 & 494 & 3.9 & 1 & 26 & 46 & 72 & 115 & 64 & 196 & 142 & 589 \\
\hline 41WN88 & TLP & $\mathrm{n} / \mathrm{a}$ & $\mathrm{n} / \mathrm{a}$ & $\mathrm{n} / \mathrm{a}$ & $\mathrm{n} / \mathrm{a}$ & $\mathrm{n} / \mathrm{a}$ & $\mathrm{n} / \mathrm{a}$ & 50 & 60 & 22 & 147 & 80 & 359 \\
\hline TOTALS & & 169,007 & 9291 & & 7 & 128 & 492 & 669 & 518 & 185 & 963 & 598 & 2934 \\
\hline
\end{tabular}

To answer these questions, we converted the tool cost data in Table 10-1 to percentages and looked for overall increases or decreases through time in tool costs at the component level. Figure 10-3 presents box plots of the percentage of bifacial and hafted tools by component using the data in Table 10-1. While not statistically valid as the variability in percentage data is limited to values of between 0 and 100, box plots do provide a convenient summary format. We initially combine the bifacial and hafted categories as an "expensive" tool group because, as we noted previously, a majority of bifaces probably reflect steps in the production of hafted tools, rather than finished tools as such. Focusing on the relative positions of the boxes and the median values in Figure 10-3, there appears to be little change in the percentage of "expensive" tools through the Late Archaic. Overall, median values decline slightly from the Initial Late Archaic through the Terminal Late Archaic rather than increase as we expected. However, to the degree that shifts in the median percentage values reflect relative importance of tool groups, there is clearly

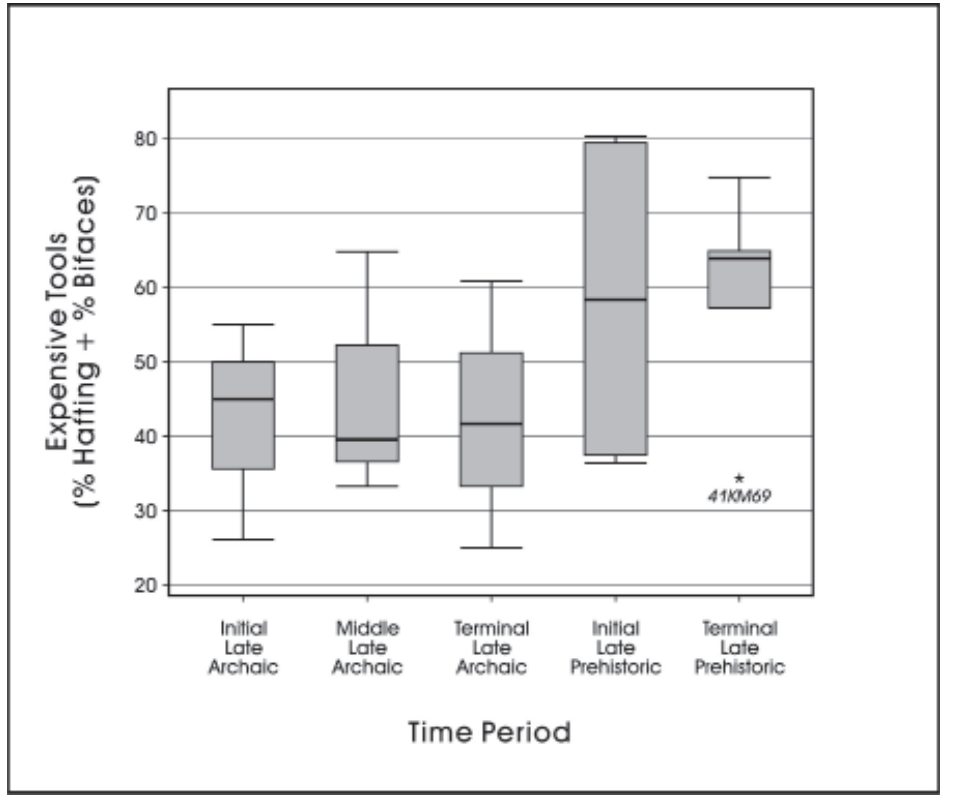

Figure 10-3. Percentage of expensive tools through time (see Table 10-1). 


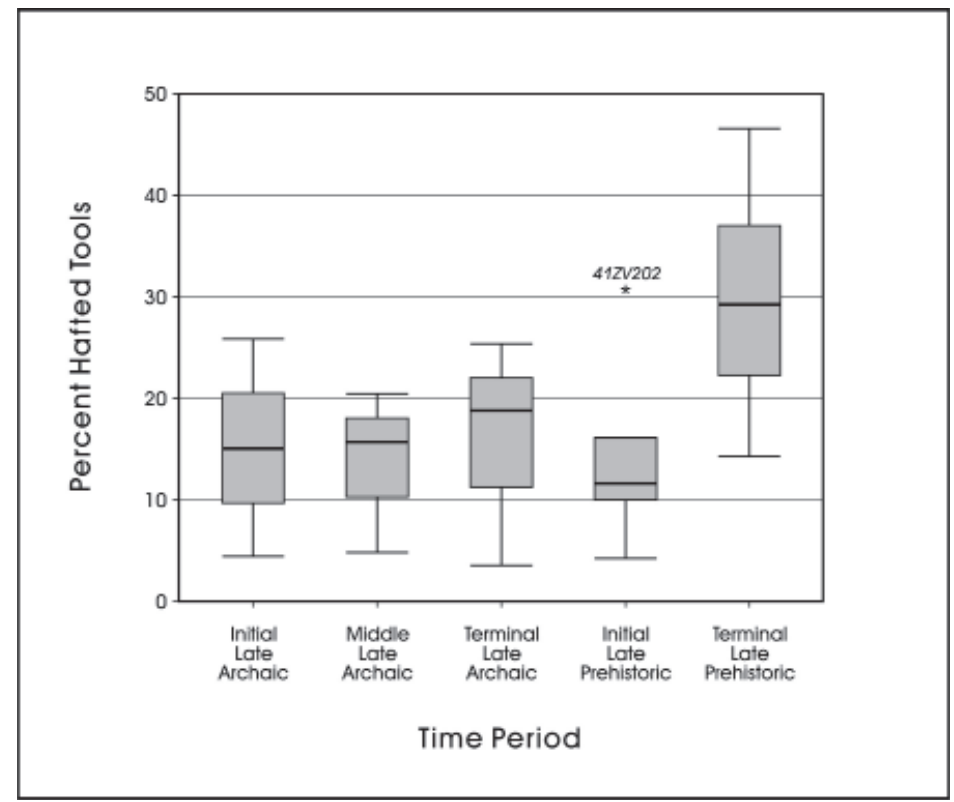

Figure 10-4. Percentage of hafted tools through time (see Table 10-1).

a large increase in the use of expensive tools between the Terminal Late Archaic and the Initial Late Prehistoric. That increase continues into the Terminal Late Prehistoric. Five of the six Terminal Late Prehistoric components have expensive tools represented at percentages in excess of $57 \%$. These aspects of the overall pattern are consistent with expectations. Finally, note the extreme range in percentage values in the expensive tool percentages for the Initial Late Prehistoric. We expected this higher variability to be present later in time. It is at this time that, based on climate data, that we suggested high variability in production was present.

Figure 10-4 uses a similar presentation format and focuses on the hafted tool class. Within this group, there is a gradual increase in median values throughout the Late Archaic, and the Terminal Late Prehistoric does show a significant increase over all other time periods. Both of these match our expectations for this tool class. However, the Initial Late Prehistoric pattern declines relative to the Late Archaic. This does not fit with expectations. We expected an increase during this period as bison populations declined. The single exception to this Initial Late Prehistoric decline, identified as an outlier in Figure 10-4, is 41ZV202.

Finally, Figure 10-5 presents box plots for shifts in "inexpensive" or more expediently produced tools. Here we have combined utilized flakes and retouched items. Unifaces are not included in the plots. However, because they make up only a small number of tools at any given component, the Figure 10-5 patterns is, in effect, a mirror image of the 10-3 plot. The role of inexpensive tools increases throughout the Late Archaic, with a rapid and significant drop through the Late Prehistoric as expensive tools increase. As with the Figure 10-3 pattern, there is significant variability shown in the percentage values for the Initial Late Prehistoric.

\section{Summary}

Several aspects of the tool data, then, are consistent with expectations derived from our model of declining bison. It appears that hunters and gatherers will increasingly invest time in the production of specialized tools under conditions of declining high return resources. Under such conditions, the increasing cost associated with production is justified if it increases the return rates. This increased investment is especially clear late in the archeological sequence, where we see a significant jump in the importance of more specialized, and more expensive, tools at a time when grassland data suggests declining overall bison availability and significant temporal and spatial fluctuations. The changes through the Late Archaic are less clear. Changes in expensive tools may (Figure 10-4) or may not (Figure 10-3) follow the suggested gradual increase. What is clear, however, is that any directional change evidenced by shifts in the use of more expensive, specialized tools is minimal over this long period. To the degree that shifts in the availability of bison are driving those changes, it appears that these shifts are minimal.

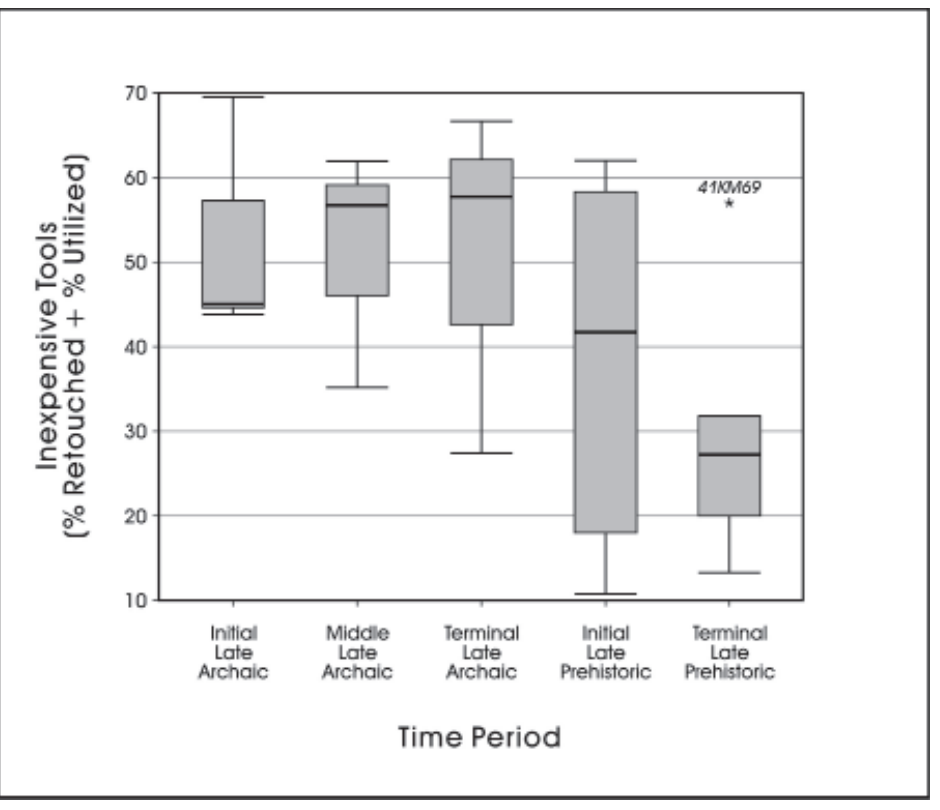

Figure 10-5. Percentage of inexpensive tools through time (see Table 10-1). 


\section{Monitoring Gearing-Up}

While the subsequent chapter considers shifts in mobility strategies that are associated with changes in resource structure, this section focuses on shifts in tool manufacturing, use, and replacement strategies, all of which are closely related to changes in mobility strategies. Specifically, in this section we investigate the frequency of "gearing-up" strategies. Gearing-up involves the manufacture, at one location, of large numbers of tools in response to anticipated needs and failure rates rather than ongoing needs for tool replacement. This strategy of manufacturing tools for future needs contrasts with a strategy where tool manufacture is responsive to on-demand replacement of failed tools. Because this strategy involves the manufacture of specimens at the location where the tool failed, on-demand replacement has the effect of immediately reintroducing a needed implement into the systemic context, resulting in the production of one replacement tool for each use-failed tool. A successful tool manufacture process will terminate in the production of a complete functional specimen that will replace the usefailed component of a tool. There is a chance, however, that the manufacture of a replacement tool will result in a manufacture-failed specimen either due to stochastic factors such as unidentified imbedded fracture lines within the parent material or technical/mechanical errors on the part of the craftsmen. We cannot estimate the actual failure rates of prehistoric tool manufacture activities. However, we will assume that mean manufacture failure rates were relatively constant through time for the period under consideration.

We suggest that comparisons of failure rates (i.e., manufacture versus use) within expensive tool classes can profitably be used to identify gearing up strategies. All else being equal, on-demand tool replacement should produce locations with slightly higher manufacturing failures relative to use failures. Conversely, if some procurement is likely to be conducted under time constraints or resources are processed for bulk transport, we anticipate that hunters will "gear-up" by placing some emphasis on tool manufacture for future use, and possibly organize that procurement logistically. If that is the case, there should also be locations where these tools, manufactured earlier, are used and sometimes broken. These locations should be dominated by higher frequencies of use-failed items relative to items broken during manufacture, because manufacturing occurred earlier at another location. Figure 10-6 presents the proposed relationship between manufacture-failed and use-failed items for locations in on-demand and gearingup systems. Note that the proposed break points and sections on the graph, divided by shading differences, are for illustrative purposes only. We do not know the exact location of these cut points, and it is probable that the dividing line will vary from case to case depending on a variety of systems specific variables.

In terms of bison procurement, when are time restricted activities, and by extension gearing-up strategies, likely to occur? Under conditions of improving grasslands, bison will be increasingly common in the environment and they will be encountered more frequently. Time-stress should be lessened under these conditions. Conversely, when grasslands are shrinking, bison populations should be declining. They may be available only seasonally, with increasing fluctuations. Hunters will encounter the animal less frequently. Under these conditions, time-stress should be increasing, and we anticipate a gearing-up strategy is more likely. One of the complicating elements, however, is the potential that even if there was no significant time stress, bison procurement could have been organized logistically, with bison processed in bulk. Such an organization would also favor the implementation of a gearing-up strategy. A logistical organization should focus on high return resources, and process material in excess of need for subsequent transport. However, high return resources do not necessarily require a logistical system. While we explore this complication in the subsequent chapter, it is the case that logistical systems are increasingly likely when critical resources exhibit increased spatial incongruence (see Binford 1980, 2001:269-276). We argue that this is most likely to occur when bison are declining in numbers, but

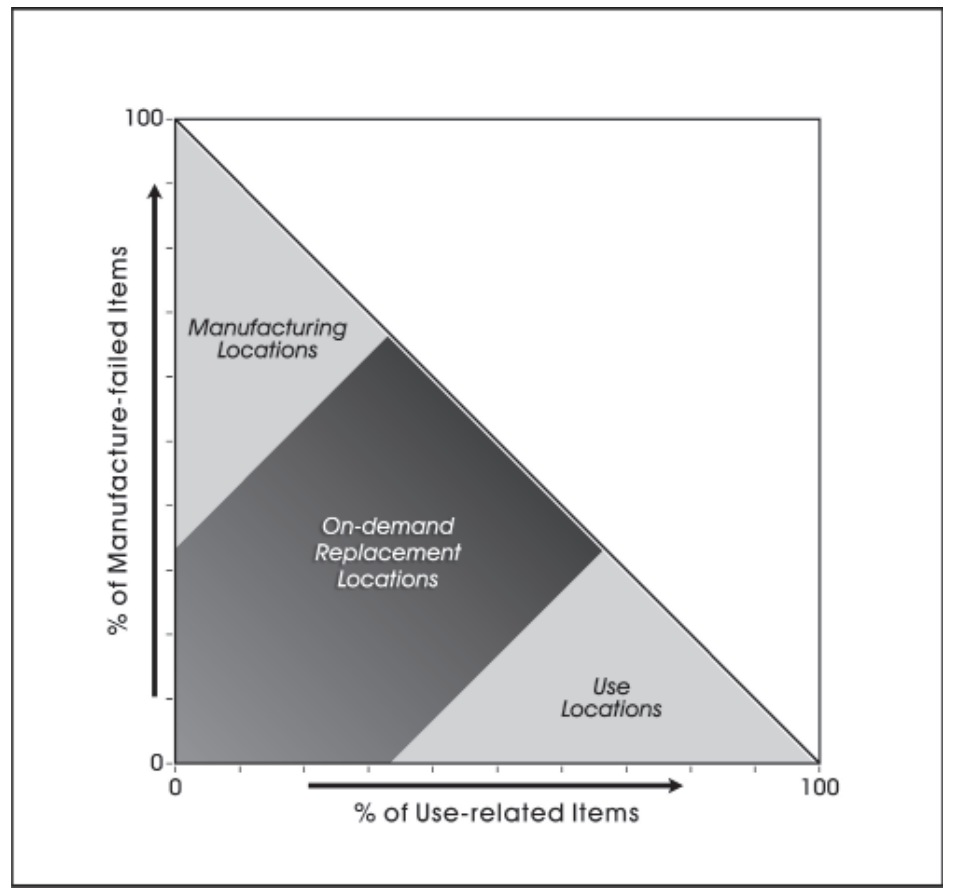

Figure 10-6. Proposed relationship between manufacture-failed and userelated items for locations in two (on-demand vs. gearing-up) strategies. 
acknowledge that some bison procurement may have been organized logistically during all periods as bison are a highreturn item. Finally, note that it is certainly possible that both a gearing-up and an on-demand replacement strategy could operate in the same system, shifting on the basis of elements such as resource type or seasonality.

To monitor the frequency of gearing up present in the prehistoric assemblages, we differentiated use-broken from manufacture-failed specimens within the formal tool category. We use the same components presented previously in Table 10-1, though we eliminated the Terminal Late Prehistoric component at $41 \mathrm{WN} 88$ because a significant number of tools were not available for review. The identification of failure cause was based on comparative specimens and descriptions of the break morphologies of experimentally broken items (Callahan 1979; Crabtree 1972; Johnson 1979, 1981; Muto 1971; Tomka 1986). Tools were classified into one of four groups. Besides manufacture and use breaks, tools could also be complete or the breakage pattern could be indeterminate.
We considered manufacture and use failure rates in projectile points and preforms, other hafted bifaces, and miscellaneous bifaces. Figure 10-7 presents examples of these various break types using tools from 41ZV202.

For the purposes of this discussion, items classified as miscellaneous bifaces are, with few exceptions that clearly have use breaks, considered to reflect manufacturing failures. As we noted above, bifaces primarily reflect a stage in the production of some more formal tool, and most specimens do have classified manufacturing breaks. In a small number of cases, a miscellaneous biface lacks any breaks and is considered "complete." These complete bifaces, discarded prior to the production of a finished tool, along with items considered as having an "indeterminate" break pattern, are classified as manufacturing failures. Conversely, complete hafted tools, including projectile points and other hafted items, are classified as use related. Items classified as "indeterminate" breaks in hafted categories are listed, but do not play a significant role in this analysis.

\section{Use Broken}
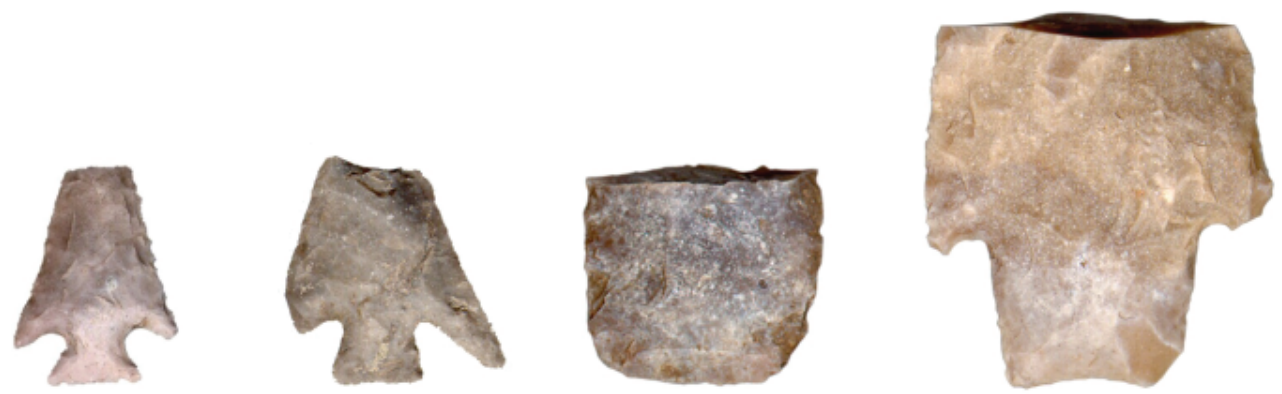

\section{Manufacture Failure}
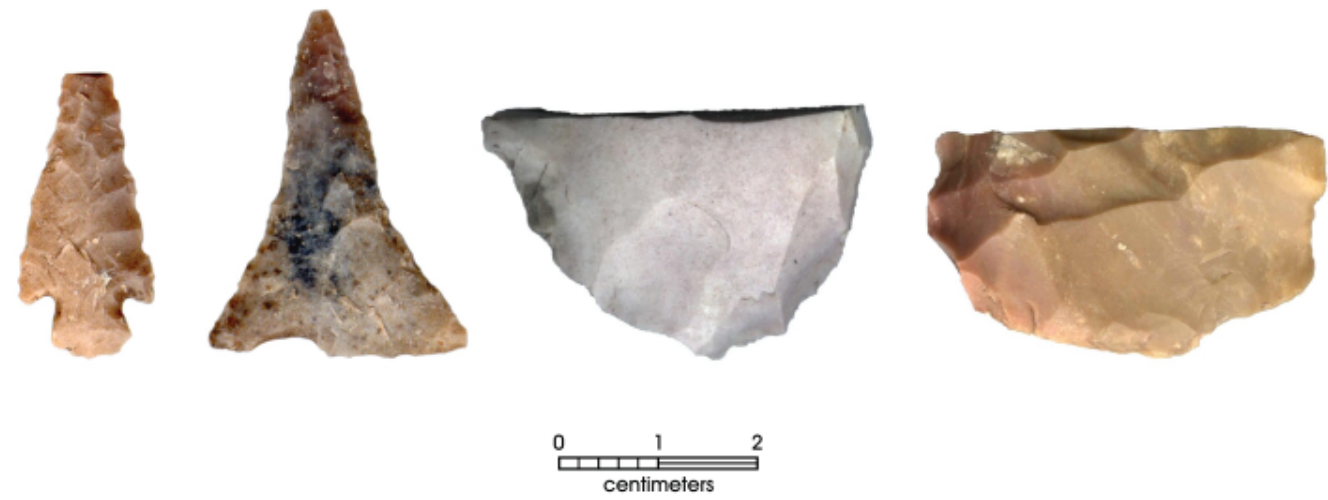

Figure 10-7. Examples of use-ware breakage and manufacture failure on artifacts from 41ZV202. 


\section{Data Acquisition}

To acquire the necessary data, we reviewed breakage patterns on the 62 formal tools recovered from 41ZV202. We also reviewed an additional 1271 formal tools from 18 other components. These tools were housed at the Center for Archaeological Research. Dr. Steven Tomka assessed all break patterns. We encountered no significant problems in recoding information on tool breakage patterns. Table 10-2 lists all 19 components, their temporal affiliation, and the number of formal tools reviewed for each component. Twelve additional columns are present in the Table, with four columns detailing various classifications of breakage on bifaces, four detailing projectile points and preforms breakage, and four detailing other hafted tools. Use related categories are highlighted in bold in the Table, while italicized counts are manufacturing related. Two columns are not used in any calculations, though they are listed. These are the indeterminate breakage groups for projectile points/preforms and for the other hafted material. Finally, note that for several of the components listed, less than 10 total tools are present. These components are 41MC296 (MLA), 41LK201 (ILA) and 41LK67 (ILA). We eliminated these cases from subsequent analysis.

\section{Shifts in Tool Replacement Strategies- Gearing-up and On-Demand Replacement}

To consider the breakage patterns, and indirectly the frequency of the two different strategies through time, we arrayed data on bivariate plots with the percentage of userelated items plotted along the $\mathrm{X}$ axis and the percentage of manufacture-failed items along the $\mathrm{Y}$ axis. Systems characterized by gearing-up behavior should have a high frequency of components clustering on the line in the upper left and lower right portion of the plot. Conversely, those systems characterized by on-demand replacement should have a high number of assemblages along a line in the central portion of the plot (see Figure 10-6). As noted previously, the location of the dividing lines between the various sections of the graph will depend on a variety of factors (e.g., failure rates, production trajectories, activity levels) which we cannot realistically estimate for prehistoric material. In spite of these limitations, however, we anticipate that if our model is useful, then assemblage patterns from Late Archaic components, when bison are slowly declining, should tend towards the center of the bivariate plots. Conversely, during the Initial Late Prehistoric, and especially during the

Table 10-2. Breakage Patterns on Formal Tools*

\begin{tabular}{|c|c|c|c|c|c|c|c|c|c|c|c|c|c|c|}
\hline 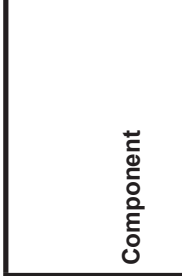 & 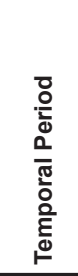 & 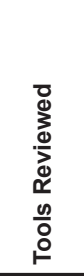 & 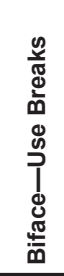 & 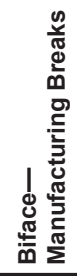 & 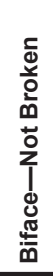 & 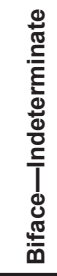 & 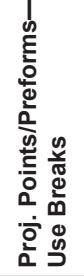 & 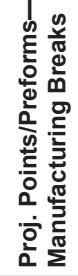 & 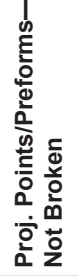 & 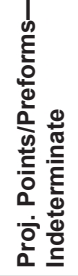 & 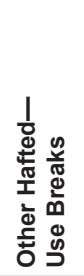 & 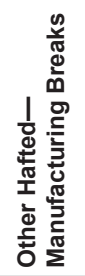 & 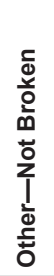 & 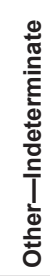 \\
\hline 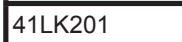 & ILA & 9 & 2 & 0 & 1 & 3 & 0 & 0 & 1 & 0 & 0 & 0 & 1 & 1 \\
\hline 41LK67 & ILA & 6 & 0 & 2 & 2 & 1 & 0 & 0 & 0 & 1 & 0 & 0 & 0 & 0 \\
\hline $41 \mathrm{MM} 340$ & ILA & 49 & 7 & 14 & 3 & 2 & 8 & 6 & 7 & 1 & 0 & 0 & 1 & 0 \\
\hline $41 \mathrm{KM} 69$ & MLA & 35 & 6 & 11 & 2 & 5 & 3 & 2 & 2 & 2 & 0 & 1 & 1 & 0 \\
\hline 41MC296 & MLA & 7 & 3 & 2 & 0 & 1 & 1 & 0 & 0 & 0 & 0 & 0 & 0 & 0 \\
\hline $41 \mathrm{MM} 340$ & MLA & 86 & 12 & 29 & 3 & 8 & 11 & 7 & 12 & 4 & 0 & 0 & 0 & 0 \\
\hline 41KM69 & TLA & 62 & 5 & 24 & 2 & 5 & 19 & 0 & 2 & 3 & 0 & 0 & 2 & 0 \\
\hline 41LK67 & TLA & 21 & 8 & 4 & 2 & 4 & 0 & 0 & 1 & 1 & 1 & 0 & 0 & 0 \\
\hline $41 \mathrm{MM} 340$ & TLA & 65 & 6 & 17 & 1 & 12 & 8 & 5 & 7 & 5 & 1 & 1 & 2 & 0 \\
\hline $41 \mathrm{KM} 69$ & ILP & 89 & 17 & 35 & 10 & 9 & 4 & 0 & 0 & 1 & 4 & 5 & 3 & 1 \\
\hline $41 \mathrm{MC} 296$ & ILP & 14 & 3 & 4 & 1 & 5 & 0 & 1 & 0 & 0 & 0 & 0 & 0 & 0 \\
\hline 41MM341-au1 & ILP & 141 & 7 & 53 & 26 & 12 & 14 & 6 & 9 & 4 & 2 & 4 & 3 & 1 \\
\hline 41MM341-au2 & ILP & 89 & 8 & 34 & 14 & 9 & 9 & 2 & 6 & 2 & 1 & 1 & 2 & 1 \\
\hline 41ZV202 & ILP & 62 & 4 & 15 & 4 & 15 & 10 & 2 & 5 & 5 & 0 & 0 & 1 & 1 \\
\hline 41JW8 & TLP & 338 & 42 & 101 & 12 & 41 & 56 & 18 & 31 & 21 & 6 & 2 & 3 & 5 \\
\hline 41KM69 & TLP & 29 & 2 & 4 & 1 & 1 & 0 & 1 & 0 & 2 & 0 & 0 & 15 & 3 \\
\hline 41LK201 & TLP & 156 & 10 & 60 & 8 & 6 & 12 & 16 & 20 & 3 & 2 & 4 & 14 & 1 \\
\hline 41LK67 & TLP & 12 & 4 & 2 & 1 & 0 & 1 & 2 & 1 & 1 & 0 & 0 & 0 & 0 \\
\hline $41 \mathrm{MC} 296$ & $\begin{array}{c}\mathrm{TLP} \\
\end{array}$ & 63 & 8 & 7 & 2 & 10 & 10 & 9 & 10 & 5 & 1 & 0 & 1 & 0 \\
\hline Totals & & 1333 & 154 & 418 & 95 & 149 & 166 & 77 & 114 & 61 & 18 & 18 & 49 & 14 \\
\hline
\end{tabular}

*bold values are counted as use related. Italicized items are manufacturing related 
Terminal Late Prehistoric, assemblages should be increasingly common in the upper left and lower right portions of the plot.

Figures 10-8, 10-9, and 10-10 present the patterns for the Late Archaic $(\mathrm{n}=6)$, Initial Late Prehistoric $(n=5)$ and the Terminal Late Prehistoric $(n=5)$, respectively. Raw counts are provided in Table 102. Note that several of Late Archaic assemblages with tool sample sizes that fell below 10 items were eliminated. While we identify the specific components used in the figure, we focus on the Late Archaic as a whole, rather than on sub periods, given the reduced sample sizes. The Figure 10-8 pattern, where locations are dominated by manufacturing breaks, is consistent with an on-demand replacement system. No components are below the 50/50 break point in the high userelated area of the graph. Figure 10-9 presents the breakage patterns for the five Initial Late Prehistoric components with data in Table 10-2. Interestingly, all five are clustered well towards the manufacturing side. Site 41ZV202, with 64\% of the material reflecting manufacturing breaks and $36 \%$ reflecting use breaks, is the closest site to the $50 / 50$ point. At the other extreme is $41 \mathrm{MC} 296$, with a manufacturing breakage pattern of just under $79 \%$. This pattern, of significant over manufacture, is consistent with a gearing-up strategy. However, we are missing the other end of this strategy, the locations at which those over manufactured items were used. Finally, Figure 10-10 presents the distribution for the five Terminal Late Prehistoric components. While several components fall near the 50/50 point, the variability shown for this period is significantly greater than either of the earlier periods, with 41LK201 having a breakage pattern dominated by manufacturing at $62 \%$, and 41KM69 having a breakage pattern dominated by use related items (71\%). Again, while the overall sample size is small, this pattern is consistent with some components focused on gearing-up strategies.

\section{Summary}

Based on suggestions that bison are slowly declining throughout the Late Archaic and were increasingly variable during the Late Prehistoric, we anticipated a gearing-up system might be increasingly present, especially in the Terminal Late Prehistoric. Gearing-up should occur under conditions of time-stress or when resources are processed in bulk. We anticipated that a gearing-up strategy was more likely when bison were declining in number.

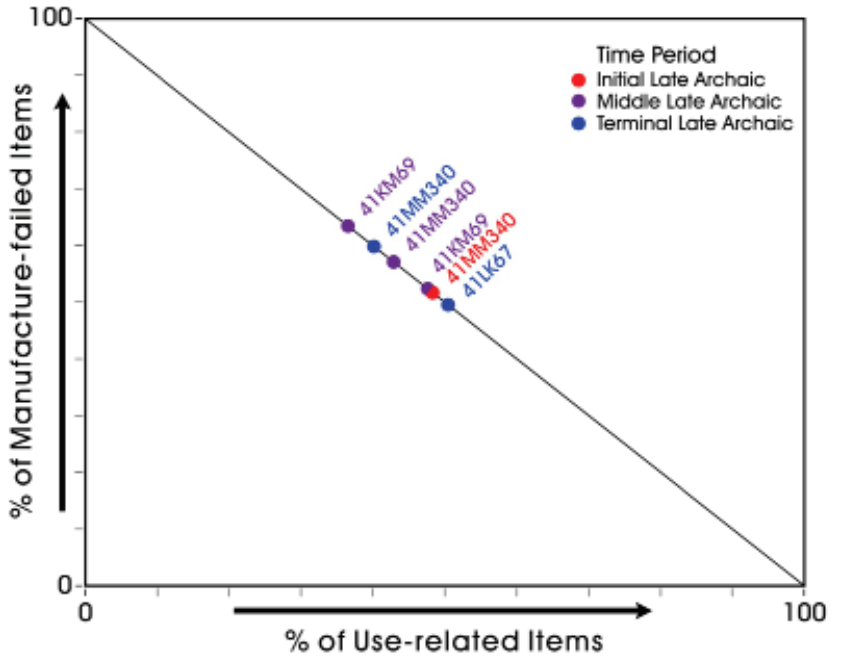

Figure 10-8. Breakage patterns for expensive tools on Late Archaic tools.

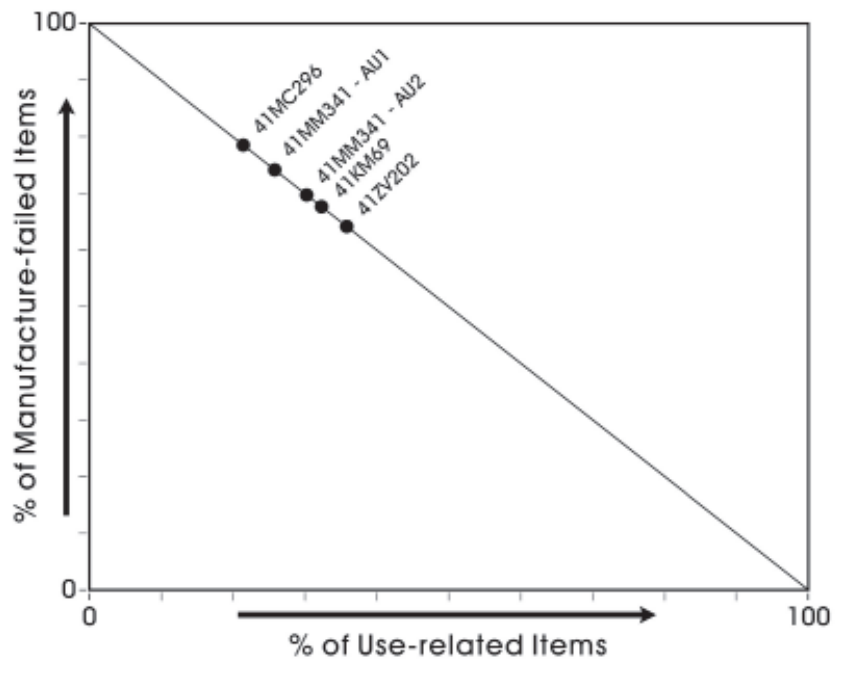

Figure 10-9. Breakage patterns for expensive tools on Initial Late Prehistoric tools.

That is, when grasslands were shrinking, bison populations should be declining and hunters should encounter the animal less frequently. Under these conditions, time-stress should be increasing. We conducted a review of breakage patterns on 41ZV202, as well as a variety of comparative components. The goal was to quantify use related relative to manufacturing related breakage. Under conditions of 


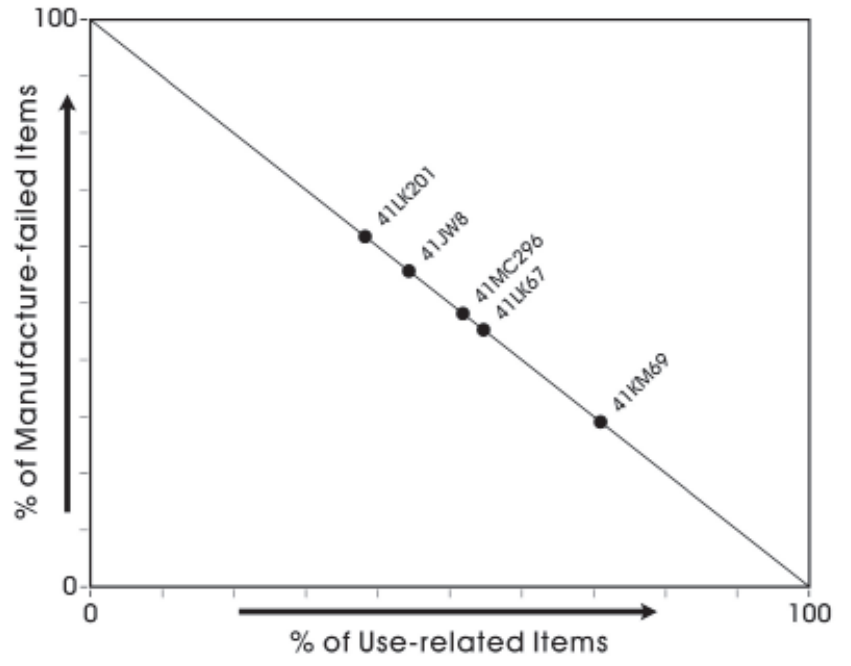

Figure 10-10. Breakage patterns for expensive tools on Terminal Late Prehistoric tools.

on-demand tool replacement, we expected that use and manufacturing breakage should approximate a 50\% split, perhaps with slightly higher percentages of manufacturing breaks as replacement of a broken tool will not always be successful. Conversely, gearing-up strategies, where materials are manufactured in anticipation of use at a later date, should have some components that are dominated by manufacturing breaks, where hunters produce tools, and some components that are dominated by use breaks, where they conduct activities under time stress without the need to replace broken items.

Our examination of the breakage patterns for the Late Archaic components in the comparative data set (Figure 108 ) shows that most cluster near the $50 \%$ point in the graph, with manufacturing breaks being slightly more common. No component is dominated by a breakage pattern that would be characterized as either high use or high manufacture. This pattern is consistent with the use of an on-demand replacement strategy. In contrast, the Initial Late Prehistoric, where we anticipated that gearing up should be more common, the pattern is significantly different. All five components are dominated by high manufacturing breaks (see Figure 10-9), a pattern at least partially consistent with expectations. We are, however, missing evidence for the use locations. The lack of use locations may simply be a sample size problem. That is, use related locations may not be reflected in the relatively small $(n=5)$ Initial Late Prehistoric data set. Use locations may, depending on the nature and frequency of the activities, be less likely to be identified as archeological sites, and so may be under represented in general. While the dramatic difference seen in Figure 10-9 relative to Figure 10-8 may also reflect other technological shifts happening at this point (e.g., use of arrow technology), the shifts are at least partially consistent with our expectations. Finally, the Terminal Late Prehistoric period, where we anticipated that the use of a gearingup strategy would be most clearly defined, does show the largest variability and has examples of both high manufacture and high use dominated components. This pattern suggests that, consistent with our expectations, a gearing-up strategy was in use late in time.

\section{Summary}

In this chapter, we focused on two aspects of technology, changes in tool manufacturing costs and changes in the way that hunters and gatherers produced, used, and replaced tools. We argued that if, as suggested by the grassland data sets, bison populations were declining throughout the Late Archaic, with a significant decline in the Late Prehistoric, that strategies of tool design, as well as tool manufacture, use, and repair, should be impacted in predictable ways. As bison become less common throughout the Late Archaic and into the Initial Late Prehistoric, the use of a tool kit that was more specialized, and consequently more expensive to produce and maintain, should increase. This would especially be the case in the Terminal Late Prehistoric, when grassland data suggest bison are temporally and spatially restricted. We also suggest that a "gearing-up" strategy, where large numbers of tools are manufactured at one location in anticipation of future needs and failure rates, would be increasingly likely under declining bison availability. We argued that hunters and gatherers are likely to use gearing-up strategies during the Terminal Late Prehistoric, when bison appear to be increasingly restricted in time and space.

Using an assessment of tool costs that relied primarily on the degree of retouch, we categorized tools on 20 components. Looking at changes through time, it appears that several of our expectations derived from our model of declining bison are supported by the cost data. Increased investment in more expensive tools under conditions of declining bison is especially evident in the Terminal Late Prehistoric. The changes through the Late Archaic are more ambiguous. It appears that any directional change through the Late Archaic investment in specialized tools was minimal. 
Our examination of the breakage patterns for the Late Archaic components suggests that a gearing-up strategy of tool manufacture, use, and replacement was not well represented during this time frame. Late Archaic components seem to be organized in an on-demand replacement format. In contrast, the Initial Late Prehistoric does have data patterns that are consistent with a gearing up strategy. High frequencies of manufacturing breaks characterize all five components. We are, however, missing the use locations during this time period. The Terminal Late Prehistoric period shows the largest variability and has examples of both high manufacture and high use dominated components. This pattern suggests that, consistent with our expectations, there is evidence for a gearing-up strategy late in time, at least at some locations. 


\title{
Chapter 11: Assessing Changes in the Organization of Mobility
}

\author{
Raymond Mauldin, Steven Tomka, and Leonard Kemp
}

In the foraging based model developed in Chapters 7 and 8, we suggested that as bison populations declined, hunters and gatherers were increasingly likely to use logistically based mobility systems and that the spatial scales of those systems would be increasing in size. This chapter investigates the first of these expectations, a proposed change in the way that mobility was organized. We briefly review the arguments regarding the expected mobility shift, and then explore two different data sets as providing potential ways to measure the proposed changes. The first of these measures centers on relationships between the variety of artifact types present on a component and the range of activities that occurred at that location. We use the 41ZV202 data, in combination with 18 other components, to explore the potential of artifact variety as an indicator of site type. The second measure involves developing ways to monitor site maintenance. We focus on the presence of trash midden deposits as an indicator of site maintenance, suggesting that midden deposits, with high artifact diversity, are increasingly likely on residential sites relative to special purpose locations. Here, we focus exclusively on 41ZV202 and try to begin to develop recognition criteria for trash midden deposits that will be applicable to other sites.

\section{The Organization of Mobility}

Binford (1980; see also Kelly 1995) originally identified the importance of understanding how different mobility systems were organized as a critical element in understanding site assemblages and overall adaptations. Using ethnographic data, he defined two different systems. Foraging systems had daily inputs of food, gathered from within a few kilometers of a residential camp, with frequent camp moves in response to declining resource returns. Foragers lack bulk storage and group size is small. Hunters and gatherers using the second system, termed collectors, rely on bulk inputs of food into residential sites generated by logistically organized task groups. Collectors have a lower frequency of residential moves and larger group size when contrasted to foragers. Collectors also frequently have some form of bulk storage. In his discussion of the two organizational types, Binford (1980) presented them as different systems by primarily referencing and contrasting the mobility systems of the Nunamiut and the !Kung San. Subsequently, several researchers (e.g., Shoocongdej 2000:1516) argued that the two organizational stances reflected extremes along what was, in effect, a continuum.

We view collectors and foragers not as two different systems or as two end points of a continuum, but rather as two different strategies that can be used at various times and in different mixes. Collector or logistical strategies should be used when there is an incongruent distribution of critical resources or some limitation on residential movement. Conversely, foraging strategies should be used when resources have a ubiquitous distribution (see Binford 1980; 2001: 269-276). It is certainly possible, then, that as the distribution of resources changes, logistical strategies may be used at some points, and foraging strategies at others, over the course of a year. Aspects of both strategies can be used at the same time, with returns from daily foraging complementing inputs from logistical strategies that are targeting specific types of resources. As we noted previously, while high return resources could be pursued with either a logistical or foraging strategy, when hunters and gatherers do use logistical strategies, they are likely to be focused on the acquisition of high return resources or resources that can be processed in bulk.

During the Late Archaic we have suggested that, based on declining grasslands, the overall density of bison would fall. We suggested that during the Initial Late Prehistoric, and especially during the Terminal Late Prehistoric, that the decline in bison was accelerating. This was coupled with more predictability in space, as grasslands shrank, but increased year to year variability in numbers. Because scheduling conflicts will increase when critical resources, such as bison, are decreasing in frequency on the landscape, hunters and gatherers should increase their reliance on logistical organization. Based on the pattern of changing grassland densities, we suggest that logistical forms of organization should be increasingly common through the Late Archaic, and increase into the Late Prehistoric. They should be especially evident in the Terminal Late Prehistoric.

\section{Distinguishing between Collecting and Foraging Locations through Artifact Variety}

There are no established methods for differentiating locations dominated by foraging from sites or components dominated by collecting forms of organization. Here, we propose to investigate the suggested changes in the organization of mobility between the Late Archaic and Late Prehistoric components by initially focusing on measures of artifact variety as a method for distinguishing locations used in a residential manner from those used for more task-specific activities. The approach has been used with some success in archeological analysis (see Thomas 1983, 1989). While not addressing the question of organization directly, 
special purpose locations with sufficient artifact densities to be observed and recorded at a site are more likely to be associated with collector organizations.

Binford's (1980) description of collector and forager systems relied on ethnographic data. While translating these ethnographic descriptions into an archeological context is complicated by problems of reuse of locations for different activities, as well as by the observation that the archeological record is generated at a much longer time scale, it appears that a wider range of activities occur at most residential sites relative to special-purpose locations. Even relatively simple foraging residential sites (e.g., Yellen 1977) show a wide variety of tasks conducted. Conversely, special purpose sites, by definition, have a narrower range of activities, and will likely have fewer types of artifacts present. Because several researchers have shown that sample size has a significant influence on variety (see Bobrowsky and Ball 1989; Kintigh 1989), we cannot simply contrast the number of different artifact types at a series of components to identify site types. However, as shown in Figure 111 , we expect that the number of different artifact types will increase at a faster rate on residential sites because hunters and gatherers are likely to conduct a wider variety of activities and occupy these camps for longer periods. Conversely, activities at most special purpose locations will differentially increase the number of artifacts relative to the addition of new artifact types. That is, conducting

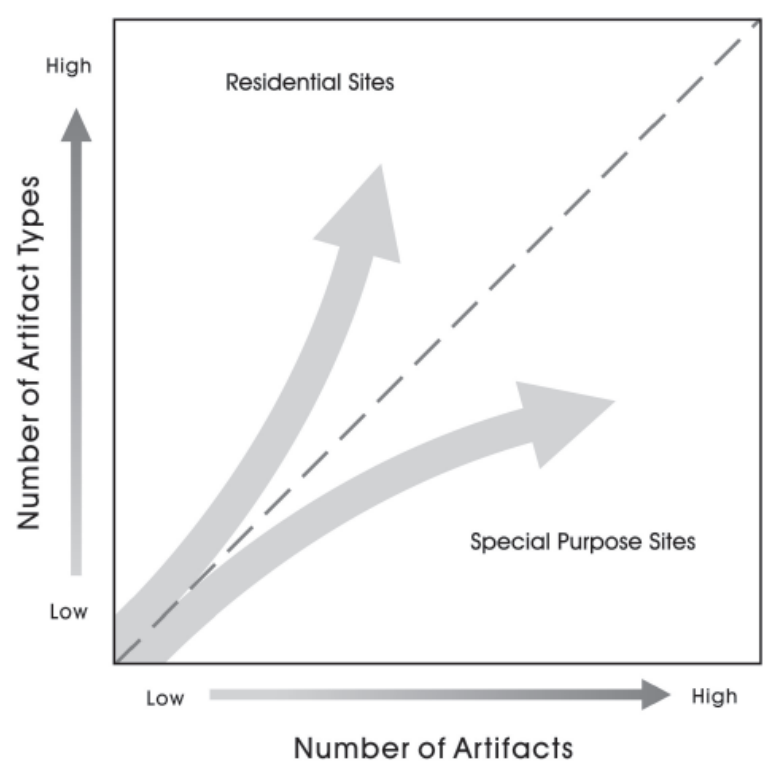

Figure 11-1.Expected relationship between the number of artifact types and sample size for different organizational components. the same set of activities will increase the number of items (sample size) without a concomitant increase in the artifact types. While the interpretations are complicated by the possibility that some special-purpose locations are reoccupied for a different range of activities, unless several such reoccupation episodes are present, we suggest that the overall pattern will remain intact. Consequently, we expect that during the Late Prehistoric we will have increasing evidence of special purpose locations when compared to the Late Archaic as hunters and gatherers will organize an increasing amount of their mobility in a logistical manner later in time.

\section{Data Acquisition}

We use the data from 41ZV202, as well as data collected from 18 additional components used in the previous chapter (see Table 10-2; Figure 10-2). All collections were housed at CAR. In order to gather data necessary to explore the proposed relationship between artifact variety and different levels of activity, we need data on the number of different types of tools present on components, as well as information on the sample size. We define tool types as broadly as possible in order to reflect a variety of behaviors at a location. We identified 15 artifact categories (Table 11-1) that may be present at the components proposed for investigation. Many of these (e.g., marginally retouched items, unifaces) are the same tool forms discussed in Chapters 9 and 10. They have been supplemented by macroscopic observations on use wear, aided by a hand lens ( $10 \mathrm{x}$ magnification), to classify utilized flakes into broad task-related categories following Tringham et al. (1974). When, on a given tool, we had evidence of only a single task (e.g., cutting), regardless of how many edges have that evidence, the utilized flake was classified as "single-use." When more than one task-specific activity was reflected (e.g., scraping, cutting, perforating), the tool was classified as "multiple-use." As we did not subject these items to high powered micoroscropy, it is possible that some classifications are in error.

We encountered no significant problems in gathering this data. Table 11-2 lists all 19 components, their temporal placement, and a series of tool types defined in Table 11-1. The numbers in each cell from columns 3 through 17 in Table 11-2 represent the number of items present for these particular tool types at that component. Column 18 in the table provides 
Table 11-1. Artifact Types Proposed for Use in Sample Size and Type Comparisons

\begin{tabular}{|l|l|}
\hline \multicolumn{1}{|c|}{ Artifact Type } & \multicolumn{1}{c|}{ Definitions/Notes on Type } \\
\hline Single-use Utilized Flake & Utilized flake with evidence of only one type of use (e.g., scraping) on one or more edges. \\
\hline Multiple-use Utilized Flake & $\begin{array}{l}\text { Utilized flake with evidence of more than one type of use (e.g., chopping and scraping) on one or } \\
\text { more edges. }\end{array}$ \\
\hline Biface with Hafting Element & $\begin{array}{l}\text { Includes formal knives but not projectile points, preforms, or drills. May include adzes and "gouges," } \\
\text { depending on how extensive the item is retouched. }\end{array}$ \\
\hline Uniface with Hafting Element & Will include most formal scrapers. If hafting element is not clear, classify as Other Uniface. \\
\hline Marginally Retouched Item & May include some scrapers, as well as items characterized as choppers and "core" tools \\
\hline Drills/Perforators & Usually bifacially worked. \\
\hline Projectile Points and Preforms & Does not include items characterized as blanks. \\
\hline Hammerstones & Evidence of hammering. If grinding is also present, count as ground stone rather than hammerstone. \\
\hline Manos & Must have evidence of grinding and a convex surface. \\
\hline Metates & Must have evidence of grinding and a concave surface. \\
\hline Cores/Tested Cobbles & Cobble or nodule with one or more flake scars present. \\
\hline Other Ground Stone & Fragments, as well as multi-use ground stone tools and pestles. \\
\hline Other Unifaces & Unifaces without any clear hafting element present. \\
\hline Other Bifaces & Bifaces without any clear hafting element present. \\
\hline Other Items & Items not covered by the above, such as worked shell. Do not count ceramics. \\
\hline
\end{tabular}

Table 11-2. Artifact Variety and Sample Sizes for 41ZV202 and Comparative Components

\begin{tabular}{|c|c|c|c|c|c|c|c|c|c|c|c|c|c|c|c|c|c|c|}
\hline$\stackrel{\Xi}{\dot{\omega}}$ & 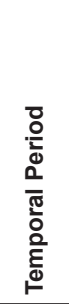 & 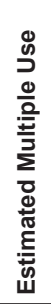 & 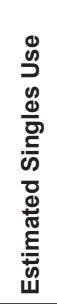 & 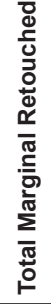 & 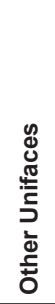 & 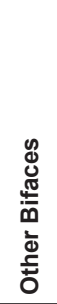 & 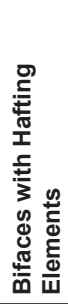 & 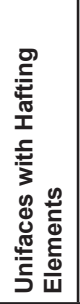 & 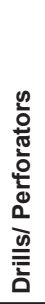 & 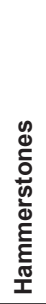 & 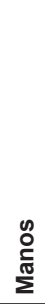 & 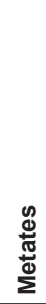 & 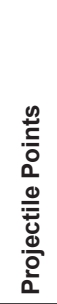 & 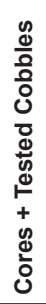 & 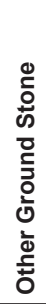 & 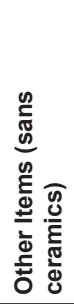 & 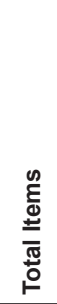 & 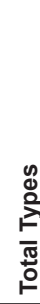 \\
\hline MM340 & ILA & 4 & 12 & 23 & 1 & 26 & 1 & 0 & 0 & 3 & 0 & 0 & 22 & 36 & 0 & 0 & 128 & 9 \\
\hline LK67 & ILA & 2 & 8 & 6 & 1 & 5 & 0 & 0 & 0 & 0 & 0 & 2 & 1 & 8 & 1 & 4 & 38 & 10 \\
\hline LK201 & ILA & 0 & 5 & 4 & 2 & 6 & 2 & 0 & 0 & 0 & 13 & 0 & 1 & 22 & 2 & 3 & 60 & 10 \\
\hline ZV202 & ILP & 1 & 2 & 11 & 2 & 38 & 1 & 1 & 1 & 0 & 0 & 0 & 21 & 5 & 0 & 0 & 83 & 10 \\
\hline KM69 & ILP & 0 & 1 & 11 & 10 & 72 & 11 & 2 & 0 & 0 & 0 & 0 & 5 & 30 & 0 & 0 & 142 & 8 \\
\hline MM341-au2 & ILP & 30 & 77 & 43 & 4 & 65 & 5 & 0 & 0 & 6 & 0 & 3 & 19 & 60 & 0 & 10 & 322 & 11 \\
\hline MM341-au1 & ILP & 47 & 101 & 73 & 16 & 98 & 8 & 0 & 2 & 11 & 0 & 4 & 33 & 90 & 0 & 18 & 501 & 12 \\
\hline MC296 & ILP & 1 & 6 & 3 & 0 & 13 & 1 & 0 & 0 & 0 & 11 & 16 & 0 & 10 & 1 & 7 & 69 & 10 \\
\hline MM340 & MLA & 28 & 66 & 29 & 8 & 52 & 0 & 0 & 0 & 4 & 0 & 1 & 34 & 36 & 0 & 0 & 258 & 9 \\
\hline KM69 & MLA & 6 & 6 & 7 & 0 & 24 & 2 & 0 & 0 & 0 & 0 & 0 & 9 & 3 & 0 & 0 & 57 & 7 \\
\hline MC296 & MLA & 4 & 4 & 5 & 1 & 6 & 0 & 0 & 0 & 0 & 11 & 16 & 1 & 20 & 4 & 0 & 72 & 10 \\
\hline LK67 & TLA & 2 & 21 & 33 & 7 & 18 & 1 & 0 & 0 & 0 & 0 & 1 & 2 & 29 & 1 & 0 & 115 & 10 \\
\hline KM69 & TLA & 0 & 23 & 5 & 11 & 36 & 1 & 0 & 1 & 0 & 0 & 0 & 24 & 9 & 0 & 0 & 110 & 8 \\
\hline MM340 & TLA & 21 & 44 & 24 & 1 & 35 & 5 & 0 & 0 & 1 & 1 & 1 & 24 & 31 & 0 & 0 & 188 & 11 \\
\hline KM69 & TLP & 1 & 0 & 5 & 10 & 8 & 0 & 18 & 0 & 0 & 0 & 0 & 3 & 7 & 0 & 0 & 52 & 7 \\
\hline LK67 & TLP & 6 & 5 & 9 & 3 & 7 & 1 & 0 & 0 & 3 & 0 & 0 & 4 & 18 & 0 & 1 & 57 & 10 \\
\hline MC296 & TLP & 2 & 2 & 19 & 11 & 27 & 2 & 0 & 0 & 0 & 8 & 17 & 34 & 21 & 0 & 2 & 145 & 11 \\
\hline LK201 & TLP & 4 & 5 & 33 & 11 & 85 & 10 & 4 & 3 & 0 & 12 & 3 & 55 & 50 & 6 & 21 & 302 & 14 \\
\hline JW8 & TLP & 23 & 49 & 115 & 64 & 196 & 12 & 4 & 1 & 7 & 5 & 20 & 125 & 35 & 6 & 41 & 703 & 15 \\
\hline
\end{tabular}


the total number of items, while column 19 present the total number of types represented on a component. Overall, 3,402 items are represented in the table. Only a single component, $41 \mathrm{JW} 8$, had all 15 artifact types present.

\section{Results}

Using the data presented in Table 11-2, we plotted the number of different types of items against the total number of items in each component (Figure 11-2). Note that the Y-axis in the Figure is the square of the number of artifact types. The original plot was non-linear, and the transformation of the $\mathrm{Y}$ variable reduces that non-linear impact. Shown in the figure is the least squares regression line through the data, along with $95 \%$ confidence bands on that line. Overall, Pearson's correlation coefficient is .78 , with a coefficient of variation $\left(\mathrm{R}^{2}\right)$ of .615 . The high values suggest a strong relationship between sample size and artifact variety. That is, most of the variation in the number of artifact types is simply a function of the number of artifacts, rather than any differences in organization.
Examination of Figure 11-2 shows that 41ZV202 follows the majority of the components, falling within the $95 \%$ confidence band. There are two components, the Terminal Late Prehistoric components at 41LK201 and 41MC296, which are well above the upper confidence limit in the "residential" area of the plot. Three additional components fall just above the upper limit. These are the Terminal Late Prehistoric component at 41LK67 and two Initial Late Archaic components at 41LK67 and 41LK201. There are also five components below the lower confidence interval in the "special purpose" area. These include two Middle Late Archaic components from 41MM340 and 41KM69 and the Terminal Late Archaic, Initial Late Prehistoric, and the Terminal Late Prehistoric components from 41KM69. The small number of cases that are not primarily determined by sample size, and therefore may provide information on site types, limits interpretation. Nevertheless, of the five Late Archaic components that are outside of the confidence intervals, three are classified as "special purpose" locations. In the following Late Prehistoric, only two of the five components are in the "special purpose" area. This is counter to our expectations that special purpose sites should be more common late in time as logistical

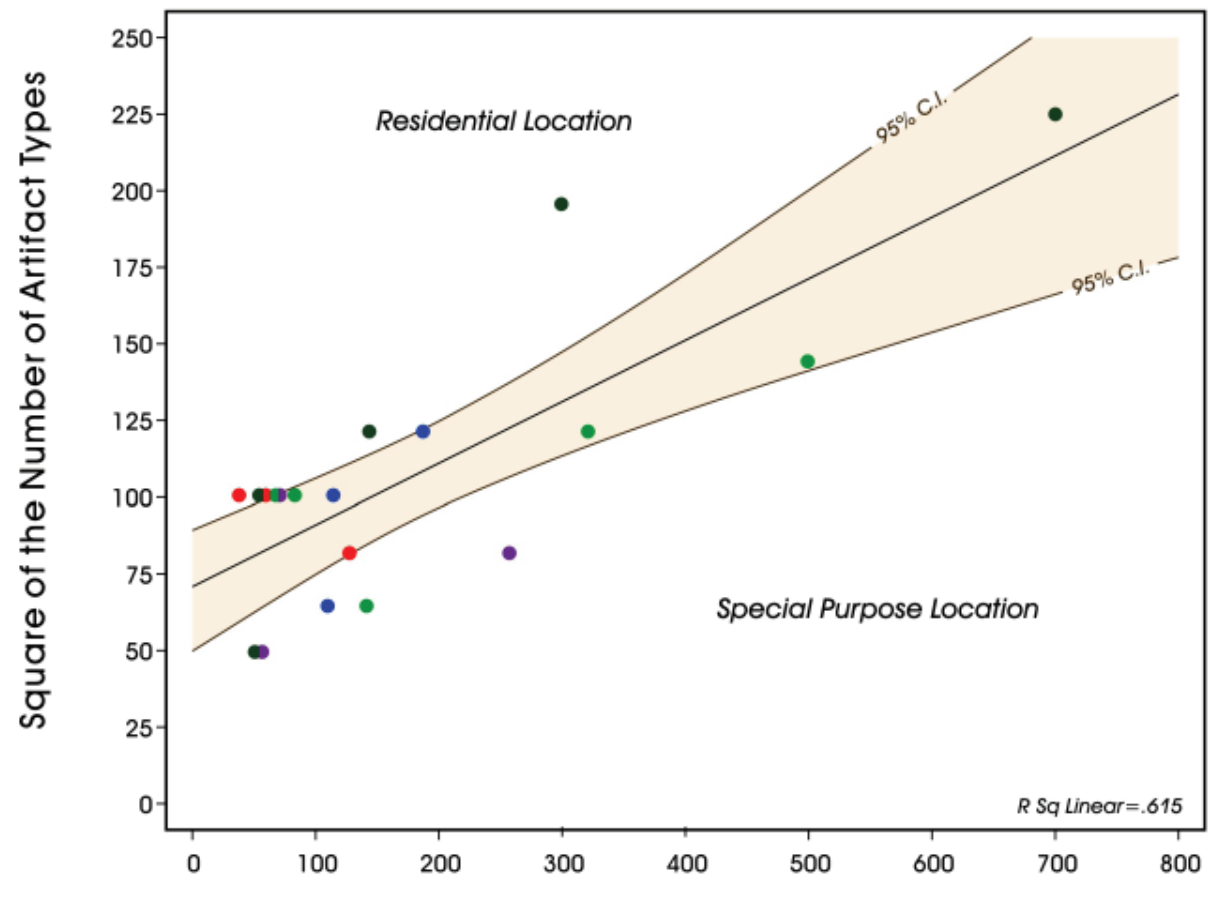

Numbers of Artifacts

- Initial Late Archaic

- Middle Late Archaic

- Terminal Late Archaic
- Initial Late Prehistoric

- Terminal Late Prehistoric

Figure 11-2. Number of artifacts plotted against the square of the number of artifact types. 
systems become increasingly common. Note, however, that all of the "residential" components in Figure 11-2 are from the Choke Canyon area, and four of the five "special purpose" components are from a single location, 41KM69. While such spatial clustering in site types is possible, it also hints at the possibility that other elements may be involved in creating the patterns.

\section{Summary}

We suggested that relationships between artifact variety and sample size could be used to identify special purpose and residential components. Special purpose locations should have a lower number of artifact types for a given sample size when contrasted to locations used in a residential manner. We further suggested that special purpose components should be more common late in the prehistoric sequence. This expectation was a consequence of declining bison availability and more emphasis on a logistical strategy of bison pursuit to increase encounter rates. The resulting patterns were not consistent with our expectations. Sample size seemed to be the primary influence on the number of artifact types. While some "special purpose" and "residential" components were identified, they clustered by project, with all "residential" components present in Choke Canyon, and four of the "special purpose" components present at site KM69. While such spatial clustering is possible, it suggests that our recognition criteria for site types are not well developed. Clearly, future research directions for investigating special purpose verses residential status might include exploring specific facilities located on each site type (e.g., burned rock middens- see Mauldin et al. 2003), distance to water, evidence of separation of activities, and site maintenance. In the following section, we use data from 41ZV202 to begin to explore the potential of shifts in site maintenance activities as a measure of site type.

\section{Distinguishing between Collecting and Foraging Locations through Site Maintenance}

Several studies (e.g., Graham et al. 1982; Kent 1991; O'Connell 1987; Oswald 1984; Varien and Ortman 2005; Wendt 2005) have suggested that the length of time a place is occupied will determine the degree of site maintenance. Locations used for short periods will have little or no maintenance activities conducted as the potential for activity areas to overlap or for debris to interfere with subsequent activities is low. Conversely, at sites with long occupations, hunters and gatherers should conduct maintenance activities, including the removal and disposal of ash/charcoal and fire-cracked rock from reused hearths and the disposal of debris generated by the processing of bulk resources. One consequence of these maintenance activities should be the generation of trash middens on some components. Note that we use the term "midden" not in reference to burned rock ovens (see Black and Creel 1997), but rather in reference to secondary deposits that consist primarily of discard artifacts, waste products, and other debris.

We distinguish two types of middens in this discussion, formal and sheet middens. Formal middens are generated through site maintenance activities, while sheet middens are the products of day-to-day use of generalized living surfaces without the removal of the resultant debris from these surfaces. While middens could certainly be present on special-purpose sites as a function of the quantity of processing conducted, or the nature of what was processed, their frequency should be low relative to the residential components as special purpose locations are often occupied for short periods of time. That is, all else being equal, trash middens should be more common on residential sites given longer occupation spans. In addition, we anticipate that residential sites generated by collector-based systems should have a higher frequency of formal trash middens relative to foraging-based residential systems. While formal trash middens may occur at some foraging-based residential sites, the shorter occupation length anticipated on these sites should result in lower overall site maintenance, and a lower frequency of formal middens, though sheet middens may be present.

Consequently, we expect that during the Late Prehistoric, we will have increasing evidence of special purpose locations when compared to the Late Archaic. This is because hunters and gatherers will increasingly use a logistical strategy later in time as bison abundance declines. Special purpose locations should, with few exceptions, lack middens because of their shorter residence time. However, some Late Prehistoric components, especially those in the Terminal Late Prehistoric, should reflect logistically organized residential occupations. Given the length of occupation, these should have high frequencies of formal middens. In contrast, sites in the Late Archaic, which we suggest will commonly use a foraging organizational strategy, should lack formal middens. If middens are recorded on sites during these earlier periods, they should be what we have termed sheet middens and be reflective of foraging residential sites. Of course, in any comparison at this level, issue of site preservation and recovery conditions should be addressed.

We initially attempted to test aspects of these suggestions through a literature review using a set of three criteria. These were (1) the presence of organic staining outside of a clearly defined thermal feature, (2) the presence of several different classes of material (e.g., bone, charcoal, chipped stone, burned rock) within the context of that organic deposits, and 
(3) the designation of a deposit as a "midden" by the original excavator. It soon became apparent that these criteria could not be applied to most cases described in the literature. The initial problem centered on recognizing organic staining in the dark soils in Central and, to a lesser extent, South Texas. In addition, data on artifacts and ecofacts recovered outside of thermal features for a given component were seldom reported in a useable format. Finally, in the comparative site data sets, no instance of a trash midden was noted by the excavators for specific components of interest in any of the reports reviewed.

Midden criteria, then, may prove to be of little use in this portion of the state. This particular criterion is not relevant to any assessment of changes in the organization of mobility derived from the larger hunter-gatherer model presented in Chapters 7 and 8 . Nevertheless, as almost no research has been done on recognizing, let alone classifying trash middens in the study area, an analysis of material from Features 4 and 5 on site 41ZV202 may provide criteria allowing for the recognition of different midden types. These criteria may eventually prove useful for investigating the more detailed suggestions that sheet middens should dominate foraging sites, while formal middens should be present at long-term, primarily logistically organized residential components. We suggest that formal trash middens, which result from the systematic maintenance of a site, should have several differences relative to sheet middens, which result from generalized activities conducted in an area. Specifically, formal middens should lack intact features, with the possible exception of burials. They should have high artifact richness and high within-midden variability in artifact content and sediment composition. The expected high richness of formal middens, as well as high variability in content from one location to another, results from the wide variety of activities that contribute discard material on residential sites, as well as the relatively longer occupation of these locations. Conversely, sheet middens may have intact features present, though they are not a necessary component in the deposits. While differences in the activities carried out adjacent to hearths and variability in the distribution of hearth-related artifacts away from the hearths themselves may produce some variability in sheet midden content, as a class sheet middens should have lower artifact richness relative to formal middens, and lower spatial variability in artifact content and sediment composition.

As discussed in Chapters 4 and 5, 41ZV202 contained two large, amorphous stains, designated Features 4 and 5 during testing, which dated to the Initial Late Prehistoric. Feature 7, a small burned rock feature with associated staining, was present in Feature 5, as was Feature 9, another small burned rock cluster. Within Feature 4, three tightly clustered burned rock features were present (Features 8, 10, and 13). Both Features 4 and 5 had charcoal and artifacts scattered at low density. Feature 4 and Feature 5 deposits, therefore, probably reflect sheet midden deposits associated with a buried soil. We can use the 41ZV202 midden material, then, to begin to develop diagnostic criteria for generalized sheet middens. Though we lack any comparative data from formal middens, we anticipate that in sheet middens, such as those present at 41ZV202, the chemical composition, magnetic signature, and debitage counts and characteristics should have low overall variability.

\section{Data Acquisition}

In order to characterize each midden, we selected 20 proveniences (1-x-1 m unit, $10-\mathrm{cm}$ level) from the broadly defined Feature 4 area, and 20 proveniences from the Feature 5 area, using randomizing functions in Microsoft Excel. Figure 11-3 shows the distribution of these units by level. During data recovery, the boundaries of Features 4 and 5, vaguely defined during testing, remained ambiguous. It appears that the two features represent an anthropicly enriched soil associated with this portion of the ridge at 41ZV202. While we could treat both features as a single analytical unit, we have arbitrarily divided the features along the 81E line (Figure 11-3). This preserves the original designation made during testing.

Soil samples, magnetic susceptibility samples, chipped stone debitage, and, when available, burned rocks from each of these 40 units were analyzed. Soil samples were submitted for chemical characterization to the Environmental Geochemistry Laboratory at UTSA for analysis of the total carbon, organic and non-organic carbon, nitrogen, and phosphate levels. The magnetic susceptibility of samples was analyzed at CAR, as were the associated cultural material. We focused on debitage counts, size, and cortex percentages. We had initially planed on counting and weighing burned rock a part of the analysis. However, six of the 40 proveniences were from testing during which burned rocks were not collected. In addition, the presence of several burned rock features in the deposits would necessarily result in significant variation in numbers and weight at the provenience level. Finally, as faunal material was minimal and has been described previously (see Appendix D), we did not consider the faunal material in this analysis.

\section{Results- Variability in Soil Chemistry and Magnetic Susceptibility Values}

As noted previously, the results from several of the specialized studies of midden deposits are presented in appendices. The analysis of carbon, nitrogen and phosphate are presented in Appendix G, with Appendix H providing the magnetic susceptibility analysis. Our primary concern here is not in the patterns of these results relative to depth or other variables as is especially common in studies of soil chemistry within sites in the region (see Black 1986; 


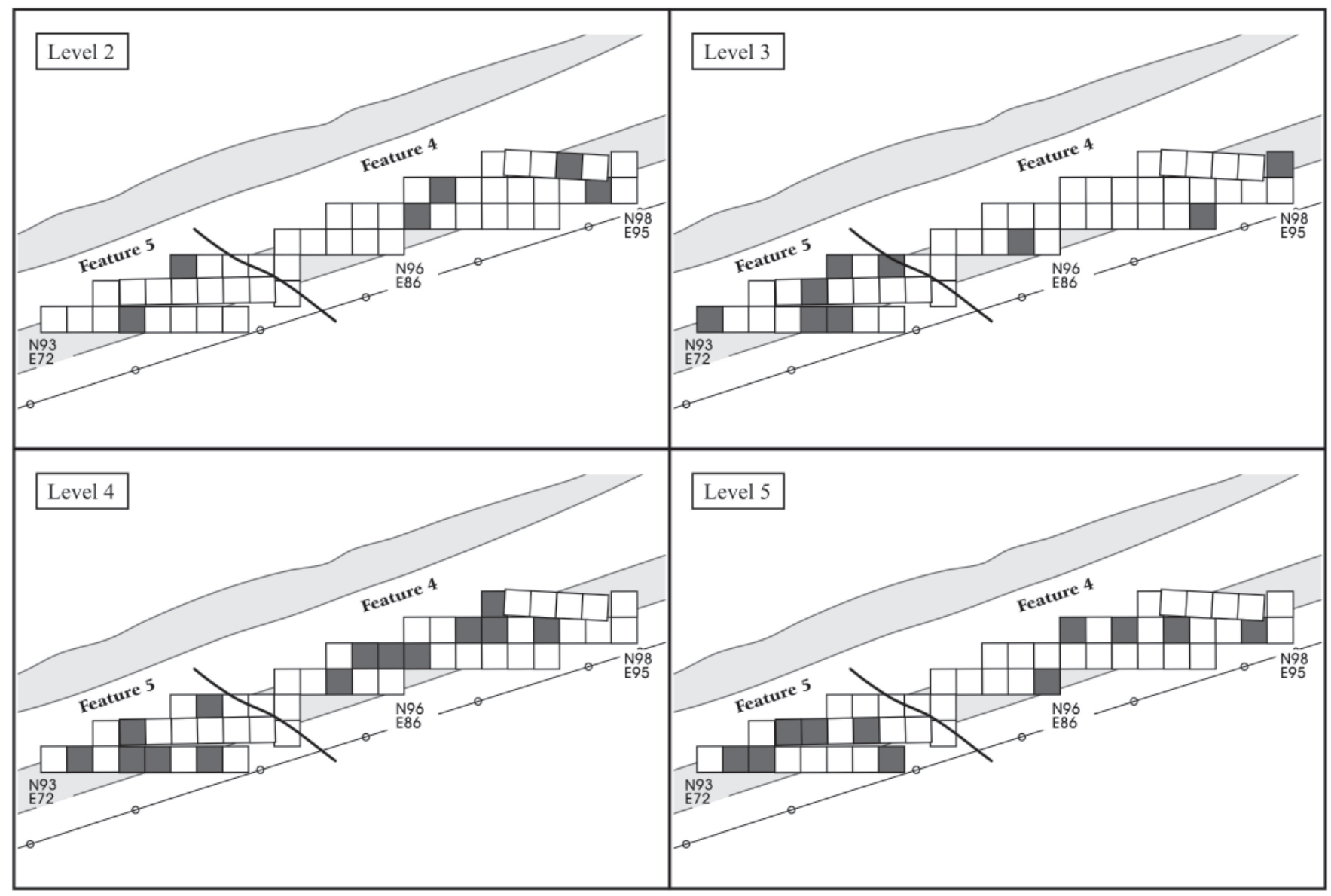

Figure 11-3. Units and levels in Features 4 and 5 selected for detailed comparison.

Lukowski 1987; McGraw 1985). Rather, we are primarily concerned with characterizing the variability present in these elements and in the magnetic signatures within the two larger features. While more detailed information on the various analyses is provided in the appendices, and while we discuss some general patterns below, those readers interested in soil chemistry in archeology can find informative discussions in Shackley (1975), Sjoberg (1976), Woods (1977), Lillios (1992), and Middleton and Price (1996). Readers interested in applications of magnetic soil susceptibility should review Dearing (1999), McClean and Kean (1993), and Reynolds and King (1995).

Table 11-3 presents summary statistics for inorganic carbon, organic carbon, total carbon (organic + inorganic), phosphates, nitrogen, and magnetic susceptibility readings for sediment collected from the 40 proveniences shown in Figure 11-3. The samples are separated by feature for ease of comparison. The table lists the mean, standard deviation, CV or coefficient of variation (standard deviation/mean), median, maximum value, and the IQR (Inter-Quartile Range) for each variable. The $\mathrm{CV}$ provides a measure of variability that is not impacted by absolute differences in the mean, but it does assume a normal distribution (see Blalock 1979). The higher the $\mathrm{CV}$ value, the greater the variability in the distribution. The inter quartile range makes no assumptions of normality and provides a measure of the spread of the values (+/- one quartile) around the median (see Chambers et al. 1983). The IQR is impacted by absolute differences, though only phosphates seem to have differences between features that might significantly influence interpretation of the IQR. The larger the inter-quartile range, the greater the spread of values in the distribution. The inter-quartile range should be evaluated relative to the median for a given comparison. We highlight the highest $\mathrm{CV}$ and IQR value in each comparison in Table 11-3.

Focusing first on the CV values, the Table 11-3 data suggest that Feature 5 has slightly greater variability relative to Feature 4. However, the overall pattern in the Table suggests that the concentration of most elements, as well as the magnetic character of the sediments, is consistent across both features. In many cases, the $\mathrm{CV}$ is below 0.5 . The obvious exception to this statement is in the comparison of phosphates, with $\mathrm{CV}$ in excess of 1.5 for both features. In addition, note that phosphate concentrations in Feature 4 are 
Table 11-3. Summary Statistics for Multiple Elements and Magnetic Soil Susceptibility Values, Features 4 and 5 at 41ZV202

\begin{tabular}{|c|l|c|c|c|c|c|c|c|}
\hline Feature & Element/ Measure & $\mathbf{n}$ & Mean & Std. Dev & $\mathbf{C V}$ & Median & Max & IQR \\
\hline 4 & Inorganic Carbon (\%) & 20 & 0.679 & 0.486 & 0.716 & 0.575 & 1.72 & 0.79 \\
\hline 5 & Inorganic Carbon (\%) & 20 & 0.579 & 0.554 & 0.957 & 0.35 & 1.64 & 0.88 \\
\hline \hline 4 & Organic Carbon (\%) & 20 & 5.702 & 1.449 & 0.254 & 5.32 & 8.47 & 1.84 \\
\hline 5 & Organic Carbon (\%) & 20 & 5.012 & 1.929 & 0.385 & 4.76 & 12.16 & 1.21 \\
\hline \hline 4 & Total Carbon (\%) & 20 & 6.381 & 1.699 & 0.266 & 5.665 & 9.8 & 2.54 \\
\hline 5 & Total Carbon (\%) & 20 & 5.591 & 2.175 & 0.389 & 4.955 & 13.81 & 1.97 \\
\hline \hline 4 & Phosphates (mg/kg) & 20 & 80.84 & 308.52 & 3.816 & 49.15 & 949.16 & 361.07 \\
\hline 5 & Phosphates (mg/kg) & 20 & 136.38 & 243.15 & 1.783 & 24.46 & 850.19 & 97.67 \\
\hline \hline 4 & Total Nitrogen (\%) & 20 & 1.944 & 1.267 & 0.652 & 1.58 & 5.48 & 1.61 \\
\hline 5 & Total Nitrogen (\%) & 20 & 3.483 & 2.671 & 0.767 & 2.76 & 12.18 & 2.56 \\
\hline \hline 4 & MS Susceptibility & 20 & 23.504 & 3.258 & 0.139 & 21.655 & 30.44 & 4.91 \\
\hline 5 & MS Susceptibility & 20 & 20.024 & 1.732 & 0.086 & 19.905 & 23.2 & 2.58 \\
\hline
\end{tabular}

significantly more variable than in Feature 5. The maximum value for this element in both features is significantly different from their respective mean values, suggesting small scale concentrations of phosphates. The variability in the IQR values, when compared to the medians, also shows low overall variability, but suggests that Feature 4 may be slightly more variable than Feature 5. As with the CV results, only the IQR for phosphate concentrations are extreme.

\section{Results- Variability in Debitage}

Table 11-4 presents summary statistics for the number of debitage as well as the average size of debitage, standard deviation on that average, and CV by analytical provenience for Features 4 and 5. Data for this table, along with information on cortex that will be used subsequently, can be found in Appendix I. We use the same 40 proveniences as in Table 11-3 (see Figure 11-3).

The average number of items in a given provenience for Feature 4 is 34.2 items, with a standard deviation on that average of 14.48 and a CV of .423. For Feature 5, the average number of debitage is significantly lower at only 12 items (standard deviation $=7.68$ ) and a CV of .64. While variability in counts suggests that Feature 5 counts are slightly more variable, comparison of the $\mathrm{CV}$ values on size shown in the Table suggests low variability, especially at a feature level. Sixteen of the 20 proveniences in Feature 4 and 17 of the 20 proveniences in Feature 5 have $\mathrm{CV}$ values below 0.5. No CV value exceeds 0.75 . Within each feature, then, there is low variability in the number of debitage and in the size of the debitage from one provenience to the next.

Finally, we consider cortex percentages on debitage (see Appendix I). Overall, a high percentage of the debitage in the sample lacks cortex, with 759 of the 924 pieces of debitage lacking cortex (82.1\%), 7.4\% $(n=68)$ have between 1 and $10 \%$ cortex, and the remaining $10.5 \%$ $(\mathrm{n}=97)$ having between 11 and $99 \%$ dorsal cortex coverage. In order to consider variability in cortex, we constructed two crosstabulations of counts of debitage in the 20 provenience units and by the three cortex categories noted above $(0 \%, 1-10 \%,+10 \%)$ for each feature. We then generated standardized adjusted residuals for each of the 60 cells in each of the two tables. Standardized adjusted residuals provide information on the contribution that each cell makes to the overall significance of a given table. Adjusted residuals are analogous to $\mathrm{Z}$ scores such that an adjusted residual value exceeding an absolute value of 1.96 suggests that the cell is significantly different from the expected value at a probability level beyond .05 (see Everitt 1997; Haberman 1973). Figures 11-4 and 11-5 plot the adjusted residuals resulting from these cross-tabs for Features 4 and 5, respectively. Red identifies significant values (+/-1.96). For Feature 4 (Figure 11-4), only one of the 60 cells had counts that were significantly different from the expected values, and for Feature 5 (Figure 11-5), there were only seven cells that did not have the expected counts. These

Table 11-4. Debitage Counts and Maximum Size for Selected Proveniences in Features 4 and 5, 41ZV202

\begin{tabular}{|c|c|c|c|c|c|c|c|}
\hline \multicolumn{9}{|c|}{ Feature 4 } & \multicolumn{4}{c|}{ Feature 5 } \\
\hline $\mathbf{n}$ & $\begin{array}{c}\text { mean } \\
(\mathbf{c m})\end{array}$ & $\mathbf{s t d e v}$ & $\mathbf{c v}$ & $\mathbf{n}$ & $\begin{array}{c}\text { mean } \\
\text { (cm) }\end{array}$ & stdev & $\mathbf{c v}$ \\
\hline 13 & 14.89 & 3.58 & 0.241 & 6 & 13.32 & 1.76 & 0.132 \\
\hline 27 & 17.14 & 5.47 & 0.319 & 12 & 12.81 & 1.96 & 0.153 \\
\hline 21 & 16.43 & 5.34 & 0.325 & 7 & 13.66 & 3.02 & 0.221 \\
\hline 47 & 15.06 & 5.27 & 0.35 & 7 & 13.66 & 3.35 & 0.245 \\
\hline 35 & 15.75 & 5.8 & 0.368 & 6 & 14.3 & 3.7 & 0.259 \\
\hline 47 & 15.68 & 5.8 & 0.37 & 9 & 15.46 & 4.48 & 0.29 \\
\hline 24 & 16.12 & 6.24 & 0.387 & 7 & 15.34 & 4.65 & 0.303 \\
\hline 59 & 16.14 & 6.39 & 0.396 & 30 & 13.48 & 4.46 & 0.331 \\
\hline 24 & 16.86 & 6.98 & 0.414 & 7 & 19.69 & 7.08 & 0.36 \\
\hline 53 & 15.86 & 6.81 & 0.429 & 29 & 14.42 & 5.46 & 0.379 \\
\hline 53 & 16.79 & 7.21 & 0.43 & 8 & 17.3 & 6.66 & 0.385 \\
\hline 56 & 16.61 & 7.46 & 0.449 & 9 & 13.71 & 5.43 & 0.396 \\
\hline 34 & 16.36 & 7.41 & 0.453 & 12 & 17.32 & 7.26 & 0.419 \\
\hline 20 & 17.38 & 8.08 & 0.465 & 19 & 15.59 & 6.59 & 0.423 \\
\hline 28 & 17.5 & 8.28 & 0.473 & 11 & 19.68 & 8.59 & 0.437 \\
\hline 44 & 16.72 & 8.3 & 0.497 & 11 & 17.4 & 7.8 & 0.448 \\
\hline 15 & 19.55 & 11.35 & 0.581 & 8 & 20.59 & 9.78 & 0.475 \\
\hline 24 & 18.33 & 11.25 & 0.614 & 4 & 24.17 & 12.18 & 0.504 \\
\hline 22 & 17.98 & 12.34 & 0.686 & 25 & 20.67 & 10.47 & 0.507 \\
\hline 38 & 18.25 & 12.78 & 0.7 & 13 & 15.07 & 9.05 & 0.6 \\
\hline
\end{tabular}




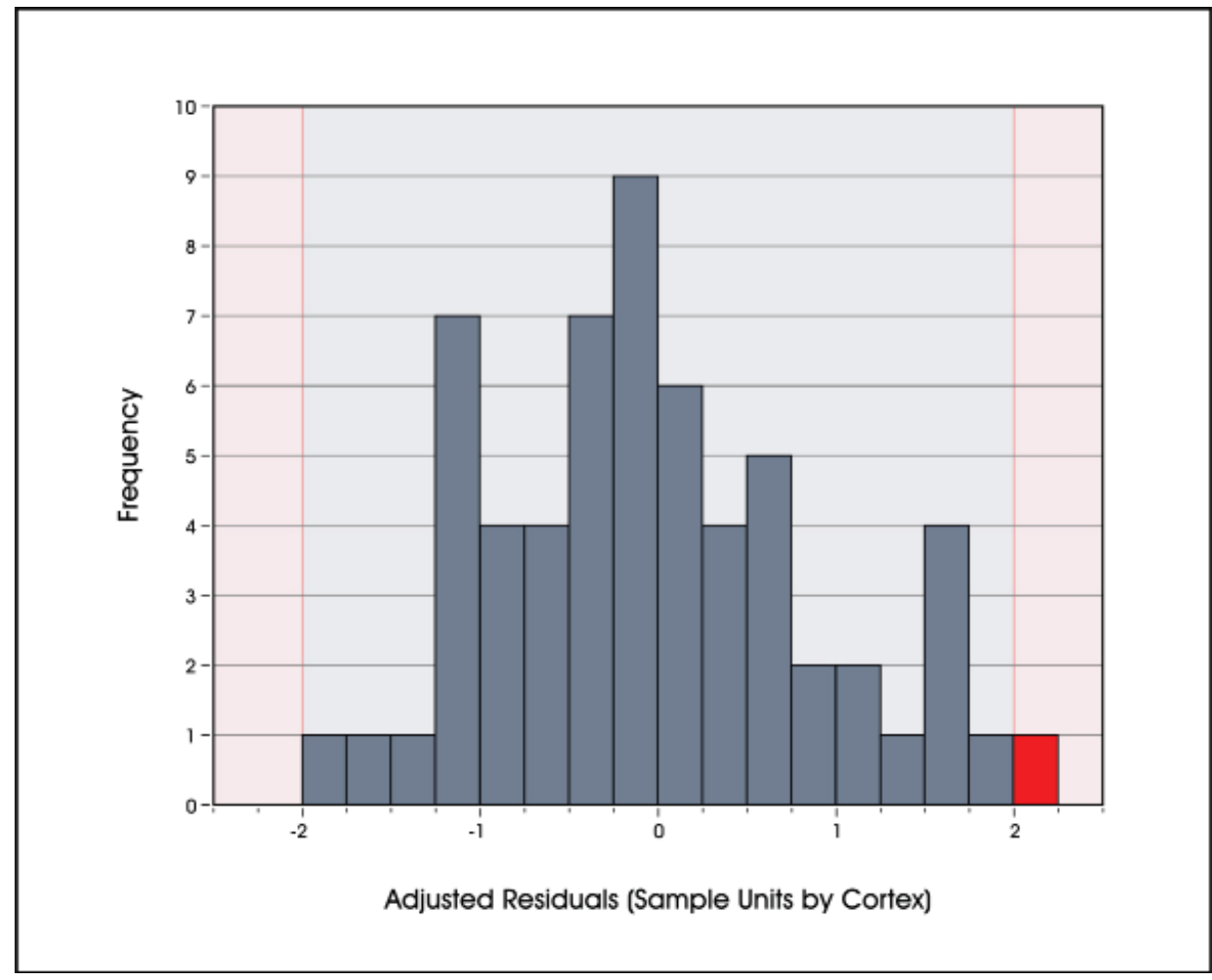

Figure 11-4. Adjusted residuals from cortex groups (0\%, 1-10\%, +10\%) by sample unit cross-tabulation, 41ZV202, Feature 4.

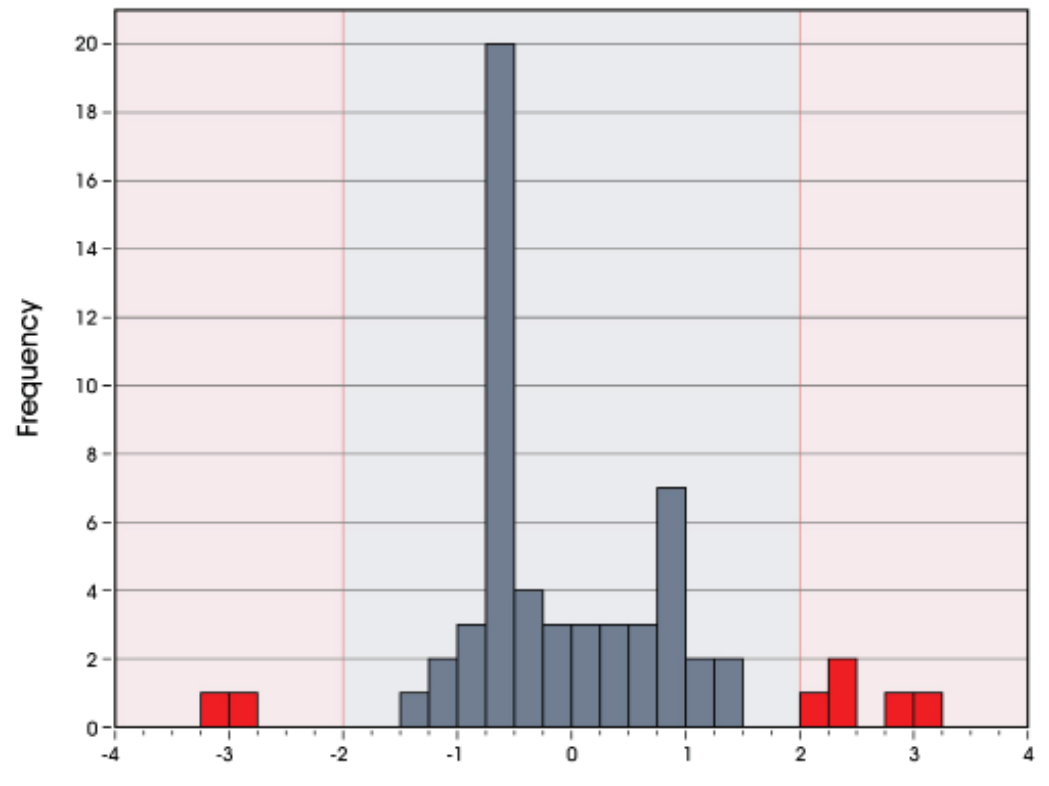

Adjusted Residuals (Sample Units by Cortex)

Figure 11-5. Adjusted residuals from cortex groups (0\%, 1-10\%, +10\%) by sample unit cross-tabulation, 41ZV202, Feature 5. 
two distributions suggest that cortex does not vary in any significant way between provenience units in these features.

\section{Results- Relationships and Spatial Patterning in Soil Chemistry and Debitage}

Table 11-5 presents Persons correlation coefficients for selected concentrations, elements, and debitage for all 40 samples. While we have identified statistically significant coefficients, highlighted in bold in the table, the application of correlation coefficients to the percentage data sets (i.e., inorganic and organic carbon, nitrogen) is done primarily for heuristic purposes. Note first that there are no significant relationships between either nitrogen percentages or phosphate concentrations and any other variables across the 40 samples. Reference to Appendix $G$ will show that with regard to nitrogen, a single value of $12.18 \%$ from level 4 at North 93, East 75 stands out from the other nitrogen values, the remainder of which all fall below $7 \%$, with most being below 4\%. This particular provenience is not associated with any of the burned rock features, and examination of the field notes did not reveal anything unique about this location. Excavators did note that the level contained two small concentrations of snail shell (Rabdotus $s p$.), but it is unclear if these are associated with the single extreme value. Similarly, Appendix G data shows that most phosphate values are commonly below $200 \mathrm{mg} / \mathrm{kg}$, though there are five extreme cases where concentrations fall between 700 and $1000 \mathrm{mg} / \mathrm{kg}$. As with the single extreme nitrogen value, the extreme values in phosphates are not associated with

Table 11-5. Pearson's Correlation Coeffients on Selected Elements in Features 4 and 5.

\begin{tabular}{|c|c|c|c|c|c|c|}
\hline & & $\begin{array}{c}\text { Inorganic } \\
\text { Carbon }\end{array}$ & $\begin{array}{l}\text { Organic } \\
\text { Carbon }\end{array}$ & Phosphates & Nitrogen & $\begin{array}{c}\text { Magnetic } \\
\text { Susceptibility }\end{array}$ \\
\hline \multirow{3}{*}{$\begin{array}{l}\text { Organic } \\
\text { Carbon }\end{array}$} & Correlation & .363 & & & & \\
\hline & Sig. (2-tailed) & .021 & & & & \\
\hline & $\mathrm{N}$ & 40 & & & & \\
\hline \multirow{3}{*}{ Phosphates } & Correlation & -.055 & -.014 & & & \\
\hline & Sig. (2-tailed) & .734 & .932 & & & \\
\hline & $\mathrm{N}$ & 40 & 40 & & & \\
\hline \multirow{3}{*}{ Nitrogen } & Correlation & -.152 & .006 & -.016 & & \\
\hline & Sig. (2-tailed) & .348 & .972 & .924 & & \\
\hline & $\mathrm{N}$ & 40 & 40 & 40 & & \\
\hline \multirow{3}{*}{$\begin{array}{c}\text { Magnetic } \\
\text { Susceptibility }\end{array}$} & Correlation & .024 & .476 & .066 & -.277 & \\
\hline & Sig. (2-tailed) & .883 & .002 & .684 & .084 & \\
\hline & $N$ & 40 & 40 & 40 & 40 & \\
\hline \multirow{3}{*}{$\begin{array}{l}\text { Debitage } \\
\text { Count }\end{array}$} & Correlation & .001 & .461 & .077 & -.233 & .727 \\
\hline & Sig. (2-tailed) & .994 & .003 & .636 & .147 & .000 \\
\hline & $\mathrm{N}$ & 40 & 40 & 40 & 40 & 40 \\
\hline
\end{tabular}

Cells with signficant differences at or exceeding the 0.05 level are in bold. any of the burned rock features and they do not pattern with any other variable in Table 11-5. Furthermore, levels with high phosphates are often surrounded with average values. That is, there is no clear spatial patterning in the phosphate values. Examination of the remaining variables, coefficients, and probability values in Table 11-5 suggest that there is a moderately positive relationships between inorganic and organic carbon percentages $(R=.362)$ and moderately strong, positive relationships between organic carbon and both magnetic susceptibility $(\mathrm{R}=.476)$ and debitage counts $(\mathrm{R}=.461)$. Finally, there is a strong, positive relationship between debitage counts and susceptibility values $(\mathrm{R}=.727)$.

Figure 11-6 presents this last relationship, between debitage counts and susceptibility values, and further identifies values by Feature. Susceptibility measures of a sample are initially dependent on the sample mineralogy. Within that sediment, however, higher susceptibility values can be produced by a variety of causes, including heating of sediment in hearths (e.g., Bellomo 1993; Crowther 2003; Mauldin and Figueroa 2006: 106-117) and the deposition, concentration, and subsequent decay of organic remains on a surface, sometimes associated with pedogenic processes (e.g., Reynolds and King 1995; Takac and Gose 1998). The strong association between susceptibility values and debitage counts shown in Figure 11-6 is most likely the result of the deposition, and concentration, of organic remains and debitage over time, rather than any relationship to increased heating of sediments with increased frequencies of debitage. Increased frequency of the deposition of organics, and their subsequent decay, would increase the soil susceptibility. If debitage was a component of that deposition, then higher concentrations of debitage would also be expected.

The suggestion that heating of sediments may not have been a primary cause of the susceptibility and debitage count relationships is supported by data in Table 11-6. Here, we present data on three different profiles at 41ZV202. These include susceptibility samples from Bousman's Profile 2, located to the north and west of Feature 5 at about 95N/72E and collected by Zone (see Figure 4-6; Appendix A), sample from Feature 5 taken at $10 \mathrm{~cm}$ levels in $94 \mathrm{~N} / 78 \mathrm{E}$, and Feature 4 samples, again taken in $10 \mathrm{~cm}$ levels, from 98N/92E. The initial column in the table presents the approximate depth of the samples, with columns two through four presenting the initial mass specific susceptibility values (see Appendix H). Each of these samples were subsequently heated at 


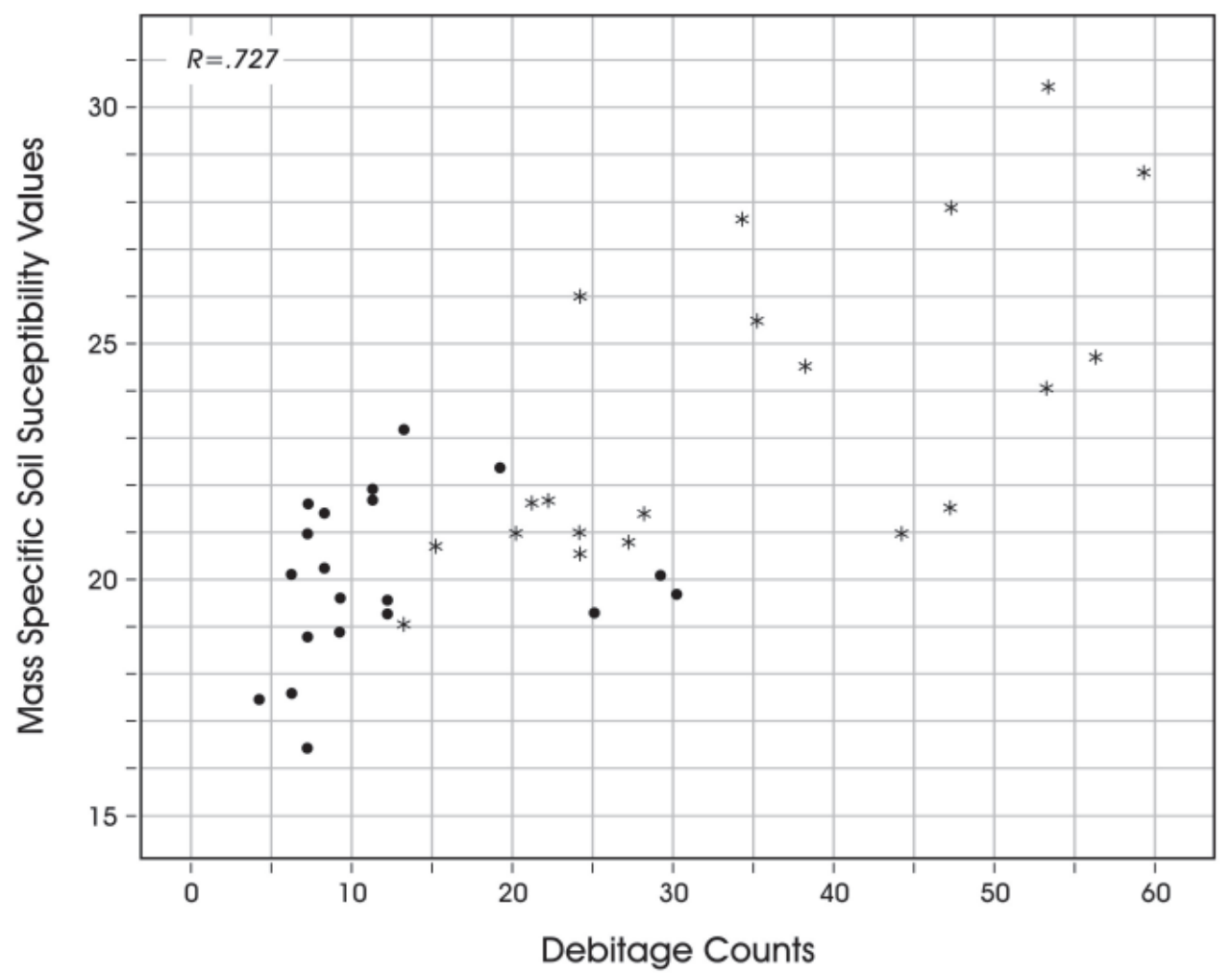

* Feature 4

- Feature 5

Figure 11-6. Bivariate plot of debitage counts and soil susceptibility values for 40 proveniences in Features 4 and 5.

$400^{\circ} \mathrm{C}$ for one hour in a Thermolyne FB 1300 furnace. After cooling, the soil susceptibility of the samples were measured. These are reported in columns five through seven. Finally, for the samples collected from Profile 2, this process was repeated, with samples heated to $500^{\circ} \mathrm{C}$, and susceptibility values again assessed. These susceptibility values are presented in column eight in Table 11-6.

Table 11-6. Mass Specific Soil Susceptibility Values for Selected Locations and Temperature Treatments.*

\begin{tabular}{|c|c|c|c|c|c|c|c|}
\hline $\begin{array}{c}\text { Cm below surface- } \\
\text { Zone/Level }\end{array}$ & $\begin{array}{l}\text { Profile } 2 \\
95 \mathrm{~N} / 72 \mathrm{E}\end{array}$ & $\begin{array}{c}\text { Feature } \\
594 \mathrm{~N} / 78 \mathrm{E}\end{array}$ & $\begin{array}{c}\text { Feature } 4 \\
98 \mathrm{~N} / 92 \mathrm{E}\end{array}$ & $\begin{array}{l}\text { Profile } 2 \\
\text { at } 400^{\circ} \mathrm{C}\end{array}$ & $\begin{array}{l}\text { Feature } 5 \\
\text { at } 400^{\circ} \mathrm{C}\end{array}$ & $\begin{array}{l}\text { Feature } 4 \\
\text { at } 400^{\circ} \mathrm{C}\end{array}$ & $\begin{array}{l}\text { Profile } 2 \\
\text { at } 500^{\circ} \mathrm{C}\end{array}$ \\
\hline 2.5-Zone 1 & 18.5 & $\mathrm{n} / \mathrm{a}$ & $\mathrm{n} / \mathrm{a}$ & 19.77 & $\mathrm{n} / \mathrm{a}$ & $\mathrm{n} / \mathrm{a}$ & 20 \\
\hline 13.5-Zone 2/Level 2 & 20 & 20 & 29.35 & 21.1 & 21.05 & 30.68 & 20.98 \\
\hline 28-Zone 3/Level 3 & 18.99 & 19.3 & 27.4 & 20.36 & 20.12 & 28.38 & 20.24 \\
\hline 35-Zone 3/Level 4 & $\mathrm{n} / \mathrm{a}$ & 18.42 & 24.91 & $\mathrm{n} / \mathrm{a}$ & 18.5 & 25.96 & $\mathrm{n} / \mathrm{a}$ \\
\hline 45-Zone 4/Level 5 & 16 & 18.39 & 20.71 & 17.2 & 19.24 & 21.47 & 17.29 \\
\hline 60.5-Zone 5 & 14.27 & $\mathrm{n} / \mathrm{a}$ & $\mathrm{n} / \mathrm{a}$ & 15.03 & $\mathrm{n} / \mathrm{a}$ & $\mathrm{n} / \mathrm{a}$ & 14.97 \\
\hline 78-Zone 6 & 12.19 & $\mathrm{n} / \mathrm{a}$ & $\mathrm{n} / \mathrm{a}$ & 12.19 & $\mathrm{n} / \mathrm{a}$ & $\mathrm{n} / \mathrm{a}$ & 12.66 \\
\hline
\end{tabular}

${ }^{*} 400^{\circ} \mathrm{C}$ exposures in BOLD, $500^{\circ} \mathrm{C}$ in ITALICS.
Focusing first on the unheated values in the table, note that the Profile 2 values are only slightly lower than the comparable depths in Feature 5, suggesting that there is minimal susceptibility enhancement associated with this particular feature designation. Secondly, all three unheated samples have peak values at roughly $13.5 \mathrm{cmbs}$, with gradual declines with increasing depth. This pattern is consistent with a stable surface, which is now buried by roughly $13.5 \mathrm{~cm}$ of deposits (see Takac and Gose 1998: 1330-1335). At $400^{\circ}$ $\mathrm{C}$, there is only minimal enhancement of the susceptibility values, with an average increase of $4.5 \%$ for the 14 samples. Values outside the features, which we presume to have not been heated previously, are enhanced, on average, $5.4 \% \quad(n=6)$ while feature values are increased by $3.8 \%(n=8)$. This suggests that some minor degree of heating of the sediments within the features have occurred previously, but note that even at $500^{\circ} \mathrm{C}$ (Table 11-6, 
Column 8), values of unheated sediment (Profile 2) do not approach the upper ranges shown in Figure 11-6. This, and the low frequency of burning in the debitage from the site, suggests that the increased susceptibility levels are primarily associated with organic deposition and decay.

The moderately significant correlation between organic carbon content and susceptibility values $(\mathrm{R}=.476)$ as well as the correlation between debitage counts and organic carbon $(\mathrm{R}=.461)$, both shown in Table 11-5, are consistent with the deposition and deterioration of organic debris and associated debitage. Organic carbon percentages averaged $5.36 \%$ for all 40 samples (Appendix G). As Figure 11-7 shows, organic carbon content is highest in Level 2, averaging $7.2 \%$. In Levels 3 and 4, the average organic carbon percentage dropped to $5.3 \%$, and by Level 5, the average had declined to $4.5 \%$ (Figure 11-7). Roughly similar patterns are present for debitage counts (Figure 11-8) and susceptibility values (Figure 11-9). High values are associated with Level 2 and values or counts generally decline with increasing depth. This is consistent with the deposition of artifacts and organic debris on a surface, or multiple surfaces, in this general area.

\section{Summary}

Though we lack any comparative data from formal middens, the analysis summarized in Tables 11-3, 11-4, 11-5, and 11-6, as well as in Figures 11-4 through 11-9, suggest that sheet middens present at 41ZV202 have surprisingly consistent content and low variability. The soils chemistry, magnetic susceptibility, debitage counts, flake size, and cortex percentages are consistent in both Features 4 and 5 at 41ZV202. The only variable that shows any significant variation is differences in phosphate levels. This low variability is consistent with our expectations for sheet middens. While recognition of formal and sheet middens will continue to be problematic given dark soils present in many parts of Central and South-Central Texas, the length of site occupation should condition site maintenance activities that will result in various types of trash midden. The presence and nature of midden deposits, in turn, should provide additional clues to identifying the types of sites reflected at a location.

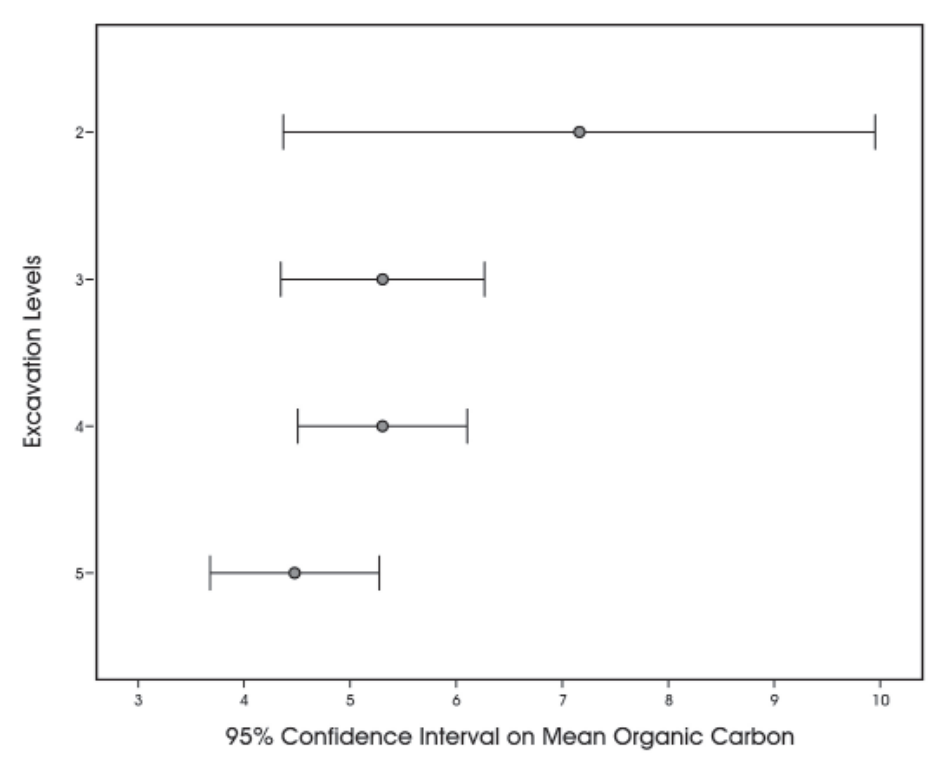

Figure 11-7. Patterning of organic carbon by level within Features 4 and 5.

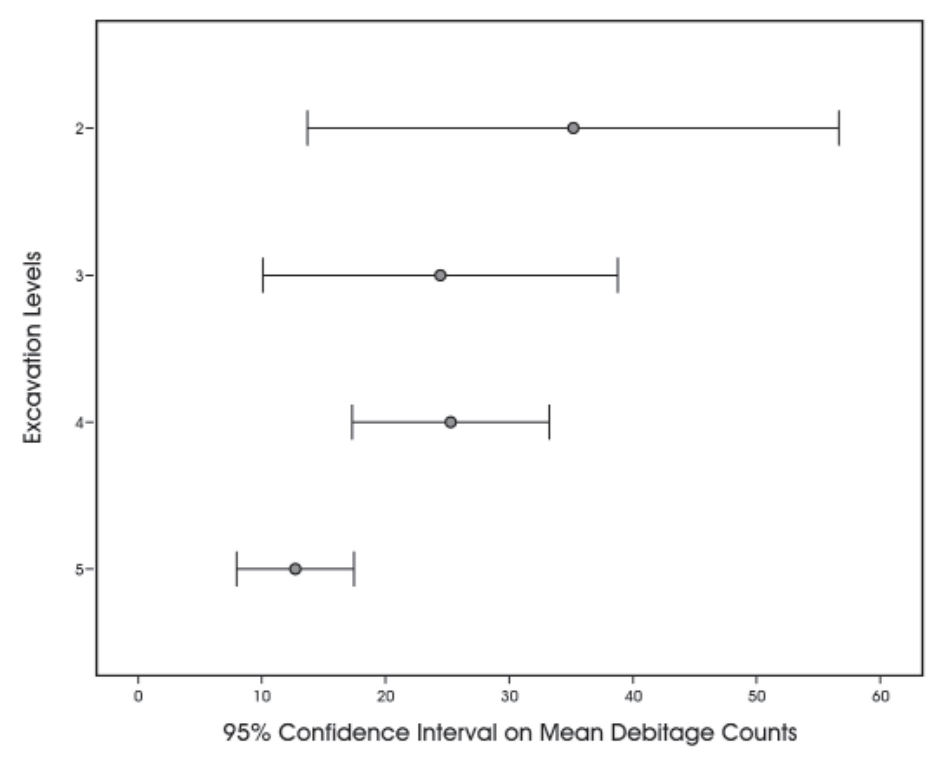

Figure 11-8. Patterning of debitage counts by level within Features 4 and 5.

\section{Summary}

Our suggestions that as bison populations declined, hunters and gatherers were increasingly likely to use logistically based mobility systems are only partially supported by the analysis conducted in this chapter. We suggested that the variety of artifact types on a component should be indicative 


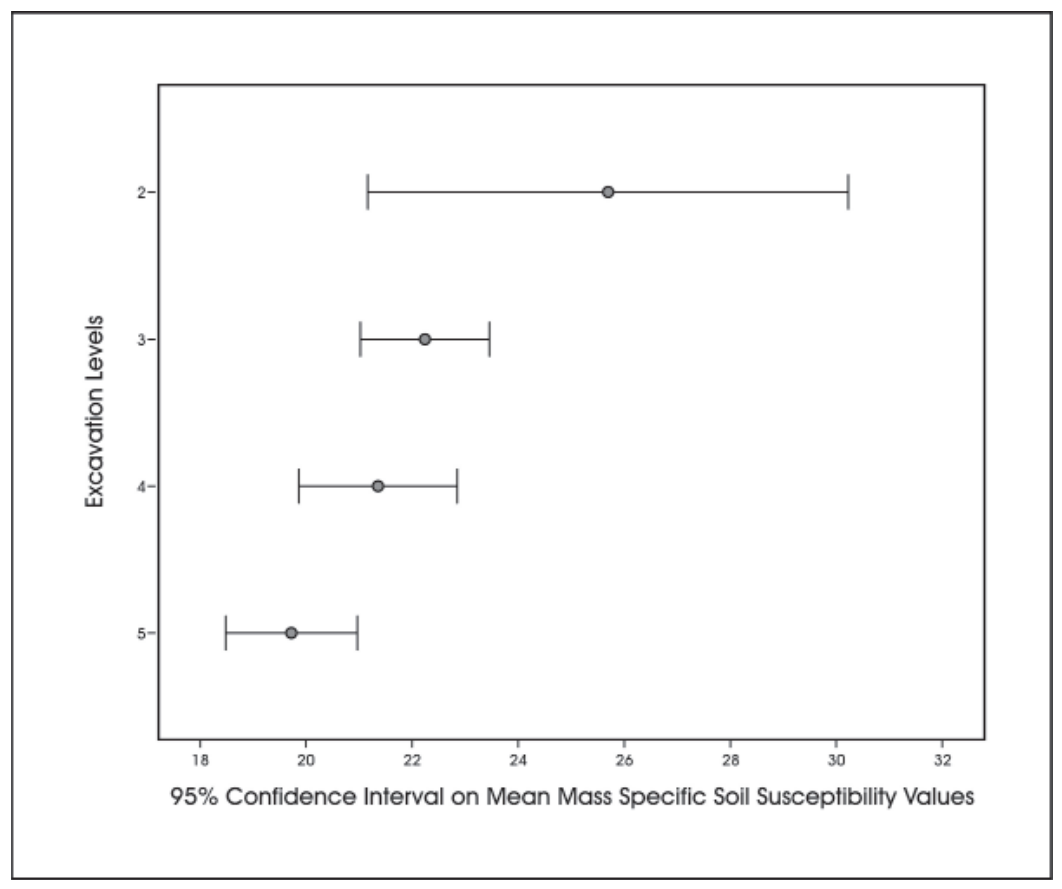

Figure 11-9. Patterning of mass specific soil susceptibility values by level within Features 4 and 5.

of the range of activities that occurred at that location. At residential sites, we expected a wider variety of types, while at special purpose locations, the range of types should be limited. These site types, in turn, broadly correlate with different types of mobility organization. Under a foraging based strategy, only residential sites should be present. In contrast, under a collector strategy, both special purpose and residential sites should be present. We used the 41ZV202 data, in combination with 18 other components, to explore the potential of artifact variety as an indicator of site types and, by extension, aspects of mobility organization. We expected that special purpose components should be more common late in the prehistoric sequence as bison availability declined and hunters and gatherers placed increasing emphasis on a logistical pursuit strategy. While some special purpose and some residential sites were identified, our analysis showed that sample size, rather than shifts in organization, was the primary influence on the number of artifact types.

We subsequently used data from 41ZV202 to begin to explore the potential of shifts in site maintenance activities as an additional measure of site types. Though we lack any comparative data from formal middens, our analysis demonstrated that sheet midden deposits, identified as Features 4 and 5 on 41ZV202, have extremely low variability in most aspects of soil chemistry, magnetic susceptibility, debitage counts, flake size, and cortex percentages. This low variability is consistent with our expectations for these types of middens. While recognition criteria for formal middens still needs to be developed, the type of midden deposits should provide additional clues to identifying the types of sites reflected at a location. 



\title{
Chapter 12: Assessing Changes in the Scale of Mobility
}

\author{
Raymond Mauldin, Cynthia Munoz, and Leonard Kemp
}

Based on expectation developed in Chapters 7 and 8, we suggested in the previous chapter that an increasing use of a logistical strategy, perhaps manifested by differing frequencies of residential and special purpose sites, should be present late in the prehistoric sequence in response to declining bison availability. A second component of that change in organization is related to shifts in the scale of the system. We suggest that when the use of logistical strategies increases, the overall scale of the system would also increase. We would expect that groups following annual foraging strategies, more common in the Late Archaic, would have operated in a relatively small area. Conversely, Late Prehistoric occupations would be part of a larger-scale, logistically organized system. This chapter considers those expectations by focusing on changes in raw materials used in chipped stone tool production.

\section{Investigating the Scale of Mobility- Chert Sources and Mobility Shifts}

Mobility levels should be responding, in part, to alterations in diet. Specifically, when diet breadth is expanding, especially during the Terminal Late Prehistoric, the scale of mobility should be increased as a function of increased search time associated with declining highranked prey. In contrast, if earlier mobility systems differentially used a foraging strategy, these earlier periods should have lower overall mobility. While the number of residential moves may increase in a foraging system relative to a logistical organized system, the scale covered by the entire mobility system should be reduced in a foraging dominated organization (see Kelly 1995). We propose to monitor shifts in scale by focusing on changes in tool stone. We suggest that as the scale of mobility increases, there should be concomitant increases in the range of raw materials encountered and used in tool production. A corollary of this is that the greater the scale of mobility the more likely that some of the tool stone present on site arrived there from nonlocal resources in the form of finished tools.

Several studies (e.g., Amick 1994) have shown that debitage and tools can be used to track mobility. While these studies often involve the matching of specific raw materials with known source locations, the relationship demonstrated by these earlier studies is applicable even if the specific tool stone source areas are not known. Figure 12-1 presents the proposed relationship between the number of raw material types present and the scale of mobility. The upper right quadrant of the graph should be dominated by logistically organized residential components. Whether the acquisition of tool stone is embedded in other activities, or is a task-specific activity, these logistical residential components should reflect the range of raw materials present in the system. Foraging components should encounter a smaller range of raw materials simply as a function of the more limited scale of mobility. For instance, forager groups centered on the exploitation of the Hill Country region of the Edwards Plateau will have access to good quality cherts characterized by tan, brown and gray color ranges. These resources would include both primary sources, as well as a variety of secondary sources available in river gravel deposits. Foraging groups off the plateau in South and South-Central Texas, such as those groups present at 41ZV202, would have a more limited selection, with tool stone primarily limited to river gravel deposits and lower quality secondary deposits. In addition, some tools, especially those that we have characterized previously as being expensive, will tend to be curated. That is, they will be maintained, stay in the system longer, and

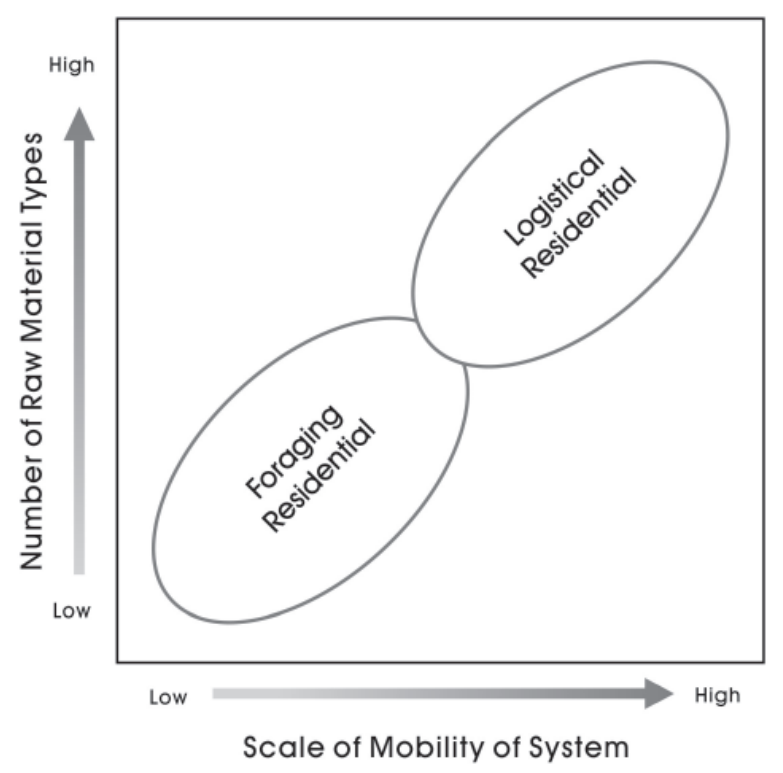

Figure 12-1. Anticipated relationship between scale and the number of raw material types. 
be increasingly likely to be moved from the location where they were initially produced. As such, these items are likely to reflect changes in the overall scale of mobility, especially when the materials are contrasted with material types present in debitage. We focused our investigation on documenting chert colors through the use of digital photography.

\section{Methodological Considerations and Data Acquisition}

Our previous investigations of raw material differences (e.g., Mauldin and Figueroa 2006; Tomka et al. 2003; see also Larson and Kornfeld 1997) have relied on grouping chert debitage by reference to colors using standardized rock color charts, and subsequently dividing these color groups by reference to the presence or absence of inclusions. While the procedure seems to be effective at characterizing large scale differences in raw materials (e.g., local vs. non-local), there are several drawbacks. The procedure is extremely time-consuming, requiring multiple passes through the data, multiple assessments of individual items, and combinations and partitions of preliminary groupings. Ultimately, the process results in the creation of groups that are frequently impossible to replicate. This is because the grouping procedure relies on qualitative impressions. At the end of the process, a number of "groups" contain only a few items of debitage, with some represented by single cases. The lack of a quantitative component in the analysis, along with a consistent definition of what constitutes a material group, results in a classification that is of limited value, especially when comparisons are made between sites. In an effort to overcome these methodological shortcomings, CAR developed procedure that use digital photography of debitage and tools followed by a quantitative assessment of colors in the photographic image using the RGB scale at a multiple pixel level. The method still contains several arbitrary elements. The new procedure essentially ignores inclusions, focusing only on color variation in stone. Items that were clearly heated or patinated were removed from the analysis. However, the procedure, discussed below, does provide quantitative data on color and is highly replicable.

Our initial step in the procedure focused on acquiring highquality, digital images of debitage and tools under consistent light conditions. All photographs were taken with a Canon Rebel XT with a $60 \mathrm{~mm}$ Canon macro lens equipped with a ring flash. Flash settings were at $1 / 4$ power from a fixed, standard camera height onto a photo-gray background. Camera settings were maintained for all photographs. To document and assess consistency between photos, four color chips were incorporated into each photo. Once the photos were taken, one of these color chips was used to assess the consistency of each image. When the Red value on the RGB scale fell outside of the range for values seen in previous work, we lightened or darkened the photograph as required to bring the image into the expected Red range. This insured that photographs were consistent through time.

Following image correction, it was necessary to select an area within each tool or debitage piece, which would be representative of the color of that item. Depending on the homogeneity of the flake surface, individual pixels may not provide an adequate representation of the overall flake color. While we experimented with several different methods, including multiple readings and subsequent averaging of pixel values, we eventually determined that color was best captured by the use of a Gaussian Blur filtering method in Corel Photo-Paint, Version 12.0. A Gaussian Blur is essentially a filter that reduces image details by homogenizing individual pixels. The procedure relies on a weighted average of pixel values and uses a normal distribution, with more weight being given to the central pixel within a chosen radius. Once calculated, the area over which the blur is applied has pixel values that are uniform relative to the original pixel ranges. For this analysis, we chose a radius of 25 pixels, meaning that approximately 1,963 pixels were involved in the blur. Figure 12-2 shows an example of the impact of the blur, which can be seen as a consistent circle of color centered within the outlined black circle. Gaussian Blurs were done on all individual flakes, and their locations identified with a black circle. This allows precise identification of where the measurements were taken, allowing for replication. Once blurs were done, pixel values were acquired from each blur with Pixeur (Version 2.9.0.9) software that records the RGB (Red, Green, Blue) values of individual pixels. Over 9,300 pieces of debitage, and roughly 945 bifaces and hafted tools from 19 components, were photographed, blurred, and recorded using this system.

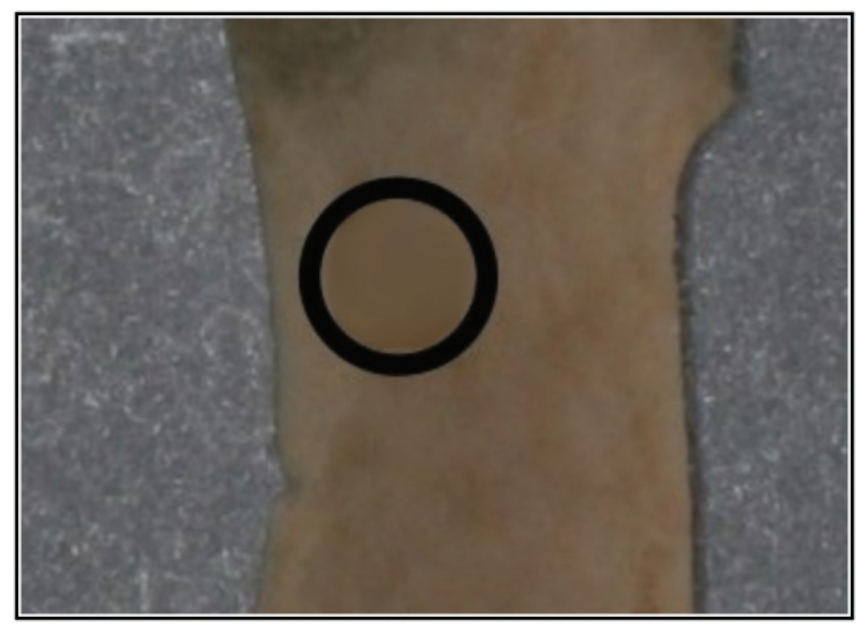

Figure 12-2. An example of the impact of a Gaussian Blur highlighted within the black circle. 
The RGB values essentially provide a description of colors seen by the human eye on a video screen with specific graphics configurations (see Cowlishaw 1985). The scale is based on the additions and intensities of three primary colors (Red, Green, Blue), with variations in hue ranging from 0 to 255 for each primary color. For reference, an RGB value of R0/G0/B0 would produce black, R255/G255/ B255 would be white, R255/G0/B0 would be red, and $\mathrm{R} 0 / \mathrm{R} 255 / \mathrm{R} 0$ would be green. With 256 potential values on each scale, well over 16.7 million color distinctions are possible $\left(256^{3}\right)$, though most of these color differences cannot be seen with the human eyes on a video screen. In fact, rock colors probably occupy only a small number of color possibilities on the RGB scale. However, the potential of over 16.7 million possible colors raises the problem of classification. Specifically, at what point is a "different" color present? Ideally, of course, groups would be defined based on variation in chert colors derived from known source locations. Unfortunately, no such comparative data base exists. A different approach would be to define colors for a given assemblage empirically, possibly with some form of cluster analysis. However, the strong empirical basis of cluster analysis (see Afifi and Clark 1984) assures that different color types will be defined on an assemblage by assemblage basis. That is, cluster analysis defines groups based on what samples are present within an assemblage. As such, it is probable that, at least in some cases, the same RGB value recorded on flakes from two different assemblages would be assigned to two different color groups because the groups are created by reference to what colors are and are not present in the rest of the assemblage. As one of the goals of this analysis is to compare assemblages in terms of the number of groups represented, this type of solution is not workable. Alternatively, clustering could be done only a single time after all analysis was complete, essentially treating all debitage at once. While this would eliminate the potential for a single RGB value to be classified into two different clusters, if the sample size changes, such as through the addition of other assemblages, a new cluster solution would be necessary, and new color groups would be created. Consequently, these clustering based solutions are probably not a viable approach for the types of comparisons undertaken here.

The approached used here treated each primary color (Red, Green, Blue) as a separate variable, and used the individual RGB values of debitage and tools at a site. Figures 12-3, 12-4, and 12-5 provide bi-variant plots of color pairs (Red/ Green; Red/Blue; Green/Blue) for the material at $41 \mathrm{ZV} 202$ as an example of the differences in tool and debitage distributions for a given area. Note that in all three plots, the majority of samples fall close together. There is no clear separation of color groups in any of the plots, with the distributions forming a continuum. Similar patterns were

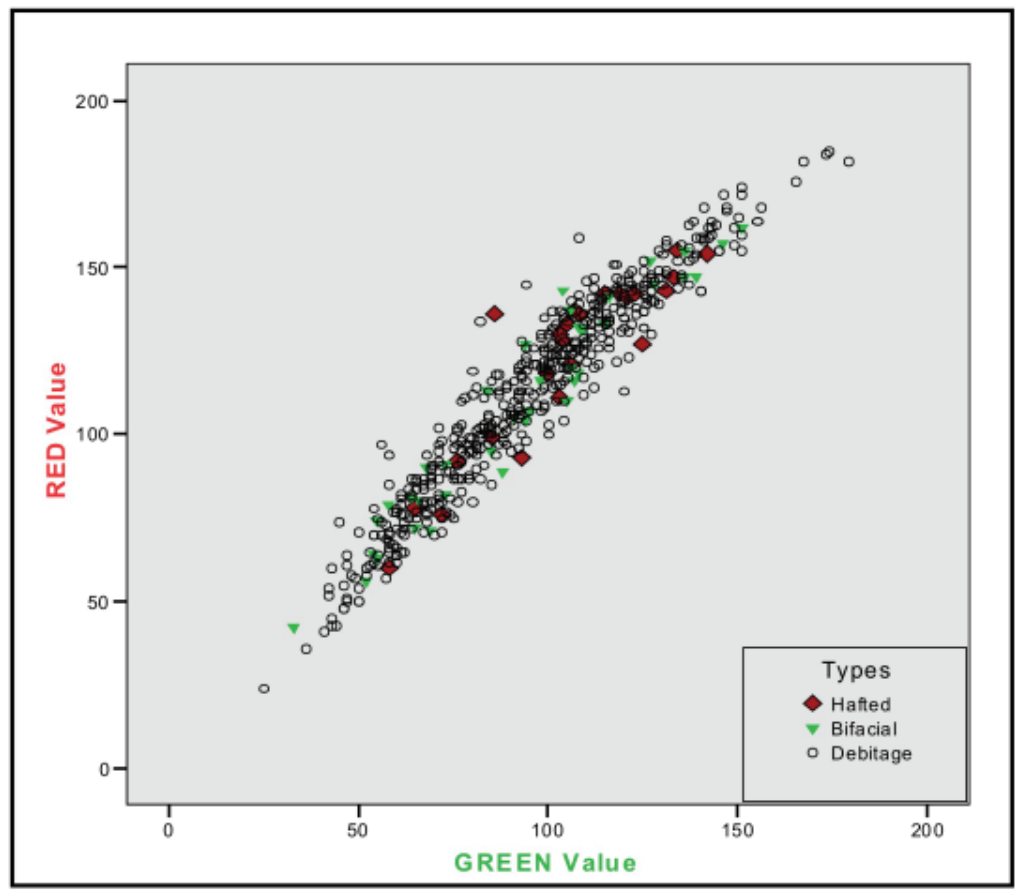

Figure 12-3. Plot of red and green values for debitage, bifacial tools, and hafted items from 41 ZV202.

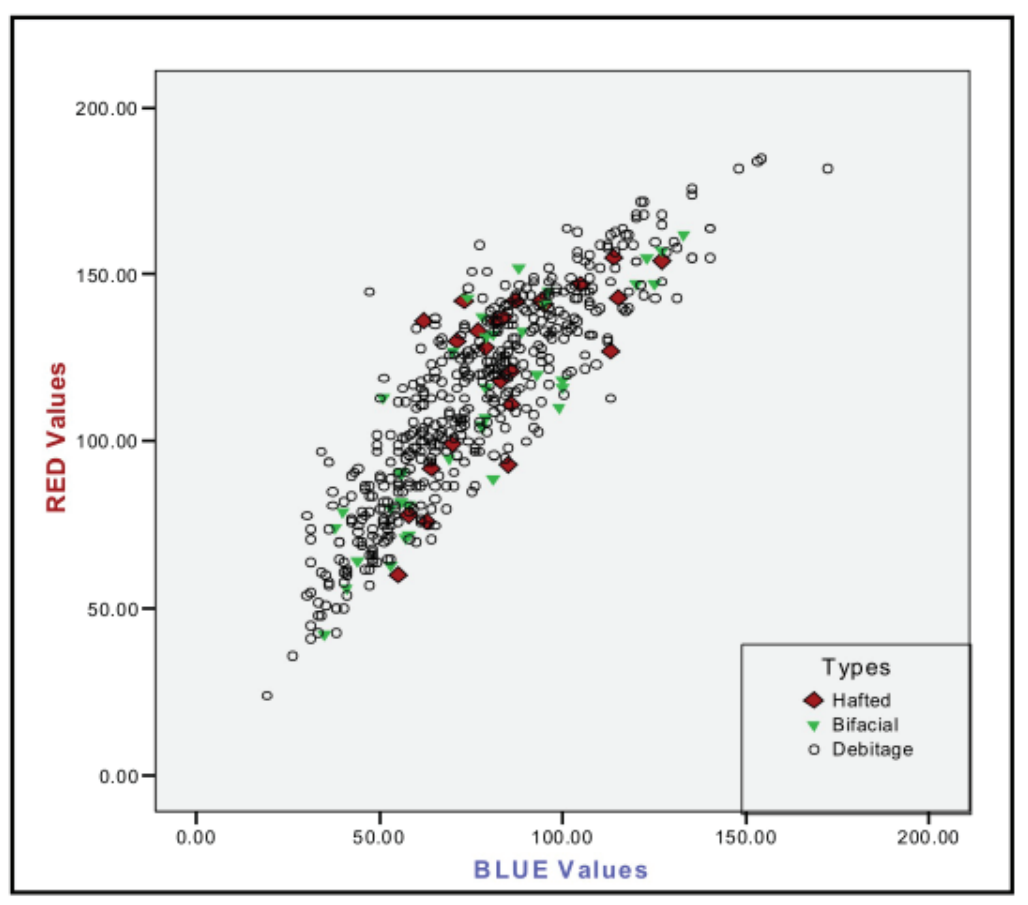

Figure 12-4. Plot of red and blue values for debitage, bifacial tools, and hafted items from $41 Z$ V202. 


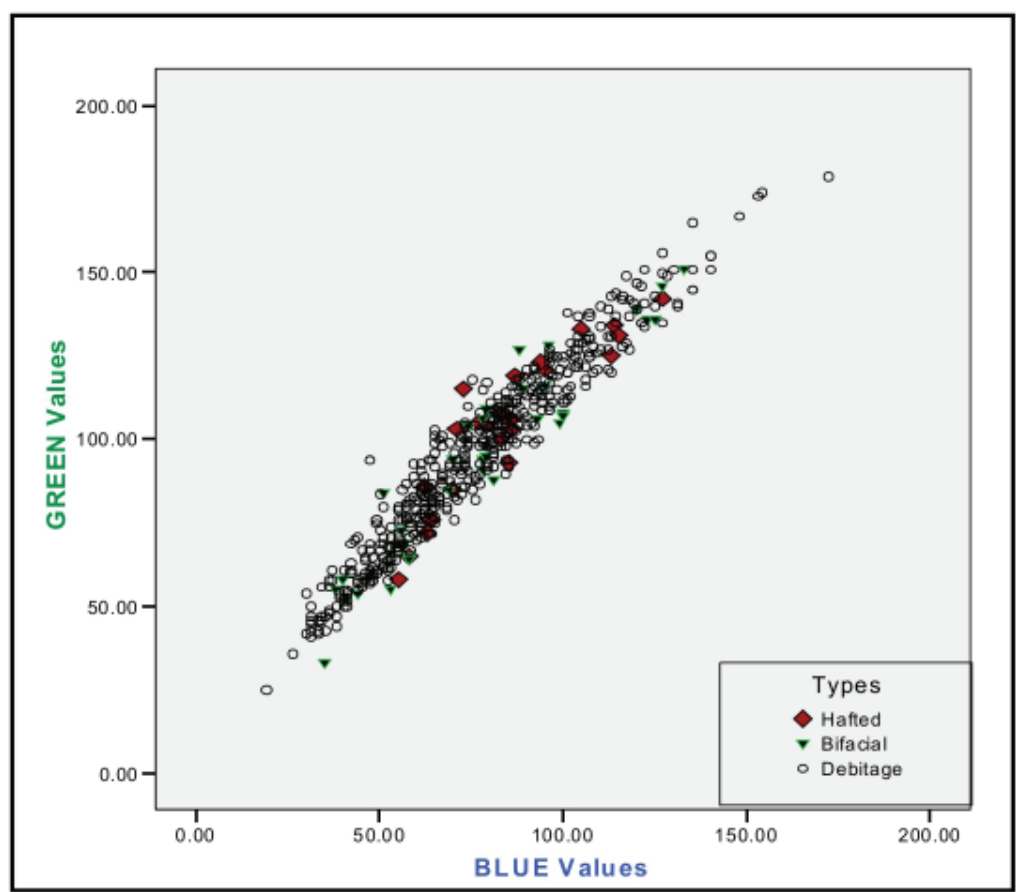

Figure 12-5. Plot of green and blue values for debitage, bifacial tools, and hafted items from $41 Z$ V202.

present in several other distributions examined. While baseline work, consisting of the collection and color assessment of nodules from known locations across the Edwards Plateau as well as from the Uvalde Gravels is required, there is no clear separation into distinct color groups when either debitage or tools are considered.

\section{Results- Difference in Chert Availability}

We characterized the minimum, mean, and maximum value for the debitage (Table 12-1) and formal, expensive tools (Table 12-2) from 41ZV202 and 18 comparative components listed in the Tables. Samples of debitage were those selected and used earlier in Chapter 10. Each table has a similar structure, with the first column listing the site, followed by the component, and the number of items photographed. Columns four, five, and six in each Table list the minimum, mean, and maximum value for the red primary color. Similar statistics are present for the green and blue scales in columns seven through 12 . Note that in Table 12-2, six components with small numbers of formal tools are highlighted in bold. Given the small sample sizes, we eliminated these cases from the detailed statistical analysis conducted later in this chapter.
Examination of the Tables and comparisons for a given site clearly suggests that chert availability in the region is likely to be a primary determinant of color difference. Figure 12-6 shows this impact. Here we plot the mean red value for debitage (Table 12-1) and the mean red value for tools (Table 12-2) from each of the 19 components. While differences between debitage and tool values are evident in both Table 12-1, Table 12-2, and in Figure 12-6, it appears that at a site level, the availability of chert is the primary determinant of the color pattern. For example, note that the five Little River components (41MM340 and 41MM341), all located in Milam County, all cluster in the upper right, portion of the figure. The 41MC296 components, from the Choke Canyon area, cluster in the left portion of the plot, and the 41KM69 components occur near the center.

To document difference in chert availability at the site level, we determination how much of a 30- kilometer radius centered on each site had chert listed in geological deposits, as well as how many different deposits contained chert. We initially plotted all eight sites in ArcGIS 9.2 using UTM coordinates given in the Texas Site Atlas. A spatial extent of $30 \mathrm{~km}$ radius, approximately $2,832 \mathrm{~km}^{2}$, was centered on each site by clipping geologic digital data (2007) developed by the USGS for the Texas Water Development Board. These data are based on the Bureau of Economic

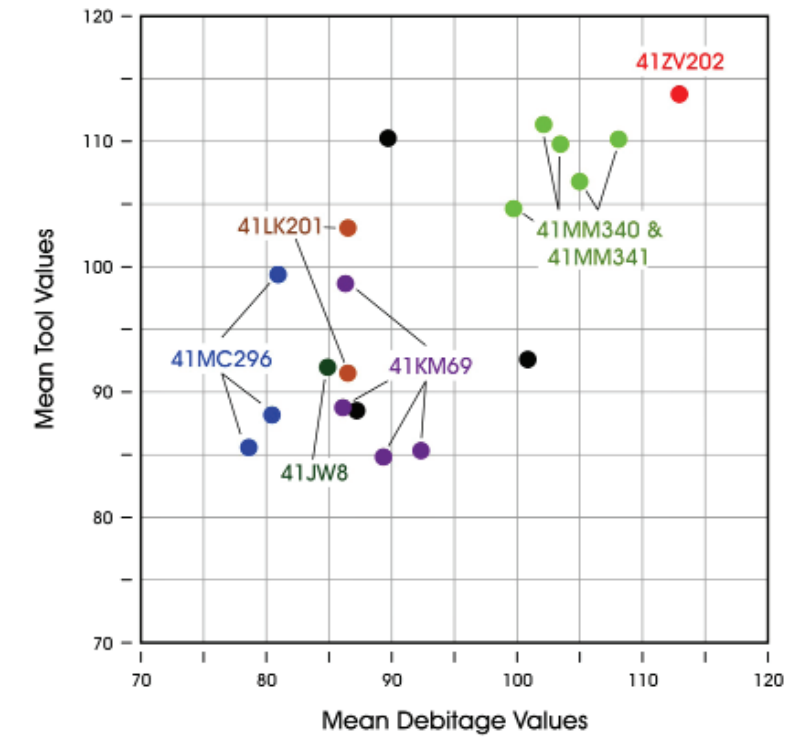

Figure 12-6. Plot of red values for debitage and tools for 19 components. 
Table 12-1. RGB Statistics for Debitage from 41ZV202 and Comparative Components

\begin{tabular}{|c|c|c|c|c|c|c|c|c|c|c|c|}
\hline \multirow[b]{2}{*}{ Site } & \multirow[b]{2}{*}{ 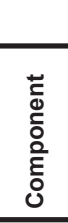 } & \multirow[b]{2}{*}{ 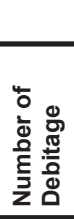 } & \multicolumn{3}{|c|}{ RED } & \multicolumn{3}{|c|}{ GREEN } & \multicolumn{3}{|c|}{ BLUE } \\
\hline & & & 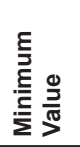 & $\begin{array}{l}\text { ॠ్ } \\
\text { ֻ๊ }\end{array}$ & 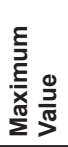 & 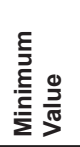 & 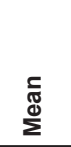 & 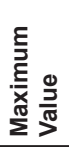 & 莺 & 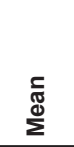 & 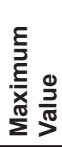 \\
\hline ZV202 & ILP & 485 & 24 & 113 & 185 & 25 & 95.8 & 174 & 19 & 76.5 & 172 \\
\hline KM69 & MLA & 521 & 38 & 89.3 & 157 & 31 & 75.6 & 126 & 22 & 61.7 & 112 \\
\hline KM69 & TLA & 447 & 27 & 86.3 & 159 & 18 & 73.2 & 150 & 11 & 59.6 & 135 \\
\hline KM69 & ILP & 552 & 24 & 86.3 & 160 & 23 & 72.6 & 148 & 17 & 58.6 & 126 \\
\hline KM69 & TLP & 465 & 29 & 92.3 & 163 & 28 & 77 & 143 & 21 & 61.2 & 116 \\
\hline JW8 & TLP & 482 & 33 & 84.9 & 152 & 23 & 71.7 & 148 & 13 & 57.2 & 136 \\
\hline LK201 & ILA & 469 & 30 & 86.5 & 140 & 26 & 74 & 135 & 17 & 59 & 123 \\
\hline LK201 & TLP & 572 & 25 & 86.5 & 140 & 20 & 71.7 & 119 & 13 & 54.9 & 96 \\
\hline LK67 & ILA & 493 & 32 & 89.6 & 156 & 27 & 73.4 & 137 & 14 & 54.4 & 115 \\
\hline LK67 & TLA & 467 & 32 & 100.8 & 179 & 27 & 83.4 & 164 & 15 & 63.1 & 143 \\
\hline LK67 & TLP & 467 & 20 & 86.9 & 146 & 15 & 71.2 & 135 & 9 & 53.6 & 118 \\
\hline MC296 & MLA & 497 & 29 & 80.4 & 166 & 29 & 67.8 & 155 & 20 & 53.5 & 137 \\
\hline MC296 & ILP & 433 & 27 & 80.9 & 160 & 26 & 68.2 & 165 & 18 & 53.7 & 161 \\
\hline MC296 & TLP & 485 & 30 & 78.6 & 139 & 23 & 65.9 & 120 & 15 & 52 & 110 \\
\hline MM340 & ILA & 469 & 43 & 108 & 153 & 38 & 90.1 & 130 & 31 & 67.6 & 112 \\
\hline MM340 & MLA & 496 & 44 & 104.9 & 163 & 37 & 85.8 & 156 & 26 & 64.7 & 142 \\
\hline MM340 & TLA & 470 & 44 & 103.4 & 154 & 41 & 84.1 & 135 & 28 & 62.2 & 110 \\
\hline MM341-2 & ILP & 503 & 42 & 102 & 152 & 30 & 83.5 & 141 & 22 & 62.1 & 119 \\
\hline MM341-1 & ILP & 553 & 36 & 99.7 & 163 & 22 & 83.9 & 152 & 14 & 64.6 & 132 \\
\hline
\end{tabular}

Table 12-2. RGB Statistics for Expensive Tools from 41ZV202 and Comparative Components

\begin{tabular}{|c|c|c|c|c|c|c|c|c|c|c|c|}
\hline \multirow[b]{2}{*}{ Site } & \multirow[b]{2}{*}{ 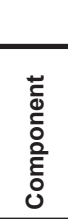 } & \multirow[b]{2}{*}{ 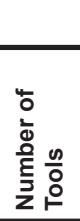 } & \multicolumn{3}{|c|}{ RED } & \multicolumn{3}{|c|}{ GREEN } & \multicolumn{3}{|c|}{ BLUE } \\
\hline & & & 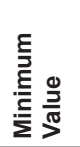 & $\begin{array}{l}\text { एٓ } \\
\text { ల్ల }\end{array}$ & 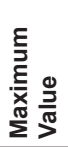 & 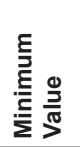 & 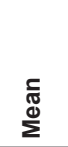 & 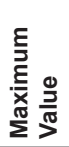 & 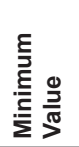 & $\begin{array}{l}\text { एँ } \\
\text { एँ }\end{array}$ & 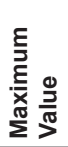 \\
\hline ZV202 & $\mathrm{ILP}$ & 62 & 42 & 114.3 & 162 & 33 & 98 & 151 & 35 & 80 & 133 \\
\hline KM69 & MLA & 34 & 39 & 84.9 & 139 & 36 & 72.9 & 116 & 29 & 59.5 & 102 \\
\hline KM69 & TLA & 62 & 34 & 98.7 & 165 & 33 & 83.3 & 146 & 28 & 67.3 & 119 \\
\hline KM69 & ILP & 89 & 38 & 88.6 & 137 & 38 & 76.7 & 135 & 29 & 62.8 & 134 \\
\hline KM69 & TLP & 29 & 73 & 85.4 & 158 & 56 & 72.8 & 152 & 41 & 58.9 & 140 \\
\hline JW8 & TLP & 95 & 33 & 92 & 151 & 33 & 75.8 & 145 & 23 & 57.2 & 131 \\
\hline LK201 & ILA & 9 & 55 & 103.1 & 131 & 47 & 86.1 & 113 & 36 & 66.3 & 89 \\
\hline LK201 & TLP & 95 & 22 & 91.5 & 147 & 23 & 75.4 & 128 & 17 & 57.6 & 102 \\
\hline LK67 & ILA & 6 & 72 & 110.3 & 137 & 55 & 94 & 122 & 37 & 74.5 & 112 \\
\hline LK67 & TLA & 21 & 12 & 92.7 & 153 & 12 & 81.2 & 138 & 12 & 68 & 117 \\
\hline LK67 & TLP & 17 & 37 & 88.5 & 126 & 34 & 73.8 & 102 & 27 & 58 & 78 \\
\hline MC296 & MLA & 7 & 58 & 88.1 & 119 & 41 & 70 & 89 & 31 & 54.4 & 67 \\
\hline MC296 & ILP & 14 & 56 & 99.4 & 144 & 43 & 81.2 & 131 & 24 & 63.9 & 115 \\
\hline MC296 & TLP & 60 & 38 & 85.5 & 141 & 33 & 71.5 & 120 & 26 & 55.8 & 90 \\
\hline MM340 & ILA & 50 & 28 & 110.3 & 155 & 29 & 91.1 & 140 & 23 & 66.4 & 109 \\
\hline MM340 & MLA & 87 & 41 & 107.1 & 158 & 32 & 90 & 144 & 25 & 67.4 & 126 \\
\hline MM340 & TLA & 64 & 48 & 109.9 & 150 & 45 & 89.7 & 143 & 36 & 67.6 & 125 \\
\hline MM341-2 & ILP & 89 & 41 & 111.5 & 153 & 31 & 92.6 & 133 & 22 & 68.9 & 103 \\
\hline MM341-1 & ILP & 100 & 39 & 104.7 & 153 & 39 & 86.4 & 133 & 26 & 62.9 & 112 \\
\hline
\end{tabular}


Geology's (BEG) Geologic Atlas of Texas (1961-1987). "Local" chert sources were defined as being within $30 \mathrm{~km}$ radius of each site. CAR used both the digital data, as well as the descriptions in the BEG Atlas, to identify chert bearing deposits for each polygon. These data are presented in Figure 12-7. Identified chert sources were not distinguished as to whether they were a primary or secondary source. Note that the polygons labeled "water" are modern reservoirs and thus exclude any potential chert resources. The Choke Canyon sites of 41MC296, 41LK67, and 41LK201 all contain this water polygon, although in all cases the polygon accounted for less than $4 \%$ of the approximately $2,832 \mathrm{~km}^{2}$ area. Using the spatial statistics tool found in the ArcToolbox, we calculated the area for each individual polygon represented by chert bearing deposits (see Figure 12-7).

Table 12-3 provides a summary of the chert availability for the eight sites. The first column lists the eight sites. The second

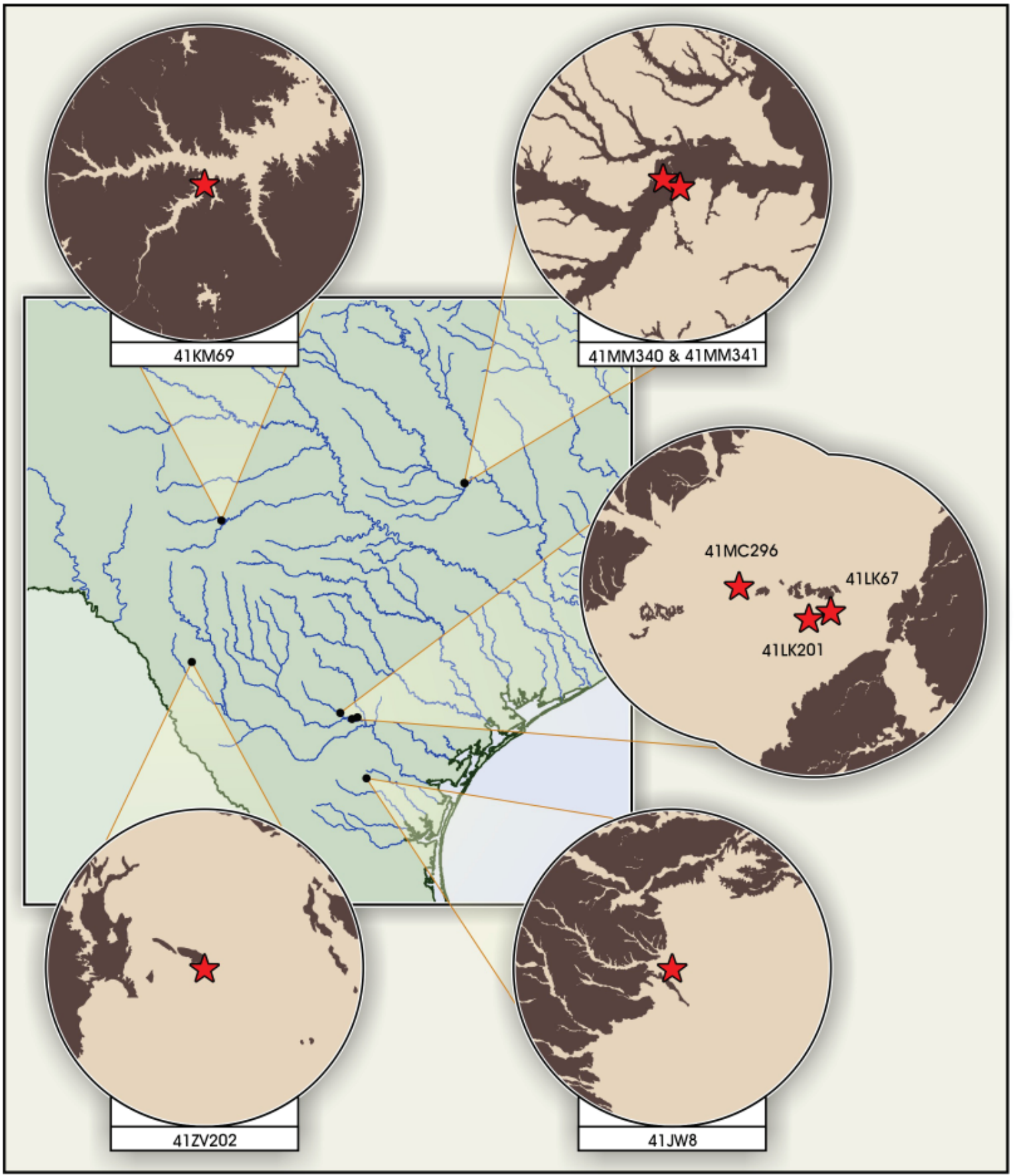

Figure 12-7. Geological units with chert (dark brown) present within $30 \mathrm{~km}$ of sites. 
Table 12-3. Chert Availability within a $30 \mathrm{Km}$ Radius of a Site

\begin{tabular}{|c|c|c|c|c|}
\hline Sites & $\begin{array}{c}\text { Number of Rock Units } \\
\text { with Chert Present }\end{array}$ & $\begin{array}{c}\text { Area of Chert Bearing } \\
\text { Deposits }\left(\mathbf{k m}^{\mathbf{2}}\right)\end{array}$ & $\begin{array}{c}\text { Percentage of Chert Bearing } \\
\text { Deposits within Area }\end{array}$ & $\begin{array}{c}\text { Ranking of Chert } \\
\text { Availability }\end{array}$ \\
\hline 41KM69 & 5 & 2280 & 79.8 & 1 \\
\hline 41JW8 & 2 & 1048 & 37 & 2 \\
\hline 41MM340 & 2 & 776 & 27.4 & 3.5 \\
\hline 41MM341 & 2 & 776 & 27.4 & 3.5 \\
\hline 41LK67 & 3 & 747 & 26.3 & 5 \\
\hline 41LK201 & 2 & 682 & 24 & 6 \\
\hline 41MC296 & 3 & 422.5 & 14.9 & 7 \\
\hline 41ZV202 & 3 & 337 & 11.9 & 8 \\
\hline
\end{tabular}

column identifies the number of distinct rock units that contained chert within the $30 \mathrm{Km}$ radius. Column 3 provides the area, in $\mathrm{Km}^{2}$, of chert. Finally, we list the percentage of availability (column 4) and ranking of availability (column 5). Examination of Table 12-3 shows that sites 41MM340 and 41MM341 are, at the scale used here, essentially the same location. Consequently, there values are redundant with both sites having moderate availability (27.4\%). Chert availability is highest at site 41KM69, with almost $80 \%$ of the area surrounding the site containing chert bearing deposits. Surprisingly, 41JW8, located in South Texas, contains the second highest availability, primarily because of areas with Uvalde Gravels. Chert bearing deposits are not common in the area of 41MC296, though LK67 and LK201 have moderate availability comparable to the Milam county locations. The highest numbers of chert sources are present at 41KM69. 41ZV202 has the lowest availability, with only $11.9 \%$ of the surrounding area contains chert.

Clearly, there is significant variation in chert availability across the eight site locations that can account for some of the differences seen in Tables 12-1 and 12-2. Given the clustering shown in Figure 12-6, local resources have a significant impact on the range of colors. Local color variation can account for differences and similarities, especially in debitage color ranges (Figure 12-6, Table 12-1). Nevertheless, we demonstrate subsequently that for a given area, comparisons of tool and debitage values along the RGB scale can provide information on shifts through time that cross-cut difference in tool stone availability.

\section{Results- Difference in Chert Colors}

Some of the possible uses of the RGB data set to look at shifts in availability are clarified by Figure 12-8. Here we consider the differences between debitage and two different groups of expensive tools (hafted items; other bifaces) using the 41ZV202 data base. The figure plots the mean value along the blue scale, with $95 \%$ confidence intervals, using the three chipped stone classes. Clear differences and similarities are now visible. There is no significant difference between the values for the debitage and the non-hafted bifaces at the site. That is, the debitage and the bifaces appear to have the same average color value on the blue scale. There are, however, major differences present between the blue values for the debitage and those of hafted tools as the means of each group appear to be bordering the $95 \%$ confidence intervals of the other group. In addition, there is only minor overlap in the confidence intervals. While theses

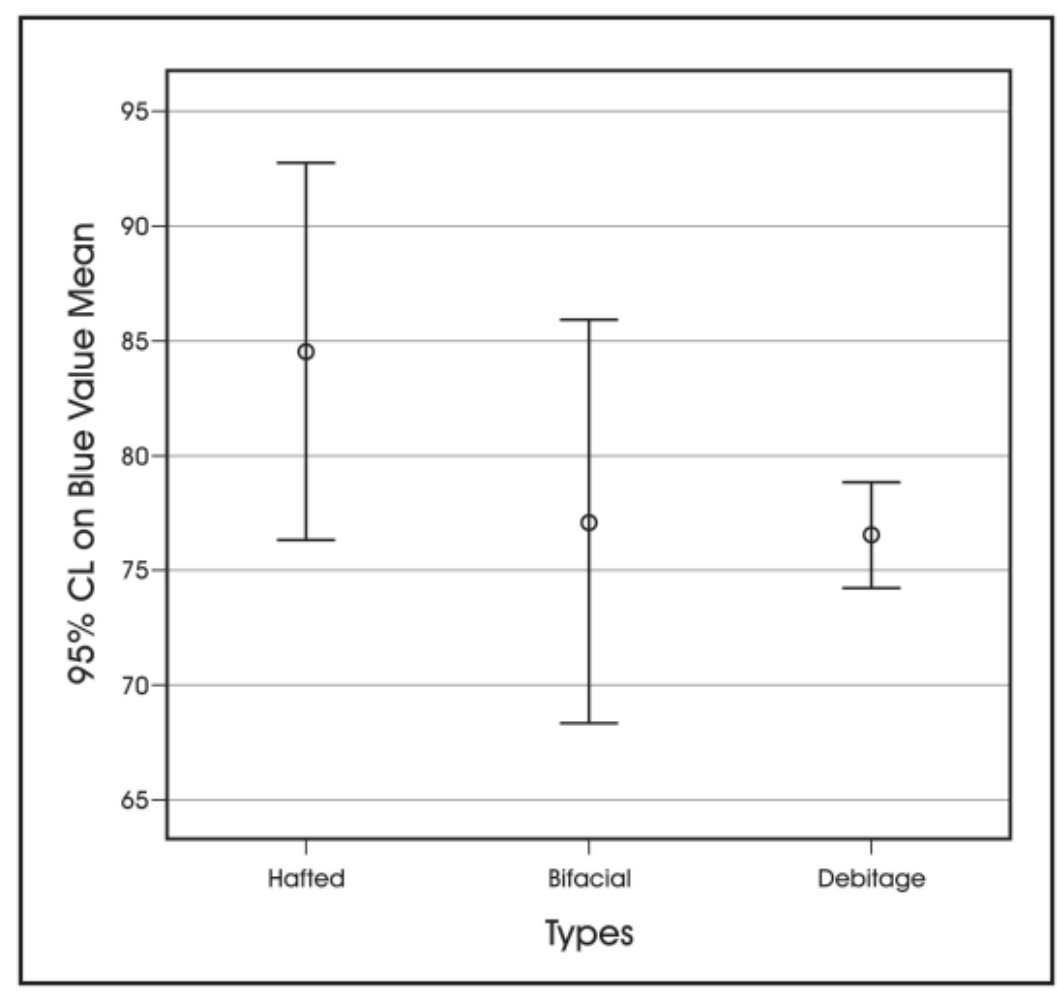

Figure 12-8. Confidence intervals (95\%) for blue mean values at $41 Z V 202$ by artifact types. 
differences may not be statistically significant, it is clear that a substantial portion of the hafted tools recovered from the site likely come from sources that have different color ranges, at least on the blue scale, when contrasted with the debitage present at the site. This suggests that a substantial portion of the hafted items may have been curated, and, assuming that the debitage primarily reflects local sources, produced from tool stone that was not locally available.

We suggested in Chapters 7 and 8 that groups following an annual foraging strategy would be more common in the Late Archaic. They would have operated in a relatively small area. In response to declining bison availability, especially in the Late Prehistoric, the use of logistical strategies to pursue bison would increase in an effort to increase encounter rates. This would also result in an increase in the overall scale of the system as more specialized task groups expanded the area covered. One outgrowth of that expansion may have been that groups increasingly encountered new tool stone sources that they incorporated into chipped stone tool production. In addition, as we argued in Chapter 10, logistically organized systems would have an increased investment in specialized, expensive tools associated with bison procurement and processing. These would tend to be curated, and therefore remain in the system longer. As such, there would be an increasing likelihood that expensive tools, especially those that were within our hafted group, would be deposited at locations that differed from where they were produced. We expect, then, that when a logistical system is in operation, comparisons of tool stone between debitage and hafted tools will show discrepancies. While discrepancies may be present in other tools, the high frequency of manufacturing failures in bifaces, shown in the previous chapter, suggest that they were primarily manufactured at locations where they were recovered. We expect these to primarily reflect local sources. These distinctions are suggested in the distributions shown at 41ZV202 (Figure 12-8).

In order to compare the tools stone colors in the various tool and debitage groups, we use t-tests to compare mean values along the RGB scales in the five Late Archaic, four Initial Late Prehistoric, and four Terminal Late Prehistoric components with adequate sample sizes (see Table 12-2). The senior author did all comparisons using SPSS Version 15.0. The means, standard deviations, and sample sizes for red, green, and blue values for debitage, other bifaces, and hafted items by component are listed in Table 12-4 (Late Archaic) and 12-5 (Late Prehistoric). We use these data in the statistical comparisons. Tables 12-6 (Late Archaic), 12-7 (Initial Late Prehistoric) and 12-8 (Terminal Late Prehistoric) present the t-statistics and associated significance levels.

We assume all samples are from a normally distributed population and that in all comparisons, sample means have equal variance. With these assumptions, and the Tables 12-4 and 12-5 data, the reader can calculate t-statistics for all comparisons made here.

The $t$-statistic is the mean value of the first group minus the mean value of the second group divided by the standard error of the difference. Degrees of freedom with these assumptions

Table 12-4. Averages and Standard Deviations on RGB for Late Archaic Assemblages

\begin{tabular}{|c|c|c|c|c|c|c|c|c|}
\hline Component & \multicolumn{2}{|l|}{ Groups } & \multicolumn{2}{|c|}{ RED } & \multicolumn{2}{|c|}{ GREEN } & \multicolumn{2}{|c|}{ BLUE } \\
\hline \multirow{4}{*}{$\begin{array}{c}\text { 41MM340 } \\
\text { ILA }\end{array}$} & & $\mathrm{n}$ & Mean & Std. Dev. & Mean & Std. Dev. & Mean & Std. Dev. \\
\hline & Debitage & 469 & 107.96 & 18.73 & 90.1 & 16.683 & 67.61 & 14.851 \\
\hline & Other Bifaces & 27 & 111.63 & 21.19 & 90.41 & 17.887 & 64.63 & 16.556 \\
\hline & Hafted Tools & 23 & 108.74 & 31.05 & 92 & 27.256 & 68.43 & 22.045 \\
\hline \multirow{4}{*}{$\begin{array}{c}41 \mathrm{KM} 69 \\
\text { MLA }\end{array}$} & & $n$ & Mean & Std. Dev. & Mean & Std. Dev. & Mean & Std. Dev. \\
\hline & Debitage & 521 & 89.32 & 21.25 & 75.55 & 17.497 & 61.71 & 15.486 \\
\hline & Other Bifaces & 23 & 87.3 & 24.61 & 73.57 & 19.621 & 59.43 & 17.066 \\
\hline & Hafted Tools & 11 & 80 & 23.186 & 71.64 & 17.54 & 59.64 & 16.806 \\
\hline \multirow{4}{*}{$\begin{array}{c}\text { 41MM340 } \\
\text { MLA }\end{array}$} & & $\mathrm{n}$ & Mean & Std. Dev. & Mean & Std. Dev. & Mean & Std. Dev. \\
\hline & Debitage & 496 & 104.89 & 19.728 & 85.76 & 18.067 & 64.72 & 16.164 \\
\hline & Other Bifaces & 53 & 108.7 & 26.715 & 90.72 & 24.265 & 67.45 & 21.513 \\
\hline & Hafted Tools & 34 & 104.5 & 21.315 & 88.94 & 17.065 & 67.44 & 13.587 \\
\hline \multirow{4}{*}{$\begin{array}{c}41 \mathrm{MM} 340 \\
\text { TLA }\end{array}$} & & $\mathrm{n}$ & Mean & Std. Dev. & Mean & Std. Dev. & Mean & Std. Dev. \\
\hline & Debitage & 470 & 103.36 & 21.444 & 84.14 & 17.86 & 62.22 & 14.755 \\
\hline & Other Bifaces & 35 & 110.29 & 22.973 & 89.31 & 20.537 & 65.97 & 16.552 \\
\hline & Hafted Tools & 29 & 109.48 & 24.166 & 90.21 & 22.203 & 69.62 & 18.585 \\
\hline \multirow{4}{*}{$\begin{array}{c}\text { 41KM69 } \\
\text { TLA }\end{array}$} & & $\mathrm{n}$ & Mean & Std. Dev. & Mean & Std. Dev. & Mean & Std. Dev. \\
\hline & Debitage & 447 & 86.26 & 23.266 & 73.24 & 19.061 & 59.6 & 16.456 \\
\hline & Other Bifaces & 36 & 96.03 & 25.299 & 80.11 & 21.881 & 63.94 & 20.038 \\
\hline & Hafted Tools & 26 & 102.38 & 37.516 & 87.73 & 31.462 & 71.85 & 27.83 \\
\hline
\end{tabular}


Table 12-5. Averages and Standard Deviations on RGB for Late Prehistoric Assemblages

\begin{tabular}{|c|c|c|c|c|c|c|c|c|}
\hline Component & Groups & & \multicolumn{2}{|c|}{ RED } & \multicolumn{2}{|c|}{ GREEN } & \multicolumn{2}{|c|}{ BLUE } \\
\hline \multirow{4}{*}{$\begin{array}{l}\text { 41ZV202 } \\
\text { ILP }\end{array}$} & & $\mathrm{n}$ & Mean & Std. Dev. & Mean & Std. Dev. & Mean & Std. Dev. \\
\hline & Debitage & 485 & 112.97 & 30.729 & 95.8 & 27.898 & 76.47 & 25.917 \\
\hline & Other Bifaces & 38 & 109.13 & 32.263 & 93.71 & 29.565 & 77.11 & 26.577 \\
\hline & Hafted Tools & 24 & 122.54 & 26.293 & 104.75 & 22.493 & 84.5 & 19.373 \\
\hline \multirow{4}{*}{$\begin{array}{c}\text { 41MM341-AU1 } \\
\text { ILP }\end{array}$} & & $\mathrm{n}$ & Mean & Std. Dev. & Mean & Std. Dev. & Mean & Std. Dev. \\
\hline & Debitage & 553 & 99.69 & 24.539 & 83.92 & 21.584 & 64.61 & 19.107 \\
\hline & Other Bifaces & 70 & 103.83 & 27.842 & 85.36 & 23.257 & 61.71 & 18.612 \\
\hline & Hafted Tools & 30 & 106.83 & 22.694 & 88.93 & 18.941 & 65.73 & 16.201 \\
\hline \multirow{4}{*}{$\begin{array}{c}\text { 41MM341-AU2 } \\
\text { ILP }\end{array}$} & & $\mathrm{n}$ & Mean & Std. Dev. & Mean & Std. Dev. & Mean & Std. Dev. \\
\hline & Debitage & 503 & 102.04 & 21.161 & 83.45 & 18.715 & 62.15 & 16.161 \\
\hline & Other Bifaces & 65 & 109.91 & 23.209 & 91.43 & 19.686 & 67.92 & 16.566 \\
\hline & Hafted Tools & 24 & 115.88 & 21.726 & 95.63 & 18.78 & 71.67 & 16.505 \\
\hline \multirow{4}{*}{$\begin{array}{l}\text { 41KM69 } \\
\text { ILP }\end{array}$} & & $\mathrm{n}$ & Mean & Std. Dev. & Mean & Std. Dev. & Mean & Std. Dev. \\
\hline & Debitage & 552 & 86.35 & 21.87 & 72.62 & 18.624 & 58.59 & 16.376 \\
\hline & Other Bifaces & 71 & 87.82 & 22.69 & 75.77 & 20.315 & 61.86 & 19.543 \\
\hline & Hafted Tools & 18 & 91.67 & 25.112 & 80.17 & 22.356 & 58.59 & 16.376 \\
\hline \multirow{4}{*}{$\begin{array}{l}\text { 41KM69 } \\
\text { TLP }\end{array}$} & & $\mathrm{n}$ & Mean & Std. Dev. & Mean & Std. Dev. & Mean & Std. Dev. \\
\hline & Debitage & 465 & 92.3 & 24.822 & 77.02 & 20.397 & 61.18 & 17.361 \\
\hline & Other Bifaces & 8 & 82.63 & 39.975 & 70.25 & 36.244 & 56.75 & 35.467 \\
\hline & Hafted Tools & 21 & 86.48 & 24.825 & 73.86 & 21.131 & 59.76 & 18.625 \\
\hline \multirow{4}{*}{$\begin{array}{l}\text { 41LK201 } \\
\text { TLP }\end{array}$} & & $\mathrm{n}$ & Mean & Std. Dev. & Mean & Std. Dev. & Mean & Std. Dev. \\
\hline & Debitage & 572 & 86.48 & 20.891 & 71.67 & 17.731 & 54.93 & 14.902 \\
\hline & Other Bifaces & 53 & 88.74 & 24.239 & 73.43 & 20.482 & 56.43 & 17.605 \\
\hline & Hafted Tools & 42 & 94.05 & 20.564 & 77.88 & 17.154 & 59.12 & 14.237 \\
\hline \multirow{4}{*}{$\begin{array}{l}41 \mathrm{MC} 296 \\
\text { TLP }\end{array}$} & & $\mathrm{n}$ & Mean & Std. Dev. & Mean & Std. Dev. & Mean & Std. Dev. \\
\hline & Debitage & 485 & 78.61 & 17.416 & 65.86 & 14.538 & 51.98 & 12.379 \\
\hline & Other Bifaces & 26 & 80.5 & 25.414 & 68.08 & 21.052 & 53.12 & 16.836 \\
\hline & Hafted Tools & 34 & 89.24 & 20.723 & 74.06 & 17.66 & 57.91 & 14.58 \\
\hline \multirow{4}{*}{$\begin{array}{l}\text { 41JW8 } \\
\text { TLP }\end{array}$} & & $\mathrm{n}$ & Mean & Std. Dev. & Mean & Std. Dev. & Mean & Std. Dev. \\
\hline & Debitage & 482 & 84.95 & 22.079 & 71.71 & 20.072 & 57.17 & 18.179 \\
\hline & Other Bifaces & 56 & 89.73 & 27.173 & 74.7 & 24.672 & 55.98 & 22.949 \\
\hline & Hafted Tools & 39 & 95.33 & 22.759 & 77.41 & 20.742 & 59.03 & 18.272 \\
\hline
\end{tabular}


Table 12-6. T-Test Results for RGB Comparisons - Late Archaic Chipped Stone Samples

\begin{tabular}{|c|c|c|c|c|c|c|}
\hline \multirow[b]{2}{*}{ Site } & \multirow[b]{2}{*}{ Color } & \multirow[b]{2}{*}{ Types } & \multicolumn{2}{|c|}{ Debitage } & \multicolumn{2}{|c|}{ Other Bifaces } \\
\hline & & & T-Statistic & Sig (2-tailed) & T-Statistic & Sig (2-tailed) \\
\hline \multirow{6}{*}{$\begin{array}{c}\text { 41MM340 } \\
\text { ILA }\end{array}$} & \multirow{2}{*}{ Red } & Other Bifaces & 0.983 & 0.326 & $n / a$ & $n / a$ \\
\hline & & Hafted & 0.188 & 0.851 & -0.389 & 0.699 \\
\hline & \multirow{2}{*}{ Green } & Other Bifaces & 0.094 & 0.925 & $n / a$ & $n / a$ \\
\hline & & Hafted & 0.515 & 0.606 & 0.248 & 0.805 \\
\hline & \multirow{2}{*}{ Blue } & Other Bifaces & -1.006 & 0.315 & $n / a$ & $n / a$ \\
\hline & & Hafted & 0.255 & 0.799 & 0.696 & 0.49 \\
\hline \multirow{6}{*}{$\begin{array}{l}\text { 41KM69 } \\
\text { MLA }\end{array}$} & \multirow{2}{*}{ Red } & Other Bifaces & -0.443 & 0.658 & $\mathrm{n} / \mathrm{a}$ & $\mathrm{n} / \mathrm{a}$ \\
\hline & & Hafted & -1.438 & 0.151 & -0.824 & 0.416 \\
\hline & \multirow{2}{*}{ Green } & Other Bifaces & -0.53 & 0.596 & $n / a$ & $n / a$ \\
\hline & & Hafted & -0.734 & 0.463 & -0.277 & 0.784 \\
\hline & \multirow{2}{*}{ Blue } & Other Bifaces & -0.688 & 0.492 & $n / a$ & $n / a$ \\
\hline & & Hafted & -0.44 & 0.66 & 0.032 & 0.974 \\
\hline \multirow{6}{*}{$\begin{array}{c}\text { 41MM340 } \\
\text { MLA }\end{array}$} & \multirow{2}{*}{ Red } & Other Bifaces & 1.286 & 0.199 & $n / a$ & $n / a$ \\
\hline & & Hafted & -0.111 & 0.921 & -0.772 & 0.442 \\
\hline & \multirow{2}{*}{ Green } & Other Bifaces & 1.829 & 0.068 & $n / a$ & $n / a$ \\
\hline & & Hafted & 0.996 & 0.32 & -0.372 & 0.711 \\
\hline & \multirow{2}{*}{ Blue } & Other Bifaces & 1.112 & 0.26 & $\mathrm{n} / \mathrm{a}$ & $\mathrm{n} / \mathrm{a}$ \\
\hline & & Hafted & 0.958 & 0.339 & -0.003 & 0.998 \\
\hline \multirow{6}{*}{$\begin{array}{c}\text { 41MM340 } \\
\text { TLA }\end{array}$} & \multirow{2}{*}{ Red } & Other Bifaces & 1.834 & 0.067 & $n / a$ & $n / a$ \\
\hline & & Hafted & 1.481 & 0.139 & -1.36 & 0.892 \\
\hline & \multirow{2}{*}{ Green } & Other Bifaces & 1.636 & 0.103 & $n / a$ & $n / a$ \\
\hline & & Hafted & 1.749 & 0.081 & 0.167 & 0.868 \\
\hline & \multirow{2}{*}{ Blue } & Other Bifaces & 1.437 & 0.151 & $n / a$ & $\mathrm{n} / \mathrm{a}$ \\
\hline & & Hafted & 2.578 & 0.01 & 0.83 & 0.409 \\
\hline \multirow{6}{*}{$\begin{array}{c}\text { 41KM69 } \\
\text { TLA }\end{array}$} & \multirow{2}{*}{ Red } & Other Bifaces & 2.407 & 0.016 & $\mathrm{n} / \mathrm{a}$ & $\mathrm{n} / \mathrm{a}$ \\
\hline & & Hafted & 3.298 & 0.001 & 0.797 & 0.428 \\
\hline & \multirow{2}{*}{ Green } & Other Bifaces & 2.058 & 0.04 & $\mathrm{n} / \mathrm{a}$ & $\mathrm{n} / \mathrm{a}$ \\
\hline & & Hafted & 3.608 & 0 & 1.126 & 0.265 \\
\hline & \multirow{2}{*}{ Blue } & Other Bifaces & 1.497 & 0.135 & n/a & $n / a$ \\
\hline & & Hafted & 3.519 & 0 & 1.301 & 0.198 \\
\hline
\end{tabular}

are calculated by summing the respective sample sizes and subtracting two (see Blalock 1979:191-195). We will consider significance at or below the 0.05 level, and assume a two-tailed test in all comparisons. Significant values are highlighted in red.

Tables 12-6, 12-7, and 12-8 show 19 comparisons produced statistically significant results. There are no statistically significant differences present in any comparison between the tool categories of "other bifaces" and "hafted tools". When comparisons are made between the "other bifaces" and debitage there are 5 significant relationships. The remaining 14 statistically significant relationships are all between hafted tools and debitage. This is, in general, consistent with our expectations that hafted items should be differentially made on non-local material.

When we consider the temporal pattern of these differences, it is apparent that there are changes between the Late Archaic and the Terminal Late Prehistoric that generally follow our expectations. For the five components with Late Archaic material (Table 12-6), two components (40\%) has significant comparisons present. Both of these are late in the period, dating to the Terminal Late Archaic. The Terminal Late Archaic component at 41MM340 has a single significant t-statistic, present on the blue scale, when mean hafted and mean debitage color values are compared. However, there are no such relationships present on the green and the red scales, though they are trending in that direction. The Terminal Late Archaic component at 41KM69 has significant differences present between hafted and debitage values in all three primary colors. In addition, two of the three primary colors have significant differences when "other bifaces" and debitage were compared (Table 12-6).

In the Initial Late Prehistoric (Table 12-7), two of the four components $(50 \%)$ have significant t-values, with 41KM69 having a significant difference between the hafted and debitage means on the blue scale. Comparisons of the green scale are trending in that direction as well, but there are no real differences between hafted and debitage 
Table 12-7. T-Test Results for RGB Comparisons - Initial Late Prehistoric Chipped Stone Samples

\begin{tabular}{|c|c|c|c|c|c|c|}
\hline \multirow[b]{2}{*}{ Site } & \multirow[b]{2}{*}{ Color } & \multirow[b]{2}{*}{ Types } & \multicolumn{2}{|c|}{ Debitage } & \multicolumn{2}{|c|}{ Other Bifaces } \\
\hline & & & T-Statistic & Sig (2-tailed) & T-Statistic & Sig (2-tailed) \\
\hline \multirow{6}{*}{ 41ZV202 } & \multirow{2}{*}{ Red } & Other Bifaces & -0.739 & 0.46 & $\mathrm{n} / \mathrm{a}$ & $\mathrm{n} / \mathrm{a}$ \\
\hline & & Hafted & 1.498 & 0.135 & 1.708 & 0.093 \\
\hline & \multirow{2}{*}{ Green } & Other Bifaces & -0.443 & 0.658 & $\mathrm{n} / \mathrm{a}$ & $\mathrm{n} / \mathrm{a}$ \\
\hline & & Hafted & 1.546 & 0.123 & 1.564 & 0.123 \\
\hline & \multirow{2}{*}{ Blue } & Other Bifaces & 0.144 & 0.885 & $n / a$ & $n / a$ \\
\hline & & Hafted & 1.496 & 0.135 & 1.178 & 0.243 \\
\hline \multirow{6}{*}{ 41MM341-AU1 } & \multirow{2}{*}{ Red } & Other Bifaces & 1.308 & 0.191 & $\mathrm{n} / \mathrm{a}$ & $\mathrm{n} / \mathrm{a}$ \\
\hline & & Hafted & 1.558 & 0.12 & 0.521 & 0.603 \\
\hline & \multirow{2}{*}{ Green } & Other Bifaces & 0.519 & 0.604 & $\mathrm{n} / \mathrm{a}$ & $\mathrm{n} / \mathrm{a}$ \\
\hline & & Hafted & 1.245 & 0.214 & 0.743 & 0.459 \\
\hline & \multirow{2}{*}{ Blue } & Other Bifaces & -1.199 & 0.231 & $n / a$ & $\mathrm{n} / \mathrm{a}$ \\
\hline & & Hafted & 0.315 & 0.752 & 1.027 & 0.307 \\
\hline \multirow{6}{*}{ 41MM341-AU2 } & \multirow{2}{*}{ Red } & Other Bifaces & 2.791 & 0.005 & $n / a$ & $\mathrm{n} / \mathrm{a}$ \\
\hline & & Hafted & 3.126 & 0.002 & 1.094 & 0.277 \\
\hline & \multirow{2}{*}{ Green } & Other Bifaces & 3.215 & 0.001 & $n / a$ & $\mathrm{n} / \mathrm{a}$ \\
\hline & & Hafted & 3.112 & 0.002 & 0.903 & 0.369 \\
\hline & \multirow{2}{*}{ Blue } & Other Bifaces & 2.704 & 0.007 & $n / a$ & $n / a$ \\
\hline & & Hafted & 2.817 & 0.005 & 0.947 & 0.346 \\
\hline \multirow{6}{*}{ 41KM69 } & \multirow{2}{*}{ Red } & Other Bifaces & 0.531 & 0.596 & $\mathrm{n} / \mathrm{a}$ & $\mathrm{n} / \mathrm{a}$ \\
\hline & & Hafted & 1.011 & 0.312 & 0.629 & 0.531 \\
\hline & \multirow{2}{*}{ Green } & Other Bifaces & 1.329 & 0.184 & $n / a$ & $\mathrm{n} / \mathrm{a}$ \\
\hline & & Hafted & 1.68 & 0.093 & 0.803 & 0.424 \\
\hline & \multirow{2}{*}{ Blue } & Other Bifaces & 1.546 & 0.123 & $\mathrm{n} / \mathrm{a}$ & $\mathrm{n} / \mathrm{a}$ \\
\hline & & Hafted & 2.041 & 0.042 & 0.923 & 0.358 \\
\hline
\end{tabular}

Table 12-8. T-Test Results for RGB Comparisons - Terminal Late Prehistoric Chipped Stone Samples

\begin{tabular}{|c|c|c|c|c|c|c|}
\hline \multirow[b]{2}{*}{ Site } & \multirow[b]{2}{*}{ Color } & \multirow[b]{2}{*}{ Types } & \multicolumn{2}{|c|}{ Debitage } & \multicolumn{2}{|c|}{ Other Bifaces } \\
\hline & & & T-Statistic & Sig (2-tailed) & T-Statistic & Sig (2-tailed) \\
\hline \multirow{6}{*}{ 41KM69 } & \multirow{2}{*}{ Red } & Other Bifaces & -1.083 & 0.279 & $\mathrm{n} / \mathrm{a}$ & $\mathrm{n} / \mathrm{a}$ \\
\hline & & Hafted & -1.052 & 0.294 & 0.326 & 0.747 \\
\hline & \multirow{2}{*}{ Green } & Other Bifaces & -0.916 & 0.36 & $\mathrm{n} / \mathrm{a}$ & $\mathrm{n} / \mathrm{a}$ \\
\hline & & Hafted & -0.694 & 0.488 & 0.335 & 0.74 \\
\hline & \multirow{2}{*}{ Blue } & Other Bifaces & -0.7 & 0.484 & $\mathrm{n} / \mathrm{a}$ & $\mathrm{n} / \mathrm{a}$ \\
\hline & & Hafted & -0.366 & 0.714 & 0.3 & 0.766 \\
\hline \multirow{6}{*}{ 41LK201 } & \multirow{2}{*}{ Red } & Other Bifaces & 0.742 & 0.458 & $\mathrm{n} / \mathrm{a}$ & $\mathrm{n} / \mathrm{a}$ \\
\hline & & Hafted & 2.269 & 0.024 & 1.133 & 0.26 \\
\hline & \multirow{2}{*}{ Green } & Other Bifaces & 0.684 & 0.495 & $\mathrm{n} / \mathrm{a}$ & $\mathrm{n} / \mathrm{a}$ \\
\hline & & Hafted & 2.196 & 0.028 & 1.128 & 0.262 \\
\hline & \multirow{2}{*}{ Blue } & Other Bifaces & 0.692 & 0.489 & $\mathrm{n} / \mathrm{a}$ & $\mathrm{n} / \mathrm{a}$ \\
\hline & & Hafted & 1.764 & 0.078 & 0.802 & 0.425 \\
\hline \multirow{6}{*}{$41 \mathrm{MC} 296$} & \multirow{2}{*}{ Red } & Other Bifaces & 0.525 & 0.6 & $\mathrm{n} / \mathrm{a}$ & $\mathrm{n} / \mathrm{a}$ \\
\hline & & Hafted & 3.394 & 0.001 & 1.467 & 0.148 \\
\hline & \multirow{2}{*}{ Green } & Other Bifaces & 0.737 & 0.462 & $\mathrm{n} / \mathrm{a}$ & $\mathrm{n} / \mathrm{a}$ \\
\hline & & Hafted & 3.13 & 0.002 & 1.196 & 0.237 \\
\hline & \multirow{2}{*}{ Blue } & Other Bifaces & 0.447 & 0.655 & $\mathrm{n} / \mathrm{a}$ & $\mathrm{n} / \mathrm{a}$ \\
\hline & & Hafted & 2.669 & 0.008 & 1.181 & 0.243 \\
\hline \multirow{6}{*}{ 41JW8 } & \multirow{2}{*}{ Red } & Other Bifaces & 1.496 & 0.135 & $\mathrm{n} / \mathrm{a}$ & $\mathrm{n} / \mathrm{a}$ \\
\hline & & Hafted & 2.819 & 0.005 & 1.055 & 0.294 \\
\hline & \multirow{2}{*}{ Green } & Other Bifaces & 1.029 & 0.304 & $\mathrm{n} / \mathrm{a}$ & $\mathrm{n} / \mathrm{a}$ \\
\hline & & Hafted & 1.703 & 0.089 & 0.562 & 0.575 \\
\hline & \multirow{2}{*}{ Blue } & Other Bifaces & -0.448 & 0.654 & $\mathrm{n} / \mathrm{a}$ & $\mathrm{n} / \mathrm{a}$ \\
\hline & & Hafted & 0.614 & 0.539 & 0.69 & 0.492 \\
\hline
\end{tabular}


mean values on the Red scale. At 41MM341-AU2 there are significant differences in all three colors when comparing both other bifaces and debitage as well as when comparing hafted items and debitage values (Table 12-7). Note also that the differences between the hafted values and the debitage values at 41ZV202 are not significantly different, but they are weakly trending in that direction on all thee colors (see also Figure 12-8). However, trending does not equal significance.

Table 12-8 shows that three of the four (75\%) components dating to the Terminal Late Prehistoric have significant relationships between mean color values shown in hafted items and those shown in debitage. At 41LK201, significant t-test statistics are present in both red and green values, with blue values trending in that direction. As 41MC296, all three primary colors means for debitage are significantly different from those present in hafted items. Finally, the mean red value for debitage at $41 \mathrm{JW} 8$ is significantly different from the hafted value, and the green value is trending in that direction (Table 12-8).

The t-test results are consistent with our suggestions that if logistical systems are present, comparisons of tool stone between debitage and hafted tools will increasingly show discrepancies. These should be increasingly apparent later in time, with the discrepancies especially apparent in hafted, expensive tools. The t-test results, however, are only meaningful if the assumptions underlying its use are valid. In general, the assumptions outlined above that underlie the use of the t-test in this case are supported when we examine individual distributions. In specific cases, the equality of variance assumptions, as well as the assumption of normality, are violated. This is especially the case with some of the tool distributions that have smaller sample sizes. Consequently, we use also compared RGB values of debitage, and their corresponding hafted and other bifaces tool groups,

Table 12-9. All Significant Mann-Whitney Test Results for RGB Comparisons on Debitage and Tool Groups

\begin{tabular}{|c|c|c|c|c|c|}
\hline Site-Component & Groups & $\mathbf{n}$ & Mean Rank & Sum of Ranks & Z-Value and Significance \\
\hline $\begin{array}{l}\text { 41MM340-TLA } \\
\text { BLUE Values }\end{array}$ & $\begin{array}{c}\text { Debitage } \\
\text { Hafted Tools }\end{array}$ & $\begin{array}{c}470 \\
29\end{array}$ & $\begin{array}{l}246.73 \\
303.03\end{array}$ & $\begin{array}{c}115962 \\
8788\end{array}$ & $\begin{array}{l}Z=-2.041 \\
\text { Sig. }=.041\end{array}$ \\
\hline $\begin{array}{l}\text { 41KM69-TLA } \\
\text { RED Values }\end{array}$ & $\begin{array}{c}\text { Debitage } \\
\text { Hafted Tools }\end{array}$ & $\begin{array}{c}447 \\
26\end{array}$ & $\begin{array}{l}233.55 \\
296.35\end{array}$ & $\begin{array}{c}104396 \\
7705\end{array}$ & $\begin{array}{l}Z=-2.278 \\
\text { Sig. }=.023\end{array}$ \\
\hline $\begin{array}{l}\text { 41KM69-TLA } \\
\text { GREEN Values }\end{array}$ & $\begin{array}{c}\text { Debitage } \\
\text { Hafted Tools }\end{array}$ & $\begin{array}{c}447 \\
26\end{array}$ & $\begin{array}{c}233.31 \\
300.5\end{array}$ & $\begin{array}{c}104288 \\
7813\end{array}$ & $\begin{array}{l}Z=-2.437 \\
\text { Sig }=.015\end{array}$ \\
\hline $\begin{array}{l}\text { 41KM69_TLA } \\
\text { BLUE Values }\end{array}$ & $\begin{array}{c}\text { Debitage } \\
\text { Hafted Tools }\end{array}$ & $\begin{array}{c}446 \\
26\end{array}$ & $\begin{array}{l}233.96 \\
289.31\end{array}$ & $\begin{array}{c}104579 \\
7522\end{array}$ & $\begin{array}{l}Z=-2.008 \\
\text { Sig. }=.045\end{array}$ \\
\hline $\begin{array}{l}\text { 41KM69-TLA } \\
\text { RED Values }\end{array}$ & $\begin{array}{c}\text { Debitage } \\
\text { Other Bifaces }\end{array}$ & $\begin{array}{c}447 \\
36\end{array}$ & $\begin{array}{l}238.22 \\
288.92\end{array}$ & $\begin{array}{c}106485 \\
10401\end{array}$ & $\begin{array}{l}Z=-2.097 \\
\text { Sig. }=.036\end{array}$ \\
\hline $\begin{array}{l}\text { 41MM341-AU2_-ILP } \\
\text { RED Values }\end{array}$ & $\begin{array}{c}\text { Debitage } \\
\text { Hafted Tools }\end{array}$ & $\begin{array}{c}503 \\
24\end{array}$ & $\begin{array}{l}259.19 \\
364.81\end{array}$ & $\begin{array}{c}130372.5 \\
8755.5\end{array}$ & $\begin{array}{l}Z=-3.320 \\
\text { Sig }=.001\end{array}$ \\
\hline $\begin{array}{l}\text { 41MM341-AU2-ILP } \\
\text { GREEN Values }\end{array}$ & $\begin{array}{c}\text { Debitage } \\
\text { Hafted Tools }\end{array}$ & $\begin{array}{c}503 \\
24\end{array}$ & $\begin{array}{l}259.39 \\
360.71\end{array}$ & $\begin{array}{c}130471 \\
8657\end{array}$ & $\begin{array}{l}Z=-3.185 \\
\text { Sig. }=.001\end{array}$ \\
\hline $\begin{array}{c}\text { 41MM341-AU2-ILP } \\
\text { BLUE Values }\end{array}$ & $\begin{array}{c}\text { Debitage } \\
\text { Hafted Tools }\end{array}$ & $\begin{array}{c}503 \\
24\end{array}$ & $\begin{array}{l}260.14 \\
344.83\end{array}$ & $\begin{array}{c}130852 \\
8276\end{array}$ & $\begin{array}{l}Z=-2.662 \\
\text { Sig. }=.008\end{array}$ \\
\hline $\begin{array}{l}\text { 41MM341-AU2-ILP } \\
\text { RED Values }\end{array}$ & $\begin{array}{c}\text { Debitage } \\
\text { Other Bifaces }\end{array}$ & $\begin{array}{c}503 \\
65 \\
\end{array}$ & $\begin{array}{l}277.58 \\
338.05 \\
\end{array}$ & $\begin{array}{c}139623 \\
21973\end{array}$ & $\begin{array}{l}Z=-2.796 \\
\text { Sig }=.005\end{array}$ \\
\hline $\begin{array}{l}\text { 41MM341-AU2-ILP } \\
\text { GREEN Values }\end{array}$ & $\begin{array}{c}\text { Debitage } \\
\text { Other Bifaces }\end{array}$ & $\begin{array}{c}503 \\
65 \\
\end{array}$ & $\begin{array}{l}276.34 \\
347.64 \\
\end{array}$ & $\begin{array}{c}138999.5 \\
22596.5 \\
\end{array}$ & $\begin{array}{l}Z=-3.297 \\
\text { Sig. }=.001\end{array}$ \\
\hline $\begin{array}{c}\text { 41MM341-AU2-ILP } \\
\text { BLUE Values }\end{array}$ & $\begin{array}{c}\text { Debitage } \\
\text { Other Bifaces }\end{array}$ & $\begin{array}{c}503 \\
65 \\
\end{array}$ & $\begin{array}{l}277.61 \\
337.79 \\
\end{array}$ & $\begin{array}{c}139639.5 \\
21956.5 \\
\end{array}$ & $\begin{array}{l}Z=-2.783 \\
\text { Sig. }=.005\end{array}$ \\
\hline $\begin{array}{l}\text { 41LK201-TLP } \\
\text { RED Values }\end{array}$ & $\begin{array}{c}\text { Debitage } \\
\text { Hafted Tools }\end{array}$ & $\begin{array}{c}572 \\
42 \\
\end{array}$ & $\begin{array}{c}303.6 \\
360.61 \\
\end{array}$ & $\begin{array}{c}173659.5 \\
15145.5 \\
\end{array}$ & $\begin{array}{l}Z=-2.010 \\
\text { Sig }=.044\end{array}$ \\
\hline $\begin{array}{c}\text { 41MC296-TLP } \\
\text { RED Values }\end{array}$ & $\begin{array}{c}\text { Debitage } \\
\text { Hafted Tools }\end{array}$ & $\begin{array}{c}485 \\
34 \\
\end{array}$ & $\begin{array}{l}254.99 \\
331.41 \\
\end{array}$ & $\begin{array}{c}123672 \\
11268 \\
\end{array}$ & $\begin{array}{l}Z=-2.873 \\
\text { Sig. }=.004\end{array}$ \\
\hline $\begin{array}{l}\text { 41MC296-TLP } \\
\text { GREEN Values }\end{array}$ & $\begin{array}{c}\text { Debitage } \\
\text { Hafted Tools }\end{array}$ & $\begin{array}{c}485 \\
34 \\
\end{array}$ & $\begin{array}{c}255.2 \\
328.44 \\
\end{array}$ & $\begin{array}{c}123773 \\
11167 \\
\end{array}$ & $\begin{array}{l}Z=-2.754 \\
\text { Sig. }=.006\end{array}$ \\
\hline $\begin{array}{l}\text { 41MC296-TLP } \\
\text { BLUE Values }\end{array}$ & $\begin{array}{c}\text { Debitage } \\
\text { Hafted Tools }\end{array}$ & $\begin{array}{c}485 \\
34\end{array}$ & $\begin{array}{c}255.9 \\
318.44\end{array}$ & $\begin{array}{c}124113 \\
10827\end{array}$ & $\begin{array}{l}Z=-2.352 \\
\text { Sig }=.019\end{array}$ \\
\hline $\begin{array}{l}\text { 41JW8-TLP } \\
\text { RED Values }\end{array}$ & $\begin{array}{c}\text { Debitage } \\
\text { Hafted Tools }\end{array}$ & $\begin{array}{c}482 \\
39\end{array}$ & $\begin{array}{l}256.24 \\
319.78\end{array}$ & $\begin{array}{c}123509.5 \\
12471.5\end{array}$ & $\begin{array}{l}Z=-2.535 \\
\text { Sig. }=.011\end{array}$ \\
\hline
\end{tabular}


using the non-parametric Mann-Whitney test. This test, also known as the Wilcoxon test, is essentially a nonparametric alternative to the t-test. It does not require normal distributions as it relies on comparing ranks for the two samples (see Conover 1980). We again assume significant relationships to have a probability level of 0.05 . Table $12-9$ presents all significant relationships identified out of the 117 tests. As with the previous discussion, all significant comparisons involve debitage and tools, with debitage and hafted tools accounting for 12 of the 16 significant parings. In addition, note that these new tests do not reveal any significance new comparisons, though three comparisons identified as significant in the parametric tests were not identified as significant in the rank comparisons.

As before, two of the five Late Archaic components have significant comparisons along some elements of the RGB scale when debitage and tool groups are compared. Only one of four Initial Late Prehistoric components have significant relationships present, while three of the four Terminal Late Prehistoric components have at least one significant RGB statistic. This is, with the exception of the elimination of an Initial Late Prehistoric component, the same pattern revealed by the parametric testing.

\section{Summary}

We suggested, based on a general model of foraging, that as bison populations declined, hunters and gatherers should increasing organize their mobility systems in a logistical manner to increase encounter rates with this high return resource. We expect that groups following annual foraging strategies, more common in the Late Archaic, would have operated in a relatively small area. Conversely, Late Prehistoric occupations, especially Terminal Late Prehistoric occupations, would be part of a larger-scale, logistically organized system. That is, we suggested that increased use of logistical strategies should increase the overall scale of the system. This would also increase encounters with non-local tools stone.

Using digital photography, we considered color differences in debitage, bifacial tools, and hafted items. Overall, it appears that an increasing frequency of expensive, hafted, Terminal Late Prehistoric tools are made with raw materials that do not match the color ranges of debitage found at the same location. In contrast, Late Archaic components, especially those in the Initial and Middle Late Archaic periods, appear to have high concurrence between tools and debitage colors. While the pattern in the Initial Late Prehistoric period is not strong, the overall trend is consistent with an increased emphasis on larger scale, logistically organized systems late in time. 



\title{
Chapter 13: Summary and Evaluation
}

\author{
Raymond Mauldin
}

The Center for Archaeological Research (CAR) at The University of Texas at San Antonio, under contract with the TxDOT, conducted archeological significance testing, followed by data recovery, in the spring and summer of 2003. The work took place at 41ZV202 in northwestern Zavala County, Texas. The testing was done in the context of anticipated road improvements to FM 481, including the potential widening of the roadway that currently bisects 41ZV202. The testing demonstrated the presence of significant Late Prehistoric (Austin Interval) deposits with good integrity in the TxDOT ROW. CAR recommended that the site was eligible for inclusion to the National Register of Historic Places under criterion d of 36CFR 60.4 , and that the site warranted designation as a State Archeological Landmark (SAL) under criteria 1 and 3 of the Texas Antiquities Code. The Texas Historical Commission (THC) and TxDOT concurred with those recommendations. As construction impacts to the site associated with the anticipated work along FM 481 could not be avoided, data recovery investigations were initiated by CAR in the summer of 2003. Dr. Russell Greaves served as project archeologist for both the testing and data recovery work. Unfortunately, following the completion of the field work, but subsequent to the production of the research design, Dr. Greaves left the CAR. Dr. Raymond Mauldin subsequently took over the project, overseeing the analysis and the production of this document, which constitutes the final report on CAR's work at $41 Z$ V202.

\section{Summary}

The initial chapters of this report summarized aspects of the project area environment and provided information on the cultural setting. We included in that review information on paleoenvironmental conditions operating in the region over the last 4,000 years. Using a variety of different data sets, we suggested that initially, warmer, and possibly drier conditions were present through sometime around 3000 BP. Cooler and possibly wetter conditions were then present, with this cooling trend becoming more pronounced over the last 1000 years. We also introduced fine-grained PDSI data based on tree-rings that go back to AD 1000. These data conflict somewhat with pollen and isotope information in that they show that between $\mathrm{AD} 1000$ and 1250, the region was dry, with low variability from year to year. After about AD 1250, all data sets, including the PDSI data, are consistent with cooler and possibly wetter conditions. In addition, the PDSI data set suggests that the AD 1250-1550 period is highly variable from year to year.
The fourth, fifth, and sixth chapters of this report describe the testing and data recovery efforts undertaken by CAR at 41ZV202, as well as the isolation of Late Prehistoric deposits at the site. Testing conducted in March of 2003 identified significant Late Prehistoric deposits in the southern portion of the TxDOT ROW. As construction impacts could not avoid these deposits, data recovery was initiated. The data recovery, conducted in July and August of 2003, involved the hand excavation of $401 \times 1-\mathrm{m}$ units. A wide variety of data types were recovered from both testing and data recovery work at 41ZV202. These included data on several features, burned rock, chipped stone debitage, a variety of tools, small amounts of vertebrate fauna and mussel shell, a large quantity of snails, charcoal samples, and soil samples. Many of these data sets were Late Prehistoric in age.

Chapters Seven and Eight provided the theoretical context for the analysis of the data from 41ZV202. Chapter Seven used a cost/benefit framework, adapted from foraging theory, to outline a number of general relationships that should be applicable to investigating aspects of subsistence, technology, and mobility in hunters and gatherers. We argued that directional changes in climate (e.g., overall increase in moisture over several decades) that may result in shifts in resource quality, type, and density, are increasingly likely to result in significant shifts in human adaptations. Those shifts could include what resources are incorporated in the diet, as well as changes in the technology and mobility strategies used to acquire those resources. The eighth chapter developed a model of adaptation based on principals presented in Chapter 7. We focused on fluctuations in bison within Central and South-Central Texas. Our review of bison presence/absence data on Late Archaic and Late Prehistoric archeological sites from a large area of Central and South-Central Texas found that, contrary to earlier reviews (e.g., Dillehay 1974; Huebner 1991), bison were constantly present in this region during the Late Archaic and Late Prehistoric periods. This included the Initial Late Prehistoric (Austin) period. Our review of climate data, however, suggested that bison populations may have been declining throughout the Late Archaic, with a rapid decline initiated sometime during the Late Prehistoric period. We suggest that if bison, a high return resource, were declining in density in Central and South Texas during Late Archaic and Late Prehistoric period, then Texas hunters and gatherers would increasingly invest in what we characterized as more costly strategies. Those strategies may include a widening of the diet breadth through the addition of smaller animals and lowreturn plants, technological changes, with more investment in specialized tools to increase processing efficiency, and shifts in mobility in order to increase encounter rates with bison. 
In Chapters 9, 10, 11, and 12 we used the foraging theory cost-benefit framework and the assumption that bison were declining throughout the Late Archaic and Late Prehistoric to consider changes in diet breadth, technology, and mobility. In Chapter 9 we considered changes in diet breadth using data from the Late Prehistoric occupation at 41ZV202 as well as a variety of early, contemporary, and later components. We suggested that if bison densities gradually declined from the Initial Late Archaic through the Terminal Late Archaic, as suggested by the climate data, hunters and gatherers should add lower ranked plants and animals to their diet, as well as intensify on those plants and animals already forming part of their diet. We expected that dietary expansion and intensification should accelerate in the Late Prehistoric period, especially in the Terminal Late Prehistoric, as bison availability declined. Looking at changes in the number of taxa present in an assemblage and changes in bone fragment weights placed in size classes, we showed that there is an overall increase in the number of faunal groups represented through time, and that the increase appears to be associated with the addition of lower ranked resources. However, we could not eliminate the possibility that taphonomic processes account for these shifts. That is, older assemblages should have a lower diversity of faunal types represented simply as a function of deterioration over time. Changes in the fragmentation data do not clarify the issues. They are only partially consistent with our overall expectations. Focusing on floral resources, we used changes in the density of FCR features and changes in the density of ground stone artifacts to estimate shifts in the intensity of plant processing and indirectly shifts in the role of plant resources in the diets. Support for the association of FCR features with plant dependence was provided both by ethnographic data, as well as by feature level data from 41ZV202 where lipid analysis of rock was consistent with a focus on plants. Only partial support for our expectation regarding FCR features was present in the larger data set. The ground stone data did demonstrate a significant increase associated with the Terminal Late Prehistoric, but patterns in the Late Archaic showed a gradual decrease in ground stone density rather than a gradual increase as anticipated. Overall, patterns in the Late Archaic tend to be opposite of what we predicted. Diet indicators suggest a contraction through time, rather than an expansion. However, the general patterns are not strong during this period. The pattern of diet expansion is clearly seen in the Terminal Late Prehistoric. The patterns here are stronger and consistent with expectations.

In Chapter 10, we focused on two aspects of technology, changes in tool manufacturing costs and changes in the way that hunters and gatherers produced, used, and replaced tools. We argued that if bison populations were declining throughout the Late Archaic, with a significant decline in the Late Prehistoric, that strategies of tool design, as well as tool manufacture, use, and repair, should be impacted in predictable ways. We suggested that as bison become less common throughout the Late Archaic and into the Initial Late Prehistoric, the use of a tool kit that was more specialized, and consequently more expensive to produce and maintain, should increase. This would especially be the case in the Terminal Late Prehistoric. We also suggest that a "gearingup" strategy, where large numbers of tools are manufactured at one location in anticipation of future needs and failure rates, would be increasingly likely under declining bison availability. Using an assessment of tool costs that relied primarily on the degree of retouch, we categorized tools on 20 components, including 41ZV202. Several of our expectations derived from our model of declining bison are supported by the cost data. Increased investment in more expensive tools under conditions of declining bison is especially evident in the Terminal Late Prehistoric. The changes through the Late Archaic are more ambiguous. Our examination of the breakage patterns for the Late Archaic components suggests that a gearing-up strategy of tool manufacture, use, and replacement was not well represented during this time frame. As we expected, Late Archaic components seem to be organized in an on-demand replacement format. In contrast, the Initial Late Prehistoric does have data patterns that are consistent with a gearing up strategy. High frequencies of manufacturing breaks characterize all five components. We are, however, missing the use locations during this time period. The Terminal Late Prehistoric period shows the largest variability and has examples of both high manufacture and high use dominated components. This pattern suggests that, consistent with our expectations, there is evidence for a gearing-up strategy late in time, at least at some locations.

Chapters 11 and 12 both considered aspects of mobility. Chapter 11 considered several measures in an attempt to recognize special purpose, and probably logistically organized sites, from residential occupations. We expected that logistically organized assemblages should be more common late in time as bison declined. We used the 41ZV202 data, in combination with 18 other components, to explore the potential of artifact variety as an indicator of site types and, by extension, aspects of mobility organization. While some special purpose and some residential sites were identified, our analysis showed that sample size, rather than shifts in organization, was the primary influence on the number of artifact types. We subsequently used data from 41ZV202 to begin to explore the potential of shifts in site maintenance activities as an additional measure of site types. Though we lack any comparative data from formal middens, our analysis demonstrated that sheet midden deposits, identified as Features 4 and 5 on 41ZV202, have extremely low 
variability in most aspects of soil chemistry, magnetic susceptibility, debitage counts, flake size, and cortex percentages. This low variability is consistent with our expectations for these types of middens. While recognition criteria for formal middens still need to be developed, the type of midden deposits should provide additional clues to identifying the types of sites reflected at a location.

Finally, Chapter 12 considered differences in the scale of mobility systems through time. We suggested that as bison populations declined, hunters and gatherers should increasingly organize their mobility systems in a logistical manner to increase encounter rates with this high return resource. We expect that groups following annual foraging strategies, more common in the Late Archaic, would have operated in a relatively small area. Conversely, Late Prehistoric occupations, especially Terminal Late Prehistoric occupations, would be part of a larger-scale, logistically organized system. This change in scale would also increase encounters with non-local tool stone. Using digital photography, and assessing chert colors using the RGB scale, we explored differences in debitage, bifacial tools, and hafted tools for a variety of sites. Using parametric and nonparametric tests comparing RGB values, we demonstrated that an increasing frequency of expensive, hafted, Terminal Late Prehistoric tools are made with raw materials that do not match the color ranges of debitage found at the same location. In contrast, Late Archaic components, especially those in the Initial and Middle Late Archaic periods, appear to have high concurrence between tools and debitage colors. While the pattern in the Initial Late Prehistoric period is not strong, the overall trend is consistent with an increased emphasis on larger scale, logistically organized systems late in time.

\section{Evaluation and Additional Research}

The research design guiding the analytical chapters in this document is based on several general principals derived from foraging theory. Foremost among these are the related ideas that cost/benefit analysis is central to human decisions and that hunters and gatherers attempt to maximize their average energy return rates when making these cost/ benefit choices. Using this cost/benefit framework, we suggested several general relationships that should be applicable to investigating aspects of diet, technology, and mobility in hunters and gatherers. As summarized above, sometimes our expectations for patterning in the archeological record, derived from that framework, are supported, sometimes they not, and sometimes the results are ambiguous. In this closing section, we briefly consider the overall approach, highlighting problems and prospects for additional research.
The major weaknesses that we see in the current configuration involve questions of scale and poorly developed methodology. The methodological problems, such as developing ways to recognize residential sites or to investigate shifts in plant dependence, have been noted at several places in this document. We have, however, essentially ignored the scale questions. These involve both temporal and spatial scales of analysis. For example, we attempted to assess the utility of our model by reference to behaviors, such as the use of logistical mobility or an expansion of diet breadth, over substantial time periods. We know that in ethnographic cases, these change at small scales, such as seasonally or yearly. These smaller scales shifts are invisible in most archaeological settings. Even with our division of the Late Archaic into smaller intervals, some of these "smaller" intervals are still over 1,000 years in length. A lot can happen over that length of time. We need finer chronological divisions of the record in order to highlight and understand changes through time.

We also need smaller partitions in space. We have treated much of Central and South-Central Texas as if it was uniform in terms of resource structure. Clearly, this is not the case. Food, water, and raw materials vary across space. Hunters and gatherers will, depending on the specific resource structure, have different responses to decreases in high ranked resources. Under some conditions, diet expansion should occur. Under other conditions, increased investment in technology and shifts in mobility may be present. Research designed to elucidate the underlying resource structure at smaller scales, and that investigates how changing environmental conditions would impact that underlying structure, is needed. In that same arena, we need to refine our paleoclimate reconstructions. While the tree-ring data is a major improvement in this area, it is currently only applicable to a portion of the Late Prehistoric period. Smaller scale data and more detailed paleoclimate data would enable our analyses to focus on a particular portion of the landscape, rather than treating Central and South-Central Texas as uniform.

Finally, the model itself needs refinement with a focus on obtaining quantitative data on costs and benefits. We currently lack this basic data for most components of the model. For example, we have argued that while diet expansion would be a viable response to declining high ranked resources, that increased investments in tools and shifts in mobility are responses that also make sense when high ranked resources are declining. However, if bison densities continue to decline there will come a point at which no amount of increased investment in technology, for example, will produce increased return. We do not know what that point is, and we will not know until we are able to develop quantitative data for basic components of the model. 



\section{Notes to Text}

1. Descriptions of the stratigraphy at 41ZV202 differ. Bousman (Appendix A) distinguishes a series of A horizons above the underlying Bk1. Earlier descriptions by Abbott (2002), as well as the profile drawings by project archeologist Russell Greaves (some of which are reproduced here in Chapter 4 as well as in Chapters 5 and 6) identify a Bw horizon immediately above the Bk1. That $\mathrm{Bw}$ is overlain by an A horizon. No Bw horizon was distinguished by Bousman. The identification of Features 4 and 5 by Greaves during testing further complicates this issue. These large, amorphous, organically enriched deposits rest on what Greaves has identified as the Bw horizon. In some cases, the features are capped by a single, thin A horizon (e.g., Figure 5-3) while in others, this horizon is missing (e.g., Figure 5-5). Final profile drawings by Greaves following data recovery work (e.g., Figures 6-1, 6-2, 6-3) show a thick A2 horizon on top of the Bw. No feature designations are present in these final drawings, though Features 4 and 5 should have been present, and designated, at some of these profile locations. All researchers agree on the underlying Bk horizons, and they agree that these lower deposits pre-date the Late Prehistoric. It appears that Bousman has designated the Bw horizon noted by Abbott and Greaves as an A horizon. It may also be the case that the multiple A horizons designated by Bousman have been variously identified as Features 4 and 5 by Greaves, at least during testing and the initial data recovery work, but not in the final drawings. Additional information on Features 4 and 5, including color photos of plan (Figure 4-8) and profile views (Figures 5-3; 5-4) are available. Finally, note that we discuss Features 4 and 5 in more detail in Chapter 11.

2. TxDOT reviewers suggest that by ignoring social factors as determinants of material patterns in prehistory, the position expounded by the authors is essentially "ecological determinism." As the primary author of this chapter and of this report (Mauldin), I would not dispute that characterization. The focus on ecological factors is a decision based on my assessment of our current methodological strengths and weaknesses. I hope that methodologies that can monitor social factors can be developed and implemented, but at present, we minimally lack the fine-grained temporal control necessary to monitor such factors, even if we could figure out a way to consistently and unambiguously identify them. By focusing on factors that we have a better, though certainly not anywhere near complete, understanding of, we at least have the potential to isolate some things that we think we understand, as well as some things that we do not understand that can be addressed in future research.

3. TxDOT reviewers point out that the model, as well as the cost and benefits as envisioned, are overly simplistic and poorly defined. They suggest that the model ignores factors such as opportunistic foraging, as well as critical factors such as health risks, preference, nutritional yield, harvestable portion vs. waste, and ancillary resource utility not related to diet. They are generally correct in much of that assessment. In our view, some of these, such as personal or cultural preference and opportunistic foraging, will be impossible to accurately assess or include in any archeological investigation. As they cannot be isolated in the archeological record given current methodologies, they are of little interest to us. Others, such as nutritional yield, harvestable portions, and ancillary resource utility, probably can be estimated given additional, focused research. We are not disputing the fact that other elements, such as nutritional yield, risk, and ancillary resource utility (other than diet) are important. In our view, the question centers on how to conduct productive research into the archeological record. We have chosen to build overly simplistic models that can be, at least to some degree, be assessed with our current methodology. We suggest that the application and assessment of these simplistic models relative to the archeological record will help isolate additional areas of investigation, which researchers can consider subsequently.

4. Specialized tools include items such as projectile points, drills/ perforators, ceramics, and scrapers with hafting elements. These tools are considered more expensive to produce in terms of time than generalized tools, such as unifaces without hafting elements, bifaces without hafting elements, and expediently flake tools. We suggest that the more complexity a tool has, defined by the number of different components (see Oswalt 1973, 1976; Torrence 1983), the greater the amount of time required to produce that tool. In part, this assertion is related to consideration of the overall tool form, which includes non-durable aspects of the technology that are not preserved, in most cases, in open air archeological sites. TxDOT reviewers suggest that as the inclusion of non-durable aspects of the technology is inappropriate in that the suggestion would be difficult to test archeologically. However, examples of the individual components of tools (e.g., bows, arrows, arrows with fletching, bow strings, hafted arrow points on fore shafts) have been recovered from a variety of shelter and cave sites, from ethnographic context, and reproduced experimentally. We acknowledge, for example, that not all tools described as arrow projectile points were necessarily hafted and used in a bow and arrow weapon. In these particular cases, the lack of this "non-durable" technology and our assumptions would produce a spurious association. However, we think that things described as arrow points based on the form and haft of the stone were, in fact, most frequently used as points on arrows and were shot with bows. 
5. TxDOT reviewers suggest that it is "absurd" to assume that shifts in the overall return rate is the sole motivation for dietary trends. They suggest that perhaps trends have more to do with factors such as: 1) bison tasting better, if only based on fat content, than smaller animals such as rats; 2) greater prestige associated with those participating in a successful bison hunt, with implications for inter-group influence and mating success; 3 ) bison produces ancillary products such as hide and bone that were also critical in the context of ancient lifeways. We would not dispute the observation that there are other factors involved with shifts in diet beyond overall return rates. Elements such as fat content and prestige have clearly been documented to influence diet choice in ethnographic contexts (e.g., Kaplan and Hill 1985, 1992). As we noted above (note 3), the question for us centers on how to efficiently conduct research into the archeological record given our current methodologies. Acknowledging that "inter-group influence" and "mating success" may play a role does not advance our understanding if we lack ways to monitor these activities in the archeological record.

6. TxDOT reviewers suggest that the presence of bison remains by time period provides a direct proxy measure for bison abundance and that the climate proxies that we use are a far more tenuous measure. We suggest that the bison data are not an independent measure of abundance, for the multiple reasons stated in the text (i.e., must assume that bison are hunted whenever they are encountered, that they are encountered at a similar rate to their presence in the environment, that hunting technology, success rates, butchering patterns, disposal patterns, occupation length, and a host of other parameters would have to remain constant for the roughly 3,000 year period considered here). While presence/ absence data work fine if bison are, in fact, absent from some period, such as was originally suggested by Dillehay (1974), once it is clear that bison are present, the issue becomes one of assessing different levels of bison abundance. Presence/absence data at a component level provides no information on increases or decreases of bison abundance in the environment unless one makes a series of assumptions that we know to be wrong. While the climate data certainly are indirect and while any given climate data set may have interpretive problems, in our opinion these data do provide an assessment that can be evaluated independently of the archeological record.

7. Box plots, also referred to as box and whisker plots, summarize distributional characteristic of data sets. They rely primarily on quartiles. The box is defined by the location of the first and third quartile. The horizontal line within the box identifies the median (second quartile). The whiskers (lines extending above and below the box) are defined by adjacent values. The upper adjacent value is the largest value above the box that is less than or equal to the upper quartile plus 1.5 times the inter-quartile range ( 1.5 times the length of the box). The lower adjacent value is the smallest data point that is less than or equal to the first quartile minus 1.5 the inter-quartile range. If any values are above or below the adjacent values (i.e., above or below $1.5+/$ - the inter-quartile range), then these are identified by outliers (Tukey 1977).

8. TxDOT reviewers suggest that the cost categories are "entirely etic constructs" and that if they do reflect energetic investment, "such an investment was not likely perceived as increasing the probability of high-yield returns, but rather simply perceived as the functional requirement of a given task unrefracted through the lens of probability modeling."They further suggest that a more realistic assessment of costs in tool production would consider the following: 1) ease of acquiring raw material; 2) lithic raw material quality, including flakeability, appropriateness, need for thermal treatment, breakage/ failure rates; 3) time required per successful production unit, including variation in individual skill level and technical difficulty. We agree with TxDOT reviewers that our cost categories are etic in nature. How they were perceived, or even if hunters and gatherers perceived them thousands of years ago is, in our view, both unknowable and irrelevant to our investigation. We would not dispute that other elements, including some of those listed above, are relevant to assessing tool cost for some purposes. It would clearly be useful, for example, to have quantitative information on time requirements for a successful tool production and past breakage/failure rates. However, this information is not available at present.

9. TxDOT reviewers suggest that relationships "posited between mobility and declining availability of high-ranked prey exists purely in an unrealistic vacuum." They further suggest that "the model, as posed, eliminates social motives of mobility to elevate pure ecological determinants. The direct correlation drawn between mobility and tool stone variability assumes that local resources are not highly variable, and that materials did not arrive through trade networks." Finally, they suggest that we 1) assume a relationship between specific sources and raw material variability that has not been demonstrated and the 2) the measures would "work poorly" in areas such as the Edwards Plateau and areas with Uvalde Gravels as these areas have "high resource heterogeneity within a geographically limited area." The comments regarding the deterministic, ecological nature of the model are accurate. We view this as strength. We certainly acknowledge that trade networks and "social motives" may impact both what artifacts are recovered at a site and the scale of mobility. However, acknowledging that does little to advance our understanding in any specific case since "social motives" operate at a temporal scale that is, in our view, invisible archeologically and they do not, in and of themselves, provide any explanation for changes in mobility. Identifying items possibly related to "trade networks" is, however, certainly possible, and can be done once we establish what is, and is not, locally available. Our approach, then, can provide a first step in that identification process. We do, in addition, assume a 
relationship between specific sources and raw material colors which has not been demonstrated, but which can be assessed with additional work. Whether there is high variability, as TxDOT suggests, or low variability, is dependent, at least in part, on the spatial scale considered as well as the underlying geology. However, regardless of the underlying variability, if there is some variation in color across sources, increases in the level of mobility should, depending on the scale, increase access to materials and introduce more colors of chert. Conversely, decreases in mobility should decrease access and reduce color variation. We are currently conducting research to document color variation from different sources across the Central Texas area. 



\section{References Cited}

Abbott, J.

2002 Appendix 1 Geoarcheological Observations Made During Mechanical Assessment of 41ZV202, November 14, 2002, FM 481, Zavala County. In Archeological Survey of 41ZV202 in Zavala County, Texas Department of Transportation, by T. Meade, Unpublished document on file. Texas Department of Transportation, Environmental Affairs Division, Austin.

Afifi, A.A., and V. Clark

1984 Computer-Aided Multivariate Analysis. Wadsworth, Inc. Belmont, California.

Alexander, R.K.

1970 Archeological Investigations at Parida Cave, Val Verde County, Texas. Papers of the Texas Archeological Salvage Project 19. The University of Texas at Austin.

1974 The Archeology of Conejo Shelter: A Study of Cultural Stability at an Archaic Rockshelter Site in Southwestern Texas. Unpublished Ph.D. Dissertation, Department of Anthropology, The University of Texas at Austin.

Alley, W.M.

1984 The Palmer Drought Severity Index: Limitations and Applications. Journal of Climate and Applied Meteorology 23:1100-1109.

Amick, D.S.

1994 Folsom Diet Breadth and Land Use in the American Southwest. Unpublished Ph.D. Dissertation, Department of Anthropology, University of New Mexico, Albuquerque.

Anderson, A.E., D.E. Medin, and D.C. Bowden 1972 Indices of Carcass Fat in a Colorado Mule Deer Population. Journal of Wildlife Management 36(2):579-594.

Baerreis, D.A. and R.A. Bryson

1965 Historical Climatology and the Southern Plains: A Preliminary Statement. Bulletin, Oklahoma Archeological Society 13:69-76.

Bailey, D.W., J.E. Gross, E.A. Laca, L.R. Rittenhouse, M.B. Coughenour, D.M. Swift, and P.L. Sims

1996 Mechanisms that result in large herbivore grazing distribution patters. Journal of Range Management 49(5):386-400.

Bamforth, D.B

1988 Ecology and Human Organization on the Great Plains. Plenum Press, New York.

Bamforth, D.B., and P. Bleed

1997 Technology, Flake Stone Technology, and Risk. In Rediscovering Darwin: Evolutionary Theory in Archaeological Explanation, edited by C.M. Barton and G.A. Clark, pp. 109-140. Archaeological Papers of the American Anthropological Association. No. 7. Arlington, Virginia.

Barnes, V.E.

1977 Geologic Atlas of Texas: Del Rio Sheet. Bureau of Economic Geology, The University of Texas at Austin. 
1983 Geologic Atlas of Texas: San Antonio Sheet. Bureau of Economic Geology, The University of Texas at Austin.

Baugh, S.T.

1986 Late Prehistoric Bison Distribution in Oklahoma. In Current Trends in Southern Plains Archaeology, edited by T. Baugh, 83-86. Plains Anthropologist 31 (114, Part 2), Memoir 21.

Bellomo, R.V.

1983 A methodological approach to identifying archaeological evidence of fire resulting from human activities. Journal of Archaeological Science 20:523-553.

Bender, M.M., I. Rouhani, H.M. Vines, and C.C. Black, Jr.

$1973{ }^{13} \mathrm{C} /{ }^{12} \mathrm{C}$ Ratio Changes in Crassulacean Acid Metabolism Plants. Plant Physiology 52:427-430.

Bettinger, R.L.

1982 Explanatory/Predictive Models of Hunter-Gatherer Adaptation. In Advances in Archaeological Method and Theory: Selections from Students from Volumes 1 through 4, edited by M.B. Schiffer, pp. 157-223. Academic Press, New York.

Binford, L.R.

1977 Forty-seven Trips: A Case Study in the Character of Archaeological Formation Process. In Stone Tools as Cultural Markers, edited by R.V.S. Wright, pp 24-36. Australian Institute of Aboriginal Studies. Canberra, Australia.

1978 Nunamiut Ethnoarchaeology. Academic Press, New York.

1979 Organization and Formation Processes: Looking at Curated Techniques. Journal of Anthropological Research 35:255273.

1980 Willow Smoke and Dog's Tails: Hunter-Gatherer Settlement Systems and Archaeological Site Formation. American Antiquity 45:4-20.

1983 The Archaeology of Place. In Working at Archaeology, edited by L.R. Binford, pp. 357-378. Academic Press, New York.

1992 Seeing the Present and Interpreting the Past and Keeping Things Straight. In Space, Time, and Archaeological Landscape, edited by J. Rossignol and L. Wandsnider, pp. 43-59. Plenum Press, New York.

2001 Constructing Frames of Reference. University of California Press, Berkeley.

Bird, D.W. and J.F. O’Connell

2006 Behavioral Ecology and Archaeology. Journal of Archaeological Research 14:143-188.

Black, S.L.

1986 The Clemente and Herminia Hinojosa Site, 41JW8: A Toyah Horizon Campsite in Southern Texas. Special Report No. 18. Center for Archaeological Research, The University of Texas at San Antonio.

1989 South Texas Plain. In From the Gulf Coast to the Rio Grande: Human Adaptation in the Central, South, and Lower Pecos Texas, by T.R. Hester, S.L. Black, D.G. Steele, B.W. Olive, A.A. Fox, K.J. Reinhard, and L.C. Bement, pp. 39-62. Research Series No. 33. Arkansas Archeological Survey, Fayetteville. 
2003 Research Module 2: Studying the Hearths of the Greater Edwards Plateau. In Pavo Real (41BX52):A Paleoindian and Archaic Camp and Workshop on the Balcones Escarpment, South-Central Texas, by M.B. Collins, D.B. Hudler, and S.L. Black, pp. 375-405. Studies in Archeology, No. 41. The Texas Archeological Research Laboratory. Archeological Studies Program, Report 50. Environmental Affairs Division, Texas Department of Transportation, Austin.

Black, S.L. and D. Creel

1997 The Central Texas Burned Rock Midden Reconsidered. In Hot Rock Cooking on the Greater Edwards Plateau: Four Burned Rock Midden Sites in West Central Texas. Vol. 1, edited by S.L. Black, L.W. Ellis, D.G. Creel, and G.T. Goode, pp. 269-314. Studies in Archaeology, No. 22, Texas Archaeological Research Laboratory, The University of Texas at Austin. Archeology Studies Program. Report 2. TEnvironmental Affairs Division, Texas Department of Transportation, Austin.

Blair, W.F.

1950 The Biotic Provinces of Texas. Texas Journal of Science 2(1):93-117.

Blalock, H.M.

1979 Social Statistics. McGraw-Hill Book Company, New York.

Bleed, P.

1986 The Optimal Design of Hunting Weapons: Maintainability or Reliability. American Antiquity 51:734-747.

Bobrowsky, P.T., and B.F. Ball

1989 The Theory and Mechanics of Ecological Diversity in Archaeology. In Quantifying Diversity in Archaeology, edited by R.D. Leonard and G.T. Jones, pp. 4-12. Cambridge University Press, New York.

Bomar, G.W.

1995 Texas Weather. Second edition, revised. University of Texas Press, Austin.

Bond, C.L.

1978 Three Archeological Sites at Hoxie Bridge, Williamson County, Texas. Anthropology Laboratory, Report 43. Texas A\&M University, College Station.

Bousman, C.B.

1998 Paleoenvironmental Change in Central Texas: The Palynological Evidence. Plains Anthropologist 43(164):201-219.

Boutton, T.W., S.A. Archer, A.J. Midwood, S.F. Zitzer, and R. Bol

$1998 \delta^{13} \mathrm{C}$ values of Soil Organic Carbon and Their Use in Documenting Vegetation Changes in a Subtropical Savanna Ecosystem. Geoderma 82:541.

Brown, D.A.

1993 Early Nineteenth-Century Grasslands of the Midcontinent Plains. Annals of the Association of American Geographers 83:589-612.

Brown, K.M., D.R. Potter, G.D. Hall, and S.L. Black

1982 Excavations at 41LK67, A Prehistoric Site in the Choke Canyon Reservoir, South Texas. Choke Canyon Series, Vol. 7. Center for Archaeological Research, The University of Texas at San Antonio. 
Brownlow, R.K.

2003 Archeological Investigations at 41WM815 A Blackland Prairie Site Williamson County, Texas. Studies in Archeology 36, Texas Archeological Research Laboratory, The University of Texas at Austin, and Archeology Studies Program Report, No. 23, Environmental Affairs Division, Texas Department of Transportation, Austin.

Bryant, V.M., Jr., and R.G. Holloway

1985 A Late-Quaternary Paleoenvironmental Record of Texas: An Overview of the Pollen Evidence. In Pollen Records of Late-Quaternary North American Sediments, edited by V.T. Bryant, Jr., and R.G. Holloway, pp. 39-70. American Association of Stratigraphic Palynologists Foundation, Dallas.

Burger, O., M.J. Hamilton, and R. Walker

2005 The prey as patch model: optimal handling of resources with diminishing returns. Journal of Archaeological Science 32:1147-1158.

Cabeza de Vaca, A.N.

1555 La relacion y comentarios del goubernador Aluar Nuñez Cabeça de Vaca, de lo acaescido en las dos jornadas que hizo a las Indias. Published under Royal Authorization at Valladolid, Spain. Scanned copy with English translation by M. A. Favata and J. B. Fernández is available online at http://www.library.txstate.edu/swwc/cdv/index.html. Accessed December, 2006.

Callahan, E.

1979 The Basics of Biface Knapping in the Eastern Fluted Point Tradition: A Manual for Flintknappers and Lithic Analysts. Archaeology of Eastern North America 7:1-180.

Campbell, T.N.

1947 The Johnson Site: Type Site of the Aransas Focus of the Texas Coast. Bulletin of the Texas Archeological and Paleontological Society 18:40-75.

1956 Archeological Materials from Five Islands in the Laguna Madre, Texas Coast. Bulletin of the Texas Archeological Society 27:7-46.

Camper, H.A.

1991 Pollen Analysis of Patschke Bog. Unpublished Master's thesis, Department of Botany, Texas A\&M University, College Station. Data archived at the World Data Center System, http://www.ncdc.noaa.gov/paleo/datalist.html, accessed January, 2006. North American Pollen Database, made available by the NOAA Paleoclimatology Program, National Climatic Data Center (NCDC), Boulder. Contributor of data to site is V. M. Bryant, Jr.

Cane, S.

1987 Australian Aboriginal Subsistence in the Western Desert. Human Ecology 15:391-434.

Cannon, M.D.

2003 Large mammal relative abundance in Pithouse and Pueblo Period archaeofaunas from southwestern New Mexico: resource depression among the Mimbres-Mogollon? Journal of Anthropological Archaeology 19:317-347.

Chambers, J.M., W.S. Cleveland, B. Kleiner, and P.A. Tukey

1983 Graphical Methods of Data Analysis. Duxbury Press, Boston.

Charnov, E.L.

1976 Optimal Foraging, the Marginal Value Theorem. Theoretical Population Biology 9(2):129-136. 
Charnov, E.L., G.H. Orians, and K. Hyatt

1976 The Ecological Implications of Resource Depression. American Naturalist 110:247-259.

Collins, M.B.

1968 The Andrews Lake Locality: New Archeological Data from the Southern Llano Estacado, Texas. M.A. Thesis on file, The University of Texas at Austin.

1969 Texas Excavations at Amistad International Reservoir, Fall 1967. Papers of the Texas Archeological Salvage Project 16. The University of Texas at Austin.

1995 Forty Years of Archeology in Texas. Bulletin of the Texas Archeological Society 66:361-400.

2004 Archeology in Central Texas. In The Prehistory of Texas, edited by T.K. Perttula, pp. 205-265. Texas A\&M University Press, College Station.

Condamin, J., F. Formenti, M.O. Metais, M. Michel, and P. Blond

1976 Application of Gas Chromatography to the Tracing of Oil in Ancient Amphorae. Archaeometry 18(2):195-201.

Conover, W.J.

1980 Practical Nonparametric Statistics. John Wiley and Sons, New York.

Cook, E.R. and P.J. Krusic

2004 The North American Drought Atlas. Lamont-Doherty Earth Observatory and the National Science Foundation. Colombia University, Palisades, New York. available at http://iridl.ldeo.columbia.edu/SOURCES/.LDEO/.TRL/. NADA2004/.pdsi-atlas.html.

Cook, E.R., D.M. Meko, D.W. Stahle, and M.K. Cleveland

1999 Drought Reconstruction for the Continental United States. Journal of Climate 12:1145-1162.

Cooke, M.J.

2005 Soil Formation and Erosion in Central Texas: Insights from Relict Soils and Cave Deposits. Unpublished Ph.D. Dissertation, Department of Geological Sciences, The University of Texas at Austin.

Coppedge, B.R., D.M. Leslie, Jr., and J.H. Shaw

1998 Botanical Composition of Bison Diets on Tallgrass Prairie in Oklahoma. Journal of Range Management 51(4):379382.

Coppock, D.L., J.E. Ellis, J.K. Detling, and M.L. Dryer

1983 Plant-herbivore interactions in a North American mixed-grass prairie II. Responses of bison to modification of vegetation by prairie dogs. Oecologia 56:10-15.

Cowlishaw, M.F.

1985 Fundamental Requirements for Picture Presentation. Proceedings of the Society for Information Display 26 (2): $101-$ 107.

Crabtree, D.E.

1972 An Introduction to Flintworking. Occasional Papers of the Idaho State Museum, No. 28. Idaho State University, Pocatello. 
Crawford, D.

1981 Texas Archeological Sites Atlas. Site Survey Form. Texas Archeological Research Laboratory. Austin.

Creel, D.

1990 Excavations at 41TG91, Tom Green County, 1978. Publications in Archeology, No. 38. Texas State Department of Highways and Public Transportation, Austin.

1991 Bison Hides in Late Prehistoric Exchange in the Southern Plains. American Antiquity 56(1):40-49.

Crowther, J.

2003 Potential Magnetic Susceptibility and Fractional Conversion Studies of Archaeological Soils and Sediments. Archaeometry 45:686-701.

Davis, W.B. and D.J. Schmidly

1997 The Mammals of Texas- Online Edition. Electronic database available at http://www.nsrl.ttu.edu/tmot1/Default.htm. Accessed January, 2006. Texas Tech University and Texas Parks and Wildlife Department, Nongame and Urban Program, Austin.

Dearing, J.A.

1999 Environmental Magnetic Susceptibility. Chi Publishing, Kenilworth, England.

Deines, P.

1980 The Isotopic Composition of Reduced Organic Carbon. In Handbook of Environmental Isotope Geochemistry; Volume 1, the Terrestrial Environment, edited by P. Fritz and J.C. Fontes, pp 329-406. Elsevier, Amsterdam.

Dering, J.P.

2002 Rainfall Reconstruction Using Mesquite Wood Charcoal from Archeological Sites in South Texas. In Archeological Data Recovery Excavations along Becerra Creek (41WB556), Webb County, Texas, by R.B. Mahoney, R.P. Mauldin, and S.A. Tomka, pp. 206-216. Archaeological Survey Report, No. 321, Center for Archaeological Research, The University of Texas at San Antonio and Archeological Studies Program, Report No. 30, Environmental Affairs Division, Texas Department of Transportation, Austin.

2003 Appendix E: Macrobotanical Assemblage from 41MM340. In Data Recovery Excavations at 41MM340, A Late Archaic Site along Little River in Milam County, Texas, by R.B. Mahoney, S.A. Tomka, R.P. Mauldin, H.J. Shafer, L.C. Nordt, R.D. Greaves, and R.R. Galdeano, pp 224-233. Archaeological Survey Report, No. 340, Center for Archaeological Research, The University of Texas at San Antonio. Archeological Studies Program, Report No. 54, Environmental Affairs Division, Texas Department of Transportation, Austin.

2004 Xylem Analysis of Mesquite Wood Charcoal. In Archeological Survey and Testing of Selected Prehistoric Sites along FM481, Zavala County, Texas, by R.P. Mauldin, B.K. Moses, R.G. Greaves, S.A. Tomka, J.P. Dering and J.D. Weston, pp. 69-72. Archeological Studies Program, Report No. 67, Environmental Affairs Division, Texas Department of Transportation, Austin and Archaeological Survey Report No. 352, Center for Archaeological Research, The University of Texas at San Antonio.

2008 Late Prehistoric Subsistence Economy on the Edwards Plateau. Plains Anthropologist 53(205):59-77.

Dibble, D.S.

1968 Bonfire Shelter: A Stratified Bison Kill Site in the Amistad Reservoir Area, Val Verde County, Texas. Miscellaneous Papers of the Texas Archeological Salvage Project 5, The University of Texas, Austin. 
Dickens, W.A. and J.E. Wiederhold

2003 Some Notes on Bison, the Texas Post Oak Savanna, and the Late Prehistoric Period of Texas. Bulletin of the Texas Archeological Society 74:31-54.

Dillehay, T.

1974 Late Quaternary Bison Population Changes on the Southern Plains. Plains Anthropologist 19:180-196.

Doughty, R.W.

1983 Wildlife and Man in Texas. Texas A\&M University Press, College Station.

Duncan, D.E.

1997 Hernando de Soto: A Savage Quest in the Americas. University of Oklahoma Press.

Dunnell, R.C.

1992 The Notion of Site. In Space, Time, and Archaeological Landscapes, edited by J. Rossignol and L. Wandsnider, pp. 21-41. Plenum Press, New York.

Ebert, J.I.

1992 Distributional Archaeology. University of New Mexico Press, Albuquerque.

Eddy, F.W.

1973 Salvage Archeology in the Laneport Reservoir District: Central Texas. Report on file, Texas Archeological Survey, The University of Texas at Austin.

Ehleringer, J.R., T.E. Cerling, and B.R. Helliker

$1997 \mathrm{C}_{4}$ Photosynthesis, Atmospheric $\mathrm{CO}_{2}$, and Climate. Oecologia 112:285-299.

Ellis, L.W.

1997 Hot Rock Technology. In Hot Rock Cooking on the Greater Edwards Plateau: Four Burned Rock Midden Sites in West Central Texas, by S.L. Black, L.W. Ellis, D.G. Creel, and G.T. Goode, pp 43-81. Studies in Archeology 22, Texas Archeological Research Laboratory, The University of Texas at Austin. Archeological Studies Program, Report No. 2, Environmental Affairs Division, Texas Department of Transportation, Austin.

Ellis, L.W., G.L. Ellis, and C.D. Fredrick

1995 Implications of Environmental Diversity in the Central Texas Archeological Region. Bulletin of the Texas Archeological Society 66:401-426.

Emerson, A.M.

1990 Implications of Variability in the Economic Anatomy of Bison bison. Ph.D. Dissertation, Washington State University. University Microfilms, Ann Arbor.

1993 The Role of Body Part Utility in Small-scale Hunting under Two Strategies of Carcass Recovery. In From Bones to Behavior, edited by Jean Hudson, pp. 138-155. Center for Archaeological Investigations, Occasional Paper No. 21, Board of Trustees, Southern Illinois University, Carbondale.

Emlen, J.M.

1966 The Role of Time and Energy in Food Preference. American Naturalist 100:611-617. 
Epp, H.T.

1988 Way of the Migrant Herds: Dual Dispersion Strategy among Bison. Plains Anthropologist 33:309-320.

Epstein, H.E., W.K. Lauenroth, I.C. Burke, and D.P. Coffin

1997 Productivity Patterns of $\mathrm{C}_{3}$ and $\mathrm{C}_{4}$ Functional Types in the U.S. Great Plains. Ecology 78(3):722-731.

Epstein, J.F.

1963 Centipede and Damp Caves: Excavations in Val Verde County Texas, 1958. Bulletin of the Texas Archeological Society 33:1-129.

Everitt, B.S.

1977 The Analysis of Contingency Tables. Chapman and Hall, London.

Folmer, $\mathrm{H}$.

1940 De Bellisle on the Texas Coast. Southwestern Historical Quarterly 44:204-231.

Fox, D.E.

1979 Archaeological Investigation of Two Prehistoric Sites on the Coleto Creek Drainage, Goliad County, Texas. Archaeological Survey Report 69, Center for Archaeological Research, The University of Texas at San Antonio.

Gadus, E.F., R.C. Fields, and K.W. Kibler

2006 Data Recovery Excavations at the J.B. White Site (41MM341), Milam County, Texas. Reports of Investigations 145, Prewitt and Associates, Austin and Archeology Studies Program Report, No. 87, Environmental Affairs Division, Texas Department of Transportation, Austin.

Gamble, C.

1986 The Palaeolithic Settlement of Europe. Cambridge University Press, Cambridge.

Gardner, K.M.

2006aAppendix A: Analysis of Mussel Shells from 41MM341. In Data Recovery Excavations at the J.B. White Site (41MM341), Milam County, Texas, by E. Gadus F., R.C. Fields, and K.W. Kibler, pp 195-206. Reports of Investigations 145, Prewitt and Associates, Austin and Archeology Studies Program Report, No. 87, Environmental Affairs Division, Texas Department of Transportation, Austin.

2006b Appendix B: Analysis of Gastropod Shells from 41MM341. In Data Recovery Excavations at the J.B. White Site (41MM341), Milam County, Texas, by E. Gadus F., R.C. Fields, and K.W. Kibler, pp 207-217. Reports of Investigations 145, Prewitt and Associates, Austin and Archeology Studies Program Report, No. 87, Environmental Affairs Division, Texas Department of Transportation, Austin.

Gilbow, D.

1972 Preliminary Identification of Faunal Remains from the Holdsworth Site (41ZV14). Bulletin of the Texas Archeological Society 43:73-75.

Gile, L.H., J.W. Hawley, and R.B. Grossman

1981 Soils and Geomorphology in the Basin and Range area of Southern New Mexico-Guidebook to the Desert Project. Memoir 39, New Mexico Bureau of Mines \& Mineral Resources. New Mexico Institute of Mining \& Technology, Socorro, New Mexico. 
Goode, G.T.

2002 The Anthon Site: A Prehistoric Encampment in Southern Uvalde County, Texas. Archeological Studies Program, Report No. 38, Environmental Affairs Division, Texas Department of Transportation, Austin.

Graham, M., C. Raish, and L. Sebastian

1982 Site Structure and Nunamiut Ethnoarchaeology. Haliksa'i 1:110-119

Greaves, R.D.

2002 An Assessment of Selected Archeological Sites along FM 481, Zavala County, Texas. Unpublished document on file. Center for Archaeological Research, University of Texas at San Antonio.

2003 Archeological Test Excavations at 41ZV202, Zavala County, Texas, Interim Report. Unpublished document on file. Center for Archaeological Research, The University of Texas at San Antonio.

Greer, J.W.

1968 The Cammack Site: A Neo-American Pit-Oven Ring Midden Site in Val Verde County, Texas. Unpublished Master's thesis, Department of Anthropology, The University of Texas at Austin

1976 Notes on Bison in Val Verde County, Texas: Additions to Dillehay. Plains Anthropologist Part 1:21-73.

Greer, J.W. and T.R. Hester

1973 The Finnis Frost Site: A Toyah Phase Occupation in San Saba County, Texas. Bulletin of the Texas Archeological Society 44:69-88.

Griffiths, H.

1992 Carbon Isotope Discrimination and the Integration of Carbon Assimilation Pathways in Terrestrial CAM Plants. Plant Cell Environment 15:1051-1062.

Haberman, S.J.

1973 The Analysis of Residuals in Cross-classified Tables. Biometrics 29:205-220.

Hall, G.D.

1985 Comparative Ecologies: The Texas Chaparral versus the Australian Outback. La Tierra 12(3):6-19.

1998 Prehistoric Human Food Resources Patches on the Texas Coastal Plain. Bulletin of Texas Archeological Society 69:110.

Hall, G.D., S.L. Black, and C. Graves

1982 Archaeological Investigations at Choke Canyon Reservoir, South Texas: The Phase I Findings. Choke Canyon Series, No. 5. Center for Archaeological Research, The University of Texas at San Antonio.

Hall, G.D., T.R. Hester, and S.L. Black

1986 The Prehistoric Sites at Choke Canyon Reservoir, Southern Texas: Results of the Phase II Archaeological Investigations. Choke Canyon Series, No. 10. Center for Archaeological Research, The University of Texas at San Antonio.

Hames, R.

1992 Time Allocation. In Evolutionary Ecology and Human Behavior, edited by E.A. Smith and B. Winterhalder, pp 203235. Aldine De Gruyter, New York. 
Hammond, G.P. and A. Rey

1940 Narratives of the Coronado Expedition 1540-1542. University of New Mexico Press, Albuquerque.

Hanley. T.A.

1982 The nutritional basis of food selection by ungulates. Journal of Range Management 35:146-151.

Hart, R.H., O.M. Abdalla, D.H. Clark, M.B. Marshall, M.H. Hamid, J.A. Hagar, and J.W. Waggoner, Jr. 1983 Quality of Forage and Cattle Diets on the Wyoming High Plains, Journal of Range Management 36:46-51.

Hartle, D.D., and R.L. Stephenson

1951 Archaeological Excavations at the Falcon Reservoir, Starr County, Texas. In River Basin Surveys, prepared for the Smithsonian Institution, Washington D.C.

Henderson, J.

2001 Excavations at the Rainey Site (41BN33), A Late Prehistoric Sinkhole Site in Bandera County, Texas. Archeological Studies Program, Report 5. Environmental Affairs Department, Texas Department of Transportation, Austin.

Hester, T.R

1975 Late Prehistoric Cultural Patterns Along the Lower Rio Grande of Texas. Bulletin of the Texas Archeological Society 46:107-125

1978 Background to the Archaeology of Chaparrosa Ranch, Southern Texas. Volume 1: Studies in the Archaeology of Chaparrosa Ranch. Special Report, No. 6. Center for Archaeological Research, The University of Texas at San Antonio.

1980 Digging into South Texas Prehistory. Corona Publishing, San Antonio, Texas.

1995 The Prehistory of South Texas. Bulletin of the Texas Archeological Society 66:427-459.

2004 The Prehistory of South Texas. In The Prehistory of Texas, edited by T.K. Perttula, pp. 127-151. Texas A\&M University Press, College Station.

Hester, T.R., and T.C. Hill, Jr.

1972 Prehistoric Occupation at the Holdsworth and Stewart Sites on the Rio Grande Plain of Texas. Bulletin of the Texas Archeological Society 43:33-76.

Hester, T.R. and R.C. Parker

1970 The Berclair Site: A Late Prehistoric Component in Goliad County, Southern Texas. Bulletin of the Texas Archeological Society 41:1-24.

Hester, T.R., D. Gilbow, and A.D. Albee

1973 A Functional Analysis of "Clear Fork" Artifacts from the Rio Grande Plain of Texas. American Antiquity 38(1):90-96.

Hester, T.R., S.L. Black, D.G. Steele, B.W. Olive, A.A. Fox, K.J. Reinhard and L.C. Bement

1989 From the Gulf to the Rio Grande: Human Adaptation in Central, South, and Lower Pecos Texas. Study Unit 3 of the Southwestern Division Archeological Overview. Center for Archaeological Research, The University of Texas at San Antonio.

Highley, C.L.

1986 Archaeological Investigations at 41LK201, Choke Canyon Reservoir, Southern Texas. Choke Canyon Series, No. 11. Center for Archaeological Research, The University of Texas at San Antonio. 
Hill, K.

1988 Macronutrient Modifications of Optimal Foraging Theory: An Approach Using Indifference Curves Applied to Some Modern Foragers. Human Ecology 16:157-197.

Hill, K. and K. Hawkes

1983 Neotropical Hunting among the Ache of Eastern Paraguay. In Adaptive Responses of Native Amazonians, edited by R.B. Hames and W.T. Vickers, pp. 139-188. Academic Press, New York.

Houk, B.A., K. Lawrence, and K. Miller

2003 An Archeological Survey and Geoarcheological Evaluation of Portions of FM 481 in Zavala County, Texas. SWCA Environmental Consultants, Archeological Survey Report, Eight Properties, Unpublished document on file, Environmental Affairs Division, Texas Department of Transportation, Austin.

Howells, R.G. J. Neel-Hartman, and S.A. Wagner

2003 Appendix G: Freshwater Mussel Shell from 41MM340. In Data Recovery Excavations at 41MM340, A Late Archaic Site along Little River in Milam County, Texas. By R.B. Mahoney, S.A. Tomka, R.P. Mauldin, H.J. Shafer, L.C. Nordt, R.D. Greaves, and R.R. Galdeano, pp 245-260. Archaeological Survey Report, No. 340, Center for Archaeological Research, The University of Texas at San Antonio. Archeological Studies Program, Report No. 54, Environmental Affairs Division, Texas Department of Transportation, Austin.

Huebner, J.A.

1987 Archaeological Test Excavations at the Burris Site (41VT66) Victoria County, Texas: A Preliminary Summary. Friends of Archaeology Newsletter 4:13-16.

1991 Late Prehistoric Bison Populations in Central and Southern Texas. Plains Anthropologist 36(137):343-358.

Inman, B., T.R. Hester, and T.C. Hill, Jr.

1998 Archeological Investigations at the Tortuga Flat Site (41ZV155), Zavala County, Southern Texas. Bulletin of the Texas Archeological Society 69:11-33.

Jelks, E.B.

1962 The Kyle Site: A Stratified Central Texas Aspect Site in Hill County, Texas. Anthropology Series, No. 5. Department of Anthropology, The University of Texas at Austin.

Jochim, M.

1975 Hunter-gatherer Subsistence and Settlement: A predictive model. Academic Press, New York.

Johnson, A.L. and R.J. Hard

2008 Exploring Texas Archaeology with a Model of Intensification. Plains Anthropologist 53(205):137-153.

Johnson, J.K.

1979 Archaic Biface Manufacture: Production Failures, a Chronicle of the Misbegotten. Lithic Technology 8(2):25-35.

1981 Further Additional Biface Production Failures. Lithic Technology 10(20):26-28.

Johnson, L., Jr.,

1994 The Life and Times of Toyah-Culture Folk as Seen from the Buckhollow Encampment, Site 41KM16, of Kimble County, Texas. Office of the State Archeologist Report 38. Texas Department of Transportation and Texas Historical Commission, Austin. 
1995 Past Cultures and Climates at Jonas Terrace 41 ME29 Medina County, Texas. Office of the State Archeologist, Report 40. Texas Department of Transportation and Texas Historical Commission, Austin.

Johnson, L. Jr., and G. Goode

1994 A New Try at Dating and Characterizing Holocene Climates, as well as Archaeological Periods, on the Eastern Edwards Plateau. Bulletin of the Texas Archaeological Society 65:1-15.

Johnson, L., Jr., D.A. Suhm, and C.D. Tunnell

1962 Salvage Archaeology of Canyon Reservoir: The Wunderlich, Footbridge, and Oblate Sites. Bulletin No. 5. Texas Memorial Museum, The University of Texas at Austin.

Jones, K.T., and D.B. Madsen

1989 Calculating the Cost of Resource Transportation: A Great Basin Example. Current Anthropology 30:529-534.

Kaplan, H. and K. Hill

1985 Hunting Ability and Reproductive Success among Male Ache Foragers: Preliminary Results. Current Anthropology 26:223-246.

1992 The Evolutionary Ecology of Food Acquisition. In Evolutionary Ecology and Human Behavior, edited by E.A. Smith and B. Winterhalder, pp 167-201. Aldine De Gruyter, New York.

Karbula, J.W.

2003 The Toyah Bluff Site (41TV441) _ Changing Notions of Late Prehistoric Subsistence in the Blackland Prairie Along the Eastern Edge of the Edwards Plateau, Travis County, Texas. Bulletin of the Texas Archeological Society 74:55-81.

Karbula, J.W., R. Feit, and T. Griffith

2001 Changing Perspectives on the Toyah: Data Recovery Investigations of 41TV441, the Toyah Bluff Site, Travis County, Texas. Hicks \& Company, Austin.

Karl, T.R.

1986 The Sensitivity of the Palmer Drought Severity Index and Palmer's Z-Index to their Calibration Coefficients Including Potential Evapotranspiration. Journal of Climate and Applied Meteorology 25:77-86.

Kelly, R.L.

1995 The Foraging Spectrum. Smithsonian Institution Press, Washington, D.C.

Kemp, L.

2008 Buffaloed by Bison. Unpublished MA thesis, Department of Anthropology, The University of Texas at San Antonio.

Kent, S.

1990 Domestic Architecture and the Use of Space. Cambridge University Press, Cambridge.

Kintigh, K.W.

1989 Sample Size, Significance, and Measures of Diversity. In Quantifying Diversity in Archaeology, edited by R.D. Leonard and G.T. Jones, pp. 25-36. Cambridge University Press, New York. 
Kirch, P.

1982 The Archaeological Study of Adaptation: Theoretical and Methodological Issues. In Advances in Archaeological Method and Theory: Selections from Students from Volumes 1 through 4, edited by M.B. Schiffer. pp. 101-156. Academic Press, New York.

Knapp, A.K., J.M. Briggs and J.K. Koelliker

2001 Frequency and Extent of Water Limitation to Primary Production in a Mesic Temperate Grassland. Ecosystems 4:1928

Knapp, A.K., J.M. Blair, J.M. Briggs, S.L. Collins, D.C. Hartnett, L.C. Johnson, and E.G. Towne 1999 The Keystone Role of Bison in North American Tallgrass Prairie. Bioscience 49:39-50.

Kuehn, D.D.

2002 Appendix A: Report on Geoarcheological Investigations. In Untitled archaeological survey report: of FM 481 in Zavala County. Prepared for TxDOT by SWCA Environmental Consultants. Unpublished document on file, Environmental Affairs Division, Texas Department of Transportation, Austin.

Larson, M.L., and M. Kornfeld

1997 Chipped Stone Nodules:Theory, Method, and Examples. Lithic Technology 22(1):4-18.

Lewis, P.J., E. Johnson, B. Buchanan, and S.E. Churchill

2007 The Evolution of Bison bison: A View from the Southern Plains. Bulletin of the Texas Archeology Society 78:197-204.

Lillios, K.T.

1992 Phosphate Fractionation of Soils at Agroal, Portugal. American Antiquity 57(3):495-506.

Lintz, C., A.C. Treece, F.M. Oglesby, K. Kibler, P.L. O’Neill, W.N. Trierweiler, C. Frederick, J.M. Quigg, and A.J. Taylor 1993 Cultural Resource Investigations in the O. H. Ivie Reservoir, Concho, Coleman, and Runnels Counties, Texas. Volume II and IIb Test Excavations at Prehistoric Sites and Assessment of Rock Cairn Features, Technical Report 346-II. Mariah Associates, Inc., Austin.

Long, S.P.

1999 Environmental Responses. In $C_{4}$ Plant Biology, edited by R.F. Sage and R.K. Monson, pp 215-249. Academic Press, New York.

Lord, K.H.

1977 Appendix V Faunal Analysis of the Cedar Bridge Sites (41FY74). In, Archeological Investigations at the Fayette Power Project, Fayette County, Texas, by D. Skelton, pp. 237-242. Research Report No. 60. Texas Archeological Survey, The University of Texas at Austin.

Loy, T.

1994 Residue Analysis of Artifacts and Burned Rock from the Mustang Branch and Barton Sites (41HY209 and 41HY202). In Archaic and Late Prehistoric Human Ecology in the Middle Onion Creek Valley, Hays County, Texas, Vol. 2: Topical Studies, by R.A. Ricklis and M.B. Collins, pp. 607-627. Studies in Archeology 19, Texas Archeological Research Laboratory, University of Texas, Austin.

Lukowski, P.D.

1987 Archaeological Investigations along the Leona River Watershed, Uvalde County, Texas. Archaeological Survey Report, No. 132. Center for Archaeological Research, The University of Texas at San Antonio. 
Lyman, R.L.

1984 Bone Density and Differential Survivorship of Fossil Classes. Journal of Anthropological Archaeology 3:259-299.

1994 Vertebrate Taphonomy. Cambridge University Press, Cambridge.

Lynott, M.J.

1978 An Archaeological Assessment of the Bear Creek Shelter, Lake Whitney, Texas. Research Report 115, Archaeology Research Program. Department of Anthropology, Southern Methodist University, Dallas.

1979 Prehistoric Bison Populations of North Central Texas. Bulletin of the Texas Archeological Society 50:89-101.

MacArthur, R.H., and E.R. Pianka

1966 On Optimal Use of a Patchy Environment. American Naturalist 100:603-609.

Mahoney, R.B., R.P., Mauldin, and S.A. Tomka

2002 Archeological Data Recovery Excavations Along Becerra Creek (41WB556), Webb County, Texas. Archaeological Survey Report, No. 321, Center for Archaeological Research, The University of Texas at San Antonio. Archeological Studies Program, Report No. 44, Environmental Affairs Division, Texas Department of Transportation, Austin.

Mahoney, R.B., S.A. Tomka, R.P. Mauldin, H.J. Shafer, L.C. Nordt, R.D. Greaves, and R.R. Galdeano

2003 Data Recovery Excavations at 41MM340, A Late Archaic Site along Little River in Milam County, Texas. Archaeological Survey Report, No. 340, Center for Archaeological Research, The University of Texas at San Antonio. Archeological Studies Program, Report No. 54, Environmental Affairs Division, Texas Department of Transportation, Austin.

Malainey, M.E.

2000 Appendix K Analysis of Fatty Acid Compositions of Burned Rock Residues from Site 41ZP364, Zapata County, Texas. In Data Recovery at 41ZP364: An Upland Campsite at Falcon Reservoir, Zapata County, Texas, by J.M. Quigg and C. Cordova, pp. 331-345. Technical Report, No. 22317. TRC Mariah Associates, Austin

Marchbanks, M.L.

1989 Lipid Analysis in Archaeology: An Initial Study of Ceramics and Subsistence at the George C. Davis Site. Unpublished Master's thesis, The University of Texas at Austin.

Marks, S.A.

1976 Large Mammals and a Brave People, Subsistence Hunters in Zambia. University of Washington Press, Seattle.

Mauldin, R P.

2003 Exploring Drought in the San Antonio Area between 1700 and 1979. Special Report No. 29, The Center for Archaeological Research, The University of Texas at San Antonio.

Mauldin, R.P. and A. Figueroa

2006 Data Recovery Excavations at 41PR44, Fort Wolters, Parker County, Texas. Archaeological Report No. 369. Center for Archaeological Research, The University of Texas at San Antonio.

Mauldin, R.P., T. Graves and M. Bentley

1998 Small Sites in the Central Hueco Bolson: A Final Report on Project 90-11. Wendy Lopez and Associates, Dallas.

Mauldin, R.P., C. Munoz, and J. Thompson

2008 Assessing Hearth Reuse Frequency through Patterning in Burned Rock Size. Paper presented at the $79^{\text {th }}$ Annual Meeting of the Texas Archaeological Society, Lubbock. 
Mauldin, R.P., D.L. Nickels, and C.J. Broehm

2003 Archaeological Testing to Determine the National Register Eligibility Status of 18 Prehistoric Sites on Camp Bowie, Brown County, Texas. Archaeological Survey Report, No. 334. Center for Archaeological Research, University of Texas at San Antonio.

Mauldin, R.P., J. Thompson, C.M. Munoz, and L. Kemp

2009 Hunter-Gatherer Research Intensification and Changing Patterns of Fire-Cracked Rock Features in Central and South Texas. Poster Presented at 2009 Meetings of the Society of American Archaeologists, Atlanta Georgia.

Mauldin, R.P., B.K. Moses, R.D. Greaves, S.A. Tomka, J.P. Dering, and J.D. Weston

2004 Archeological Survey and Testing of Selected Prehistoric Sites along FM 481, Zavala County, Texas. Archaeological Survey Report, No. 352, Center for Archaeological Research, The University of Texas at San Antonio. Archeological Studies Program, Report No. 67, Environmental Affairs Division, Texas Department of Transportation, Austin.

McClean, R.G., and W.F. Kean

1993 Contributions of Wood Ash Magnetism to Archeomagnetic Properties of Fire Pits and Hearths. Earth and Planetary Science Letters 119:387-394.

McDonald, J.N.

1981 North American Bison, Their Classification and Evolution. University of California Press, Berkeley.

McGraw, A.J.

1985 Soil Chemestry In The Panther Springs Creek Site: Cultural Change and Continuity in the Upper Salado Creek Drainage, South-Central Texas, by S.L Black and A.J. McGraw, pp. 223-234. Archaeological Survey Report, No. 100. Center for Archaeological Research, The University of Texas at San Antonio.

McGraw, A.J., and K. Hindes

1987 Chipped Stone and Adobe: A Cultural Resources Assessment of the Proposed Applewhite Reservoir, Bexar County, Texas. Archaeological Survey Report, No. 163. Center for Archaeological Research, The University of Texas at San Antonio.

McGraw, A.J., and D.A. Knepper

1983 The East Chacon Project: 11,000 Years of Prehistory along the Upper Nueces River, Southern Texas. Archaeological Survey Report No. 125 (1983). Unpublished document on file, Center for Archaeological Research, The University of Texas at San Antonio.

Meissner, B.

2008 Data Files for Task 3, Supplemental Work Authorization No. 5 to WA57518SA005. On File at the Center for Archaeological Research, The University of Texas at San Antonio.

Meissner, B. and R. Mahoney

2003 Appendix B: Vertebrate Remains. In Data Recovery Excavations at 41MM340, A Late Archaic Site along Little River in Milam County, Texas, by R.B. Mahoney, S.A. Tomka, R.P. Mauldin, H.J. Shafer, L.C. Nordt, R.D. Greaves, and R.R. Galdeano, pp 198-206. Archaeological Survey Report, No. 340, Center for Archaeological Research, The University of Texas at San Antonio. Archeological Studies Program, Report No. 54, Environmental Affairs Division, Texas Department of Transportation, Austin.

Metcalfe, D., and K.R. Barlow

1992 A Model for Exploring the Optimal Tradeoff between Field Processing and Transport. American Anthropologist 94:340-356. 
Middleton, W.D. and T.D. Price

1996 Identification of Activity Areas by Multi-element Characterization of Sediments from Modern and Archaeological House Floors using Inductively Coupled Plasma-Atomic Emission Spectroscopy. Journal of Archaeological Science 23(5):673-687.

Miller, K.A., O.S. Carpenter, L.C. Nordt, and C.W. Ringstaff

2000 Archaeological Investigations along the Camino Colombia Toll Road, Webb County, Texas. Cultural Resource Report, No. 97-120. SWCA, Inc., Austin.

Miller, K.A., A. O’Farrell, and D.D. Kuehn 2002 Archeological Survey Report: Enhancement of FM 481, Zavala County. SWCA, Inc. Austin.

Montgomery, J.L.

1978 The Mariposa Site: A Late Prehistoric Site on the Rio Grande Plain of Texas. Special Report, 6(2). Center for Archaeological Research, The University of Texas at San Antonio.

Moses, B.K., R.D. Greaves, R.P. Maulind, and J.D. Weston

2004 Archeological Methods and Site Descriptions. In Archeological Survey and Testing of Selected Prehistoric Sites along FM481, Zavala County, Texas, by R.P. Mauldin, B.K. Moses, R.G. Greaves, S.A. Tomka, J.P. Dering and J.D. Weston, pp. 23-64. Environmental Affairs Division, Texas Department of Transportation, Archeological Studies Program, Report No. 67, Austin. Archaeological Survey Report No. 352, Center for Archaeological Research, the University of Texas at San Antonio.

Muto, G.R.

1971 A Technological Analysis of the Early Stages in the Manufacture of Lithic Artifacts. Unpublished Master's thesis. Idaho State University, Pocatello.

National Climate Data Center (NCDC)

2004 Online Climate Data for Uvalde, Texas. Available at <http://lwf.ncdc.noaa.gov/ oa/climate/climatedata.html $>$. Accessed January 2004.

Netting, R.McC.

1986 Cultural Ecology. Waveland Press, Prospect Heights, Illinois

Newcomb, W.W.Jr.

1961 The Indians of Texas from Prehistoric to Modern Times. University of Texas Press, Austin.

Nickels, D.L.

2000 The Biesenbach Site (41WN88), Wilson County, Texas: A Study of Toyah Diet-breadth. Unpublished Master's thesis, Department of Anthropology, The University of Texas at San Antonio.

Nickels, D.L., and R.P. Mauldin

2001 Chapter 3 The Project Environment. In An Archaeological Survey of Twin Buttes Reservoir, Tom Green County, Texas, Volume 1, by R.P. Mauldin and D.L. Nickels, pp. 25-38. Archaeological Survey Report, No. 300. Center for Archaeological Research, The University of Texas at San Antonio.

Nordt, L.C.

1992 Archaeological Geology of the Fort Hood Military Reservation, Fort Hood, Texas. Research Report Number 25, United States Army Fort Hood, Archaeological Resource Management Series. 
1998 Chapter 7:Geoarchaeology of the Rio Grande and Elm Creek in the Vicinity of Site 41MV120. In 41MV120: A Stratified Late Archaic Site in Maverick County, Texas, by B.J. Vierra, pp. 43-77. Archaeological Survey Report, No. 251. Center for Archaeological Research, The University of Texas at San Antonio. Archeology Studies Program Report No. 7, Environmental Affairs Division, Texas Department of Transportation, Austin.

Nordt, L.C., T.W. Boutton, J.S. Jacob, and R. Mandel

$2002 \mathrm{C}_{4}$ Plant Productivity and Climate- $\mathrm{CO}_{2}$ Variations in South-Central Texas during the Late Quaternary. Quaternary Research 58(2):182-188

1994 Late Quaternary Climates of Central Texas Based on the Stable Isotopic Composition of Organic Carbon. Program and Abstracts, 52nd Plains Conference, 65th Annual Meeting of the Texas Archeological Society, Lubbock.

Nunley, J.P., L.F. Duffield, and E.B. Jelks

1965 Excavations at Amistad Reservoir, 1962 Season. Miscellaneous Papers, No. 3. Texas Archeological Salvage Project, The University of Texas, Austin.

O'Connell, J.

1987 Alyawara Site Structure and Its Archaeological Implications. American Antiquity 52:74-108.

O’Connell, J.F. and K. Hawkes

1981 Alyawara Plant Use and Optimal Foraging Theory. In Hunter-Gatherer Foraging Strategies: Ethnographic and Archaeological Analyses, edited by B. Winterhalder and E.A. Smith, pp. 13-35. The University of Chicago Press, Chicago.

O'Farrell, A., and K. Miller

2002 Archaeological Survey and Testing of Seven Archaeological Sites and the West Side of Turkey Creek. Enhancement of FM 481 from Uvalde Co. Line to Maverick Co. Line. SWCA. Unpublished document on file Center for Archaeological Research, University of Texas at San Antonio.

O'Leary, M.H.

1988 Carbon Isotopes in Photosynthesis. Bioscience 38:328-336.

Oswald, D.

1984 The Use of Site Structure to Infer Social and Technological Organization from the Archaeological Record. In Frontiers: Southern African Archaeology Today, edited by M. Hall, G. Avery, D.M. Avery, M.L. Wilson, and A.J. B. Humphreys, pp. 297-309. Cambridge Monographs in African Archaeology No. 10. BAR International Series No. 207.

Oswalt, W.H.

1973 Habitat and Technology. Holt, Rinehart and Winston, Inc. New York.

1976 An Anthropological Analysis of Food-Getting Technology. Wiley and Sons, New York.

Outram, A. K.

2001 A new approach to identifying bone marrow and grease exploitation: why the "indeterminate" fragments should not be ignored. Journal of Archaeological Science 28:401-410.

Palmer, W.C.

1965 Meteorological Drought. US Weather Bureau, Research Paper No. 45. Washington, D.C. 
Parkman, F.

1883 La Salle and the Discovery of the West. Little, Brown, and Company. Twelfth Edition. The Parkman Anthology, Vol. 3. Digital Antiqueria, Morristown.

Parsons, M.L.

19651963 Test Excavations at Fate Bell Shelter, Amistad Reservoir, Val Verde County, Texas. Miscellaneous Papers 4. Texas Archeological Salvage Project, The University of Texas at Austin.

Paruelo, J.M. and W.K. Lauenroth

1996 Relative Abundance of Plant Functional Types in Grasslands and Shrublands of North America. Ecological Applications 6(4):1212-1224.

Patterson, P.E. and M.M. Ford

1974 Oso Creek Flood Control Project Area, Nueces County, Texas: A Report on the Archeological and Historical Resources. Texas Archeological Survey, Research Report 35. The University of Texas at Austin.

Peden, D.G.

1976 Botanical Composition of Bison Diets on Shortgrass Plains. American Midland Naturalist 96(1):225-229.

Peden, D.G., G.M. Van Dyne, R.W. Rice, and R.M. Hansen

1974 The Trophic Ecology of Bison bison L. on Shortgrass Plains. The Journal of Applied Ecology 11(2):489-497.

Peter, D.E., Prikryl, O.F. McCormick, and M. Demuynck

1982 Site Excavation Reports: Primary Contract. In Archaeological Investigations at the San Gabriel Site Reservoir Districts, Central Texas, Vol. 1, pp. 8-1-297. Institute of Applied Sciences, University of North Texas, Denton.

Prewitt, E.R.

1974 Archeological Investigations at the Loeve-Fox Site, Williams County, Texas. Research Report 49. Texas Archeological Survey, The University of Texas at Austin.

1982 The 1982 TAS Field School Rowe Valley, Texas. Texas Archeology 26(3):2-5.

Quigg, J.M.

1997 Bison Processing at the Rush Site, 41TG346, and Evidence for Pemmican Production in the Southern Plains. In Southern Plains Bison Procurement and Utilization from Paleoindian to Historic, edited by L.C. Bement and K.J. Buehler, pp. 145-161. Plains Anthropologist 42(159), Memoir 29.

2000 Appendix M: Stable Carbon and Nitrogen Isotope Data on Modern Plant and Animal Resources from South Texas. In Data Recovery at 41ZP364: An Upland Campsite at Falcon Reservoir, Zapata County, Texas, by J.M. Quigg and C. Cordova, pp. 353-364. Technical Report No. 22317. TRC Mariah Associates Inc., Austin.

Quigg, J.M., and C. Cordova

2000 Data Recovery at 41ZP364: An Upland Campsite at Falcon Reservoir, Zapata County, Texas. Technical Report No. 22317. TRC Mariah Associates Inc., Austin.

Quigg, J.M., and J. Peck

1995 The Rush Site (41TG346): A Stratified Late Prehistoric Locale in Tom Green County, Texas. Technical Report, No. 816C. TRC Mariah Associates, Inc., Austin. 
Quigg, J.M., M.S. Pritchard, and G. Smith

2002 The Boiler Site (41WB557): Utilization of an Upland Setting Over the Last 4200 Years, Webb County, Texas. Technical Report No. 27277, TRC Mariah Associates, Inc. Archeological Studies Program, Report No. 45, Environmental Affairs Division, Texas Department of Transportation, Austin.

Quigg, J.M., C. Lintz, G. Smith, and S. Wilcox

2000 The Lino Site: A Stratified Late Archaic Campsite in a Terrace of San Idelfonzo Creek, Webb County, Southern Texas. Technical Report No. 23756, TRC Mariah Associates, Inc.; Archeological Studies Program, Report No. 20, Environmental Affairs Division, Texas Department of Transportation, Austin.

Ramsey, C.B.

2003 Oxcal Program Version 3.0. Radiocarbon Accelerator Unit, University of Oxford, Oxford, U.K.

Ranson, S.L. and M. Thomas

1960 Crassulacean Acid Metabolism. Annual Review of Plant Physiology 11:81-110.

Rauzi, F., and A.K. Dobrenz

1970 Seasonal Variation of Chlorophyll in Western Wheatgrass and Blue Grama, Journal of Range Management 23:372373.

Reynolds, R.L., and J.W. King

1995 Magnetic Records of Climate Change. U.S. National Report to I.U.G.G., 1991-1994. American Geophysical Union. $<$ http://www.agu.ong/revgeophys/reyno100/reyno100 .html> Accessed April 2001.

Ricklis, R.A.

1987 Archeological Investigations at the McKinzie Site (41NU221), Nueces County, Texas: Descriptions and Contextual Interpretations. Bulletin of the Texas Archeological Society 58:1-76.

1990 A Historical Cultural Ecology of the Karankawan Indians of the Central Texas Coast: A Case Study in the Roots of Adaptive Chance. Ph.D. Dissertation, Department of Geography, The University of Texas at Austin.

1996 The Karankawa Indians of Texas. University of Texas Press, Austin.

Ricklis, R.A., and M.B. Collins

1994 Archaic and Late Prehistoric Human Ecology in the Middle Onion Creek Valley, Hays County, Texas, Volume 1. Studies in Archeology 19, Texas Archeological Research Laboratory, The University of Texas at Austin.

Robbins, E.A.

1998 The First Routes into Texas: A Review of Early Diaries. In A Texas Legacy: The Old San Antonio Road and the Caminos Reales, A Tricentennial History 1691-1991, edited by A.J. McGraw, J.W. Clark, and E.A. Robbins, pp. 61-113. Second printing. Environmental Affairs Davison, Texas Department of Transportation, Austin.

Robinson, R.L.

1979 Biosilica and Climatic Change at 41GD21 and 41GD21A. In Archaeological Investigations of Two Prehistoric Sites on the Colette Creek Drainage, Goliad County, Texas, edited by D.E. Fox, pp. 102-113. Archaeological Survey Report, No. 69. Center for Archaeological Research, The University of Texas at San Antonio.

1982 Biosilica Analysis of Three Prehistoric Archaeological Sites in the Choke Canyon Reservoir, Live Oak County, Texas: Preliminary Summary of Climatic Implications. In Archaeological Investigations at Choke Canyon Reservoir, South Texas: The Phase I Findings, edited by G.D. Hall, S.L. Black, and C. Graves, pp. 597-610. Choke Canyon Series, No. 5. Center for Archaeological Research, The University of Texas at San Antonio. 
Ross, R.E.

1965 The Archeology of Eagle Cave. Papers of the Texas Archeological Salvage Project 7. The University of Texas at Austin.

Sala, O.E. and W.K. Lauenroth

1982 Small Rainfall Events: an Ecological Role in Semiarid Regions. Oecologia 53:301-314.

Schiffer, M.B.

1987 Formation Processes of the Archaeological Record. University of New Mexico Press, Albuquerque.

Scott, R.F., and D.E. Fox

1982 Excavations at Sites 41LK31/32 and 41LK202 in the Choke Canyon Reservoir, South Texas. Choke Canyon Series, No.

8. Center for Archaeological Research, The University of Texas at San Antonio.

Senft, R.L., M.B. Coughenour, D.W. Bailey, L.R. Rittenhouse, O.E. Sala, and D.M. Swift

1987 Large herbivore foraging and ecological hierarchies. BioScience 37:789-799.

Shackley, M.L.

1975 Archaeological Sediments: a Survey of Analytical Methods. Wiley, New York.

Shafer, H.J.

1969 Archeological Investigations in Robert Lee Reservoir Basin, West Central Texas. Survey Reports No. 17. Papers of the Texas Archeological Salvage Project, The University of Texas at Austin.

1971 Investigations into South Plains Prehistory, West Central Texas. Survey Reports No. 20. Papers of the Texas Archeological Salvage Project, The University of Texas at Austin.

Shafer, H.J., and T.R. Hester

1971 A Study of the Function and Technology of Certain Bifacial Tools from Southern Texas. Texas Historical Survey Committee, Archeological Report No. 20, Austin.

Shaffer, B.S.

2006 Appendix E: Analysis of Vertebrate Remains from 41MM341. In Data Recovery Excavations at the J.B. White Site (41MM341), Milam County, Texas, by E. Gadus F., R.C. Fields, and K.W. Kibler, pp 237-260. Reports of Investigations 145, Prewitt and Associates, Austin and Archeology Studies Program Report, No. 87, Environmental Affairs Division, Texas Department of Transportation, Austin.

Sharp, Z.

2007 Principles of Stable Isotope Geochemistry. Pearson Prentice Hall, Upper Saddle River, New Jersey.

Shoocongdej, R.

2000 Forager Mobility Organization in Seasonal Tropical Environments of Western Thailand. World Archaeology 32(1):1440.

Sih, A. and K. Milton

1985 Optimal Diet Theory: Should the !Kung Eat Mongongos? American Anthropologist 87:395-401.

Simms, S.R.

1987 Behavioral Ecology and Hunter-Gatherer Foraging: An Example from the Great Basin. British Archaeological Reports, International Series 381. Oxford. 
Sims, P.L., J.S. Singh and W.K. Lauenroth

1978 The Structure and Function of Ten Western North American Grasslands I. Abiotic and Vegetational Characteristics. Journal of Ecology 66:251-285.

Sjoberg, A.

1976 Phosphate Analysis of Anthropic Soils. Journal of Field Archaeology 3:447-454.

Skibo, J.M.

1992 Pottery Function: A Use-Alteration Perspective. Plenum Press, New York.

Smith, E.A.

1991 Inujjuamiut Foraging Strategies. Aldine De Gruyter, New York.

Sorrow, W.M., H.J. Shafer, and R.E. Ross

1967 Excavations at Stillhouse Hollow Reservoir. Papers of the Texas Archeological Salvage Project, No. 11. The University of Texas at Austin.

Southern Regional Climate Center (SRCC)

2003a Normal Daily Minimum Temperature <http://www.srcc.lsu.edu/7100/tmin/USMap.html $>$ Accessed December 2003.

2003b Normal Daily Maximum Temperature.<http://www.srcc.lsu.edu/7100/tmax/TX.html> Accessed December 2003

2003c Normal Monthly Precipitation.<http://www.srcc.lsu.edu/7100/prcp/TX.html> Accessed December 2003.

Speth, J.D.

1983 Bison Kills and Bone Counts Decision Making by Ancient Hunters. Prehistoric Archeology and Ecology Series. University of Chicago Press, Chicago.

Speth, J.D. and A. Rautman

2003 Bison Hunting at the Henderson Site. In Life on the Periphery: Change in Late Prehistoric Southeastern New Mexico, edited by J.D. Speth, pp. 98-147. Memoirs of the Museum of Anthropology No. 37, University of Michigan.

Speth, J.D., and K.A. Spielmann

1983 Energy Source, Protein Metabolism and Hunter-Gatherer Subsistence Strategies. Journal of Anthropological Archaeology 2:1-31.

Steele, G.D.

1986 Analysis of Vertibrate Faunal Remains. In The Clemente and Herminia Hinojosa Site, 41JW8: A Toyah Horizon Campsite in Southern Texas, by S.L. Black, pp. 108-136. Report No. 18. Center for Archaeological Research, The University of Texas at San Antonio.

Stephens, D.W., and J.R. Krebs 1986 Foraging Theory. Princeton University Press, Princeton, New Jersey.

Stephenson, R.L.

1970 Archaeological Investigations in the Whitney Reservoir Area, Central Texas. Bulletin of the Texas Archeological Society 40:37-257. 
Stevens, J., and D. Arriaga

1985 Soil Survey of Dimmit and Zavala Counties, Texas. United States Department of Agriculture, Soil Conservation Service, Washington, D.C.

Stevens, J, and D. Richmond

1976 Soil Survey of Uvalde County, Texas. United States Department of Agriculture, Soil Conservation Service, Washington, D.C.

Story, D.A., and H.J. Shafer

19651964 Excavations at Waco Reservoir, McLennan County, Texas: The Baylor and Britton Sites. Miscellaneous Papers No. 6. Texas Archeological Salvage Project, The University of Texas at Austin.

Stowe, L.G. and J.A. Teeri

1978 Geographic Distribution of $\mathrm{C}_{4}$ Species of Dicotyledonae in Relation to Climate. American Naturalist 112(985):609623.

Suhm, D.A.

1957 Excavations at the Smith Rockshelter, Travis County, Texas. The Texas Journal of Science 9(1):26-58.

Suhm, D.A., A.D. Krieger, and E.B. Jelks 1954 An Introductory Handbook of Texas Archeology. Bulletin of the Texas Archeological Society 25.

Sutton, M.Q. and E.N. Anderson

2004 Introduction to Cultural Ecology. AltaMira Press, Walnut Creek, California.

Takac, P.R., and W.A. Gose

1998 Magnetic Susceptibility of Sediments. In Wilson-Leonard. An 11,000-year Archeological Record of Hunter-Gatherers in Central Texas. Volume IV: Archeological Features and Technical Analyses, assembled and edited by M.B. Collins, pp:1329-1341. Studies in Archeology 31. Texas Archeological Research Laboratory, The University of Texas at Austin, and Archeology Studies Program, Report 10, Texas Department of Transportation, Environmental Affairs Division, Austin.

Taylor, A.J., and C.L. Highley

1995 Archeological Investigations at the Loma Sandia Site (41LK28): A Prehistoric Cemetery and Campsite in Live Oak County, Texas. 2 volumes. Studies in Archeology No. 20. Texas Archeological Research Laboratory, The University of Texas at Austin.

Teeri, J.A. and L.G. Stowe

1976 Climatic Patterns and the Distribution of $\mathrm{C}_{4}$ Grasses in North America. Oecologia 23:1-12.

Texas Parks and Wildlife Department (TPWD)

1999 TPWD GIS Data. On file Center for Archaeological Research, The University of Texas at San Antonio.

Thomas, D.H.

1983 The Archaeology of Monitor Valley: 2. Gatecliff Shelter. Anthropological Papers Vol. 59, Pt. 1. American Museum of Natural History, New York.

1989 Diversity in Hunter-Gatherer Cultural Geography. In Quantifying Diversity in Archaeology, edited by R.D. Leonard and G.T. Jones, pp. 85-91. Cambridge University Press, Cambridge. 
Thompson, J. and R.P. Mauldin

2008 Resource Intensification and Changing Patterns of Thermal Feature Use throughout the Late Archaic and Late Prehistoric Periods in Central and South Texas. Paper presented at the $79^{\text {th }}$ Annual Meeting of the Texas Archaeological Society, Lubbock.

Thompson, J., R.P. Mauldin and S.A. Tomka

2007 A Research Design for the Analysis of Data Recovered at 41KM69, Kimble County, Texas. Manuscript on file at the Center for Archaeological Research, University of Texas at San Antonio and Environmental Affairs Division, Texas Department of Transportation, Austin, Texas.

Thoms, A.V.

2008 Ancient Savannah Roots of the Carbohydrate Revolution in South-Central North America. Plains Anthropologist 53(205):121-136.

2009 Rocks of Ages: Propagation of Hot-Rock Cookery in Western North America. Journal of Archaeological Science 36(3):573-591.

Tomka, S.A.

1986 Biface Manufacture Failures. Manuscript on file, Texas Archeological Research Laboratory, The University of Texas at Austin.

2001 The Effect of Processing Requirements on Reduction Strategies and Tool Form: A New Perspective. In Lithic Debitage Context, Form and Meaning, edited by W. Andrefsky, Jr., pp. 207-223. The University of Utah Press, Salt Lake City.

Tomka, S.A., R.P. Mauldin, and R.D. Greaves

2004aResearch Design for Analysis of Testing and Data Recovery Materials from 41ZV202, Zavala County, Texas. Report on file at Center for Archaeological Research, The University of Texas at San Antonio.

2004b Chapter 7 Late Prehistoric and Late Archaic Subsistence Practices A Comparative Analysis. In Millican Bench (41TV163) A Multicomponent Site in Travis County, Texas. Archaeological Survey Report, No. 351, Center for Archaeological Research, The University of Texas at San Antonio. Archeological Studies Program, Report No. 66, Environmental Affairs Division, Texas Department of Transportation, Austin.

Tomka, S.A., H.J. Shafer, and R.P Mauldin

2003 Chapter 12 Lithic Technology at 41MM340. In Data Recovery Excavations at $41 M M 340$ A Late Archaic Site along Little River in Milam County, Texas, by R.B. Mahoney and S.A. Tomka, pp. 133-154. Archaeological Survey Report No. 340. Environmental Affairs Division, Texas Department of Transportation, Austin.

Toomey, R.S.

1993 Late Pleistocene and Holocene Faunal Environmental Changes at Hall's Cave, Kerr County, Texas. Ph.D. Dissertation, The University of Texas at Austin. University Microfilms, Ann Arbor.

Toomey, R.S., M.D. Blum and S. Valastro, Jr.

1993 Late Quaternary Climates and Environments of the Edwards Plateau, Texas. Global and Planetary Change 7:299-320.

Torrence, R.

1983 Time Budgeting and Hunter-Gathering Technology. In Hunter-Gatherer Economy in Prehistory: A European Perspective, edited by G. Bailey, pp 11-22. Cambridge University Press, New York. 
1989 Tools as Optimal Solutions. In Time, Energy, and Stone Tools, edited by R. Torrence, pp. 1-6. Cambridge University Press, New York.

TPWD

2009 Fish Programs. http://www.tpwd.state.tx.us/fishboat/fish/programs/fishrecords/

Treece, A.C., C. Lintz, W.N. Trierweiler, J.M. Quigg, and K.A. Miller

1993 Cultural Resource Investigations in the O. H. Ivie Reservoir, Concho, Coleman, and Runnels Counties, Texas: Volume IV: Data Recovery from Ceramic Sites. Technical Report No. 346-IV, TRC Mariah Associates, Austin.

Tringham, R., G. Cooper, G. Odell, R. Voytek, and A. Whitman

1974 Experimentation in the Formation of Edge Damage: A New Approach to Lithic Analysis. Journal of Field Archaeology 1:171-196.

Tukey, J.W.

1977 Exploratory Data Analysis. Addison-Wesley. Reading.

Turner, E.S., and T.R. Hester

1999 A Field Guide to Stone Artifacts of Texas Indians. 3rd edition. Gulf Publishing, Houston.

Turpin, S.A.

2004 The Lower Pecos River Region of Texas and Northern Mexico. In The Prehistory of Texas, edited by T.K. Perttula, pp 266-295. Texas A\&M University Press, College Station.

Varien, M.D. and S.G. Ortman

2005 Accumulations research in the Southwest United States: middle-range theory for big-picture problems. World Archaeology 31:132-155.

Vierra, B.J.

1998 41MV120: A Stratified Late Archaic Site in Maverick County, Texas. Archaeological Survey Report, No. 251. Center for Archaeological Research, The University of Texas at San Antonio.

Wade, M.F.

1998 The Native Americans of the Texas Edwards Plateau and Related Areas, 1582-1799. Unpublished Ph.D. Dissertation, The University of Texas at Austin.

2003 The Native Americans of the Texas Edwards Plateau, 1582-1799. University of Texas Press, Austin.

Wandsnider, L.

1997 The Roasted and the Boiled: Food Consumption and Heat Treatment with Special Emphasis on Pit-Hearth Cooking. Journal of Anthropological Archaeology 16:1-48.

Watt, F.H.

1965 Notes on the Clark Site, McLennan County, Texas. Bulletin of the Texas Archeological Society 36:99-110.

Weniger, D.

1984 The Explorers' Texas. Eakin Press. Austin. 
Windberg, L.A.

1997 Annual Fruit Production of Pricklypear (Opuntia engelmanni) and Mesquite (Prosopis glandulosa) in Southern Texas. The Texas Journal of Science 49(1):65-72.

Winship, G.P.

1904 The Journey of Coronado, 1540-1542. Fulcrum, Golden, Colorado.

Winterhalder, B.

1981 Optimal Foraging Strategies and Hunter-Gatherer Research in Anthropology: Theory and Models. In Hunter-Gatherer Foraging Strategies: Ethnographic and Archaeological Analyses, edited by B. Winterhalder and E.A. Smith, pp. 13-35. The University of Chicago Press, Chicago.

Woods, W.I.

1977 Quantitative-Analysis of Soil Phosphate. American Antiquity 42:248-252.

Word, J.H., and C.L. Douglas

1970 Excavations at Baker Cave, Val Verde County, Texas. Bulletin of the Texas Memorial Museum 16, Austin.

Yellen, J.

1977 Archaeological Approaches to the Present. Academic Press, New York.

Yost, J. and P. Kelley

1983 Shotguns, blowguns, and spears: an analysis of technological efficiency. In Adaptive Responses of Native Amazonian, edited by R. Hames and W. Vickers, pp 189-224. Academic Press, New York.

Young, G.A. and M. Hoffmann

1999 The Expedition of Hernando de Soto West of the Mississippi, 1541-1543:Proceedings of the de Soto Symposia, 1988 and 1990. University of Arkansas Press. 



\title{
APPENDIX A: \\ Geoarcheological Observations at 41ZV202
}

\author{
C. Britt Bousman \\ Center for Archaeological Studies, \\ Texas State University
}





\section{Introduction}

Geological field investigations were undertaken at 41ZV202 on March 7, 2003. Four profiles were described. Three profiles were on the south side of State Highway 481 immediately west of Muela Creek. A fourth profile was described across the road in a cut cleared by David Kuehn. Two previous investigations by geoarcheologists demonstrated that probable Holocene-aged sediments were preserved at 41ZV202 (Kuehn nd; Abbott nd). Kuehn (nd) described two profiles on both sides of the road and he characterized the site as consisting of an alluvial terrace with a single $260 \mathrm{~cm}$ thick depositional unit with a soil profile consisting of A1-A2-Bk1Bk2-Bk3 horizons. Abbott (nd) described only the upper deposits on the south side of the road, and produced a soil profile consisting of AC-ABw-Bk1-Bk2-Bk3 horizons. However, Abbott's (nd) profiles were only $65 \mathrm{~cm}$ thick. Abbott (nd: 8 ) also makes a strong case that the site is not in an alluvial landform, but it is instead on a truncated margin of an alluvial fan complex that is mapped across Muela Creek. Abbott (nd:9) also argues that this landform is probably Pleistocene in age and if archeological materials are found in place they would be restricted to a thin veneer of aeolian or aeolian/alluvial sediments marked by his A and $\mathrm{Bw}$ horizons.

\section{Setting}

Site 41ZV202 is on an elevated linear ridge on the right (west) bank of Muela Creek. Muela Creek is a small intermittent stream that terminates $\sim 27 \mathrm{~km}$ upstream from the site. The surface geology (Figure A-1) in the Muela and Chaparosa creek floodplains has been mapped as recent Quaternary alluvium (Qal). The sediments on the site are mapped as Quaternary alluvial terrace (Qt), but across Muela Creek is a Quaternary deposit mapped as an alluvial fan (Qf). The Upper Cretaceous Escondido Formation (Kes) is found in a broken linear band a few kilometers to the east and west of the site. This formation consists of shales, siltstones, and sandstones. Up stream from the site and forming the upper reaches and divide of the basin is the Upper Cretaceous Austin Chalk Formation (Kac). Although not within the drainage basin of Muela Creek, Cretaceous igneous rocks (Ki) consisting mostly of basalts are found nearby as sills, laccoliths, dikes, and volcanic necks. Down stream is the Indio Formation (Ei) and it consists of Eocene sandstones, shales, and lignite. Soils mapped at the site (Figure A-2) include Uvalde and Tobosa series. Tobosa soils (TOB) are clayey soils that form on calcareous uplands and ancient terraces, while Uvalde soils (UVB) are clayey soils that form on alluvial terraces and alluvial fans. It is apparent that the Tobosa soils are mapped on higher elevations of the Quaternary terrace and fan deposits (Qt and Qf), while the Uvalde soils occur on lower elevations on deposits mapped as recent Quaternary alluvium, Quaternary terrace and fan deposits (Qal, Qt and Qf).

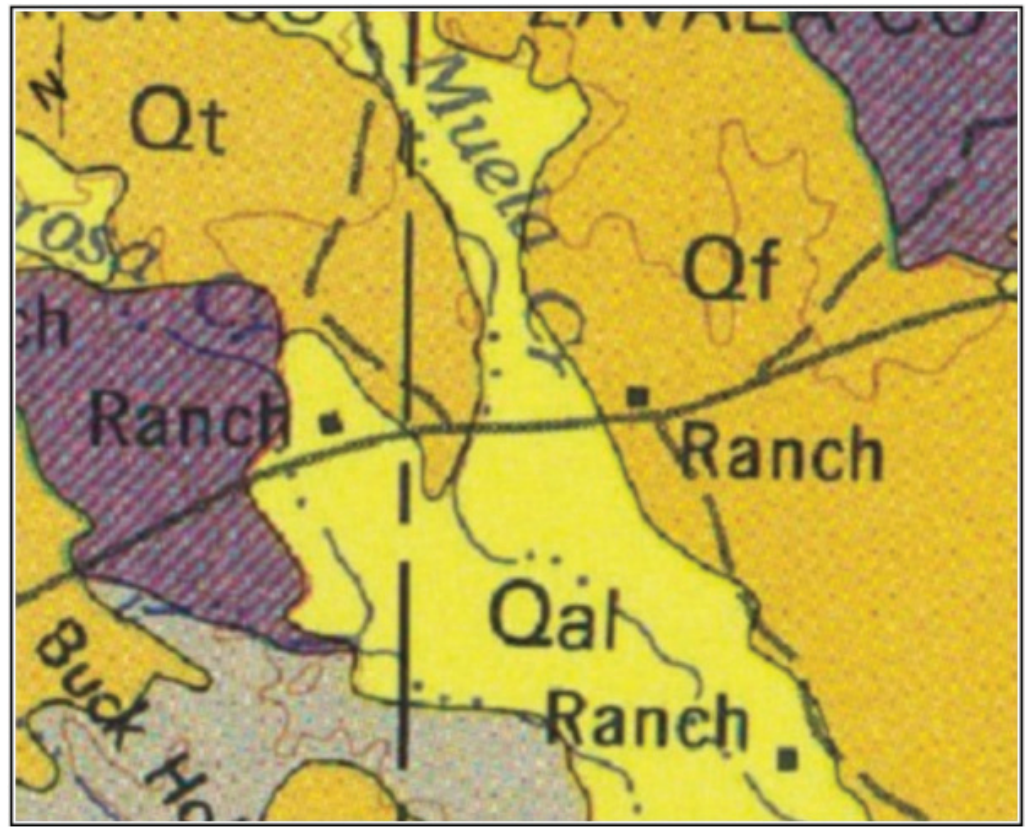

A-1. Surface Geology.

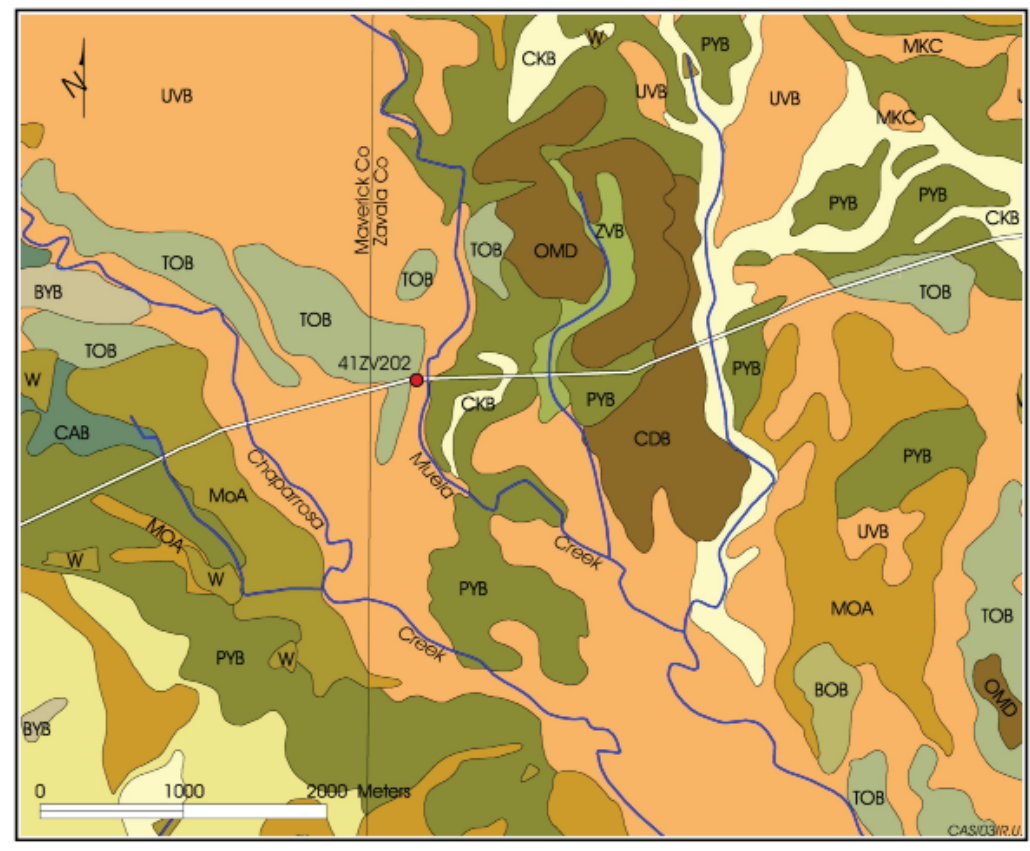

A-2. Soils at 41ZV202. 
Table 1. Description of Soil Profiles

Profile 1-western edge of the long profile

\begin{tabular}{|c|c|l|}
\hline Zone & $\begin{array}{c}\text { Depth } \\
\text { (cm) }\end{array}$ & \multicolumn{1}{|c|}{ Description } \\
\hline 1 & $0-3$ & $\begin{array}{l}\text { Pale brown (10YR 6/3) fine sand with thin (0.5 mm) brown (10YR 5/3) silt layering, zone is very thin and discontinuous, moderately } \\
\text { effervescent to 10\% hydrochloric acid solution, very abrupt smooth to wavy lower boundary, AC horizon. }\end{array}$ \\
\hline 2 & $3-12$ & $\begin{array}{l}\text { Dark yellowish brown (10YR 4/4) fine sandy loam, very weak fine subangular blocky, common insect burrows }(1 \times 3 \mathrm{~cm}), \text { some insect burrows } \\
\text { are hollow while others filled with pale brown (10YR 6/3) sand, moderately effervescent to 10\% hydrochloric acid solution, few CaCO3 } \\
\text { nodules and two are in rodent burrows, rodent burrows extend lower boundary down to 20cm, but mostly at } 12 \mathrm{~cm} \text { the lower boundary varies } \\
\text { from abrupt to clear and from smooth to wavy, A horizon. }\end{array}$ \\
\hline 3 & $12-27$ & $\begin{array}{l}\text { Reddish yellow (7.5YR 6/6) fine sandy loam with more silt than Zone 2 and possibly some clay, common insect burrows filled with reddish } \\
\text { yellow (7.5YR 6.5/6) to brown (7.5YR 4/3) fine sand, moderately to moderately strong effervescent to 10\% hydrochloric acid solution, burned } \\
\text { rock at 20 cm, clear to abrupt wavy lower boundary, Bk1 horizon. }\end{array}$ \\
\hline 4 & $27-43$ & $\begin{array}{l}\text { Reddish yellow (7.5YR 6/6) friable to slightly firm, sandy loam, common faint insect burrows, few (<1\%) CaCO3 films, few hard white small } \\
\text { CaCO3 nodules, matrix and nodules strongly effervescent to 10\% hydrochloric acid solution, clear smooth to wavy lower boundary, Bk2 horizon. }\end{array}$ \\
\hline 5 & $43-63$ & $\begin{array}{l}\text { Reddish yellow (7.5YR 6.5/6 to 6/6) sandy loam but with more silt than Zone 4, 5\% CaCO3 nodules range from hard white to soft very pale } \\
\text { brown (10YR 8/4), matrix and nodules strongly effervescent to 10\% hydrochloric acid solution, abundant insect burrows, lower boundary not } \\
\text { observed, Bk3. }\end{array}$ \\
\hline
\end{tabular}

\section{Profile 2-mid profile}

\begin{tabular}{|c|c|l|}
\hline Zone & $\begin{array}{c}\text { Depth } \\
\text { (cm) }\end{array}$ & \multicolumn{1}{|c|}{ Description } \\
\hline 1 & $0-5$ & $\begin{array}{l}\text { Brown (10YR 5/3) friable silty fine sand, few rootlets, few very small insect burrows, very weak medium subangular blocky structure but in } \\
\text { some areas structure ranges to platy, zone is discontinuous across profile, abrupt smooth-wavy lower boundary, AC horizon. }\end{array}$ \\
\hline 2 & $5-22$ & $\begin{array}{l}\text { Brown to dark brown (10YR 4/3-3/3) slightly firm sandy loam, common insect burrows filled with very pale brown (10YR 7/4) very fine } \\
\text { sand, few rootlets, 40 cm east of profile is a lithic artifact at 10 cm, rare CaCO3 nodules at 7 cm, weakly-moderately effervescent to 10\% } \\
\text { hydrochloric acid solution, insect burrows compose 1-2\% of Zone 2, clear smooth lower boundary, A1 horizon. }\end{array}$ \\
\hline 3 & $22-34$ & $\begin{array}{l}\text { Brown (7.5YR 4/4) fine sandy loam with more silt than Zone 2, very weak medium subangular blocky to structureless, 40 cm west of profile is a } \\
\text { lithic artifact at 20 cm, common (<1\%) insect burrows similar to those in Zone 2, other insect burrows and small rodent burrows (?3 cm diameter) } \\
\text { filled with dark brown (10YR 3/3) fine sand, very weakly effervescent to 10\% hydrochloric acid solution, few rare white CaCO3 nodules, two small } \\
\text { vertically aligned rocks (1 possibly FCR), clear wavy-irregular lower boundary highly bioturbated by insect burrows, A2 horizon. }\end{array}$ \\
\hline 4 & $34-53$ & $\begin{array}{l}\text { Brown (7.5YR 5/4) silty fine sand, weak medium subangular blocky, common insect burrows filled with brown (7.5YR 5/3) fine sand, few } \\
\text { (<1\%) hard white CaCO3 nodules, some cluster in burrows, few rootlets, strongly-violently effervescent to 10\% hydrochloric acid solution, } \\
\text { clear smooth lower boundary, Bk1 horizon. }\end{array}$ \\
\hline 5 & $53-68$ & $\begin{array}{l}\text { Reddish yellow (7.5YR 6/6) sandy loam with more fines than Zone 4, weak medium subangular blocky, common insect burrows filled with } \\
\text { very dark gray (7.5YR 3/1) loam, few rootlets, few CaCO3 nodules, strongly effervescent to 10\% hydrochloric acid solution, clear wavy lower } \\
\text { boundary, Bk2. }\end{array}$ \\
\hline 6 & $68-88$ & $\begin{array}{l}\text { Reddish yellow (7.5YR 6/5-6/6) to light brown (7.5YR 6/4 to 10YR 6/4) at bottom, sandy loam, 3-5\% small white CaCO3 nodules, strongly } \\
\text { effervescent to 10\% hydrochloric acid solution, lower boundary not observed, Bk3. }\end{array}$ \\
\hline
\end{tabular}

Profile 3

\begin{tabular}{|c|c|l|}
\hline Zone & $\begin{array}{c}\text { Depth } \\
\mathbf{( c m )}\end{array}$ & \multicolumn{1}{|c|}{ Description } \\
\hline 1 & $0-15$ & $\begin{array}{l}\text { Dark grayish brown (10YR 4/2) friable sandy loam, weak fine subangular blocky, few insect burrows that increase in number down profile } \\
\text { are filled with light yellowish brown (10YR 6/4) sand, few rootlets, small FCR cluster at 15cm, moderately effervescent, clear smooth lower } \\
\text { boundary, A1 horizon. }\end{array}$ \\
\hline 2 & $15-30$ & $\begin{array}{l}\text { Brown (10YR 4/3) firm sandy loam with no observable structure, few CaCO3 filaments on root pores, few rootlets, FCR clusters at 20 cm and } \\
25 \mathrm{~cm}, \text { flake at 21 cm, common insect burrows with fill similar to those in Zone 1 and very dark brown (10YR 3/2) sand, clear smooth lower } \\
\text { boundary. A2 horizon. }\end{array}$ \\
\hline 3 & $30-51$ & $\begin{array}{l}\text { Brown (10YR 5/3) firm sand, weak medium subangular blocky, strongly effervescent to 10\% hydrochloric acid solution, common insect } \\
\text { burrows indicating much bioturbation, common CaCO3 filaments in root pores and films on ped faces, firmness of zone due to cementation } \\
\text { of CaCO3, few vertical root casts infilled from Zone 2 sediment, few hard white CaCO3 nodules, few larger (?15 cm diameter) rodent } \\
\text { burrows filled with dark grayish brown (10YR 4/2) sand, clear wavy lower boundary, Bk1 horizon. }\end{array}$ \\
\hline 4 & $51-72+$ & $\begin{array}{l}\text { Yellowish brown (10YR 5.5/4) friable sandy loam, weak medium subangular blocky, < 7\% small white to very pale brown (10YR 8/1-8/2) very } \\
\text { hard to friable CaCO3 nodules, strongly effervescent to 10\% hydrochloric acid solution, lower boundary not observed, Bk2 horizon. }\end{array}$ \\
\hline
\end{tabular}


Table 1. Continued...

Profile 4-Across Highway 481 at David Kuehn's BHT 2.

\begin{tabular}{|c|c|l|l|}
\hline Zone & $\begin{array}{c}\text { Depth } \\
\text { (cm) }\end{array}$ & \multicolumn{1}{|c|}{ Description } \\
\hline 1 & $0-11$ & $\begin{array}{l}\text { Dark grayish brown (10YR 4/2) friable fine sand, weak fine subangular blocky, rare white hard CaCO3 nodules, moderately effervescent to } \\
10 \% \text { hydrochloric acid solution, few rootlets, clear smooth lower boundary, A1 horizon. }\end{array}$ \\
\hline 2 & $11-19$ & $\begin{array}{l}\text { Brown (10YR 4/3) fine sand, few white CaCO3 nodules, few rootlets, common small insect burrows, moderately effervescent but slightly } \\
\text { stronger than Zone 1, clear smooth lower boundary. A2 horizon. }\end{array}$ \\
\hline 3 & $19-36$ & $\begin{array}{l}\text { Pale brown (10YR 6/3) slightly firm sandy loam, weak fine subangular blocky, slightly more CaCO3 nodules than in Zone 2, few insect burrows, } \\
\text { few CaCO3 filaments lining rootlet pores, strongly effervescent to 10\% hydrochloric acid solution, clear smooth lower boundary, Bk1 horizon. }\end{array}$ \\
\hline 5 & $36-62$ & $\begin{array}{l}\text { Pale brown (10YR 6/3) friable sandy loam, increase in CaCO3 filaments on rootlet pores, weak medium subangular blocky, few white CaCO3 } \\
\text { nodules, clear smooth lower boundary, Bk2 horizon. }\end{array}$ \\
\hline 6 & $125-155$ & $\begin{array}{l}\text { Reddish yellow (7.5YR 7/6) firm loam, weak medium subangular blocky, 3\% CaCO3 nodules and dispersed filaments, filaments are } \\
\text { throughout sediment, CaCO3 nodules are larger ( } 12.5 \mathrm{~cm} \text { diameter) than in upper zones ( 1 cm diameter), upper boundary probably is an } \\
\text { unconformity, clear smooth lower boundary, 2Bk1 horizon. }\end{array}$ \\
\hline 7 & $155-172$ & $\begin{array}{l}\text { Reddish yellow (7.5YR 6.5/6) fine sand, 15\% small to large ( } \leq 2.5 \mathrm{~cm}) \text { CaCO3 nodules and soft masses, few filaments lining rootlet pores, } \\
\text { no visible structure, clear smooth lower boundary, 2Bk2 horizon. }\end{array}$ \\
\hline 8 & $172-250$ & $\begin{array}{l}\text { Very pale brown (10YR 7/4) to gray (10YR 6/1) firm fine sand, weak medium subangular blocky, 3\% CaCO3 nodules and filaments lining } \\
\text { pores, maximum diameter of nodules is 1-2cm and they are smaller than in Zones 6 and 7, 2Bk3 horizon. }\end{array}$ \\
\hline
\end{tabular}

\section{Discussion}

In Profile 4, two depositional units are present (Figure A-3). The lower unit (Unit 2) consists of Zones 6,7 and 8, and the upper unit (Unit 1)consists of Zones 1-5. The lower unit is firmer, more weathered, it has more carbonate, and the carbonate nodules are larger. A similar lower deposit was visible on the eastern, stream-side, end of the long profile across the highway. No A-horizon was observed capping this unit as it was probably removed by erosion. The maximum observed thickness of Unit 2 and Unit 1 were both $125 \mathrm{~cm}$. However, the bottom of Unit 2 was not observed and it is probably thicker.

Unit 1 is capped by an A-horizon on both sides of the road. On the long profile (south side of road), the A-horizon has been removed completely by erosion on the east side by Muela Creek, but, while somewhat truncated on the west, the A-horizon roughly follows the modern slope (Figure A-4). The general hydrochloric acid reaction pattern strongly suggests that the A-horizon is genetically linked to the underlying B-horizons in Unit 1. Zone 2 in Profile 1 and Zones 2 and 3 in Profile 2 had calcium carbonate nodules, but these were probably transported up profile by rodent burrowing and are not thought to be in situ pedogenic features. No artifacts or features were observed in the Unit 2 and it contains a greater amount $(\leq 15 \%)$ of calcium carbonate. Stone artifacts and features were observed in the upper portion of Unit 1 and at

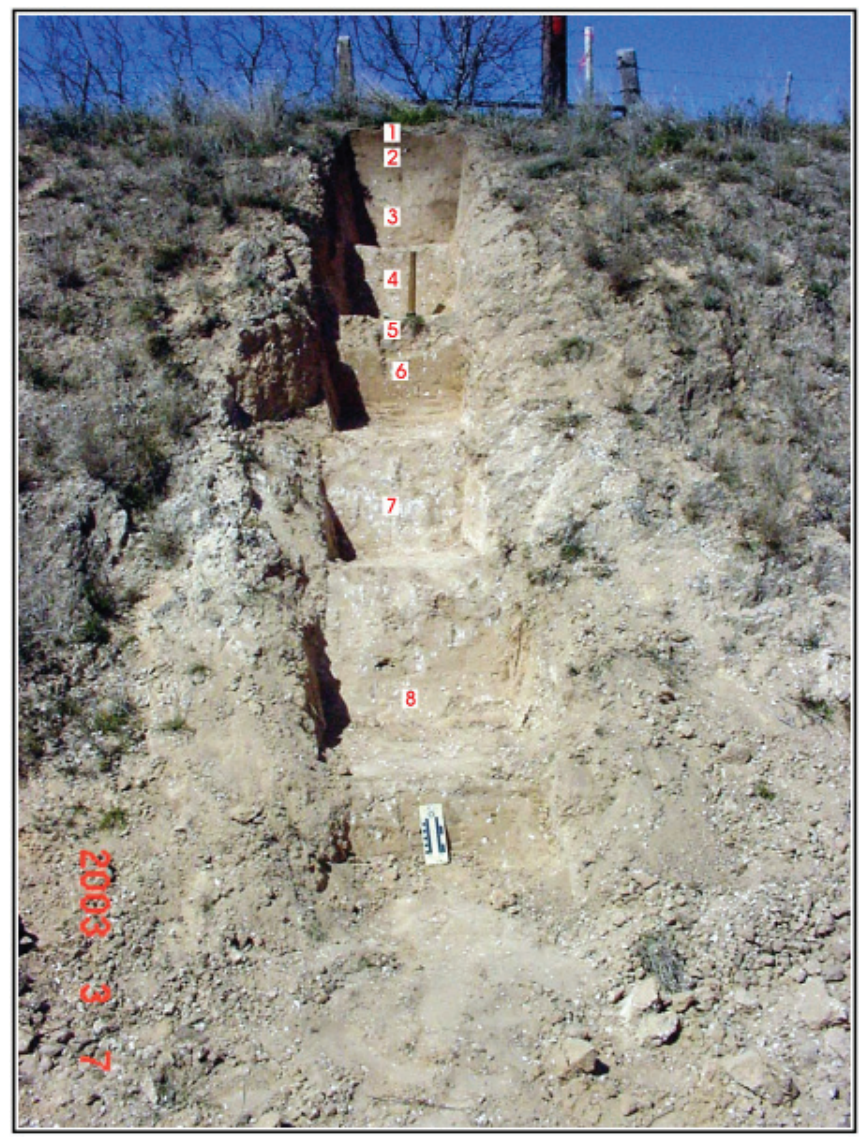

A-3. Profile 4 located across Highway 481. 


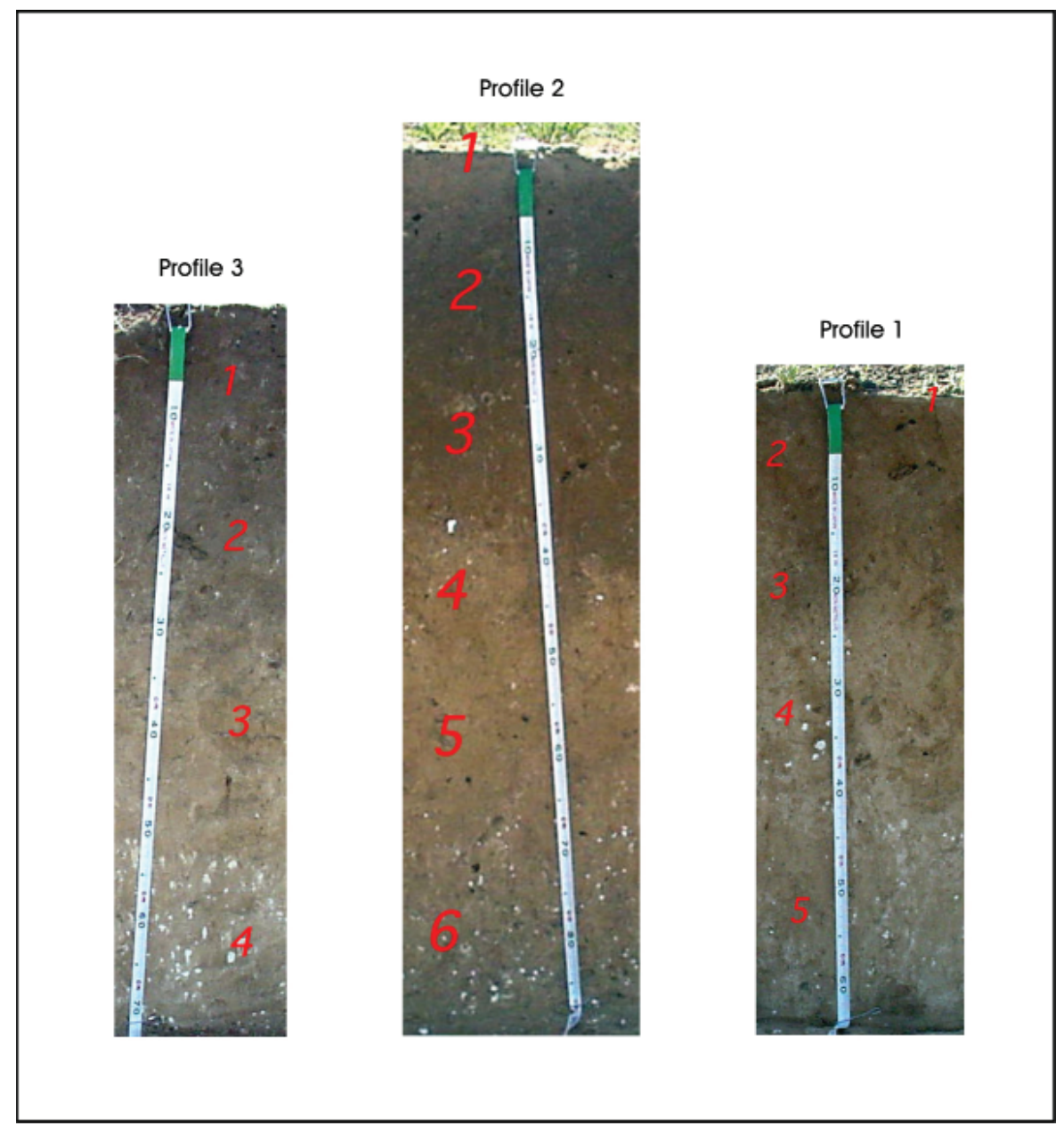

A-4. Photographic representations of profiles at locations 1-3. depths that were below the A-horizon. Abbott (2002) suggests that only the A-horizon in Unit 1 should contain intact prehistoric occupations, and this has not been confirmed by the more recent observations.

Abbott (2002) also contested Kuehn's (2002) interpretation that the entire landscape feature was a Holocene terrace of Muela Creek. The height of the feature $(\sim 10$ meters above the creek thalweg), the asymmetry of the feature, the elevation above the larger Chaparrosa valley to the west, the size of Muela Creek, and the internal soil stratigraphy all suggest that this is not a terrace of Muela Creek. As the schematic profile (Figure A-5) shows, both Unit1 and Unit 2 are truncated by stream erosion on the east side of the landscape feature. Furthermore, the soil is not completely truncated by erosion on the west side, but tends to follow the slope. This suggests that the west slope is much older than the east slope. Abbott (2002) suggests that this landscape feature was part of a much larger colluvial fan that was cut off from the remainder of the colluvial body by the incision of Muela Creek. A 3-D landscape projection also suggests that the ridge with the site appears to

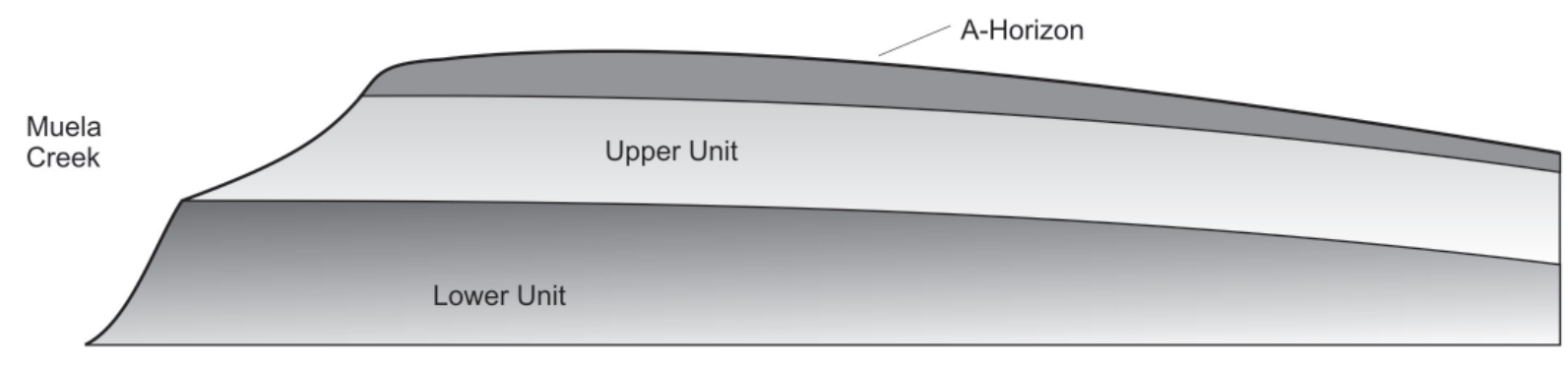

A-5. Schematic soil profile west of Muela Creek. 
be a projection of the alluvial fan complex on the east side of Muela Creek (Figure A-6). This implies that the creek erosion is Late Holocene as the A horizons, with a series of Late Holocene radiocarbon ages, is truncated. While it is possible that Unit 2 formed during the Pleistocene, it is also possible that this unit is more recent. The poorly developed soil structure in the entire feature suggests a younger age, and the amount of calcium carbonate is not too great for a Holocene age estimate.

In conclusion, it appears that the landscape feature that contains site $41 \mathrm{ZV} 202$ is probably part of the alluvial fan complex which is mapped on the east side of Muela Creek and not an alluvial terrace. However, two sedimentary units were deposited to form this feature. The age of the lower sedimentary unit is unknown, but the upper unit certainly dates to the Late Holocene. The upper sedimentary unit may have colluvial, aeolian and alluvial components to the sedimentary matrix. Lateral stream erosion has truncated this feature on the east side of the site. During and after the accumulation of the upper sedimentary unit, burrowing has disturbed the deposits in some areas, and finally the thin accumulation of cover sediments by aeolian processes form a thin veneer over the surface.

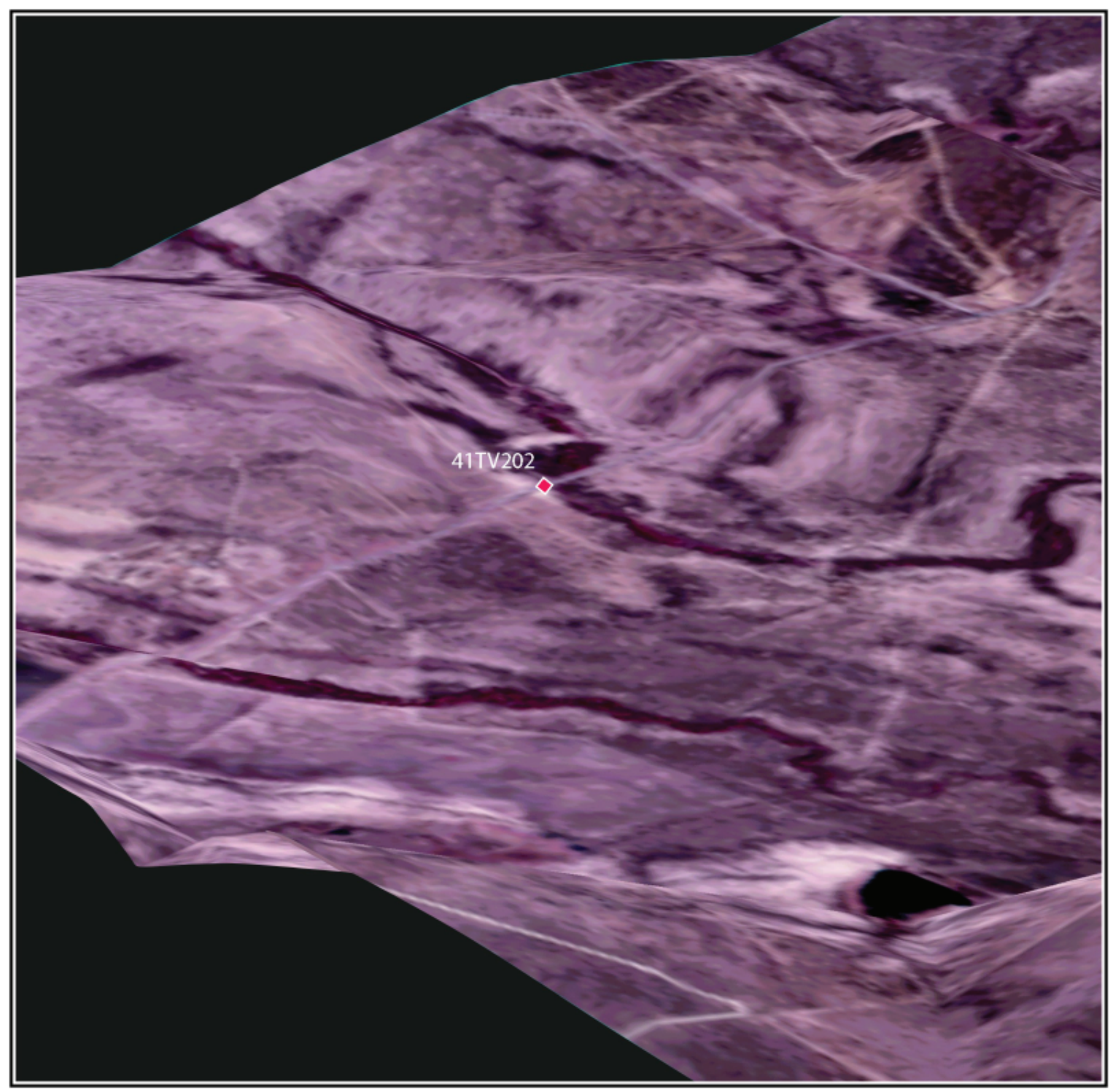

A-6. 3-D landscape projection. 

APPENDIX B

Radiocarbon Dates from 41ZV202

Darden Hood

Beta Analytic,

Miami, FL 

FROM: Darden Hood, Director (mailto:mailto:dhood@radiocarbon.com)

(This is a copy of the letter being mailed. Invoices/receipts follow only by mail.)

April 7, 2003

Dr. Raymond Mauldin

University of Texas at San Antonio

Center for Archaeological Research

6900 North Loop 1604 West

San Antonio, TX 78249

USA

RE: Radiocarbon Dating Results For Samples CAT\#257, CAT\#259, CAT\#253, CAT\#251, CAT\#245, CAT\#206, CAT\#192, CAT\#199, CAT\#194, CAT\#197, CAT\#157-004

Dear Ray:

Enclosed are the radiocarbon dating results for samples recently sent to us. They each provided plenty of carbon for accurate measurements and all the analyses went normally. As usual, the method of analysis is listed on the report with the results and calibration data is provided where applicable.

As always, no students or intern researchers who would necessarily be distracted with other obligations and priorities were used in the analyses. We analyzed them with the combined attention of our entire professional staff.

If you have specific questions about the analyses, please contact us. We are always available to answer your questions.

Our invoice is enclosed. Please, forward it to the appropriate officer or send VISA change authorization. Thank you. As always, if you have any questions or would like to discuss the results, don't hesitate to contact me.

Sincerely,

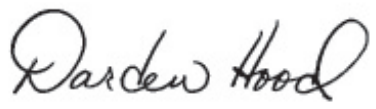


Dr. Raymond Mauldin

Report Date: 4/7/2003

University of Texas at San Antonio

Material Received: 3/24/2003

\begin{tabular}{|c|c|c|c|}
\hline Sample Data & $\begin{array}{c}\text { Measured } \\
\text { Radiocarbon Age }\end{array}$ & $\begin{array}{c}13 \mathrm{C} / 12 \mathrm{C} \\
\text { Ratio }\end{array}$ & $\begin{array}{c}\text { Conventional } \\
\text { Radiocarbon Age }\left(^{*}\right)\end{array}$ \\
\hline $\begin{array}{l}\text { Beta - } 177697 \\
\text { SAMPLE : CAT } 257 \\
\text { ANALYSIS : AMS-Advance } \\
\text { MATERIAL/PRETREATME } \\
2 \text { SIGMA CALIBRATION : }\end{array}$ & $\begin{array}{l}1450+/-40 \mathrm{BP} \\
540 \text { to } 660 \text { (Cal BP } 141\end{array}$ & $-25.3 \mathrm{o} / \mathrm{oo}$ & $1450+/-40 \mathrm{BP}$ \\
\hline $\begin{array}{l}\text { Beta - } 177698 \\
\text { SAMPLE : CAT\#259 } \\
\text { ANALYSIS : AMS-Advance } \\
\text { MATERIAL/PRETREATME } \\
2 \text { SIGMA CALIBRATION : }\end{array}$ & $\begin{array}{l}910+/-40 \mathrm{BP} \\
1030 \text { to } 1230 \text { (Cal BP }\end{array}$ & $-25.9 \mathrm{o} / 00$ & $900+/-40 \mathrm{BP}$ \\
\hline $\begin{array}{l}\text { Beta - } 177699 \\
\text { SAMPLE : CAT } \# 253 \\
\text { ANALYSIS : AMS-Advance } \\
\text { MATERIAL/PRETREATME } \\
2 \text { SIGMA CALIBRATION : }\end{array}$ & $\begin{array}{l}930+/-40 \mathrm{BP} \\
1010 \text { to } 1190 \text { (Cal BP }\end{array}$ & $-24.5 \mathrm{o} / \mathrm{oo}$ & $940+/-40 \mathrm{BP}$ \\
\hline $\begin{array}{l}\text { Beta - } 177700 \\
\text { SAMPLE : CAT\#251 } \\
\text { ANALYSIS : AMS-Advance } \\
\text { MATERIAL/PRETREATME } \\
2 \text { SIGMA CALIBRATION : }\end{array}$ & $\begin{array}{l}1890+/-40 \mathrm{BP} \\
60 \text { to } 240 \text { (Cal BP } 189 \text { ( }\end{array}$ & $-26.2 \mathrm{o} / \mathrm{oo}$ & $1870+/-40 \mathrm{BP}$ \\
\hline $\begin{array}{l}\text { Beta - } 177701 \\
\text { SAMPLE : CAT\#245 } \\
\text { ANALYSIS : AMS-Advance } \\
\text { MATERIAL/PRETREATME } \\
2 \text { SIGMA CALIBRATION : }\end{array}$ & $\begin{array}{l}960+/-40 \mathrm{BP} \\
1000 \text { to } 1180 \text { (Cal BP }\end{array}$ & $-25.2 \mathrm{o} / \mathrm{oo}$ & $960+/-40 \mathrm{BP}$ \\
\hline
\end{tabular}


Dr. Raymond Mauldin

Report Date: 4/7/2003

\begin{tabular}{|c|c|c|c|}
\hline Sample Data & $\begin{array}{c}\text { Measured } \\
\text { Radiocarbon Age }\end{array}$ & $\begin{array}{c}13 \mathrm{C} / 12 \mathrm{C} \\
\text { Ratio }\end{array}$ & $\begin{array}{c}\text { Conventional } \\
\text { Radiocarbon Age }\left(^{*}\right)\end{array}$ \\
\hline $\begin{array}{l}\text { Beta - } 177702 \\
\text { SAMPLE : CAT\#206 } \\
\text { ANALYSIS : AMS-Advance } \\
\text { MATERIAL/PRETREATME } \\
2 \text { SIGMA CALIBRATION : }\end{array}$ & $\begin{array}{l}970+/-40 \mathrm{BP} \\
990 \text { to } 1160 \text { (Cal BP } 9\end{array}$ & $-24.1 \mathrm{o} / \mathrm{oo}$ & $980+/-40 \mathrm{BP}$ \\
\hline $\begin{array}{l}\text { Beta - } 177703 \\
\text { SAMPLE : CAT\#192 } \\
\text { ANALYSIS : AMS-Advance } \\
\text { MATERIAL/PRETREATME } \\
2 \text { SIGMA CALIBRATION : }\end{array}$ & $\begin{array}{l}1020+/-40 \mathrm{BP} \\
960 \text { to } 1040 \text { (Cal BP } 9\end{array}$ & $-24.10 / 00$ & $1030+/-40 \mathrm{BP}$ \\
\hline $\begin{array}{l}\text { Beta - } 177704 \\
\text { SAMPLE : CAT\#199 } \\
\text { ANALYSIS : AMS-Advance } \\
\text { MATERIAL/PRETREATME } \\
2 \text { SIGMA CALIBRATION : }\end{array}$ & $\begin{array}{l}1600+/-40 \mathrm{BP} \\
380 \text { to } 540 \text { (Cal BP } 15\end{array}$ & $-24.60 / 00$ & $1610+/-40 \mathrm{BP}$ \\
\hline $\begin{array}{l}\text { Beta - } 177705 \\
\text { SAMPLE : CAT\#194 } \\
\text { ANALYSIS : AMS-Advance } \\
\text { MATERIAL/PRETREATME } \\
2 \text { SIGMA CALIBRATION : }\end{array}$ & $\begin{array}{l}970+/-40 \mathrm{BP} \\
990 \text { to } 1160 \text { (Cal BP } 9\end{array}$ & $-24.5 \mathrm{o} / \mathrm{oo}$ & $980+/-40 \mathrm{BP}$ \\
\hline $\begin{array}{l}\text { Beta - } 177706 \\
\text { SAMPLE : CAT\#197 } \\
\text { ANALYSIS : AMS-Advance } \\
\text { MATERIAL/PRETREATME } \\
2 \text { SIGMA CALIBRATION : }\end{array}$ & $\begin{array}{l}1000+/-40 \mathrm{BP} \\
960 \text { to } 1040 \text { (Cal BP } 9\end{array}$ & $-23.4 \mathrm{o} / 00$ & $1030+/-40 \mathrm{BP}$ \\
\hline
\end{tabular}


Dr. Raymond Mauldin

Report Date: 4/7/2003

\begin{tabular}{|c|c|c|c|}
\hline Sample Data & $\begin{array}{c}\text { Measured } \\
\text { Radiocarbon Age }\end{array}$ & $\begin{array}{c}13 \mathrm{C} / 12 \mathrm{C} \\
\text { Ratio }\end{array}$ & $\begin{array}{c}\text { Conventional } \\
\left.\text { Radiocarbon Age( }{ }^{*}\right)\end{array}$ \\
\hline $\begin{array}{l}\text { Beta - } 177707 \\
\text { SAMPLE : CAT\#157-004 } \\
\text { ANALYSIS : AMS-Advance deliven } \\
\text { MATERIAL/PRETREATMENT : } \\
2 \text { SIGMA CALIBRATION : }\end{array}$ & $\begin{array}{l}950+/-40 \mathrm{BP} \\
\text { material): acid/alkali/a } \\
990 \text { to } 1160 \text { (Cal BP } 96\end{array}$ & $-23.0 \mathrm{o} / 00$ & $980+/-40 \mathrm{BP}$ \\
\hline
\end{tabular}




\section{CALIBRATION OF RADIOCARBON AGE TO CALENDAR YEARS}

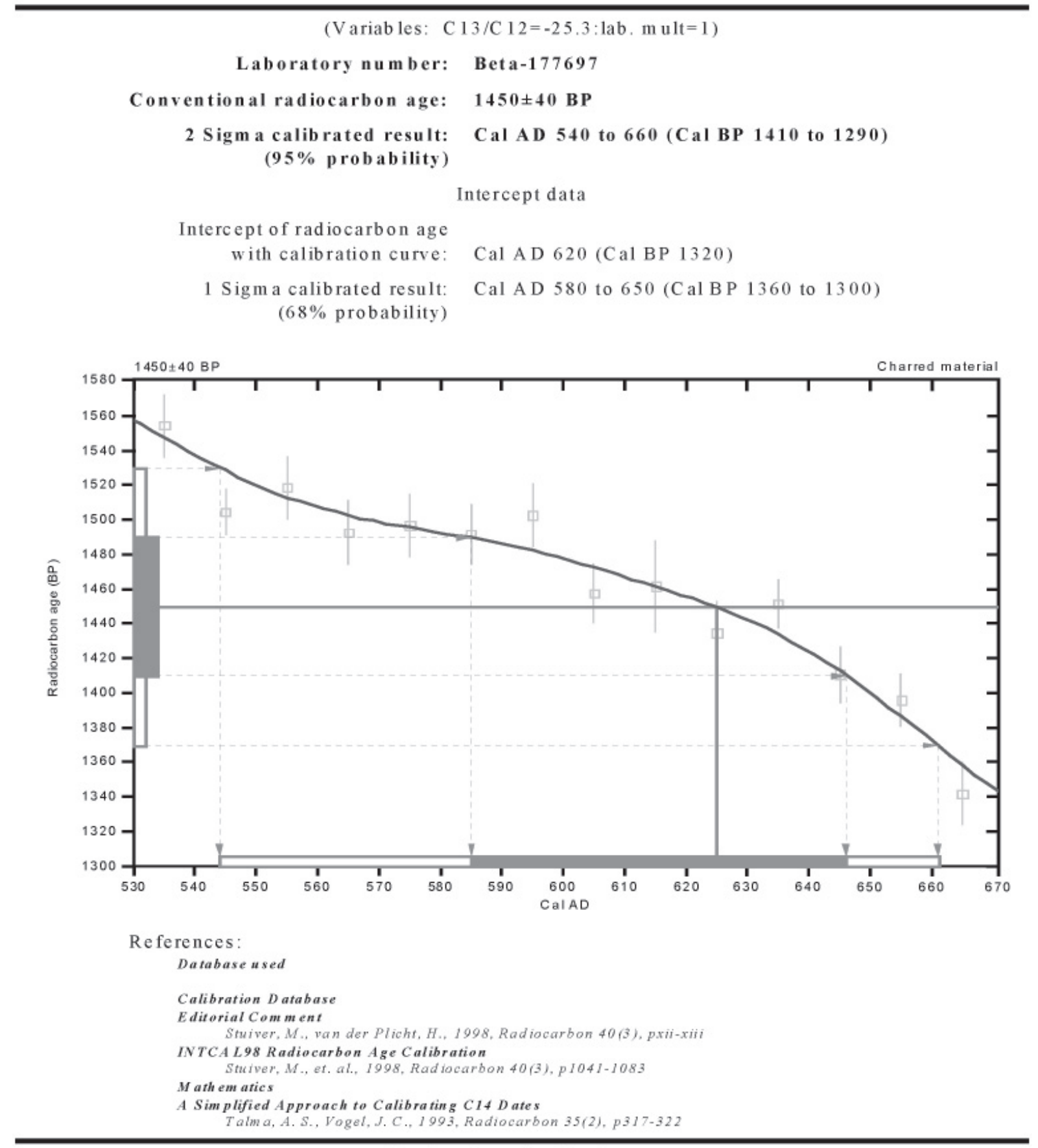

\section{Beta Analytic Inc.}

4985 SW 74 Court, Miami, Florida 33155 USA Tel: (305) $6675167 \cdot$ Fax: (305) $6630964 \cdot$ E-Mail: beta@ radiocarbon.com 


\section{CALIBRATION OF RADIOCARBON AGE TO CALENDAR YEARS}

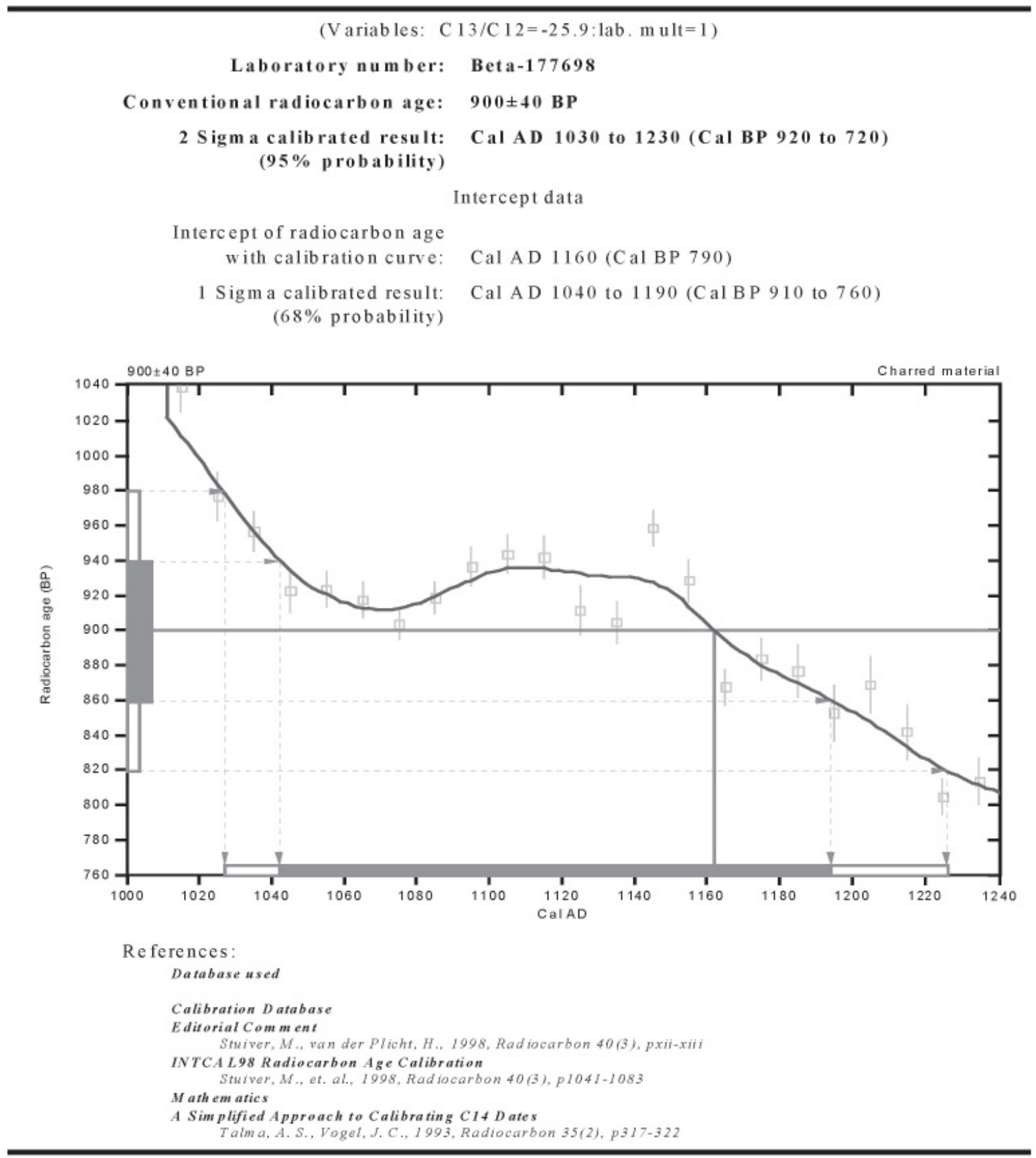

\section{Beta Analytic Inc.}

4985 SW 74 Court, Miami, Florida 33155 USA Tel: (305) 667 5167 Fax: (305) $6630964 \cdot$ E-Mail: beta(a radiocarbon.com 


\section{CALIBRATION OF RADIOCARBON AGE TO CALENDAR YEARS}

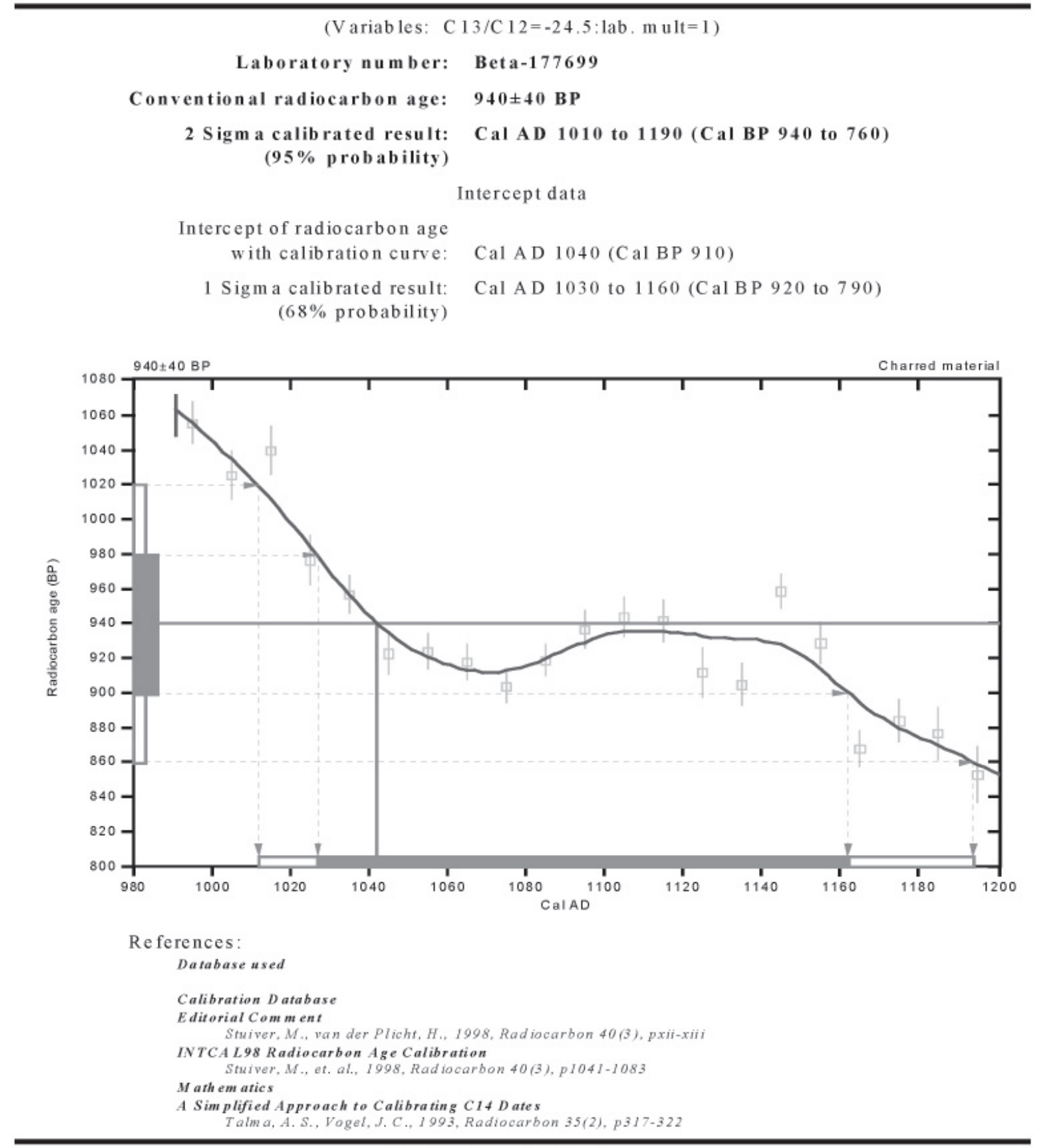

\section{Beta Analytic Inc.}

4985 SW 74 Court, Miami, Florida 33155 USA $\cdot$ Tel: (305) $6675167 \cdot$ Fax: (305) $6630964 \cdot$ E-Mail: beta(a) radiocarbon.com 


\section{CALIBRATION OF RADIOCARBON AGE TO CALENDAR YEARS}

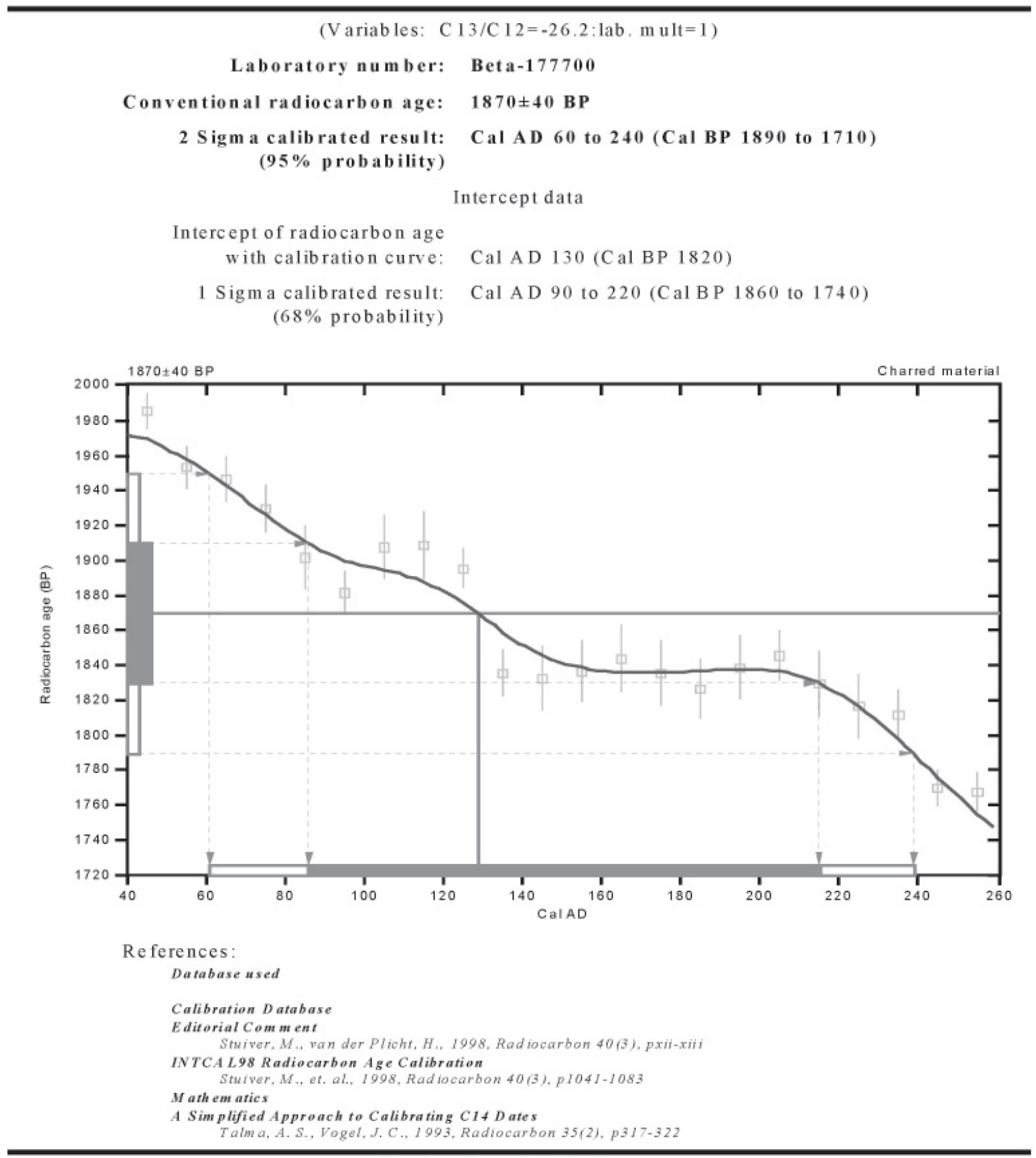

\section{Beta Analytic Inc.}

4985 SW 74 Court, Miami, Florida 33155 USA $\cdot$ Tel: (305) $6675167 \cdot$ Fax: (305) $6630964 \cdot$ E-Mail: beta@ radiocarbon.com 


\section{CALIBRATION OF RADIOCARBON AGE TO CALENDAR YEARS}

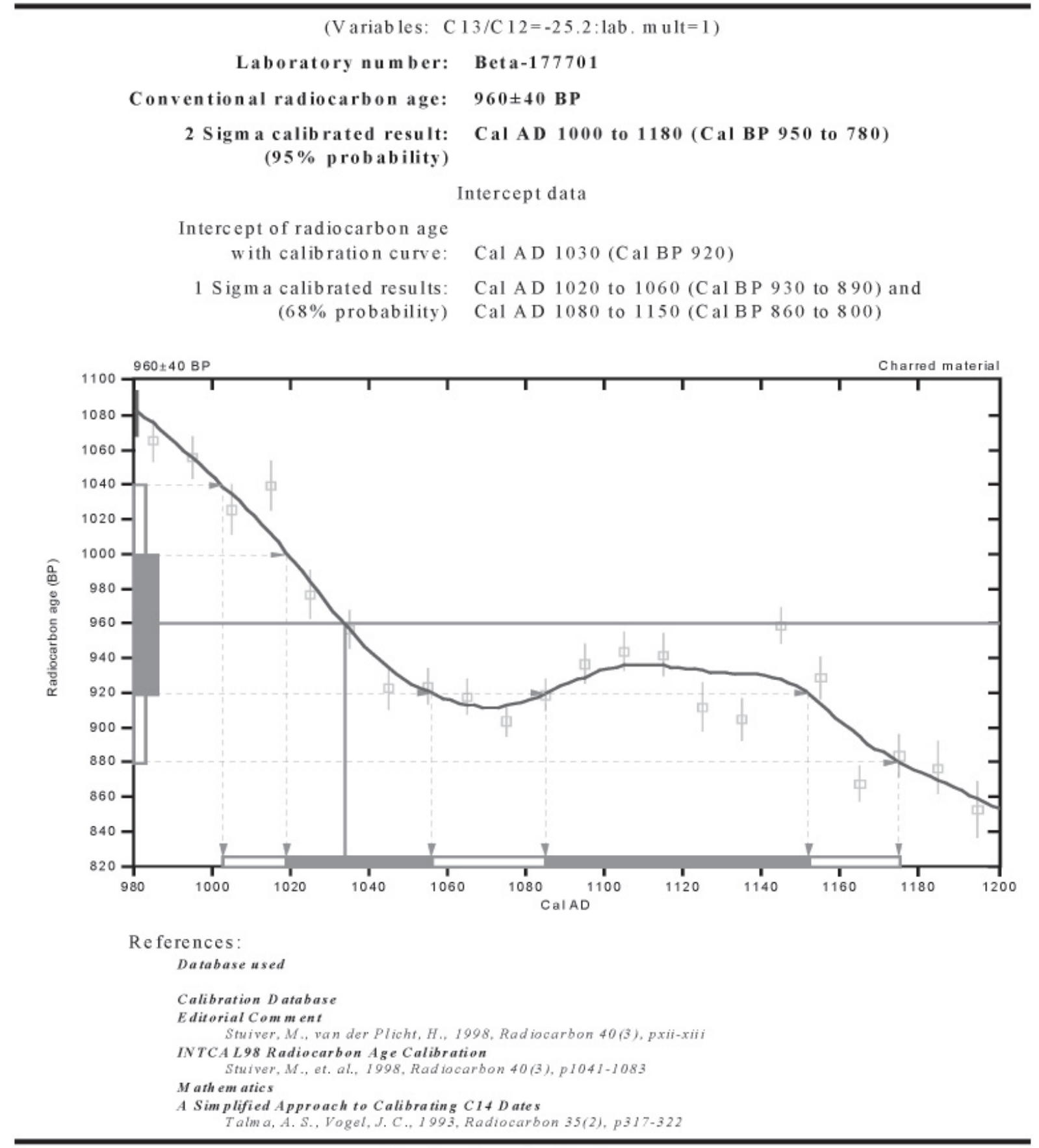

\section{Beta Analytic Inc.}

4985 SW 74 Court, Miami, Florida 33155 USA $\cdot$ Tel: (305) $6675167 \cdot$ Fax: (305) $6630964 \cdot$ E-Mail: beta(a) radiocarbon.com 


\section{CALIBRATION OF RADIOCARBON AGE TO CALENDAR YEARS}

(V ariables: $\mathrm{C} 13 / \mathrm{C} 12=-24,1:$ lab, $\mathrm{mult}=1$ )

Laboratory number: Beta-177702

Conventional radiocarbon age: $980 \pm 40 \mathrm{BP}$

2 Sigm a calib rated result: Cal AD 990 to 1160 (Cal BP 960 to 790 )

(95\% probability)

Intercept data

Intercept of radiocarbon age

with calibration curve: Cal A D 1030 (Cal BP 920)

1 Sigma calibrated result: Cal A D 1010 to 1040 (Cal B P 940 to 910 ) (68\% probability)

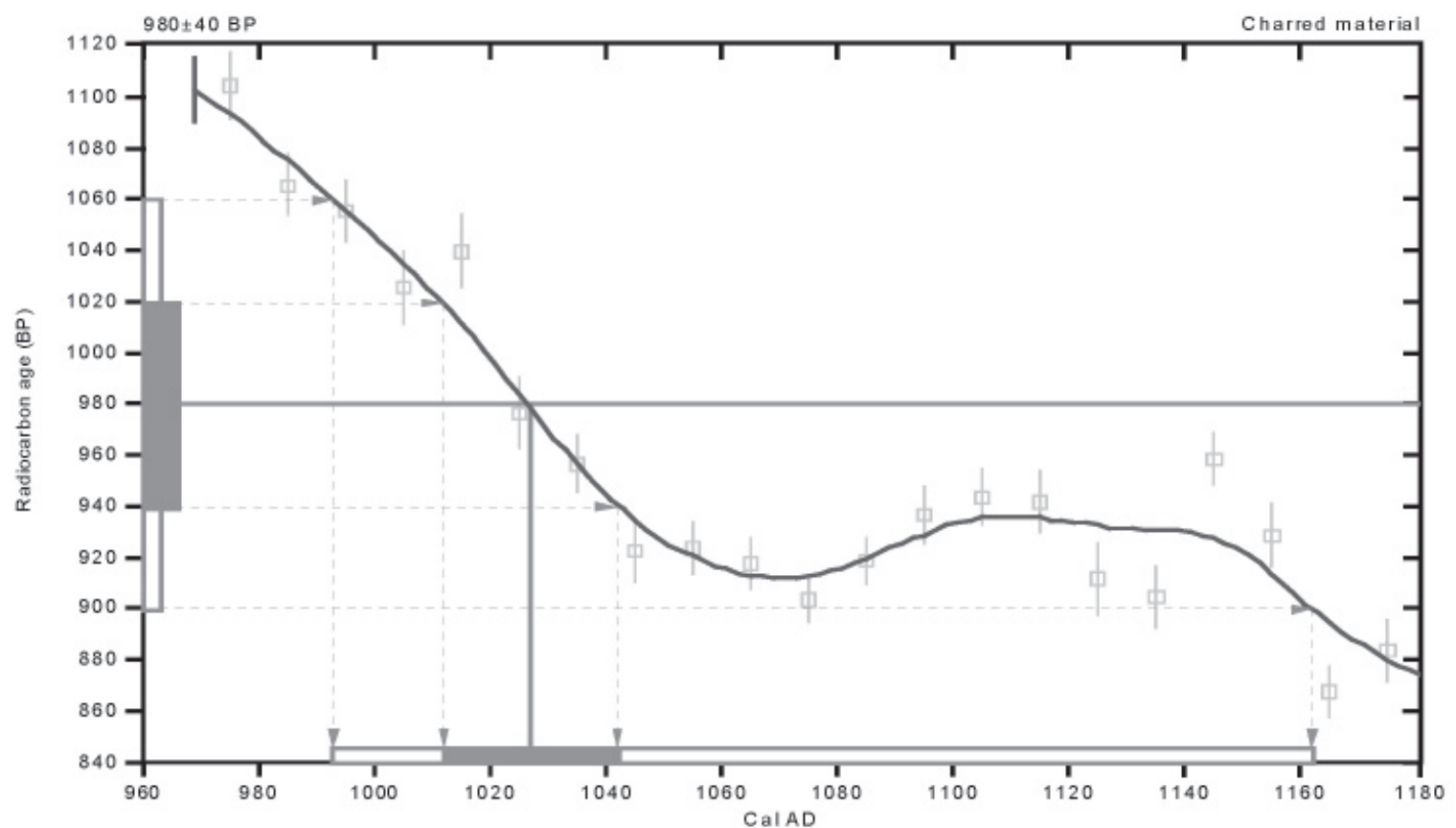

References:

Database used

Calibration Database

Editorial Comment

Stuiver, M. van der Plicht, H., 1998, Radiocarbon 40 (3), pxii-xiii

INTCA L98 Radiocarbon Age Calibration

Stuiver, M., et. al., I998, Radiocarbon 40(3), p1041-1083

M ath em atics

A Simplified Approach to Calibrating C1 D ates

Talma, A. S., Vogel, J. C., 1993, Radiocarbon 35(2), p317-322

\section{Beta Analytic Inc.}

4985 SW 74 Court, Miami, Florida 33155 USA $\cdot$ Tel: (305) 667 5167 * Fax: (305) $6630964 \cdot$ E-Mail: beta@ radiocarbon.com 


\section{CALIBRATION OF RADIOCARBON AGE TO CALENDAR YEARS}

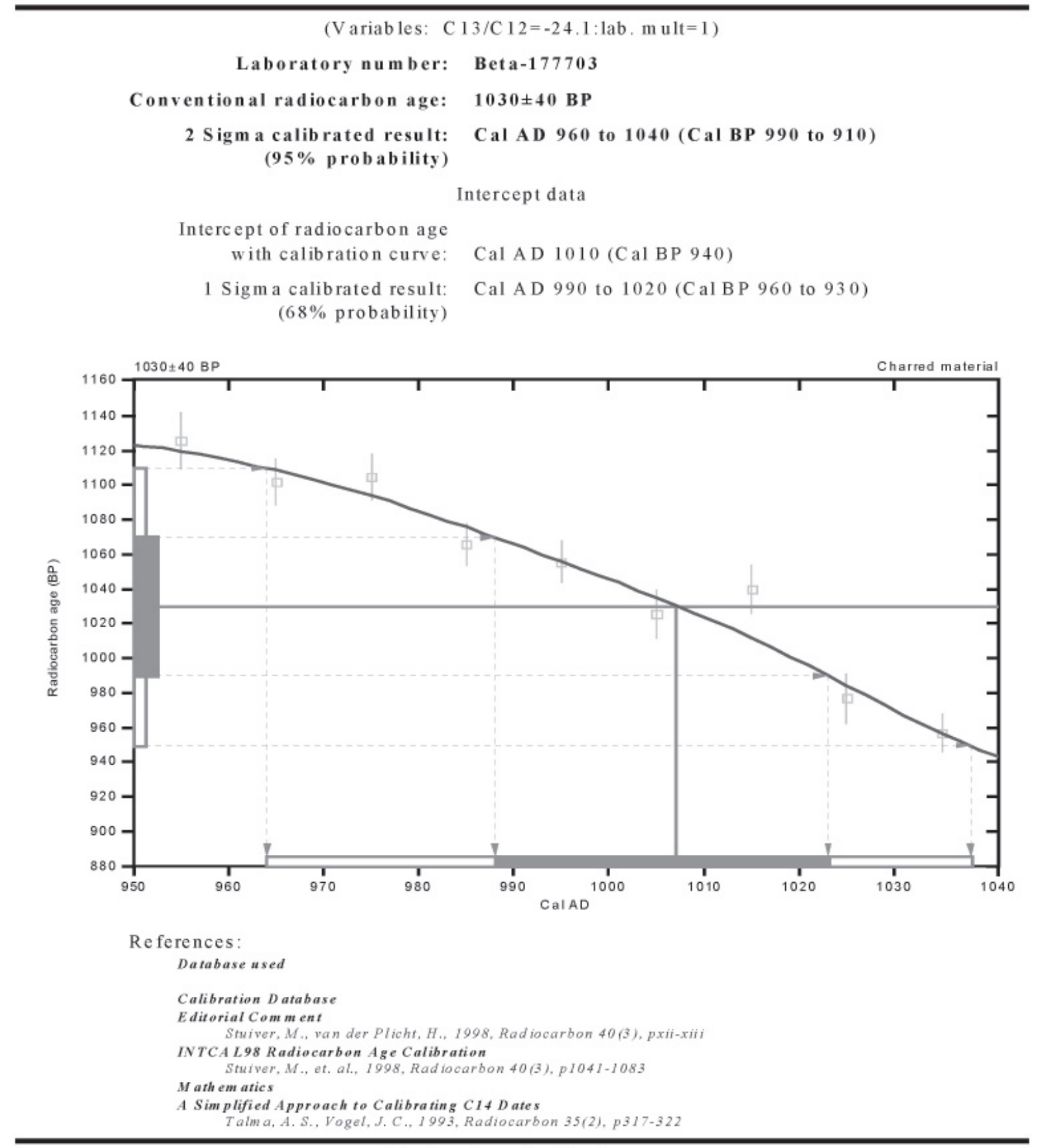

\section{Beta Analytic Inc.}

4985 SW 74 Court, Miami, Florida 33155 USA Tel: (305) $6675167 \cdot$ Fax: (305) $6630964 \cdot$ E-Mail: betala radiocarbon.com 


\section{CALIBRATION OF RADIOCARBON AGE TO CALENDAR YEARS}

(V ariables: $\mathrm{C} 13 / \mathrm{C} 12=-24,6: 1 \mathrm{ab}, \mathrm{mult}=1$ )

Laboratory number: Beta-177704

Conventional radiocarbon age: $1610 \pm 40 \mathrm{BP}$

2 Sigm a calibrated result: Cal AD 380 to 540 (Cal BP 1570 to 1410)

(95\% probability)

Intercept data

Intercept of radiocarbon age

with calibration curve: Cal A D 430 (Cal BP 1520)

$1 \mathrm{Sigma}$ calibrated results: Cal A D 410 to 460 (Cal B P 1540 to 1480 ) and

(68\% probability) Cal A D 480 to 520 (Cal B P 1470 to 1430 )

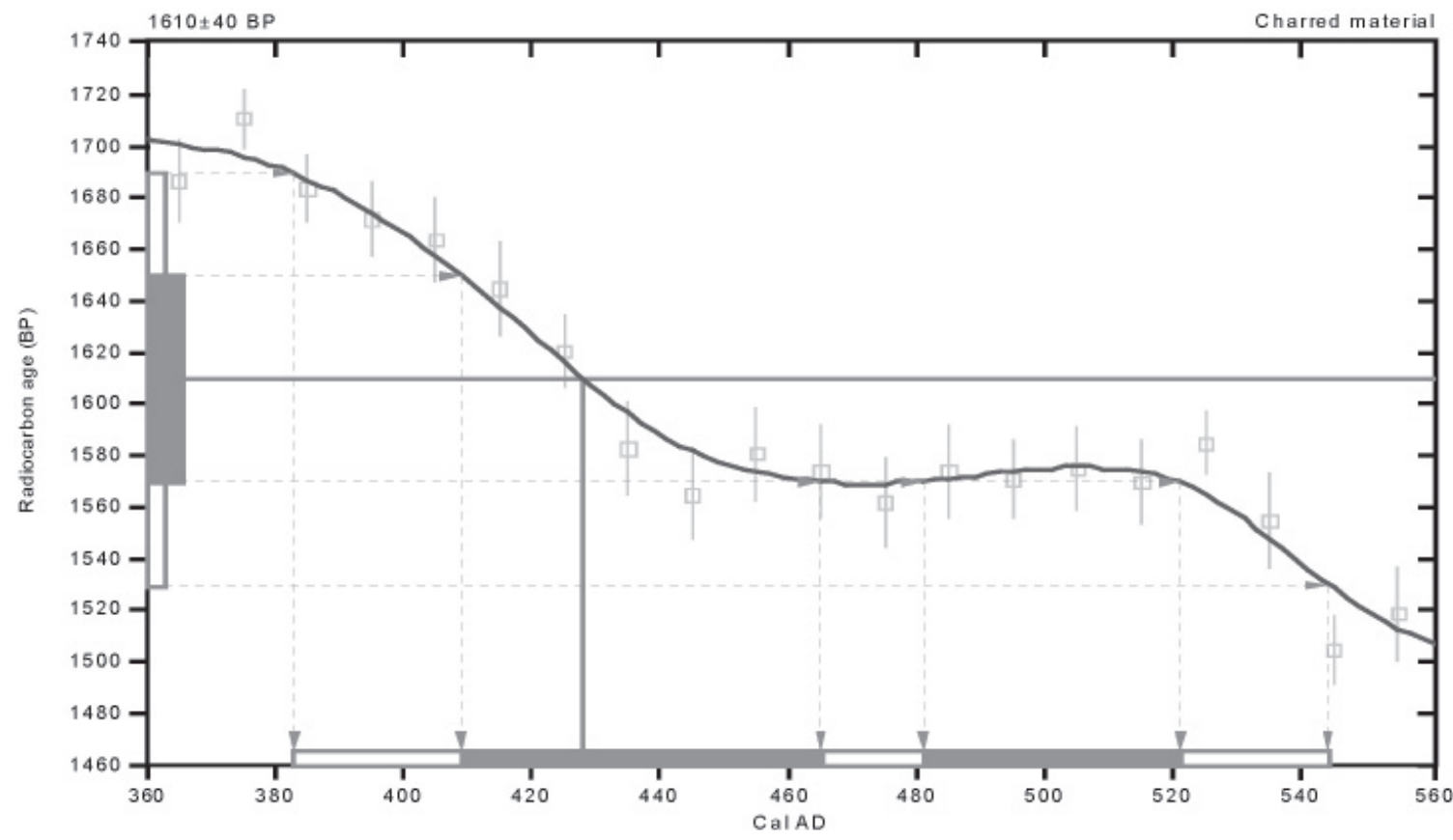

References:

Database used

Calibration Database

Editorial Comment

Stuiver, M.. van der Plicht, H., 1998, Radiocarbon 40(3), pxii-xiii

INTCA L98 Radiocarbon Age Calibration

Stuiver, M., et. al., I998, Radiocarbon 40(3), p1041-1083

M ath em atics

A Simplified Approach to Calibrating C1 D ates

Talma, A. S., Vogel, J. C., 1993, Radiocarbon 35(2), p317-322

\section{Beta Analytic Inc.}

4985 SW 74 Court, Miami, Florida 33155 USA $\cdot$ Tel: (305) 667 5167 * Fax: (305) $6630964 \cdot$ E-Mail: beta@ radiocarbon.com 


\section{CALIBRATION OF RADIOCARBON AGE TO CALENDAR YEARS}

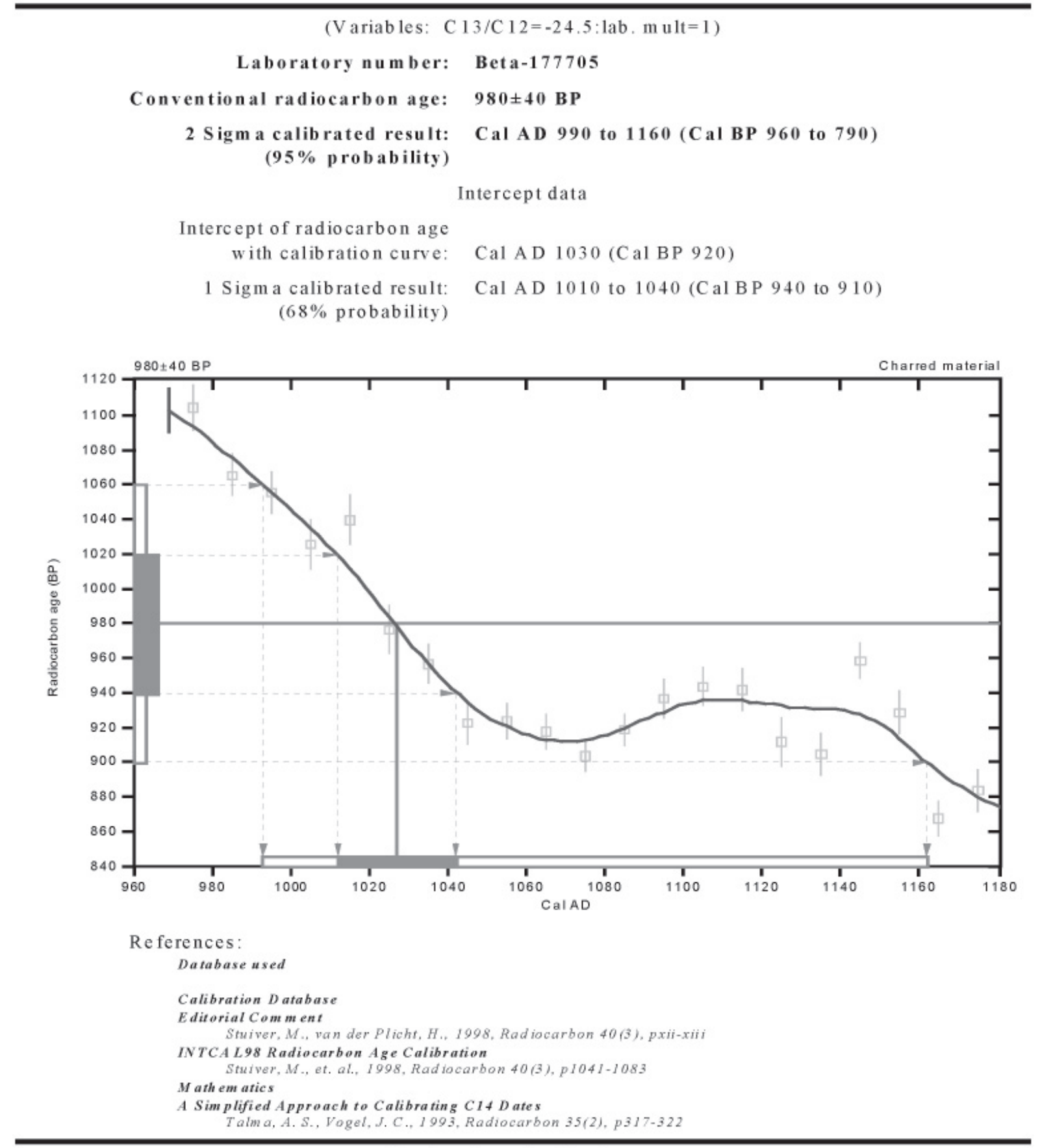

\section{Beta Analytic Inc.}

4985 SW 74 Court, Miami, Florida 33155 USA $\cdot$ Tel: (305) $6675167 \cdot$ Fax: (305) $6630964 \cdot$ E-Mail: betala radiocarbon.com 


\section{CALIBRATION OF RADIOCARBON AGE TO CALENDAR YEARS}

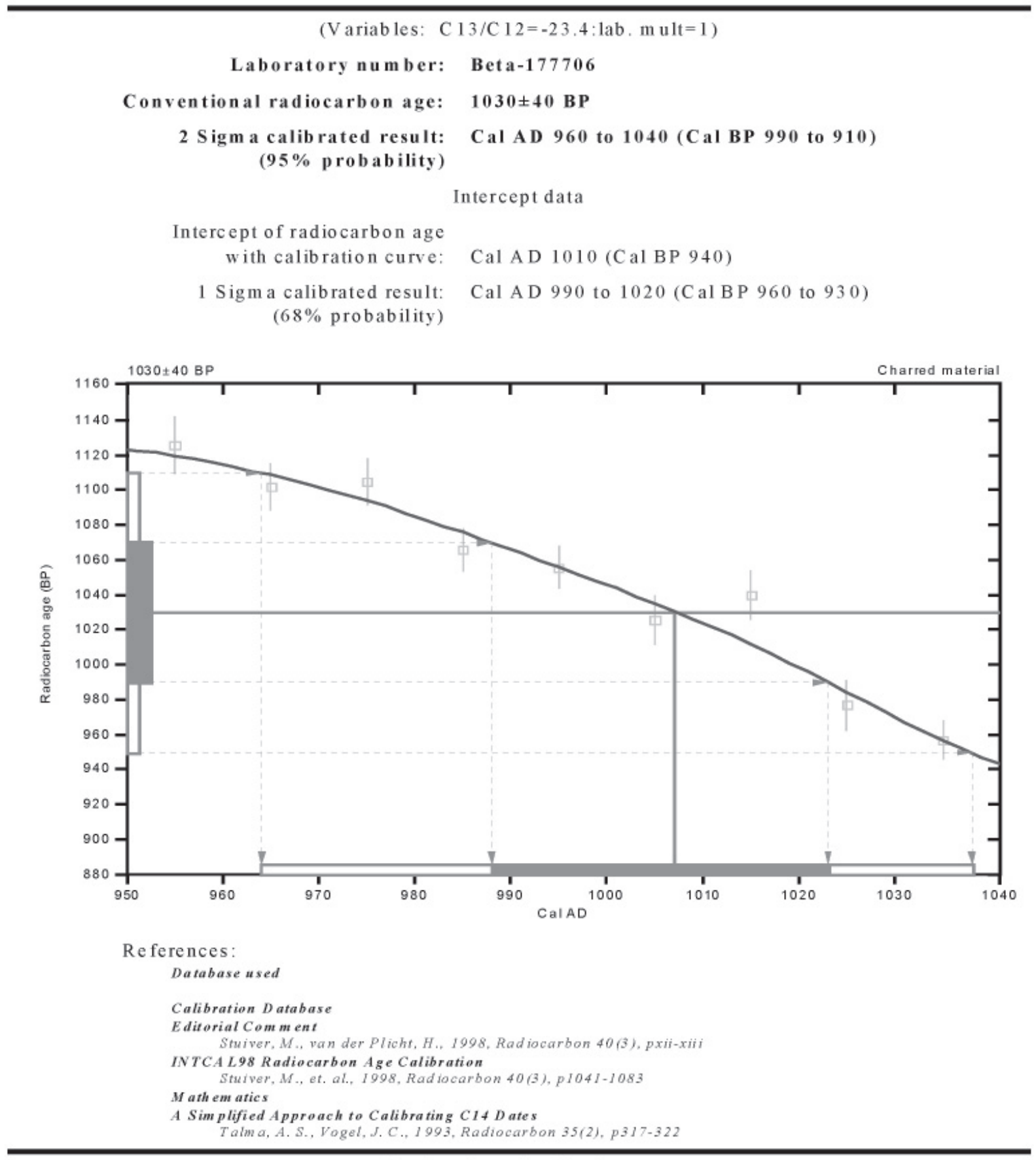

\section{Beta Analytic Inc.}

4985 SW 74 Court, Miami, Florida 33155 USA $\cdot$ Tel: (305) $6675167 \cdot$ Fax: (305) $6630964 \cdot$ E-Mail: beta@ radiocarbon.com 


\section{CALIBRATION OF RADIOCARBON AGE TO CALENDAR YEARS}

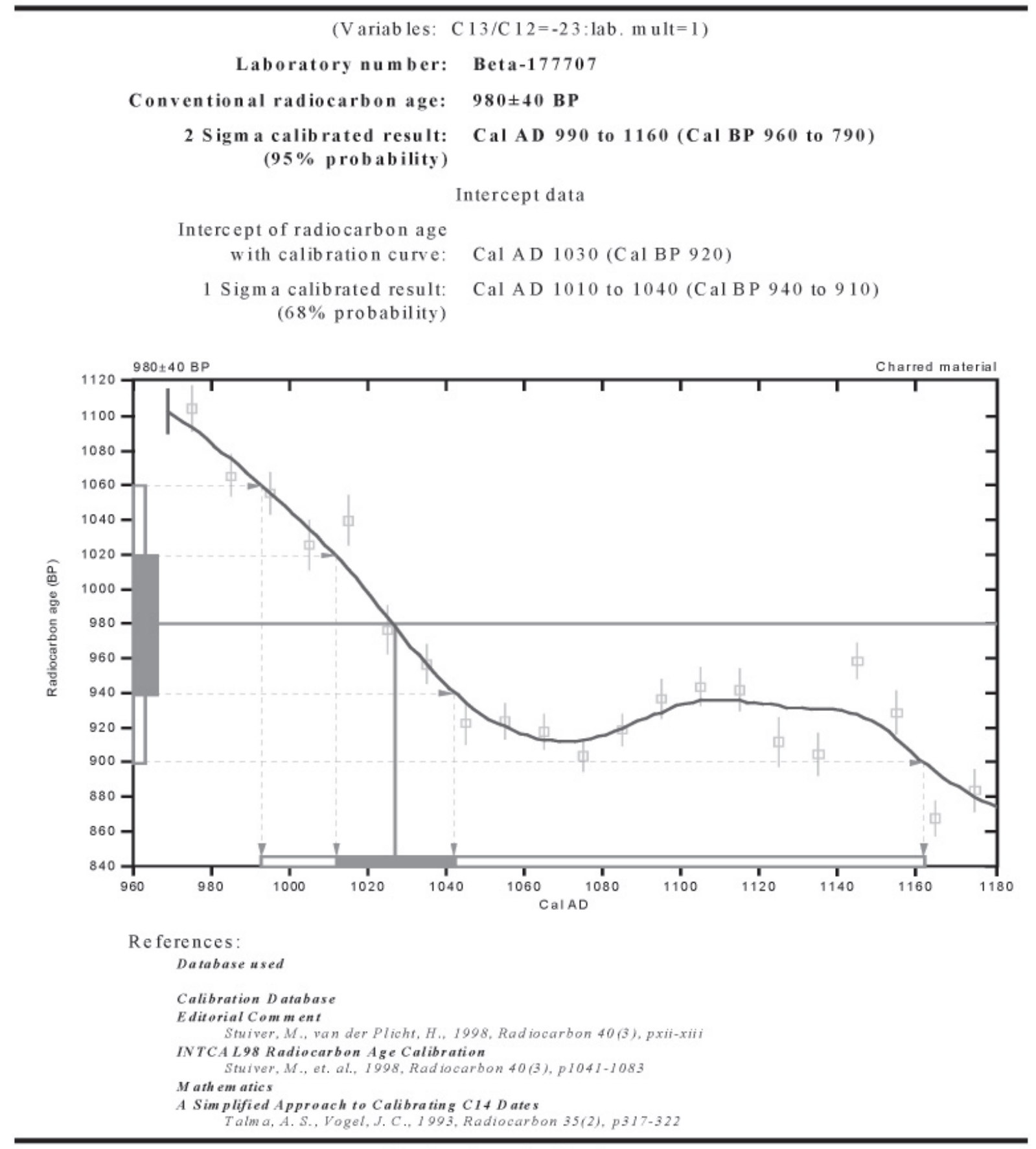

\section{Beta Analytic Inc.}

4985 SW 74 Court, Miami, Florida 33155 USA $\cdot$ Tel: (305) $6675167 \cdot$ Fax: (305) $6630964 \cdot$ E-Mail: betala radiocarbon.com 



\section{APPENDIX C \\ Late Archaic and Late Prehistoric Bison Remains from South and Central Texas}

Raymond Mauldin and

Leonard Kemp

CAR -UTSA 



\section{Association of Bison and Diagnostics or Radiocarbon Dates}

1. Direct association between radiocarbon dated material and bison. That is, there is at least 1 case where a radiocarbon date comes from the same provenience (level or feature) as bison remains for the site. This would include situations where we have a direct date on bison bone. Also, there are NO other data that indicate earlier or later occupations at the site level.

2. Direct association between radiocarbon dated material and bison. That is, there is at least 1 case where a radiocarbon date comes from the same provenience (level or feature) as bison remains for the site. This would include situations where we have a direct date on bison bone. There are some data that indicate earlier or later occupations at the site level.

3. There is a direct association (same level or feature) of bison with diagnostic artifacts from a single phase or period, and there are no other data indicating earlier or later use of the site.

4. There are no direct associations (same level or feature) between radiocarbon dates or diagnostics and bison that could be clearly documented given available data, but all materials from the site date to a single phase or period. Or there is a direct association (same level or feature) of bison with diagnostic artifacts from a single phase or period, but there are also material that indicate earlier or later use of the site.

5. There are no direct associations (same level or feature) between bison and radiocarbon dates or diagnostic artifacts that could be clearly documented given available data, and while there are indications of earlier or later uses of the site, the majority of dates and/or diagnostics indicate a single period or phase of use.

6. There are no direct associations at a level or feature between diagnostics or dates and bison, and there is no clearly dominant period of use indicated by diagnostics or dates at the site level.

7. There is simply not enough detail reported to make any assessment of association, the original researcher discounts the association, or the secondary researcher presents additional data that appears to contradict the original report.

Note that the code of 0 indicates no bison were present at this component.

Table C-1.

\begin{tabular}{|c|c|c|}
\hline Fields & Explanation & Codes \\
\hline Status & Status of site or component & $1=$ used, $0=$ not used. \\
\hline Trinomial & trinomial number & \\
\hline Site Name & site name, if available & \\
\hline County & Texas county & \\
\hline Bison +/- & $\begin{array}{l}\text { Presence/absence of bison. Note that cases of "Very } \\
\text { Large Mammal", "Cow/Bison", "Probably Bison", and } \\
\text { "cf. Bison" are not included as present }\end{array}$ & $\begin{array}{l}1=\text { present, } 0=\text { absent. Note that if blank the component should } \\
\text { have a "0" status. }\end{array}$ \\
\hline Interval & numeric equivalent of period. & $\begin{array}{l}\text { Five possible values. } 1=\text { Terminal Late Prehistoric, } 2=\text { Initial Late } \\
\text { Prehistoric, } 3=\text { Terminal Late Archaic, } 4=\text { Middle Late Archaic, } 5= \\
\text { Initial Late Archaic. (see Table } 8-3 \text { ). }\end{array}$ \\
\hline Association. & $\begin{array}{l}\text { Association-an assessment of the strength of the } \\
\text { association between bison presence and dates. }\end{array}$ & 0 through 7 . See accompanying sheet above for details. \\
\hline NISP & Number of Identifiable Specimens (bison) & $\begin{array}{l}\text { only securely identified bison included in this count. " } x " \text { code is } \\
\text { used for present but no counts }\end{array}$ \\
\hline Prim. Table & Primary source for site & 1= CAR research design. 2= Dillehay 1974. 3=Huebner 1991 \\
\hline Sec. Table & Secondary source for site & 2= Dillehay 1974. 3=Huebner 1991 \\
\hline Tert. Table & Tertiary source for site & 2= Dillehay 1974. 3=Huebner 1991 \\
\hline Notes & Any additional observations & \\
\hline
\end{tabular}


Table C-2.

\begin{tabular}{|c|c|c|c|c|c|c|c|c|c|c|c|}
\hline Status & Trinomial & Site Name & County & $\begin{array}{c}\text { Bison } \\
+/-\end{array}$ & Interval & Assos. & NISP & \begin{tabular}{c|} 
Prim. \\
Source
\end{tabular} & $\begin{array}{c}\text { Sec. } \\
\text { Source }\end{array}$ & \begin{tabular}{|c|} 
Tert. \\
Source \\
\end{tabular} & NOTES \\
\hline 0 & $41 \mathrm{CM} 1$ & Oblate Site & Comal & 1 & 1 & 7 & 7 & 1 & 2 & 3 & $\begin{array}{l}\text { Mixed: both Perdiz and Scallorn points along } \\
\text { with bison }\end{array}$ \\
\hline 0 & 41BL23 & Penny Winkle & Bell & 0 & 1 & 0 & 0 & 1 & & & $\begin{array}{l}\text { No faunal numbers referenced - faunal material } \\
\text { present. No anlaysis. }\end{array}$ \\
\hline 0 & 41BL23 & Penny Winkle & Bell & 0 & 2 & 0 & 0 & 1 & & & $\begin{array}{l}\text { No faunal numbers referenced - faunal material } \\
\text { present. No anlaysis. }\end{array}$ \\
\hline 0 & 41BL23 & Penny Winkle & Bell & 0 & 3 & 0 & 0 & 1 & & & $\begin{array}{l}\text { No faunal numbers referenced - faunal material } \\
\text { present. No anlaysis. }\end{array}$ \\
\hline 0 & $41 \mathrm{FY} 42$ & Frisch Auf! & Fayette & 0 & & & 0 & 1 & & & $\begin{array}{l}\text { Site consists of burials - no faunal material is } \\
\text { specifically referenced. }\end{array}$ \\
\hline 0 & $41 \mathrm{HI} 8$ & Blum Shelter & Hill & 0 & 1 & 0 & 0 & 1 & & & Also known as $41-26 D 7-42$, no faunal referenced \\
\hline 0 & $41 \mathrm{HI} 8$ & Blum Shelter & Hill & 0 & 2 & 0 & 0 & 1 & & & Also known as $41-26 D 7-42$, no faunal referenced \\
\hline 0 & 41TV87 & Barton Road & Travis & 0 & & 0 & 0 & 2 & & & $\begin{array}{l}\text { No provenince for bison. "non-cultural unit } \\
\text { associated with bison present" - zero details }\end{array}$ \\
\hline 0 & $41 \mathrm{VV} 3$ & Doss & Val Verde & 0 & 5 & 0 & 0 & 2 & & & $\begin{array}{l}\text { No faunal referenced in report - unclear if any } \\
\text { were recovered or what they were. }\end{array}$ \\
\hline 0 & 41VV422 & Techo Bravo & Val Verde & 0 & & 0 & 0 & 2 & & & $\begin{array}{l}\text { Bison absent - but only } 4 \text { projectile points were } \\
\text { present - reflect at least two time periods }\end{array}$ \\
\hline 0 & $41 \mathrm{AS} 1$ & Johnston & Aransas & 1 & & & $x$ & 2 & & & $\begin{array}{l}\text { Bison noted as present but no provenince given. } \\
\text { Multiple time periods. }\end{array}$ \\
\hline 0 & 41AS2 & $\begin{array}{c}\text { Live Oak Point } \\
\text { Site }\end{array}$ & Aransas & 1 & & & 1 & 3 & & & $\begin{array}{l}\text { One femur present with what looks like metal cut } \\
\text { marks. Some Eupopean goods. Probably late. }\end{array}$ \\
\hline 0 & 41BP279 & Wagner Site & Bastrop & 1 & & & $\mathrm{x}$ & 3 & & & $\begin{array}{l}\text { Bison may be present - but not clearly identified. } \\
\text { No provenience. Multiple time periods }\end{array}$ \\
\hline 0 & $41 \mathrm{~B} \times 228$ & $\begin{array}{c}\text { Panther } \\
\text { Springs Creek }\end{array}$ & Bexar & 1 & & & 5 & 1 & 3 & & Bison present but contexts are distubed. \\
\hline 0 & $41 \mathrm{CK} 87$ & Airosa & Coke & 1 & & & & 2 & & & $\begin{array}{l}\text { Bison present, but no provenience and multiple } \\
\text { time periods }\end{array}$ \\
\hline 0 & $41 \mathrm{CM} 2$ & Footbridge & Comal & 1 & & & $x$ & 2 & & & $\begin{array}{l}\text { Bison noted as present - but no details given - } \\
\text { multiple point types present - no bison prov. }\end{array}$ \\
\hline 0 & $41 \mathrm{CM} 3$ & Wunderlich & Comal & 1 & & & & 2 & & & $\begin{array}{l}\text { Bison noted as present - but no detials given - } \\
\text { multiple point types present - no bison prov. }\end{array}$ \\
\hline 0 & 41FY135 & Sandbur Site & Fayette & 1 & & & & 1 & & & No clearly defined components at this site \\
\hline 0 & $41 \mathrm{GD} 30$ & $\begin{array}{l}\text { Berger Bluff } \\
\text { Site }\end{array}$ & Goliad & 1 & & & 4 & 3 & & & cf. Bos/ cf. bison only. - no clear identification. \\
\hline 0 & 41GL1 & $\begin{array}{l}\text { Lehman } \\
\text { Rockshelter }\end{array}$ & Gillespie & 1 & & & $\mathrm{x}$ & 1 & 2 & & No faunal provenince - mixed time periods \\
\hline 0 & $41 \mathrm{HI} 53$ & $\begin{array}{l}\text { Pictograph } \\
\text { Shelter }\end{array}$ & Hill & 1 & & & 1 & 1 & & & $\begin{array}{l}\text { No provenince for bison - several time periods } \\
\text { represented }\end{array}$ \\
\hline 0 & $41 \mathrm{HY} 209 \mathrm{M}$ & $\begin{array}{l}\text { Mustang } \\
\text { Branch }\end{array}$ & Hays & 1 & & & 90 & 1 & 3 & & $\begin{array}{l}\text { Bison is primarily levels } 0,1 \text {, and } 2 \text { - these levels } \\
\text { are mixed with a variety of point types present }\end{array}$ \\
\hline 0 & $41 \mathrm{KR} 10$ & Bammel site & Kerr & 1 & & & & 1 & & & $\begin{array}{l}\text { Bison present - but strata have multiple time } \\
\text { periods represented }\end{array}$ \\
\hline 0 & 41LK41 & 41LK41 & Live Oak & 1 & & & 3 & 3 & & & $\begin{array}{l}\text { Cow/bison noted - diagnostics dominated by } \\
\text { terminal late prehistoric material. }\end{array}$ \\
\hline 0 & 41ME19 & 41ME19 & Medina & 1 & & & & 3 & & & Bison or cow \\
\hline 0 & 41ME29 & Jonas Terrace & Medina & 1 & & & 13 & 1 & & & $\begin{array}{l}\text { Bison is present with a variety of point styles in } \\
\text { the same unit and level }\end{array}$ \\
\hline 0 & 41TV151 & $\begin{array}{l}\text { Jetta Court } \\
\text { Site }\end{array}$ & Travis & 1 & & & 4 & 3 & & & Bison present but mixed context. \\
\hline 0 & 41TV163 & Millican Bench & Travis & 1 & & & & 1 & & & $\begin{array}{l}\text { Bison sized - associaiton unclear - only identified } \\
\text { to Area E - Late Archaic AU }\end{array}$ \\
\hline 0 & $41 T V 69$ & $\begin{array}{l}\text { Boy Scout } \\
\text { Shelter }\end{array}$ & Travis & 1 & & & $\mathrm{x}$ & 2 & 3 & & $\begin{array}{l}\text { Bison present but no provenince and multiple } \\
\text { time periods. }\end{array}$ \\
\hline 0 & 41UV21 & La Jita Site & Uvalde & 1 & & & 28 & 3 & & & $\begin{array}{l}\text { Bison identified only by size and morphology - no } \\
\text { provenince given - multiple time periods }\end{array}$ \\
\hline
\end{tabular}


Table C-2. Continued...

\begin{tabular}{|c|c|c|c|c|c|c|c|c|c|c|c|}
\hline Status & Trinomial & Site Name & County & $\begin{array}{c}\text { Bison } \\
+/-\end{array}$ & Interval & Assos. & NISP & \begin{tabular}{|l|} 
Prim. \\
Source
\end{tabular} & $\begin{array}{l}\text { Sec. } \\
\text { Source }\end{array}$ & \begin{tabular}{|c|} 
Tert. \\
Source
\end{tabular} & NOTES \\
\hline 0 & $41 \mathrm{VV} 263$ & $\begin{array}{l}\text { Piedra del } \\
\text { Diablo }\end{array}$ & Val Verde & 1 & & & & 2 & & & $\begin{array}{l}\text { Text cites only large mammal which author says is } \\
\text { deer, antelope and bison - multiple time periods }\end{array}$ \\
\hline 0 & 41WM133 & Loeve Site & Williamson & 1 & & & $x$ & 1 & & & $\begin{array}{l}\text { Site is too early - and provenince data is non- } \\
\text { existent. }\end{array}$ \\
\hline 0 & $41 \mathrm{MC} 290$ & $41 \mathrm{MC} 290$ & McMullen & & & & 0 & 3 & & & Historic site - probably a typo in Huebner \\
\hline 0 & 41NU103 & $41 \mathrm{NU} 103$ & Nueces & & & & & 3 & & & $\begin{array}{l}\text { No data to support Huebner's assertaion that } \\
\text { bison is present. No testing at site. }\end{array}$ \\
\hline 0 & $41 N U 185$ & Allison Site & Nueces & & & & 1 & 3 & & & Bovid ( $n=1$ ) "probably" represents bison \\
\hline 0 & $41 \mathrm{NU} 33$ & $41 \mathrm{NU} 33$ & Nueces & & & & & 3 & & & $\begin{array}{l}\text { No data to support Huebner's assertaion that } \\
\text { bison is present. }\end{array}$ \\
\hline 0 & $41 \mathrm{TV} 40$ & Collins Site & Travis & & & & & 3 & & & $\begin{array}{l}\text { No faunal material mentioned in report - Huebner } \\
\text { cites as bison present }\end{array}$ \\
\hline 0 & $41 \mathrm{VV} 11$ & $41 \mathrm{VV} 11$ & Val Verde & & & & & 2 & & & $\begin{array}{l}\text { Error in Dillehay - the McClurkan } 1966 \text { reference } \\
\text { is for work near LA border. No testing at 41VV11 }\end{array}$ \\
\hline 0 & 41VV99 & $\begin{array}{l}\text { Arenosa } \\
\text { Shelter }\end{array}$ & Val Verde & & & & & 2 & & & $\begin{array}{l}\text { Report states faunal collection has not yet been } \\
\text { studied. - not clear if bison present or absent }\end{array}$ \\
\hline 0 & 41WM49 & $\begin{array}{l}\text { John Ischy } \\
\text { Site }\end{array}$ & Williamson & & & & & 2 & & & $\begin{array}{l}\text { cf. Bison identified - mutiple time periods } \\
\text { reflected in types. }\end{array}$ \\
\hline 1 & 41BL104 & Evoe Terrace & Bell & 1 & 5 & 5 & 21 & 2 & & & \\
\hline 1 & 41BL104 & Evoe Terrace & Bell & 1 & 4 & 5 & 15 & 2 & & & \\
\hline 1 & 41BL104 & Evoe Terrace & Bell & 1 & 3 & 5 & 17 & 2 & & & \\
\hline 1 & 41BL104 & Evoe Terrace & Bell & 1 & 1 & 5 & 1 & 2 & & & \\
\hline 1 & 41BL85 & Landslide & Bell & 1 & 5 & 2 & $x$ & 2 & & & $\begin{array}{l}\text { No numbers referenced in report - direct date on } \\
\text { bison bone! }\end{array}$ \\
\hline 1 & 41BN33 & $\begin{array}{l}\text { Rainey } \\
\text { Sinkhole }\end{array}$ & Bandera & 1 & 2 & 5 & 9 & 1 & 3 & & \\
\hline 1 & 41BN33 & $\begin{array}{l}\text { Rainey } \\
\text { Sinkhole }\end{array}$ & Bandera & 1 & 1 & 5 & 23 & 1 & 3 & & \\
\hline 1 & 41BR420 & 41BR420 & Brown & 1 & 2 & 5 & 3 & 1 & & & \\
\hline 1 & 41BR420 & 41BR420 & Brown & 0 & 3 & 0 & 0 & 1 & & & \\
\hline 1 & $41 \mathrm{CC} 131$ & Currie Site & Concho & 1 & 1 & 4 & 3421 & 1 & 3 & & $\begin{array}{l}83 \text { Bos/bison - problem with counts - could be } \\
3240\end{array}$ \\
\hline 1 & $41 \mathrm{CC} 222$ & $41 \mathrm{CC} 222$ & Concho & 1 & 5 & 7 & $x$ & 3 & & & $\begin{array}{l}\text { Bison noted as present, but distribuiton relies on } \\
\text { "bison sized" data }\end{array}$ \\
\hline 1 & $41 \mathrm{CC} 222$ & $41 \mathrm{CC} 222$ & Concho & 1 & 0 & 7 & $x$ & 3 & & & $\begin{array}{l}\text { Bison noted as present, but distribuiton relies on } \\
\text { "bison sized" data }\end{array}$ \\
\hline 1 & 41CK30 & Agarita & Coke & 1 & 1 & 7 & $x$ & 2 & & & See notes page \\
\hline 1 & 41CK76 & Gypsum Bluff & Coke & 1 & 1 & 7 & 4 & 2 & & & \\
\hline 1 & $41 C K 79$ & Sand Creek & Coke & 1 & 1 & 7 & 1 & 2 & & & $\begin{array}{l}\text { No prov. on bison. Note also earlier point types } \\
\text { present in small quantities }\end{array}$ \\
\hline 1 & 41CM1 & Oblate Site & Comal & 0 & 2 & 0 & 0 & 1 & 2 & 3 & $\begin{array}{l}\text { Mixed: both terminal late archaic and initial late } \\
\text { prehistoric forms present - no bison }\end{array}$ \\
\hline 1 & $41 \mathrm{CM} 1$ & Oblate Site & Comal & 1 & 4 & 7 & 2 & 1 & 2 & 3 & A few initial late archaic points also present \\
\hline 1 & $41 \mathrm{CM} 1$ & Oblate Site & Comal & 1 & 3 & 7 & $x$ & 1 & 2 & 3 & A few middle late archaic points present \\
\hline 1 & 41CN95 & 41CN95 & Coleman & 0 & 3 & 0 & 0 & 1 & & & \\
\hline 1 & 41CN95 & 41CN95 & Coleman & 1 & 1 & 3 & 938 & 1 & & & \\
\hline 1 & $41 \mathrm{FY} 74$ & $\begin{array}{l}\text { Cedar Bridge } \\
\text { Site }\end{array}$ & Fayette & 1 & 1 & 5 & 28 & 1 & 3 & & See notes page \\
\hline 1 & $41 \mathrm{GD} 21$ & 41GD21 & Goliad & 1 & 5 & 5 & 1 & 3 & & & $\begin{array}{l}\text { Some earlier point types present - c14 dates } \\
\text { place at beginning of interval } 5\end{array}$ \\
\hline 1 & $41 \mathrm{GD} 21$ & $41 \mathrm{GD} 21$ & Goliad & 1 & 1 & 7 & 3 & 3 & & & $\begin{array}{l}\text { Early point types and c14 dates present in "Area } \\
\text { A" }\end{array}$ \\
\hline 1 & $41 \mathrm{GD} 4$ & Berclair & Goliad & 1 & 1 & 6 & $x$ & 2 & 3 & & No numbers referenced \\
\hline
\end{tabular}


Table C-2. Continued...

\begin{tabular}{|c|c|c|c|c|c|c|c|c|c|c|c|}
\hline Status & Trinomial & Site Name & County & $\begin{array}{c}\text { Bison } \\
+/-\end{array}$ & Interval & Assos. & NISP & \begin{tabular}{|l|} 
Prim. \\
Source
\end{tabular} & \begin{tabular}{c|} 
Sec. \\
Source
\end{tabular} & \begin{tabular}{|c|} 
Tert. \\
Source
\end{tabular} & NOTES \\
\hline 1 & $41 \mathrm{HI} 1$ & Kyle Shelter & Hill & 0 & 2 & 0 & 0 & 1 & 3 & & \\
\hline 1 & $41 \mathrm{HI} 1$ & Kyle Shelter & Hill & 1 & 1 & 7 & 4 & 1 & 3 & & \\
\hline 1 & 41HI117 & $\begin{array}{l}\text { Bear Creek } \\
\text { Shelter }\end{array}$ & Hill & 1 & 5 & 4 & 1 & 3 & & & \\
\hline 1 & $41 \mathrm{HI} 117$ & $\begin{array}{l}\text { Bear Creek } \\
\text { Shelter }\end{array}$ & Hill & 1 & 4 & 4 & 1 & 3 & & & \\
\hline 1 & 41HI117 & $\begin{array}{l}\text { Bear Creek } \\
\text { Shelter }\end{array}$ & Hill & 1 & 1 & 4 & 3 & 3 & & & \\
\hline 1 & 41HI54 & $\begin{array}{l}\text { Buzzard } \\
\text { Shelter }\end{array}$ & Hill & 0 & 2 & 0 & 0 & 1 & & & Also known as $41-26 \mathrm{D} 7-12$ \\
\hline 1 & $41 \mathrm{HI} 54$ & $\begin{array}{l}\text { Buzzard } \\
\text { Shelter }\end{array}$ & Hill & 0 & 1 & 0 & 0 & 1 & & & Also known as $41-26 \mathrm{D} 7-12$ \\
\hline 1 & 41HI55 & Sheep Shelter & Hill & 0 & 2 & 0 & 0 & 1 & & & Also known as $41-26 \mathrm{D} 7-20$ \\
\hline 1 & $41 \mathrm{HI} 55$ & Sheep Shelter & Hill & 0 & 4 & 0 & 0 & 1 & & & Also known as $41-26 \mathrm{D} 7-20$ \\
\hline 1 & 41HI55 & Sheep Shelter & Hill & 0 & 3 & 0 & 0 & 1 & & & Also known as $41-26 \mathrm{D} 7-20$ \\
\hline 1 & 41HI55 & Sheep Shelter & Hill & 0 & 1 & 0 & 0 & 1 & & & Also known as $41-26 \mathrm{D} 7-20$ \\
\hline 1 & $41 \mathrm{HY} 202 \mathrm{~A}$ & $\begin{array}{l}\text { Mustang } \\
\text { Branch }\end{array}$ & Hays & 1 & 1 & 4 & 32 & 1 & & & \\
\hline 1 & 41HY202B & $\begin{array}{l}\text { Mustang } \\
\text { Branch }\end{array}$ & Hays & 1 & 4 & 2 & 46 & 1 & & & 73 bison-sized \\
\hline 1 & 41HY209T & $\begin{array}{l}\text { Mustang } \\
\text { Branch }\end{array}$ & Hays & 1 & 2 & 4 & 1 & 1 & 3 & & \\
\hline 1 & 41HY209T & $\begin{array}{l}\text { Mustang } \\
\text { Branch }\end{array}$ & Hays & 0 & 3 & 0 & 0 & 1 & 3 & & \\
\hline 1 & 41HY209T & $\begin{array}{l}\text { Mustang } \\
\text { Branch }\end{array}$ & Hays & 1 & 1 & 4 & 121 & 1 & 3 & & \\
\hline 1 & 41JW8 & Hinojosa Site & Jim Wells & 1 & 1 & 4 & 45 & 1 & 3 & & \\
\hline 1 & $41 \mathrm{KM} 16$ & $\begin{array}{l}\text { Buckhollow } \\
\text { site }\end{array}$ & Kimble & 1 & 1 & 5 & 5 & 1 & & & \\
\hline 1 & 41KM69 & Flatrock Road & Kimble & 0 & 2 & 0 & 0 & 1 & & & \\
\hline 1 & 41KM69 & Flatrock Road & Kimble & 0 & 3 & 0 & 0 & 1 & & & \\
\hline 1 & 41KM69 & Flatrock Road & Kimble & 1 & 1 & 4 & 1 & 1 & & & \\
\hline 1 & 41LK201 & 41LK201 & Live Oak & 1 & 5 & 5 & 1 & 1 & 3 & & \\
\hline 1 & 41LK201 & 41LK201 & Live Oak & 1 & 1 & 4 & 15 & 1 & 3 & & \\
\hline 1 & 41LK67 & 41LK67 & Live Oak & 0 & 5 & 0 & 0 & 3 & & & Huebner cites as bison present - report says not. \\
\hline 1 & $41 \mathrm{LK} 67$ & 41LK67 & Live Oak & 0 & 4 & 0 & 0 & 3 & & & Huebner cites as bison present - report says not. \\
\hline 1 & 41LK67 & 41LK67 & Live Oak & 0 & 1 & 0 & 0 & 3 & & & Huebner cites as bison present - report says not. \\
\hline 1 & $41 \mathrm{MC} 222$ & $\begin{array}{l}\text { Skillet } \\
\text { Mountain }\end{array}$ & McMullen & 1 & 1 & 5 & 33 & 1 & 3 & & \\
\hline 1 & $41 \mathrm{MC} 296$ & $41 \mathrm{MC} 296$ & McMullen & 1 & 2 & 5 & 5 & 1 & & & \\
\hline 1 & $41 \mathrm{MC} 296$ & $41 \mathrm{MC} 296$ & McMullen & 1 & 4 & 5 & 1 & 1 & & & \\
\hline 1 & $41 \mathrm{MC} 296$ & $41 \mathrm{MC} 296$ & McMullen & 1 & 1 & 5 & 4 & 1 & & & \\
\hline 1 & 41MC55 & 41MC55 & McMullen & 1 & 1 & 4 & $x$ & 3 & & & No numbers referenced \\
\hline 1 & 41ML35 & Baylor Site & McLennan & 0 & 2 & 0 & 0 & 1 & 2 & & \\
\hline 1 & 41ML35 & Baylor Site & McLennan & 0 & 3 & 0 & 0 & 1 & 2 & & \\
\hline 1 & 41ML35 & Baylor Site & McLennan & 0 & 1 & 0 & 0 & 1 & 2 & & \\
\hline 1 & 41ML37 & Britton Site & McLennan & 0 & 3 & 0 & 0 & 1 & 2 & & \\
\hline 1 & 41ML39 & 41ML39 & McLennan & 0 & 1 & 0 & 0 & 3 & & & $\begin{array}{l}\text { Huebner cites bison - no bison is cited in this } \\
\text { report }\end{array}$ \\
\hline
\end{tabular}


Table C-2. Continued...

\begin{tabular}{|c|c|c|c|c|c|c|c|c|c|c|c|}
\hline Status & Trinomial & Site Name & County & $\begin{array}{c}\text { Bison } \\
+/-\end{array}$ & Interval & Assos. & NISP & \begin{tabular}{|l|} 
Prim. \\
Source
\end{tabular} & $\begin{array}{l}\text { Sec. } \\
\text { Source }\end{array}$ & \begin{tabular}{c|} 
Tert. \\
Source
\end{tabular} & NOTES \\
\hline 1 & $41 \mathrm{MM} 340$ & 41MM340 & Milam & 0 & 5 & 0 & 0 & 1 & & & Bison sized present \\
\hline 1 & $41 \mathrm{MM} 340$ & $41 \mathrm{MM} 340$ & Milam & 1 & 4 & 4 & 1 & 1 & & & Bison sized present \\
\hline 1 & $41 \mathrm{MM} 340$ & $41 \mathrm{MM} 340$ & Milam & 0 & 3 & 0 & 0 & 1 & & & Bison sized present \\
\hline 1 & $41 \mathrm{MM} 341$ & J.B. White & Milam & 0 & 2 & 0 & 0 & 1 & & & \\
\hline 1 & $41 \mathrm{MM} 341$ & J.B. White & Milam & 0 & 2 & 0 & 0 & 1 & & & \\
\hline 1 & 41NU221 & McKinzie Site & Nueces & 1 & 1 & 4 & 19 & 3 & & & \\
\hline 1 & 41NU37 & 41NU37 & Nueces & 1 & 1 & 7 & 6 & 3 & & & \\
\hline 1 & $41 \mathrm{NU} 4$ & $41 \mathrm{NU} 4$ & Nueces & 0 & 1 & 7 & 0 & 3 & & & $\begin{array}{l}\text { No bison noted in report - Huebner cites as present } \\
\text { and cites TARL as reference - He may have id. }\end{array}$ \\
\hline 1 & $41 \mathrm{RF} 21$ & $41 \mathrm{RF} 21$ & Refugio & 1 & 1 & 5 & 289 & 3 & & & \\
\hline 1 & 41RN169 & $\begin{array}{l}\text { Rocky Branch } \\
\text { Site }\end{array}$ & Runnels & 1 & 1 & 3 & 10666 & 1 & 3 & & 418 bison sized \\
\hline 1 & 41SP103 & 41SP103 & $\begin{array}{l}\text { San } \\
\text { Patricio }\end{array}$ & 1 & 1 & 7 & 3 & 3 & & & \\
\hline 1 & 41SP120 & Holmes Site & $\begin{array}{l}\text { San } \\
\text { Patricio }\end{array}$ & 1 & 2 & 5 & 2 & 3 & & & \\
\hline 1 & 41SP120 & Holmes Site & $\begin{array}{l}\text { San } \\
\text { Patricio }\end{array}$ & 1 & 1 & 5 & 8 & 3 & & & \\
\hline 1 & 41SP160 & $41 \mathrm{SP} 160$ & $\begin{array}{l}\text { San } \\
\text { Patricio }\end{array}$ & 1 & 1 & 5 & 2 & 3 & & & \\
\hline 1 & 41SP167 & 41SP167 & $\begin{array}{l}\text { San } \\
\text { Patricio }\end{array}$ & 1 & 1 & 4 & 23 & 3 & & & \\
\hline 1 & 41SP168 & 41SP168 & $\begin{array}{l}\text { San } \\
\text { Patricio }\end{array}$ & 1 & 1 & 5 & 6 & 3 & & & \\
\hline 1 & $41 \mathrm{SP} 170$ & 41SP170 & $\begin{array}{l}\text { San } \\
\text { Patricio }\end{array}$ & 1 & 1 & 4 & 31 & 3 & & & $\begin{array}{l}\text { Notes indicate that this site should be split into } \\
\text { Rockport and Toyah phases }\end{array}$ \\
\hline 1 & $41 \mathrm{SP} 43$ & $41 \mathrm{SP} 43$ & $\begin{array}{l}\text { San } \\
\text { Patricio }\end{array}$ & 0 & 2 & 0 & 0 & 3 & & & $\begin{array}{l}\text { No bison - c14 dates suggest } 800-1000 \text { ad; but } \\
\text { ceramics and perdiz points are diagnostics. }\end{array}$ \\
\hline 1 & $41 \mathrm{SP} 43$ & $41 \mathrm{SP} 43$ & $\begin{array}{c}\text { San } \\
\text { Patricio }\end{array}$ & 0 & 1 & 0 & 0 & 3 & & & $\begin{array}{l}\text { No bison - c14 dates suggest } 800-1000 \text { ad; but } \\
\text { ceramics and perdiz points are diagnostics. }\end{array}$ \\
\hline 1 & $41 S S 20$ & Finis Frost & San Saba & 1 & 1 & 4 & $\mathrm{x}$ & 1 & 3 & & No numbers referenced \\
\hline 1 & 41TG346 & Rush Site & Tom Green & 1 & 1 & 2 & 1111 & 1 & & & 9911 bison sized- occupation 4 only \\
\hline 1 & 41TG91 & $\begin{array}{l}\text { East Levee } \\
\text { Site }\end{array}$ & Tom Green & 0 & 4 & 0 & 0 & 1 & 3 & & \\
\hline 1 & 41TG91 & $\begin{array}{l}\text { East Levee } \\
\quad \text { Site }\end{array}$ & Tom Green & 1 & 1 & 4 & 143 & 1 & 3 & & 880 bison sized, 1 buffalo? \\
\hline 1 & 41TV42 & $\begin{array}{l}\text { Smith } \\
\text { Rockshelter }\end{array}$ & Travis & 0 & 2 & 0 & 0 & 1 & 2 & 3 & Some mixing \\
\hline 1 & 41TV42 & $\begin{array}{l}\text { Smith } \\
\text { Rockshelter }\end{array}$ & Travis & 1 & 3 & 7 & $\mathrm{x}$ & 1 & 2 & 3 & Some mixing \\
\hline 1 & 41TV42 & $\begin{array}{l}\text { Smith } \\
\text { Rockshelter }\end{array}$ & Travis & 1 & 1 & 7 & $x$ & 1 & 2 & 3 & Some mixing \\
\hline 1 & 41TV441 & $\begin{array}{l}\text { Toyah Bluff } \\
\text { Site }\end{array}$ & Travis & 1 & 1 & 5 & 3 & 1 & & & $\begin{array}{l}\text { Block } 1 \text { data only - block } 2 \text { contains Scallorn, } \\
\text { Perdiz, and Ensor along with bison. }\end{array}$ \\
\hline 1 & 41VT66 & Burris Site & Victoria & 1 & 1 & 4 & 60 & 3 & & & Approximate number of NISP \\
\hline 1 & 41VV161 & 41VV161 & Val Verde & 0 & 4 & 0 & 0 & 2 & & & \\
\hline 1 & 41VV161 & 41VV161 & Val Verde & 0 & 3 & 0 & 0 & 2 & & & \\
\hline 1 & 41VV162 & $41 \mathrm{VV} 162$ & Val Verde & 0 & 5 & 0 & 0 & 2 & & & $\begin{array}{l}\text { Other periods represented by small quantities of } \\
\text { diagnostics }\end{array}$ \\
\hline 1 & 41VV162 & 41VV162 & Val Verde & 0 & 4 & 0 & 0 & 2 & & & $\begin{array}{l}\text { Other periods represented by small quantities of } \\
\text { diagnostics }\end{array}$ \\
\hline 1 & 41VV162 & $41 \mathrm{VV} 162$ & Val Verde & 0 & 3 & 0 & 0 & 2 & & & $\begin{array}{l}\text { Other periods represented by small quantities of } \\
\text { diagnostics }\end{array}$ \\
\hline
\end{tabular}


Table C-2. Continued...

\begin{tabular}{|c|c|c|c|c|c|c|c|c|c|c|c|}
\hline Status & Trinomial & Site Name & County & $\begin{array}{c}\text { Bison } \\
+/-\end{array}$ & Interval & Assos. & NISP & \begin{tabular}{|l|} 
Prim. \\
Source
\end{tabular} & \begin{tabular}{c|} 
Sec. \\
Source
\end{tabular} & \begin{tabular}{c|} 
Tert. \\
Source
\end{tabular} & NOTES \\
\hline 1 & 41VV167 & Eagle Cave & Val Verde & 0 & 5 & 0 & 0 & 2 & & & $\begin{array}{l}\text { Dillehay cites as both present and absent in same } \\
\text { time period-no faunal recovery cited in report }\end{array}$ \\
\hline 1 & 41VV167 & Eagle Cave & Val Verde & 0 & 3 & 0 & 0 & 2 & & & $\begin{array}{l}\text { Dillehay cites as both present and absent in same } \\
\text { time period-no faunal recovery cited in report }\end{array}$ \\
\hline 1 & 41VV186 & 41VV186 & Val Verde & 0 & 5 & 0 & 0 & 2 & & & \\
\hline 1 & 41VV187 & Parida Cave & Val Verde & 0 & 5 & 0 & 0 & 2 & & & \\
\hline 1 & $41 \mathrm{VV} 187$ & Parida Cave & Val Verde & 0 & 3 & 0 & 0 & 2 & & & \\
\hline 1 & 41VV189 & Damp Cave & Val Verde & 0 & 5 & 0 & 0 & 2 & & & Presence period III \\
\hline 1 & 41VV189 & Damp Cave & Val Verde & 0 & 3 & 0 & 0 & 2 & & & Absence period II \\
\hline 1 & 41VV213 & Baker Cave & Val Verde & 0 & 5 & 0 & 0 & 2 & & & $\begin{array}{l}\text { Some earlier and later points also present in } \\
\text { small quantities }\end{array}$ \\
\hline 1 & 41VV213 & Baker Cave & Val Verde & 0 & 4 & 0 & 0 & 2 & & & $\begin{array}{l}\text { Some earlier and later points also present in } \\
\text { small quantities }\end{array}$ \\
\hline 1 & 41VV213 & Baker Cave & Val Verde & 0 & 3 & 0 & 0 & 2 & & & $\begin{array}{l}\text { Some earlier and later points also present in } \\
\text { small quantities }\end{array}$ \\
\hline 1 & 41VV215 & $\begin{array}{l}\text { Mosquito } \\
\text { Cave }\end{array}$ & Val Verde & 0 & 5 & 0 & 0 & 2 & & & $\begin{array}{l}\text { Earlier and later point types present in small } \\
\text { quantities }\end{array}$ \\
\hline 1 & 41VV215 & $\begin{array}{l}\text { Mosquito } \\
\text { Cave }\end{array}$ & Val Verde & 0 & 4 & 0 & 0 & 2 & & & $\begin{array}{l}\text { Earlier and later point types present in small } \\
\text { quantities }\end{array}$ \\
\hline 1 & 41VV215 & $\begin{array}{l}\text { Mosquito } \\
\text { Cave }\end{array}$ & Val Verde & 0 & 3 & 0 & 0 & 2 & & & $\begin{array}{l}\text { Earlier and later point types present in small } \\
\text { quantities }\end{array}$ \\
\hline 1 & 41VV216 & Zapilote Cave & Val Verde & 0 & 4 & 0 & 0 & 2 & & & $\begin{array}{l}\text { Other periods represented by small quantities of } \\
\text { diagnostics }\end{array}$ \\
\hline 1 & 41VV216 & Zapilote Cave & Val Verde & 0 & 3 & 0 & 0 & 2 & & & $\begin{array}{l}\text { Other periods represented by small quantities of } \\
\text { diagnostics }\end{array}$ \\
\hline 1 & 41VV218 & $\begin{array}{l}\text { Bonfire } \\
\text { Shelter }\end{array}$ & Val Verde & 1 & 4 & 4 & 2152 & 2 & & & Bone bed 3 \\
\hline 1 & 41VV260 & Commack Site & Val Verde & 0 & 4 & 0 & 0 & 2 & & & $\begin{array}{l}\text { Earlier and later point types present in small } \\
\text { quantities }\end{array}$ \\
\hline 1 & 41VV260 & Commack Site & Val Verde & 0 & 3 & 0 & 0 & 2 & & & $\begin{array}{l}\text { Earlier and later point types present in small } \\
\text { quantities }\end{array}$ \\
\hline 1 & 41VV260 & Cammack Site & Val Verde & 0 & 1 & 0 & 0 & 2 & & & Earlier point types present in small quantities \\
\hline 1 & $41 \mathrm{VV} 74$ & $\begin{array}{l}\text { Fate Bell } \\
\text { Shelter }\end{array}$ & Val Verde & 0 & 5 & 0 & 0 & 2 & & & $\begin{array}{l}\text { Other periods represented by small quantities of } \\
\text { diagnostics }\end{array}$ \\
\hline 1 & $41 \mathrm{VV} 74$ & $\begin{array}{l}\text { Fate Bell } \\
\text { Shelter }\end{array}$ & Val Verde & 0 & 3 & 0 & 0 & 2 & & & $\begin{array}{l}\text { Other periods represented by small quantities of } \\
\text { diagnostics }\end{array}$ \\
\hline 1 & $41 \mathrm{VV} 82$ & Coontail Spin & Val Verde & 0 & 5 & 0 & 0 & 2 & & & \\
\hline 1 & $41 \mathrm{VV} 82$ & Coontail Spin & Val Verde & 0 & 4 & 0 & 0 & 2 & & & \\
\hline 1 & $41 \mathrm{VV} 82$ & Coontail Spin & Val Verde & 0 & 3 & 0 & 0 & 2 & & & \\
\hline 1 & 41VV87 & Perry Calk & Val Verde & 0 & 3 & 0 & 0 & 2 & & & \\
\hline 1 & $41 \mathrm{VV} 87$ & Perry Calk & Val Verde & 1 & 1 & 7 & $x$ & 2 & & & $\begin{array}{l}\text { Bison hide - some earlier point sytles also } \\
\text { present. }\end{array}$ \\
\hline 1 & 41WM118 & Dobias-Vitek & Williamson & 1 & 3 & 6 & 1 & 1 & 3 & & \\
\hline 1 & 41WM118 & Dobias-Vitek & Williamson & 1 & 1 & 4 & 1 & 1 & 3 & & \\
\hline 1 & 41WM130 & Hoxie Bridge & Williamson & 1 & 2 & 6 & 1 & 1 & & & Total diagnostics $=24$; average depth $b s=29.7 \mathrm{~cm}$ \\
\hline 1 & 41WM130 & Hoxie Bridge & Williamson & 1 & 3 & 6 & 4 & 1 & & & Total diagnostics $=14 ;$ average depth $\mathrm{bs}=52 \mathrm{~cm}$ \\
\hline 1 & 41WM130 & Hoxie Bridge & Williamson & 1 & 1 & 6 & 1 & 1 & & & $\begin{array}{l}\text { Total diagnostics=ca } 27 \text {; average depth bs= } \\
20.43 \mathrm{~cm}-\end{array}$ \\
\hline 1 & 41WM2 & Merrell Site & Williamson & 1 & 5 & 6 & $x$ & 2 & & & $\begin{array}{l}\text { No numbers referenced-earlier point forms also } \\
\text { present }\end{array}$ \\
\hline 1 & 41WM2 & Merrell Site & Williamson & 1 & 3 & 6 & $x$ & 2 & & & $\begin{array}{l}\text { No numbers referenced-earlier point forms also } \\
\text { present }\end{array}$ \\
\hline
\end{tabular}


Table C-2. Continued...

\begin{tabular}{|c|c|c|c|c|c|c|c|c|c|c|c|}
\hline Status & Trinomial & Site Name & County & $\begin{array}{c}\text { Bison } \\
+/-\end{array}$ & Interval & Assos. & NISP & \begin{tabular}{|l|} 
Prim. \\
Source
\end{tabular} & $\begin{array}{l}\text { Sec. } \\
\text { Source }\end{array}$ & \begin{tabular}{c|} 
Tert. \\
Source
\end{tabular} & NOTES \\
\hline 1 & 41WM230 & $\begin{array}{l}\text { Loeve-Fox } \\
\quad \text { Site }\end{array}$ & Williamson & 1 & 2 & 4 & 1 & 1 & 3 & & \\
\hline 1 & 41WM230 & $\begin{array}{l}\text { Loeve-Fox } \\
\quad \text { Site }\end{array}$ & Williamson & 0 & 4 & 0 & 0 & 1 & 3 & & \\
\hline 1 & 41WM230 & $\begin{array}{l}\text { Loeve-Fox } \\
\quad \text { Site }\end{array}$ & Williamson & 0 & 3 & 0 & 0 & 1 & 3 & & \\
\hline 1 & 41WM230 & $\begin{array}{l}\text { Loeve-Fox } \\
\quad \text { Site }\end{array}$ & Williamson & 0 & 1 & 0 & 0 & 1 & 3 & & \\
\hline 1 & 41WM267 & Cervenka Site & Williamson & 0 & 4 & 0 & 0 & 1 & & & Bison present from earlier phases \\
\hline 1 & 41WM267 & Cervenka Site & Williamson & 0 & 3 & 0 & 0 & 1 & & & Bison present from earlier phases \\
\hline 1 & 41WM437 & Rowe Valley & Williamson & 1 & 1 & 7 & $\mathrm{x}$ & 3 & & & $\begin{array}{l}\text { No numbers referenced - "lots of bison" - "single } \\
\text { component toyah" - no evidence }\end{array}$ \\
\hline 1 & 41WM56 & Hawes Site & Williamson & 0 & 2 & 0 & 0 & 1 & & & Bison present from earlier phases \\
\hline 1 & 41WM56 & Hawes Site & Williamson & 0 & 4 & 0 & 0 & 1 & & & Bison present from earlier phases \\
\hline 1 & 41WM56 & Hawes Site & Williamson & 0 & 3 & 0 & 0 & 1 & & & Bison present from earlier phases \\
\hline 1 & 41WM815 & $\begin{array}{l}\text { Rice's } \\
\text { Crossing }\end{array}$ & Williamson & 0 & 4 & 0 & 0 & 1 & & & \\
\hline 1 & $41 \mathrm{WN} 88$ & Beisenback & Wilson & 1 & 1 & & 1 & 1 & & & \\
\hline 1 & 41ZV155 & $\begin{array}{l}\text { Tortuga Flat } \\
\text { Site }\end{array}$ & Zavala & 1 & 2 & 4 & 1 & 3 & & & \\
\hline 1 & 41ZV155 & $\begin{array}{l}\text { Tortuga Flat } \\
\quad \text { Site }\end{array}$ & Zavala & 1 & 1 & 6 & 2 & 3 & & & \\
\hline 1 & 41ZV202 & 41ZV202 & Zavala & 0 & 2 & 0 & 0 & 1 & & & \\
\hline
\end{tabular}

NB: Codes are explained in Table C-1 

APPENDIX D

Faunal Material from 41ZV202

Barbara A. Meissner

CAR -UTSA 

Table D-1.

\begin{tabular}{|c|c|c|c|c|}
\hline Lot & Taxon & Common Name & Count & Body Size \\
\hline $0-0$ & Unionidae & Unidentified Freshwater Mussels & 1 & \\
\hline $100-2$ & Mammal - VLg & & & $M-V l g$ \\
\hline $1006-0$ & Unionidae & Unidentified Freshwater Mussels & 4 & \\
\hline $1008-4$ & Unionidae & Unidentified Freshwater Mussels & 8 & \\
\hline 101-0 & Canis sp. & Dogs, Wolves, Coyotes & 21 & M-Med \\
\hline $101-0$ & Mammal - Med & & & M-Med \\
\hline 101-0 & Sigmodon hispidus & Hispid Cotton Rat & 1 & M-Vsm \\
\hline 101-0 & Taxidea taxus & American Badger & 2 & $\mathrm{M}-\mathrm{Sm}$ \\
\hline $102-0$ & Mammal & & & \\
\hline $102-0$ & Rodentia & Unidentified Rodents & 1 & M-Vsm \\
\hline $102-0$ & Taxidea taxus & American Badger & 117 & $\mathrm{M}-\mathrm{Sm}$ \\
\hline 1027-6 & Toxolasma sp. & Lilliputs & 1 & \\
\hline 1027-6 & Unionidae & Unidentified Freshwater Mussels & 2 & \\
\hline $1027-7$ & Lepus californicus & Blacktailed Jackrabbit & 5 & $\mathrm{M}-\mathrm{Sm}$ \\
\hline $1027-7$ & Mammal - Lg & & & M-Lg \\
\hline $1027-7$ & Mammal - Sm & & & M-Sm \\
\hline $1027-7$ & Sylvilagus sp. & Cottontailed Rabbits & 4 & $\mathrm{M}-\mathrm{Sm}$ \\
\hline $1060-5$ & Unionidae & Unidentified Freshwater Mussels & 1 & \\
\hline $1090-3$ & Unionidae & Unidentified Freshwater Mussels & 2 & \\
\hline $1103-1$ & Lampsilis sp. & Freshwater Pearlymussel & 1 & \\
\hline $1107-3$ & Unionidae & Unidentified Freshwater Mussels & 1 & \\
\hline $1119-5$ & Unionidae & Unidentified Freshwater Mussels & 1 & \\
\hline $1124-6$ & Lampsilis sp. & Freshwater Pearlymussel & 2 & \\
\hline $1124-6$ & Unionidae & Unidentified Freshwater Mussels & 6 & \\
\hline $1135-5$ & Unionidae & Unidentified Freshwater Mussels & 1 & \\
\hline $1136-2$ & Mammal & & & \\
\hline $1136-3$ & Unionidae & Unidentified Freshwater Mussels & 1 & \\
\hline 1169-8 & Unionidae & Unidentified Freshwater Mussels & 8 & \\
\hline $1174-5$ & Unionidae & Unidentified Freshwater Mussels & 4 & \\
\hline $1201-2$ & Unionidae & Unidentified Freshwater Mussels & 2 & \\
\hline $1202-5$ & Unionidae & Unidentified Freshwater Mussels & 2 & \\
\hline $1206-4$ & Lampsilis sp. & Freshwater Pearlymussel & 1 & \\
\hline 1234-3 & Lampsilis sp. & Freshwater Pearlymussel & 1 & \\
\hline 1234-3 & Unionidae & Unidentified Freshwater Mussels & 1 & \\
\hline 1239-3 & Unionidae & Unidentified Freshwater Mussels & 7 & \\
\hline $1247-1$ & Sigmodon hispidus & Hispid Cotton Rat & 1 & $\mathrm{M}-\mathrm{V}$ sm \\
\hline $1247-3$ & Unionidae & Unidentified Freshwater Mussels & 9 & \\
\hline $1247-8$ & Unionidae & Unidentified Freshwater Mussels & 1 & \\
\hline $1254-2$ & Unionidae & Unidentified Freshwater Mussels & 1 & \\
\hline $1275-3$ & Unionidae & Unidentified Freshwater Mussels & 3 & \\
\hline 1284-4 & Unionidae & Unidentified Freshwater Mussels & 1 & \\
\hline $1286-4$ & Unionidae & Unidentified Freshwater Mussels & 13 & \\
\hline 1291-4 & Unionidae & Unidentified Freshwater Mussels & 6 & \\
\hline $1323-5$ & Unionidae & Unidentified Freshwater Mussels & 1 & \\
\hline $1411-4$ & Unionidae & Unidentified Freshwater Mussels & 1 & \\
\hline $1460-4$ & Lampsilis sp. & Freshwater Pearlymussel & 1 & \\
\hline $1460-4$ & Toxolasma sp. & Lilliputs & 2 & \\
\hline $1460-4$ & Unionidae & Unidentified Freshwater Mussels & 14 & \\
\hline $147-3$ & Unionidae & Unidentified Freshwater Mussels & 5 & \\
\hline $149-3$ & Unionidae & Unidentified Freshwater Mussels & 1 & \\
\hline $1533-2$ & Unionidae & Unidentified Freshwater Mussels & 1 & \\
\hline 153-6 & Gastropoda & Unidentified Gastropods & 2 & \\
\hline $153-6$ & Gastropoda & Marine/Estuarine Taxa & 2 & \\
\hline $153-6$ & Gastropoda & Land Taxa & 2 & \\
\hline $153-6$ & Gastropoda & Fresh water Taxa & 2 & \\
\hline $155-3$ & Unionidae & Unidentified Freshwater Mussels & 3 & \\
\hline
\end{tabular}


Table D-1. Continued...

\begin{tabular}{|c|c|c|c|c|}
\hline Lot & Taxon & Common Name & Count & Body Size \\
\hline $156-3$ & Unionidae & Unidentified Freshwater Mussels & 3 & \\
\hline $156-5$ & Toxolasma sp. & Lilliputs & 1 & \\
\hline $157-3$ & Unionidae & Unidentified Freshwater Mussels & 1 & \\
\hline $1585-5$ & Unionidae & Unidentified Freshwater Mussels & 4 & \\
\hline 1586-5 & Unionidae & Unidentified Freshwater Mussels & 2 & \\
\hline 1586-6 & Unionidae & Unidentified Freshwater Mussels & 13 & \\
\hline 1594-5 & Unionidae & Unidentified Freshwater Mussels & 3 & \\
\hline $166-4$ & Lepus californicus & Blacktailed Jackrabbit & 1 & M-Sm \\
\hline $167-0$ & Unionidae & Unidentified Freshwater Mussels & 1 & \\
\hline 1675-6 & Rodentia & Unidentified Rodents & 1 & $M-V s m$ \\
\hline $1682-3$ & Unionidae & Unidentified Freshwater Mussels & 2 & \\
\hline $1727-5$ & Cyronaias tampicoensis & Tampico Pearly Mussel & 1 & \\
\hline $1738-6$ & Unionidae & Unidentified Freshwater Mussels & 9 & \\
\hline $174-2$ & Lampsilis teres & Yellow Sandshell & 1 & \\
\hline 1742-6 & Unionidae & Unidentified Freshwater Mussels & 20 & \\
\hline $1750-4$ & Unionidae & Unidentified Freshwater Mussels & 3 & \\
\hline 1763-2 & Canis sp. & Dogs, Wolves, Coyotes & 1 & M-Med \\
\hline 1763-3 & Unionidae & Unidentified Freshwater Mussels & 8 & \\
\hline $1764-2$ & Unionidae & Unidentified Freshwater Mussels & 7 & \\
\hline 1780-2 & Unionidae & Unidentified Freshwater Mussels & 1 & \\
\hline $178-2$ & Unionidae & Unidentified Freshwater Mussels & 1 & \\
\hline $179-2$ & Toxolasma sp. & Lilliputs & 1 & \\
\hline $179-2$ & Unionidae & Unidentified Freshwater Mussels & 1 & \\
\hline $1798-6$ & Unionidae & Unidentified Freshwater Mussels & 3 & \\
\hline $1799-5$ & Unionidae & Unidentified Freshwater Mussels & 2 & \\
\hline $1802-5$ & Unionidae & Unidentified Freshwater Mussels & 3 & \\
\hline $1804-5$ & Unionidae & Unidentified Freshwater Mussels & 1 & \\
\hline $1847-6$ & Unionidae & Unidentified Freshwater Mussels & 2 & \\
\hline $1856-6$ & Unionidae & Unidentified Freshwater Mussels & 13 & \\
\hline $1881-5$ & Unionidae & Unidentified Freshwater Mussels & 1 & \\
\hline $1886-5$ & Unionidae & Unidentified Freshwater Mussels & 1 & \\
\hline $1895-4$ & Unionidae & Unidentified Freshwater Mussels & 1 & \\
\hline $1934-6$ & Unionidae & Unidentified Freshwater Mussels & 1 & \\
\hline $1940-5$ & Lampsilis sp. & Freshwater Pearlymussel & 1 & \\
\hline $1940-5$ & Unionidae & Unidentified Freshwater Mussels & 1 & \\
\hline $2006-5$ & Unionidae & Unidentified Freshwater Mussels & 7 & \\
\hline 2053-5 & Lampsilis sp. & Freshwater Pearlymussel & 1 & \\
\hline $2062-5$ & Unionidae & Unidentified Freshwater Mussels & 1 & \\
\hline 2068-5 & Unionidae & Unidentified Freshwater Mussels & 1 & \\
\hline $207-1$ & Lampsilis sp. & Freshwater Pearlymussel & 1 & \\
\hline $207-1$ & Unionidae & Unidentified Freshwater Mussels & 12 & \\
\hline 2074-5 & Cyronaias tampicoensis & Tampico Pearly Mussel & 1 & \\
\hline $2075-5$ & Unionidae & Unidentified Freshwater Mussels & 2 & \\
\hline 2090-3 & Unionidae & Unidentified Freshwater Mussels & 4 & \\
\hline $2104-4$ & Unionidae & Unidentified Freshwater Mussels & 1 & \\
\hline $2115-4$ & Unionidae & Unidentified Freshwater Mussels & 1 & \\
\hline 2117-4 & Unionidae & Unidentified Freshwater Mussels & 4 & \\
\hline $2124-4$ & Unionidae & Unidentified Freshwater Mussels & 6 & \\
\hline $2154-3$ & Unionidae & Unidentified Freshwater Mussels & 1 & \\
\hline $2185-4$ & Mammal - VLg & & & $M-V l g$ \\
\hline $228-3$ & Unionidae & Unidentified Freshwater Mussels & 1 & \\
\hline $231-3$ & Unionidae & Unidentified Freshwater Mussels & 2 & \\
\hline $232-2$ & Unionidae & Unidentified Freshwater Mussels & 1 & \\
\hline $252-1$ & Cyronaias tampicoensis & Tampico Pearly Mussel & 1 & \\
\hline $252-1$ & Unionidae & Unidentified Freshwater Mussels & 14 & \\
\hline $324-5$ & Unionidae & Unidentified Freshwater Mussels & 1 & \\
\hline
\end{tabular}


Table D-1. Continued...

\begin{tabular}{|c|c|c|c|c|}
\hline Lot & Taxon & Common Name & Count & Body Size \\
\hline $333-5$ & Unionidae & Unidentified Freshwater Mussels & 2 & \\
\hline $334-2$ & Canis sp. & Dogs, Wolves, Coyotes & 1 & M-Med \\
\hline $376-4$ & Unionidae & Unidentified Freshwater Mussels & 1 & \\
\hline $379-3$ & Testudines & Unidentified Turtles & 1 & \\
\hline $382-4$ & Unionidae & Unidentified Freshwater Mussels & 2 & \\
\hline $385-0$ & Unionidae & Unidentified Freshwater Mussels & 5 & \\
\hline $389-7$ & Unionidae & Unidentified Freshwater Mussels & 2 & \\
\hline $394-5$ & Unionidae & Unidentified Freshwater Mussels & 1 & \\
\hline $412-4$ & Unionidae & Unidentified Freshwater Mussels & 3 & \\
\hline 416-4 & Unionidae & Unidentified Freshwater Mussels & 1 & \\
\hline $419-5$ & Unionidae & Unidentified Freshwater Mussels & 5 & \\
\hline $431-4$ & Unionidae & Unidentified Freshwater Mussels & 2 & \\
\hline $453-5$ & Unionidae & Unidentified Freshwater Mussels & 1 & \\
\hline $527-5$ & Unionidae & Unidentified Freshwater Mussels & 2 & \\
\hline $537-5$ & Unionidae & Unidentified Freshwater Mussels & 1 & \\
\hline $578-6$ & Artiodactyla & Unidentified Artiodactyls & 1 & M-Lg \\
\hline $578-6$ & Mammal - Lg & & & M-Lg \\
\hline $581-3$ & Unionidae & Unidentified Freshwater Mussels & 6 & \\
\hline $591-2$ & Unionidae & Unidentified Freshwater Mussels & 5 & \\
\hline $598-2$ & Unionidae & Unidentified Freshwater Mussels & 3 & \\
\hline $610-2$ & Unionidae & Unidentified Freshwater Mussels & 1 & \\
\hline $629-4$ & Unionidae & Unidentified Freshwater Mussels & 1 & \\
\hline $630-4$ & Unionidae & Unidentified Freshwater Mussels & 2 & \\
\hline $630-4$ & Unionidae & Unidentified Freshwater Mussels & 2 & \\
\hline $659-4$ & Unionidae & Unidentified Freshwater Mussels & 1 & \\
\hline $664-3$ & Artiodactyla & Unidentified Artiodactyls & 1 & M-Lg \\
\hline $664-3$ & Canis sp. & Dogs, Wolves, Coyotes & 1 & M-Med \\
\hline $664-3$ & Vertebrata & Unidentified Bone & & \\
\hline $665-4$ & Unionidae & Unidentified Freshwater Mussels & 1 & \\
\hline $671-3$ & Toxolasma sp. & Lilliputs & 1 & \\
\hline $671-3$ & Unionidae & Unidentified Freshwater Mussels & 5 & \\
\hline 679-3 & Unionidae & Unidentified Freshwater Mussels & 1 & \\
\hline $695-5$ & Mammal & & & \\
\hline $695-5$ & Sigmodon hispidus & Hispid Cotton Rat & 1 & M-Vsm \\
\hline $695-5$ & Sigmodon hispidus & Hispid Cotton Rat & 1 & $\mathrm{M}-\mathrm{Vsm}$ \\
\hline $707-2$ & Mammal - Med & & & M-Med \\
\hline $712-2$ & Unionidae & Unidentified Freshwater Mussels & 6 & \\
\hline $725-2$ & Unionidae & Unidentified Freshwater Mussels & 14 & \\
\hline $726-0$ & Lampsilis sp. & Freshwater Pearlymussel & 1 & \\
\hline $726-0$ & Unionidae & Unidentified Freshwater Mussels & 12 & \\
\hline $732-3$ & Unionidae & Unidentified Freshwater Mussels & 2 & \\
\hline $743-4$ & Unionidae & Unidentified Freshwater Mussels & 4 & \\
\hline $762-3$ & Unionidae & Unidentified Freshwater Mussels & 9 & \\
\hline $776-5$ & Unionidae & Unidentified Freshwater Mussels & 3 & \\
\hline $789-3$ & Unionidae & Unidentified Freshwater Mussels & 3 & \\
\hline $804-4$ & Unionidae & Unidentified Freshwater Mussels & 2 & \\
\hline $813-5$ & Unionidae & Unidentified Freshwater Mussels & 1 & \\
\hline $817-4$ & Unionidae & Unidentified Freshwater Mussels & 8 & \\
\hline $820-0$ & Unionidae & Unidentified Freshwater Mussels & 4 & \\
\hline $834-4$ & Unionidae & Unidentified Freshwater Mussels & 2 & \\
\hline $856-4$ & Lampsilis sp. & Freshwater Pearlymussel & 1 & \\
\hline $856-4$ & Unionidae & Unidentified Freshwater Mussels & 1 & \\
\hline 868-4 & Toxolasma sp. & Lilliputs & 1 & \\
\hline $881-4$ & Unionidae & Unidentified Freshwater Mussels & 1 & \\
\hline $881-5$ & Unionidae & Unidentified Freshwater Mussels & 1 & \\
\hline $896-4$ & Cyronaias tampicoensis & Tampico Pearly Mussel & 1 & \\
\hline
\end{tabular}


Table D-1. Continued...

\begin{tabular}{|l|l|l|c|c|}
\hline \multicolumn{1}{|c|}{ Lot } & \multicolumn{1}{|c|}{ Coxon } & \multicolumn{1}{c|}{ Common Name } & Body Size \\
\hline $896-4$ & Unionidae & Unidentified Freshwater Mussels & 4 & \\
\hline $914-4$ & Rodentia & Unidentified Rodents & 4 & M-Vsm \\
\hline $935-0$ & Unionidae & Unidentified Freshwater Mussels & 4 & \\
\hline $939-5$ & Lepus californicus & Blacktailed Jackrabbit & 1 & M-Sm \\
\hline $939-5$ & Mammal - Sm & & & M-Sm \\
\hline $944-3$ & Lepus californicus & Blacktailed Jackrabbit & 10 & M-Sm \\
\hline $944-3$ & Mammal - Sm & & & M-Sm \\
\hline $954-6$ & Mammal - VSm & & & M-VSm \\
\hline $954-6$ & Sigmodon hispidus & Hispid Cotton Rat & 1 & M-Vsm \\
\hline $968-4$ & Unionidae & Unidentified Freshwater Mussels & 3 & \\
\hline $968-5$ & Mammal - Lg & & & M-Lg \\
\hline $982-5$ & Unionidae & Unidentified Freshwater Mussels & 6 & \\
\hline
\end{tabular}




\title{
APPENDIX E \\ Plant Remains Identified from 41ZV202
}

\author{
Phil Dering
}

Shumla Archaeobotanical Services 

Five flotation samples totaling 6.5-liters were examined in this study. The flotation effort averaged 1.3-liters-per-sample. The samples were collected from five features, each of which were described as fire-cracked rock concentrations of varying sizes. Feature 7 was a hearth. The remaining features are described as fire-cracked rock (FCR) concentrations of varying size. Feature 8 measured $130 \times 80 \mathrm{~cm}$ in plan view, and was up to 10 -cm thick. Feature 10 measured $30 x$ 40-cm in plan view and between 8 to $10-\mathrm{cm}$ thick. Feature 13 was $110 \times 90-\mathrm{cm}$ in plan view measuring up to $24-\mathrm{cm}$ thick. Feature 9 consisted of six FCR rocks covering an area about $30 \times 30-\mathrm{cm}$.

\section{Laboratory Method}

The analysis follows standard archeobotanical laboratory procedures. The light fraction of each flotation sample is passed through a nested set of screens of 4-mm, 2-mm, $1-\mathrm{mm}$, and $0.450-\mathrm{mm}$ mesh and examined for charred material that is separated for identification. Carbonized wood from the $4 \mathrm{~mm}$ and $2 \mathrm{~mm}$ screens (smaller pieces are seldom identifiable) is separated in a 25-piece grab sample and identified. If there is a large quantity of charcoal, care is taken to select representative materials from both levels (cf. Diehl 2003:213; Huckell 2002:645; Miksicek 1994:243). Charred material caught on 1-mm and .450-mm sieve levels, as well as the bottom pan, is scanned for floral parts, fruits, seeds, and other potentially edible plant parts such as agave or maize fragments, and these plant parts are counted and examined for identification. Screen- or point-collected macrobotanical samples (radiocarbon samples, etc.) are also sorted, identified, and weighed to the nearest $0.1 \mathrm{~g}$.

Disturbance Indicators. Sample content may be affected by various biological disturbance factors, including insect or small mammal activity, and plant root growth. In an effort to assess this impact, the amounts of insect parts, termite pellets, gastropods, mammal remains (including fecal pellets), leaves, and modern uncharred seeds are estimated for each flotation sample. These amounts are reported on a scale of 1-25 (+), 25-50 (++), and over $50(+++)$.

Identification. Identification of carbonized wood is accomplished by using the snap technique, examining the transverse, radial, and tangential surfaces at 8 to 45 power with a binocular dissecting microscope, and comparing the material to reference specimens in the Shumla Archeobotanical Services herbarium. The wood of mesquite, acacia, and paloverde, all members of the legume family (Fabaceae), are also difficult to distinguish. Mesquite usually can be separated from other woody members of that family, but in cases where this is a problem, the material is assigned to the Fabaceae-type (woody legume).

\section{Results and Conclusion}

The overview in Table E-1 summarizes flotation sample volume, seed density, seed taxa abundance, and disturbance indicators. Table E-2 presents the identifications and counts of material recovered from the flotation and macrobotanical samples.

Table E-1. Flotation Sample Summary

\begin{tabular}{|c|c|c|c|c|c|c|c|c|c|}
\hline Sample & 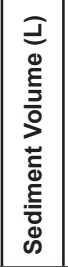 & 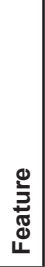 & 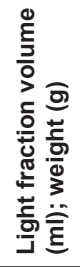 & 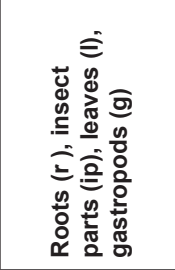 & 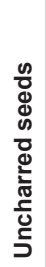 & 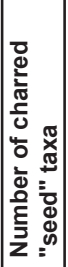 & 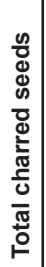 & 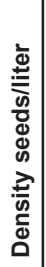 & 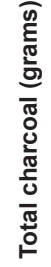 \\
\hline 268-2; 269-1 & 2.4 & 7 & $\begin{array}{l}\text { 18-ml; } \\
2.8-\mathrm{g}\end{array}$ & $\begin{array}{c}\mathrm{r}+++, \text { ip }++ \\
\mathrm{g}++\end{array}$ & 4 & 0 & 0 & 0 & 0.9 \\
\hline $\begin{array}{c}1892-6,1893-5 \\
2006-7,2221\end{array}$ & 2.1 & 8 & \begin{tabular}{|l}
$13-\mathrm{ml}$, \\
$2.1-\mathrm{g}$
\end{tabular} & $r+++, g++$ & 9 & 0 & 0 & 0 & 0.2 \\
\hline $520-5$ & 0.75 & 9 & $\begin{array}{l}3-\mathrm{ml}, \\
0.2-\mathrm{g}\end{array}$ & $\begin{array}{c}\mathrm{r}+++, \text { ip }++, \\
\mathrm{I++}\end{array}$ & 2 & 0 & 0 & 0 & 0 \\
\hline 1594-8 & 0.6 & 10 & $\begin{array}{l}3-\mathrm{ml}, \\
0.4-\mathrm{g}\end{array}$ & $\begin{array}{c}\mathrm{r}+++, \text { ip }++ \\
\mathrm{g}+++\end{array}$ & 5 & 0 & 0 & 0 & $<.1$ \\
\hline $1411-7$ & 0.6 & 13 & $\begin{array}{l}3-\mathrm{ml} \\
.3-\mathrm{g}\end{array}$ & $r+++, i p+, g+$ & 3 & 0 & 0 & 0 & 0 \\
\hline
\end{tabular}

Table E-2. Contents of the Flotation and Macrobotanical Samples

\begin{tabular}{|c|c|c|c|c|c|c|c|}
\hline Site & $\begin{array}{l}\# \\
\stackrel{+}{0}\end{array}$ & 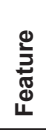 & 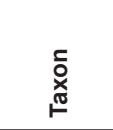 & 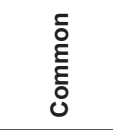 & $\begin{array}{c}\frac{t}{0} \\
0\end{array}$ & $\begin{array}{l}\text { 芌 } \\
\text { ơ }\end{array}$ & $\begin{array}{l}\text { क्ञ } \\
\text { ș }\end{array}$ \\
\hline 41ZV202 & $268-2 ; 269-1$ & 7 & $\begin{array}{c}\text { Prosopis } \\
\text { sp. }\end{array}$ & Mesquite & Wood & 20 & 0.9 \\
\hline 41ZV202 & $\begin{array}{c}1892- \\
6,1893-5 \\
2006-7 \\
2221\end{array}$ & 8 & $\begin{array}{l}\text { Prosopis } \\
\text { sp. }\end{array}$ & Mesquite & Wood & 23 & 0.2 \\
\hline 41ZV202 & $520-5$ & 9 & \multicolumn{3}{|c|}{$\begin{array}{c}\text { No identifiable carbonized } \\
\text { plant remains }\end{array}$} & -- & -- \\
\hline 41ZV202 & $1594-8$ & 10 & $\begin{array}{c}\text { Prosopis } \\
\text { sp. }\end{array}$ & Mesquite & Wood & 3 & $<.1$ \\
\hline $41 Z V 202$ & $1411-7$ & 13 & \multicolumn{3}{|c|}{$\begin{array}{c}\text { No identifiable carbonized } \\
\text { plant remains }\end{array}$} & -- & -- \\
\hline
\end{tabular}

Modern contaminants were noted in abundant quantities in all of the flotation samples. Roots were most common, occurring abundantly in all samples, insect parts and gastropods were noted in four samples, and leaves in one sample. All five samples contained uncharred seeds, including Chenopodium sp. (pigweed), Asteraceae (sunflower family), and Poaceae (grass family).

No carbonized seeds or edible plant parts such as bulb or corm fragments were recovered from the samples. Wood charcoal was noted in very small quantities, exceeding $0.1-\mathrm{g}$ in only two of the samples. Features 7 and 8 contained the largest amount of charcoal, 0.9- and 0.2-g each. The charred plant assemblage consisted of wood fragments that were 
reduced in size; only a few of were larger than 3-mm, and most of them were 2-mm or smaller. Two of the samples, from Features 9 and 13, did not contain fragments of charcoal that were larger than $0.5-\mathrm{mm}$, and consequently no material could be identified from these contexts.

Table E-2 presents the results of the plant identifications by Feature and sample number. Mesquite was the only wood type identified in the flotation samples. Feature 7, the hearth, contained the largest quantity of charcoal, and the only charcoal large enough to be caught on the 4-mm screen. A much smaller amount of charcoal, 0.2-g, was identified from Feature 8 as mesquite.

The remaining three samples contained very little material, as in Lot 1594-8, or no material whatsoever. These features, all of them FCR concentrations of varying sizes, were sampled with small flotation samples varying between 0.-6 and 0.75 -liters in volume. In two cases these sample sizes reflect the small size of the feature, as in Features 9 and 10.

The flotation samples reflect a depauperate botanical assemblage typical of highly turbated archeological deposits. Disturbance indicators were abundant in each sample, and included roots and fresh seeds as well as insect parts in four of the five samples. The very small size of the flotation samples reduced the chances of recovering carbonized plant materials from the deposits, and the low carbon content of three of the five samples indicates that the preservation environment for botanical remains was poor. The mesquite wood identified in three of the indicate that mesquite was present in the region during the time of occupation and was used for fuel. Given the location of the site, in the Rio Grande Plains of southern Texas, this is not earth-shattering information, but it is all the information that these samples contained.

\section{References}

\section{Diehl, M.}

2003 Prehistoric Subsistence Strategies and the Macrobotanical Assemblage. In Hohokam Farming on the Salt River Floodplain, edited by T. Kathleen Henderson, pp. 211-230. Anthropological Papers No. 42, Center for Desert Archaeology. Tucson, Arizona. Anthropological Papers No. 9. Pueblo Grande Museum. Phoenix, Arizona.

Greaves, R.

2003 Interim Report of Archeological Mitigation at 41ZV202, Zavala County, Texas. Center for Archaeological Research, The University of Texas at San Antonio.

Huckell, L.

2002 Paleoethnobotany. In Tonto Creek Archaeological Project Artifact and Environmental Analyses. Volume 2: Stone Tool and Subsistence Studies, ed. Jeffery J. Clark, pp. 643-709. Anthropological Papers No. 23. Center for Desert Archaeology, Tucson.

Miksicek, C.

1994 Deceptive Barrenness: Archaeobotanical Material From the Schuk Toak Project Area. In Archaeological Studies of the Avra Valley, Arizona: Excavations in the Schuk Toak District. Vol 2. Scientific Studies and Interpretations, ed. by Allen Dart, pp. 243-266. Anthropological Papers No. 16. Center for Desert Archaeology, Tucson. 


\begin{abstract}
APPENDIX F
Analysis of the Fatty Acid Compositions of

Archeological Rock Residues from 41ZV202
\end{abstract}

M. E. Malainey

Winnipeg, Canada 



\section{INTRODUCTION}

Fifteen burned rocks were submitted for analysis; where necessary, subsamples were taken from large rocks. Exterior surfaces were ground off to remove any contaminants and samples were crushed. Absorbed lipid residues were extracted with organic solvents. Fatty acid components of the lipid extracts were analyzed using gas chromatography. Residues were identified using criteria developed from the decomposition patterns of experimental residues. The first section of this report outlines the development of the identification criteria. Following this, analytical procedures and results are presented.

\section{Fatty Acids and Development of the Identification Criteria}

\section{Introduction and Previous Research}

Fatty acids are the major constituents of fats and oils (lipids) and occur in nature as triglycerides, consisting of three fatty acids attached to a glycerol molecule by ester-linkages. The shorthand convention for designating fatty acids, Cx:y $\omega z$, contains three components. The " $\mathrm{Cx}$ " refers to a fatty acid with a carbon chain length of $x$ atoms. The " $y$ " represents the number of double bonds of unsaturation, and the " $\omega \mathrm{z}$ " indicates the location of the most distal double bond on the carbon chain, i.e. closest to the methyl end. The fatty acid expressed as $\mathrm{C} 18: 1 \omega 9$, refers to a mono-unsaturated isomer with a chain length of 18 carbon atoms with a single double bond located nine carbons from the methyl end of the chain. The shorthand designation, C16:0, refers to a saturated fatty acid with a chain length of 16 carbons.

Their insolubility in water and relative abundance compared to other classes of lipids, such as sterols and waxes, make fatty acids suitable for residue analysis. Since employed by Condamin et al. (1976), gas chromatography has been used extensively to analyze the fatty acid component of absorbed archeological residues. The composition of uncooked plants and animals provides important baseline information, but it is not possible to directly compare modern uncooked plants and animals with highly degraded archeological residues. Unsaturated fatty acids, which are found widely in fish and plants, decompose more readily than saturated fatty acids, sterols or waxes. In the course of decomposition, simple addition reactions might occur at points of unsaturation (Solomons 1980) or peroxidation might lead to the formation of a variety of volatile and non-volatile products which continue to degrade (Frankel 1991). Peroxidation occurs most readily in fatty acids with more than one point of unsaturation.

Attempts have been made to identify archeological residues using criteria that discriminate uncooked foods (Marchbanks 1989; Skibo 1992; Loy 1994). Marchbanks' (1989) percent of saturated fatty acids $(\% \mathrm{~S})$ criteria has been applied to residues from a variety of materials including pottery, stone tools and burned rocks (Marchbanks 1989; Marchbanks and Quigg 1990; Collins et al. 1990). Skibo (1992:89) could not apply the \%S technique and instead used two ratios of fatty acids, C18:0/C16:0 and C18:1/C16:0. He (1992) reported that it was possible to link the uncooked foods with residues extracted from modern cooking pots actively used to prepare one type of food; however, the ratios could not identify food mixtures. The utility of these ratios did not extend to residues extracted from archeological potsherds because the ratios of the major fatty acids in the residue changed with decomposition (Skibo 1992:97). Loy (1994) proposed the use of a Saturation Index (SI), determined by the ratio: SI = 1- $[(\mathrm{C} 18: 1+\mathrm{C} 18: 2) / \mathrm{C} 12: 0+\mathrm{C} 14: 0+\mathrm{C} 16: 0+\mathrm{C} 18: 0)]$. He (1994) admitted, however, that poorly understood decompositional changes to the original suite of fatty acids make it difficult to develop criteria for distinguishing animal and plant fatty acid profiles in archeological residues.

The major drawback of the distinguishing ratios proposed by Marchbanks (1989), Skibo (1992) and Loy (1994) is they have never been empirically tested. The proposed ratios are based on criteria that discriminate food classes on the basis of their original fatty acid composition. The resistance of these criteria to the effects of decompositional changes has not been demonstrated. Rather, Skibo (1992) found his fatty acid ratio criteria could not be used to identify highly decomposed archeological samples.

In order to identify a fatty acid ratio unaffected by degradation, Patrick et al. (1985) simulated the long-term decomposition of one sample and monitored the resulting changes. An experimental cooking residue of seal was prepared and degraded in order to identify a stable fatty acid ratio. Patrick et al. (1985) found that the ratio of two C18:1 isomers, oleic and vaccenic, did not change with decomposition; this fatty acid ratio was then used to identify an archeological vessel residue as seal. While the fatty acid composition of uncooked foods must be known, Patrick et al. (1985) showed that the effects of cooking and decomposition over long periods of time on the fatty acids must also be understood. 


\section{Development of the Identification Criteria}

As the first stage in developing the identification criteria used herein, the fatty acid compositions of more than 130 uncooked Native food plants and animals from Western Canada were determined using gas chromatography (Malainey 1997; Malainey et al. 1999a). When the fatty acid compositions of modern food plants and animals were subject to cluster and principal component analyses, the resultant groupings generally corresponded to divisions that exist in nature (Table F-1). Clear differences in the fatty acid composition of large mammal fat, large herbivore meat, fish, plant roots, greens and berries/seeds/nuts were detected, but the fatty acid composition of meat from medium-sized mammals resembles berries/seeds/nuts.

Samples in cluster A, the large mammal and fish cluster had elevated levels of $\mathrm{C} 16: 0$ and C18:1 (Table F-1). Divisions within this cluster stemmed from the very high level of C18:1 isomers in fat, high levels of C18:0 in bison and deer meat and high levels of very long chain unsaturated fatty acids (VLCU) in fish. Differences in the fatty acid composition of plant roots, greens and berries/ seeds/nuts reflect the amounts of $\mathrm{C} 18: 2$ and $\mathrm{C} 18: 3 \square 3$ present. The berry, seed, nut and small mammal meat samples appearing in cluster B have very high levels of C18:2, ranging from $35 \%$ to $64 \%$ (Table F-1). Samples in subclusters V, VI and VII have levels of C18:1 isomers from $29 \%$ to $51 \%$, as well. Plant roots, plant greens and some berries appear in cluster C. All cluster C samples have moderately high levels of C18:2; except for the berries in subcluster XII, levels of C16:0 are also elevated. Higher levels of C18:3 $\square 3$ and/or very long chain saturated fatty acids (VLCS) are also common except in the roots which form subcluster XV.

Secondly, the effects of cooking and degradation over time on fatty acid compositions were examined. Originally, 19 modern residues of plants and animals from the plains, parkland and forests of Western Canada were prepared by cooking samples of meats, fish and plants, alone or combined, in replica vessels over an open fire (Malainey 1997; Malainey et al. 1999b). After four days at room temperature, the vessels were broken and a set of sherds analysed to determine changes after a short term of decomposition. A second set of sherds remained at room temperature for 80 days, then placed in an oven at $75 \square \mathrm{C}$ for a period of 30 days in order to simulate the processes of long term decomposition. The relative percentages were calculated on the basis of the ten fatty acids (C12:0, C14:0, C15:0, C16:0, C16:1, C17:0, C18:0, C18:1w9, C18:1w11, C18:2) that regularly appeared in Precontact Period vessel residues from Western Canada. Observed changes in fatty acid composition of the experimental cooking residues enabled the development of a method for identifying the archeological residues (Table F-2).

It was determined that levels of medium chain fatty acids (C12:0, C14:0 and C15:0), C18:0 and C18:1 isomers in the sample could be used to distinguish degraded experimental cooking residues (Malainey 1997; Malainey et al. 1999b). These fatty acids are suitable for the identification criteria because saturated fatty acids are stable and the monounsaturated fatty acid degrades very slowly, as compared to polyunsaturated fatty acids (deMan 1992). Higher levels of medium chain fatty acids, combined with low levels of C18:0 and C18:1 isomers, were detected in the decomposed experimental residues of plants, such as roots, greens and most berries. High levels of C18:0 indicated the presence of large herbivores. Moderate levels of C18:1 isomers, with low levels of C18:0, indicated the presence of either fish or foods similar in composition to corn. High levels of C18:1 isomers with low levels of $\mathrm{C} 18: 0$, were found in residues of beaver or foods of similar fatty acid composition. The criteria for identifying six types of residues were established experimentally; the seventh type, plant with large herbivore, was inferred (Table F-2). These criteria were applied to residues extracted from more than 200 pottery cooking vessels from 18 Western Canadian sites (Malainey 1997;

Table F-1. Summary of Average Fatty Acid Compositions of Modern Food Groups Generated by Hierarchical Cluster Analysis

\begin{tabular}{|c|c|c|c|c|c|c|c|c|c|c|c|c|c|c|c|}
\hline Cluster & \multicolumn{4}{|c|}{$\bar{A}$} & \multicolumn{6}{|c|}{ B } & \multicolumn{5}{|c|}{ C } \\
\hline Subcluster & $I$ & II & III & IV & $\mathrm{V}$ & VI & VII & VIII & IX & $\bar{x}$ & $\mathbf{X I}$ & XII & XIII & XIV & $\overline{X V}$ \\
\hline Type & \begin{tabular}{|l|} 
Mammal \\
Fat and \\
Marrow
\end{tabular} & $\begin{array}{c}\text { Large } \\
\text { Herbivore } \\
\text { Meat }\end{array}$ & Fish & Fish & $\begin{array}{l}\text { Berries } \\
\text { and } \\
\text { Nuts }\end{array}$ & Mixed & $\begin{array}{c}\begin{array}{c}\text { Seeds } \\
\text { and } \\
\text { Berries }\end{array} \\
\end{array}$ & Roots & Seeds & Mixed & Greens & Berries & Roots & Greens & Roots \\
\hline C16:0 & 19.9 & 19.39 & 16.07 & 14.1 & 3.75 & 12.06 & 7.48 & 19.98 & 7.52 & 10.33 & 18.71 & 3.47 & 22.68 & 24.19 & 18.71 \\
\hline C18:0 & 7.06 & 20.35 & 3.87 & 2.78 & 1.47 & 2.36 & 2.58 & 2.59 & 3.55 & 2.43 & 2.48 & 1.34 & 3.15 & 3.66 & 5.94 \\
\hline C18:1 & 56.77 & 35.79 & 18.28 & 31.96 & 51.14 & 35.29 & 29.12 & 6.55 & 10.02 & 15.62 & 5.03 & 14.95 & 12.12 & 4.05 & 3.34 \\
\hline C18:2 & 7.01 & 8.93 & 2.91 & 4.04 & 41.44 & 35.83 & 54.69 & 48.74 & 64.14 & 39.24 & 18.82 & 29.08 & 26.24 & 16.15 & 15.61 \\
\hline C18:3 & 0.68 & 2.61 & 4.39 & 3.83 & 1.05 & 3.66 & 1.51 & 7.24 & 5.49 & 19.77 & 35.08 & 39.75 & 9.64 & 17.88 & 3.42 \\
\hline VLCS & 0.16 & 0.32 & 0.23 & 0.15 & 0.76 & 4.46 & 2.98 & 8.5 & 5.19 & 3.73 & 6.77 & 9.1 & 15.32 & 18.68 & 43.36 \\
\hline VLCU & 0.77 & 4.29 & 39.92 & 24.11 & 0.25 & 2.7 & 1 & 2.23 & 0.99 & 2.65 & 1.13 & 0.95 & 2.06 & 0.72 & 1.1 \\
\hline
\end{tabular}

VLCS- Very Long Chain (C20, C22 and C24) Saturated Fatty Acids 
Table F-2. Criteria for the Identification of Archaeological Residues Based on the Decomposition Patterns of Experimental Cooking Residues Prepared in Pottery Vessels

\begin{tabular}{|l|c|c|c|}
\hline \multicolumn{1}{|c|}{ Identification } & $\begin{array}{c}\text { Medium } \\
\text { Chain }\end{array}$ & C18:0 & C18:1 isomers \\
\hline Large herbivore & $\leq 15 \%$ & $\geq 27.5 \%$ & $\leq 15 \%$ \\
\hline $\begin{array}{l}\text { Large herbivore with plant } \\
\text { OR Bone marrow }\end{array}$ & low & $\geq 25 \%$ & $15 \% \leq \mathrm{X} \leq 25 \%$ \\
\hline Plant with large herbivore & $\geq 15 \%$ & $\geq 25 \%$ & no data \\
\hline Beaver & low & Low & $\geq 25 \%$ \\
\hline Fish or Corn & low & $\leq 25 \%$ & $15 \% \leq X \leq 27.5 \%$ \\
\hline Fish or Corn with Plant & $\geq 15 \%$ & $\leq 25 \%$ & $15 \% \leq X \leq 27.5 \%$ \\
\hline Plant (except corn) & $\geq 10 \%$ & $\leq 27.5 \%$ & $\leq 15 \%$ \\
\hline
\end{tabular}

Malainey et al. 1999c; 2001b). The identifications were found to be consistent with the evidence from faunal and tool assemblages for each site.

Work has continued to understand the decomposition patterns of various foods and food combinations (Malainey et al. 2000a, 2000b, 2000c, 2001a; Quigg et al. 2001). The collection of modern foods has expanded to include plants from the Southern Plains. The fatty acid compositions of mesquite beans (Prosopis glandulosa), Texas ebony seeds (Pithecellobium ebano Berlandier), tasajillo berry (Opuntia leptocaulis), prickly pear fruit and pads (Opuntia engelmannii), Spanish dagger pods (Yucca treculeana), cooked sotol (Dasylirion wheeler), agave (Agave lechuguilla), cholla (Opuntia imbricata), piñon (Pinus edulis) and Texas mountain laurel (or mescal) seed (Sophora secundiflora) have been determined. Experimental residues of many of these plants, alone or in combination with deer meat, have been prepared by boiling foods in clay cylinders or using sandstone for either stone boiling (Quigg et al. 2000) or as a griddle. In order to accelerate the processes of oxidative degradation that naturally occur at a slow rate with the passage of time, the rock or clay tile containing the experimental residue was placed in an oven at $75^{\circ} \mathrm{C}$. After either 30 or 68 days, residues were extracted and analysed using gas chromatography. The results of these decomposition studies enabled refinement of the identification criteria.

\section{Methodology}

Descriptions of the samples are presented in Table F-3; they are quite large due to the friable nature of the material. Exterior surfaces were removed by grinding off exterior surfaces with a Dremel ${ }^{\circledR}$ tool fitted with a silicon carbide bit. Immediately thereafter, the sample was crushed with a hammer mortar and pestle and the powder transferred to an Erlenmeyer flask. Lipids were extracted using a variation of the method developed by Folch et al. (1957). The powdered sample was mixed with a 2:1 mixture, by volume, of chloroform and methanol ( 2 X $25 \mathrm{~mL})$ using ultrasonication ( 2 X $10 \mathrm{~min}$ ). Solids were removed by filtering the solvent mixture into a separatory funnel. The lipid/solvent filtrate was washed with $13 \mathrm{~mL}$ of ultrapure water. Once separation into two phases was complete, the lower chloroform-lipid phase was transferred to a round-bottomed flask and the chloroform removed by rotary evaporation. Any remaining water was removed by evaporation with benzene $(1.5 \mathrm{~mL}) ; 1.5 \mathrm{~mL}$ of chloroform-methanol $(2: 1, \mathrm{v} / \mathrm{v})$ was used to transfer the dry total lipid extract to a screw-top glass vial with a Teflon $\AA$ lined cap. The sample was flushed with nitrogen and stored in a $-20^{\circ} \mathrm{C}$ freezer.

A $400 \mu \mathrm{L}$ sample of the total lipid extract solution was placed in a screw-top test tube and dried in a heating block under nitrogen. Fatty acid methyl esters (FAMES) were prepared by treating the dry lipid with $5 \mathrm{~mL}$ of $0.5 \mathrm{~N}$ anhydrous hydrochloric acid in methanol $\left(68^{\circ} \mathrm{C} ; 60 \mathrm{~min}\right)$. Fatty acids that occur in the sample as di- or triglycerides are detached from the glycerol molecule and converted to methyl esters. After cooling to room temperature, $3.4 \mathrm{~mL}$ of ultrapure water was added. FAMES were recovered with petroleum ether $(2.5 \mathrm{~mL})$ and transferred to a vial. The solvent was removed by heat under a gentle stream of nitrogen; the FAMES were dissolved in $75 \mu \mathrm{L}$ of $i s o$-octane then transferred to a GC vial with a conical glass insert.

Solvents and chemicals were checked for purity by running a sample blank. The entire lipid extraction and methyl esterification process was performed and FAMES were

Table F-3. List of Samples Analyzed from Site 41ZV202

\begin{tabular}{|c|c|c|c|c|}
\hline Sample \# & $\begin{array}{c}\text { Lot } / \\
\text { Catalogue \# }\end{array}$ & $\begin{array}{c}\text { Feature } \\
\text { Number }\end{array}$ & P.P. & $\begin{array}{c}\text { Sample } \\
\text { Size (g) }\end{array}$ \\
\hline 7UT 1 & $268-001$ & 7 & - & 63.219 \\
\hline 7UT 2 & $270-002$ & 7 & - & 55.305 \\
\hline 7UT 3 & $269-002$ & 7 & - & 59.424 \\
\hline 7UT 4 & 1922 & 8 & 27 & 59.853 \\
\hline 7UT 5 & $1951-001$ & 8 & 9 & 59.118 \\
\hline 7UT 6 & 1983 & 8 & 41 & 59.427 \\
\hline 7UT 7 & 518 & 9 & 36 & 57.352 \\
\hline 7UT 8 & 517 & 9 & 35 & 62.436 \\
\hline 7UT 9 & 515 & 9 & 31 & 57.733 \\
\hline 7UT 10 & 1610 & 10 & 21 & 62.95 \\
\hline 7UT 11 & $1625-001$ & 10 & 36 & 60.373 \\
\hline 7UT 12 & 1609 & 10 & 20 & 62.687 \\
\hline 7UT 13 & 1344 & 13 & 12 & 58.704 \\
\hline 7UT 14 & 1406 & 13 & 75 & 58.188 \\
\hline 7UT 15 & 1365 & 13 & 64 & 59.091 \\
\hline
\end{tabular}


dissolved in $75 \mu \mathrm{L}$ of iso-octane. Traces of contamination were subtracted from sample chromatograms. The relative percentage composition was calculated by dividing the integrated peak area of each fatty acid by the total area of fatty acids present in the sample.

The step in the extraction procedure where the chloroform, methanol and lipid mixture is washed with water is standard procedure for the extraction of lipids from modern samples. Following Evershed et al. (1990), who reported that this step was unnecessary for the analysis of archeological residues, previously the solvent-lipid mixture was not washed. This step was adopted to remove impurities so that clearer chromatograms could be obtained in the region where very long chain fatty acids (C20:0, C20:1, C22:0 and C24:0) occur. It was anticipated that the detection and accurate assessment of these fatty acids could be instrumental in separating residues of animal origin from those of plant (Malainey et al. 2000a, 2000b, 2000c, 2001a).

In order to identify the residue, the relative percentage composition was determined first with respect to all fatty acids present in the sample (including very long chain fatty acids) (see Table F-4) and secondly with respect to the ten fatty acids utilized in the development of the identification criteria (C12:0, C14:0, C15:0, C16:0, C16:1, C17:0, C18:0, C18:1w9, C18:1w11 and C18:2) (not shown). The second step is necessary for the application of the identification criteria presented in Table F-2.

It must be understood that the identifications given do not necessarily mean that those particular foods were actually

Table F-4. Fatty Acid Composition and Identification of Residues from Site 41ZV202

\begin{tabular}{|c|c|c|c|c|c|c|c|c|c|c|c|c|c|c|}
\hline & & \multicolumn{13}{|c|}{ Samples } \\
\hline \multicolumn{2}{|c|}{ Identification } & $\begin{array}{l}\text { Medium } \\
\text { Fat } \\
\text { Content }\end{array}$ & $\begin{array}{c}\text { Boardline } \\
\text { Medium } \\
\text { and } \\
\text { Moderate- } \\
\text { High Fat } \\
\text { Content }\end{array}$ & \begin{tabular}{|} 
Medium \\
Fat \\
Content
\end{tabular} & $\begin{array}{l}\text { Moderate- } \\
\text { High Fat } \\
\text { Content }\end{array}$ & $\begin{array}{c}\text { Boardline } \\
\text { Medium } \\
\text { and } \\
\text { Moderate- } \\
\text { High Fat } \\
\text { Content }\end{array}$ & $\begin{array}{l}\text { Medium } \\
\text { Fat } \\
\text { Content }\end{array}$ & $\begin{array}{l}\text { Medium } \\
\text { Fat } \\
\text { Content }\end{array}$ & $\begin{array}{l}\text { Moderate- } \\
\text { High Fat } \\
\text { Content }\end{array}$ & $\begin{array}{c}\text { Moderate- } \\
\text { High Fat } \\
\text { Content }\end{array}$ & \begin{tabular}{|c|} 
Boarder \\
Moderate- \\
High and \\
High Fat \\
Content
\end{tabular} & $\begin{array}{c}\text { Moderate- } \\
\text { High Fat } \\
\text { Content }\end{array}$ & \begin{tabular}{|} 
Medium \\
Fat \\
Content
\end{tabular} & $\begin{array}{c}\text { Moderate- } \\
\text { High Fat } \\
\text { Content }\end{array}$ \\
\hline \multicolumn{2}{|c|}{ Fatty Acid } & 7UT1 & 7UT2 & 7UT3 & 7UT4 & 7UT5 & 7UT7 & 7UT9 & 7UT10 & 7UT11 & 7UT12 & 7UT13 & 7UT14 & 7UT15 \\
\hline \multirow{2}{*}{ C12:0 } & Area & 2906 & 3792 & 3869 & 0 & 0 & 0 & 2105 & 8252 & 2882 & 7721 & 2247 & 5629 & 0 \\
\hline & Rel \% & 0.52 & 0.47 & 1.13 & 0.00 & 0.00 & 0.00 & 0.49 & 0.42 & 0.22 & 1.30 & 0.36 & 1.23 & 0.00 \\
\hline \multirow{2}{*}{ C14:0 } & Area & 16176 & 37443 & 15500 & 12193 & 9373 & 10629 & 17541 & 29037 & 15350 & 27120 & 15166 & 22512 & 12547 \\
\hline & Rel \% & 2.92 & 4.66 & 4.51 & 2.43 & 2.36 & 2.98 & 4.10 & 1.48 & 1.19 & 4.56 & 2.45 & 4.93 & 2.56 \\
\hline \multirow{2}{*}{ C14:1 } & Area & 3851 & 10375 & 2407 & 0 & 8190 & 6756 & 8589 & 9739 & 18101 & 0 & 3216 & 10138 & 7900 \\
\hline & Rel \% & 0.69 & 1.29 & 0.70 & 0.00 & 2.06 & 1.89 & 2.01 & 0.50 & 1.40 & 0.00 & 0.52 & 2.22 & 1.61 \\
\hline \multirow{2}{*}{ C15:0 } & Area & 16767 & 82407 & 25897 & 19253 & 12401 & 19666 & 38389 & 31794 & 17738 & 12254 & 9343 & 16586 & 2328 \\
\hline & Rel \% & 3.02 & 10.25 & 7.53 & 3.84 & 3.12 & 5.51 & 8.98 & 1.63 & 1.37 & 2.06 & 1.51 & 3.63 & 0.47 \\
\hline \multirow{2}{*}{ C16:0 } & Area & 239638 & 336370 & 143081 & 199678 & 170507 & 195668 & 200910 & 1039917 & 667696 & 246336 & 319629 & 156474 & 199375 \\
\hline & Rel \% & 43.21 & 41.85 & 41.62 & 39.86 & 42.92 & 54.84 & 46.98 & 53.15 & 51.61 & 41.38 & 51.54 & 34.24 & 40.64 \\
\hline \multirow{2}{*}{ C16:1 } & Area & 254 & 937 & 0 & 0 & 0 & 9375 & 22172 & 0 & 0 & 0 & 0 & 40195 & 0 \\
\hline & Rel \% & 0.05 & 0.12 & 0.00 & 0.00 & 0.00 & 2.63 & 5.18 & 0.00 & 0.00 & 0.00 & 0.00 & 8.80 & 0.00 \\
\hline \multirow{2}{*}{ C17:0 } & Area & 0 & 11125 & 2687 & 5781 & 2723 & 10104 & 1896 & 4951 & 4254 & 3324 & 5175 & 5119 & 3841 \\
\hline & Rel \% & 0.00 & 1.38 & 0.78 & 1.15 & 0.69 & 2.83 & 0.44 & 0.25 & 0.33 & 0.56 & 0.83 & 1.12 & 0.78 \\
\hline \multirow{2}{*}{ C17:1 } & Area & 8244 & 11789 & 5708 & 7737 & 4102 & 2351 & 3386 & 5364 & 7434 & 4733 & 3365 & 6561 & 4254 \\
\hline & Rel \% & 1.49 & 1.47 & 1.66 & 1.54 & 1.03 & 0.66 & 0.79 & 0.27 & 0.57 & 0.79 & 0.54 & 1.44 & 0.87 \\
\hline \multirow{2}{*}{ C18:0 } & Area & 76394 & 16056 & 30443 & 59579 & 8583 & 10798 & 0 & 57475 & 20950 & 16979 & 16245 & 49962 & 45564 \\
\hline & Rel \% & 13.77 & 2.00 & 8.86 & 11.89 & 2.16 & 3.03 & 0.00 & 2.94 & 1.62 & 2.85 & 2.62 & 10.93 & 9.29 \\
\hline \multirow{2}{*}{ C18:1s } & Area & 100090 & 206510 & 72482 & 156488 & 147141 & 74067 & 103441 & 630174 & 460637 & 218451 & 177869 & 96936 & 162917 \\
\hline & Rel \% & 18.05 & 25.69 & 21.08 & 31.24 & 37.04 & 20.67 & 24.19 & 32.21 & 35.61 & 36.70 & 28.68 & 21.21 & 33.21 \\
\hline \multirow{2}{*}{ C18:2 } & Area & 33814 & 23730 & 6106 & 15502 & 19595 & 3875 & 13384 & 75165 & 40639 & 16965 & 17027 & 12841 & 16711 \\
\hline & Rel \% & 6.10 & 2.95 & 1.78 & 3.09 & 4.93 & 1.09 & 3.13 & 3.84 & 3.14 & 2.85 & 2.75 & 2.81 & 3.41 \\
\hline \multirow{2}{*}{$\begin{array}{l}\text { C18: } \\
\text { 3w3 }\end{array}$} & Area & 6490 & 9416 & 2942 & 3012 & 2625 & 2968 & 5544 & 8510 & 148 & 4246 & 3569 & 3389 & 2231 \\
\hline & Rel \% & 1.17 & 1.17 & 0.86 & 0.60 & 0.66 & 0.83 & 1.30 & 0.43 & 0.01 & 0.71 & 0.58 & 0.74 & 0.45 \\
\hline \multirow{2}{*}{ C20:0 } & Area & 13232 & 12433 & 9322 & 7780 & 1123 & 3937 & 2199 & 5464 & 8270 & 4336 & 5748 & 5078 & 3731 \\
\hline & Rel \% & 2.39 & 1.55 & 2.71 & 1.55 & 0.28 & 1.10 & 0.51 & 0.28 & 0.64 & 0.73 & 0.93 & 1.11 & 0.76 \\
\hline \multirow{2}{*}{ C20:1 } & Area & 10064 & 20378 & 6863 & 13944 & 10921 & 6614 & 8129 & 50709 & 29514 & 32832 & 41569 & 25551 & 29184 \\
\hline & Rel \% & 1.81 & 2.54 & 2.00 & 2.78 & 2.75 & 1.85 & 1.90 & 2.59 & 2.28 & 5.52 & 6.70 & 5.59 & 5.95 \\
\hline \multirow{2}{*}{ C24:0 } & Area & 26709 & 20981 & 16491 & 0 & 0 & 0 & 0 & 0 & 0 & 0 & 0 & 0 & 0 \\
\hline & Rel \% & 4.82 & 2.61 & 4.80 & 0.00 & 0.00 & 0.00 & 0.00 & 0.00 & 0.00 & 0.00 & 0.00 & 0.00 & 0.00 \\
\hline \multirow{2}{*}{ Total } & Area & 554629 & 803742 & 343799 & 500948 & 397285 & 356809 & 427685 & 1956552 & 1293614 & 595298 & 620169 & 456972 & 490584 \\
\hline & Rel \% & 100.00 & 100.00 & 100.00 & 100.00 & 100.00 & 100.00 & 100.00 & 100.00 & 100.00 & 100.00 & 100.00 & 100.00 & 100.00 \\
\hline
\end{tabular}


prepared because different foods of similar fatty acid composition and lipid content would produce similar residues. It is possible only to say that the material of origin for the residue was similar in composition to the food(s) indicated.

\section{Gas Chromatography Analysis Parameters}

The GC analysis was performed on a Varian 3800 gas chromatograph fitted with a flame ionization detector connected to a personal computer. Samples were separated using a DB-23 fused silica capillary column ( $30 \mathrm{~m} \mathrm{X} 0.25 \mathrm{~mm}$ I.D.; J\&W Scientific; Folsom, CA). An autosampler injected a $3 \mu \mathrm{L}$ sample using a split/splitless injection system. Hydrogen was used as the carrier gas with a column flow of $1.0 \mathrm{~mL} /$ min. Column temperature was held at $80^{\circ} \mathrm{C}$ for 1 minute then increased to $140{ }^{\circ} \mathrm{C}$ at a rate of $20^{\circ} \mathrm{C}$ per minute. It was then programmed from 140 to $230^{\circ} \mathrm{C}$ at $4^{\circ} \mathrm{C}$ per minute. The upper temperature was held for 5 minutes. Chromatogram peaks were integrated using Varian MS Workstation ${ }^{\circledR}$ software and identified through comparisons with external qualitative standards (NuCheck Prep; Elysian, MN).

\section{RESUltS OF ARCHEOLOGICAL DATA ANALYSIS}

The fatty acid compositions of residues extracted from the 13 samples are presented in Table F-4. The term, Area, represents the area under the chromatographic peak of a given fatty acid, as calculated by the Varian MS Workstation ${ }^{\circledR}$ software minus the solvent blank. The term, Rel\%, represents the relative percentage of the fatty acid with respect to the total fatty acids in the sample. Hydroxide or peroxide degradation products interfered with the integration of the $\mathrm{C} 22: 0$ and $\mathrm{C} 22: 1$ peaks; these fatty acids were excluded from the analysis. Insufficient lipids were present in residues 7UT 6 and 7UT 8 to attempt their identification. Lipid recoveries from samples 7UT 3, 7UT 5, 7UT 7 and 7UT 9 were relatively low.

Five residues, 7UT 1, 7UT 3, 7UT 7, 7UT 9 and 7UT 14, appear to result from the preparation of medium fat content foods. These residues have elevated levels of C18:1 isomers and relatively lower levels of C18:0. Plant foods known to produce similar residues include mesquite, corn and cholla. Certain animal foods, such as fish, Rabdotus snail and fatdepleted elk meat also produce similar residues. Given the elevated levels of medium chain fatty acids in 7UT 3, 7UT 9 and 7UT 14, plant origins for these residues may be more likely. The presence of very long chain fatty acids in residues 7UT 1 and 7UT 3 also indicate a probable plant origin. Conversely, residues 7UT 7, 7UT 9 and 7UT 14 have elevated levels of C14:0 and and/or C16:1; these appear in the decomposed residues of some freshwater fish and snails. For this reason, the origins of most of the medium fat content residues are ambiguous.

Five residues, 7UT 4, 7UT 10, 7UT 11, 7UT 13 and 7UT 15 are typical of foods of moderate-high fat content. These residues have fairly high levels of C18:1 isomers and somewhat lower levels of C18:0. Examples of moderatehigh fat content foods include Texas ebony seeds and the fatty meat of medium-sized mammals, such as beaver. The levels of medium chain fatty acids in all five of these residues are low. The levels of C18:0 are also very low in all residues, except 7UT 4. While there is no strong indication of origin, the elevated levels of C18:2 suggest that a plant source is more likely.

The fatty acid composition of one residue, 7UT 2, fell on the border between medium and moderate-high fat content food. Given the higher levels of medium and very long chain saturated fatty acids in the residue, it is more likely to be of plant origin.

The fatty acid compositions of two residues, 7UT 5 and 7UT 12 , border that of moderate-high and high fat content foods. As noted above, seeds, including Texas ebony, and the fatty meat of medium-sized mammals, such as beaver, are known to produce moderate-high fat content food residues. High fat content residues can result from the processing of locally available high fat content seeds and nuts or rendered animal fat. Higher levels of medium chain fatty acids, such as those observed in residue $7 \mathrm{UT} 12$, are generally associated with foods of plant origin. The origin of residue 7UT 5 is not clear. 


\section{References Cited}

Collins M. B., B. Ellis and C. Dodt-Ellis

1990 Excavations at the Camp Pearl Wheat Site (41KR243): An Early Archaic Campsite on Town Creek, Kerr County, Texas. Studies in Archaeology 6. Texas Archaeological Research Laboratory, The University of Texas at Austin.

Condamin, J., F. Formenti, M. O. Metais, M. Michel, and P. Blond 1976 The Application of Gas Chromatography to the Tracing of Oil in Ancient Amphorae. Archaeometry 18(2):195-201.

deMan, J. M.

1992 Chemical and Physical Properties of Fatty Acids. In: Fatty Acids in Foods and their Health Implications, edited by C. K. Chow, pp. 17-39. Marcel Dekker, New York.

Evershed, R. P., C. Heron and L. J. Goad

1990 Analysis of Organic Residues of Archaeological Origin by High Temperature Gas Chromatography and Gas Chromatography-Mass Spectroscopy. Analyst 115:1339-1342.

Folch, J., M. Lees and G. H. Sloane-Stanley

1957 A simple method for the isolation and purification of lipid extracts from brain tissue. Journal of Biological Chemistry 191:833.

Frankel, E. N.

1991 Recent Advances in Lipid Oxidation. Journal of the Science of Food and Agriculture 54:465-511.

Loy, T.

1994 Residue Analysis of Artifacts and Burned Rock from the Mustang Branch and Barton Sites (41HY209 and 41HY202). In: Archaic and Late Prehistoric Human Ecology in the Middle Onion Creek Valley, Hays County, Texas. Volume 2: Topical Studies, by R. A. Ricklis and M. B. Collins, pp. 607- 627. Studies in Archeology 19, Texas Archaeological Research Laboratory, The University of Texas at Austin.

Malainey, M. E.

1997 The Reconstruction and Testing of Subsistence and Settlement Strategies for the Plains, Parkland and Southern boreal forest. Unpublished Ph.D. thesis, University of Manitoba.

Malainey, M. E., K. L. Malisza, R. Przybylski and G. Monks

2001a The Key to Identifying Archaeological Fatty Acid Residues. Paper presented at the $34^{\text {th }}$ Annual Meeting of the Canadian Archaeological Association, Banff, Alberta, May 2001.

Malainey, M. E., R. Przybylski and B. L. Sherriff

1999a The Fatty Acid Composition of Native Food Plants and Animals of Western Canada. Journal of Archaeological Science 26:83-94.

1999b The Effects of Thermal and Oxidative Decomposition on the Fatty Acid Composition of Food Plants and Animals of Western Canada: Implications for the Identification of archaeological vessel residues. Journal of Archaeological Science 26:95-103.

1999c Identifying the former contents of Late Precontact Period pottery vessels from Western Canada using gas chromatography. Journal of Archaeological Science 26(4): 425-438. 
2001b One Person's Food: How and Why Fish Avoidance May Affect the Settlement and Subsistence Patterns of HunterGatherers. American Antiquity 66(1): 141-161.

Malainey, M. E., R. Przybylski and G. Monks

2000a The identification of archaeological residues using gas chromatography and applications to archaeological problems in Canada, United States and Africa. Paper presented at The $11^{\text {th }}$ Annual Workshops in Archaeometry, State University of New York at Buffalo, February 2000.

2000b Refining and testing the criteria for identifying archaeological lipid residues using gas chromatography. Paper presented at the $33^{r d}$ Annual Meeting of the Canadian Archaeological Association, Ottawa, May 2000.

2000c Developing a General Method for Identifying Archaeological Lipid Residues on the Basis of Fatty Acid Composition. Paper presented at the Joint Midwest Archaeological \& Plains Anthropological Conference, Minneapolis, Minnesota, November 2000.

Marchbanks, M. L.

1989 Lipid Analysis in Archaeology: An Initial Study of Ceramics and Subsistence at the George C. Davis Site. Unpublished M.A. thesis, The University of Texas at Austin.

Marchbanks, M. L. and J. M. Quigg 1990 Appendix G: Organic Residue and Phytolith Analysis. In: Phase II Investigations at Prehistoric and Rock Art Sites, Justiceburg Reservoir, Garza and Kent Counties, Texas, Volume II, by D. K. Boyd, J. T. Abbott, W. A.Bryan, C. M. Garvey, S. A. Tomka and R. C. Fields. pp. 496-519. Reports of Investigations No. 71. Prewitt and Associates, Inc, Austin.

Patrick, M., A. J. de Konig and A. B. Smith

1985 Gas Liquid Chromatographic Analysis of Fatty Acids in Food Residues from Ceramics Found in the Southwestern Cape, South Africa. Archaeometry 27(2): 231-236.

Quigg, J. M., C. Lintz, S. Smith and S. Wilcox

2000 The Lino Site: A Stratified Late Archaic Campsite in a Terrace of the San Idelfonzo Creek, Webb County, Southern Texas. Technical Report No. 23765, TRC Mariah Associates Inc., Austin. Texas Department of Transportation, Environmental Affairs Division, Archaeological Studies Program Report 20, Austin.

Quigg, J. M., M. E. Malainey, R. Przybylski and G. Monks

2001 No bones about it: using lipid analysis of burned rock and groundstone residues to examine Late Archaic subsistence practices in South Texas. Plains Anthropologist 46(177): 283-303.

Skibo, J. M.

1992 Pottery Function: A Use-Alteration Perspective. Plenum Press, New York.

Solomons, T. W. G.

1980 Organic Chemistry. John Wiley \& Sons, Toronto. 



\section{APPENDIX G \\ Sediment Analysis Report \\ (Total C, Organic and Inorganic C, \\ Total Nitrogen and Phosphate Analysis)}

Rupali Datta

Environmental Geochemistry Laboratory

UTSA 



\section{METHODS:}

Phosphate Analysis: Malachite Green Colorimetric method (D’ Angelo et al, 2001).

Inorganic Carbon Analysis: Gravimetric method (Sparks, 1996; Gavlak et al., 2003)

Organic Carbon Analysis: Walkley - Black Titration method (Sparks, 1996; Gavlak et al., 2003)

Table G-1. Results: Inorganic, Organic, and Total Carbon (Mean Values $\pm \mathrm{SD}$ )

\begin{tabular}{|c|c|c|c|c|}
\hline $\begin{array}{c}\text { Sample } \\
\text { No. }\end{array}$ & $\begin{array}{c}\text { Sample } \\
\text { id }\end{array}$ & $\begin{array}{l}\text { Inorganic } \\
\text { Carbon (\%) }\end{array}$ & $\begin{array}{c}\text { Organic } \\
\text { Carbon (\%) }\end{array}$ & $\begin{array}{c}\text { Total } \\
\text { Carbon (\%) }\end{array}$ \\
\hline 1 & $2034-5$ & $0.19 \pm 0.01$ & $5.21 \pm 0.32$ & $5.39 \pm 0.33$ \\
\hline 2 & $2083-5$ & $0.36 \pm 0.04$ & $8.08 \pm 0.18$ & $8.45 \pm 0.14$ \\
\hline 3 & $2104-6$ & $1.49 \pm 0.04$ & $6.34 \pm 0.20$ & $7.84 \pm 0.25$ \\
\hline 4 & $1234-7$ & $1.11 \pm 0.05$ & $6.58 \pm 0.53$ & $7.69 \pm 0.48$ \\
\hline 5 & $228-5$ & $1.35 \pm 0.17$ & $6.34 \pm 0.88$ & $7.69 \pm 0.72$ \\
\hline 6 & $2185-7$ & $0.12 \pm 0.01$ & $6.45 \pm 0.35$ & $6.57 \pm 0.35$ \\
\hline 7 & $671-6$ & $1.07 \pm 0.04$ & $5.20 \pm 0.03$ & $6.27 \pm 0.01$ \\
\hline 8 & $776-8$ & $1.42 \pm 0.14$ & $5.08 \pm 0.57$ & $6.50 \pm 0.71$ \\
\hline 9 & $1078-5$ & $0.03 \pm 0.00$ & $5.21 \pm 0.37$ & $5.24 \pm 0.37$ \\
\hline 10 & $1107-6$ & $1.72 \pm 0.05$ & $8.08 \pm 0.86$ & $9.81 \pm 0.92$ \\
\hline 11 & $1145-5$ & $0.69 \pm 0.05$ & $4.72 \pm 0.38$ & $5.42 \pm 0.33$ \\
\hline 12 & $1206-7$ & $0.32 \pm 0.03$ & $4.71 \pm 0.41$ & $5.02 \pm 0.43$ \\
\hline 13 & $1247-8$ & $1.21 \pm 0.12$ & $8.47 \pm 0.16$ & $9.68 \pm 0.28$ \\
\hline 14 & $1291-7$ & $0.58 \pm 0.06$ & $6.92 \pm 0.61$ & $7.49 \pm 0.54$ \\
\hline 15 & $1675-8$ & $0.24 \pm 0.02$ & $5.05 \pm 0.26$ & $5.29 \pm 0.24$ \\
\hline 16 & $1283-5$ & $0.57 \pm 0.07$ & $5.92 \pm 0.31$ & $6.49 \pm 0.37$ \\
\hline 17 & $2224-0$ & $0.63 \pm 0.05$ & $4.08 \pm 0.54$ & $4.72 \pm 0.49$ \\
\hline 18 & $1762-6$ & $0.32 \pm 0.02$ & $5.43 \pm 0.61$ & $5.75 \pm 0.59$ \\
\hline 19 & $1801-5$ & $0.57 \pm 0.04$ & $4.55 \pm 0.59$ & $5.12 \pm 0.63$ \\
\hline 20 & $1802-6$ & $0.79 \pm 0.04$ & $4.79 \pm 0.23$ & $5.58 \pm 0.27$ \\
\hline 21 & $1881-6$ & $0.29 \pm 0.02$ & $3.96 \pm 0.38$ & $4.25 \pm 0.41$ \\
\hline 22 & $1894-5$ & $1.00 \pm 0.04$ & $3.15 \pm 0.24$ & $4.15 \pm 0.20$ \\
\hline 23 & $304-5$ & $0.18 \pm 0.03$ & $4.66 \pm 0.41$ & $4.84 \pm 0.43$ \\
\hline 24 & $340-7$ & $0.76 \pm 0.05$ & $4.09 \pm 0.19$ & $4.85 \pm 0.24$ \\
\hline 25 & $343-6$ & $1.69 \pm 1.16$ & $3.10 \pm 0.21$ & $4.79 \pm 0.05$ \\
\hline 26 & $373-5$ & $0.62 \pm 0.03$ & $4.22 \pm 0.34$ & $4.85 \pm 0.31$ \\
\hline 27 & $380-5$ & $1.22 \pm 0.07$ & $5.06 \pm 0.20$ & $6.28 \pm 0.27$ \\
\hline 28 & $389-8$ & $0.12 \pm 0.01$ & $5.19 \pm 0.31$ & $5.31 \pm 0.30$ \\
\hline 29 & $431-7$ & $0.11 \pm 0.01$ & $4.22 \pm 0.35$ & $4.33 \pm 0.36$ \\
\hline 30 & $453-8$ & $0.28 \pm 0.03$ & $3.73 \pm 0.36$ & $4.01 \pm 0.39$ \\
\hline 31 & $483-7$ & $0.15 \pm 0.02$ & $5.06 \pm 0.55$ & $5.21 \pm 0.53$ \\
\hline 32 & $537-6$ & $0.05 \pm 0.00$ & $4.98 \pm 0.01$ & $5.03 \pm 0.00$ \\
\hline 33 & $569-6$ & $0.36 \pm 0.02$ & $3.94 \pm 0.37$ & $4.30 \pm 0.34$ \\
\hline 34 & $149-4$ & $0.85 \pm 0.02$ & $4.86 \pm 0.18$ & $5.71 \pm 0.15$ \\
\hline 35 & $269-1$ & $0.34 \pm 0.02$ & $6.71 \pm 0.71$ & $7.05 \pm 0.73$ \\
\hline 36 & $148-3$ & $0.14 \pm 0.01$ & $3.95 \pm 0.38$ & $4.09 \pm 0.37$ \\
\hline 37 & $155-4$ & $0.05 \pm 0.00$ & $3.97 \pm 0.34$ & $4.03 \pm 0.34$ \\
\hline 38 & $172-3$ & $0.36 \pm 0.06$ & $3.34 \pm 0.14$ & $3.70 \pm 0.08$ \\
\hline 39 & $732-6$ & $0.13 \pm 0.01$ & $6.72 \pm 0.70$ & $6.85 \pm 0.71$ \\
\hline 40 & $665-6$ & $1.65 \pm 0.13$ & $12.16 \pm 1.43$ & $13.81 \pm 1.57$ \\
\hline
\end{tabular}

Comment: Error within $20 \%$ limit set by EGL; Data ACCURATE $\underline{\text { Total Carbon }}=$ Inorganic Carbon + Organic Carbon

Total Nitrogen: Samples were first digested using a modified acid digestion method (EPA 3050B, 1996). Concentrated Sulfuric Acid was used for the digestion instead of concentrated Nitric Acid. Acid digestion converted all forms of nitrogen into nitrate, which was measured using ion selective electrode (Cole-Parmer®: Nitrate combination Electrode).

Table G-2. Inorganic Carbon Reproducibility-(Replicate Check)

\begin{tabular}{|c|c|c|c|c|}
\hline \multirow{2}{*}{$\begin{array}{c}\text { Sample } \\
\text { No. }\end{array}$} & \multirow[b]{2}{*}{ Sample id } & \multicolumn{2}{|c|}{ Inorganic Carbon (\%) } & \multirow[b]{2}{*}{$\%$ Difference } \\
\hline & & Replication 1 & Replication 2 & \\
\hline 1 & $2034-5$ & 0.18 & 0.19 & 7.43 \\
\hline 2 & $2083-5$ & 0.39 & 0.34 & 13.13 \\
\hline 3 & 2104-6 & 1.52 & 1.46 & 4.02 \\
\hline 4 & $1234-7$ & 1.07 & 1.14 & 6.11 \\
\hline 5 & $228-5$ & 1.47 & 1.24 & 15.91 \\
\hline 6 & $2185-7$ & 0.11 & 0.12 & 7.48 \\
\hline 7 & $671-6$ & 1.04 & 1.1 & 5.26 \\
\hline 8 & $776-8$ & 1.52 & 1.32 & 13.09 \\
\hline 9 & $1078-5$ & 0.03 & 0.03 & 8.03 \\
\hline 10 & $1107-6$ & 1.68 & 1.76 & 4.36 \\
\hline 11 & $1145-5$ & 0.73 & 0.66 & 9.6 \\
\hline 12 & $1206-7$ & 0.3 & 0.34 & 11.28 \\
\hline 13 & $1247-8$ & 1.12 & 1.29 & 13.25 \\
\hline 14 & $1291-7$ & 0.62 & 0.53 & 14.25 \\
\hline 15 & $1675-8$ & 0.23 & 0.26 & 11.33 \\
\hline 16 & $1675-8$ & 0.52 & 0.62 & 15.41 \\
\hline 17 & 2224-0 & 0.6 & 0.67 & 10.71 \\
\hline 18 & $1762-6$ & 0.33 & 0.31 & 8.33 \\
\hline 19 & $1801-5$ & 0.6 & 0.54 & 9.21 \\
\hline 20 & $1802-6$ & 0.82 & 0.76 & 7.09 \\
\hline 21 & 1881-6 & 0.31 & 0.28 & 10.62 \\
\hline 22 & $1894-5$ & 1.02 & 0.97 & 5.18 \\
\hline 23 & $304-5$ & 0.2 & 0.16 & 18.63 \\
\hline 24 & $340-7$ & 0.73 & 0.8 & 9.29 \\
\hline 25 & $343-6$ & 1.57 & 1.81 & 12.89 \\
\hline 26 & $373-5$ & 0.65 & 0.6 & 7.33 \\
\hline 27 & $380-5$ & 1.27 & 1.17 & 7.6 \\
\hline 28 & 389-8 & 0.13 & 0.11 & 14.74 \\
\hline 29 & $431-7$ & 0.12 & 0.11 & 8.82 \\
\hline 30 & $453-8$ & 0.26 & 0.3 & 13.55 \\
\hline 31 & 483-7 & 0.14 & 0.16 & 14.64 \\
\hline 32 & 537-6 & 0.05 & 0.05 & 9.9 \\
\hline 33 & 569-6 & 0.34 & 0.37 & 8.53 \\
\hline 34 & $149-4$ & 0.84 & 0.87 & 3.62 \\
\hline 35 & 269-1 & 0.32 & 0.35 & 9.84 \\
\hline 36 & $148-3$ & 0.14 & 0.13 & 6.55 \\
\hline 37 & $155-4$ & 0.05 & 0.05 & 8.64 \\
\hline 38 & $172-3$ & 0.32 & 0.4 & 19.77 \\
\hline 39 & $732-6$ & 0.14 & 0.12 & 11.32 \\
\hline 40 & $665-6$ & 1.75 & 1.56 & 10.89 \\
\hline
\end{tabular}

Comment: Error within $20 \%$ limit set by EGL; Data ACCURATE 
Table G-3. Organic Carbon Reproducibility-(Replicate Check)

\begin{tabular}{|c|c|c|c|c|}
\hline \multirow{2}{*}{$\begin{array}{c}\text { Sample } \\
\text { No. }\end{array}$} & Sample & \multicolumn{2}{|c|}{ Organic Carbon (\%) } & \multirow{2}{*}{} \\
\cline { 3 - 4 } & Replication 1 & Replication 2 & \% Difference \\
\hline 1 & $2034-5$ & 4.98 & 5.43 & 8.38 \\
\hline 2 & $2083-5$ & 7.96 & 8.21 & 3.07 \\
\hline 3 & $2104-6$ & 6.49 & 6.2 & 4.64 \\
\hline 4 & $1234-7$ & 6.96 & 6.2 & 10.86 \\
\hline 5 & $228-5$ & 5.72 & 6.97 & 17.93 \\
\hline 6 & $2185-7$ & 6.2 & 6.7 & 7.35 \\
\hline 7 & $671-6$ & 5.22 & 5.18 & 0.85 \\
\hline 8 & $776-8$ & 5.48 & 4.68 & 14.71 \\
\hline 9 & $1078-5$ & 5.47 & 4.95 & 9.54 \\
\hline 10 & $1107-6$ & 7.47 & 8.7 & 14.06 \\
\hline 11 & $1145-5$ & 4.46 & 4.99 & 10.73 \\
\hline 12 & $1206-7$ & 4.42 & 4.99 & 11.48 \\
\hline 13 & $1247-8$ & 8.36 & 8.59 & 2.65 \\
\hline 14 & $1291-7$ & 6.49 & 7.35 & 11.65 \\
\hline 15 & $1675-8$ & 5.23 & 4.87 & 6.93 \\
\hline 16 & $1675-8$ & 5.71 & 6.14 & 7.07 \\
\hline 17 & $2224-0$ & 4.47 & 3.7 & 17.16 \\
\hline 18 & $1762-6$ & 5 & 5.86 & 14.73 \\
\hline 19 & $1801-5$ & 4.97 & 4.13 & 16.88 \\
\hline 20 & $1802-6$ & 4.95 & 4.63 & 6.89 \\
\hline 21 & $1881-6$ & 4.23 & 3.69 & 12.84 \\
\hline 22 & $1894-5$ & 2.98 & 3.32 & 10.09 \\
\hline 23 & $304-5$ & 4.95 & 4.38 & 11.59 \\
\hline 24 & $340-7$ & 3.96 & 4.22 & 6.22 \\
\hline 25 & $343-6$ & 3.25 & 2.95 & 9.15 \\
\hline 26 & $373-5$ & 3.98 & 4.46 & 10.79 \\
\hline 27 & $380-5$ & 5.21 & 4.92 & 5.49 \\
\hline 28 & $389-8$ & 4.97 & 5.41 & 8.94 \\
\hline 29 & $431-7$ & 4.47 & 3.97 & 11.09 \\
\hline 30 & $453-8$ & 3.47 & 3.99 & 12.85 \\
\hline 31 & $483-7$ & 5.45 & 4.67 & 14.18 \\
\hline 32 & $537-6$ & 4.98 & 4.99 & 0.18 \\
\hline 33 & $569-6$ & 4.2 & 3.68 & 12.37 \\
\hline 34 & $149-4$ & 4.98 & 4.74 & 4.98 \\
\hline 35 & $269-1$ & 6.21 & 7.21 & 13.88 \\
\hline 36 & $148-3$ & 3.69 & 4.22 & 14.41 \\
\hline 37 & $155-4$ & 3.74 & 4.21 & 12.68 \\
\hline 38 & $172-3$ & 3.44 & 3.24 & 5.64 \\
\hline 39 & $732-6$ & 7.21 & 6.22 & 13.76 \\
\hline 40 & $665-6$ & 13.17 & 11.15 & 15.36 \\
\hline & & & $D a A C C$ & \\
\hline
\end{tabular}

Comment: Error within $20 \%$ limit set by EGL; Data ACCURATE

Table G-5. Standard Material Reproducibility-(Replicate Check)

\begin{tabular}{|c|c|c|c|c|}
\hline \multirow{2}{*}{$\begin{array}{c}\text { Sample } \\
\text { No. }\end{array}$} & \multirow{2}{*}{$\begin{array}{c}\text { Standard } \\
\text { Sample }\end{array}$} & \multicolumn{2}{|c|}{ Carbon (\%) } & \multirow{2}{*}{$\%$} \\
\cline { 3 - 4 } & Replication 1 & Replication 2 & Difference \\
\hline 1 & $\begin{array}{c}\text { Inorganic } \\
\text { Carbon (\%) }\end{array}$ & 19.9 & 20.88 & 4.7 \\
\hline 2 & $\begin{array}{c}\text { Organic } \\
\text { Carbon (\%) }\end{array}$ & 43.02 & 42.61 & 0.95 \\
\hline 3 & $\begin{array}{c}\text { Total Carbon } \\
(\%)\end{array}$ & 62.92 & 63.49 & 0.91 \\
\hline
\end{tabular}

Table G-4. Total Carbon Reproducibility-(Replicate Check)

\begin{tabular}{|c|c|c|c|c|}
\hline \multirow{2}{*}{$\begin{array}{c}\text { Sample } \\
\text { No. }\end{array}$} & Sample & \multicolumn{2}{|c|}{ Total Carbon $(\%)$} & \multirow{2}{*}{} \\
\cline { 3 - 4 } & id & Replication 1 & Replication 2 & \% Difference \\
\hline 1 & $2034-5$ & 5.16 & 5.63 & 8.35 \\
\hline 2 & $2083-5$ & 8.35 & 8.55 & 2.35 \\
\hline 3 & $2104-6$ & 8.01 & 7.66 & 4.36 \\
\hline 4 & $1234-7$ & 8.03 & 7.35 & 8.54 \\
\hline 5 & $228-5$ & 7.19 & 8.2 & 12.38 \\
\hline 6 & $2185-7$ & 6.32 & 6.82 & 7.35 \\
\hline 7 & $671-6$ & 6.26 & 6.27 & 0.21 \\
\hline 8 & $776-8$ & 7.01 & 6 & 14.36 \\
\hline 9 & $1078-5$ & 5.5 & 4.98 & 9.44 \\
\hline 10 & $1107-6$ & 9.16 & 10.46 & 12.43 \\
\hline 11 & $1145-5$ & 5.18 & 5.65 & 8.24 \\
\hline 12 & $1206-7$ & 4.72 & 5.33 & 11.47 \\
\hline 13 & $1247-8$ & 9.48 & 9.88 & 4.03 \\
\hline 14 & $1291-7$ & 7.11 & 7.88 & 9.74 \\
\hline 15 & $1675-8$ & 5.46 & 5.13 & 6.12 \\
\hline 16 & $1675-8$ & 6.23 & 6.76 & 7.83 \\
\hline 17 & $2224-0$ & 5.07 & 4.37 & 13.72 \\
\hline 18 & $1762-6$ & 5.33 & 6.17 & 13.56 \\
\hline 19 & $1801-5$ & 5.56 & 4.67 & 16.06 \\
\hline 20 & $1802-6$ & 5.77 & 5.39 & 6.54 \\
\hline 21 & $1881-6$ & 4.54 & 3.96 & 12.69 \\
\hline 22 & $1894-5$ & 4 & 4.29 & 6.58 \\
\hline 23 & $304-5$ & 5.15 & 4.54 & 11.86 \\
\hline 24 & $340-7$ & 4.69 & 5.02 & 6.71 \\
\hline 25 & $343-6$ & 4.82 & 4.76 & 1.33 \\
\hline 26 & $373-5$ & 4.63 & 5.06 & 8.58 \\
\hline 27 & $380-5$ & 6.47 & 6.09 & 5.91 \\
\hline 28 & $389-8$ & 5.09 & 5.52 & 7.71 \\
\hline 29 & $431-7$ & 4.59 & 4.08 & 11.04 \\
\hline 30 & $453-8$ & 3.73 & 4.28 & 12.9 \\
\hline 31 & $483-7$ & 5.58 & 4.84 & 13.4 \\
\hline 32 & $537-6$ & 5.03 & 5.03 & 0.07 \\
\hline 33 & $569-6$ & 4.54 & 4.05 & 10.74 \\
\hline 34 & $149-4$ & 5.82 & 5.6 & 3.73 \\
\hline 35 & $269-1$ & 6.53 & 7.57 & 13.69 \\
\hline 36 & $148-3$ & 3.83 & 4.35 & 12 \\
\hline 37 & $155-4$ & 3.79 & 4.26 & 11.22 \\
\hline 38 & $172-3$ & 3.76 & 3.64 & 3.06 \\
\hline 39 & $732-6$ & 7.35 & 6.35 & 13.71 \\
\hline 40 & $665-6$ & 14.92 & 12.7 & 14.84 \\
\hline
\end{tabular}

Comment: Error within $20 \%$ limit set by EGL; Data ACCURATE

Table G-6. QA/QC (Total Carbon)

\begin{tabular}{|c|c|c|c|}
\hline Name & Expected & Experimental & \% Accuracy \\
\hline Standard material (Rep 1) & 71.09 & 62.92 & 88.51 \\
\hline Standard material (Rep 2) & 71.09 & 63.49 & 89.31 \\
\hline
\end{tabular}


Table G-7. Total Nitrogen (Mean values \pm SD)

\begin{tabular}{|c|c|c|}
\hline Sample No. & Sample id & Total Nitrogen (\%) \\
\hline 1 & $2034-5$ & $0.20 \pm 0.01$ \\
\hline 2 & $2083-5$ & $0.49 \pm 0.06$ \\
\hline 3 & $2104-6$ & $1.11 \pm 0.02$ \\
\hline 4 & $1234-7$ & $1.49 \pm 0.02$ \\
\hline 5 & $228-5$ & $1.56 \pm 0.19$ \\
\hline 6 & $2185-7$ & $1.50 \pm 0.14$ \\
\hline 7 & $671-6$ & $0.72 \pm 0.04$ \\
\hline 8 & $776-8$ & $0.70 \pm 0.04$ \\
\hline 9 & $1078-5$ & $2.49 \pm 0.14$ \\
\hline 10 & $1107-6$ & $4.16 \pm 0.07$ \\
\hline 11 & $1145-5$ & $0.67 \pm 0.06$ \\
\hline 12 & $1206-7$ & $1.60 \pm 0.07$ \\
\hline 13 & $1247-8$ & $1.11 \pm 0.02$ \\
\hline 14 & $1291-7$ & $1.40 \pm 0.07$ \\
\hline 15 & $1675-8$ & $1.64 \pm 0.2$ \\
\hline 16 & $1283-5$ & $1.65 \pm 0.06$ \\
\hline 17 & $2224-0$ & $2.02 \pm 0.07$ \\
\hline 18 & $1762-6$ & $2.89 \pm 0.00$ \\
\hline 19 & $1801-5$ & $2.94 \pm 0.07$ \\
\hline 20 & $1802-6$ & $3.08 \pm 0.07$ \\
\hline 21 & $1881-6$ & $5.48 \pm 0.85$ \\
\hline 22 & $1894-5$ & $1.40 \pm 0.07$ \\
\hline 23 & $304-5$ & $1.78 \pm 0.14$ \\
\hline 24 & $340-7$ & $2.88 \pm 0.14$ \\
\hline 25 & $343-6$ & $4.01 \pm 0.49$ \\
\hline 26 & $373-5$ & $2.19 \pm 0.14$ \\
\hline 27 & $380-5$ & $2.64 \pm 0.07$ \\
\hline 28 & $389-8$ & $12.18 \pm 0.42$ \\
\hline 29 & $431-7$ & $3.98 \pm 0.28$ \\
\hline 30 & $453-8$ & $2.19 \pm 0.14$ \\
\hline 31 & $483-7$ & $1.90 \pm 0.0$ \\
\hline 32 & $537-6$ & $1.2 \pm 0.19$ \\
\hline 33 & $569-6$ & $0.96 \pm 0.28$ \\
\hline 34 & $149-4$ & $3.69 \pm 0.28$ \\
\hline 35 & $269-1$ & $3.58 \pm 0.21$ \\
\hline 36 & 148-3 & $2.58 \pm 0.28$ \\
\hline 37 & $155-4$ & $6.15 \pm 0.21$ \\
\hline 38 & $172-3$ & $4.49 \pm 0.35$ \\
\hline 39 & $732-6$ & $6.84 \pm 0.42$ \\
\hline 40 & $665-6$ & $5.00 \pm 0.08$ \\
\hline
\end{tabular}

Table G-9. Internal Standard Check (Total Nitrogen)

\begin{tabular}{|c|c|c|c|}
\hline Standards & Rep 1 & Rep 2 & \% Difference \\
\hline QC 100 ppb & 98.6 & 99 & 0.4 \\
\hline QC 10 ppb & 11.4 & 11.6 & 1.7 \\
\hline
\end{tabular}

Comment: Error within $20 \%$ limit set by EGL; Data ACCURATE
Table G-8. Reproducibility (Replicate Check)

\begin{tabular}{|c|c|c|c|c|}
\hline $\begin{array}{c}\text { Sample } \\
\text { No. }\end{array}$ & Sample id & Replicate 1 & Replicate 2 & $\%$ Reproducibility \\
\hline 1 & $2034-5$ & 0.21 & 0.19 & 9.52 \\
\hline 2 & 2083-5 & 0.49 & 0.41 & 16.33 \\
\hline 3 & $2104-6$ & 1.09 & 1.12 & 2.73 \\
\hline 4 & $1234-7$ & 1.49 & 1.46 & 2 \\
\hline 5 & $228-5$ & 1.7 & 1.43 & 15.88 \\
\hline 6 & $2185-7$ & 1.5 & 1.3 & 13.33 \\
\hline 7 & 671-6 & 0.7 & 0.75 & 7.14 \\
\hline 8 & $776-8$ & 0.7 & 0.65 & 7.14 \\
\hline 9 & $1078-5$ & 2.59 & 2.39 & 7.69 \\
\hline 10 & $1107-6$ & 4.16 & 4.06 & 2.38 \\
\hline 11 & $1145-5$ & 0.71 & 0.63 & 11.27 \\
\hline 12 & $1206-7$ & 1.48 & 1.58 & 6.67 \\
\hline 13 & $1247-8$ & 1.59 & 1.62 & 1.88 \\
\hline 14 & $1291-7$ & 1.4 & 1.3 & 7.14 \\
\hline 15 & $1675-8$ & 1.78 & 1.5 & 15.79 \\
\hline 16 & $1675-8$ & 1.65 & 1.75 & 5.26 \\
\hline 17 & $2224-0$ & 1.97 & 2.07 & 4.76 \\
\hline 18 & $1762-6$ & 2.89 & 2.89 & 0 \\
\hline 19 & $1801-5$ & 2.99 & 2.9 & 3.13 \\
\hline 20 & $1802-6$ & 3.08 & 2.98 & 3.23 \\
\hline 21 & $1881-6$ & 6.08 & 4.88 & 19.67 \\
\hline 22 & $1894-5$ & 2.1 & 2.2 & 4.55 \\
\hline 23 & $304-5$ & 2.18 & 2.38 & 8.33 \\
\hline 24 & $340-7$ & 2.88 & 3.07 & 6.45 \\
\hline 25 & $343-6$ & 3.67 & 4.36 & 15.91 \\
\hline 26 & $373-5$ & 2.19 & 2.39 & 8.33 \\
\hline 27 & $380-5$ & 3.03 & 3.13 & 3.13 \\
\hline 28 & $389-8$ & 12.18 & 12.78 & 4.69 \\
\hline 29 & 431-7 & 3.78 & 4.18 & 9.52 \\
\hline 30 & 453-8 & 2.19 & 2.59 & 15.38 \\
\hline 31 & $483-7$ & 1.8 & 2 & 10 \\
\hline 32 & $537-6$ & 1.29 & 1.29 & 0 \\
\hline 33 & 569-6 & 0.83 & 1.1 & 24.55 \\
\hline 34 & 149-4 & 3.69 & 4.09 & 9.76 \\
\hline 35 & 269-1 & 3.38 & 3.78 & 10.53 \\
\hline 36 & $148-3$ & 2.58 & 2.87 & 10.34 \\
\hline 37 & 155-4 & 5.95 & 6.34 & 6.25 \\
\hline 38 & $172-3$ & 4.49 & 4.79 & 6.25 \\
\hline 39 & $732-6$ & 6.59 & 7.09 & 7.04 \\
\hline 40 & $665-6$ & 5 & 5.6 & 10.71 \\
\hline
\end{tabular}

Comment: Error within 20\% limit set by EGL; Data ACCURATE

Table G-10. QA/QC (Standard Material)

\begin{tabular}{|c|c|c|c|}
\hline Name & Expected & Experimental & \% Accuracy \\
\hline Standard material (Rep 1) & 10.36 & 12.9 & 118.58 \\
\hline Standard material (Rep 2) & 10.36 & 14 & 126.26 \\
\hline
\end{tabular}


Table G-11. Phosphate Analysis Data (Mean values \pm SD)

\begin{tabular}{|c|c|c|}
\hline Sample No. & Sample id & $\begin{array}{c}\text { Phosphate } \\
\text { (mg/kg) }\end{array}$ \\
\hline 1 & $2034-5$ & $18.31 \pm 0.24$ \\
\hline 2 & $2083-5$ & $19.22 \pm 0.00$ \\
\hline 3 & 2104-6 & $25.48 \pm 1.23$ \\
\hline 4 & $1234-7$ & $19.36 \pm 0.24$ \\
\hline 5 & $228-5$ & $23.45 \pm 0.50$ \\
\hline 6 & $2185-7$ & $949.16 \pm 6.90$ \\
\hline 7 & $671-6$ & $758.48 \pm 3.11$ \\
\hline 8 & $776-8$ & $22.77 \pm 1.98$ \\
\hline 9 & $1078-5$ & $15.92 \pm 0.43$ \\
\hline 10 & $1107-6$ & $509.88 \pm 9.07$ \\
\hline 11 & $1145-5$ & $20.34 \pm 1.04$ \\
\hline 12 & $1206-7$ & $343.52 \pm 1.49$ \\
\hline 13 & $1247-8$ & $18.40 \pm 0.23$ \\
\hline 14 & 1291-7 & $18.29 \pm 1.48$ \\
\hline 15 & $1675-8$ & $59.94 \pm 9.94$ \\
\hline 16 & $1283-5$ & $729.89 \pm 19.34$ \\
\hline 17 & $2224-0$ & $195.04 \pm 3.59$ \\
\hline 18 & 1762-6 & $392.59 \pm 11.79$ \\
\hline 19 & $1801-5$ & $46.63 \pm 5.26$ \\
\hline 20 & $1802-6$ & $164.22 \pm 8.39$ \\
\hline 21 & 1881-6 & $883.30 \pm 9.18$ \\
\hline 22 & 1894-5 & $51.67 \pm 2.22$ \\
\hline 23 & $304-5$ & $23.45 \pm 2.19$ \\
\hline 24 & $340-7$ & $126.05 \pm 9.13$ \\
\hline 25 & $343-6$ & $22.01 \pm 1.21$ \\
\hline 26 & $373-5$ & $850.19 \pm 1.31$ \\
\hline 27 & $380-5$ & $20.13 \pm 0.69$ \\
\hline 28 & $389-8$ & $17.39 \pm 0.50$ \\
\hline 29 & $431-7$ & $20.44 \pm 0.24$ \\
\hline 30 & $453-8$ & $25.48 \pm 0.99$ \\
\hline 31 & $483-7$ & $20.98 \pm 0.50$ \\
\hline 32 & $537-6$ & $15.58 \pm 0.93$ \\
\hline 33 & $569-6$ & $42.66 \pm 2.67$ \\
\hline 34 & $149-4$ & $59.62 \pm 1.92$ \\
\hline 35 & 269-1 & $368.79 \pm 12.12$ \\
\hline 36 & $148-3$ & $48.80 \pm 4.16$ \\
\hline 37 & $155-4$ & $93.36 \pm 1.45$ \\
\hline 38 & $172-3$ & $155.19 \pm 2.26$ \\
\hline 39 & $732-6$ & $16.13 \pm 0.21$ \\
\hline 40 & $665-6$ & $20.01 \pm 2.30$ \\
\hline
\end{tabular}

Table G-12. Internal Standard Check (Phosphate)

\begin{tabular}{|c|r|r|c|}
\hline Standards & \multicolumn{1}{|c|}{ Rep 1 } & Rep 2 & \% Difference \\
\hline QC 100 ppb & 120.67 & 123.02 & 1.95 \\
\hline QC 100 ppb & 118.32 & 118.91 & 0.49 \\
\hline QC 100 ppb & 121.26 & 119.49 & 1.48 \\
\hline QC 500 ppb & 568.32 & 569.49 & 0.21 \\
\hline QC 500 ppb & 567.73 & 564.2 & 0.63 \\
\hline
\end{tabular}




\section{References:}

D’Angelo E., J. Crutchfield, and M. Vandiviere

2001 Rapid, Sensitive, Microscale Determination of Phosphate in Water and Soil. J. Env. Qual. 30:2206-2209.

Gavlak R., Horneck D., Miller R.O., Kotuby-Amacher J.

2003 Inorganic Carbon: Gravimetric Determination. Soil, Plant and Water Reference Methods For the Western Region. WREP $125,2^{\text {nd }}$ Edition. pp 125.

Gavlak R., Horneck D., Miller R.O., Kotuby-Amacher J.

2003 Soil Organic Matter: Walkley - Black, Titration. Soil, Plant and Water Reference Methods For the Western Region. WREP 125, $2^{\text {nd }}$ Edition. pp 107.

Sparks D.

1996 Total Carbon, Organic Carbon, and Organic Matter. Methods of soil analysis. Part 2: Chemical Methods. SSSA Publications, Madison, WI. pp 961-1010.

Sparks D.

1996 Total Carbon, Organic Carbon, and Organic Matter. Methods of soil analysis. Part 2: Chemical Methods. SSSA Publications, Madison, WI. pp 961-1010.

USEPA

1996 Test methods for evaluating solid waste, SW 846 ( $3^{\text {rd }}$ Edition). Office of solid waste and emergency response. Washington, D.C. 



\section{APPENDIX H \\ Magnetic Soil Susceptibility Results from \\ Features 4 and 5 at $41 \mathrm{ZV202}$}

Raymond Mauldin

CAR-UTSA 

Magnetic soil susceptibility (MSS) has been used in a variety of contexts. In archaeological research, it has primarily been used on sediment as a discovery method on survey projects, a method to help identify buried soils that may be associated with occupation, and as an aid in identifying heated sediment. The magnetic susceptibility of a given sample can be thought of as a measure of how easily that sample can be magnetized (Dearing 1999). While the measure of susceptibility is initially dependent on the mineralogy of a particular sample, that is the concentration and grain size of ferro- and ferrimagnetic minerals, a number of processes can result in an increase in MSS values in a sediment sample. These processes include an increase in the organic constitutes of the sediment and changes in the mineralogy of sediments in a given sample (see McClean and Kean 1993). Sediments with higher organic content tend to have higher magnetic susceptibility values, probably as a result of the production of maghemite, an iron oxide, during organic decay (Reynolds and King 1995). Pedogenic processes, such as soil formation and weathering, can result in the concentration of organic material, as well as alterations in the mineralogy of a given zone. These processes can significantly increase susceptibility readings. Cultural processes, such as the concentration of ash, charcoal, and organic refuse, would also produce higher MSS readings.

\section{Procedures}

All samples discussed in this appendix were processed in the CAR laboratory. Sediment samples were air dried on a nonmetal surface. After drying, sediment samples were ground to a uniform grain size using a ceramic mortar and pestle. After each sample was prepared, the mortar and pestle were washed with tap water and wiped dry with a paper towel to avoid cross-sample contamination. The ground samples were then poured into sample containers consisting of plastic cubes with external dimensions of $2.54 \times 2.54 \times 1.94 \mathrm{~cm}$. The cubes have an average weight of 4.85 grams. The sediment filled cube was then weighed, and the weight of the sample calculated by subtracting the empty cube weight. This was done to correct for differences in mass. Assuming that sample volume and material is constant, larger samples should have higher susceptibility values simply as a function of greater mass.
The cube was then placed into a MS2B Dual Frequency Sensor that, in conjunction with a MS2 Magnetic Susceptibility Meter, provided a measure of the magnetic susceptibility of the sample (see Dearing 1999). For each cube, two readings were taken using the SI (standard international) scale, and the values were averaged. The resulting average value, referred to as volume specific susceptibility and noted with the symbol $\mathcal{K}_{0}$ (Kappa), was recorded on a scale of $10^{-5}$, though there are no units associated with the value. That is, the value is dimensionless (Dearing 1999).

In order to correct for differences in sample weight, and provide units to the value $\%$, the mass specific susceptibility value $\left(\chi_{0}\right)$ was calculated using the formula

$$
\chi_{0}=\left(K_{0} / p\right)
$$

where $p$ is the sample bulk density expressed in $\mathrm{kg} \mathrm{m}^{-3}$. The bulk density is determined by dividing the sample mass by volume. However, as all samples were measured in identical cubes, and all cubes were full, the sample volume is assumed to be constant. Only the mass of the sample varied. Mass specific susceptibility can be determined by

$$
\chi_{0}=\chi^{*} \text { calibrated mass/ sample mass }
$$

where sample mass is determined by subtracting the cube weight from the total sample weight (Dearing 1999). Calibrated mass is assumed to be 10 grams.

While the resulting values now have both a scale and associated units, the critical element for the current discussion is related to relative differences between sample values as a result of exposure to heat. That is, the principal interest here is in changes in the mass specific susceptibility values at the feature level. In the current analysis, 20 samples from Feature 4 and 20 samples from Feature 5 were analyzed following the procedure outlined above. The results are presented in Table 1. 
Table H-1. Mss Results for Sediment from Feature 4 and 5, 41ZV202

\begin{tabular}{|c|c|c|c|c|c|c|c|c|}
\hline Lot & FS \# & Northing & Easting & Level (bs) & Feature & Weight (gr.) & Reading & MSS Value \\
\hline $1283-005$ & 1352 & 97 & 86 & 2 & 4 & 11.42 & 17.1 & 26.03 \\
\hline $1762-6$ & 841 & 98 & 87 & 2 & 4 & 12.11 & 22.1 & 30.44 \\
\hline $2083-5$ & $227 / 216$ & 98 & 93 & 2 & 4 & 12.22 & 21.1 & 28.63 \\
\hline $228-005$ & $35 / 37$ & 99 & 92 & 2 & 4 & 11.44 & 18.4 & 27.92 \\
\hline $1107-6$ & $2034 / 2046$ & 96 & 84 & 3 & 4 & 11.3 & 13.9 & 21.55 \\
\hline $1675-8$ & 597 & 97 & 91 & 3 & 4 & 11.92 & 17.5 & 24.75 \\
\hline $2185-7$ & $372 / 382$ & 99 & 94 & 3 & 4 & 12.14 & 17.9 & 24.55 \\
\hline $1078-8$ & $1678 / 1690$ & 96 & 83 & 4 & 4 & 11.95 & 14.6 & 20.56 \\
\hline $1206-7$ & $1786 / 1791$ & 97 & 84 & 4 & 4 & 11.04 & 13 & 21 \\
\hline $1247-8$ & $1695 / 1534$ & 97 & 85 & 4 & 4 & 11.82 & 16.8 & 24.1 \\
\hline $1291-7$ & $1362 / 1376$ & 97 & 86 & 4 & 4 & 11.59 & 17.2 & 25.52 \\
\hline $1801-5$ & $774 / 800$ & 98 & 88 & 4 & 4 & 11.9 & 14.8 & 20.99 \\
\hline $1881-6$ & $449 / 452$ & 98 & 89 & 4 & 4 & 11.86 & 14.6 & 20.83 \\
\hline $2034-5$ & 340 & 98 & 91 & 4 & 4 & 11.39 & 14 & 21.41 \\
\hline $1234-7$ & $2057 / 2073$ & 99 & 89 & 4 & 4 & 11.97 & 19.7 & 27.67 \\
\hline $1145-5$ & $1756 / 1774$ & 96 & 85 & 5 & 4 & 12.46 & 16 & 21.02 \\
\hline 2224 & 1056 & 98 & 86 & 5 & 4 & 11.74 & 14.9 & 21.63 \\
\hline $1802-6$ & $784 / 801$ & 98 & 88 & 5 & 4 & 11.03 & 13.4 & 21.68 \\
\hline $1894-005$ & $441 / 439$ & 98 & 90 & 5 & 4 & 11.09 & 11.9 & 19.07 \\
\hline $2104-6$ & $346 / 354$ & 98 & 93 & 5 & 4 & 11.99 & 14.8 & 20.73 \\
\hline $380-5$ & $197 / 199$ & 93 & 75 & 2 & 5 & 11.2 & 12 & 18.9 \\
\hline $665-6$ & 1845 & 95 & 77 & 2 & 5 & 11.06 & 13.9 & 22.38 \\
\hline $301-5$ & 16 & 93 & 72 & 3 & 5 & 12.62 & 16.3 & 20.98 \\
\hline $431-7$ & $488 / 510$ & 93 & 76 & 3 & 5 & 12.35 & 17.4 & 23.2 \\
\hline $483-7$ & $560 / 570$ & 93 & 77 & 3 & 5 & 12.11 & 14.6 & 20.11 \\
\hline $155-4$ & $125 / 129$ & 94 & 76 & 3 & 5 & 12.41 & 16.2 & 21.43 \\
\hline $671-6$ & $1851 / 1859$ & 95 & 77 & 3 & 5 & 11.88 & 15.4 & 21.91 \\
\hline $776-8$ & $1082 / 1095$ & 95 & 79 & 3 & 5 & 11.11 & 13.6 & 21.73 \\
\hline $340-7$ & $222 / 225$ & 93 & 73 & 4 & 5 & 11.45 & 12.4 & 18.79 \\
\hline $389-8$ & $309 / 314$ & 93 & 75 & 4 & 5 & 11.02 & 11.9 & 19.29 \\
\hline $453-8$ & $511 / 527$ & 93 & 76 & 4 & 5 & 13.65 & 17 & 19.32 \\
\hline $537-6$ & $819 / 824$ & 93 & 78 & 4 & 5 & 11.75 & 13.9 & 20.14 \\
\hline $148-003$ & $185 / 186$ & 94 & 75 & 4 & 5 & 11.63 & 13.3 & 19.62 \\
\hline $732-006$ & 917 & 95 & 78 & 4 & 5 & 12.77 & 15.6 & 19.7 \\
\hline $343-6$ & $361 / 226$ & 93 & 73 & 5 & 5 & 10.69 & 10.2 & 17.47 \\
\hline $373-5$ & $121 / 124$ & 93 & 74 & 5 & 5 & 10.62 & 9.5 & 16.46 \\
\hline $569-6$ & $1128 / 1134$ & 93 & 79 & 5 & 5 & 13.03 & 16 & 19.56 \\
\hline $269-1$ & 165 & 94 & 76 & 5 & 5 & 12.02 & 15.5 & 21.62 \\
\hline $149-004$ & $187 / 191$ & 94 & 75 & 5 & 5 & 12.6 & 15.7 & 20.26 \\
\hline $172-003$ & $109 / 217$ & 94 & 78 & 5 & 5 & 11.04 & 10.9 & 17.61 \\
\hline
\end{tabular}

\section{References:}

\section{Dearing, J.A.}

1999 Environmental Magnetic Susceptibility. Chi Publishing, Kenilworth, England.

McClean, R.G., and W.F. Kean

1993 Contributions of Wood Ash Magnetism to Archeomagnetic Properties of Fire Pits and Hearths. Earth and Planetary Science Letters 119:387-394.

Reynolds, R.L., and J.W. King

1995 Magnetic Records of Climate Change. U.S. National Report to I.U.G.G., 1991-1994. American Geophysical Union. $<$ http://www.agu.ong/revgeophys/reyno100/reyno100 .html> Accessed April 2001. 


\section{APPENDIX I \\ Debitage from Features 4 and 5 at $41 \mathrm{ZV202}$}

Raymond Mauldin

CAR-UTSA 

Table I-1. Debitage from Features 4 and 5

\begin{tabular}{|c|c|c|c|c|c|c|c|}
\hline Cat no. & Unique no. & $\begin{array}{c}\text { Max. Size } \\
(\mathrm{mm})\end{array}$ & Cortex \% & Northing & Easting & Level (bs) & Feature \\
\hline $304-001$ & 304-001-002 & 18.28 & 0 & 93 & 72 & 3 & 5 \\
\hline $304-001$ & $304-001-003$ & 13.25 & 0 & 93 & 72 & 3 & 5 \\
\hline $304-001$ & 304-001-004 & 14.6 & 0 & 93 & 72 & 3 & 5 \\
\hline $304-001$ & 304-001-005 & 15.33 & 0 & 93 & 72 & 3 & 5 \\
\hline $304-001$ & 304-001-006 & 11.34 & 0 & 93 & 72 & 3 & 5 \\
\hline $304-001$ & 304-001-007 & 10.47 & 0 & 93 & 72 & 3 & 5 \\
\hline $304-001$ & 304-001-001 & 24.08 & 5 & 93 & 72 & 3 & 5 \\
\hline $340-001$ & $340-001-002$ & 19.86 & 0 & 93 & 73 & 4 & 5 \\
\hline $340-001$ & $340-001-003$ & 15.38 & 0 & 93 & 73 & 4 & 5 \\
\hline $340-001$ & $340-001-004$ & 11.97 & 0 & 93 & 73 & 4 & 5 \\
\hline $340-001$ & $340-001-005$ & 14.74 & 0 & 93 & 73 & 4 & 5 \\
\hline $340-001$ & $340-001-006$ & 11.61 & 0 & 93 & 73 & 4 & 5 \\
\hline $340-001$ & $340-001-007$ & 12.37 & 0 & 93 & 73 & 4 & 5 \\
\hline $340-001$ & $340-001-008$ & 9.66 & 0 & 93 & 73 & 4 & 5 \\
\hline $343-001$ & $343-001-001$ & 18.68 & 0 & 93 & 73 & 5 & 5 \\
\hline $343-001$ & $343-001-002$ & 17.38 & 0 & 93 & 73 & 5 & 5 \\
\hline $343-001$ & $343-001-003$ & 18.19 & 0 & 93 & 73 & 5 & 5 \\
\hline $345-000$ & $345-001$ & 42.41 & 5 & 93 & 73 & 5 & 5 \\
\hline 373-001 & 373-001-001 & 19.61 & 0 & 93 & 74 & 5 & 5 \\
\hline $373-001$ & 373-001-002 & 14.65 & 0 & 93 & 74 & 5 & 5 \\
\hline $373-001$ & $373-001-003$ & 12.87 & 0 & 93 & 74 & 5 & 5 \\
\hline $373-001$ & 373-001-004 & 13.99 & 0 & 93 & 74 & 5 & 5 \\
\hline $373-001$ & 373-001-005 & 12.74 & 0 & 93 & 74 & 5 & 5 \\
\hline 373-001 & 373-001-007 & 11.77 & 0 & 93 & 74 & 5 & 5 \\
\hline $373-001$ & 373-001-006 & 10.01 & 45 & 93 & 74 & 5 & 5 \\
\hline $379-001$ & 379-001-001 & 15.32 & 0 & 93 & 75 & 2 & 5 \\
\hline $379-001$ & 379-001-002 & 8.8 & 0 & 93 & 75 & 2 & 5 \\
\hline $379-001$ & 379-001-003 & 22.01 & 45 & 93 & 75 & 2 & 5 \\
\hline $380-001$ & 380-001-002 & 21.17 & 0 & 93 & 75 & 2 & 5 \\
\hline $380-001$ & $380-001-003$ & 18.84 & 0 & 93 & 75 & 2 & 5 \\
\hline 380-001 & 380-001-004 & 14.11 & 0 & 93 & 75 & 2 & 5 \\
\hline 380-001 & 380-001-005 & 15.4 & 0 & 93 & 75 & 2 & 5 \\
\hline $380-001$ & $380-001-006$ & 11.68 & 0 & 93 & 75 & 2 & 5 \\
\hline $380-001$ & $380-001-007$ & 11.79 & 0 & 93 & 75 & 2 & 5 \\
\hline $389-002$ & $389-002-002$ & 14.76 & 0 & 93 & 75 & 4 & 5 \\
\hline $389-002$ & $389-002-003$ & 13.91 & 0 & 93 & 75 & 4 & 5 \\
\hline $389-002$ & 389-002-004 & 11.83 & 0 & 93 & 75 & 4 & 5 \\
\hline $389-002$ & 389-002-005 & 12.66 & 0 & 93 & 75 & 4 & 5 \\
\hline $389-002$ & 389-002-006 & 12.1 & 0 & 93 & 75 & 4 & 5 \\
\hline $389-002$ & $389-002-007$ & 12.95 & 0 & 93 & 75 & 4 & 5 \\
\hline $389-002$ & 389-002-008 & 9.7 & 0 & 93 & 75 & 4 & 5 \\
\hline $389-002$ & 389-002-009 & 11.65 & 0 & 93 & 75 & 4 & 5 \\
\hline 389-002 & 389-002-011 & 9.96 & 0 & 93 & 75 & 4 & 5 \\
\hline $389-002$ & $389-002-012$ & 13.47 & 0 & 93 & 75 & 4 & 5 \\
\hline $389-002$ & $389-002-013$ & 14.19 & 0 & 93 & 75 & 4 & 5 \\
\hline $389-002$ & $389-002-010$ & 16.58 & 45 & 93 & 75 & 4 & 5 \\
\hline $431-001$ & 431-001-001 & 43.37 & 0 & 93 & 76 & 3 & 5 \\
\hline $431-001$ & 431-001-002 & 19 & 0 & 93 & 76 & 3 & 5 \\
\hline $431-001$ & 431-001-003 & 15.99 & 0 & 93 & 76 & 3 & 5 \\
\hline $431-001$ & 431-001-004 & 14.73 & 0 & 93 & 76 & 3 & 5 \\
\hline $431-001$ & 431-001-006 & 14.8 & 0 & 93 & 76 & 3 & 5 \\
\hline $431-001$ & 431-001-007 & 11.82 & 0 & 93 & 76 & 3 & 5 \\
\hline $431-001$ & 431-001-011 & 15.47 & 0 & 93 & 76 & 3 & 5 \\
\hline $431-001$ & 431-001-012 & 11.94 & 0 & 93 & 76 & 3 & 5 \\
\hline $431-001$ & $431-001-013$ & 10.14 & 0 & 93 & 76 & 3 & 5 \\
\hline
\end{tabular}


Table I-1. Continued...

\begin{tabular}{|c|c|c|c|c|c|c|c|}
\hline Cat no. & Unique no. & $\begin{array}{l}\text { Max. Size } \\
(\mathrm{mm})\end{array}$ & Cortex \% & Northing & Easting & Level (bs) & Feature \\
\hline $431-001$ & $431-001-014$ & 9.53 & 0 & 93 & 76 & 3 & 5 \\
\hline $431-001$ & $431-001-015$ & 10.28 & 0 & 93 & 76 & 3 & 5 \\
\hline $431-001$ & $431-001-016$ & 10.59 & 0 & 93 & 76 & 3 & 5 \\
\hline $431-001$ & $431-001-010$ & 8.26 & 45 & 93 & 76 & 3 & 5 \\
\hline $435-000$ & $435-001$ & 27.56 & 5 & 93 & 76 & 4 & 5 \\
\hline $436-000$ & $436-001$ & 26.99 & 55 & 93 & 76 & 4 & 5 \\
\hline $440-000$ & $440-001$ & 31.31 & 25 & 93 & 76 & 4 & 5 \\
\hline $441-000$ & $441-001-001$ & 8.99 & 0 & 93 & 76 & 4 & 5 \\
\hline $441-000$ & $441-002-002$ & 41.84 & 0 & 93 & 76 & 4 & 5 \\
\hline $442-000$ & $442-001$ & 25.01 & 0 & 93 & 76 & 4 & 5 \\
\hline $443-000$ & $443-001$ & 31.45 & 0 & 93 & 76 & 4 & 5 \\
\hline $444-000$ & $444-001$ & 38.95 & 25 & 93 & 76 & 4 & 5 \\
\hline 453-001 & $453-001-002$ & 26.88 & 0 & 93 & 76 & 4 & 5 \\
\hline 453-001 & 453-001-003 & 19.29 & 0 & 93 & 76 & 4 & 5 \\
\hline $453-001$ & $453-001-004$ & 23.31 & 0 & 93 & 76 & 4 & 5 \\
\hline $453-001$ & $453-001-005$ & 8.3 & 0 & 93 & 76 & 4 & 5 \\
\hline 453-001 & 453-001-006 & 9.24 & 0 & 93 & 76 & 4 & 5 \\
\hline $453-001$ & $453-001-011$ & 8.94 & 0 & 93 & 76 & 4 & 5 \\
\hline $453-001$ & $453-001-012$ & 10.87 & 0 & 93 & 76 & 4 & 5 \\
\hline $453-001$ & $453-001-013$ & 8.95 & 0 & 93 & 76 & 4 & 5 \\
\hline $453-001$ & $453-001-014$ & 9.64 & 0 & 93 & 76 & 4 & 5 \\
\hline $453-001$ & $453-001-015$ & 9.6 & 0 & 93 & 76 & 4 & 5 \\
\hline $453-001$ & $453-001-016$ & 25.42 & 0 & 93 & 76 & 4 & 5 \\
\hline 453-001 & 453-001-019 & 11.13 & 0 & 93 & 76 & 4 & 5 \\
\hline $453-001$ & $453-001-021$ & 12.49 & 0 & 93 & 76 & 4 & 5 \\
\hline 453-001 & 453-001-001 & 32.37 & 5 & 93 & 76 & 4 & 5 \\
\hline $453-001$ & 453-001-009 & 26.87 & 5 & 93 & 76 & 4 & 5 \\
\hline $453-001$ & $453-001-008$ & 14.46 & 35 & 93 & 76 & 4 & 5 \\
\hline $460-000$ & $460-001$ & 26.78 & 0 & 93 & 76 & 4 & 5 \\
\hline 483-003 & 483-003-001 & 33.28 & 0 & 93 & 77 & 3 & 5 \\
\hline $483-003$ & $483-003-003$ & 22.48 & 0 & 93 & 77 & 3 & 5 \\
\hline $483-003$ & $483-003-004$ & 22.54 & 0 & 93 & 77 & 3 & 5 \\
\hline $483-003$ & 483-003-005 & 20.02 & 0 & 93 & 77 & 3 & 5 \\
\hline 483-003 & 483-003-006 & 15.64 & 0 & 93 & 77 & 3 & 5 \\
\hline $483-003$ & 483-003-007 & 11.35 & 0 & 93 & 77 & 3 & 5 \\
\hline $483-003$ & 483-003-008 & 12.99 & 0 & 93 & 77 & 3 & 5 \\
\hline 483-003 & 483-003-009 & 15.56 & 0 & 93 & 77 & 3 & 5 \\
\hline 483-003 & 483-003-011 & 12.31 & 0 & 93 & 77 & 3 & 5 \\
\hline $483-003$ & $483-003-012$ & 12.01 & 0 & 93 & 77 & 3 & 5 \\
\hline $483-003$ & $483-003-013$ & 13.61 & 0 & 93 & 77 & 3 & 5 \\
\hline $483-003$ & $483-003-014$ & 10.3 & 0 & 93 & 77 & 3 & 5 \\
\hline 483-003 & 483-003-015 & 9.72 & 0 & 93 & 77 & 3 & 5 \\
\hline 483-003 & 483-003-016 & 15.64 & 0 & 93 & 77 & 3 & 5 \\
\hline 483-003 & 483-003-017 & 11.78 & 0 & 93 & 77 & 3 & 5 \\
\hline 483-003 & 483-003-018 & 12.94 & 0 & 93 & 77 & 3 & 5 \\
\hline $483-003$ & 483-003-019 & 9.68 & 0 & 93 & 77 & 3 & 5 \\
\hline 483-003 & $483-003-021$ & 15.42 & 0 & 93 & 77 & 3 & 5 \\
\hline 483-003 & 483-003-022 & 8.86 & 0 & 93 & 77 & 3 & 5 \\
\hline $483-003$ & $483-003-023$ & 9.74 & 0 & 93 & 77 & 3 & 5 \\
\hline 483-003 & $483-003-024$ & 8.73 & 0 & 93 & 77 & 3 & 5 \\
\hline $483-003$ & $483-003-025$ & 11.97 & 0 & 93 & 77 & 3 & 5 \\
\hline 483-003 & 483-003-027 & 10.9 & 0 & 93 & 77 & 3 & 5 \\
\hline $483-003$ & $483-003-028$ & 9.26 & 0 & 93 & 77 & 3 & 5 \\
\hline 483-003 & 483-003-029 & 10.37 & 0 & 93 & 77 & 3 & 5 \\
\hline $483-003$ & $483-003-031$ & 16.45 & 0 & 93 & 77 & 3 & 5 \\
\hline
\end{tabular}


Table I-1. Continued...

\begin{tabular}{|c|c|c|c|c|c|c|c|}
\hline Cat no. & Unique no. & $\begin{array}{l}\text { Max. Size } \\
(\mathrm{mm})\end{array}$ & Cortex \% & Northing & Easting & Level (bs) & Feature \\
\hline 483-003 & 483-003-032 & 14.17 & 0 & 93 & 77 & 3 & 5 \\
\hline $483-003$ & $483-003-026$ & 20.42 & 5 & 93 & 77 & 3 & 5 \\
\hline 483-003 & $483-003-020$ & 20.12 & 55 & 93 & 77 & 3 & 5 \\
\hline $537-003$ & $537-003-001$ & 13.57 & 0 & 93 & 78 & 4 & 5 \\
\hline $537-003$ & $537-003-002$ & 18.32 & 0 & 93 & 78 & 4 & 5 \\
\hline $537-003$ & 537-003-003 & 18.49 & 0 & 93 & 78 & 4 & 5 \\
\hline $537-003$ & 537-003-004 & 14.84 & 0 & 93 & 78 & 4 & 5 \\
\hline $537-003$ & $537-003-005$ & 11.12 & 0 & 93 & 78 & 4 & 5 \\
\hline 537-003 & $537-003-006$ & 9.43 & 0 & 93 & 78 & 4 & 5 \\
\hline $569-001$ & 569-001-001 & 32.61 & 0 & 93 & 79 & 5 & 5 \\
\hline 569-001 & 569-001-002 & 24.06 & 0 & 93 & 79 & 5 & 5 \\
\hline $569-001$ & 569-001-003 & 23.36 & 0 & 93 & 79 & 5 & 5 \\
\hline 569-001 & $569-001-004$ & 12.34 & 0 & 93 & 79 & 5 & 5 \\
\hline 569-001 & 569-001-005 & 14.85 & 0 & 93 & 79 & 5 & 5 \\
\hline $569-001$ & $569-001-006$ & 12.52 & 0 & 93 & 79 & 5 & 5 \\
\hline $569-001$ & 569-001-007 & 23.56 & 0 & 93 & 79 & 5 & 5 \\
\hline 569-001 & 569-001-008 & 9.81 & 0 & 93 & 79 & 5 & 5 \\
\hline 569-001 & 569-001-009 & 12.45 & 0 & 93 & 79 & 5 & 5 \\
\hline 569-001 & $569-001-010$ & 13.46 & 0 & 93 & 79 & 5 & 5 \\
\hline $569-001$ & $569-001-012$ & 19.8 & 0 & 93 & 79 & 5 & 5 \\
\hline 569-001 & 569-001-015 & 8.97 & 0 & 93 & 79 & 5 & 5 \\
\hline $148-002$ & $148-002-001$ & 26.44 & 0 & 94 & 75 & 4 & 5 \\
\hline $148-002$ & $148-002-002$ & 12.49 & 0 & 94 & 75 & 4 & 5 \\
\hline $148-002$ & $148-002-003$ & 15.32 & 0 & 94 & 75 & 4 & 5 \\
\hline $148-002$ & $148-002-004$ & 13.75 & 0 & 94 & 75 & 4 & 5 \\
\hline $148-002$ & $148-002-005$ & 9.33 & 0 & 94 & 75 & 4 & 5 \\
\hline $148-002$ & $148-002-006$ & 15.88 & 0 & 94 & 75 & 4 & 5 \\
\hline $148-002$ & $148-002-007$ & 11.46 & 0 & 94 & 75 & 4 & 5 \\
\hline $148-002$ & $148-002-008$ & 8.18 & 0 & 94 & 75 & 4 & 5 \\
\hline $148-002$ & $148-002-009$ & 10.53 & 0 & 94 & 75 & 4 & 5 \\
\hline 149-002 & $149-002-001$ & 36.7 & 0 & 94 & 75 & 5 & 5 \\
\hline $149-002$ & $149-002-003$ & 33.96 & 0 & 94 & 75 & 5 & 5 \\
\hline $149-002$ & $149-002-005$ & 14.65 & 0 & 94 & 75 & 5 & 5 \\
\hline $149-002$ & $149-002-006$ & 13.66 & 0 & 94 & 75 & 5 & 5 \\
\hline $149-002$ & $149-002-008$ & 17.23 & 0 & 94 & 75 & 5 & 5 \\
\hline $149-002$ & 149-002-009 & 11.42 & 0 & 94 & 75 & 5 & 5 \\
\hline $149-002$ & $149-002-004$ & 23.27 & 5 & 94 & 75 & 5 & 5 \\
\hline $149-002$ & $149-002-010$ & 13.84 & 5 & 94 & 75 & 5 & 5 \\
\hline $155-002$ & $155-002-001$ & 19.73 & 0 & 94 & 76 & 3 & 5 \\
\hline $155-002$ & $155-002-002$ & 19.25 & 0 & 94 & 76 & 3 & 5 \\
\hline $155-002$ & $155-002-003$ & 17.09 & 0 & 94 & 76 & 3 & 5 \\
\hline $155-002$ & $155-002-004$ & 12.53 & 0 & 94 & 76 & 3 & 5 \\
\hline $155-002$ & $155-002-005$ & 12.94 & 0 & 94 & 76 & 3 & 5 \\
\hline $155-002$ & $155-002-006$ & 11.96 & 0 & 94 & 76 & 3 & 5 \\
\hline $155-002$ & $155-002-007$ & 13.02 & 0 & 94 & 76 & 3 & 5 \\
\hline $155-002$ & $155-002-008$ & 31.88 & 0 & 94 & 76 & 3 & 5 \\
\hline $157-002$ & 157-002-002 & 10.95 & 0 & 94 & 76 & 5 & 5 \\
\hline $157-002$ & $157-002-004$ & 16.95 & 0 & 94 & 76 & 5 & 5 \\
\hline $157-002$ & $157-002-006$ & 27.52 & 0 & 94 & 76 & 5 & 5 \\
\hline $157-002$ & $157-002-007$ & 27.99 & 0 & 94 & 76 & 5 & 5 \\
\hline $157-002$ & $157-002-008$ & 21.89 & 0 & 94 & 76 & 5 & 5 \\
\hline $157-002$ & 157-002-009 & 21.69 & 0 & 94 & 76 & 5 & 5 \\
\hline $157-002$ & $157-002-010$ & 10.85 & 0 & 94 & 76 & 5 & 5 \\
\hline $172-001$ & 172-001-002 & 14.82 & 0 & 94 & 78 & 5 & 5 \\
\hline $172-001$ & 172-001-003 & 14.54 & 0 & 94 & 78 & 5 & 5 \\
\hline
\end{tabular}


Table I-1. Continued...

\begin{tabular}{|c|c|c|c|c|c|c|c|}
\hline Cat no. & Unique no. & $\begin{array}{l}\text { Max. Size } \\
(\mathrm{mm})\end{array}$ & Cortex \% & Northing & Easting & Level (bs) & Feature \\
\hline $172-001$ & $172-001-004$ & 15.18 & 0 & 94 & 78 & 5 & 5 \\
\hline $172-001$ & $172-001-005$ & 11 & 0 & 94 & 78 & 5 & 5 \\
\hline $172-001$ & $172-001-006$ & 12.55 & 0 & 94 & 78 & 5 & 5 \\
\hline $172-001$ & $172-001-007$ & 11.81 & 0 & 94 & 78 & 5 & 5 \\
\hline $665-001$ & $665-001-001$ & 13.87 & 0 & 95 & 77 & 2 & 5 \\
\hline $665-001$ & $665-001-002$ & 24.98 & 0 & 95 & 77 & 2 & 5 \\
\hline $665-001$ & $665-001-003$ & 20.27 & 0 & 95 & 77 & 2 & 5 \\
\hline $665-001$ & $665-001-005$ & 16.38 & 0 & 95 & 77 & 2 & 5 \\
\hline $665-001$ & $665-001-006$ & 12.66 & 0 & 95 & 77 & 2 & 5 \\
\hline $665-001$ & $665-001-007$ & 12.83 & 0 & 95 & 77 & 2 & 5 \\
\hline $665-001$ & $665-001-008$ & 11.35 & 0 & 95 & 77 & 2 & 5 \\
\hline $665-001$ & $665-001-009$ & 9.26 & 0 & 95 & 77 & 2 & 5 \\
\hline $665-001$ & $665-001-010$ & 10.58 & 0 & 95 & 77 & 2 & 5 \\
\hline $665-001$ & $665-001-013$ & 16.26 & 0 & 95 & 77 & 2 & 5 \\
\hline $665-001$ & $665-001-015$ & 20.94 & 0 & 95 & 77 & 2 & 5 \\
\hline $665-001$ & $665-001-016$ & 12.05 & 0 & 95 & 77 & 2 & 5 \\
\hline $665-001$ & $665-001-017$ & 9.96 & 0 & 95 & 77 & 2 & 5 \\
\hline $665-001$ & $665-001-018$ & 10.03 & 0 & 95 & 77 & 2 & 5 \\
\hline $665-001$ & $665-001-019$ & 11.4 & 0 & 95 & 77 & 2 & 5 \\
\hline $665-001$ & $665-001-020$ & 10.33 & 0 & 95 & 77 & 2 & 5 \\
\hline $665-001$ & $665-001-021$ & 13.81 & 0 & 95 & 77 & 2 & 5 \\
\hline $665-001$ & $665-001-004$ & 26.42 & 35 & 95 & 77 & 2 & 5 \\
\hline $668-000$ & $668-001$ & 32.91 & 0 & 95 & 77 & 2 & 5 \\
\hline 671-001 & 671-001-001 & 37.44 & 0 & 95 & 77 & 3 & 5 \\
\hline $671-001$ & $671-001-002$ & 23.45 & 0 & 95 & 77 & 3 & 5 \\
\hline $671-001$ & $671-001-003$ & 11.29 & 0 & 95 & 77 & 3 & 5 \\
\hline 671-001 & $671-001-004$ & 13.94 & 0 & 95 & 77 & 3 & 5 \\
\hline $671-001$ & $671-001-005$ & 13.12 & 0 & 95 & 77 & 3 & 5 \\
\hline $671-001$ & 671-001-006 & 11.63 & 0 & 95 & 77 & 3 & 5 \\
\hline $671-001$ & $671-001-007$ & 9.99 & 0 & 95 & 77 & 3 & 5 \\
\hline $671-001$ & $671-001-008$ & 15.05 & 0 & 95 & 77 & 3 & 5 \\
\hline $671-001$ & 671-001-009 & 18.77 & 0 & 95 & 77 & 3 & 5 \\
\hline $671-001$ & $671-001-010$ & 20.05 & 0 & 95 & 77 & 3 & 5 \\
\hline $671-001$ & 671-001-011 & 16.67 & 25 & 95 & 77 & 3 & 5 \\
\hline $732-001$ & $732-001-001$ & 19.75 & 0 & 95 & 78 & 4 & 5 \\
\hline $732-001$ & $732-001-002$ & 26.04 & 0 & 95 & 78 & 4 & 5 \\
\hline $732-001$ & $732-001-003$ & 16.07 & 0 & 95 & 78 & 4 & 5 \\
\hline $732-001$ & $732-001-004$ & 17.05 & 0 & 95 & 78 & 4 & 5 \\
\hline $732-001$ & $732-001-005$ & 14.13 & 0 & 95 & 78 & 4 & 5 \\
\hline $732-001$ & $732-001-006$ & 18.09 & 0 & 95 & 78 & 4 & 5 \\
\hline $732-001$ & $732-001-007$ & 13.93 & 0 & 95 & 78 & 4 & 5 \\
\hline $732-001$ & $732-001-008$ & 16.99 & 0 & 95 & 78 & 4 & 5 \\
\hline $732-001$ & 732-001-009 & 12.37 & 0 & 95 & 78 & 4 & 5 \\
\hline $732-001$ & $732-001-010$ & 11.11 & 0 & 95 & 78 & 4 & 5 \\
\hline $732-001$ & $732-001-011$ & 23.48 & 0 & 95 & 78 & 4 & 5 \\
\hline $732-001$ & $732-001-012$ & 9.36 & 0 & 95 & 78 & 4 & 5 \\
\hline 732-001 & $732-001-013$ & 12.03 & 0 & 95 & 78 & 4 & 5 \\
\hline $732-001$ & 732-001-014 & 8.45 & 0 & 95 & 78 & 4 & 5 \\
\hline $732-001$ & $732-001-015$ & 10.49 & 0 & 95 & 78 & 4 & 5 \\
\hline $732-001$ & $732-001-016$ & 12.07 & 0 & 95 & 78 & 4 & 5 \\
\hline $732-001$ & $732-001-017$ & 10.77 & 0 & 95 & 78 & 4 & 5 \\
\hline $732-001$ & 732-001-018 & 7.89 & 0 & 95 & 78 & 4 & 5 \\
\hline $732-001$ & $732-001-019$ & 9.08 & 0 & 95 & 78 & 4 & 5 \\
\hline 732-001 & $732-001-020$ & 10.1 & 0 & 95 & 78 & 4 & 5 \\
\hline $732-001$ & $732-001-021$ & 9.15 & 0 & 95 & 78 & 4 & 5 \\
\hline
\end{tabular}


Table I-1. Continued...

\begin{tabular}{|c|c|c|c|c|c|c|c|}
\hline Cat no. & Unique no. & $\begin{array}{l}\text { Max. Size } \\
(\mathrm{mm})\end{array}$ & Cortex \% & Northing & Easting & Level (bs) & Feature \\
\hline $732-001$ & 732-001-022 & 10.04 & 0 & 95 & 78 & 4 & 5 \\
\hline 732-001 & $732-001-023$ & 14.25 & 0 & 95 & 78 & 4 & 5 \\
\hline $732-001$ & $732-001-024$ & 8.4 & 0 & 95 & 78 & 4 & 5 \\
\hline $732-001$ & $732-001-025$ & 12.5 & 0 & 95 & 78 & 4 & 5 \\
\hline $732-001$ & $732-001-026$ & 12.27 & 0 & 95 & 78 & 4 & 5 \\
\hline $732-001$ & $732-001-028$ & 15.3 & 0 & 95 & 78 & 4 & 5 \\
\hline $732-001$ & $732-001-029$ & 13.62 & 0 & 95 & 78 & 4 & 5 \\
\hline $732-001$ & $732-001-032$ & 11.1 & 0 & 95 & 78 & 4 & 5 \\
\hline $732-001$ & $732-001-030$ & 18.5 & 25 & 95 & 78 & 4 & 5 \\
\hline $776-001$ & $776-001-001$ & 29.6 & 0 & 95 & 79 & 3 & 5 \\
\hline $776-001$ & $776-001-003$ & 11.89 & 0 & 95 & 79 & 3 & 5 \\
\hline $776-001$ & 776-001-004 & 11.28 & 0 & 95 & 79 & 3 & 5 \\
\hline $776-001$ & 776-001-005 & 8.2 & 0 & 95 & 79 & 3 & 5 \\
\hline 776-001 & 776-001-008 & 17.7 & 0 & 95 & 79 & 3 & 5 \\
\hline 776-001 & 776-001-009 & 12.53 & 0 & 95 & 79 & 3 & 5 \\
\hline 776-001 & 776-001-010 & 23.43 & 0 & 95 & 79 & 3 & 5 \\
\hline $776-001$ & $776-001-012$ & 22.03 & 5 & 95 & 79 & 3 & 5 \\
\hline $776-001$ & 776-001-002 & 18.41 & 25 & 95 & 79 & 3 & 5 \\
\hline $778-001$ & 778-001-001 & 36.09 & 45 & 95 & 79 & 3 & 5 \\
\hline $786-001$ & $786-001-001$ & 25.26 & 65 & 95 & 79 & 3 & 5 \\
\hline $1078-001$ & 1078-001-002 & 28.4 & 0 & 96 & 83 & 4 & 4 \\
\hline $1078-001$ & $1078-001-003$ & 22.38 & 0 & 96 & 83 & 4 & 4 \\
\hline $1078-001$ & 1078-001-004 & 42.59 & 0 & 96 & 83 & 4 & 4 \\
\hline $1078-001$ & 1078-001-007 & 14.97 & 0 & 96 & 83 & 4 & 4 \\
\hline $1078-001$ & 1078-001-008 & 17 & 0 & 96 & 83 & 4 & 4 \\
\hline $1078-001$ & 1078-001-009 & 12.19 & 0 & 96 & 83 & 4 & 4 \\
\hline $1078-001$ & $1078-001-012$ & 20.29 & 0 & 96 & 83 & 4 & 4 \\
\hline $1078-001$ & $1078-001-014$ & 13.34 & 0 & 96 & 83 & 4 & 4 \\
\hline $1078-001$ & $1078-001-015$ & 20.97 & 0 & 96 & 83 & 4 & 4 \\
\hline $1078-001$ & 1078-001-016 & 13.29 & 0 & 96 & 83 & 4 & 4 \\
\hline $1078-001$ & $1078-001-018$ & 11.43 & 0 & 96 & 83 & 4 & 4 \\
\hline $1078-001$ & 1078-001-019 & 11.51 & 0 & 96 & 83 & 4 & 4 \\
\hline $1078-001$ & $1078-001-020$ & 11.27 & 0 & 96 & 83 & 4 & 4 \\
\hline $1078-001$ & $1078-001-021$ & 9.34 & 0 & 96 & 83 & 4 & 4 \\
\hline $1078-001$ & 1078-001-022 & 8.8 & 0 & 96 & 83 & 4 & 4 \\
\hline $1078-001$ & $1078-001-023$ & 9.06 & 0 & 96 & 83 & 4 & 4 \\
\hline $1078-001$ & 1078-001-024 & 11.99 & 0 & 96 & 83 & 4 & 4 \\
\hline $1078-001$ & $1078-001-025$ & 9.02 & 0 & 96 & 83 & 4 & 4 \\
\hline $1078-001$ & $1078-001-013$ & 15.53 & 5 & 96 & 83 & 4 & 4 \\
\hline $1078-001$ & 1078-001-027 & 16.22 & 5 & 96 & 83 & 4 & 4 \\
\hline $1078-001$ & $1078-001-029$ & 13.04 & 5 & 96 & 83 & 4 & 4 \\
\hline $1078-001$ & 1078-001-005 & 38.01 & 35 & 96 & 83 & 4 & 4 \\
\hline $1078-001$ & $1078-001-011$ & 52.01 & 45 & 96 & 83 & 4 & 4 \\
\hline $1078-001$ & $1078-001-028$ & 17.34 & 45 & 96 & 83 & 4 & 4 \\
\hline 1103-002 & 1103-002-002 & 19.44 & 0 & 96 & 84 & 3 & 4 \\
\hline $1103-002$ & $1103-002-003$ & 13.57 & 0 & 96 & 84 & 3 & 4 \\
\hline $1103-002$ & $1103-002-004$ & 19.66 & 0 & 96 & 84 & 3 & 4 \\
\hline 1103-002 & 1103-002-005 & 10.37 & 0 & 96 & 84 & 3 & 4 \\
\hline $1103-002$ & $1103-002-006$ & 10.75 & 0 & 96 & 84 & 3 & 4 \\
\hline 1103-002 & 1103-002-007 & 11.33 & 0 & 96 & 84 & 3 & 4 \\
\hline 1103-002 & $1103-002-010$ & 18.3 & 0 & 96 & 84 & 3 & 4 \\
\hline $1103-002$ & $1103-002-012$ & 9.37 & 0 & 96 & 84 & 3 & 4 \\
\hline 1103-002 & 1103-002-015 & 16.29 & 0 & 96 & 84 & 3 & 4 \\
\hline $1103-002$ & $1103-002-016$ & 21.12 & 0 & 96 & 84 & 3 & 4 \\
\hline 1103-002 & $1103-002-017$ & 11.89 & 0 & 96 & 84 & 3 & 4 \\
\hline
\end{tabular}


Table I-1. Continued...

\begin{tabular}{|c|c|c|c|c|c|c|c|}
\hline Cat no. & Unique no. & $\begin{array}{l}\text { Max. Size } \\
(\mathrm{mm})\end{array}$ & Cortex \% & Northing & Easting & Level (bs) & Feature \\
\hline $1103-002$ & $1103-002-018$ & 16.27 & 0 & 96 & 84 & 3 & 4 \\
\hline $1103-002$ & $1103-002-019$ & 16.41 & 0 & 96 & 84 & 3 & 4 \\
\hline $1103-002$ & $1103-002-022$ & 12.32 & 0 & 96 & 84 & 3 & 4 \\
\hline $1103-002$ & $1103-002-023$ & 23.04 & 0 & 96 & 84 & 3 & 4 \\
\hline 1103-002 & $1103-002-024$ & 15.77 & 0 & 96 & 84 & 3 & 4 \\
\hline $1103-002$ & $1103-002-008$ & 21.86 & 25 & 96 & 84 & 3 & 4 \\
\hline $1103-002$ & $1103-002-021$ & 22.54 & 25 & 96 & 84 & 3 & 4 \\
\hline $1103-002$ & $1103-002-026$ & 23.34 & 25 & 96 & 84 & 3 & 4 \\
\hline $1103-002$ & 1103-002-009 & 10.51 & 35 & 96 & 84 & 3 & 4 \\
\hline 1103-002 & $1103-002-020$ & 12.01 & 45 & 96 & 84 & 3 & 4 \\
\hline 1103-002 & $1103-002-025$ & 19.82 & 45 & 96 & 84 & 3 & 4 \\
\hline 1107-005 & $1107-005-002$ & 17.64 & 0 & 96 & 84 & 3 & 4 \\
\hline 1107-005 & $1107-005-003$ & 15.59 & 0 & 96 & 84 & 3 & 4 \\
\hline 1107-005 & $1107-005-005$ & 15.29 & 0 & 96 & 84 & 3 & 4 \\
\hline $1107-005$ & 1107-005-007 & 10.58 & 0 & 96 & 84 & 3 & 4 \\
\hline $1107-005$ & $1107-005-008$ & 10.96 & 0 & 96 & 84 & 3 & 4 \\
\hline $1107-005$ & $1107-005-012$ & 18.44 & 0 & 96 & 84 & 3 & 4 \\
\hline 1107-005 & $1107-005-013$ & 22.17 & 0 & 96 & 84 & 3 & 4 \\
\hline $1107-005$ & $1107-005-015$ & 13.27 & 0 & 96 & 84 & 3 & 4 \\
\hline $1107-005$ & $1107-005-016$ & 12.69 & 0 & 96 & 84 & 3 & 4 \\
\hline $1107-005$ & $1107-005-017$ & 12.04 & 0 & 96 & 84 & 3 & 4 \\
\hline $1107-005$ & $1107-005-018$ & 9.73 & 0 & 96 & 84 & 3 & 4 \\
\hline 1107-005 & $1107-005-021$ & 29.11 & 0 & 96 & 84 & 3 & 4 \\
\hline 1107-005 & $1107-005-022$ & 14.66 & 0 & 96 & 84 & 3 & 4 \\
\hline $1107-005$ & $1107-005-023$ & 15.16 & 0 & 96 & 84 & 3 & 4 \\
\hline $1107-005$ & $1107-005-024$ & 17.1 & 0 & 96 & 84 & 3 & 4 \\
\hline $1107-005$ & $1107-005-025$ & 11.11 & 0 & 96 & 84 & 3 & 4 \\
\hline $1107-005$ & $1107-005-026$ & 9.75 & 0 & 96 & 84 & 3 & 4 \\
\hline 1107-005 & $1107-005-027$ & 10.24 & 0 & 96 & 84 & 3 & 4 \\
\hline $1107-005$ & $1107-005-028$ & 9.59 & 0 & 96 & 84 & 3 & 4 \\
\hline 1107-005 & $1107-005-029$ & 9.18 & 0 & 96 & 84 & 3 & 4 \\
\hline $1107-005$ & $1107-005-019$ & 10.93 & 5 & 96 & 84 & 3 & 4 \\
\hline $1107-005$ & $1107-005-020$ & 13.82 & 15 & 96 & 84 & 3 & 4 \\
\hline 1107-005 & $1107-005-001$ & 23.18 & 35 & 96 & 84 & 3 & 4 \\
\hline $1107-005$ & $1107-005-006$ & 11.63 & 35 & 96 & 84 & 3 & 4 \\
\hline 1107-005 & $1107-005-011$ & 37.33 & 35 & 96 & 84 & 3 & 4 \\
\hline $1145-002$ & $1145-002-001$ & 32.1 & 0 & 96 & 85 & 5 & 4 \\
\hline $1145-002$ & $1145-002-002$ & 30.07 & 0 & 96 & 85 & 5 & 4 \\
\hline $1145-002$ & $1145-002-003$ & 32.33 & 0 & 96 & 85 & 5 & 4 \\
\hline $1145-002$ & $1145-002-004$ & 15.5 & 0 & 96 & 85 & 5 & 4 \\
\hline $1145-002$ & $1145-002-005$ & 21.27 & 0 & 96 & 85 & 5 & 4 \\
\hline $1145-002$ & $1145-002-006$ & 12.86 & 0 & 96 & 85 & 5 & 4 \\
\hline $1145-002$ & $1145-002-007$ & 10.71 & 0 & 96 & 85 & 5 & 4 \\
\hline $1145-002$ & $1145-002-009$ & 13.67 & 0 & 96 & 85 & 5 & 4 \\
\hline $1145-002$ & $1145-002-010$ & 9.93 & 0 & 96 & 85 & 5 & 4 \\
\hline $1145-002$ & $1145-002-011$ & 18.78 & 0 & 96 & 85 & 5 & 4 \\
\hline $1145-002$ & $1145-002-012$ & 10.48 & 0 & 96 & 85 & 5 & 4 \\
\hline $1145-002$ & $1145-002-013$ & 12.57 & 0 & 96 & 85 & 5 & 4 \\
\hline $1145-002$ & $1145-002-014$ & 11.28 & 0 & 96 & 85 & 5 & 4 \\
\hline $1145-002$ & $1145-002-017$ & 18.37 & 0 & 96 & 85 & 5 & 4 \\
\hline $1145-002$ & $1145-002-018$ & 12.33 & 0 & 96 & 85 & 5 & 4 \\
\hline $1145-002$ & $1145-002-019$ & 10.54 & 0 & 96 & 85 & 5 & 4 \\
\hline $1145-002$ & $1145-002-021$ & 10.41 & 0 & 96 & 85 & 5 & 4 \\
\hline $1145-002$ & $1145-002-022$ & 16.78 & 0 & 96 & 85 & 5 & 4 \\
\hline $1145-002$ & $1145-002-023$ & 17.23 & 0 & 96 & 85 & 5 & 4 \\
\hline
\end{tabular}


Table I-1. Continued...

\begin{tabular}{|c|c|c|c|c|c|c|c|}
\hline Cat no. & Unique no. & $\begin{array}{l}\text { Max. Size } \\
(\mathrm{mm})\end{array}$ & Cortex \% & Northing & Easting & Level (bs) & Feature \\
\hline $1145-002$ & $1145-002-016$ & 22.77 & 5 & 96 & 85 & 5 & 4 \\
\hline $1145-002$ & $1145-002-030$ & 11.69 & 5 & 96 & 85 & 5 & 4 \\
\hline $1145-002$ & $1145-002-026$ & 20.06 & 15 & 96 & 85 & 5 & 4 \\
\hline $1145-002$ & $1145-002-027$ & 10.56 & 15 & 96 & 85 & 5 & 4 \\
\hline 1145-002 & $1145-002-028$ & 22.35 & 25 & 96 & 85 & 5 & 4 \\
\hline $1206-001$ & $1206-001-001$ & 35.41 & 0 & 97 & 84 & 4 & 4 \\
\hline $1206-001$ & $1206-001-003$ & 35.46 & 0 & 97 & 84 & 4 & 4 \\
\hline $1206-001$ & $1206-001-005$ & 19.48 & 0 & 97 & 84 & 4 & 4 \\
\hline $1206-001$ & $1206-001-006$ & 30.35 & 0 & 97 & 84 & 4 & 4 \\
\hline 1206-001 & 1206-001-007 & 14.68 & 0 & 97 & 84 & 4 & 4 \\
\hline $1206-001$ & $1206-001-008$ & 12.11 & 0 & 97 & 84 & 4 & 4 \\
\hline $1206-001$ & 1206-001-009 & 16.25 & 0 & 97 & 84 & 4 & 4 \\
\hline $1206-001$ & $1206-001-010$ & 13.63 & 0 & 97 & 84 & 4 & 4 \\
\hline $1206-001$ & $1206-001-011$ & 15.52 & 0 & 97 & 84 & 4 & 4 \\
\hline $1206-001$ & 1206-001-012 & 9.15 & 0 & 97 & 84 & 4 & 4 \\
\hline $1206-001$ & $1206-001-013$ & 10.54 & 0 & 97 & 84 & 4 & 4 \\
\hline $1206-001$ & $1206-001-014$ & 10.39 & 0 & 97 & 84 & 4 & 4 \\
\hline $1206-001$ & $1206-001-015$ & 16.64 & 0 & 97 & 84 & 4 & 4 \\
\hline $1206-001$ & $1206-001-016$ & 9.18 & 0 & 97 & 84 & 4 & 4 \\
\hline 1206-001 & 1206-001-017 & 8.42 & 0 & 97 & 84 & 4 & 4 \\
\hline $1206-001$ & $1206-001-018$ & 13.32 & 0 & 97 & 84 & 4 & 4 \\
\hline $1206-001$ & $1206-001-019$ & 9.44 & 0 & 97 & 84 & 4 & 4 \\
\hline $1206-001$ & $1206-001-020$ & 9.98 & 0 & 97 & 84 & 4 & 4 \\
\hline $1206-001$ & $1206-001-021$ & 17.5 & 0 & 97 & 84 & 4 & 4 \\
\hline $1206-001$ & $1206-001-022$ & 14.26 & 0 & 97 & 84 & 4 & 4 \\
\hline $1206-001$ & $1206-001-023$ & 10.9 & 0 & 97 & 84 & 4 & 4 \\
\hline $1206-001$ & $1206-001-024$ & 9.8 & 0 & 97 & 84 & 4 & 4 \\
\hline $1206-001$ & $1206-001-025$ & 8.26 & 0 & 97 & 84 & 4 & 4 \\
\hline $1206-001$ & $1206-001-026$ & 15.73 & 0 & 97 & 84 & 4 & 4 \\
\hline $1206-001$ & 1206-001-027 & 12.43 & 0 & 97 & 84 & 4 & 4 \\
\hline $1206-001$ & $1206-001-029$ & 19.17 & 0 & 97 & 84 & 4 & 4 \\
\hline $1206-001$ & $1206-001-030$ & 9.06 & 0 & 97 & 84 & 4 & 4 \\
\hline $1206-001$ & $1206-001-031$ & 11.92 & 0 & 97 & 84 & 4 & 4 \\
\hline $1206-001$ & $1206-001-032$ & 12.81 & 0 & 97 & 84 & 4 & 4 \\
\hline $1206-001$ & 1206-001-034 & 13.24 & 0 & 97 & 84 & 4 & 4 \\
\hline $1206-001$ & $1206-001-035$ & 15.19 & 0 & 97 & 84 & 4 & 4 \\
\hline $1206-001$ & $1206-001-038$ & 14.92 & 0 & 97 & 84 & 4 & 4 \\
\hline $1206-001$ & $1206-001-046$ & 16.1 & 0 & 97 & 84 & 4 & 4 \\
\hline $1206-001$ & $1206-001-047$ & 10.78 & 0 & 97 & 84 & 4 & 4 \\
\hline $1206-001$ & 1206-001-004 & 28.56 & 5 & 97 & 84 & 4 & 4 \\
\hline $1206-001$ & 1206-001-037 & 10.44 & 5 & 97 & 84 & 4 & 4 \\
\hline $1206-001$ & $1206-001-039$ & 28.35 & 5 & 97 & 84 & 4 & 4 \\
\hline $1206-001$ & $1206-001-040$ & 16.02 & 5 & 97 & 84 & 4 & 4 \\
\hline $1206-001$ & $1206-001-041$ & 16.77 & 5 & 97 & 84 & 4 & 4 \\
\hline $1206-001$ & 1206-001-042 & 23.35 & 5 & 97 & 84 & 4 & 4 \\
\hline $1206-001$ & 1206-001-043 & 12.63 & 5 & 97 & 84 & 4 & 4 \\
\hline $1206-001$ & $1206-001-036$ & 20.83 & 15 & 97 & 84 & 4 & 4 \\
\hline $1206-001$ & $1206-001-002$ & 39.93 & 45 & 97 & 84 & 4 & 4 \\
\hline $1206-001$ & $1206-001-033$ & 36.56 & 45 & 97 & 84 & 4 & 4 \\
\hline $1247-002$ & $1247-002-002$ & 23.12 & 0 & 97 & 85 & 4 & 4 \\
\hline $1247-002$ & $1247-002-003$ & 13.39 & 0 & 97 & 85 & 4 & 4 \\
\hline $1247-002$ & $1247-002-004$ & 20.79 & 0 & 97 & 85 & 4 & 4 \\
\hline $1247-002$ & $1247-002-005$ & 21.44 & 0 & 97 & 85 & 4 & 4 \\
\hline $1247-002$ & $1247-002-006$ & 21.82 & 0 & 97 & 85 & 4 & 4 \\
\hline $1247-002$ & $1247-002-007$ & 16.08 & 0 & 97 & 85 & 4 & 4 \\
\hline
\end{tabular}


Table I-1. Continued...

\begin{tabular}{|c|c|c|c|c|c|c|c|}
\hline Cat no. & Unique no. & $\begin{array}{l}\text { Max. Size } \\
(\mathrm{mm})\end{array}$ & Cortex \% & Northing & Easting & Level (bs) & Feature \\
\hline $1247-002$ & $1247-002-008$ & 15.47 & 0 & 97 & 85 & 4 & 4 \\
\hline $1247-002$ & $1247-002-009$ & 16.65 & 0 & 97 & 85 & 4 & 4 \\
\hline $1247-002$ & $1247-002-010$ & 11.7 & 0 & 97 & 85 & 4 & 4 \\
\hline $1247-002$ & $1247-002-011$ & 17.85 & 0 & 97 & 85 & 4 & 4 \\
\hline $1247-002$ & $1247-002-012$ & 23.58 & 0 & 97 & 85 & 4 & 4 \\
\hline $1247-002$ & $1247-002-013$ & 15.69 & 0 & 97 & 85 & 4 & 4 \\
\hline $1247-002$ & $1247-002-014$ & 11.56 & 0 & 97 & 85 & 4 & 4 \\
\hline $1247-002$ & $1247-002-015$ & 11.81 & 0 & 97 & 85 & 4 & 4 \\
\hline $1247-002$ & $1247-002-016$ & 17.6 & 0 & 97 & 85 & 4 & 4 \\
\hline $1247-002$ & $1247-002-017$ & 13.57 & 0 & 97 & 85 & 4 & 4 \\
\hline $1247-002$ & $1247-002-018$ & 14.13 & 0 & 97 & 85 & 4 & 4 \\
\hline $1247-002$ & $1247-002-019$ & 10.68 & 0 & 97 & 85 & 4 & 4 \\
\hline $1247-002$ & $1247-002-020$ & 12.04 & 0 & 97 & 85 & 4 & 4 \\
\hline $1247-002$ & $1247-002-021$ & 21.36 & 0 & 97 & 85 & 4 & 4 \\
\hline $1247-002$ & $1247-002-022$ & 13.74 & 0 & 97 & 85 & 4 & 4 \\
\hline $1247-002$ & $1247-002-023$ & 14.93 & 0 & 97 & 85 & 4 & 4 \\
\hline $1247-002$ & $1247-002-024$ & 12.28 & 0 & 97 & 85 & 4 & 4 \\
\hline $1247-002$ & $1247-002-025$ & 9.03 & 0 & 97 & 85 & 4 & 4 \\
\hline $1247-002$ & $1247-002-027$ & 22.14 & 0 & 97 & 85 & 4 & 4 \\
\hline $1247-002$ & $1247-002-028$ & 10.27 & 0 & 97 & 85 & 4 & 4 \\
\hline $1247-002$ & $1247-002-029$ & 16.58 & 0 & 97 & 85 & 4 & 4 \\
\hline $1247-002$ & $1247-002-030$ & 12.42 & 0 & 97 & 85 & 4 & 4 \\
\hline $1247-002$ & $1247-002-031$ & 10.56 & 0 & 97 & 85 & 4 & 4 \\
\hline $1247-002$ & $1247-002-032$ & 13 & 0 & 97 & 85 & 4 & 4 \\
\hline $1247-002$ & $1247-002-033$ & 7.53 & 0 & 97 & 85 & 4 & 4 \\
\hline $1247-002$ & $1247-002-034$ & 7.03 & 0 & 97 & 85 & 4 & 4 \\
\hline $1247-002$ & $1247-002-037$ & 11.52 & 0 & 97 & 85 & 4 & 4 \\
\hline $1247-002$ & $1247-002-038$ & 14.01 & 0 & 97 & 85 & 4 & 4 \\
\hline $1247-002$ & $1247-002-039$ & 11.62 & 0 & 97 & 85 & 4 & 4 \\
\hline $1247-002$ & $1247-002-040$ & 11.55 & 0 & 97 & 85 & 4 & 4 \\
\hline $1247-002$ & $1247-002-041$ & 12.3 & 0 & 97 & 85 & 4 & 4 \\
\hline $1247-002$ & $1247-002-046$ & 10.44 & 0 & 97 & 85 & 4 & 4 \\
\hline $1247-002$ & $1247-002-047$ & 13.46 & 0 & 97 & 85 & 4 & 4 \\
\hline $1247-002$ & $1247-002-049$ & 9.78 & 0 & 97 & 85 & 4 & 4 \\
\hline $1247-002$ & $1247-002-051$ & 9.33 & 0 & 97 & 85 & 4 & 4 \\
\hline $1247-002$ & $1247-002-053$ & 13.36 & 0 & 97 & 85 & 4 & 4 \\
\hline $1247-002$ & $1247-002-056$ & 11.47 & 0 & 97 & 85 & 4 & 4 \\
\hline $1247-002$ & $1247-002-001$ & 25.2 & 5 & 97 & 85 & 4 & 4 \\
\hline $1247-002$ & $1247-002-035$ & 10.6 & 5 & 97 & 85 & 4 & 4 \\
\hline $1247-002$ & $1247-002-044$ & 26.28 & 5 & 97 & 85 & 4 & 4 \\
\hline $1247-002$ & $1247-002-055$ & 14.94 & 5 & 97 & 85 & 4 & 4 \\
\hline $1247-002$ & $1247-002-026$ & 28.97 & 15 & 97 & 85 & 4 & 4 \\
\hline $1247-002$ & $1247-002-042$ & 21.75 & 15 & 97 & 85 & 4 & 4 \\
\hline $1247-002$ & $1247-002-052$ & 21.82 & 25 & 97 & 85 & 4 & 4 \\
\hline $1247-002$ & $1247-002-043$ & 8.69 & 45 & 97 & 85 & 4 & 4 \\
\hline $1247-002$ & $1247-002-045$ & 29.3 & 45 & 97 & 85 & 4 & 4 \\
\hline $1252-000$ & $1252-001$ & 44.53 & 45 & 97 & 85 & 4 & 4 \\
\hline $1283-004$ & 1283-004-001 & 20.26 & 0 & 97 & 86 & 2 & 4 \\
\hline $1283-004$ & 1283-004-002 & 20.18 & 0 & 97 & 86 & 2 & 4 \\
\hline $1283-004$ & 1283-004-003 & 21.72 & 0 & 97 & 86 & 2 & 4 \\
\hline $1283-004$ & 1283-004-006 & 13.01 & 0 & 97 & 86 & 2 & 4 \\
\hline $1283-004$ & 1283-004-007 & 10.89 & 0 & 97 & 86 & 2 & 4 \\
\hline $1283-004$ & 1283-004-009 & 25.63 & 0 & 97 & 86 & 2 & 4 \\
\hline $1283-004$ & 1283-004-010 & 7.78 & 0 & 97 & 86 & 2 & 4 \\
\hline $1283-004$ & 1283-004-011 & 12.78 & 0 & 97 & 86 & 2 & 4 \\
\hline
\end{tabular}


Table I-1. Continued...

\begin{tabular}{|c|c|c|c|c|c|c|c|}
\hline Cat no. & Unique no. & $\begin{array}{c}\text { Max. Size } \\
(\mathrm{mm})\end{array}$ & Cortex \% & Northing & Easting & Level (bs) & Feature \\
\hline $1283-004$ & $1283-004-012$ & 12.47 & 0 & 97 & 86 & 2 & 4 \\
\hline $1283-004$ & $1283-004-013$ & 19.26 & 0 & 97 & 86 & 2 & 4 \\
\hline $1283-004$ & $1283-004-014$ & 9.33 & 0 & 97 & 86 & 2 & 4 \\
\hline $1283-004$ & $1283-004-015$ & 22.14 & 0 & 97 & 86 & 2 & 4 \\
\hline $1283-004$ & $1283-004-016$ & 12.66 & 0 & 97 & 86 & 2 & 4 \\
\hline $1283-004$ & $1283-004-018$ & 11.5 & 0 & 97 & 86 & 2 & 4 \\
\hline $1283-004$ & 1283-004-019 & 15.27 & 0 & 97 & 86 & 2 & 4 \\
\hline $1283-004$ & $1283-004-020$ & 10.13 & 0 & 97 & 86 & 2 & 4 \\
\hline $1283-004$ & $1283-004-017$ & 23.29 & 5 & 97 & 86 & 2 & 4 \\
\hline $1283-004$ & 1283-004-021 & 9.88 & 15 & 97 & 86 & 2 & 4 \\
\hline $1284-005$ & $1284-005-001$ & 31.5 & 0 & 97 & 86 & 2 & 4 \\
\hline $1284-005$ & 1284-005-002 & 23.63 & 0 & 97 & 86 & 2 & 4 \\
\hline $1284-005$ & $1284-005-004$ & 14.14 & 0 & 97 & 86 & 2 & 4 \\
\hline $1284-005$ & $1284-005-005$ & 10.38 & 0 & 97 & 86 & 2 & 4 \\
\hline $1284-005$ & 1284-005-006 & 11.3 & 0 & 97 & 86 & 2 & 4 \\
\hline $1284-005$ & $1284-005-008$ & 17.86 & 0 & 97 & 86 & 2 & 4 \\
\hline $1291-005$ & 1291-005-003 & 17.49 & 0 & 97 & 86 & 4 & 4 \\
\hline 1291-005 & $1291-005-004$ & 19.81 & 0 & 97 & 86 & 4 & 4 \\
\hline $1291-005$ & $1291-005-005$ & 15.19 & 0 & 97 & 86 & 4 & 4 \\
\hline $1291-005$ & $1291-005-007$ & 23.6 & 0 & 97 & 86 & 4 & 4 \\
\hline $1291-005$ & 1291-005-008 & 11.67 & 0 & 97 & 86 & 4 & 4 \\
\hline $1291-005$ & 1291-005-009 & 15.18 & 0 & 97 & 86 & 4 & 4 \\
\hline $1291-005$ & $1291-005-010$ & 11.71 & 0 & 97 & 86 & 4 & 4 \\
\hline $1291-005$ & $1291-005-011$ & 18.09 & 0 & 97 & 86 & 4 & 4 \\
\hline $1291-005$ & $1291-005-013$ & 11.76 & 0 & 97 & 86 & 4 & 4 \\
\hline $1291-005$ & $1291-005-014$ & 11.05 & 0 & 97 & 86 & 4 & 4 \\
\hline $1291-005$ & $1291-005-015$ & 14.73 & 0 & 97 & 86 & 4 & 4 \\
\hline $1291-005$ & $1291-005-016$ & 14.41 & 0 & 97 & 86 & 4 & 4 \\
\hline $1291-005$ & $1291-005-017$ & 14.71 & 0 & 97 & 86 & 4 & 4 \\
\hline 1291-005 & $1291-005-018$ & 17.51 & 0 & 97 & 86 & 4 & 4 \\
\hline $1291-005$ & 1291-005-019 & 16.47 & 0 & 97 & 86 & 4 & 4 \\
\hline $1291-005$ & $1291-005-020$ & 11.98 & 0 & 97 & 86 & 4 & 4 \\
\hline $1291-005$ & $1291-005-021$ & 11.63 & 0 & 97 & 86 & 4 & 4 \\
\hline $1291-005$ & $1291-005-022$ & 12.78 & 0 & 97 & 86 & 4 & 4 \\
\hline 1291-005 & 1291-005-023 & 11.98 & 0 & 97 & 86 & 4 & 4 \\
\hline $1291-005$ & $1291-005-024$ & 11.84 & 0 & 97 & 86 & 4 & 4 \\
\hline $1291-005$ & $1291-005-026$ & 13.12 & 0 & 97 & 86 & 4 & 4 \\
\hline $1291-005$ & 1291-005-028 & 14.49 & 0 & 97 & 86 & 4 & 4 \\
\hline 1291-005 & $1291-005-029$ & 12.47 & 0 & 97 & 86 & 4 & 4 \\
\hline $1291-005$ & $1291-005-031$ & 11.81 & 0 & 97 & 86 & 4 & 4 \\
\hline $1291-005$ & $1291-005-032$ & 9.01 & 0 & 97 & 86 & 4 & 4 \\
\hline $1291-005$ & $1291-005-040$ & 16.94 & 0 & 97 & 86 & 4 & 4 \\
\hline $1291-005$ & 1291-005-041 & 14.12 & 0 & 97 & 86 & 4 & 4 \\
\hline $1291-005$ & $1291-005-002$ & 37.9 & 5 & 97 & 86 & 4 & 4 \\
\hline $1291-005$ & $1291-005-030$ & 23.52 & 5 & 97 & 86 & 4 & 4 \\
\hline $1291-005$ & $1291-005-001$ & 30.48 & 15 & 97 & 86 & 4 & 4 \\
\hline 1291-005 & $1291-005-037$ & 19.39 & 15 & 97 & 86 & 4 & 4 \\
\hline $1291-005$ & $1291-005-043$ & 12.01 & 35 & 97 & 86 & 4 & 4 \\
\hline $1291-005$ & $1291-005-027$ & 16.06 & 45 & 97 & 86 & 4 & 4 \\
\hline $1291-005$ & $1291-005-034$ & 10.25 & 45 & 97 & 86 & 4 & 4 \\
\hline $1291-005$ & $1291-005-039$ & 16.12 & 45 & 97 & 86 & 4 & 4 \\
\hline $1675-001$ & $1675-001-001$ & 38.81 & 0 & 97 & 91 & 3 & 4 \\
\hline $1675-001$ & $1675-001-004$ & 13.82 & 0 & 97 & 91 & 3 & 4 \\
\hline $1675-001$ & 1675-001-006 & 29.44 & 0 & 97 & 91 & 3 & 4 \\
\hline $1675-001$ & $1675-001-007$ & 25.36 & 0 & 97 & 91 & 3 & 4 \\
\hline
\end{tabular}


Table I-1. Continued...

\begin{tabular}{|c|c|c|c|c|c|c|c|}
\hline Cat no. & Unique no. & $\begin{array}{l}\text { Max. Size } \\
(\mathrm{mm})\end{array}$ & Cortex \% & Northing & Easting & Level (bs) & Feature \\
\hline $1675-001$ & 1675-001-008 & 23.3 & 0 & 97 & 91 & 3 & 4 \\
\hline $1675-001$ & 1675-001-009 & 16.55 & 0 & 97 & 91 & 3 & 4 \\
\hline $1675-001$ & $1675-001-010$ & 20.23 & 0 & 97 & 91 & 3 & 4 \\
\hline $1675-001$ & $1675-001-012$ & 32.72 & 0 & 97 & 91 & 3 & 4 \\
\hline $1675-001$ & $1675-001-013$ & 25.99 & 0 & 97 & 91 & 3 & 4 \\
\hline $1675-001$ & $1675-001-017$ & 19.92 & 0 & 97 & 91 & 3 & 4 \\
\hline $1675-001$ & 1675-001-018 & 13.82 & 0 & 97 & 91 & 3 & 4 \\
\hline $1675-001$ & 1675-001-021 & 12.66 & 0 & 97 & 91 & 3 & 4 \\
\hline $1675-001$ & $1675-001-023$ & 11.81 & 0 & 97 & 91 & 3 & 4 \\
\hline $1675-001$ & $1675-001-024$ & 26.64 & 0 & 97 & 91 & 3 & 4 \\
\hline $1675-001$ & $1675-001-025$ & 9.56 & 0 & 97 & 91 & 3 & 4 \\
\hline $1675-001$ & $1675-001-027$ & 20.27 & 0 & 97 & 91 & 3 & 4 \\
\hline $1675-001$ & $1675-001-030$ & 10.37 & 0 & 97 & 91 & 3 & 4 \\
\hline $1675-001$ & $1675-001-031$ & 24.29 & 0 & 97 & 91 & 3 & 4 \\
\hline $1675-001$ & $1675-001-032$ & 12.85 & 0 & 97 & 91 & 3 & 4 \\
\hline $1675-001$ & $1675-001-033$ & 9.78 & 0 & 97 & 91 & 3 & 4 \\
\hline $1675-001$ & $1675-001-034$ & 14.07 & 0 & 97 & 91 & 3 & 4 \\
\hline $1675-001$ & $1675-001-035$ & 11.53 & 0 & 97 & 91 & 3 & 4 \\
\hline $1675-001$ & $1675-001-036$ & 21.7 & 0 & 97 & 91 & 3 & 4 \\
\hline $1675-001$ & $1675-001-037$ & 14.53 & 0 & 97 & 91 & 3 & 4 \\
\hline $1675-001$ & $1675-001-038$ & 15.34 & 0 & 97 & 91 & 3 & 4 \\
\hline $1675-001$ & $1675-001-040$ & 11.89 & 0 & 97 & 91 & 3 & 4 \\
\hline $1675-001$ & $1675-001-041$ & 8.29 & 0 & 97 & 91 & 3 & 4 \\
\hline $1675-001$ & $1675-001-042$ & 12.37 & 0 & 97 & 91 & 3 & 4 \\
\hline $1675-001$ & $1675-001-044$ & 9.93 & 0 & 97 & 91 & 3 & 4 \\
\hline $1675-001$ & $1675-001-045$ & 12.52 & 0 & 97 & 91 & 3 & 4 \\
\hline $1675-001$ & $1675-001-046$ & 11.54 & 0 & 97 & 91 & 3 & 4 \\
\hline $1675-001$ & $1675-001-047$ & 14.45 & 0 & 97 & 91 & 3 & 4 \\
\hline 1675-001 & 1675-001-048 & 11.29 & 0 & 97 & 91 & 3 & 4 \\
\hline $1675-001$ & 1675-001-049 & 7.77 & 0 & 97 & 91 & 3 & 4 \\
\hline $1675-001$ & $1675-001-052$ & 18.89 & 0 & 97 & 91 & 3 & 4 \\
\hline $1675-001$ & $1675-001-053$ & 11.97 & 0 & 97 & 91 & 3 & 4 \\
\hline $1675-001$ & 1675-001-055 & 9.36 & 0 & 97 & 91 & 3 & 4 \\
\hline $1675-001$ & 1675-001-056 & 10.16 & 0 & 97 & 91 & 3 & 4 \\
\hline $1675-001$ & 1675-001-057 & 19.37 & 0 & 97 & 91 & 3 & 4 \\
\hline $1675-001$ & 1675-001-058 & 11.89 & 0 & 97 & 91 & 3 & 4 \\
\hline $1675-001$ & 1675-001-062 & 17.18 & 0 & 97 & 91 & 3 & 4 \\
\hline $1675-001$ & $1675-001-063$ & 18.45 & 0 & 97 & 91 & 3 & 4 \\
\hline $1675-001$ & $1675-001-068$ & 8.6 & 0 & 97 & 91 & 3 & 4 \\
\hline $1675-001$ & 1675-001-069 & 12.57 & 0 & 97 & 91 & 3 & 4 \\
\hline $1675-001$ & $1675-001-072$ & 10.23 & 0 & 97 & 91 & 3 & 4 \\
\hline $1675-001$ & $1675-001-002$ & 40.49 & 5 & 97 & 91 & 3 & 4 \\
\hline $1675-001$ & 1675-001-019 & 18.07 & 5 & 97 & 91 & 3 & 4 \\
\hline $1675-001$ & $1675-001-020$ & 17.33 & 5 & 97 & 91 & 3 & 4 \\
\hline $1675-001$ & $1675-001-043$ & 12.38 & 5 & 97 & 91 & 3 & 4 \\
\hline $1675-001$ & 1675-001-059 & 12.23 & 5 & 97 & 91 & 3 & 4 \\
\hline $1675-001$ & $1675-001-060$ & 14.16 & 5 & 97 & 91 & 3 & 4 \\
\hline $1675-001$ & 1675-001-064 & 12.77 & 5 & 97 & 91 & 3 & 4 \\
\hline $1675-001$ & 1675-001-016 & 30.33 & 15 & 97 & 91 & 3 & 4 \\
\hline $1675-001$ & $1675-001-065$ & 19.58 & 15 & 97 & 91 & 3 & 4 \\
\hline $1675-001$ & $1675-001-070$ & 9.65 & 35 & 97 & 91 & 3 & 4 \\
\hline $1675-001$ & $1675-001-029$ & 19.16 & 45 & 97 & 91 & 3 & 4 \\
\hline $1750-001$ & $1750-001-001$ & 25.11 & 0 & 98 & 86 & 5 & 4 \\
\hline $1750-001$ & $1750-001-002$ & 22.78 & 0 & 98 & 86 & 5 & 4 \\
\hline $1750-001$ & $1750-001-003$ & 25.04 & 0 & 98 & 86 & 5 & 4 \\
\hline
\end{tabular}


Table I-1. Continued...

\begin{tabular}{|c|c|c|c|c|c|c|c|}
\hline Cat no. & Unique no. & $\begin{array}{l}\text { Max. Size } \\
(\mathrm{mm})\end{array}$ & Cortex \% & Northing & Easting & Level (bs) & Feature \\
\hline $1750-001$ & $1750-001-004$ & 20.81 & 0 & 98 & 86 & 5 & 4 \\
\hline $1750-001$ & 1750-001-005 & 21.51 & 0 & 98 & 86 & 5 & 4 \\
\hline $1750-001$ & 1750-001-006 & 12.43 & 0 & 98 & 86 & 5 & 4 \\
\hline $1750-001$ & 1750-001-007 & 12.96 & 0 & 98 & 86 & 5 & 4 \\
\hline $1750-001$ & 1750-001-008 & 15.54 & 0 & 98 & 86 & 5 & 4 \\
\hline $1750-001$ & $1750-001-009$ & 12.17 & 0 & 98 & 86 & 5 & 4 \\
\hline $1750-001$ & $1750-001-010$ & 13.35 & 0 & 98 & 86 & 5 & 4 \\
\hline $1750-001$ & 1750-001-011 & 14.48 & 0 & 98 & 86 & 5 & 4 \\
\hline $1750-001$ & $1750-001-012$ & 12.15 & 0 & 98 & 86 & 5 & 4 \\
\hline $1750-001$ & $1750-001-013$ & 11.62 & 0 & 98 & 86 & 5 & 4 \\
\hline $1750-001$ & $1750-001-014$ & 8.24 & 0 & 98 & 86 & 5 & 4 \\
\hline $1750-001$ & $1750-001-015$ & 12.1 & 0 & 98 & 86 & 5 & 4 \\
\hline $1750-001$ & $1750-001-016$ & 14.73 & 0 & 98 & 86 & 5 & 4 \\
\hline $1750-001$ & 1750-001-017 & 17.47 & 0 & 98 & 86 & 5 & 4 \\
\hline $1750-001$ & $1750-001-018$ & 19.52 & 0 & 98 & 86 & 5 & 4 \\
\hline $1750-001$ & $1750-001-019$ & 12.95 & 0 & 98 & 86 & 5 & 4 \\
\hline $1750-001$ & $1750-001-024$ & 27 & 5 & 98 & 86 & 5 & 4 \\
\hline $1750-001$ & $1750-001-023$ & 13.04 & 15 & 98 & 86 & 5 & 4 \\
\hline $1762-001$ & $1762-001-001$ & 13.16 & 0 & 98 & 87 & 2 & 4 \\
\hline $1762-001$ & $1762-001-003$ & 15.88 & 0 & 98 & 87 & 2 & 4 \\
\hline $1762-001$ & $1762-001-005$ & 16.83 & 0 & 98 & 87 & 2 & 4 \\
\hline $1762-001$ & $1762-001-007$ & 30.08 & 0 & 98 & 87 & 2 & 4 \\
\hline $1762-001$ & 1762-001-008 & 12.13 & 0 & 98 & 87 & 2 & 4 \\
\hline $1762-001$ & $1762-001-010$ & 19.12 & 0 & 98 & 87 & 2 & 4 \\
\hline $1762-001$ & $1762-001-011$ & 7.59 & 0 & 98 & 87 & 2 & 4 \\
\hline $1762-001$ & $1762-001-013$ & 13.72 & 0 & 98 & 87 & 2 & 4 \\
\hline $1762-001$ & $1762-001-015$ & 10.36 & 0 & 98 & 87 & 2 & 4 \\
\hline $1762-001$ & $1762-001-016$ & 11.15 & 0 & 98 & 87 & 2 & 4 \\
\hline $1762-001$ & $1762-001-017$ & 9.77 & 0 & 98 & 87 & 2 & 4 \\
\hline $1762-001$ & $1762-001-020$ & 13.33 & 0 & 98 & 87 & 2 & 4 \\
\hline $1762-001$ & $1762-001-024$ & 8.46 & 0 & 98 & 87 & 2 & 4 \\
\hline $1762-001$ & $1762-001-009$ & 25.68 & 5 & 98 & 87 & 2 & 4 \\
\hline $1762-001$ & $1762-001-019$ & 15.4 & 15 & 98 & 87 & 2 & 4 \\
\hline $1762-001$ & $1762-001-021$ & 12.84 & 25 & 98 & 87 & 2 & 4 \\
\hline $1762-001$ & $1762-001-022$ & 11.59 & 25 & 98 & 87 & 2 & 4 \\
\hline $1762-001$ & $1762-001-002$ & 48.64 & 35 & 98 & 87 & 2 & 4 \\
\hline $1762-001$ & 1762-001-018 & 11.74 & 35 & 98 & 87 & 2 & 4 \\
\hline $1763-001$ & $1763-001-001$ & 13.89 & 0 & 98 & 87 & 2 & 4 \\
\hline $1763-001$ & $1763-001-008$ & 10.89 & 0 & 98 & 87 & 2 & 4 \\
\hline $1763-001$ & $1763-001-011$ & 31.2 & 0 & 98 & 87 & 2 & 4 \\
\hline $1763-001$ & $1763-001-014$ & 16.94 & 0 & 98 & 87 & 2 & 4 \\
\hline $1763-001$ & $1763-001-015$ & 16.69 & 0 & 98 & 87 & 2 & 4 \\
\hline $1763-001$ & $1763-001-016$ & 17.79 & 0 & 98 & 87 & 2 & 4 \\
\hline $1763-001$ & $1763-001-017$ & 14.47 & 0 & 98 & 87 & 2 & 4 \\
\hline $1763-001$ & 1763-001-019 & 15.15 & 0 & 98 & 87 & 2 & 4 \\
\hline $1763-001$ & $1763-001-021$ & 19.36 & 0 & 98 & 87 & 2 & 4 \\
\hline $1763-001$ & $1763-001-022$ & 18.12 & 0 & 98 & 87 & 2 & 4 \\
\hline 1763-001 & $1763-001-023$ & 17.15 & 0 & 98 & 87 & 2 & 4 \\
\hline 1763-001 & $1763-001-025$ & 14.64 & 0 & 98 & 87 & 2 & 4 \\
\hline $1763-001$ & 1763-001-027 & 14.9 & 0 & 98 & 87 & 2 & 4 \\
\hline $1763-001$ & $1763-001-029$ & 8.69 & 0 & 98 & 87 & 2 & 4 \\
\hline $1763-001$ & $1763-001-031$ & 14.74 & 0 & 98 & 87 & 2 & 4 \\
\hline 1763-001 & 1763-001-033 & 14.33 & 0 & 98 & 87 & 2 & 4 \\
\hline $1763-001$ & $1763-001-034$ & 11.59 & 0 & 98 & 87 & 2 & 4 \\
\hline $1763-001$ & $1763-001-036$ & 14.47 & 0 & 98 & 87 & 2 & 4 \\
\hline
\end{tabular}


Table I-1. Continued...

\begin{tabular}{|c|c|c|c|c|c|c|c|}
\hline Cat no. & Unique no. & $\begin{array}{l}\text { Max. Size } \\
(\mathrm{mm})\end{array}$ & Cortex \% & Northing & Easting & Level (bs) & Feature \\
\hline $1763-001$ & 1763-001-037 & 12.06 & 0 & 98 & 87 & 2 & 4 \\
\hline $1763-001$ & $1763-001-038$ & 12.47 & 0 & 98 & 87 & 2 & 4 \\
\hline $1763-001$ & 1763-001-039 & 16.1 & 0 & 98 & 87 & 2 & 4 \\
\hline $1763-001$ & 1763-001-041 & 25.86 & 0 & 98 & 87 & 2 & 4 \\
\hline $1763-001$ & $1763-001-042$ & 15.3 & 0 & 98 & 87 & 2 & 4 \\
\hline $1763-001$ & 1763-001-044 & 12.12 & 0 & 98 & 87 & 2 & 4 \\
\hline $1763-001$ & $1763-001-002$ & 18.29 & 5 & 98 & 87 & 2 & 4 \\
\hline $1763-001$ & 1763-001-005 & 30.66 & 5 & 98 & 87 & 2 & 4 \\
\hline $1763-001$ & 1763-001-009 & 25.65 & 5 & 98 & 87 & 2 & 4 \\
\hline $1763-001$ & 1763-001-010 & 27.9 & 5 & 98 & 87 & 2 & 4 \\
\hline $1763-001$ & 1763-001-013 & 25.43 & 5 & 98 & 87 & 2 & 4 \\
\hline $1763-001$ & $1763-001-020$ & 12.47 & 5 & 98 & 87 & 2 & 4 \\
\hline $1763-001$ & 1763-001-035 & 15.42 & 5 & 98 & 87 & 2 & 4 \\
\hline $1763-001$ & $1763-001-004$ & 15.51 & 15 & 98 & 87 & 2 & 4 \\
\hline $1763-001$ & 1763-001-040 & 15.86 & 15 & 98 & 87 & 2 & 4 \\
\hline $1763-001$ & $1763-001-043$ & 16.17 & 25 & 98 & 87 & 2 & 4 \\
\hline $1801-003$ & $1801-003-002$ & 42.86 & 0 & 98 & 88 & 4 & 4 \\
\hline $1801-003$ & $1801-003-004$ & 20.73 & 0 & 98 & 88 & 4 & 4 \\
\hline $1801-003$ & $1801-003-005$ & 22.5 & 0 & 98 & 88 & 4 & 4 \\
\hline 1801-003 & 1801-003-006 & 17.67 & 0 & 98 & 88 & 4 & 4 \\
\hline $1801-003$ & $1801-003-008$ & 15.68 & 0 & 98 & 88 & 4 & 4 \\
\hline $1801-003$ & $1801-003-010$ & 13.79 & 0 & 98 & 88 & 4 & 4 \\
\hline $1801-003$ & $1801-003-011$ & 17.41 & 0 & 98 & 88 & 4 & 4 \\
\hline $1801-003$ & $1801-003-012$ & 11.82 & 0 & 98 & 88 & 4 & 4 \\
\hline $1801-003$ & $1801-003-013$ & 14.1 & 0 & 98 & 88 & 4 & 4 \\
\hline $1801-003$ & $1801-003-014$ & 14.93 & 0 & 98 & 88 & 4 & 4 \\
\hline $1801-003$ & 1801-003-015 & 12.36 & 0 & 98 & 88 & 4 & 4 \\
\hline $1801-003$ & $1801-003-016$ & 15.13 & 0 & 98 & 88 & 4 & 4 \\
\hline $1801-003$ & $1801-003-017$ & 11.73 & 0 & 98 & 88 & 4 & 4 \\
\hline $1801-003$ & 1801-003-018 & 14.15 & 0 & 98 & 88 & 4 & 4 \\
\hline $1801-003$ & $1801-003-020$ & 10.94 & 0 & 98 & 88 & 4 & 4 \\
\hline $1801-003$ & $1801-003-021$ & 9.94 & 0 & 98 & 88 & 4 & 4 \\
\hline $1801-003$ & 1801-003-007 & 11.97 & 5 & 98 & 88 & 4 & 4 \\
\hline $1801-003$ & 1801-003-009 & 21.55 & 5 & 98 & 88 & 4 & 4 \\
\hline $1801-003$ & 1801-003-019 & 14.56 & 15 & 98 & 88 & 4 & 4 \\
\hline $1801-003$ & $1801-003-003$ & 33.71 & 45 & 98 & 88 & 4 & 4 \\
\hline $1802-003$ & $1802-003-002$ & 13.41 & 0 & 98 & 88 & 5 & 4 \\
\hline $1802-003$ & 1802-003-003 & 11.3 & 0 & 98 & 88 & 5 & 4 \\
\hline $1802-003$ & $1802-003-004$ & 8.3 & 0 & 98 & 88 & 5 & 4 \\
\hline $1802-003$ & $1802-003-005$ & 14.07 & 0 & 98 & 88 & 5 & 4 \\
\hline $1802-003$ & 1802-003-006 & 11.61 & 0 & 98 & 88 & 5 & 4 \\
\hline $1802-003$ & $1802-003-007$ & 13.02 & 0 & 98 & 88 & 5 & 4 \\
\hline $1802-003$ & 1802-003-008 & 16.28 & 0 & 98 & 88 & 5 & 4 \\
\hline $1802-003$ & $1802-003-009$ & 10.37 & 0 & 98 & 88 & 5 & 4 \\
\hline $1802-003$ & $1802-003-010$ & 8.92 & 0 & 98 & 88 & 5 & 4 \\
\hline $1802-003$ & $1802-003-011$ & 11.09 & 0 & 98 & 88 & 5 & 4 \\
\hline $1802-003$ & $1802-003-012$ & 9.44 & 0 & 98 & 88 & 5 & 4 \\
\hline $1802-003$ & 1802-003-013 & 15.19 & 0 & 98 & 88 & 5 & 4 \\
\hline $1802-003$ & $1802-003-014$ & 13.89 & 0 & 98 & 88 & 5 & 4 \\
\hline $1802-003$ & $1802-003-015$ & 11.21 & 0 & 98 & 88 & 5 & 4 \\
\hline $1802-003$ & $1802-003-017$ & 14.15 & 0 & 98 & 88 & 5 & 4 \\
\hline $1802-003$ & 1802-003-020 & 29.6 & 0 & 98 & 88 & 5 & 4 \\
\hline $1802-003$ & 1802-003-001 & 19.74 & 5 & 98 & 88 & 5 & 4 \\
\hline $1802-003$ & 1802-003-018 & 10.84 & 15 & 98 & 88 & 5 & 4 \\
\hline $1829-000$ & $1829-001$ & 33.66 & 0 & 98 & 88 & 5 & 4 \\
\hline
\end{tabular}


Table I-1. Continued...

\begin{tabular}{|c|c|c|c|c|c|c|c|}
\hline Cat no. & Unique no. & $\begin{array}{l}\text { Max. Size } \\
(\mathrm{mm})\end{array}$ & Cortex \% & Northing & Easting & Level (bs) & Feature \\
\hline $1830-000$ & $1830-001$ & 29.61 & 0 & 98 & 88 & 5 & 4 \\
\hline $1832-000$ & $1832-001$ & 62.08 & 45 & 98 & 88 & 5 & 4 \\
\hline $1837-000$ & $1837-001$ & 27.79 & 15 & 98 & 88 & 5 & 4 \\
\hline $1881-003$ & 1881-003-002 & 28.13 & 0 & 98 & 89 & 4 & 4 \\
\hline $1881-003$ & 1881-003-003 & 25.31 & 0 & 98 & 89 & 4 & 4 \\
\hline $1881-003$ & 1881-003-004 & 17.92 & 0 & 98 & 89 & 4 & 4 \\
\hline $1881-003$ & 1881-003-005 & 10.4 & 0 & 98 & 89 & 4 & 4 \\
\hline 1881-003 & 1881-003-006 & 16.89 & 0 & 98 & 89 & 4 & 4 \\
\hline 1881-003 & $1881-003-007$ & 8.1 & 0 & 98 & 89 & 4 & 4 \\
\hline 1881-003 & 1881-003-009 & 14.41 & 0 & 98 & 89 & 4 & 4 \\
\hline $1881-003$ & $1881-003-010$ & 15.9 & 0 & 98 & 89 & 4 & 4 \\
\hline $1881-003$ & 1881-003-011 & 16.2 & 0 & 98 & 89 & 4 & 4 \\
\hline 1881-003 & $1881-003-013$ & 13.63 & 0 & 98 & 89 & 4 & 4 \\
\hline $1881-003$ & 1881-003-014 & 15.91 & 0 & 98 & 89 & 4 & 4 \\
\hline 1881-003 & 1881-003-015 & 10.25 & 0 & 98 & 89 & 4 & 4 \\
\hline 1881-003 & $1881-003-016$ & 19.14 & 0 & 98 & 89 & 4 & 4 \\
\hline $1881-003$ & 1881-003-018 & 13.56 & 0 & 98 & 89 & 4 & 4 \\
\hline 1881-003 & 1881-003-019 & 14.66 & 0 & 98 & 89 & 4 & 4 \\
\hline $1881-003$ & $1881-003-020$ & 12.15 & 0 & 98 & 89 & 4 & 4 \\
\hline 1881-003 & 1881-003-024 & 18.91 & 0 & 98 & 89 & 4 & 4 \\
\hline 1881-003 & 1881-003-027 & 13.52 & 0 & 98 & 89 & 4 & 4 \\
\hline $1881-003$ & 1881-003-028 & 14.66 & 0 & 98 & 89 & 4 & 4 \\
\hline 1881-003 & $1881-003-025$ & 19.87 & 5 & 98 & 89 & 4 & 4 \\
\hline 1881-003 & 1881-003-029 & 27.38 & 5 & 98 & 89 & 4 & 4 \\
\hline 1881-003 & 1881-003-021 & 16.81 & 25 & 98 & 89 & 4 & 4 \\
\hline 1881-003 & $1881-003-022$ & 21.3 & 35 & 98 & 89 & 4 & 4 \\
\hline $1881-003$ & 1881-003-001 & 27.95 & 45 & 98 & 89 & 4 & 4 \\
\hline 1881-003 & 1881-003-023 & 23.68 & 45 & 98 & 89 & 4 & 4 \\
\hline 1881-003 & $1881-003-026$ & 13.09 & 45 & 98 & 89 & 4 & 4 \\
\hline $1881-003$ & $1881-003-030$ & 13.07 & 45 & 98 & 89 & 4 & 4 \\
\hline 1894-001 & 1894-001-001 & 19.23 & 0 & 98 & 90 & 5 & 4 \\
\hline 1894-001 & 1894-001-002 & 17.8 & 0 & 98 & 90 & 5 & 4 \\
\hline 1894-001 & 1894-001-003 & 10.05 & 0 & 98 & 90 & 5 & 4 \\
\hline 1894-001 & 1894-001-004 & 13.84 & 0 & 98 & 90 & 5 & 4 \\
\hline 1894-001 & 1894-001-005 & 15.58 & 0 & 98 & 90 & 5 & 4 \\
\hline 1894-001 & 1894-001-006 & 9.82 & 0 & 98 & 90 & 5 & 4 \\
\hline 1894-001 & 1894-001-007 & 15.44 & 0 & 98 & 90 & 5 & 4 \\
\hline 1894-001 & 1894-001-008 & 19.67 & 0 & 98 & 90 & 5 & 4 \\
\hline 1894-001 & 1894-001-010 & 9.81 & 0 & 98 & 90 & 5 & 4 \\
\hline 1894-001 & 1894-001-011 & 13.97 & 0 & 98 & 90 & 5 & 4 \\
\hline 1894-001 & 1894-001-012 & 17.11 & 0 & 98 & 90 & 5 & 4 \\
\hline 1894-001 & 1894-001-013 & 18.81 & 5 & 98 & 90 & 5 & 4 \\
\hline 1894-001 & 1894-001-014 & 12.43 & 35 & 98 & 90 & 5 & 4 \\
\hline 2034-003 & 2034-003-003 & 18.76 & 0 & 98 & 91 & 4 & 4 \\
\hline 2034-003 & 2034-003-004 & 13.21 & 0 & 98 & 91 & 4 & 4 \\
\hline 2034-003 & 2034-003-005 & 16.54 & 0 & 98 & 91 & 4 & 4 \\
\hline 2034-003 & 2034-003-006 & 37.84 & 0 & 98 & 91 & 4 & 4 \\
\hline 2034-003 & 2034-003-007 & 11.97 & 0 & 98 & 91 & 4 & 4 \\
\hline 2034-003 & 2034-003-008 & 15.24 & 0 & 98 & 91 & 4 & 4 \\
\hline 2034-003 & 2034-003-009 & 12.53 & 0 & 98 & 91 & 4 & 4 \\
\hline 2034-003 & 2034-003-010 & 7.66 & 0 & 98 & 91 & 4 & 4 \\
\hline 2034-003 & 2034-003-011 & 10.91 & 0 & 98 & 91 & 4 & 4 \\
\hline 2034-003 & 2034-003-012 & 13.54 & 0 & 98 & 91 & 4 & 4 \\
\hline 2034-003 & 2034-003-013 & 11.95 & 0 & 98 & 91 & 4 & 4 \\
\hline $2034-003$ & 2034-003-014 & 12.52 & 0 & 98 & 91 & 4 & 4 \\
\hline
\end{tabular}


Table I-1. Continued...

\begin{tabular}{|c|c|c|c|c|c|c|c|}
\hline Cat no. & Unique no. & $\begin{array}{l}\text { Max. Size } \\
(\mathrm{mm})\end{array}$ & Cortex \% & Northing & Easting & Level (bs) & Feature \\
\hline $2034-003$ & 2034-003-015 & 22.9 & 0 & 98 & 91 & 4 & 4 \\
\hline $2034-003$ & 2034-003-016 & 16.26 & 0 & 98 & 91 & 4 & 4 \\
\hline $2034-003$ & 2034-003-017 & 12.28 & 0 & 98 & 91 & 4 & 4 \\
\hline $2034-003$ & 2034-003-018 & 9.61 & 0 & 98 & 91 & 4 & 4 \\
\hline $2034-003$ & $2034-003-022$ & 16.57 & 0 & 98 & 91 & 4 & 4 \\
\hline $2034-003$ & $2034-003-023$ & 18.93 & 0 & 98 & 91 & 4 & 4 \\
\hline $2034-003$ & $2034-003-025$ & 15.89 & 0 & 98 & 91 & 4 & 4 \\
\hline $2034-003$ & $2034-003-026$ & 11.52 & 0 & 98 & 91 & 4 & 4 \\
\hline 2034-003 & $2034-003-028$ & 15.12 & 0 & 98 & 91 & 4 & 4 \\
\hline $2034-003$ & $2034-003-030$ & 13.02 & 0 & 98 & 91 & 4 & 4 \\
\hline $2034-003$ & $2034-003-024$ & 25.04 & 5 & 98 & 91 & 4 & 4 \\
\hline $2034-003$ & 2034-003-001 & 44.02 & 15 & 98 & 91 & 4 & 4 \\
\hline $2034-003$ & $2034-003-033$ & 17.96 & 15 & 98 & 91 & 4 & 4 \\
\hline $2034-003$ & 2034-003-029 & 21.22 & 25 & 98 & 91 & 4 & 4 \\
\hline 2034-003 & 2034-003-031 & 16.06 & 45 & 98 & 91 & 4 & 4 \\
\hline $2034-003$ & $2034-003-002$ & 30.99 & 55 & 98 & 91 & 4 & 4 \\
\hline 2083-001 & 2083-001-002 & 36.1 & 0 & 98 & 93 & 2 & 4 \\
\hline 2083-001 & 2083-001-003 & 32.39 & 0 & 98 & 93 & 2 & 4 \\
\hline 2083-001 & 2083-001-004 & 17.45 & 0 & 98 & 93 & 2 & 4 \\
\hline $2083-001$ & 2083-001-005 & 27.48 & 0 & 98 & 93 & 2 & 4 \\
\hline $2083-001$ & 2083-001-007 & 13.33 & 0 & 98 & 93 & 2 & 4 \\
\hline 2083-001 & 2083-001-008 & 14.04 & 0 & 98 & 93 & 2 & 4 \\
\hline $2083-001$ & 2083-001-009 & 18.11 & 0 & 98 & 93 & 2 & 4 \\
\hline 2083-001 & 2083-001-010 & 14.85 & 0 & 98 & 93 & 2 & 4 \\
\hline $2083-001$ & 2083-001-011 & 20 & 0 & 98 & 93 & 2 & 4 \\
\hline $2083-001$ & 2083-001-012 & 19.43 & 0 & 98 & 93 & 2 & 4 \\
\hline 2083-001 & 2083-001-013 & 13.19 & 0 & 98 & 93 & 2 & 4 \\
\hline $2083-001$ & 2083-001-014 & 15.6 & 0 & 98 & 93 & 2 & 4 \\
\hline $2083-001$ & 2083-001-015 & 13.86 & 0 & 98 & 93 & 2 & 4 \\
\hline $2083-001$ & 2083-001-016 & 14.84 & 0 & 98 & 93 & 2 & 4 \\
\hline $2083-001$ & 2083-001-017 & 23.48 & 0 & 98 & 93 & 2 & 4 \\
\hline $2083-001$ & 2083-001-018 & 12.6 & 0 & 98 & 93 & 2 & 4 \\
\hline $2083-001$ & 2083-001-019 & 17.32 & 0 & 98 & 93 & 2 & 4 \\
\hline 2083-001 & 2083-001-020 & 11.24 & 0 & 98 & 93 & 2 & 4 \\
\hline 2083-001 & 2083-001-022 & 14.06 & 0 & 98 & 93 & 2 & 4 \\
\hline $2083-001$ & 2083-001-023 & 11.95 & 0 & 98 & 93 & 2 & 4 \\
\hline 2083-001 & 2083-001-024 & 15.63 & 0 & 98 & 93 & 2 & 4 \\
\hline $2083-001$ & 2083-001-025 & 12.78 & 0 & 98 & 93 & 2 & 4 \\
\hline 2083-001 & 2083-001-026 & 9.7 & 0 & 98 & 93 & 2 & 4 \\
\hline 2083-001 & 2083-001-027 & 12.63 & 0 & 98 & 93 & 2 & 4 \\
\hline 2083-001 & 2083-001-028 & 11.56 & 0 & 98 & 93 & 2 & 4 \\
\hline $2083-001$ & $2083-001-029$ & 13.54 & 0 & 98 & 93 & 2 & 4 \\
\hline $2083-001$ & $2083-001-030$ & 14.72 & 0 & 98 & 93 & 2 & 4 \\
\hline $2083-001$ & 2083-001-031 & 9.74 & 0 & 98 & 93 & 2 & 4 \\
\hline $2083-001$ & $2083-001-032$ & 10.71 & 0 & 98 & 93 & 2 & 4 \\
\hline $2083-001$ & 2083-001-033 & 12.94 & 0 & 98 & 93 & 2 & 4 \\
\hline $2083-001$ & 2083-001-035 & 14.33 & 0 & 98 & 93 & 2 & 4 \\
\hline $2083-001$ & $2083-001-036$ & 12.57 & 0 & 98 & 93 & 2 & 4 \\
\hline $2083-001$ & $2083-001-040$ & 9.65 & 0 & 98 & 93 & 2 & 4 \\
\hline $2083-001$ & 2083-001-041 & 11.56 & 0 & 98 & 93 & 2 & 4 \\
\hline 2083-001 & 2083-001-043 & 11.54 & 0 & 98 & 93 & 2 & 4 \\
\hline $2083-001$ & 2083-001-044 & 10.58 & 0 & 98 & 93 & 2 & 4 \\
\hline $2083-001$ & 2083-001-045 & 21.93 & 0 & 98 & 93 & 2 & 4 \\
\hline $2083-001$ & 2083-001-046 & 12.59 & 0 & 98 & 93 & 2 & 4 \\
\hline $2083-001$ & 2083-001-048 & 11.52 & 0 & 98 & 93 & 2 & 4 \\
\hline
\end{tabular}


Table I-1. Continued...

\begin{tabular}{|c|c|c|c|c|c|c|c|}
\hline Cat no. & Unique no. & $\begin{array}{l}\text { Max. Size } \\
(\mathrm{mm})\end{array}$ & Cortex \% & Northing & Easting & Level (bs) & Feature \\
\hline $2083-001$ & 2083-001-049 & 9.2 & 0 & 98 & 93 & 2 & 4 \\
\hline 2083-001 & 2083-001-054 & 12.96 & 0 & 98 & 93 & 2 & 4 \\
\hline 2083-001 & 2083-001-055 & 12.85 & 0 & 98 & 93 & 2 & 4 \\
\hline $2083-001$ & 2083-001-059 & 13.55 & 0 & 98 & 93 & 2 & 4 \\
\hline $2083-001$ & $2083-001-060$ & 15.23 & 0 & 98 & 93 & 2 & 4 \\
\hline 2083-001 & 2083-001-062 & 11.47 & 0 & 98 & 93 & 2 & 4 \\
\hline 2083-001 & 2083-001-067 & 14.84 & 0 & 98 & 93 & 2 & 4 \\
\hline 2083-001 & 2083-001-053 & 14.01 & 5 & 98 & 93 & 2 & 4 \\
\hline $2083-001$ & 2083-001-065 & 35.95 & 5 & 98 & 93 & 2 & 4 \\
\hline $2083-001$ & $2083-001-066$ & 12.14 & 5 & 98 & 93 & 2 & 4 \\
\hline 2083-001 & 2083-001-070 & 25.31 & 5 & 98 & 93 & 2 & 4 \\
\hline 2083-001 & 2083-001-071 & 15.87 & 5 & 98 & 93 & 2 & 4 \\
\hline $2083-001$ & 2083-001-021 & 17.21 & 15 & 98 & 93 & 2 & 4 \\
\hline 2083-001 & 2083-001-038 & 17.77 & 15 & 98 & 93 & 2 & 4 \\
\hline $2083-001$ & 2083-001-063 & 15.77 & 25 & 98 & 93 & 2 & 4 \\
\hline $2083-001$ & 2083-001-051 & 22.22 & 35 & 98 & 93 & 2 & 4 \\
\hline 2083-001 & 2083-001-047 & 28.75 & 45 & 98 & 93 & 2 & 4 \\
\hline $2083-001$ & 2083-001-056 & 14.14 & 45 & 98 & 93 & 2 & 4 \\
\hline $2083-001$ & 2083-001-068 & 30.29 & 45 & 98 & 93 & 2 & 4 \\
\hline $2083-001$ & 2083-001-058 & 11.32 & 55 & 98 & 93 & 2 & 4 \\
\hline $2104-001$ & 2104-001-002 & 43.42 & 0 & 98 & 93 & 5 & 4 \\
\hline $2104-001$ & 2104-001-003 & 21.27 & 0 & 98 & 93 & 5 & 4 \\
\hline $2104-001$ & 2104-001-004 & 16.44 & 0 & 98 & 93 & 5 & 4 \\
\hline $2104-001$ & 2104-001-005 & 12.31 & 0 & 98 & 93 & 5 & 4 \\
\hline $2104-001$ & 2104-001-006 & 21.22 & 0 & 98 & 93 & 5 & 4 \\
\hline $2104-001$ & 2104-001-007 & 12.27 & 0 & 98 & 93 & 5 & 4 \\
\hline $2104-001$ & 2104-001-009 & 18.71 & 0 & 98 & 93 & 5 & 4 \\
\hline $2104-001$ & 2104-001-011 & 9.2 & 0 & 98 & 93 & 5 & 4 \\
\hline $2104-001$ & 2104-001-012 & 10.03 & 0 & 98 & 93 & 5 & 4 \\
\hline $2104-001$ & 2104-001-013 & 15.17 & 0 & 98 & 93 & 5 & 4 \\
\hline $2104-001$ & 2104-001-014 & 17.73 & 0 & 98 & 93 & 5 & 4 \\
\hline $2104-001$ & 2104-001-015 & 12.9 & 0 & 98 & 93 & 5 & 4 \\
\hline $2104-001$ & 2104-001-001 & 48.02 & 5 & 98 & 93 & 5 & 4 \\
\hline $2104-001$ & 2104-001-010 & 13.55 & 5 & 98 & 93 & 5 & 4 \\
\hline 2104-6A-2 & $2104-6 A-2$ & 20.97 & 0 & 98 & 93 & 5 & 4 \\
\hline $1234-005$ & $1234-005-001$ & 33.96 & 0 & 99 & 89 & 4 & 4 \\
\hline $1234-005$ & $1234-005-005$ & 26.38 & 0 & 99 & 89 & 4 & 4 \\
\hline $1234-005$ & $1234-005-007$ & 22.09 & 0 & 99 & 89 & 4 & 4 \\
\hline $1234-005$ & $1234-005-008$ & 20.18 & 0 & 99 & 89 & 4 & 4 \\
\hline $1234-005$ & 1234-005-009 & 19.9 & 0 & 99 & 89 & 4 & 4 \\
\hline $1234-005$ & $1234-005-010$ & 21.26 & 0 & 99 & 89 & 4 & 4 \\
\hline $1234-005$ & $1234-005-011$ & 21.69 & 0 & 99 & 89 & 4 & 4 \\
\hline $1234-005$ & $1234-005-012$ & 20.03 & 0 & 99 & 89 & 4 & 4 \\
\hline $1234-005$ & $1234-005-014$ & 14.4 & 0 & 99 & 89 & 4 & 4 \\
\hline $1234-005$ & $1234-005-016$ & 15.25 & 0 & 99 & 89 & 4 & 4 \\
\hline $1234-005$ & $1234-005-017$ & 14.24 & 0 & 99 & 89 & 4 & 4 \\
\hline $1234-005$ & $1234-005-018$ & 9.77 & 0 & 99 & 89 & 4 & 4 \\
\hline $1234-005$ & $1234-005-021$ & 17.31 & 0 & 99 & 89 & 4 & 4 \\
\hline $1234-005$ & $1234-005-022$ & 13.78 & 0 & 99 & 89 & 4 & 4 \\
\hline $1234-005$ & $1234-005-023$ & 14.83 & 0 & 99 & 89 & 4 & 4 \\
\hline $1234-005$ & $1234-005-024$ & 15.16 & 0 & 99 & 89 & 4 & 4 \\
\hline $1234-005$ & $1234-005-025$ & 14.83 & 0 & 99 & 89 & 4 & 4 \\
\hline $1234-005$ & $1234-005-026$ & 10.58 & 0 & 99 & 89 & 4 & 4 \\
\hline $1234-005$ & $1234-005-027$ & 12.7 & 0 & 99 & 89 & 4 & 4 \\
\hline $1234-005$ & $1234-005-028$ & 14.25 & 0 & 99 & 89 & 4 & 4 \\
\hline
\end{tabular}


Table I-1. Continued...

\begin{tabular}{|c|c|c|c|c|c|c|c|}
\hline Cat no. & Unique no. & $\begin{array}{l}\text { Max. Size } \\
\quad(\mathrm{mm})\end{array}$ & Cortex \% & Northing & Easting & Level (bs) & Feature \\
\hline $1234-005$ & $1234-005-029$ & 11.46 & 0 & 99 & 89 & 4 & 4 \\
\hline $1234-005$ & $1234-005-030$ & 11.69 & 0 & 99 & 89 & 4 & 4 \\
\hline $1234-005$ & $1234-005-031$ & 10.53 & 0 & 99 & 89 & 4 & 4 \\
\hline $1234-005$ & $1234-005-032$ & 12.96 & 0 & 99 & 89 & 4 & 4 \\
\hline $1234-005$ & $1234-005-033$ & 11.2 & 0 & 99 & 89 & 4 & 4 \\
\hline $1234-005$ & $1234-005-034$ & 9.89 & 0 & 99 & 89 & 4 & 4 \\
\hline $1234-005$ & $1234-005-035$ & 10.18 & 0 & 99 & 89 & 4 & 4 \\
\hline $1234-005$ & $1234-005-036$ & 10.87 & 0 & 99 & 89 & 4 & 4 \\
\hline $1234-005$ & $1234-005-037$ & 12.03 & 0 & 99 & 89 & 4 & 4 \\
\hline $1234-005$ & $1234-005-038$ & 8.81 & 0 & 99 & 89 & 4 & 4 \\
\hline $1234-005$ & $1234-005-040$ & 9.78 & 0 & 99 & 89 & 4 & 4 \\
\hline $1234-005$ & $1234-005-004$ & 37.13 & 5 & 99 & 89 & 4 & 4 \\
\hline $1234-005$ & $1234-005-003$ & 35.31 & 25 & 99 & 89 & 4 & 4 \\
\hline $1234-005$ & $1234-005-039$ & 11.93 & 85 & 99 & 89 & 4 & 4 \\
\hline $228-001$ & 228-001-004 & 30.53 & 0 & 99 & 92 & 2 & 4 \\
\hline 228-001 & 228-001-005 & 15.3 & 0 & 99 & 92 & 2 & 4 \\
\hline 228-001 & 228-001-007 & 20.42 & 0 & 99 & 92 & 2 & 4 \\
\hline 228-001 & 228-001-009 & 17.51 & 0 & 99 & 92 & 2 & 4 \\
\hline $228-001$ & 228-001-010 & 15.3 & 0 & 99 & 92 & 2 & 4 \\
\hline 228-001 & 228-001-011 & 19.56 & 0 & 99 & 92 & 2 & 4 \\
\hline $228-001$ & 228-001-012 & 16.22 & 0 & 99 & 92 & 2 & 4 \\
\hline $228-001$ & 228-001-014 & 14.9 & 0 & 99 & 92 & 2 & 4 \\
\hline $228-001$ & 228-001-019 & 17.11 & 0 & 99 & 92 & 2 & 4 \\
\hline 228-001 & 228-001-020 & 21.27 & 0 & 99 & 92 & 2 & 4 \\
\hline $228-001$ & $228-001-021$ & 21.47 & 0 & 99 & 92 & 2 & 4 \\
\hline 228-001 & $228-001-022$ & 12.59 & 0 & 99 & 92 & 2 & 4 \\
\hline 228-001 & $228-001-023$ & 21.76 & 0 & 99 & 92 & 2 & 4 \\
\hline 228-001 & 228-001-024 & 13.5 & 0 & 99 & 92 & 2 & 4 \\
\hline 228-001 & $228-001-025$ & 16.24 & 0 & 99 & 92 & 2 & 4 \\
\hline $228-001$ & $228-001-027$ & 13.79 & 0 & 99 & 92 & 2 & 4 \\
\hline $228-001$ & 228-001-028 & 15.91 & 0 & 99 & 92 & 2 & 4 \\
\hline $228-001$ & 228-001-031 & 12.34 & 0 & 99 & 92 & 2 & 4 \\
\hline $228-001$ & 228-001-032 & 13 & 0 & 99 & 92 & 2 & 4 \\
\hline $228-001$ & $228-001-033$ & 17.4 & 0 & 99 & 92 & 2 & 4 \\
\hline $228-001$ & 228-001-034 & 13.19 & 0 & 99 & 92 & 2 & 4 \\
\hline $228-001$ & 228-001-035 & 15.57 & 0 & 99 & 92 & 2 & 4 \\
\hline $228-001$ & 228-001-037 & 14.71 & 0 & 99 & 92 & 2 & 4 \\
\hline $228-001$ & $228-001-038$ & 12.83 & 0 & 99 & 92 & 2 & 4 \\
\hline 228-001 & 228-001-039 & 8.49 & 0 & 99 & 92 & 2 & 4 \\
\hline 228-001 & $228-001-040$ & 10.85 & 0 & 99 & 92 & 2 & 4 \\
\hline 228-001 & 228-001-041 & 10.55 & 0 & 99 & 92 & 2 & 4 \\
\hline 228-001 & 228-001-042 & 9.39 & 0 & 99 & 92 & 2 & 4 \\
\hline 228-001 & 228-001-043 & 13.51 & 0 & 99 & 92 & 2 & 4 \\
\hline $228-001$ & 228-001-045 & 11.13 & 0 & 99 & 92 & 2 & 4 \\
\hline 228-001 & 228-001-046 & 12.33 & 0 & 99 & 92 & 2 & 4 \\
\hline $228-001$ & 228-001-047 & 9.78 & 0 & 99 & 92 & 2 & 4 \\
\hline $228-001$ & 228-001-048 & 9.46 & 0 & 99 & 92 & 2 & 4 \\
\hline $228-001$ & 228-001-049 & 10.08 & 0 & 99 & 92 & 2 & 4 \\
\hline $228-001$ & $228-001-052$ & 7.95 & 0 & 99 & 92 & 2 & 4 \\
\hline $228-001$ & 228-001-053 & 13.18 & 0 & 99 & 92 & 2 & 4 \\
\hline 228-001 & 228-001-054 & 7.68 & 0 & 99 & 92 & 2 & 4 \\
\hline 228-001 & 228-001-008 & 21.54 & 5 & 99 & 92 & 2 & 4 \\
\hline $228-001$ & 228-001-016 & 18.84 & 5 & 99 & 92 & 2 & 4 \\
\hline 228-001 & 228-001-026 & 21.52 & 5 & 99 & 92 & 2 & 4 \\
\hline $228-001$ & 228-001-030 & 7.12 & 5 & 99 & 92 & 2 & 4 \\
\hline
\end{tabular}


Table I-1. Continued...

\begin{tabular}{|c|c|c|c|c|c|c|c|}
\hline Cat no. & Unique no. & $\begin{array}{l}\text { Max. Size } \\
(\mathrm{mm})\end{array}$ & Cortex \% & Northing & Easting & Level (bs) & Feature \\
\hline $228-001$ & 228-001-036 & 14.32 & 5 & 99 & 92 & 2 & 4 \\
\hline $228-001$ & $228-001-044$ & 11.21 & 5 & 99 & 92 & 2 & 4 \\
\hline $228-001$ & 228-001-006 & 31.31 & 15 & 99 & 92 & 2 & 4 \\
\hline $228-001$ & 228-001-017 & 17.3 & 15 & 99 & 92 & 2 & 4 \\
\hline $228-001$ & 228-001-001 & 18.33 & 25 & 99 & 92 & 2 & 4 \\
\hline $228-001$ & 228-001-055 & 9.62 & 45 & 99 & 92 & 2 & 4 \\
\hline $2185-001$ & $2185-001-001$ & 30.84 & 0 & 99 & 94 & 3 & 4 \\
\hline $2185-001$ & 2185-001-002 & 19.67 & 0 & 99 & 94 & 3 & 4 \\
\hline $2185-001$ & $2185-001-003$ & 17.87 & 0 & 99 & 94 & 3 & 4 \\
\hline $2185-001$ & 2185-001-004 & 25.39 & 0 & 99 & 94 & 3 & 4 \\
\hline $2185-001$ & $2185-001-005$ & 10.93 & 0 & 99 & 94 & 3 & 4 \\
\hline $2185-001$ & 2185-001-006 & 31.99 & 0 & 99 & 94 & 3 & 4 \\
\hline $2185-001$ & 2185-001-008 & 20.01 & 0 & 99 & 94 & 3 & 4 \\
\hline $2185-001$ & 2185-001-009 & 24.85 & 0 & 99 & 94 & 3 & 4 \\
\hline $2185-001$ & 2185-001-010 & 13.19 & 0 & 99 & 94 & 3 & 4 \\
\hline $2185-001$ & 2185-001-011 & 19.63 & 0 & 99 & 94 & 3 & 4 \\
\hline $2185-001$ & $2185-001-012$ & 12 & 0 & 99 & 94 & 3 & 4 \\
\hline $2185-001$ & 2185-001-013 & 16.54 & 0 & 99 & 94 & 3 & 4 \\
\hline $2185-001$ & 2185-001-014 & 11.59 & 0 & 99 & 94 & 3 & 4 \\
\hline $2185-001$ & 2185-001-015 & 21.24 & 0 & 99 & 94 & 3 & 4 \\
\hline $2185-001$ & 2185-001-017 & 12.13 & 0 & 99 & 94 & 3 & 4 \\
\hline $2185-001$ & $2185-001-018$ & 15.12 & 0 & 99 & 94 & 3 & 4 \\
\hline $2185-001$ & 2185-001-019 & 13.38 & 0 & 99 & 94 & 3 & 4 \\
\hline $2185-001$ & $2185-001-020$ & 11.84 & 0 & 99 & 94 & 3 & 4 \\
\hline $2185-001$ & $2185-001-021$ & 8.99 & 0 & 99 & 94 & 3 & 4 \\
\hline $2185-001$ & $2185-001-022$ & 9.82 & 0 & 99 & 94 & 3 & 4 \\
\hline $2185-001$ & $2185-001-023$ & 11.62 & 0 & 99 & 94 & 3 & 4 \\
\hline $2185-001$ & $2185-001-024$ & 10.91 & 0 & 99 & 94 & 3 & 4 \\
\hline $2185-001$ & $2185-001-025$ & 9.69 & 0 & 99 & 94 & 3 & 4 \\
\hline $2185-001$ & $2185-001-026$ & 18 & 0 & 99 & 94 & 3 & 4 \\
\hline $2185-001$ & $2185-001-027$ & 26.61 & 0 & 99 & 94 & 3 & 4 \\
\hline $2185-001$ & $2185-001-028$ & 13.04 & 0 & 99 & 94 & 3 & 4 \\
\hline $2185-001$ & 2185-001-029 & 21.89 & 0 & 99 & 94 & 3 & 4 \\
\hline $2185-001$ & $2185-001-043$ & 14.9 & 0 & 99 & 94 & 3 & 4 \\
\hline $2185-001$ & 2185-001-048 & 13.11 & 0 & 99 & 94 & 3 & 4 \\
\hline $2185-001$ & 2185-001-049 & 8.18 & 0 & 99 & 94 & 3 & 4 \\
\hline $2185-001$ & $2185-001-036$ & 13.01 & 5 & 99 & 94 & 3 & 4 \\
\hline $2185-001$ & 2185-001-037 & 23.95 & 5 & 99 & 94 & 3 & 4 \\
\hline $2185-001$ & 2185-001-032 & 21.65 & 15 & 99 & 94 & 3 & 4 \\
\hline $2185-001$ & 2185-001-046 & 8.72 & 35 & 99 & 94 & 3 & 4 \\
\hline $2185-001$ & 2185-001-016 & 85.49 & 45 & 99 & 94 & 3 & 4 \\
\hline $2185-001$ & $2185-001-038$ & 14.18 & 45 & 99 & 94 & 3 & 4 \\
\hline $2185-001$ & 2185-001-039 & 18.62 & 45 & 99 & 94 & 3 & 4 \\
\hline $2185-001$ & $2185-001-041$ & 13.08 & 45 & 99 & 94 & 3 & 4 \\
\hline
\end{tabular}


ISBN: 1-930788-90-8 